UNIVERSIDADE DE SÃO PAULO

ESCOLA DE ENGENHARIA DE SÃO CARLOS

PROGRAMA DE PÓS-GRADUAÇÃO EM ENGENHARIA HIDRÁULICA E SANEAMENTO

GIOVANNA LOVATO

ProduÇão de Biohidrogênio EM ANSBBR TRATANDO EFLUENTE do Processo de Produção de Biodiesel EFeito da CARga Orgânica E do Tempo de EnCHIMENTo 


\section{ProduÇão de BiohidrogêNio EM AnSBBR TRATANDo EFLUENTE do Processo de Produção de Biodiesel -

\author{
Efeito da Carga Orgânica e do Tempo de Enchimento
}

Dissertação apresentada à Escola de Engenharia de São Carlos, da Universidade de São Paulo, como parte dos requisitos para obtenção do título de Mestre em Ciências: Engenharia Hidráulica e Saneamento.

Orientador: Prof. Dr. José Alberto Domingues Rodrigues

VERSÃO CORRIGIDA

SÃO CARLOS

2014 


\section{AUTORIZO A REPRODUÇÃO TOTAL OU PARCIAL DESTE TRABALHO POR QUALQUER MEIO CONVENCIONAL OU ELETRÔNICO, PARA FINS DE ESTUDO E PESQUISA, DESDE QUE CITADA A FONTE.}

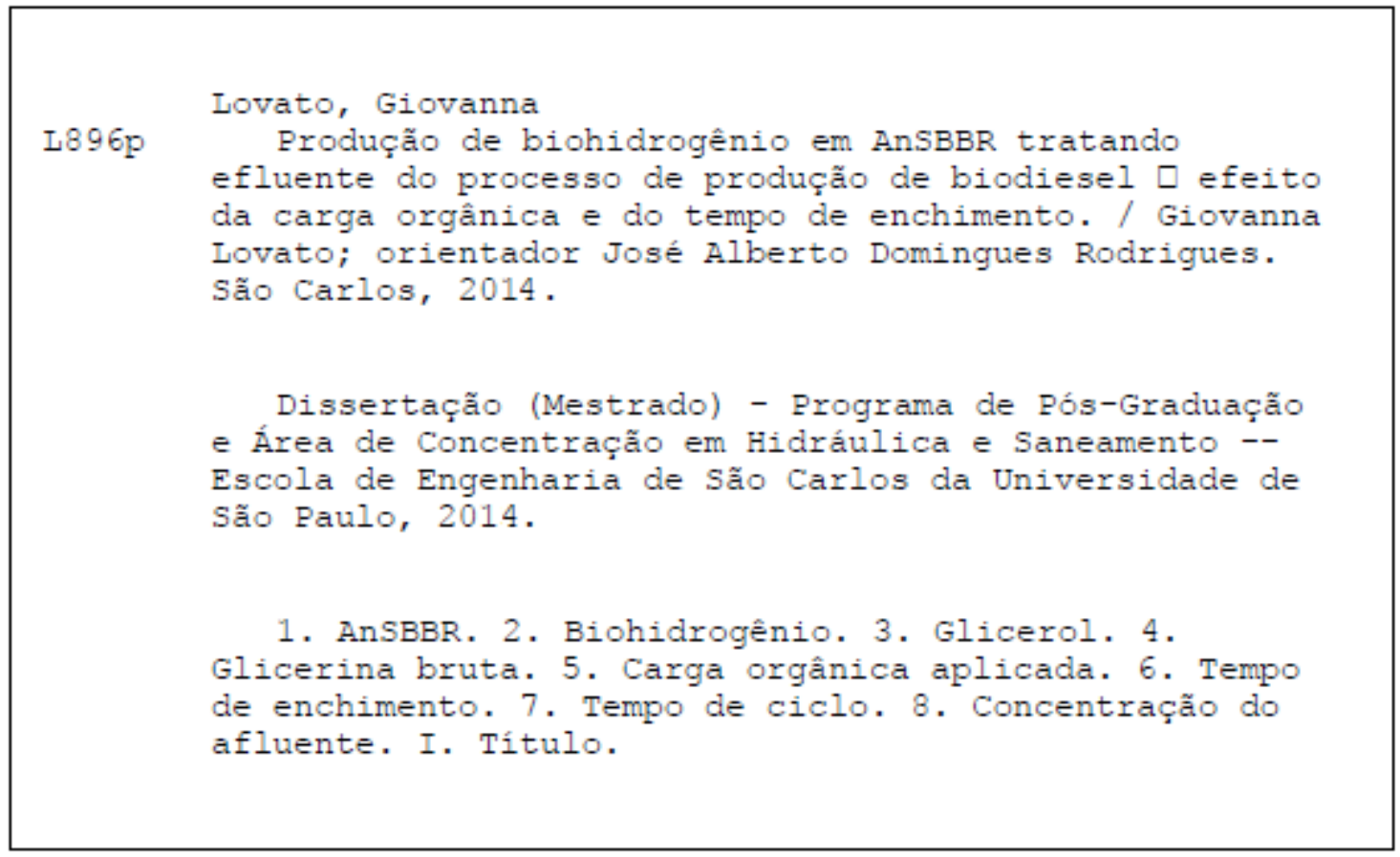




\section{FOLHA DE JULGAMENTO}

Candidata: Engenheira GIOVANNA LOVATO.

Título da dissertação: "Produção de biohidrogênio em ansbbr tratando efluente do processo de produção de biodiesel - efeito da carga orgânica e do tempo de enchimento".

Data da defesa: 14/03/2014

\section{Comissão Julgadora:}

Prof. Dr. José Alberto Domingues Rodrigues (Orientador) (Escola de Engenharia de Mauá/EEM)

Profa. Dra. Suzana Maria Ratusznei

(Escola de Engenharia de Mauá/EEM)

Prof. Dr. Luiz Olinto Monteggia

(Universidade Federal do Rio Grande do Sul/UFRS)

\section{Resultado:}
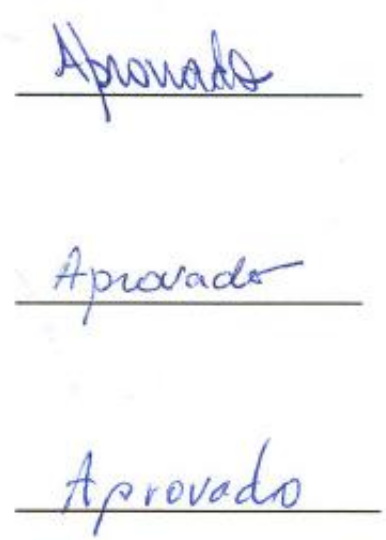

Coordenadora do Programa de Pós-Graduação em Engenharia Hidráulica e Saneamento:

Profa. Associada Maria Bernadete A. Varesche Silva

Presidente da Comissão de Pós-Graduação:

Prof. Titular Denis Vinicius Coury 


\section{DEDICATÓRIA}

Aos meus familiares, namorado e amigos queridos.

Ao Professor José Alberto por toda orientação e amizade desde o começo da faculdade. 


\section{AGRADECIMENTOS}

Em primeiro lugar, a minha mãe, pelo apoio, paciência e amor incondicional, e, além disso, por ter sido a minha heroína durante toda a minha vida.

A minha família, pelo apoio e o carinho, eles permitiram essa conquista.

Ao Departamento de Hidráulica e Saneamento da Escola de Engenharia de São Carlos da Universidade de São Paulo SHS/EESC/USP e a Escola de Engenharia Mauá do Instituto Mauá de Tecnologia EEM/IMT que disponibilizaram o espaço e o apoio necessário para a realização deste projeto.

Aos professores do SHS pela qualidade do ensino que constitui uma etapa importante deste trabalho.

Ao Dr. José Alberto Domingues Rodrigues, pela orientação, pela disponibilidade, pelo apoio, pela dedicação e, acima de tudo, pela grande amizade desde o começo da faculdade. Devo toda a minha carreira acadêmica a ele.

À Dra. Suzana Maria Ratusznei, pela orientação e pela amizade. Uma pessoa sempre disposta a ajudar no crescimento profissional e pessoal de cada um de seus alunos.

Ao CNPQ, pela bolsa de estudos concedida.

À FAPESP, pela bolsa de mestrado concedida (processo no 12/04.829-7) e pelo auxílio financeiro no Projeto Temático "Produção de Bioenergia no Tratamento de Águas Residuárias e Adequação Ambiental dos Efluentes e Resíduos Gerados” (processo n 09/15.984-0).

Às pessoas que, cada uma a sua maneira, contribuíram para realização deste trabalho, minha sincera gratidão. 
"Let the future tell the truth and evaluate each one according to his work and accomplishments. The present is theirs; the future, for which I really worked, is mine." 


\section{RESUMO}

LOVATO, G. Produção de biohidrogênio em AnSBBR tratando efluente do processo de produção de biodiesel - Efeito da carga orgânica e do tempo de enchimento. Dissertação (Mestrado) - Escola de Engenharia de São Carlos - Departamento de Hidráulica e Saneamento, Universidade de São Paulo, 2014.

Este estudo investigou a aplicação de um AnSBBR com recirculação da fase líquida tratando água residuária a base de glicerina (efluente do processo de produção de biodiesel) para a produção de biohidrogênio, sendo o desempenho do biorreator avaliado de acordo com a influência conjunta do tempo de alimentação, do tempo de ciclo e da concentração afluente. O biorreator teve um volume de meio tratado por ciclo de 1,5 L, volume residual de meio de 2,0 L e volume de suporte inerte com biomassa de $2,1 \mathrm{~L}$, sendo mantido a $30^{\circ} \mathrm{C}$ durante todo o estudo. O trabalho foi divido em três fases: a Fase I foi realizada para determinar os melhores parâmetros de operação do reator (tipo de inóculo, tipo de glicerina, tipo de suporte, concentração de $\mathrm{NaHCO}_{3}$ e velocidade ascensional) para dar seguimento com a Fase II que estudou apenas o efeito da concentração do afluente, tempo de ciclo e tempo de enchimento. Os parâmetros utilizados na Fase II foram: lodo de abatedouro de aves pré-tratado por HST (Heat Shock Treatment $-90^{\circ} \mathrm{C}$ por 10 minutos) como inóculo, glicerina pura comercial para eliminar interferência de possíveis resíduos, suporte de PEBD (polietileno de baixa densidade) e $100 \mathrm{mg} . \mathrm{L}^{-1}$ de $\mathrm{NaHCO}_{3}$. Na Fase II, foram aplicadas 6 condições experimentais com cargas orgânica volumétrica $\left(\mathrm{COVA}_{\mathrm{S}}\right)$ de 7,7 a 17,1 gDQO.L $\mathrm{L}^{-1} \cdot \mathrm{d}^{-1}$, combinando diferentes concentrações afluentes (3000, 4000 e 5000 mgDQO.L $\left.{ }^{-1}\right)$ e tempos de ciclo $(4$ e 3 h), sendo o tempo de alimentação igual a metade do tempo de ciclo. Os resultados mostraram que houve baixa remoção de DQO (máximo de $38 \%$ para amostras filtradas) e que houve predomínio do ácido acético e do ácido butírico em todas as condições. O aumento da 
concentração do afluente e a diminuição do tempo de ciclo favoreceram a produtividade e rendimento molares de hidrogênio nas condições investigadas. $\mathrm{O}$ ensaio com melhores resultados foi com carga orgânica de 17,1 gDQO.L $\mathrm{L}^{-1} \cdot \mathrm{d}^{-1}$ no qual obteve-se $100,8 \mathrm{molH}_{2} \cdot \mathrm{m}^{-3} \cdot \mathrm{d}^{-1}$ e $20,0 \mathrm{molH}_{2} \cdot \mathrm{kgDQO}^{-1}$, com $68 \%$ de $\mathrm{H}_{2}$ e apenas $3 \%$ de $\mathrm{CH}_{4}$ no biogás. Na Fase III, determinou-se a influência do pré-tratamento do inóculo e a viabilidade do sistema tratando glicerina bruta industrial, sendo verificado que o pré-tratamento do lodo por HST melhora ligeiramente a produtividade e rendimento do processo e o uso da glicerina bruta industrial diminuiu consideravelmente a quantidade e qualidade do biogás obtido.

Palavras-chave: AnSBBR; biohidrogênio; glicerol; glicerina bruta; carga orgânica aplicada, tempo de enchimento, tempo de ciclo, concentração do afluente. 


\begin{abstract}
LOVATO, G. Biohydrogen production in an AnSBBR treating effluent from biodiesel production - Effects of organic loading rate and fill time. Dissertation (Master's degree) School of Engineering of São Carlos - Department of Hydraulics and Sanitation, University of São Paulo, 2014.
\end{abstract}

This study investigated the feasibility of an AnSBBR with recirculation of the liquid phase treating glycerin-based wastewater (effluent from biodiesel production process) on biohydrogen production; the performance of the bioreactor was evaluated according the combined influence of fill time, cycle period and influent concentration. The bioreactor had 1.5L of feeding volume per cycle, $2.0 \mathrm{~L}$ of residual medium, $2.1 \mathrm{~L}$ of inert support and biomass and it was kept at $30^{\circ} \mathrm{C}$. This study was divided into three phases. Phase I was conducted to determine the best operational parameters for the reactor (type of inoculum, type of glycerin, type of support for biomass, $\mathrm{NaHCO}_{3}$ concentration and upflow velocity), so Phase II would use these parameters to study only the influence of affluent concentration, cycle time and filling time. The parameters used in Phase II were: sludge from poultry slaughterhouse pretreated by HST (Heat Shock Treatment $-90^{\circ} \mathrm{C}$ for 10 minutes) as inoculum, pure glycerin so there would be no interferences from possible residues, LDPE (low density polyethylene) support, $100 \mathrm{mg} . \mathrm{L}^{-1}$ of $\mathrm{NaHCO}_{3}$ and $10.6 \mathrm{~m} \cdot \mathrm{h}^{-1}$ of upflow velocity. Phase II was operated under six conditions with different $\mathrm{AOLR}_{\mathrm{S}}$ ranging from 7.7 to $17.1 \mathrm{gCOD} . \mathrm{L}^{-1} \cdot \mathrm{d}^{-1}$, obtained by the combination of different influent concentrations (3000, 4000 and $5000 \mathrm{mgCOD} . \mathrm{L}^{-1}$ ) and cycle periods ( 4 and $3 \mathrm{~h}$ ), the filling time was equal to half of the cycle lenght. The results showed low COD removal (maximum of $38 \%$ for filtrated samples) and high concentrations of acetic acid and butyric acid in all conditions. Increasing the affluent concentration and decreasing the cycle length improved the molar productivy and hydrogen yield in the 
investigated conditions. The condition with better results was the one operated with 17.1gCOD.L $\mathrm{L}^{-1} \cdot \mathrm{d}^{-1}$ of AVOL, it reached $100.8 \mathrm{molH}_{2} \cdot \mathrm{m}^{-3} \cdot \mathrm{d}^{-1}$ and $20.0 \mathrm{molH}_{2} \cdot \mathrm{kgCOD}^{-1}$, with $68 \%$ of $\mathrm{H}_{2}$ and only $3 \%$ of $\mathrm{CH}_{4}$ in its biogas. Phase III determined whether there is a real influence on the pretreatment of the sludge and the feasibility of this system treating industrial glycerin, the results show that the pretreatment of the sludge by HST slightly improves the productivity and the process yield and the wastewater made from industrial glycerin substantially decreased the quantity and the quality of the biogas generated.

Keywords: AnSBBR; biohydrogen; glycerol; crude glycerin; applied organic loading rate; fill time, cycle period; influent concentration. 


\section{LISTA DE FIGURAS}

Figura 3.1 - ASBR e AnSBBR com agitação mecânica com impelidor (Manssouri, 2013). 9

Figura 3.2 - ASBR e AnSBBR com mistura por recirculação da fase líquida (Lovato et al., 2012) 9

Figura 3.3 - Perfis de concentração de matéria orgânica efluente durante os ensaios para a condição sem recirculação (a) e com recirculação com velocidade superficial de $0,19 \mathrm{~cm} / \mathrm{s}$ (b) (Camargo et al., 2005).

Figura 3.4 - Tipos de impelidor utilizados nos experimentos de Cubas et al. (2010). (1) Helical turbine; (2) Flat-blade turbine; (3) Inclined-blade turbine; (4) Curved-blade turbine. .11

Figura 3.5 - Fotografia da biomassa granulada (Novaes et al., 2010a e 2010b) 12

Figura 3.6 - Fotografias das partículas de suporte inerte de espuma de poliuretano (a) e de polietileno de baixa densidade (b) depois e antes da imobilização (direita e esquerda, respectivamente) (Lovato et al., 2012 e Manssouri, 2013)

Figura 3.7 - Perfis de concentração de matéria orgânica na operação com tempo de enchimento (ta) de

$$
\text { 2, } \left.4 \text { e } 6 \text { h }(\mathrm{COV}=4,5 \text { gDQO.(L.d })^{-1}\right) \text { (Lovato et al., 2012) }
$$

Figura 3.8 - Distribuição do tempo no ciclo de remoção de nitrogênio (Albanez et al. 2009)

Figura 3.9 - Conversão da DQO disponível em resíduos biodegradáveis (Chandra et al., 2012)

Figura 3.10 - Perfis de concentração de metano na operação com tempo de alimentação $\left(t_{a}\right)$ de

$$
\text { 2, } \left.4 \text { e } 6 \text { h }(\text { COVA = 4,5 gDQO.(L.d })^{-1}\right) \text { (Lovato et al., 2012) }
$$

Figura 3.11 - Caminho metabólico durante a fermentação de vários substratos pelo Clostridium sp. 1:

Sacarose 6-P hidrolase; 2: Hexoquinase; 3: Fosforoglicose isomerase; 4: Fosforofructoquinase; 5: Aldolase; 6: Gliceraldeído-3-P-dehidrogenase; 7: Fosfogliceroquinase; 8: Enolase; 9: Piruvato quinase; 10: Piruvato-ferredoxin oxidoreductase; 11: Hidrogenase; 12: NAD(P)H-ferredoxin redutase; 13: Ferredoxin$\mathrm{NAP}(\mathrm{P})^{+}$redutase; 14: Fosfotranscetilase quinase; 15: Acetato linase; 16: 
Fosfotransbutilase quinase; 17: Butirato quinase; 18: Glicerol dehidrogenase; 19: DNA quinase; 20: Glicerol dehidratase; 21: 1,3-propanodiol dehidrogenase; 22: Xilose isomerase; 23: Xiluloquinase (Adaptada de Sá et al., 2013)

Figura 3.12 - Rendimento entre produção de hidrogênio e consumo de sacarose obtidos por inóculo sem tratamento e pré-tratado (calor, ácido e alcalino) (Adaptado de Sá et al. 2013) 30

Figura 3.13 - Curva típica de produção de hidrogênio ajustada pelo modelo modificado de Gompertz.........38

Figura 4.1 - Esquema do AnSBBR com recirculação utilizado nos ensaios .42

Figura 4.2 - Detalhes do: (a) reator, $(b)$ suporte da tela de aço, $(c)$ tela de aço, $(d)$ reservatório. .42

Figura 4.3 - Fotografia do aparato experimental utilizado nos ensaios 43

Figura 4.4 - Fotografia do material suporte com (esquerda) e sem (direita) biomassa. 44

Figura 4.5 - Reação de transesterificação de glicerídeos que produz glicerina .46

Figura 4.6 - Esquema das três fases de operação .54

Figura 5.1 - Concentração de matéria orgânica na forma de DQO na Condição Preliminar: afluente amostras não filtradas; • - efluente amostras não filtradas; ○ - efluente amostras filtradas 65

Figura 5.2 - Eficiência de remoção de matéria orgânica na forma de DQO na Condição Preliminar: - amostras não filtradas; $\bigcirc-$ amostras filtradas .65

Figura 5.3 - Valores de pH na Condição Preliminar: $\square-$ afluente; $\bullet$ - efluente ..................................................66

Figura 5.4 - Valores de alcalinidade total (AT) na Condição Preliminar: $\square$-afluente; • - efluente. 66

Figura 5.5 - Valores de ácidos voláteis totais (AVT) na Condição Preliminar: $\square$ - afluente; • efluente 66

Figura 5.6 - Perfis de produção de biogás (dias de ensaio 16 e 17) na Condição Preliminar 67

Figura 5.7 - Concentração de matéria orgânica na forma de DQO na Fase I: $\mathbf{~ - ~ a f l u e n t e ~ a m o s t r a s ~ n a ̃ o ~}$

filtradas; • - efluente amostras não filtradas; ○ - efluente amostras filtradas .73 
Figura 5.8 - Eficiência de remoção de matéria orgânica na forma de DQO na Fase I: • - amostras não filtradas; $\circ-$ amostras filtradas

Figura 5.9 - Valores de pH na Fase I: $\square$-afluente; $\bullet$ - efluente....................................................................... 74

Figura 5.10 - Valores de alcalinidade total (AT) na Fase I: $\square$-afluente; $\bullet$ - efluente ….................................. 75

Figura 5.11 - Valores de ácidos voláteis totais (AVT) na Fase I: $\square-$ afluente; $\bullet$ - efluente............................. 75

Figura 5.12 - Volume de biogás $\left(\mathrm{V}_{\mathrm{G}}\right)$ e de hidrogênio $\left(\mathrm{V}_{\mathrm{H} 2}\right)$ na CNTP na Fase I e porcentagens $\left(\mathrm{Y}_{\mathrm{G}}\right)$ dos compostos do biogás: • - biogás, • - hidrogênio, • - metano, ○ - dióxido de carbono

Figura 5.13 - Concentração de matéria orgânica na forma de DQO nos ensaios 12 e 13: $\square$ - afluente amostras não filtradas; • - efluente amostras não filtradas; ○ - efluente amostras filtradas ........80

Figura 5.14 - Eficiência de remoção de matéria orgânica na forma de DQO nos ensaios 12 e 13: • amostras não filtradas; $\bigcirc-$ amostras filtradas .80

Figura 5.15 - Valores de pH nos ensaios 12 e 13: $\square$-afluente; $\bullet$ - efluente

Figura 5.16 - Valores de alcalinidade total (AT) nos ensaios 12 e 13: $\square$-afluente; $\bullet$ - efluente. 81

Figura 5.17 - Valores de ácidos voláteis totais (AVT) nos ensaios 12 e 13: $\square$-afluente; $\bullet-$ efluente ....... 81

Figura 5.18 - Volume de biogás $\left(\mathrm{V}_{\mathrm{G}}\right)$ e de hidrogênio $\left(\mathrm{V}_{\mathrm{H} 2}\right)$ na CNTP nos ensaios 12 e 13: a -biogás;

$\bullet$ - hidrogênio. .82

Figura 5.19 - Concentração de matéria orgânica na forma de DQO no ensaio 14: $\square$ - afluente amostras não filtradas; • - efluente amostras não filtradas; ○ - efluente amostras filtradas 84

Figura 5.20 - Eficiência de remoção de matéria orgânica na forma de DQO no ensaio 14: • - amostras não filtradas; $\bigcirc-$ amostras filtradas .84

Figura 5.21 - Valores de pH no ensaio 14: $\square$-afluente; • - efluente. .85

Figura 5.22 - Valores de alcalinidade total (AT) no ensaio 14: $\square$-afluente; $\bullet$ - efluente .85

Figura 5.23 - Valores de ácidos voláteis totais (AVT) no ensaio 14: $\square$-afluente; • - efluente. .85 
Figura 5.24 - Volume de biogás $\left(\mathrm{V}_{\mathrm{G}}\right)$ e de hidrogênio $\left(\mathrm{V}_{\mathrm{H} 2}\right)$ na CNTP no ensaio 14: a -Biogás; o Hidrogênio 86

Figura 5.25 - Concentrações dos componentes do biogás no final do ciclo no ensaio 14: $\odot-\mathrm{H}_{2}$;

$\mathrm{CH}_{4} ; \Delta-\mathrm{CO}_{2}$ 86

Figura 5.26 - Concentração e eficiência de degradação de matéria orgânica durante o ciclo ensaio 14:

$\bullet-\mathrm{C}_{\mathrm{SF}} ; \mathrm{O}-\varepsilon_{\mathrm{SF}}$ .87

Figura 5.27 - Valores de $\mathrm{pH}$ durante o ciclo no ensaio 14 .87

Figura 5.28 - Concentração de alcalinidade total durante o ciclo no ensaio 14 87

Figura 5.29 - Concentração de AVT durante o ciclo no ensaio 14 .88

Figura 5.30 - Concentração dos compostos intermediários ao longo do ciclo no ensaio 14: $\square$ - ácido acético; $\Delta$ - etanol; ○ - ácido butírico; $\boldsymbol{\square}$ - ácido isobutírico; $\boldsymbol{\Delta}$ - ácido capróico; ácido valérico; -x-ácido propiônico; $\diamond$ butanol; + ácido isovalérico .88

Figura 5.31 - Produção volumétrica média acumulada do biogás durante o ciclo no ensaio 14 .89

Figura 5.32 - Concentração dos compostos do biogás durante o ciclo e suas respectivas porcentagens no ensaio 14: ○ $-\mathrm{H}_{2} ; \bullet-\mathrm{CH}_{4} ; \Delta-\mathrm{CO}_{2}$

Figura 5.33 - Concentração de matéria orgânica na forma de DQO no ensaio 15: $\square$ - afluente amostras não filtradas; • - efluente amostras não filtradas; ○ - efluente amostras filtradas. .91

Figura 5.34 - Eficiência de remoção de matéria orgânica na forma de DQO no ensaio 15: • - amostras não filtradas; ○ - amostras filtradas

Figura 5.35 - Valores de pH no ensaio 15: $\square-$ afluente; $\bullet$ - efluente. 92

Figura 5.36 - Valores de alcalinidade total (AT) no ensaio 15: $\square$-afluente; $\bullet$ - efluente .................................92

Figura 5.37 - Valores de ácidos voláteis totais (AVT) no ensaio 15: $\square$-afluente; $\bullet-$ efluente. .92

Figura 5.38 - Volume de biogás $\left(\mathrm{V}_{\mathrm{G}}\right)$ e de hidrogênio $\left(\mathrm{V}_{\mathrm{H} 2}\right)$ na CNTP no ensaio 15: a -Biogás; o Hidrogênio. 
Figura 5.39 - Concentrações dos componentes do biogás no final do ciclo no ensaio 15: ○ $-\mathrm{H}_{2}$;

$\mathrm{CH}_{4} ; \Delta-\mathrm{CO}_{2}$

Figura 5.40 - Concentração e eficiência de degradação de matéria orgânica durante o ciclo ensaio 15:

$\bullet-\mathrm{C}_{\mathrm{SF}} ; \circ-\varepsilon_{\mathrm{SF}}$

Figura 5.41 - Valores de $\mathrm{pH}$ durante o ciclo no ensaio 15 94

Figura 5.42 - Concentração de alcalinidade total durante o ciclo no ensaio 15

Figura 5.43 - Concentração de AVT durante o ciclo no ensaio 15

Figura 5.44 - Concentração dos compostos intermediários ao longo do ciclo no ensaio 15: $\square$ - ácido acético; $\Delta$ - etanol; ○ - ácido butírico; $\mathbf{\square}$ - ácido isobutírico; $\boldsymbol{\Delta}$ - ácido capróico; $\bullet-$ ácido valérico; -X-ácido propiônico; $\diamond$ butanol; + ácido isovalérico

Figura 5.45 - Produção volumétrica média acumulada do biogás durante o ciclo no ensaio 15 .96

Figura 5.46 - Concentração dos compostos do biogás durante o ciclo e suas respectivas porcentagens no ensaio 15: $\circ-\mathrm{H}_{2} ; \bullet-\mathrm{CH}_{4} ; \Delta-\mathrm{CO}_{2}$ 96

Figura 5.47 - Concentração de matéria orgânica na forma de DQO no ensaio 16: $\square-$ afluente amostras não filtradas; • - efluente amostras não filtradas; ○ - efluente amostras filtradas .98

Figura 5.48 - Eficiência de remoção de matéria orgânica na forma de DQO no ensaio 16: • - amostras não filtradas; ○ - amostras filtradas. .98

Figura 5.49 - Valores de pH no ensaio 16: $\square-$ afluente; $\bullet$ - efluente..

Figura 5.50 - Valores de alcalinidade total (AT) no ensaio 16: $\square-$ afluente; $\bullet$ - efluente

Figura 5.51 - Valores de ácidos voláteis totais (AVT) no ensaio 16: $\square$-afluente; $\bullet$ - efluente. 99

Figura 5.52 - Volume de biogás $\left(\mathrm{V}_{\mathrm{G}}\right)$ e de hidrogênio $\left(\mathrm{V}_{\mathrm{H} 2}\right)$ na CNTP no ensaio 16: - -Biogás; o Hidrogênio 100

Figura 5.53 - Concentrações dos componentes do biogás no final do ciclo no ensaio 16: ० $-\mathrm{H}_{2}$;

$\mathrm{CH}_{4} ; \Delta-\mathrm{CO}_{2}$ 100 
Figura 5.54 - Concentração e eficiência de degradação de matéria orgânica durante o ciclo ensaio 16:

$\bullet-\mathrm{C}_{\mathrm{SF}} ; \mathrm{O}-\varepsilon_{\mathrm{SF}}$ .101

Figura 5.55 - Valores de $\mathrm{pH}$ durante o ciclo no ensaio 16. 101

Figura 5.56 - Concentração de alcalinidade total durante o ciclo no ensaio 16 101

Figura 5.57 - Concentração de AVT durante o ciclo no ensaio 16

Figura 5.58 - Concentração dos compostos intermediários ao longo do ciclo no ensaio 16: $\square$ - ácido acético; $\Delta$ - etanol; ○ - ácido butírico; - - ácido isobutírico; $\boldsymbol{\Delta}$ - ácido capróico; ácido valérico; -x-ácido propiônico; $\diamond$ butanol; + ácido isovalérico

Figura 5.59 - Produção volumétrica média acumulada do biogás durante o ciclo no ensaio 16 .103

Figura 5.60 - Concentração dos compostos do biogás durante o ciclo e suas respectivas porcentagens no ensaio 16: $\odot-\mathrm{H}_{2} ; \bullet-\mathrm{CH}_{4} ; \Delta-\mathrm{CO}_{2}$

Figura 5.61 - Concentração de matéria orgânica na forma de DQO no ensaio 17: $\square$ - afluente amostras não filtradas; • - efluente amostras não filtradas; ○ - efluente amostras filtradas. 105

Figura 5.62 - Eficiência de remoção de matéria orgânica na forma de DQO no ensaio 17: • - amostras não filtradas; ○ - amostras filtradas .105

Figura 5.63 - Valores de pH no ensaio 17: $\square-$ afluente; $\bullet$ - efluente 106

Figura 5.64 - Valores de alcalinidade total (AT) no ensaio 17: $\square$-afluente; $\bullet$ - efluente .106

Figura 5.65 - Valores de ácidos voláteis totais (AVT) no ensaio 17: $\square$-afluente; • - efluente. 106

Figura 5.66 - Volume de biogás $\left(\mathrm{V}_{\mathrm{G}}\right)$ e de hidrogênio $\left(\mathrm{V}_{\mathrm{H} 2}\right)$ na CNTP no ensaio 17: a -Biogás; o Hidrogênio .107

Figura 5.67 - Concentrações dos componentes do biogás no final do ciclo no ensaio 17: $\circ-\mathrm{H}_{2}$;

$\mathrm{CH}_{4} ; \Delta-\mathrm{CO}_{2}$ 107

Figura 5.68 - Concentração e eficiência de degradação de matéria orgânica durante o ciclo ensaio 17:

$$
\text { - }-\mathrm{C}_{\mathrm{SF}} ; \circ-\varepsilon_{\mathrm{SF}} \text {. }
$$

Figura 5.69 - Valores de $\mathrm{pH}$ durante o ciclo no ensaio 17. 108 
Figura 5.70 - Concentração de alcalinidade total durante o ciclo no ensaio 17

Figura 5.71 - Concentração de AVT durante o ciclo no ensaio 17

Figura 5.72 - Concentração dos compostos intermediários ao longo do ciclo no ensaio 17: $\square$ - ácido acético; $\Delta$ - etanol; ○ - ácido butírico; $\mathbf{-}$ - ácido isobutírico; $\boldsymbol{\Delta}$ - ácido capróico; • ácido valérico; -X-ácido propiônico; $\diamond$ butanol; + ácido isovalérico 109

Figura 5.73 - Produção volumétrica média acumulada do biogás durante o ciclo no ensaio 17 110

Figura 5.74 - Concentração dos compostos do biogás durante o ciclo e suas respectivas porcentagens no ensaio 17: $\circ-\mathrm{H}_{2} ; \bullet-\mathrm{CH}_{4} ; \Delta-\mathrm{CO}_{2}$

Figura 5.75 - Concentração de matéria orgânica na forma de DQO no ensaio 18: $\square-$ afluente amostras não filtradas; • - efluente amostras não filtradas; ○ - efluente amostras filtradas 112

Figura 5.76 - Eficiência de remoção de matéria orgânica na forma de DQO no ensaio 18: • - amostras não filtradas; $\bigcirc-$ amostras filtradas 112

Figura 5.77 - Valores de pH no ensaio 18: $\square-$ afluente; $\bullet$ - efluente.. 113

Figura 5.78 - Valores de alcalinidade total (AT) no ensaio 18: $\square$-afluente; $\bullet$ - efluente 113

Figura 5.79 - Valores de ácidos voláteis totais (AVT) no ensaio 18: $\square$-afluente; $\bullet$ - efluente. 113

Figura 5.80 - Volume de biogás $\left(\mathrm{V}_{\mathrm{G}}\right)$ e de hidrogênio $\left(\mathrm{V}_{\mathrm{H} 2}\right)$ na CNTP no ensaio 18: a -Biogás; o Hidrogênio

Figura 5.81 - Concentrações dos componentes do biogás no final do ciclo no ensaio 18: $\bigcirc-\mathrm{H}_{2}$; • $\mathrm{CH}_{4} ; \Delta-\mathrm{CO}_{2}$ 114

Figura 5.82 - Concentração e eficiência de degradação de matéria orgânica durante o ciclo ensaio 18:

- $-\mathrm{C}_{\mathrm{SF}} ; \circ-\varepsilon_{\mathrm{SF}}$ 115

Figura 5.83 - Valores de $\mathrm{pH}$ durante o ciclo no ensaio 18 115

Figura 5.84 - Concentração de alcalinidade total durante o ciclo no ensaio 18 115

Figura 5.85 - Concentração de AVT durante o ciclo no ensaio 18 116 
Figura 5.86 - Concentração dos compostos intermediários ao longo do ciclo no ensaio 18: $\square$ - ácido acético; $\Delta$ - etanol; o - ácido butírico; $\mathbf{a}$ - ácido isobutírico; $\boldsymbol{\Delta}$ - ácido capróico; ácido valérico; -x-ácido propiônico; $\diamond$ butanol; + ácido isovalérico.

Figura 5.87 - Produção volumétrica média acumulada do biogás durante o ciclo no ensaio 18 .117

Figura 5.88 - Concentração dos compostos do biogás durante o ciclo e suas respectivas porcentagens no ensaio 18: $\odot-\mathrm{H}_{2} ; \bullet-\mathrm{CH}_{4} ; \Delta-\mathrm{CO}_{2}$

Figura 5.89 - Concentração de matéria orgânica na forma de DQO no ensaio 19: $\square$ - afluente amostras não filtradas; • - efluente amostras não filtradas; ○ - efluente amostras filtradas.

Figura 5.90 - Eficiência de remoção de matéria orgânica na forma de DQO no ensaio 19: • - amostras não filtradas; ○ - amostras filtradas

Figura 5.91 - Valores de pH no ensaio 19: $\square-$ afluente; $\bullet$ - efluente.

Figura 5.92 - Valores de alcalinidade total (AT) no ensaio 19: $\square-$ afluente; $\bullet$ - efluente 120

Figura 5.93 - Valores de ácidos voláteis totais (AVT) no ensaio 19: $\square-$ afluente; $\bullet$ - efluente

Figura 5.94 - Volume de biogás $\left(\mathrm{V}_{\mathrm{G}}\right)$ e de hidrogênio $\left(\mathrm{V}_{\mathrm{H} 2}\right)$ na CNTP no ensaio 19: - -Biogás; o Hidrogênio

Figura 5.95 - Concentrações dos componentes do biogás no final do ciclo no ensaio 19: $\circ-\mathrm{H}_{2}$;

$\mathrm{CH}_{4} ; \Delta-\mathrm{CO}_{2}$

Figura 5.96 - Concentração e eficiência de degradação de matéria orgânica durante o ciclo ensaio 19:

$$
\bullet-\mathrm{C}_{\mathrm{SF}} ; \circ-\varepsilon_{\mathrm{SF}}
$$

Figura 5.97 - Valores de pH durante o ciclo no ensaio 19

Figura 5.98 - Concentração de alcalinidade total durante o ciclo no ensaio 19

Figura 5.99 - Concentração de AVT durante o ciclo no ensaio 19.

Figura 5.100 - Concentração dos compostos intermediários ao longo do ciclo no ensaio 19: $\square$ - ácido acético; $\Delta$ - etanol; ○ - ácido butírico; $\mathbf{\square}$ - ácido isobutírico; $\boldsymbol{\Delta}$ - ácido capróico; ácido valérico; -X-ácido propiônico; $\diamond$ butanol; + ácido isovalérico 
Figura 5.101 - Produção volumétrica média acumulada do biogás durante o ciclo no ensaio 19.

Figura 5.102 - Concentração dos compostos do biogás durante o ciclo e suas respectivas porcentagens

no ensaio 19: $\circ-\mathrm{H}_{2} ; \bullet-\mathrm{CH}_{4} ; \Delta-\mathrm{CO}_{2}$

Figura 5.103 - Monitoramento da DQO nos ensaios de 12 a 19: $\square$ - afluente amostras não filtradas;

- efluente amostras não filtradas; $\circ$ - efluente amostras filtradas

Figura 5.104 - Eficiência de remoção de matéria orgânica na forma de DQO nos ensaios de 12 a 19:

- amostras não filtradas; 0 - amostras filtradas. 126

Figura 5.105 - Valores de $\mathrm{pH}$ nos ensaios de 12 a 19: $\square-$ afluente; $\bullet-$ efluente

Figura 5.106 - Valores de alcalinidade total (AT) entre os ensaios de 12 a 19: $\square$-afluente; $\bullet$ - efluente .... 131

Figura 5.107 - Valores de ácidos voláteis totais (AVT) nos ensaios de 12 a 19: $\square$-afluente;

efluente

Figura 5.108 - Porcentagens $\left(\mathrm{Y}_{\mathrm{G}}\right)$ dos compostos do biogás: $\bullet$ - hidrogênio, • - metano, ○ - dióxido

de carbono.

Figura 5.109 - Reação de transformação da glicerina em ácido acético e hidrogênio

Figura 5.110 - Concentração de matéria orgânica na forma de DQO no ensaio 20: $\square$ - afluente

amostras não filtradas; • - efluente amostras não filtradas; ○ - efluente amostras filtradas ..... 139

Figura 5.111 - Eficiência de remoção de matéria orgânica na forma de DQO no ensaio 20:

amostras não filtradas; $\bigcirc-$ amostras filtradas. 139

Figura 5.112 - Valores de pH no ensaio 20: $\square-$ afluente; $\bullet$ - efluente .

Figura 5.113 - Valores de alcalinidade total (AT) no ensaio 20: $\square$-afluente; $\bullet-$ efluente. 140

Figura 5.114 - Valores de ácidos voláteis totais (AVT) no ensaio 20: $\square$-afluente; • - efluente. 140

Figura 5.115 - Volume de biogás $\left(\mathrm{V}_{\mathrm{G}}\right)$ e de hidrogênio $\left(\mathrm{V}_{\mathrm{H} 2}\right)$ na CNTP no ensaio 20: - -Biogás; o -

Hidrogênio

Figura 5.116 - Concentrações dos componentes do biogás no final do ciclo no ensaio 20: ० $-\mathrm{H}_{2}$;

$\mathrm{CH}_{4} ; \Delta-\mathrm{CO}_{2}$ 
Figura 5.117 - Concentração e eficiência de degradação de matéria orgânica durante o ciclo ensaio 20:

$\bullet-\mathrm{C}_{\mathrm{SF}} ; \circ-\varepsilon_{\mathrm{SF}}$

Figura 5.118 - Valores de $\mathrm{pH}$ durante o ciclo no ensaio 20

Figura 5.119 - Concentração de alcalinidade total durante o ciclo no ensaio 20. .142

Figura 5.120 - Concentração de AVT durante o ciclo no ensaio 20.

Figura 5.121 - Concentração dos compostos intermediários ao longo do ciclo no ensaio 20: $\square$ - ácido acético; $\Delta$ - etanol; ○ - ácido butírico; - - ácido isobutírico; $\boldsymbol{\Delta}$ - ácido capróico; ácido valérico; -x-ácido propiônico; $\diamond$ butanol; + ácido isovalérico

Figura 5.122 - Produção volumétrica média acumulada do biogás durante o ciclo no ensaio 20 .144

Figura 5.123 - Concentração dos compostos do biogás durante o ciclo e suas respectivas porcentagens no ensaio 20: $\odot-\mathrm{H}_{2} ; \bullet-\mathrm{CH}_{4} ; \Delta-\mathrm{CO}_{2}$ 144

Figura 5.124 - Reator ao final da operação do ensaio 21 145

Figura 5.125 - Concentração de matéria orgânica na forma de DQO no ensaio 21: $\square-$ afluente amostras não filtradas; • - efluente amostras não filtradas; ○ - efluente amostras filtradas

Figura 5.126 - Eficiência de remoção de matéria orgânica na forma de DQO no ensaio 21: amostras não filtradas; $\odot-$ amostras filtradas 147

Figura 5.127 - Valores de pH no ensaio 21: $\square-$ afluente; $\bullet$ - efluente. 148

Figura 5.128 - Valores de alcalinidade total (AT) no ensaio 21: $\square$-afluente; $\bullet$ - efluente 148

Figura 5.129 - Valores de ácidos voláteis totais (AVT) no ensaio 21: $\square$-afluente; • - efluente 148

Figura 5.130 - Volume de biogás $\left(\mathrm{V}_{\mathrm{G}}\right)$ e de hidrogênio $\left(\mathrm{V}_{\mathrm{H} 2}\right)$ na $\mathrm{CNTP}$ no ensaio 21: a -Biogás; o Hidrogênio 149

Figura 5.131 - Concentrações dos componentes do biogás no final do ciclo no ensaio 21: $\circ-\mathrm{H}_{2}$;

$\mathrm{CH}_{4} ; \Delta-\mathrm{CO}_{2}$ 149

Figura 5.132 - Concentração e eficiência de degradação de matéria orgânica durante o ciclo ensaio 21:

$\bullet-\mathrm{C}_{\mathrm{SF}} ; \circ-\varepsilon_{\mathrm{SF}}$ 
Figura 5.133 - Valores de $\mathrm{pH}$ durante o ciclo no ensaio 21

Figura 5.134 - Concentração de alcalinidade total durante o ciclo no ensaio 21

Figura 5.135 - Concentração de AVT durante o ciclo no ensaio 21

Figura 5.136 - Concentração dos compostos intermediários ao longo do ciclo no ensaio 21: $\square$ - ácido acético; $\Delta$ - etanol; ○ - ácido butírico; $\mathbf{\square}$ - ácido isobutírico; $\boldsymbol{\Delta}$ - ácido capróico; • ácido valérico; -x-ácido propiônico; $\diamond$ butanol; + ácido isovalérico

Figura 5.137 - Produção volumétrica média acumulada do biogás durante o ciclo no ensaio 21 152

Figura 5.138 - Concentração dos compostos do biogás durante o ciclo e suas respectivas porcentagens no ensaio 21: $\odot-\mathrm{H}_{2} ; \bullet-\mathrm{CH}_{4} ; \Delta-\mathrm{CO}_{2}$ 152

Figura 5.139 - Exame microbiológico realizado na biomassa do reator no ensaio 21 160 


\section{LISTA DE TABELAS}

Tabela 3.1 - Comparação entre trabalhos que avaliaram o tempo de enchimento do reator 15

Tabela 3.2 - Comparação de trabalhos para remoção de nitrogênio 20

Tabela 3.3 - Comparação de trabalhos para remoção de enxofre 21

Tabela 3.4 - Comparação de trabalhos para produção de metano 24

Tabela 3.5 - Comparação de trabalhos para produção de hidrogênio

Tabela 3.6 - Estudo comparativo entre culturas puras para produção de $\mathrm{H}_{2}$ 36

Tabela 3.7 - Estudo comparativo entre diferentes substratos para produção de $\mathrm{H}_{2}$ (adaptado de Sá et al., 2013) .36

Tabela 3.8 - Estudo comparativo entre culturas mistas para produção de $\mathrm{H}_{2}$ 36

Tabela 4.1 - Parâmetros operacionais do biorreator 43

Tabela 4.2 - Características do material suporte inerte .44

Tabela 4.3 - Tipos de inóculo utilizados nos experimentos 45

Tabela 4.4 - Tipos de glicerina utilizados nos experimentos. 46

Tabela 4.5 - Composição da água residuária utilizada nos ensaios de produção de biohidrogênio em AnSBBR com recirculação. 46

Tabela 4.6 - Cronograma das análises realizadas nos ensaios .48

Tabela 4.7 - Resumo das três fases de operação 53

Tabela 4.8 - Resumo das condições experimentais estudadas 55

Tabela 5.1 - Parâmetros monitorados na Condição Preliminar (3000 mgDQO.L $\mathrm{L}^{-1}-\mathrm{t}_{\mathrm{C}} 4 \mathrm{~h}$ - Sacarose) 64

Tabela 5.2 - Produção e fração molar referente ao biogás na Condição Preliminar 67

Tabela 5.3 - Parâmetros monitorados na Fase I

Tabela 5.4 - Produção e fração molar referente ao biogás na Fase I .77

Tabela 5.5 - Parâmetros médios monitorados nos ensaios 12 e 13. 79 
Tabela 5.6 - Produção e fração molar referente ao biogás nos ensaios 12 e 13 .82

Tabela 5.7 - Parâmetros médios monitorados no ensaio 14 .83

Tabela 5.8 - Parâmetros médios monitorados no ensaio 15 .90

Tabela 5.9 - Parâmetros médios monitorados no ensaio 16 .97

Tabela 5.10 - Parâmetros médios monitorados no ensaio 17 104

Tabela 5.11 - Parâmetros médios monitorados no ensaio 18 111

Tabela 5.12 - Parâmetros médios monitorados no ensaio 19 118

Tabela 5.13 - Comparação entre COVA, COVR, COEA e COER nos ensaios de 12 a 19 127

Tabela 5.14 - Equações bioquímicas e equivalente-grama dos compostos em DQO 128

Tabela 5.15 - Balanço de massa durante o monitoramento diário nos ensaios de 12 a 19 128

Tabela 5.16 - Balanço de massa durante os perfis nos ensaios de 12 a 19

Tabela 5.17 - Porcentagens molares dos ácidos voláteis intermediários para todos os ensaios 132

Tabela 5.18 - Comparação entre $\mathrm{n}_{\mathrm{H} 2}$, PrM, PrME, RMCA e RMCR nos ensaios de 12 a 19 133

Tabela 5.19 - Fração molar referente ao biogás nos ensaios de 12 a 19

Tabela 5.20 - Rendimento molar de hidrogênio em relação a glicerina nos ensaios de 14 a 19 136

Tabela 5.21 - Comparação entre trabalhos para avaliar o rendimento molar de hidrogênio em relação a glicerina .136

Tabela 5.22 - Parâmetros médios monitorados no ensaio 20 138

Tabela 5.23 - Parâmetros médios monitorados no ensaio 21 146

Tabela 5.24 - Condições experimentais dos ensaios 19, 20 e 21 153

Tabela 5.25 - Parâmetros relacionados a matéria orgânica nos ensaios 19, 20 e 21 154

Tabela 5.26 -Parâmetros relacionados a alcalinidade e ácidos nos ensaios 19, 20 e 21 155

Tabela 5.27 - Balanço de massa durante o monitoramento diário nos ensaios 19, 20 e 21 156

Tabela 5.28 - Balanço de massa durante os perfis nos ensaios 19, 20 e 21 156 
Tabela 5.29 - Comparação entre os parâmetros relativos à produção de biohidrogênio nos ensaios 19, 20 e 21

Tabela 5.30 - Resultado para o teste-T para amostras emparelhadas nos ensaios 19 e 20 158

Tabela 5.31 - Resultado para o teste ANOVA nos ensaios 19 e 20. 158

Tabela 5.32 - Comparação entre trabalhos que utilizaram glicerina bruta industrial como efluente. 159 


\section{LISTA DE ABREVIATURAS E SIGLAS}

\begin{tabular}{cc}
\hline Abreviatura/Símbolo & Denominação \\
\hline AM & Agitação Mecânica \\
AnSBBR & Reator Anaeróbio Operado em Batelada Sequencial com Biomassa \\
& Imobilizada em Suporte Inerte \\
ASBR & (Anaerobic Sequencing Batch Biofilm Reactor) \\
& Reator Anaeróbio Operado em Batelada Sequencial \\
CNTP & (Anaerobic Sequencing Batch Reactor) \\
DQO & Condições Normais de Temperatura e Pressão ( ${ }^{\circ} \mathrm{C}$ e 1atm) \\
EEM & Demanda Química de Oxigênio \\
EESC & Escola de Engenharia Mauá \\
IMT & Escola de Engenharia de São Carlos \\
PEBD & Instituto Mauá de Tecnologia \\
RFL & Polietileno de baixa densidade \\
GPA & Recirculação da Fase Líquida \\
GBL & Glicerina pura comercial (P.A.) \\
GBI & Glicerina bruta de laboratório \\
USP & Glicerina bruta industrial \\
& Universidade de São Paulo \\
\hline
\end{tabular}




\section{LISTA DE SÍMBOLOS}

\begin{tabular}{|c|c|c|}
\hline Símbolo & Denominação & Unidade \\
\hline $\mathrm{AP}$ & Alcalinidade parcial & $\left(\mathrm{mgCaCO}_{3} \cdot \mathrm{L}^{-1}\right)$ \\
\hline AI & Alcalinidade intermediária & $\left(\mathrm{mgCaCO}_{3} \cdot \mathrm{L}^{-1}\right)$ \\
\hline AT & Alcalinidade total & $\left(\mathrm{mgCaCO}_{3} \cdot \mathrm{L}^{-1}\right)$ \\
\hline $\mathrm{AB}$ & Alcalinidade a bicarbonato & $\left(\mathrm{mgCaCO}{ }_{3} \cdot \mathrm{L}^{-1}\right)$ \\
\hline AVT & Ácidos voláteis totais & $\left(\operatorname{mgHAc} . \mathrm{L}^{-1}\right)$ \\
\hline ST & Sólidos totais & $\left(\mathrm{mgST} . \mathrm{L}^{-1}\right)$ \\
\hline SVT & Sólidos voláteis totais & $\left(\operatorname{mgSVT} . L^{-1}\right)$ \\
\hline SST & Sólidos suspensos totais & $\left(\operatorname{mgSST} . \mathrm{L}^{-1}\right)$ \\
\hline SSV & Sólidos suspensos voláteis & $\left(\operatorname{mgSSV} . \mathrm{L}^{-1}\right)$ \\
\hline $\mathrm{pH}$ & Potencial hidrogeniônico & (u) \\
\hline $\mathrm{V}_{\mathrm{Gi}-\mathrm{BA}}$ & $\begin{array}{l}\text { Volume acumulado de biogás obtido em determinado ponto do } \\
\text { período em batelada alimentada }\end{array}$ & $(\mathrm{mL})$ \\
\hline $\mathrm{V}_{\mathrm{M}-\mathrm{i}}$ & Volume obtido pelo medidor de biogás & $(\mathrm{mL})$ \\
\hline $\mathrm{N}_{\mathrm{i}}$ & Número do ponto do perfil do biogás & \\
\hline $\mathrm{N}_{\mathrm{t}-\mathrm{BA}}$ & $\begin{array}{l}\text { Número total de pontos do perfil durante a batelada } \\
\text { alimentada }\end{array}$ & \\
\hline $\mathrm{V}_{\mathrm{Gi}-\mathrm{B}}$ & $\begin{array}{l}\text { Volume acumulado de biogás obtido em determinado ponto } \\
\qquad \text { do período em batelada }\end{array}$ & $(\mathrm{mL})$ \\
\hline $\mathrm{V}_{\mathrm{N}}$ & Volume de biogás nas CNTP & $(\mathrm{mL}-\mathrm{CNTP})$ \\
\hline $\mathrm{V}_{\mathrm{i}}$ & Volume de biogás a ser convertido & $(\mathrm{mL})$ \\
\hline $\mathrm{P}_{\mathrm{a}}$ & Pressão do ar no local da medição & (mbar) \\
\hline $\mathrm{P}_{\mathrm{V}}$ & Pressão parcial de vapor d’água & (mbar) \\
\hline $\mathrm{P}_{\mathrm{L}}$ & Pressão da coluna líquida acima da câmara de medição & (mbar) \\
\hline $\mathrm{P}_{\mathrm{N}}$ & Pressão normal (1013,25 mbar) & (mbar) \\
\hline $\mathrm{T}_{\mathrm{N}}$ & Temperatura normal $(273,15 \mathrm{~K})$ & $(\mathrm{K})$ \\
\hline $\mathrm{T}_{\mathrm{a}}$ & Temperatura no local da medição & $(\mathrm{K})$ \\
\hline $\mathrm{M}_{\mathrm{T}-\mathrm{SI}+\mathrm{B}}$ & Massa de suporte inerte e biomassa do reator & $(\mathrm{g})$ \\
\hline $\mathrm{M}_{\mathrm{A}-\mathrm{SI}+\mathrm{B}}$ & Massa da amostra de suporte inerte e biomassa do reator & $(\mathrm{g})$ \\
\hline $\mathrm{M}_{\mathrm{A}-\mathrm{ST}}$ & Massa de sólidos totais (ST) da amostra de biomassa & (g) \\
\hline $\mathrm{M}_{\mathrm{A}-\mathrm{SVT}}$ & Massa de sólidos voláteis totais (SVT) da amostra de biomassa & $(\mathrm{g})$ \\
\hline $\mathrm{M}_{\mathrm{SVT}}$ & Massa de sólidos voláteis totais (SVT) no interior do reator & (g) \\
\hline
\end{tabular}




\begin{tabular}{|c|c|c|}
\hline $\mathrm{C}_{\mathrm{X}}$ & Massa de sólidos voláteis totais (SVT) por volume de meio líquido & $\left(\mathrm{g} . \mathrm{L}^{-1}\right)$ \\
\hline $\mathrm{C}_{\mathrm{X}}^{\prime}$ & $\begin{array}{l}\text { Massa de sólidos voláteis totais (SVT) por massa de material } \\
\text { suporte }\end{array}$ & $\left(\mathrm{g} \cdot \mathrm{g}^{-1}\right)$ \\
\hline $\mathrm{V}_{\mathrm{A}}$ & Volume de água residuária alimentado por ciclo & (L) \\
\hline $\mathrm{V}_{\mathrm{R}}$ & Volume de meio líquido total no reator & (L) \\
\hline $\mathrm{V}_{\text {Res }}$ & $\begin{array}{l}\text { Volume de meio líquido residual no reator após a etapa de } \\
\qquad \text { descarga }\end{array}$ & (L) \\
\hline $\mathrm{V}_{\mathrm{u}}$ & Volume útil do reator & (L) \\
\hline $\mathrm{F}_{\mathrm{AFL}}$ & Vazão de alimentação do período em batelada alimentada & $\left(\mathrm{L} . \mathrm{h}^{-1}\right)$ \\
\hline $\mathrm{t}_{\mathrm{i}}$ & $\begin{array}{l}\text { Tempo de alimentação percorrido (período em batelada } \\
\text { alimentada) }\end{array}$ & (h) \\
\hline$t_{\mathrm{BA}}$ & Tempo de batelada alimentada & (h) \\
\hline $\mathrm{N}$ & Número de ciclos por dia & $\left(\right.$ ciclos. $\left.\mathrm{d}^{-1}\right)$ \\
\hline $\mathrm{C}_{\mathrm{SAFL}}$ & $\begin{array}{l}\text { Concentração de matéria orgânica não filtrada no afluente na } \\
\text { forma de DQO }\end{array}$ & $\left(\mathrm{mgDQO} \cdot \mathrm{L}^{-1}\right)$ \\
\hline $\mathrm{C}_{\mathrm{S} 0}$ & $\begin{array}{l}\text { Concentração de matéria orgânica filtrada no tempo inicial do } \\
\text { ciclo na forma de DQO (perfis) }\end{array}$ & $\left(\mathrm{mgDQO} . \mathrm{L}^{-1}\right)$ \\
\hline $\mathrm{C}_{\mathrm{ST}}$ & Concentração de matéria orgânica não filtrada na forma de DQO & $\left(\mathrm{mgDQO} \cdot \mathrm{L}^{-1}\right)$ \\
\hline $\mathrm{C}_{\mathrm{SF}}$ & Concentração de matéria orgânica filtrada na forma de DQO & $\left(\mathrm{mgDQO} \cdot \mathrm{L}^{-1}\right)$ \\
\hline$\varepsilon_{\mathrm{ST}}$ & $\begin{array}{l}\text { Eficiência de remoção de matéria orgânica não filtrada na forma } \\
\qquad \text { de DQO }\end{array}$ & $(\%)$ \\
\hline$\varepsilon_{\mathrm{SF}}$ & $\begin{array}{l}\text { Eficiência de remoção de matéria orgânica filtrada na forma de } \\
\qquad \text { DQO }\end{array}$ & $(\%)$ \\
\hline$\varepsilon_{\mathrm{S}}$ & $\begin{array}{l}\text { Eficiência de remoção de matéria orgânica filtrada na forma de } \\
\text { DQO ao longo do ciclo (perfis) }\end{array}$ & $(\%)$ \\
\hline COVA & $\begin{array}{c}\text { Carga orgânica volumétrica aplicada em termos de matéria } \\
\text { orgânica na forma de DQO }\end{array}$ & $\left(\mathrm{gDQO} \cdot \mathrm{L}^{-1} \cdot \mathrm{d}^{-1}\right)$ \\
\hline COEA & $\begin{array}{l}\text { Carga orgânica específica aplicada em termos de matéria orgânica } \\
\text { na forma de DQO }\end{array}$ & $\left(\right.$ gDQO.gSVT $\left.{ }^{-1} \cdot \mathrm{d}^{-1}\right)$ \\
\hline COVR & $\begin{array}{l}\text { Carga orgânica volumétrica removida em termos de matéria } \\
\text { orgânica na forma de DQO }\end{array}$ & $\left(\mathrm{gDQO} \cdot \mathrm{L}^{-1} \cdot \mathrm{d}^{-1}\right)$ \\
\hline COER & $\begin{array}{c}\text { Carga orgânica específica removida em termos de matéria } \\
\text { orgânica na forma de DQO }\end{array}$ & $\left(\right.$ gDQO.gSVT $\left.{ }^{-1} \cdot \mathrm{d}^{-1}\right)$ \\
\hline $\mathrm{n}_{\mathrm{H} 2}$ & Vazão molar de hidrogênio diária & $\left(\mathrm{molH}_{2} \cdot \mathrm{d}^{-1}\right)$ \\
\hline PrM & Produtividade molar de hidrogênio volumétrica & $\left(\mathrm{molH}_{2} \cdot \mathrm{m}^{-3} \cdot \mathrm{d}^{-1}\right)$ \\
\hline PrME & Produtividade molar de hidrogênio específica & $\left(\mathrm{molH}_{2} \cdot \mathrm{kgSVT}^{-1} \cdot \mathrm{d}^{-1}\right)$ \\
\hline
\end{tabular}




\begin{tabular}{|c|c|c|}
\hline $\mathrm{RMCA}_{\mathrm{DQO}}$ & $\begin{array}{l}\text { Rendimento entre hidrogênio (molar) produzido e matéria } \\
\text { orgânica (massa) aplicada na forma de DQO }\end{array}$ & $\left(\mathrm{molH}_{2} \cdot \mathrm{kgDQO}^{-1}\right)$ \\
\hline $\mathrm{RMCR}_{\mathrm{DQO}}$ & $\begin{array}{l}\text { Rendimento entre hidrogênio (molar) produzido e matéria } \\
\text { orgânica (massa) removida na forma de DQO }\end{array}$ & $\left(\mathrm{molH}_{2} \cdot \mathrm{kgDQO}^{-1}\right)$ \\
\hline $\mathrm{RMCA}_{\text {Glicerina }}$ & $\begin{array}{l}\text { Rendimento entre hidrogênio (molar) produzido e glicerina } \\
\text { aplicada (mols) }\end{array}$ & $\left(\mathrm{molH}_{2} \cdot \mathrm{mol}\right.$ glicerina $\left.{ }^{-1}\right)$ \\
\hline $\mathrm{RMCR}_{\text {GlicerinaAVT }}$ & $\begin{array}{l}\text { Rendimento entre hidrogênio (molar) produzido e glicerina } \\
\text { removida (mols) calculado pelo balanço diário }\end{array}$ & $\left(\mathrm{molH}_{2} \cdot \mathrm{mol}\right.$ glicerina $\left.{ }^{-1}\right)$ \\
\hline $\mathrm{RMCR}_{\text {GliceriaAVI }}$ & $\begin{array}{l}\text { Rendimento entre hidrogênio (molar) produzido e glicerina } \\
\text { removida (mols) calculado pelo balanço dos perfis }\end{array}$ & $\left(\mathrm{molH}_{2} \cdot \mathrm{mol} \mathrm{glicerina}^{-1}\right)$ \\
\hline $\mathrm{C}_{\mathrm{G}}$ & $\begin{array}{l}\text { Concentração de um componente do biogás }\left(\mathrm{H}_{2}, \mathrm{CH}_{4} \mathrm{ou}\right. \\
\left.\mathrm{CO}_{2}\right) \text { da amostra retirada do "head-space" do reator }\end{array}$ & $\left(\mathrm{mmol} . \mathrm{L}^{-1}\right)$ \\
\hline $\mathrm{V}_{\mathrm{G}}$ & Volume na CNTP de biogás total produzido por ciclo & $\left(\mathrm{mL}-\mathrm{CNTP} \cdot \mathrm{ciclo}^{-1}\right)$ \\
\hline $\mathrm{V}_{\mathrm{H} 2}$ & Volume na CNTP de hidrogênio produzido por ciclo & $\left(\mathrm{mL}-\mathrm{CNTP} \cdot\right.$ ciclo $\left.^{-1}\right)$ \\
\hline $\mathrm{N}_{\mathrm{G}}$ & $\begin{array}{l}\text { Vazão molar de cada componente do biogás }\left(\mathrm{H}_{2}, \mathrm{CH}_{4} \text { ou }\right. \\
\left.\qquad \mathrm{CO}_{2}\right) \text { produzido durante o ciclo }\end{array}$ & $(\mathrm{mmol})$ \\
\hline B & Reator operado em bateladas sequenciais & - \\
\hline BA & Reator operado em bateladas alimentadas & - \\
\hline$t_{\mathrm{F}}$ & Tempo pelo qual o reator foi alimentado & (h) \\
\hline$t_{C}$ & Tempo de ciclo & (h) \\
\hline $\mathrm{Y}_{\mathrm{CH} 4 / \mathrm{DQO}}$ & Rendimento entre metano produzido e DQO consumida & $\left(\mathrm{NmL} \cdot \mathrm{gDQO}{ }^{-1}\right)$ \\
\hline $\mathrm{DQO}_{\mathrm{AVI}}$ & $\begin{array}{l}\text { DQO dos ácidos voláteis intermediários discriminados } \\
\text { durante o perfil }\end{array}$ & $\left(\mathrm{mgDQO} \cdot \mathrm{L}^{-1}\right)$ \\
\hline $\mathrm{DQO}_{\mathrm{AVT}}$ & $\begin{array}{l}\text { DQO dos ácidos voláteis totais durante o monitoramento } \\
\qquad \text { diário }\end{array}$ & $\left(\mathrm{mgDQO} . \mathrm{L}^{-1}\right)$ \\
\hline $\mathrm{DQO}_{\text {Biomassa }}$ & DQO resultante do crescimento da biomassa & $\left(\mathrm{mgDQO} . \mathrm{L}^{-1}\right)$ \\
\hline $\mathrm{DQO}_{\mathrm{CAFL}}$ & DQO do afluente & $\left(\mathrm{mgDQO} . \mathrm{L}^{-1}\right)$ \\
\hline $\mathrm{DQO}_{\mathrm{CSF}}$ & DQO do efluente filtrado & $\left(\mathrm{mgDQO} . \mathrm{L}^{-1}\right)$ \\
\hline $\mathrm{DQO}_{\mathrm{GC}}$ & DQO da glicerina consumida & $\left(\mathrm{mgDQO} . \mathrm{L}^{-1}\right)$ \\
\hline $\mathrm{DQO}_{\mathrm{GNCD}}$ & $\begin{array}{c}\text { Aproximação do que seria a DQO real da glicerina não } \\
\text { consumida no monitoramento diário }\end{array}$ & $\left(\mathrm{mgDQO} . \mathrm{L}^{-1}\right)$ \\
\hline $\mathrm{DQO}_{\mathrm{GNCP}}$ & $\begin{array}{l}\text { Aproximação do que seria a DQO real da glicerina não } \\
\text { consumida no monitoramento do perfil. }\end{array}$ & $\left(\mathrm{mgDQO} . \mathrm{L}^{-1}\right)$ \\
\hline
\end{tabular}




\section{SUMÁRIO}

LISTA DE FIGURAS ...........................................................................................................XVIII

LISTA DE TABELAS ………………............................................................................................. XXX

LISTA DE ABREVIATURAS E SIGLAS.....................................................................XXXIV

LISTA DE SÍMBOLOS...................................................................................XXXVI

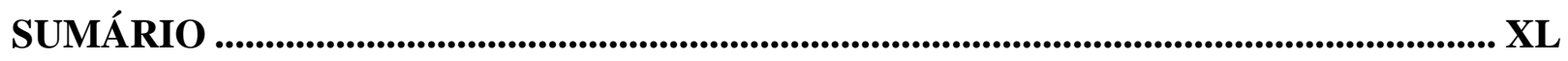

1 INTRODUÇÃO.....................................................................................................................

2 OBJETIVOS...................................................................................................................

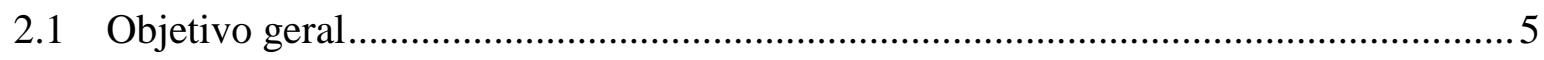

2.2 Objetivos específicos ...............................................................................

3 REVISÃO BIBLIOGRÁFICA ........................................................................................

3.1 Reatores Descontínuos ........................................................................................

3.2 Estratégias de Controle Operacional em Reatores Descontínuos ................................10

3.2.1 Influência da mistura.................................................................................... 10

3.2.2 Influência da imobilização da biomassa ............................................................. 11

3.2.3 Influência do tempo de enchimento ................................................................. 13

3.3 Remoção de Matéria Orgânica e Nutrientes em Reatores Descontínuos......................17

3.3.1 Remoção de matéria orgânica ...................................................................... 17

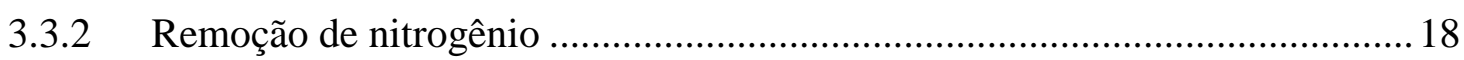

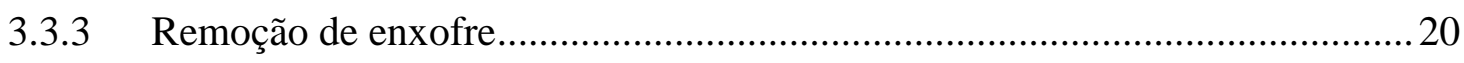

3.4 Produção de Metano em Reatores Descontínuos ............................................................21

3.5 Produção de Hidrogênio em Reatores Descontínuos ....................................................25

3.5.1 Processo fermentativo de produção de biohidrogênio .......................................2 26

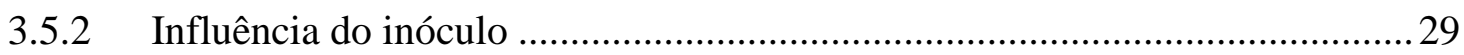

XL 
3.5.3 Influência do $\mathrm{pH}$ 30

3.5.4 Influência do tempo de detenção hidráulica ............................................... 31

3.5.5 Influência da carga orgânica aplicada e do tempo de enchimento ................. 32

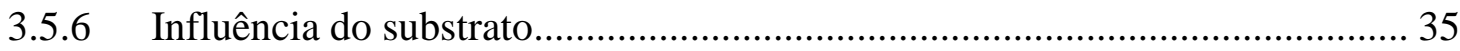

3.5.7 Modelagem cinética do processo de produção de $\mathrm{H}_{2}$ (Wu et al. 2013).......... 37

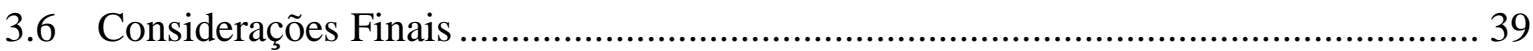

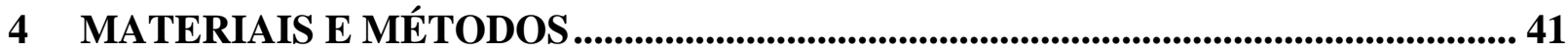

4.1 AnSBBR com biomassa imobilizada e recirculação da fase líquida......................... 41

4.2 Suporte de imobilização da biomassa anaeróbia e Inóculo ....................................... 44

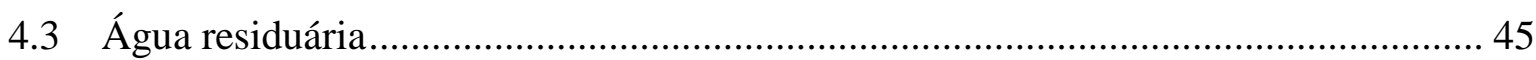

4.4 Análises físico-químicas e exames microbiológicos ................................................. 47

4.5 Procedimento experimental da operação do reator...................................................... 52

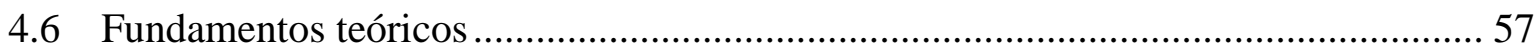

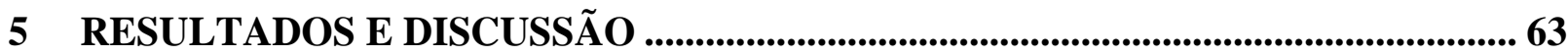

5.1 CONDIÇÃO EXPERIMENTAL PRELIMINAR - ENSAIO 0 …........................... 63

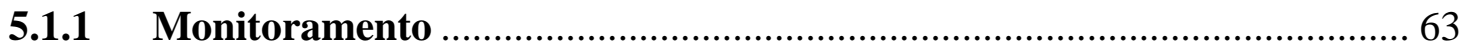

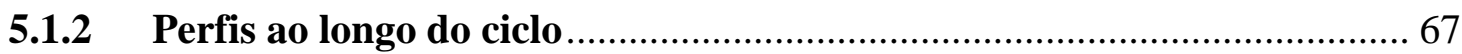

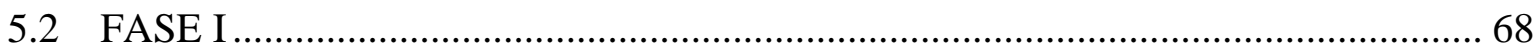

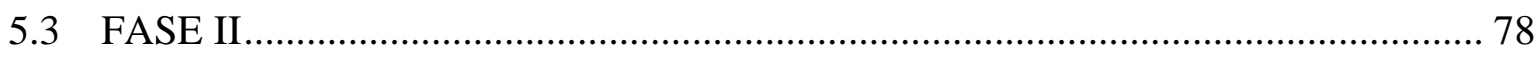

5.3.1 Ensaios 12 e 13 (1000 e 2000 mgDQO.L $^{-1}$ e 4 h de tempo de ciclo) .......... 78

5.3.2 Ensaio 14 (3000 mgDQO.L $\mathrm{L}^{-1}$ e 4 h de tempo de ciclo) ............................ 82

5.3.3 Ensaio 15 (4000 mgDQO.L $\mathrm{m}^{-1}$ e $4 \mathrm{~h}$ de tempo de ciclo) ............................ 90

5.3.4 Ensaio 16 (5000 mgDQO.L e $^{-1} 4 \mathrm{~h}$ de tempo de ciclo) .......................... 97

5.3.5 Ensaio 17 (3000 mgDQO.L ${ }^{-1}$ e 3 h de tempo de ciclo) ........................... 104

5.3.6 Ensaio 18 (4000 mgDQO.L $\mathrm{m}^{-1}$ e 3 h de tempo de ciclo) ........................... 111 
5.3.7 Ensaio 19 (5000 mgDQO.L $\mathrm{L}^{-1}$ e 3 h de tempo de ciclo) ........................... 118

5.3.8 Análise comparativa entre os ensaios 12 a 19.................................. 125

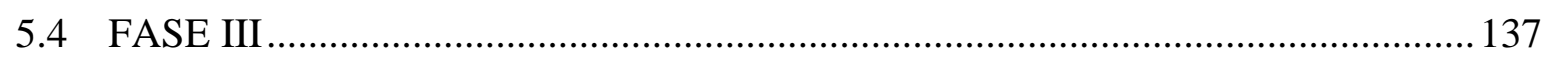

5.4.1 Ensaio 20 (5000 mgDQO.L $\mathrm{L}^{-1}, 3$ horas de tempo de ciclo e inóculo sem

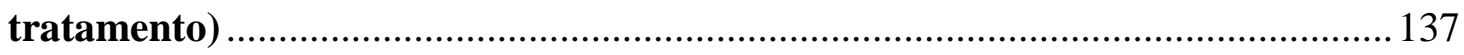

5.4.2 Ensaio 21 (5000 $\mathrm{mgDQO}^{-1}, \mathbf{3}$ horas de tempo de ciclo e GBI) ............. 145

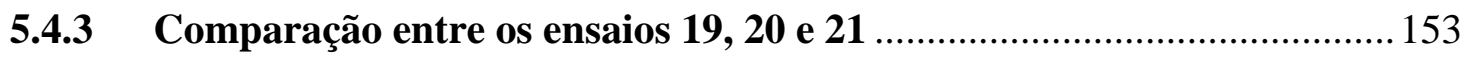

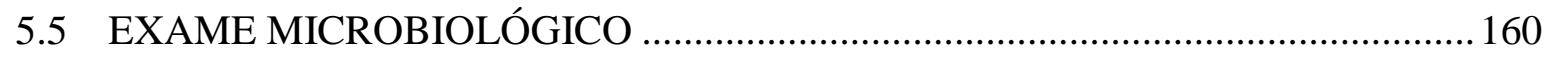

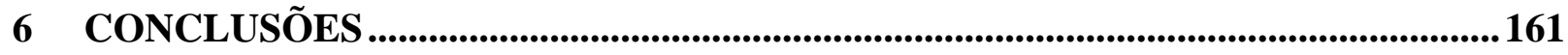

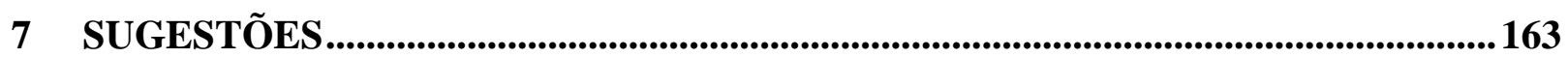

8 REFERÊNCIAS BIBLIOGRÁFICAS ....................................................................... 165

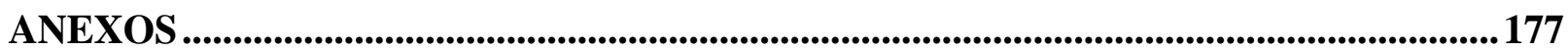





\section{INTRODUÇÃO}

As últimas décadas têm sido marcadas pela convergência de duas áreas de pesquisa no tratamento de águas residuárias: sua purificação e sua reutilização como uma fonte renovável de energia e produtos. Ambos os casos levam ao objetivo comum de benefício econômico através do consumo racional da água e produção de produtos e energia a partir de uma fonte limpa e renovável (Leite et al., 2008).

Cerca de $80 \%$ da demanda de energia global vem de combustíveis fósseis (petróleo, gás natural e carvão). Os óxidos resultantes, tais como COx, NOx e SOx causam o efeito estufa, destruição da camada de ozônio, chuva ácida e poluição. Recentemente, os esforços têm-se centrado no desenvolvimento de alternativas de energia limpa e, entre todos os potenciais candidatos, o hidrogênio $\left(\mathrm{H}_{2}\right)$ destaca-se como promissor para a energia do futuro por seu alto teor de energia por massa $\left(122 \mathrm{~kJ}^{-1}\right)$ e, mais importante, por só produzir água ao reagir com o oxigênio em células combustíveis. Seguindo essa linha, a substituição da energia proveniente de combustíveis fósseis por $\mathrm{H}_{2}$ parece ser uma opção razoável para sustentar o contínuo crescimento da economia global e, ao mesmo tempo, amenizar a situação do agravamento do clima global (Leite et al., 2008 e Wu et al., 2013).

A produção biológica de hidrogênio é uma forma interessante de produção desse gás, pois é uma tecnologia de baixo custo quando comparada a outras técnicas e requer menos energia para sua geração, podendo ocorrer por meio de dois processos: fotossíntese e processo fermentativo. A fermentação é tecnicamente mais simples e o hidrogênio pode ser obtido de matéria orgânica presente em águas residuárias. Diversas pesquisas demonstram a viabilidade da utilização do $\mathrm{H}_{2}$, produzido biologicamente, para geração de energia (Wu et al., 2009; Alzate-Gaviria et al., 2007; Leite et al., 2008). 
Diferentes águas residuárias são utilizadas como substrato para a produção de biohidrogênio, nas quais a fonte de matéria orgânica carbonácea consta de sacarose, amido de trigo, fração orgânica de resíduos sólidos, efluente de reatores biológicos, óleos vegetais e resíduos da produção de biodiesel. O objetivo comum de tais estudos consta da avaliação da produtividade de hidrogênio e da estabilidade operacional (Alzate-Gaviria et al, 2007; Jeong et al., 2007; Argun et al., 2008; Lin e Lay, 2004a-b, 2005; O-Thong et al., 2008; Oztekin et al., 2008; Sabourin-Provost et al., 2009; Ito et al., 2005; Nishio e Nakashimada, 2007; Yang et al., 2008) e, além disso, investigam a melhoria da composição das águas residuárias em termos do equilíbrio de nutrientes no intuito de possibilitar acréscimo de produtividade de hidrogênio e, assim, otimizar a aplicação desses diversos efluentes (Lin e Lay, 2005; Argun et al., 2008; Turcot et al., 2008).

No contexto desta linha de pesquisa, o Laboratório de Engenharia Bioquímica da Escola de Engenharia Mauá do Instituto Mauá de Tecnologia (EEM/IMT) e o Laboratório de Processos Biológicos (LPB) da Escola de Engenharia de São Carlos da Universidade de São Paulo (EESC/USP) tem realizado um grande esforço de desenvolvimento e otimização de configurações de reatores anaeróbios visando à produção de biohidrogênio por via fermentativa, nas quais os projetos têm enfoque no estudo da otimização de novas propostas de configurações visando uma futura aplicação para viabilização do uso do sistema em escala plena.

Desta forma, esse projeto tem por objetivo principal a aplicação do reator anaeróbio operado em batelada alimentada com recirculação da fase líquida e biomassa imobilizada em suporte inerte (AnSBBR), aplicado ao tratamento de efluente do processo de produção de biodiesel (glicerina) visando à produção de biohidrogênio.

A justificativa da escolha deste resíduo é que, embora a glicerina possua valor comercial como coproduto, sendo muitas vezes aproveitada como tal, o processo de produção 
de biodiesel gera entre 10 e 18\% (base mássica) de glicerina que, com a crescente produção do biocombustível pretendida para os próximos anos, dificilmente poderá ser vendida na sua totalidade como matéria-prima para as indústrias. Assim, a importância desse trabalho se baseia na produção de biogás juntamente com a potencial necessidade de tratamento desse efluente, no qual será avaliada a influência da carga orgânica, o tempo de ciclo e o tempo de enchimento sobre a eficiência e fator de conversão (entre a matéria orgânica utilizada e o hidrogênio produzido) como também a estabilidade das variáveis monitoradas no intuito de se obter um criterioso conhecimento sobre a viabilidade biotecnológica desse sistema.

A justificativa da escolha do biorreator e do protocolo experimental realizado se baseia no objetivo principal que se constitui em estudar opções tecnológicas da operação descontínua como alternativa à operação contínua, comumente empregada, no intuito de avaliar as principais vantagens relacionadas ao melhor controle operacional (carga-reação-descarga), à flexibilidade no modo de alimentação (diferentes tempos de ciclo) devido aos diferentes períodos de interrupção da produção, e à adequação a diferentes concentrações da água residuária disponível para a geração do biogás em "pequenas" unidades de produção. Tem-se também o intuito de avaliar as principais limitações deste reator relacionadas à possibilidade de sobre-carga e a consequente inibição microbiana, à menor "produtividade" pela necessidade de carga-descarga, e ao comportamento transiente inerente à operação descontínua. 


\section{OBJETIVOS}

Na sequência, são mostrados o objetivo geral e os objetivos específicos deste trabalho.

\subsection{OBJETIVO GERAL}

Esse projeto teve como objetivo principal avaliar a aplicação do reator anaeróbio operado em batelada alimentada sequencial com biomassa imobilizada em suporte inerte e recirculação da fase líquida $(\mathrm{AnSBBR})$ à produção de biohidrogênio pelo tratamento de resíduo do processo de produção de biodiesel (glicerina). Tal aplicação foi avaliada em função da estabilidade e eficiência do reator em obter hidrogênio a partir da biotransformação da matéria orgânica presente no resíduo utilizado.

\subsection{OBJETIVOS ESPECÍFICOS}

Com forma de atingir o objetivo geral do trabalho, teve os seguintes objetivos específicos:

- Avaliar a aplicação do AnSBBR à produção de biohidrogênio analisando a estabilidade e a eficiência do processo;

- Avaliar qualitativamente alguns fatores de influência do processo, como: velocidade ascensional do líquido, tipo de suporte, concentração de bicarbonato de sódio e suplementação da água residuária.

- Avaliar a remoção de matéria orgânica, produção de biogás, produtividade de hidrogênio e fator de rendimento entre o hidrogênio formado e a matéria orgânica consumida;

- Avaliar o comportamento do AnSBBR com relação aos indicadores anteriormente citados em função da carga orgânica aplicada/removida volumétrica/específica, 
implementando diferentes concentrações do afluente, tempos de ciclo e tempos de enchimento. 


\section{REVISÃO BIBLIOGRÁFICA}

A seguinte revisão bibliográfica relaciona o contexto científico referente ao desenvolvimento do reator anaeróbio operado em batelada sequencial com biomassa imobilizada (AnSBBR) com os avanços realizados no uso de processos anaeróbios na produção de bioenergia, enfatizando as variáveis que influenciam o processo e os dois principais compostos produzidos: metano e hidrogênio.

\subsection{REATORES DESCONTÍNUOS}

O desenvolvimento de processos anaeróbios para tratamento de águas residuárias tem mostrado grande progresso nos últimos anos devido aos novos projetos de reatores mais eficientes, mais estáveis e com menores custos de manutenção e operação. Um destes reatores é o reator anaeróbio operado em batelada e batelada alimentada, cujo ciclo típico compreende quatro etapas: (i) alimentação que pode ter o tempo de enchimento variável, definindo a estratégia de enchimento como batelada e/ou batelada alimentada; (ii) tratamento propriamente dito, por meio das biotransformações dos constituintes da água residuária por microrganismos; (iii) sedimentação quando a biomassa se encontrar na forma granulada (ASBR), pois quando a biomassa se encontra na forma imobilizada em suporte inerte (AnSBBR) esta etapa não é necessária; e (iv) descarga, com retirada do líquido tratado e clarificado (Dague et al., 1992; Fernandes et al., 1993; Zaiat et al., 2001). As maiores vantagens desse tipo de operação são a sua simplicidade, controle de qualidade eficiente do efluente, possibilidade de aplicação em diferentes escalas e em uma grande quantidade de águas residuárias.

Os reatores descontínuos usando biomassa granulada (ASBR) e imobilizada (AnSBBR) foram aplicados ao tratamento de vários tipos de águas residuárias como: esgotos 
sanitários, indústria alimentícia (soro de leite), indústria química (produtos de higiene pessoal, indústria automobilística, indústria metalúrgica, resíduos da produção de biodiesel, resíduos contento nitrogênio amoniacal, resíduos contendo sulfato), lixiviados de aterros, e resíduos de suinocultura (Canto et al., 2008; Damasceno et al., 2007 e 2008; Zimmer et al., 2008; Mockaitis et al., 2010; Bezerra et al., 2007, 2009 e 2011; Oliveira et al., 2008 e 2009; Albanez et al., 2009; Novaes et al., 2010a e 2010b; Carvalhinha et al., 2010, Archilha et al., 2010; Selma et al., 2010; Rodrigues et al., 2011; Costabile et al., 2011; Lovato et al., 2012; Silva et al., 2013).

As Figuras 3.1 e 3.2 mostram configurações típicas dos reatores ASBR e AnSBBR (Manssouri et al., 2013; Lovato et al., 2012). Para aperfeiçoar o sistema de tratamento biológico, existem diversas estratégias de controle operacional nos reatores; as seguintes seções desta revisão bibliográfica são dedicadas a mostrar as variáveis que desempenham um papel importante no controle dos reatores em estudo. 


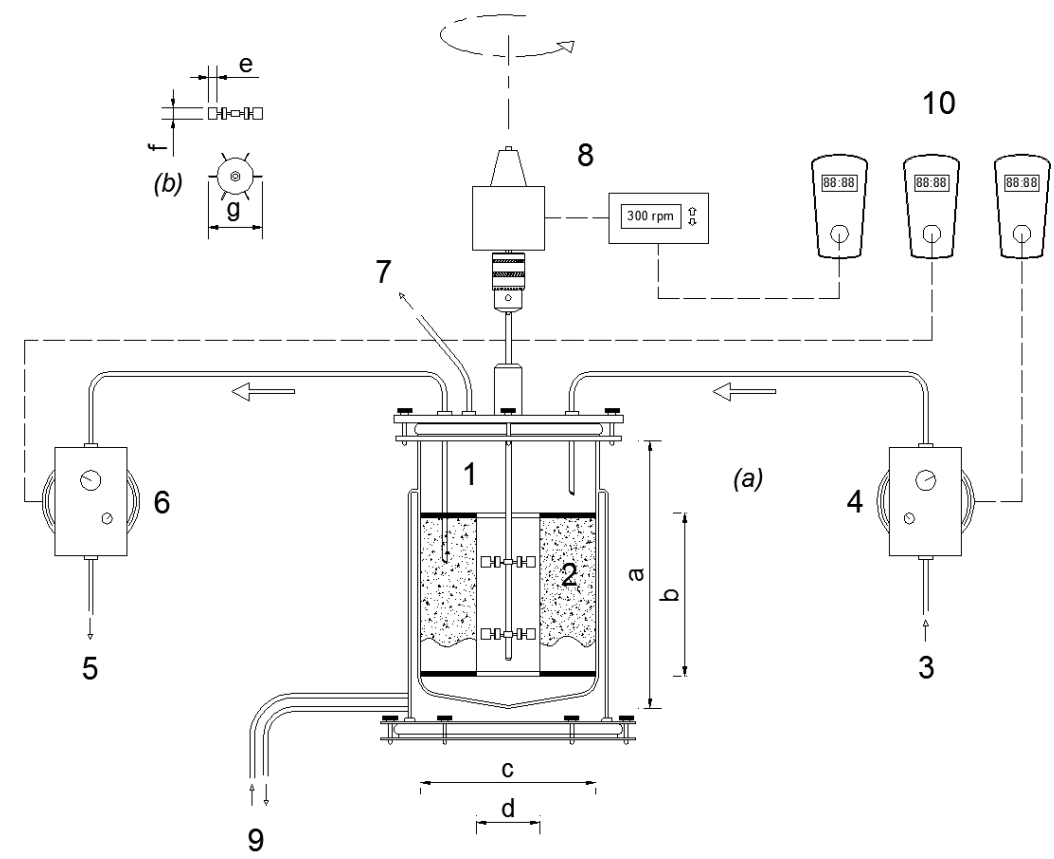

Figura 3.1 - ASBR e AnSBBR com agitação mecânica com impelidor (Manssouri, 2013) Notação: 1 - Reator; 2 - Cesto contendo material de suporte para a biomassa; 3 - Afluente; 4 Bomba de alimentação; 5 - Efluente; 6 - Bomba de descarga; 7 - Saída de biogás; 8 - Sistema de agitação; 9 - Controle de temperatura (banho termostático); 10 - Sistema de automação.

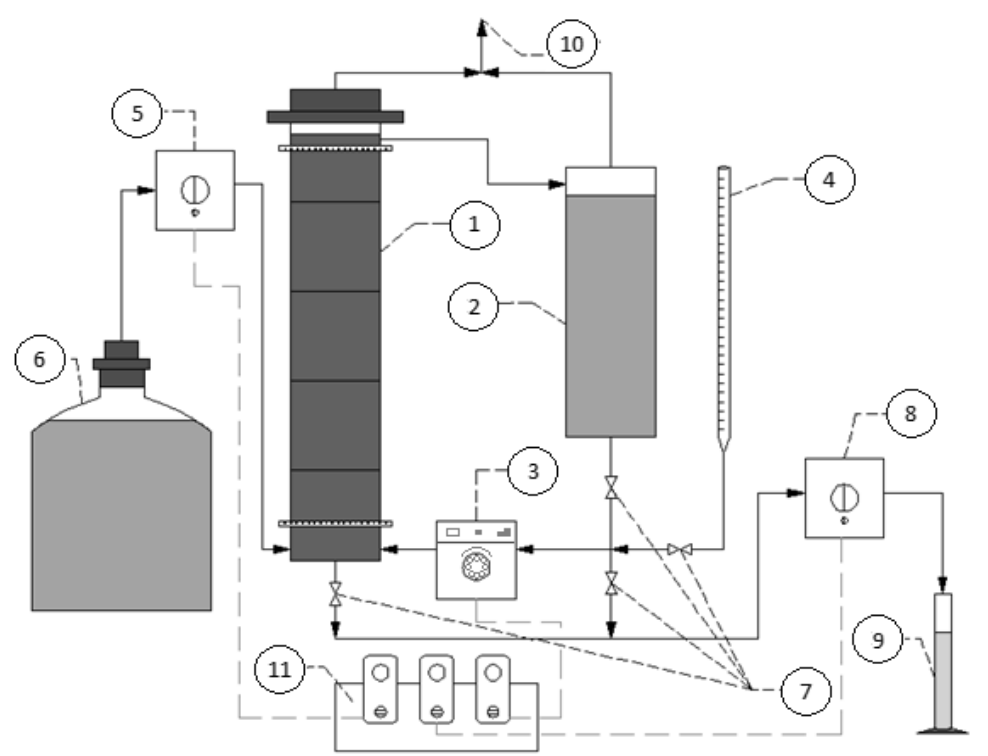

Figura 3.2 - ASBR e AnSBBR com mistura por recirculação da fase líquida (Lovato et al., 2012) Notação: 1 - Reator contendo biomassa imobilizada; 2 - Reservatório lateral; 3 - Bomba de reciclo; 4 - Medidor de vazão; 5 - Bombas de alimentação; 6 - Reservatório de água residuária; 7 - Válvulas de descarga; 8 - Bomba de descarga; 9 - Saída do efluente; 10 - Saída de biogás; 11 - Unidade de controle; —— Ligações hidráulicas; - - - Ligações elétricas. 


\subsection{ESTRATÉGIAS DE CONTROLE OPERACIONAL EM REATORES DESCONTÍNUOS}

\subsubsection{Influência da mistura}

A mistura natural em sistemas descontínuos é essencialmente feita por reciclo do gás gerado, sendo esta muito suave e não levando a grandes mudanças na carga orgânica removida no efluente (Zaiat et al., 2001). No entanto, a mistura com a recirculação da fase líquida ou o uso de agitadores com impelidores implica na melhora da transferência de massa dentro do reator (Ramos et al. 2003, Rodrigues et al., 2004; Novaes et al., 2010b). A Figura 3.3 (Camargo et al., 2005) ilustra essa melhora, onde Cs é a concentração de matéria orgânica no efluente da água residuária sintética com base de glucose tratada e o sistema contava com recirculação da fase líquida.

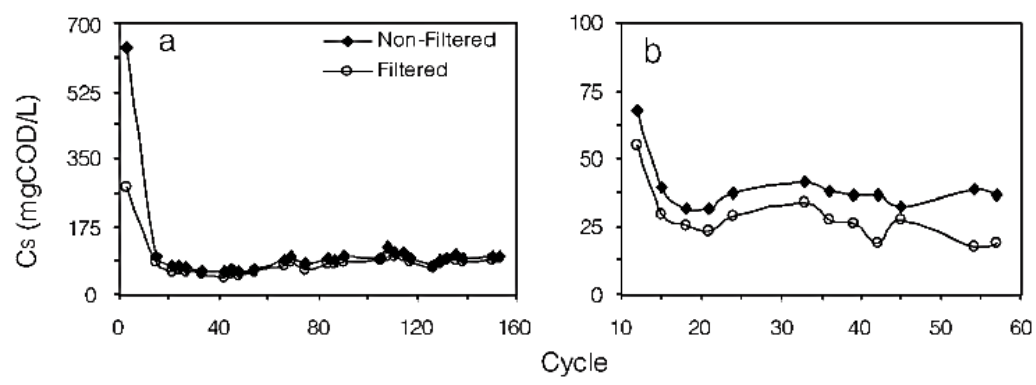

Figura 3.3 - Perfis de concentração de matéria orgânica efluente durante os ensaios para a condição sem recirculação (a) e com recirculação com velocidade superficial de $0,19 \mathrm{~cm} / \mathrm{s}$ (b) (Camargo et al., 2005)

A utilização de agitadores com impelidores requer um estudo sobre o tipo de impelidor e a intensidade de agitação que será utilizado no trabalho (no uso de recirculação, deve ser estudar a velocidade de recirculação). Cubas et al. (2011) fez esse estudo em um reator ASBR tratando água residuária sintética utilizando os impelidores da Figura 3.4, tendo sido verificado que os impelidores do tipo "flat-blade turbine" proporcionaram o melhor desempenho. 


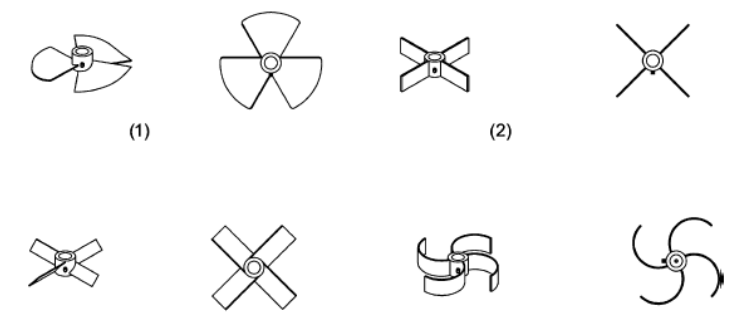

(3)

(4)

Figura 3.4 - Tipos de impelidor utilizados nos experimentos de Cubas et al. (2010). (1) Helical turbine; (2) Flat-blade turbine; (3) Inclined-blade turbine; (4) Curved-blade turbine

\subsubsection{Influência da imobilização da biomassa}

A grande diferença entre os dois reatores descontínuos mencionados reside no fator de imobilização da biomassa: o ASBR conta com biomassa granulada e o AnSBBR, com biomassa imobilizada em suporte inerte. O AnSBBR surgiu como uma alternativa ao ASBR por este apresentar um período de operação muito grande devido ao tempo que a biomassa leva para ficar granulada. Além disso, o uso de um suporte inerte melhora a retenção de sólidos e não requer nem a formação de grânulos e nem a etapa de sedimentação, permitindo um menor tempo de ciclo e melhorando a superfície de contato entre a biomassa e o meio (Ratusznei et al., 2000).

No entanto, Sarti et al. (2006) observaram similaridade significativa no desempenho dos dois reatores ASBR e AnSBBR no tratamento de esgoto sanitário em relação à remoção de matéria orgânica, havendo produção de biogás no ASBR anterior ao AnSBBR. Também foi feito uma avaliação da estrutura microbiana presente nos dois tipos de reatores e detectouse que as estruturas das comunidades domínio Bactéria presentes nos reatores no $35^{\circ}$ e $70^{\circ}$ dias de operação foram distintas, podendo-se inferir que a imobilização de biomassa empregada nas unidades pode ter proporcionado a seleção das populações bacterianas diferentemente. Em relação ao domínio Archaea verificou-se maior similaridade na estrutura microbiana nos reatores, provavelmente devido ao fato de essas populações utilizarem 
substratos específicos formados ao final do processo anaeróbio. Então, a escolha do tipo de reator deve ser feita realizando a análise para cada processo em particular.

A metodologia proposta por Zaiat et al. (1994) tem sido amplamente utilizada para a imobilização do lodo anaeróbio. Segundo esta metodologia, as partículas do suporte inerte deverão ser colocadas em recipiente e o lodo será adicionado até que todo o suporte esteja em contato com ele. Este contato se dará por 2 horas. Decorrido este período, as matrizes com as células aderidas serão colocadas em meio (o mesmo a ser utilizado nos experimentos) para lavagem dos sólidos fracamente aderidos. O meio será drenado e o inóculo estará pronto para ser inserido no reator.

A Figura 3.5 mostra a biomassa granulada e a Figura 3.6 mostra a imobilização feita em espumas de poliuretano e polietileno.

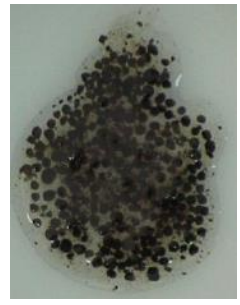

Figura 3.5 - Fotografia da biomassa granulada (Novaes et al., 2010a e 2010b)

(a)

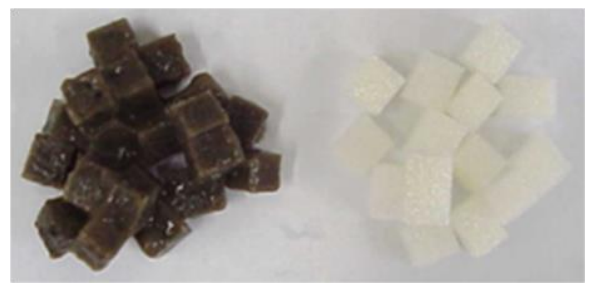

(b)

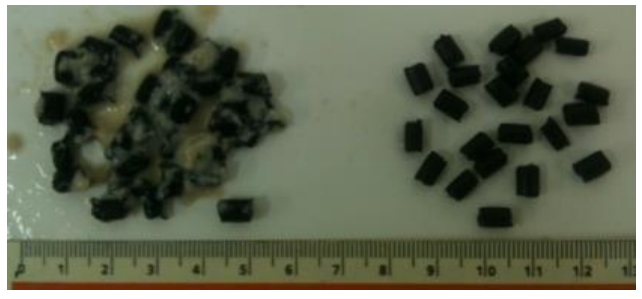

Figura 3.6 - Fotografias das partículas de suporte inerte de espuma de poliuretano (a) e de polietileno de baixa densidade (b) depois e antes da imobilização (direita e esquerda, respectivamente) (Lovato et al., 2012 e Manssouri, 2013) 


\subsubsection{Influência do tempo de enchimento}

Uma das variáveis mais relevantes dos reatores descontínuos é a estratégia de alimentação dos mesmos. Utilizar o tempo de enchimento mais adequado ao sistema permite uma melhor eficiência e estabilidade; enquanto o modo batelada consegue atingir concentrações maiores de biogás, o modo batelada alimentada permite manter baixas concentrações dos compostos no meio reacional e, portanto, inibir os efeitos da degradação do substrato; além disso, é possível realizar o tratamento de efluentes contendo elevadas cargas orgânicas, absorvendo elevados picos de ácidos voláteis que normalmente desestabilizariam o processo (Rodrigues et al., 2011).

Shizas e Bagley (2002) concluíram que longos tempos de alimentação tem uma influência positiva no desempenho do sistema. No entanto, Ratusznei et al. (2000) observaram que a eficiência de remoção pode diminuir e a estabilidade pode não ser atingida quando longos tempos de enchimentos são aplicados ao AnSBBR e a espuma de poliuretano é utilizada como suporte inerte. Os resultados negativos foram creditados ao "stress" da biomassa e escassez de alimento, já que parte do leito ficou sem substrato durante o período de enchimento do ciclo.

Utilizar como estratégia de alimentação a batelada ou a batelada alimentada tem importância não somente na remoção de matéria orgânica, mas na remoção de compostos como enxofre e nitrogênio. Friedl et al. (2009), por exemplo, concluiu que o aumento do tempo de enchimento favorece as bactérias redutoras de enxofre na competição por matéria orgânica e desfavorece outros microrganismos anaeróbios na assimilação de substrato.

Novaes et al. (2010a) inferiu que embora os reatores AnSBBR e ASBR apresentem comportamento similar no modo batelada alimentada, o AnSBBR apresenta vantagem em relação ao ASBR em relação a sensibilidade da biomassa exposta a agente externos, 
conferindo robustez na presença de eventuais cargas tóxicas e/ou de choque, assim como em relação a eventuais falhas no sistema de automação, que podem resultar em perda da biomassa. No entanto, o ASBR é mais seguro no quesito de entupimento do leito por sólidos presentes no afluente.

A Tabela 3.1 apresenta alguns estudos com diferentes tipos de efluentes que focaram na estratégia de alimentação do biorreator. A tendência é que a utilização do modo batelada alimentada aumente a eficiência do reator em relação à remoção de matéria orgânica e nutrientes, especialmente com a razão $t_{\mathrm{F}} / \mathrm{t}_{\mathrm{C}} \leq 0,5$, mas há exceções como no caso de Carvalhinha et al. (2010). Neste caso, o decréscimo na eficiência de remoção no modo batelada alimentada foi creditado ao substrato de difícil degradação e a não haver efeito inibitório com o efluente de indústria metalúrgica. Isso demonstra a necessidade do experimento em escala laboratorial para determinação do melhor modo de operação do biorreator. 
Tabela 3.1 - Comparação entre trabalhos que avaliaram o tempo de enchimento do reator

\begin{tabular}{|c|c|c|c|c|c|c|c|c|c|c|c|}
\hline Referência & Reator & Água Residuária & $\begin{array}{c}\text { Processo } \\
\text { (B/BA) }\end{array}$ & $\mathrm{t}_{\mathrm{F}} \cdot \mathrm{t}_{\mathrm{C}}^{-1}$ & tc $(\min )$ & $\begin{array}{c}\text { COVA } \\
\left(\mathrm{gDQO} \cdot \mathrm{L}^{-1} \cdot \mathrm{d}^{-1}\right)\end{array}$ & $\mathrm{C}_{\mathrm{saf}}\left(\mathrm{mgDQO} \cdot \mathrm{L}^{-1}\right)$ & $\mathrm{V}_{\mathrm{A}}\left(\mathrm{L} \cdot \operatorname{ciclo}^{-1}\right)$ & $\mathrm{V}_{\mathrm{R}}(\mathrm{L})$ & $\mathrm{C}_{\mathrm{sf}}\left(\mathrm{mgDQO} \cdot \mathrm{L}^{-1}\right)$ & $\begin{array}{l}\varepsilon_{\mathrm{SF}} \\
(\%)\end{array}$ \\
\hline \multirow{8}{*}{$\begin{array}{l}\text { Rodrigues et } \\
\text { al., } 2011\end{array}$} & \multirow{8}{*}{ AnSBBR } & \multirow{8}{*}{$\begin{array}{l}\text { Indústria de } \\
\text { cuidados pessoais }\end{array}$} & $\mathrm{B}$ & 0,02 & 480 & 1,50 & 500 & 2,5 & 2,5 & 205 & 60 \\
\hline & & & B & 0,02 & 480 & 1,50 & 1425 & 0,88 & 2,5 & 630 & 54 \\
\hline & & & $\mathrm{B}$ & 0,02 & 480 & 0,90 & 300 & 2,5 & 2,5 & 89 & 71 \\
\hline & & & $\mathrm{B}$ & 0,02 & 480 & 0,90 & 850 & 0,88 & 2,5 & 259 & 70 \\
\hline & & & BA & 0,50 & 480 & 1,50 & 500 & 2,5 & 2,5 & 129 & 74 \\
\hline & & & BA & 0,50 & 480 & 1,50 & 1425 & 0,88 & 2,5 & 257 & 80 \\
\hline & & & BA & 0,50 & 480 & 0,90 & 300 & 2,5 & 2,5 & 75 & 75 \\
\hline & & & BA & 0,50 & 480 & 0,90 & 850 & 0,88 & 2,5 & 134 & 85 \\
\hline \multirow{5}{*}{$\begin{array}{l}\text { Borges et al., } \\
2004\end{array}$} & \multirow{5}{*}{ ASBR } & \multirow{5}{*}{$\begin{array}{l}\text { Água residuária } \\
\text { sintética }\end{array}$} & B & 0,02 & 480 & 1,50 & 500 & 2,5 & 2,5 & 109 & 78 \\
\hline & & & BA & 0,25 & 480 & 1,50 & 500 & 2,5 & 2,5 & 101 & 80 \\
\hline & & & BA & 0,50 & 480 & 1,50 & 500 & 2,5 & 2,5 & 115 & 77 \\
\hline & & & BA & 0,75 & 480 & 1,50 & 500 & 2,5 & 2,5 & 134 & 73 \\
\hline & & & BA & 1,00 & 480 & 1,50 & 500 & 2,5 & 2,5 & 154 & 69 \\
\hline \multirow{9}{*}{$\begin{array}{l}\text { Bezerra et al., } \\
2009\end{array}$} & \multirow{9}{*}{ AnSBBR } & \multirow{9}{*}{ Soro de queijo } & BA & 0,25 & 480 & 3,00 & 1700 & 1,5 & 2,5 & 43 & 98 \\
\hline & & & $\mathrm{BA}$ & 0,50 & 480 & 3,00 & 1700 & 1,5 & 2,5 & 42 & 98 \\
\hline & & & BA & 0,75 & 480 & 3,00 & 1700 & 1,5 & 2,5 & 41 & 98 \\
\hline & & & BA & 0,25 & 480 & 6,00 & 3400 & 1,5 & 2,5 & 49 & 99 \\
\hline & & & BA & 0,50 & 480 & 6,00 & 3400 & 1,5 & 2,5 & 55 & 98 \\
\hline & & & BA & 0,75 & 480 & 6,00 & 3400 & 1,5 & 2,5 & 91 & 97 \\
\hline & & & $\mathrm{BA}$ & 0,25 & 480 & 12,00 & 6700 & 1,5 & 2,5 & 220 & 97 \\
\hline & & & BA & 0,50 & 480 & 12,00 & 6700 & 1,5 & 2,5 & 336 & 95 \\
\hline & & & BA & 0,75 & 480 & 12,00 & 6700 & 1,5 & 2,5 & 484 & 93 \\
\hline
\end{tabular}


Tabela 3.1 - Comparação entre trabalhos que avaliaram o tempo de enchimento do reator (continuação)

\begin{tabular}{|c|c|c|c|c|c|c|c|c|c|c|c|}
\hline \multirow{10}{*}{$\begin{array}{l}\text { Novaes et al., } \\
2010 \mathrm{a}\end{array}$} & \multirow{5}{*}{ ASBR } & \multirow{5}{*}{$\begin{array}{l}\text { Esgoto sanitário } \\
\text { doméstico }\end{array}$} & B & 0,03 & 390 & 1,37 & 703 & 650 & 1000 & 207 & 70 \\
\hline & & & BA & 0,25 & 390 & 1,19 & 609 & 650 & 1000 & 239 & 62 \\
\hline & & & BA & 0,50 & 390 & 1,51 & 775 & 650 & 1000 & 224 & 68 \\
\hline & & & BA & 0,75 & 390 & 1,27 & 650 & 650 & 1000 & 194 & 70 \\
\hline & & & BA & 1,00 & 390 & 1,01 & 518 & 650 & 1000 & 237 & 54 \\
\hline & \multirow{5}{*}{ AnSBBR } & \multirow{5}{*}{$\begin{array}{l}\text { Esgoto sanitário } \\
\text { doméstico }\end{array}$} & B & 0,02 & 450 & 1,42 & 730 & 650 & 1000 & 221 & 69 \\
\hline & & & BA & 0,25 & 450 & 1,19 & 609 & 650 & 1000 & 268 & 57 \\
\hline & & & BA & 0,50 & 450 & 1,51 & 775 & 650 & 1000 & 221 & 70 \\
\hline & & & BA & 0,75 & 450 & 1,27 & 650 & 650 & 1000 & 191 & 70 \\
\hline & & & $\mathrm{BA}$ & 1,00 & 450 & 1,01 & 518 & 650 & 1000 & 250 & 51 \\
\hline \multirow{8}{*}{$\begin{array}{l}\text { Selma et al., } \\
2010\end{array}$} & \multirow{8}{*}{ ASBR } & \multirow{8}{*}{$\begin{array}{c}\text { Efluente sintético } \\
\text { de produção de } \\
\text { biodiesel }\end{array}$} & B & 0,02 & 480 & 0,60 & 500 & 2 & 5 & 24 & 93 \\
\hline & & & B & 0,02 & 480 & 1,20 & 1000 & 2 & 5 & 151 & 81 \\
\hline & & & B & 0,02 & 480 & 2,40 & 2000 & 2 & 5 & 547 & 66 \\
\hline & & & $\mathrm{B}$ & 0,02 & 480 & 3,60 & 3000 & 2 & 5 & 1526 & 40 \\
\hline & & & BA & 0,25 & 480 & 1,20 & 1000 & 2 & 5 & 162 & 78 \\
\hline & & & BA & 0,50 & 480 & 1,20 & 1000 & 2 & 5 & 163 & 81 \\
\hline & & & BA & 0,25 & 480 & 2,40 & 2000 & 2 & 5 & 409 & 75 \\
\hline & & & BA & 0,50 & 480 & 2,40 & 2000 & 2 & 5 & 458 & 73 \\
\hline \multirow{3}{*}{$\begin{array}{l}\text { Oliveira et al., } \\
2008\end{array}$} & \multirow{3}{*}{ AnSBBR } & \multirow{3}{*}{$\begin{array}{l}\text { Efluente de } \\
\text { indústria } \\
\text { automobilística }\end{array}$} & B & 0,02 & 480 & 1,04 & 869 & 2 & 5 & 486 & 78 \\
\hline & & & $\mathrm{B} / \mathrm{BA}$ & 0,52 & 480 & 1,03 & 858 & 2 & 5 & 496 & 77 \\
\hline & & & $\mathrm{BA}$ & 0,50 & 480 & 1,18 & 987 & 2 & 5 & 193 & 80 \\
\hline \multirow{5}{*}{$\begin{array}{l}\text { Carvalinha et } \\
\text { al., } 2010\end{array}$} & \multirow{5}{*}{ ASBR } & \multirow{5}{*}{$\begin{array}{l}\text { Efluente sintético } \\
\text { de indústria } \\
\text { metalúrgica }\end{array}$} & $\mathrm{B}$ & 0,02 & 480 & 0,60 & 500 & 2 & 5 & 67 & 87 \\
\hline & & & B & 0,02 & 480 & 1,25 & 1039 & 2 & 5 & 151 & 86 \\
\hline & & & B & 0,02 & 480 & 2,43 & 2026 & 2 & 5 & 397 & 80 \\
\hline & & & B & 0,02 & 480 & 3,75 & 3125 & 2 & 5 & 1099 & 65 \\
\hline & & & FB & 0,50 & 480 & 2,46 & 2052 & 2 & 5 & 577 & 72 \\
\hline
\end{tabular}




\subsection{REMOÇÃO DE MATÉRIA ORGÂNICA E NUTRIENTES EM REATORES DESCONTÍNUOS}

O tratamento de águas residuárias consiste na remoção de poluentes para que as mesmas possam ser despejadas em um corpo receptor sem alterar a qualidade do mesmo. Tornar esses efluentes ambientalmente adequados exige tanto a remoção da matéria orgânica quanto a de outros compostos como nitrogênio, fósforo e enxofre que podem causar a eutrofização dos corpos d'água e problemas de saúde para quem entra em contanto com os mesmos. A seguir, é feita uma breve revisão sobre a remoção de matéria orgânica, nitrogênio e enxofre em ASBRs e AnSBBRs.

\subsubsection{Remoção de matéria orgânica}

A matéria orgânica presente nos corpos d'água e nos esgotos é a causadora do principal problema de poluição das águas: o consumo de oxigênio dissolvido pelos microrganismos nos seus processos metabólicos de utilização e estabilização da matéria orgânica. Os principais componentes orgânicos são os compostos de proteína, os carboidratos, a gordura e os óleos, além da uréia, surfactantes, fenóis, pesticidas e outros em menor quantidade. A matéria carbonácea divide-se nas seguintes frações: (a) não biodegradável (em suspensão e dissolvida) e (b) biodegradável (em suspensão e dissolvida).

Praticamente todo o trabalho que realiza o tratamento de águas residuárias por biorreatores, tem como um de seus objetivos a remoção de matéria orgânica de seu afluente. Neste contexto, é pertinente citar que o tempo de enchimento do reator em relação à remoção de matéria orgânica deve ser tal que permita um ganho de velocidade de reação maior do que a perda devido à inibição causada pelo acúmulo de ácidos. 
A Figura 3.7 (Lovato et al., 2012) mostra a influência do tempo de enchimento no perfil de concentração de matéria orgânica em um reator AnSBBR tratando efluente do processo de produção de biodiesel; enquanto o ciclo do reator era de 8 horas, foram estudados tempos de alimentação de 2, 4 e 6 horas para uma carga orgânica volumétrica de 4,5 gDQO.(L.d $)^{-1}$. Pode notar que o tempo de enchimento de 6 horas se mostrou menos eficiente na remoção de DQO do que o tempo de enchimento de 4 horas justamente por ter menor velocidade de reação. Neste caso, nenhuma das duas condições apresentou inibição por concentração de substrato.

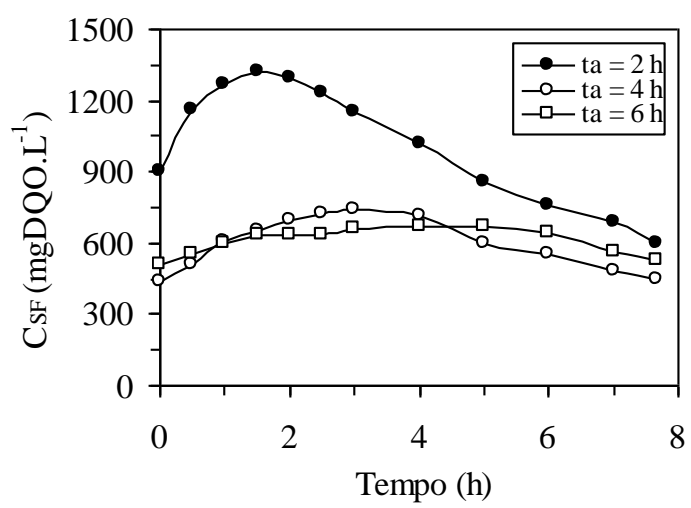

Figura 3.7 - Perfis de concentração de matéria orgânica na operação com tempo de enchimento (ta) de 2, 4 e 6 h (COV = 4,5 gDQO.(L.d) ${ }^{-1}$ (Lovato et al., 2012)

\subsubsection{Remoção de nitrogênio}

As maiores fontes de emissão de nitrogênio incluem a aplicação de nitrogênio em excesso como fertilizante em culturas e criação intensiva de animais. No entanto, efluentes industriais, particularmente de indústrias localizadas em pequenas e médias comunidades desempenham um papel importante neste processo. Esses efluentes prejudicam a qualidade da água de muitos aquíferos e podem causar sérios problemas de eutrofização em vias d'água e um aumento de problemas de saúde da população relacionados à ingestão de nitrogênio em certas formas. O tratamento de efluentes líquidos contendo nitrogênio tem, portanto, atraído a atenção de muitos pesquisadores durante a última década. 
A nitrificação e a desnitrificação são os processos biológicos de larga escala mais utilizados para a remoção orgânica de nitrogênio amoniacal de águas residuárias. A nitrificação acontece por meios autotróficos aeróbios, que oxidam o nitrogênio amoniacal para nitrito e posteriormente para nitrato. A desnitrificação ocorre sobre condições anóxicas heterotróficas, nas quais as fontes orgânicas de carbono agem como doadoras de elétrons e reduzem o nitrato para nitrogênio gasoso.

Um fator crítico no processo de remoção de nitrogênio é a necessidade de oxigênio para o processo de nitrificação. Um sistema de biomassa imobilizada tende a ser vantajoso devido ao seu custo energético reduzido para a aeração (Canto et al, 2008).

O período de alimentação de reatores com propósitos de remoção de nitrogênio tende a ser diferente dos reatores que objetivam remoção de matéria orgânica apenas, já que é necessário primeiramente alimentar a água residuária, para depois realizar a aeração e, em seguida, prover fontes de carbono para a desnitrificação. A Figura 3.8 ilustra a distribuição do tempo de operação que Albanez et al. (2009) implementou em seu trabalho.

A Tabela 3.2 mostra uma comparação entra trabalhos utilizando SBR/SBBR para a remoção de nitrogênio, na qual VNFL é a carga volumétrica de nitrogênio amoniacal alimentada no sistema e VNLR é a carga volumétrica de nitrogênio amoniacal removida do sistema. Os altos índices de remoção de nitrogênio amoniacal removido indicam o potencial de aplicação dos reatores SBR/SBBR em pós-tratamentos de efluentes líquidos.

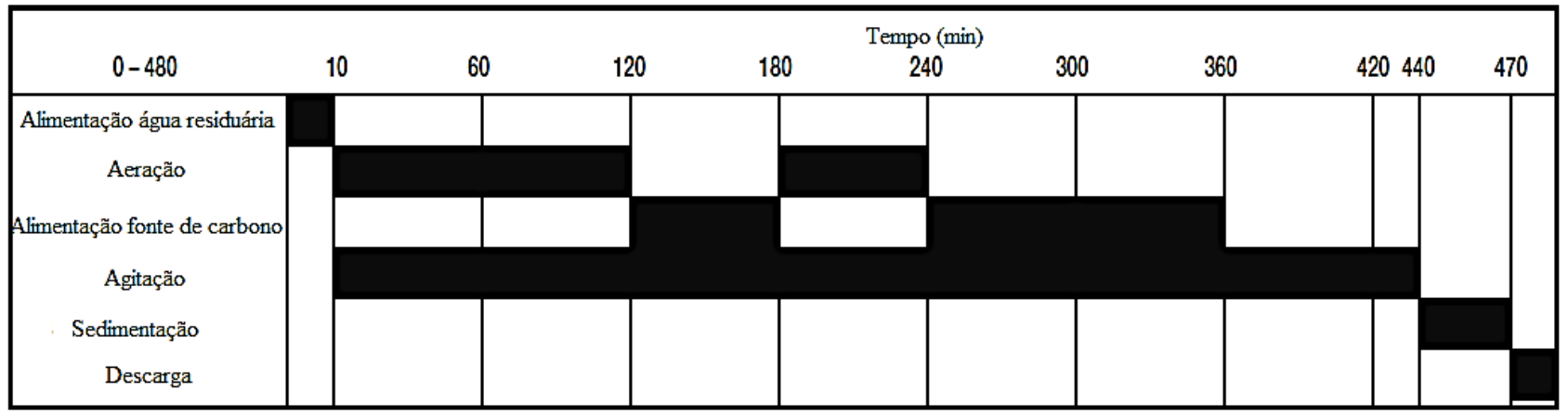

Figura 3.8 - Distribuição do tempo no ciclo de remoção de nitrogênio (Albanez et al. 2009) 
Tabela 3.2 - Comparação de trabalhos para remoção de nitrogênio

\begin{tabular}{|c|c|c|c|c|}
\hline Referência & Canto et al., 2008 & Canto et al., 2008 & Albanez et al., 2009 & Albanez et al., 2009 \\
\hline Água residuária & Sintética & Sintética & Sintética & Sintética \\
\hline Reator & SBBR & SBBR & SBR & SBR \\
\hline Processo & B -BA & B - BA & $\mathrm{B}-\mathrm{BA}$ & B - BA \\
\hline Tempo Processo (min) & 720 & 620 & 480 & 480 \\
\hline Volume reator $(\mathrm{L})$ & 4,6 & 4,6 & 5 & 5 \\
\hline Volume alimentado (L) & 2,1 & 2,1 & 1,5 & 1,5 \\
\hline $\mathrm{C}_{\mathrm{SAFL}}\left(\mathrm{mgDQO} \cdot \mathrm{L}^{-1}\right)$ & 127,9 & 126,6 & 99 & 104 \\
\hline$\varepsilon_{\mathrm{SF}}(\%)$ & 85,2 & 85,1 & 73,3 & 91,5 \\
\hline$\%\left(\mathrm{~N}-\mathrm{NO}_{2}{ }^{-}\right)_{\text {Produzido }}$ & 0,2 & 0,3 & 0,7 & 0,4 \\
\hline$\left.\%\left(\mathrm{~N}-\mathrm{NO}_{3}\right)^{-}\right)_{\text {Produzido }}$ & 21,9 & 34,4 & 0 & 0,4 \\
\hline$\%\left(\mathrm{~N} \mathrm{NH}_{4}{ }^{+}\right)_{\text {Removido }}$ & 93,8 & 97,6 & 97,6 & 99,6 \\
\hline$\%(\mathrm{~N}-\mathrm{Org})_{\text {Removido }}$ & 79,2 & 100 & 74,1 & 71,4 \\
\hline$\%(\mathrm{~N}-\text { Total })_{\text {Removido }}$ & 72,2 & 66,7 & 94,4 & 95,9 \\
\hline Carbono/Nitrogênio & 5,2 & 2,4 & 5,2 & 3,3 \\
\hline $\begin{array}{c}\text { VNFL } \\
\left(\mathrm{mgN}^{-N_{4}}{ }_{4}^{+} \cdot(\mathrm{L} \cdot \mathrm{d})^{-1}\right)\end{array}$ & 58,4 & 118,5 & 29 & 67 \\
\hline $\begin{array}{c}\text { VNLR } \\
\left(\mathrm{mgN}^{-N H} 4^{+\cdot}(\mathrm{L} . \mathrm{d})^{-1}\right)\end{array}$ & 54,8 & 115,7 & 28,3 & 66,7 \\
\hline
\end{tabular}

\subsubsection{Remoção de enxofre}

O impacto ambiental de águas residuárias contaminadas com sulfato é muito conhecido e geralmente é relacionado à acidificação de águas naturais e ao sulfeto de hidrogênio resultante do metabolismo anaeróbio. Vários processos químicos e bioquímicos têm sido utilizados para remover esse sulfato, como osmose reversa e precipitação com bário e cálcio, mas há obstáculos importantes nesse processo como o alto custo dos produtos e o descarte de resíduos químicos. Uma alternativa menos complexa e mais barata é a remoção biológica envolvendo a redução do sulfato $\left(\mathrm{SO}_{4}{ }^{2-}\right)$ para sulfeto de hidrogênio $\left(\mathrm{H}_{2} \mathrm{~S}\right)$ seguido da oxidação do sulfeto para enxofre elementar $\left(S^{o}\right)$. Portanto, a redução anaeróbia de sulfato em águas residuárias contaminadas, como estratégia de tratamento, tem sido muito visada em pesquisas recentes (Mockaitis et al., 2010). 
Estudos que trabalham com os reatores biológicos SBR/SBBR encontraram bons índices de remoção de sulfato (Tabela 3.3) e mostram que o modo batelada alimentada tende a aumentar a eficiência de remoção em relação ao modo batelada.

Tabela 3.3 - Comparação de trabalhos para remoção de enxofre

\begin{tabular}{|c|c|c|c|c|c|c|c|}
\hline Referência & $\begin{array}{l}\text { Archilha et } \\
\text { al., } 2010\end{array}$ & $\begin{array}{l}\text { Archilha et } \\
\text { al., } 2010\end{array}$ & $\begin{array}{l}\text { Costabile et } \\
\text { al., } 2011\end{array}$ & $\begin{array}{l}\text { Costabile et } \\
\text { al., } 2011\end{array}$ & $\begin{array}{l}\text { Mockaitis } \\
\text { et al., } 2010 \\
\end{array}$ & $\begin{array}{l}\text { Mockaitis } \\
\text { et al., } 2010 \\
\end{array}$ & $\begin{array}{l}\text { Mockaitis } \\
\text { et al., } 2010 \\
\end{array}$ \\
\hline Água residuária & Sintética & Sintética & Sintética & Sintética & Sintética & Sintética & Sintética \\
\hline Reator & SBBR & SBBR & SBBR & SBBR & SBR & SBR & SBR \\
\hline Processo & Batelada & B-BA & Batelada & B-BA & Batelada & BA & BA \\
\hline $\begin{array}{l}\text { Tempo Processo } \\
\text { (min) }\end{array}$ & 480 & 480 & 480 & 480 & 480 & 480 & 480 \\
\hline $\begin{array}{l}\text { Tempo Alimentação } \\
\text { (min) }\end{array}$ & 10 & $10+240$ & 10 & $10+240$ & 10 & 240 & 360 \\
\hline $\begin{array}{c}\text { Volume reator } \\
\text { (L) }\end{array}$ & 3,7 & 3,7 & 3,7 & 3,7 & 5 & 5,5 & 5,5 \\
\hline $\begin{array}{l}\text { Volume alimentado } \\
\text { (L) }\end{array}$ & 2 & 2 & 2 & 2 & 2 & 2 & 2 \\
\hline $\begin{array}{c}\mathrm{C}_{\mathrm{SAFL}} \\
\left(\mathrm{mgDQO} . \mathrm{L}^{-1}\right)\end{array}$ & 1530 & 4747 & 1544 & 1459 & 523 & 523 & 523 \\
\hline $\begin{array}{l}\varepsilon_{\mathrm{SF}} \\
(\%)\end{array}$ & 83,1 & 77,8 & 33,5 & 62,8 & 78 & 74 & 72 \\
\hline $\begin{array}{l}\text { Concentração } \mathrm{SO}_{4}{ }^{2-} \\
\left(\mathrm{mgSO}_{4}{ }^{2-} \cdot \mathrm{L}^{-1}\right)_{\text {Afluente }}\end{array}$ & 1522 & 2242 & 1551 & 782 & 1166 & 952 & 1110 \\
\hline $\begin{array}{c}\varepsilon \text { remoção } \mathrm{SO}_{4}{ }^{2-} \\
(\%)\end{array}$ & 54,2 & 84,6 & 84 & 88 & 23 & 37 & 27 \\
\hline
\end{tabular}

\subsection{PRODUÇÃO DE METANO EM REATORES DESCONTÍNUOS}

O processo metanogênico de tratamento de águas residuárias baseadas em carbono inclui as seguintes atividades microbiológicas: hidrólise, acidogênise, acetogênese, metanogênese e lise da célula. A primeira e a última dessas atividades são consideradas processos de não-crescimento, enquanto as outras são consideradas processos de crescimento. Esses processos podem ser divididos em subprocessos baseados no sistema e componentes de interesse.

$\mathrm{Na}$ acidogênese, um grande grupo de microrganismos é usado para biotransformar açúcares em ácidos com ou sem a liberação de hidrogênio e produção dos ácidos lático, butírico, propiônico e acético. $\mathrm{Na}$ acetogênese, um grupo de microrganismos acetogênicos 
produtores de hidrogênio converte ácidos graxos (ácidos butírico e propiônico) em ácido acético. No processo metanogênico, os microrganismos metanogênicos acetoclásticos e hidrogenotróficos são responsáveis pela conversão do ácido acético em dióxido de carbono e metano e pela redução do dióxido de carbono com o hidrogênio para formar metano. A lise da célula é o processo pelo qual células vivas são convertidas em partículas não vivas e material solúvel (Rodrigues et al., 2004).

A Figura 3.9 ilustra o processo de conversão da DQO e as respectivas porcentagens de conversão de cada etapa da degradação da parte volátil de resíduos biodegradáveis.
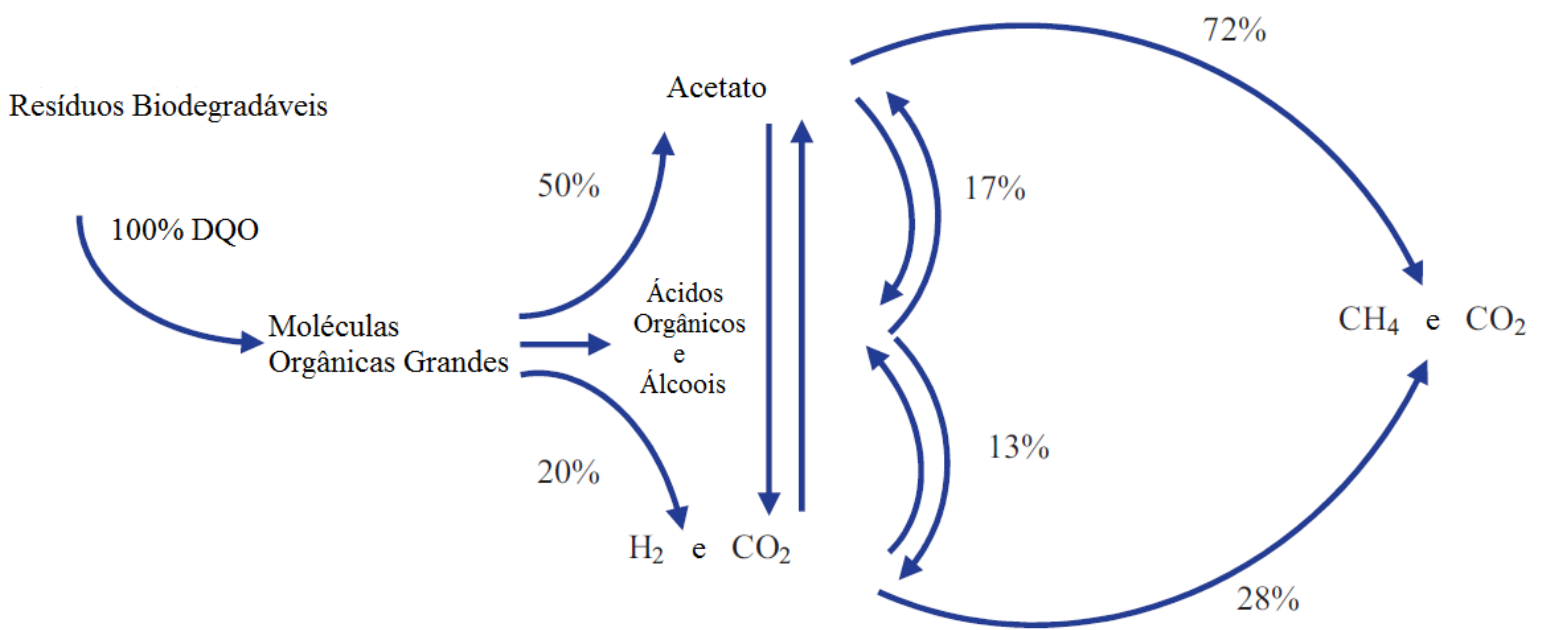

Figura 3.9 - Conversão da DQO disponível em resíduos biodegradáveis (Chandra et al., 2012)

A Tabela 3.4 mostra uma comparação com trabalhos anteriores que realizaram a produção de metano a partir do efluente de produção de biodiesel (glicerina bruta industrial ou glicerina bruta de laboratório); como é possível notar, o modo batelada alimentada favoreceu o aumento da concentração de metano no biogás gerado tanto no trabalho de Silva el al. (2013) quanto no de Lovato et al. (2012) que foi realizado em comparação com o de Bezerra et al. (2011), e a eficiência de remoção de matéria orgânica também aumentou utilizando o modo batelada alimentada. Um ponto muito interessante que deve ser ressaltado é que a razão tempo de alimentação por tempo de ciclo $\left(\mathrm{t}_{\mathrm{F}} / \mathrm{t}_{\mathrm{C}}\right)$ ótima, em relação à remoção de 
matéria orgânica, aparece como sendo 0,5 em três destes trabalhos (Selma et al., 2010; Lovato et al., 2012; Silva et al., 2013). Além disto, Borges et al. (2004) observaram que a batelada alimentada no tratamento de água residuária sintética só é eficiente enquanto $t_{\mathrm{F}} / \mathrm{t}_{\mathrm{C}}$ é menor do que 0,5 e Rodrigues et al. (2003b) também observaram que essa mesma razão não afeta a performance do ASBR quando é maior que 0,5. Pode-se inferir também que, pela comparação dos trabalhos de Selma et al. (2010), Bezerra et al. (2011) e Silva et al. (2013) nas mesmas condições de carga orgânica do afluente, o reator ASBR apresenta maiores concentrações de metano em seu biogás e produz um maior volume por ciclo; o modo batelada alimentada melhora essas duas variáveis.

A comparação entre os trabalhos de Faria et al. (2011) e Lovato (2012) permite observar que a degradação da glicerina bruta produzida em laboratório e com resíduos de metanol é mais fácil do que a da glicerina bruta industrial, que passa por um processo de destilação para purificação do biodiesel e reaproveitamento do metanol.

A Figura 3.10 mostra perfis de concentração de metano ao longo de um reator AnSBBR em função dos tempos de enchimento.

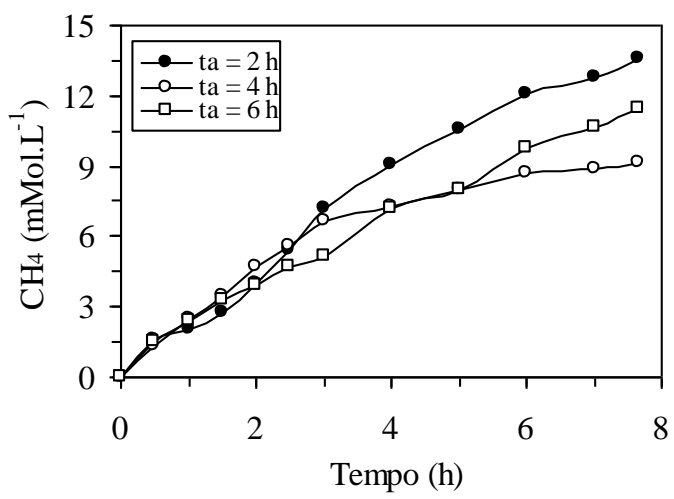

Figura 3.10 - Perfis de concentração de metano na operação com tempo de alimentação $\left(t_{a}\right)$ de 2,4 e $\left.6 \mathrm{~h}(\mathrm{COVA}=4,5 \mathrm{gDQO} \text {.(L.d })^{-1}\right)$ (Lovato et al., 2012) 
Tabela 3.4 - Comparação de trabalhos para produção de metano

\begin{tabular}{|c|c|c|c|c|c|c|c|c|c|c|c|c|c|c|}
\hline Referências & Reator & $\begin{array}{c}\text { Processo } \\
\text { (B/BA - } \\
\text { GBL/GBI) }\end{array}$ & $\mathrm{t}_{\mathrm{F}} \cdot \mathrm{t}_{\mathrm{C}}^{-1}$ & $\mathrm{t}_{\mathrm{C}}(\min )$ & $\begin{array}{c}\text { COVA } \\
\left(\mathrm{gDQO} .(\mathrm{L} . \mathrm{d})^{-1}\right)\end{array}$ & $\frac{\mathrm{C}_{\mathrm{SAFL}}}{\left(\mathrm{mgDQO} \cdot \mathrm{L}^{-1}\right)}$ & $\begin{array}{c}\mathrm{V}_{\mathrm{A}} \\
\left(\mathrm{L} . c i c l o^{-1}\right)\end{array}$ & $\begin{array}{l}\mathrm{V}_{\mathrm{R}} \\
(\mathrm{L})\end{array}$ & $\underset{\left(\mathrm{mgDQO} \cdot \mathrm{L}^{-1}\right)}{\mathrm{C}_{\mathrm{SF}}}$ & $\varepsilon_{\mathrm{SF}}(\%)$ & $\mathrm{Y}_{\mathrm{CH} 4 / \mathrm{DQO}}$ & $\begin{array}{c}\mathrm{V}_{\mathrm{CH} 4} \\
(\mathrm{NmL})\end{array}$ & $\underset{\left(\mathrm{mmol} \cdot \mathrm{L}^{-1}\right)}{\mathrm{C}_{\mathrm{CH}}}$ & $\begin{array}{c}\% \mathrm{CH}_{4} \\
\text { no } \\
\text { biogás } \\
\end{array}$ \\
\hline \multirow{5}{*}{$\begin{array}{l}\text { Selma et } \\
\text { al., } 2010\end{array}$} & ASBR & $\mathrm{B}-\mathrm{GBL}$ & 0,02 & 480 & 1,2 & 1000 & 2 & 5 & 151 & 85 & 83,8 & 153,3 & 8,95 & 74 \\
\hline & ASBR & B - GBL & 0,02 & 480 & 2,4 & 2000 & 2 & 5 & 547 & 73 & 78,1 & 231,9 & 11,8 & 69 \\
\hline & ASBR & $\mathrm{BA}-\mathrm{GBL}$ & 0,50 & 480 & 1,2 & 1000 & 2 & 5 & 163 & 85 & - & - & 8,04 & 71 \\
\hline & ASBR & $\mathrm{BA}-\mathrm{GBL}$ & 0,25 & 480 & 2,4 & 2000 & 2 & 5 & 409 & 80 & - & - & 11,4 & 69 \\
\hline & ASBR & $\mathrm{BA}-\mathrm{GBL}$ & 0,50 & 480 & 2,4 & 2000 & 2 & 5 & 458 & 77 & - & - & 11,3 & 70 \\
\hline \multirow{3}{*}{$\begin{array}{c}\text { Bezerra et } \\
\text { al., } 2011\end{array}$} & AnSBBR & $\mathrm{B}-\mathrm{GBL}$ & 0,02 & 480 & 3,0 & 2000 & 1,5 & 3 & 400 & 81 & 39,6 & 99,0 & 1,4 & 64 \\
\hline & AnSBBR & $\mathrm{B}-\mathrm{GBL}$ & 0,02 & 480 & 4,5 & 3000 & 1,5 & 3 & 1011 & 67 & 55,5 & 171,0 & 2,4 & 57 \\
\hline & AnSBBR & $\mathrm{B}-\mathrm{GBL}$ & 0,02 & 480 & 6,0 & 4000 & 1,5 & 3 & 1956 & 50 & 36,0 & 108,0 & 1,6 & 51 \\
\hline \multirow{7}{*}{$\begin{array}{c}\text { Silva et al., } \\
2013\end{array}$} & ASBR & B - GBI & 0,02 & 480 & 2,4 & 2000 & 2 & 5 & 391 & 81 & 93,7 & 318,9 & 13,9 & 68 \\
\hline & ASBR & $\mathrm{B}-\mathrm{GBI}$ & 0,04 & 240 & 1,2 & 2000 & 1 & 5 & 392 & 80 & 49,7 & 166,0 & 8,92 & 65 \\
\hline & ASBR & B - GBI & 0,04 & 240 & 1,8 & 3000 & 1 & 5 & 990 & 69 & 42,8 & 184,4 & 7,33 & 64 \\
\hline & ASBR & BA - GBI & 0,50 & 480 & 2,4 & 2000 & 2 & 5 & 391 & 81 & - & - & 12,8 & 72 \\
\hline & ASBR & BA - GBI & 0,50 & 480 & 3,6 & 3000 & 2 & 5 & 583 & 81 & - & - & 12,9 & 64 \\
\hline & ASBR & $\mathrm{BA}-\mathrm{GBI}$ & 0,50 & 240 & 1,2 & 2000 & 1 & 5 & 352 & 83 & - & - & 8,50 & 68 \\
\hline & ASBR & BA - GBI & 0,5 & 240 & 3,6 & 3000 & 1 & 5 & 941 & 70 & - & - & 10,1 & 64 \\
\hline \multirow{7}{*}{$\begin{array}{l}\text { Lovato et } \\
\text { al., } 2012\end{array}$} & AnSBBR & $\mathrm{BA}-\mathrm{GBL}$ & 0,25 & 480 & 4,5 & 3000 & 1,5 & 3 & 503 & 84 & - & - & 13,6 & 75 \\
\hline & AnSBBR & $\mathrm{BA}-\mathrm{GBL}$ & 0,50 & 480 & 4,5 & 3000 & 1,5 & 3 & 413 & 87 & - & - & 9,20 & 71 \\
\hline & AnSBBR & $\mathrm{BA}-\mathrm{GBL}$ & 0,75 & 480 & 4,5 & 3000 & 1,5 & 3 & 498 & 84 & - & - & 11,4 & 72 \\
\hline & AnSBBR & BA - GBL & 0,25 & 480 & 6,0 & 4000 & 1,5 & 3 & 1181 & 71 & - & - & 11,2 & 67 \\
\hline & AnSBBR & $\mathrm{BA}-\mathrm{GBL}$ & 0,50 & 480 & 6,0 & 4000 & 1,5 & 3 & 651 & 84 & - & - & 11,9 & 73 \\
\hline & AnSBBR & $\mathrm{BA}-\mathrm{GBL}$ & 0,75 & 480 & 6,0 & 4000 & 1,5 & 3 & 608 & 84 & - & - & 12,2 & 74 \\
\hline & AnSBBR & BA - GBL & 0,5 & 480 & 7,5 & 5000 & 1,5 & 3 & 1024 & 79 & - & - & 14,3 & 65 \\
\hline \multirow{2}{*}{$\begin{array}{l}\text { Faria et al., } \\
2011\end{array}$} & AnSBBR & BA - GBI & 0,50 & 480 & 6,0 & 4000 & 1,5 & 3 & 1064 & 74 & - & - & - & - \\
\hline & AnSBBR & $\mathrm{BA}-\mathrm{GBI}$ & 0,50 & 480 & 7,5 & 5000 & 1,5 & 3 & 1854 & 63 & - & - & 3,62 & 62 \\
\hline
\end{tabular}




\subsection{PRODUÇÃO DE HIDROGÊNIO EM REATORES DESCONTÍNUOS}

A ideia de usar o hidrogênio como fonte de energia não é nova e se iniciou em 1868 com os trabalhos do cientista E. Viel. As desvantagens do uso de combustíveis fósseis já eram conhecidas naquela época e o hidrogênio apareceu como uma alternativa segura, resultando somente na produção de água (Suzuki, 1982). O hidrogênio é um combustível eficiente com

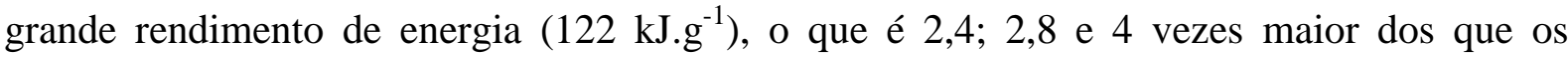
rendimentos energéticos do metano, gasolina e carvão, respectivamente (Mohammadi et al., 2012).

Atualmente, $90 \%$ do hidrogênio produzido têm origem nas reações de produtos derivados do petróleo. Estes processos, operados em altas temperaturas, necessitam um consumo intensivo de energia e fornecem hidrogênio para aplicações industriais específicas. Assim, esta forma de produção para uso de hidrogênio como fonte de energia não pode ser considerada como economicamente viável. Processos biológicos de produção de hidrogênio são operados em condições de temperatura e de pressão ambiente, então o desenvolvimento de tais processos pode oferecer alternativas sustentáveis para responder à crescente demanda de energia. (Davila-Vazquez et al., 2007).

Os processos fermentativos, quanto comparados aos fotossintéticos, são mais viáveis, possuem adequadas velocidades de crescimento de microrganismos para a manutenção do sistema, possuem alta velocidade de produção de hidrogênio sem depender da disponibilidade de energia solar e, além disso, podem utilizar a matéria orgânica presente em águas residuárias como matéria prima (Das e Veziroglu, 2001; Wang e Wan, 2009). 


\subsubsection{Processo fermentativo de produção de biohidrogênio}

Segundo Tanisho (2001) e Lee et al. (2011) o hidrogênio molecular pode ser formado através de duas rotas, pela via de decomposição do ácido fórmico (Equação 3.1) ou pela reoxidação da nicotinamida adenina dinucleotídeo (NADH para NAD ${ }^{+}$) (Equações 3.3 e 3.4).

$$
\mathrm{HCOOH} \rightarrow \mathrm{H}_{2}+\mathrm{CO}_{2}
$$

Esta via é intimamente relacionada com a fermentação via acetato, já que o piruvato é transformado em acetato e ácido fórmico (Equação 3.2).

$$
\begin{array}{ccc}
\mathrm{CH}_{3} \mathrm{COCOOH}+\mathrm{H}_{2} \mathrm{O} & \underset{3}{\mathrm{CH}_{3} \mathrm{COOH}}+\mathrm{HCOOH} \\
\text { Piruvato } & \text { Ácido } & \text { Ácido } \\
& \text { Acético } & \text { Fórmico }
\end{array}
$$

No segundo caso, o hidrogênio é formado pela reoxidação do NADH, que segundo Tanisho, (2001), ocorre nas fermentações da via acetona-butanol e na via butirato.

$$
\begin{gathered}
N A D H+H^{+}+2 \mathrm{Fd}^{2+} \rightarrow 2 \mathrm{H}^{+}+\mathrm{NAD}^{+}+2 \mathrm{Fd}^{+} \\
2 \mathrm{Fd}^{+} 2 \mathrm{H}^{+} \stackrel{\text { Hidrogenase }}{\longrightarrow} 2 \mathrm{Fd}^{2+}+\mathrm{H}_{2}
\end{gathered}
$$

A concentração de hidrogênio obtida pelo processo depende diretamente da via metabólica seguida pelas bactérias fermentativas (Equações 3.5 e 3.6) (Das e Veziroglu, 2008; Lee et al., 2011).

$$
\begin{aligned}
& \mathrm{C}_{6} \mathrm{H}_{12} \mathrm{O}_{6}+2 \mathrm{H}_{2} \mathrm{O} \rightarrow 2 \mathrm{CH}_{3} \mathrm{COOH}+2 \mathrm{CO}_{2}+4 \mathrm{H}_{2} \\
& \text { Glicose Ácido Acético } \\
& \mathrm{C}_{6} \mathrm{H}_{12} \mathrm{O}_{6} \rightarrow \mathrm{CH}_{3} \mathrm{CH}_{2} \mathrm{CH}_{2} \mathrm{COOH}+2 \mathrm{CO}_{2}+2 \mathrm{H}_{2} \\
& \text { Glicose Ácido Butírico }
\end{aligned}
$$


O ideal seria que o processo seguisse sempre a via do acetato garantindo a produção máxima do processo. Porém isso não é possível, devido ao equilíbrio nas concentrações de $\mathrm{NADH}$ e $\mathrm{NAD}^{+}$que precisa ser mantido no sistema. Um mol de acetato é gerado pelo consumo de dois mols de $\mathrm{NAD}^{+}$. Um mol de butirato não consome e nem gera $\mathrm{NAD}^{+}$. Um mol de etanol ou um mol de propionato formam dois mols de $\mathrm{NAD}^{+}$(Ren et al., 2006).

Para que o equilíbrio dinâmico na oxidação e redução de $\mathrm{NAD}^{+} / \mathrm{NADH}$ seja mantido, o NADH deve ser consumido, gerando propionato, lactato, etanol, butanol, e consequentemente diminuindo o rendimento na produção do $\mathrm{H}_{2}$ (Lee et al., 2011; Ren et al., 2006). A única maneira de influenciar o metabolismo no sentido de favorecer a realização da rota desejada é através da estratégia de operação do reator.

Sá et al. (2013) também estudou os caminhos metabólicos dos organismos do gênero Clostridium na conversão dos substratos glicerol, glicose, frutose e xilose para a produção de hidrogênio. A Figura 3.11 ilustra os processos. É interessante notar que, no caminho metabólico feito a partir da sacarose até o gliceraldeído-3-fostato, há reações que apenas liberam energia, enquanto no caminho a partir do glicerol até o mesmo composto há a reação da NAD para $\mathrm{NADH}^{+}$(que consome energia); portanto é um processo entalpicamente desfavorável e mais difícil de ser realizado. 


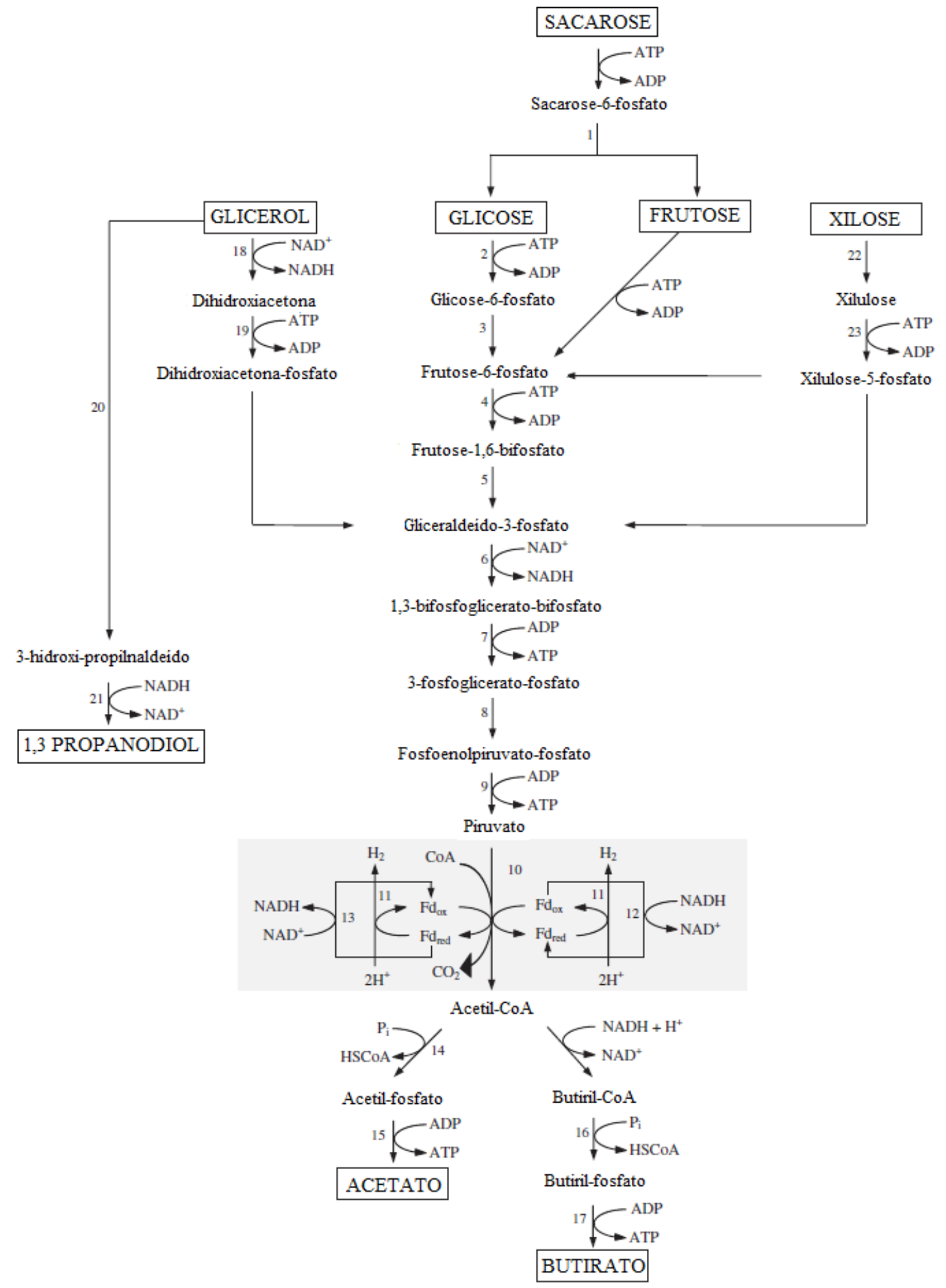

Figura 3.11 - Caminho metabólico durante a fermentação de vários substratos pelo Clostridium $s p$. 1: Sacarose 6-P hidrolase; 2: Hexoquinase; 3: Fosforoglicose isomerase; 4: Fosforofructoquinase; 5: Aldolase; 6: Gliceraldeído-3-P-dehidrogenase; 7: Fosfogliceroquinase; 8: Enolase; 9: Piruvato quinase; 10: Piruvato-ferredoxin oxidoreductase; 11: Hidrogenase; 12: NAD $(\mathrm{P}) \mathrm{H}$-ferredoxin redutase; 13: Ferredoxin-NAP(P) ${ }^{+}$redutase; 14: Fosfotranscetilase quinase; 15: Acetato linase; 16: Fosfotransbutilase quinase; 17: Butirato quinase; 18: Glicerol dehidrogenase; 19: DNA quinase; 20: Glicerol dehidratase; 21: 1,3-propanodiol dehidrogenase; 22: Xilose isomerase; 23: Xiluloquinase (Adaptada de Sá et al., 2013) 


\subsubsection{Influência do inóculo}

Quanto à natureza do inóculo, a variedade de microrganismos que podem produzir hidrogênio devem possuir as enzimas hidrogenase ou nitrogenase, podendo-se destacar os gêneros Clostridium; Escherichia coli; Termonaerobacter e Enterobacter (Fernandes, 2008). O uso de cultura pura é interessante no entendimento de aspectos relativos ao metabolismo, entretanto, de um ponto de vista da engenharia, a aplicação de culturas puras na concepção de sistemas de escala maior pode se apresentar como dificilmente viável devido aos problemas de contaminação.

Quanto às culturas mistas, elas contêm um consórcio microbiano, requerendo então certos cuidados na aplicação a fim de evitar que microrganismos indesejáveis ao processo se desenvolvam e promovam reações consumidoras de hidrogênio ou produtoras de composto inibidor das rotas desejadas. Algumas técnicas ou tratamentos podem ser aplicados antes ou durante o processo para selecionar a determinada população bacteriana, dentro das quais se destacam: choques térmicos (HST), ácidos, básicos, químicos e aeração sucessiva (Gioannis et al., 2013). Vários trabalhos destacam a necessidade de que os inóculos devam ser prétratados para eliminar os microrganismos metanogênicos e, assim, otimizar a produção de hidrogênio pela eliminação de espécies consumidoras, mas deve-se tomar cuidado com o aspecto econômico do tratamento utilizado.

Sá et al. (2013) realizou um estudo sobre a influência do tratamento do inóculo proveniente de uma planta de tratamento de esgoto doméstico para a produção de hidrogênio. Os pré tratamentos estudados foram o choque térmico, ácido e alcalino; o melhor tratamento considerando o rendimento entre hidrogênio produzido e sacarose consumida foi o HST $\left(100^{\circ} \mathrm{C}\right.$ por 60 minutos). A Figura 3.12 mostra os resultados obtidos. 


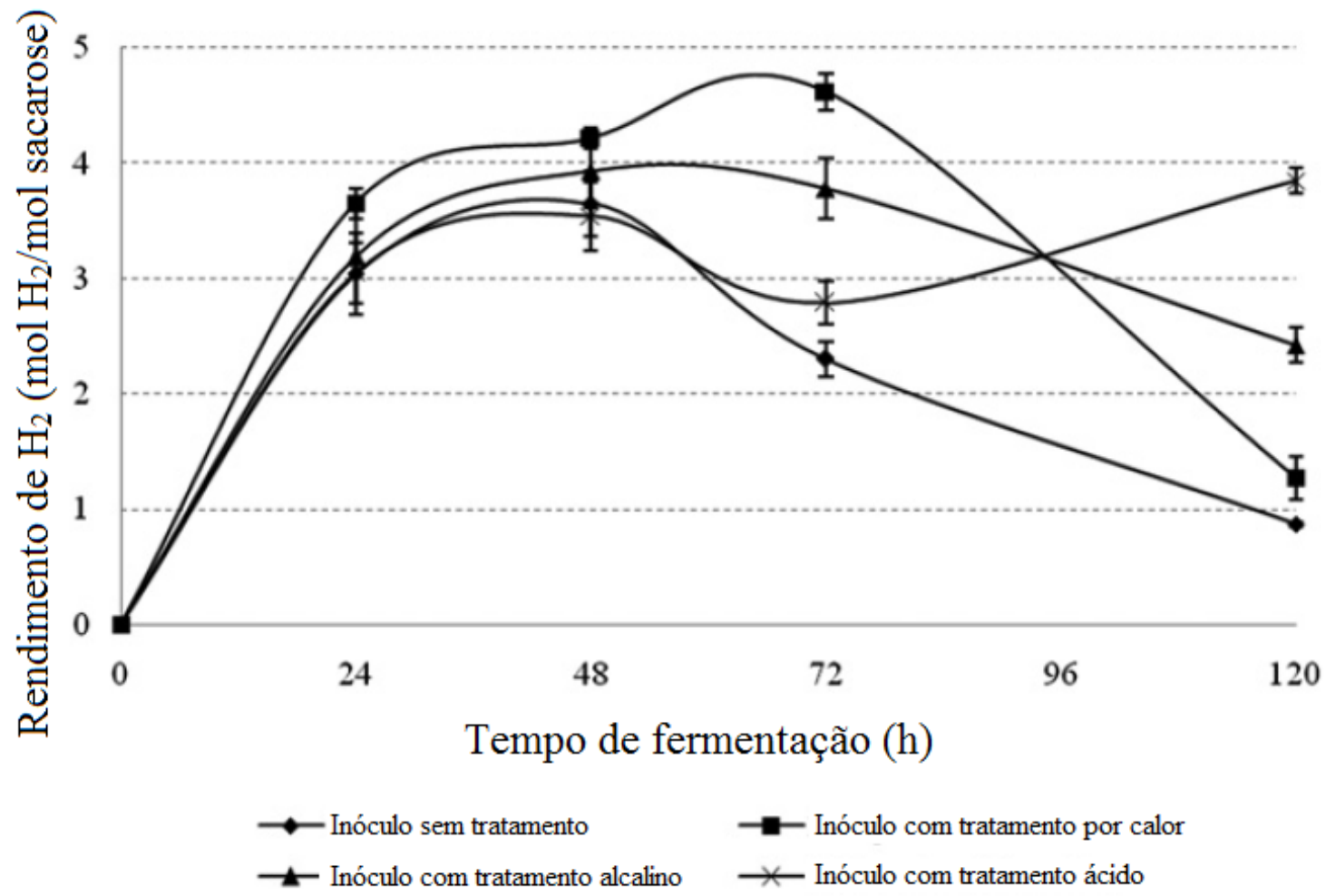

Figura 3.12 - Rendimento entre produção de hidrogênio e consumo de sacarose obtidos por inóculo sem tratamento e pré-tratado (calor, ácido e alcalino) (Adaptado de Sá et al. 2013)

\subsubsection{Influência do pH}

A influência do pH na fermentação do hidrogênio é bem controversa na literatura. No geral, o pH é considerado o parâmetro pivô devido ao seu efeito na atividade hidrogenase, caminhos metabólicos, bem como hidrólise do substrato. A concentração do íon $\mathrm{H}^{+}$no sistema também é crítica para a manutenção de níveis adequados de ATP, já que na presença de excesso de $\mathrm{H}^{+}$, a ATP é usada para assegurar a neutralidade da célula ao invés de produzir hidrogênio (Gioannis et al., 2013).

Foi verificado que menores $\mathrm{pH}$ iniciais oferecem um maior potencial de produção de hidrogênio, mas uma menor produção. Investigações foram realizadas em estudo em batelada variando o pH inicial e medindo a produção de hidrogênio, sendo obtida a produção máxima para valores de $\mathrm{pH}$ 4,5 tratando efluente sintético a base de sacarose (Khanal et al., 2003), e de 6,0 tratando soro de queijo (Ferchichi et al., 2005). 
Pesquisas similares foram conduzidas usando reatores operados em bateladas sequenciais e um dispositivo de controle de $\mathrm{pH}$ ao longo do ciclo, cujos valores de $\mathrm{pH}$ ótimos foram de 4,9 tratando efluente sintético a base de sacarose (Chen, et al., 2009) e de 5,0 tratando esterco de suínos (Wu et al., 2009). Tais discordâncias podem ser atribuídas às diferenças entre os estudos em termo de substratos, inóculo e faixas de $\mathrm{pH}$ inicial. Um valor de $\mathrm{pH}$ de operação em torno de 5,0 parece ser o mais indicado.

\subsubsection{Influência do tempo de detenção hidráulica}

Outro parâmetro importante é o tempo de permanência do líquido no reator. Para processos contínuos esta característica é avaliada pelo tempo de detenção hidráulica (TDH) (Foresti et al., 1999). O TDH relaciona a vazão ao volume do reator. Por analogia é comum citar TDH para reatores operados em bateladas sequenciais, relacionando o volume alimentado diariamente com volume do reator. Este parâmetro é útil nos cálculos de dimensionamento, permitindo relacionar os volumes de reatores com os volumes de efluentes a tratar, porém ele não representa o tempo de permanência real do líquido dentro do reator. Assim, para investigar o desempenho de processos em bateladas sequenciais é recomendável utilizar como parâmetro os tempos de ciclos $\left(\mathrm{t}_{\mathrm{C}}\right)$.

Os valores de $\mathrm{TDH}$ ou $\mathrm{t}_{\mathrm{C}}$, em processos contínuos ou sequenciais, têm influência no crescimento da biomassa, pois espécies microbianas com altas velocidades de crescimento conseguem permanecer no reator enquanto espécies com crescimento lento são removidas no efluente líquido. As arqueas metanogênicas hidrogenotróficas têm baixas velocidades de reprodução com tempos de duplicação da ordem de doze a quatorze horas; ao contrário das bactérias acidogênicas (produtoras de hidrogênio) que têm tempos de duplicação da ordem de duas a três horas. Baseado nisso, baixos valores de $\mathrm{TDH}$ ou $\mathrm{t}_{\mathrm{C}}$ podem ser ajustados com o objetivo de selecionar as espécies que permanecerão no reator. Alguns trabalhos mostram que 
o tratamento de efluente sintético a base de glicose com um ASBR, mantendo-se a carga orgânica igual e variando o volume afluente e o tempo de ciclo, encontra-se uma maior produção para um $\mathrm{t}_{\mathrm{C}}$ de 4 horas (Cheong et al., 2007) e que operando um ASBR tratando amido de milho encontra-se uma maior produção para um $t_{C}$ de 6 horas (Arooj et al., 2008).

\subsubsection{Influência da carga orgânica aplicada e do tempo de enchimento}

A disponibilidade do substrato para a biomassa deve ser avaliada pela carga orgânica volumétrica aplicada. Este parâmetro integra o tempo de permanência, o volume alimentado e a concentração do afluente. Este fator foi o objeto de investigações diretas com foco na influência da carga orgânica na produção de hidrogênio em reatores operados em bateladas sequenciais. Entretanto, outros autores estudaram a produção de hidrogênio em função da variação de parâmetros inerentes à carga orgânica, como o efeito das concentrações iniciais (Buitrón e Carvajal, 2010), dos volumes afluentes (Badiei et al., 2011) ou dos tempos de permanência (Cheong et al., 2007; Arooj et al., 2008; Chen et al., 2009). Tais parâmetros foram estudados separadamente ou de maneira combinada, mas não foram relacionados com as cargas orgânicas. A Tabela 3.5 mostra resultados obtidos por diferentes autores, relacionando diferentes indicadores de produção de hidrogênio. Vale destacar que apenas um único trabalho foi encontrado que estudava a influência do tempo de enchimento (Inoue, 2013) e, por comparação com Manssouri et al. (2013), vê-se que a batelada alimentada aumentou a produtividade molar e específica, bem como o rendimento entre hidrogênio produzido e carga orgânica aplicada. 
Tabela 3.5 - Comparação de trabalhos para produção de hidrogênio

\begin{tabular}{|c|c|c|c|c|c|c|c|c|c|}
\hline Referências & $\begin{array}{c}\text { Configuração / } \\
\text { Substrato }\end{array}$ & $\begin{array}{l}\mathrm{t}_{\mathrm{C}} \\
(\mathrm{h})\end{array}$ & $\mathrm{N}$ & $\begin{array}{l}\mathrm{V}_{\mathrm{R}} \\
(\mathrm{L}) \\
\end{array}$ & $\begin{array}{l}\mathrm{V}_{\mathrm{A}} \\
(\mathrm{L}) \\
\end{array}$ & $\begin{array}{c}\text { COVA } \\
\left(\mathrm{gDQO} . \mathrm{L}^{-1} \cdot \mathrm{d}^{-1}\right)\end{array}$ & 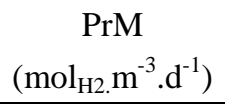 & $\begin{array}{c}\text { PrME } \\
\operatorname{mol}_{\mathrm{H} 2} \cdot \mathrm{kg}_{\mathrm{SVT}}{ }^{-1} \cdot \mathrm{d}^{-1}\end{array}$ & 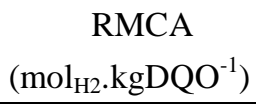 \\
\hline \multirow{6}{*}{ Inoue (2013) } & \multirow{6}{*}{$\begin{array}{c}\text { AnSBBR AM } \\
\text { em batelada } \\
\text { alimentada } \\
\left(\mathrm{t}_{\mathrm{F}} / \mathrm{t}_{\mathrm{C}}=0,5\right) / \\
\text { Efluente } \\
\text { sintético a base } \\
\text { de sacarose }\end{array}$} & 4 & 6 & 3,5 & 1,5 & 9,0 & 24,5 & 4,62 & 2,67 \\
\hline & & 3 & 8 & 3,5 & 1,5 & 12,0 & 47,3 & 7,47 & 3,87 \\
\hline & & 4 & 6 & 3,5 & 1,5 & 13,5 & 54,9 & 7,45 & 4,03 \\
\hline & & 3 & 8 & 3,5 & 1,5 & 18,0 & 67,9 & 8,51 & 3,76 \\
\hline & & 2 & 12 & 3,5 & 1,5 & 18,0 & 58,5 & 8,72 & 3,21 \\
\hline & & 2 & 12 & 3,5 & 1,5 & 27,0 & 81,2 & 8,11 & 3,11 \\
\hline \multirow{6}{*}{ Manssouri (2013) } & \multirow{6}{*}{$\begin{array}{l}\text { AnSBBR AM / } \\
\text { Efluente } \\
\text { sintético a base } \\
\text { de sacarose }\end{array}$} & 4,0 & 6,0 & 3,6 & 1,5 & 9,0 & 10,0 & 2,7 & 1,95 \\
\hline & & 3,0 & 8,0 & 3,6 & 1,5 & 12,0 & 15,6 & 4,1 & 2,30 \\
\hline & & 4,0 & 6,0 & 3,6 & 1,5 & 13,5 & 18,7 & 5,1 & 2,51 \\
\hline & & 3,0 & 8,0 & 3,6 & 1,5 & 18,0 & 18,6 & 5,0 & 2,00 \\
\hline & & 2,0 & 12,0 & 3,6 & 1,5 & 18,0 & 21,4 & 5,5 & 2,13 \\
\hline & & 2,0 & 12,0 & 3,6 & 1,5 & 27,0 & 17,0 & 4,4 & 1,17 \\
\hline \multirow{6}{*}{ Santos (2012) } & \multirow{6}{*}{$\begin{array}{l}\text { AnSBBR RFL / } \\
\text { Efluente } \\
\text { sintético a base } \\
\text { de sacarose }\end{array}$} & 4,0 & 6,0 & 4,5 & 1,9 & 9,1 & 21,0 & 6,9 & 3,66 \\
\hline & & 3,0 & 8,0 & 4,5 & 1,9 & 12,2 & 16,9 & 5,5 & 2,21 \\
\hline & & 2,0 & 12,0 & 4,5 & 1,9 & 18,2 & 24,7 & 8,2 & 2,90 \\
\hline & & 4,0 & 6,0 & 4,5 & 1,9 & 13,5 & 25,7 & 8,5 & 2,43 \\
\hline & & 3,0 & 8,0 & 4,5 & 1,9 & 18,2 & 18,2 & 5,7 & 1,55 \\
\hline & & 2,0 & 12,0 & 4,5 & 1,9 & 27,4 & 27,9 & 8,8 & 1,58 \\
\hline \multirow{7}{*}{ Arooj et al. (2008) } & \multirow{7}{*}{$\begin{array}{c}\text { ASBR AM / } \\
\text { Efluente } \\
\text { sintético a base } \\
\text { de amido milho }\end{array}$} & 9,0 & 2,7 & 3,0 & 1,5 & 26,7 & 39,0 & 10,7 & 1,46 \\
\hline & & 7,5 & 3,2 & 3,0 & 1,5 & 32,0 & 80,0 & 10,7 & 2,50 \\
\hline & & 6,0 & 4,0 & 3,0 & 1,5 & 40,0 & 106,3 & 12,9 & 2,66 \\
\hline & & 4,5 & 5,3 & 3,0 & 1,5 & 53,3 & 97,3 & 11,6 & 1,83 \\
\hline & & 3,0 & 8,0 & 3,0 & 1,5 & 80,0 & 183,3 & 21,4 & 2,29 \\
\hline & & 2,0 & 12,0 & 3,0 & 1,5 & 120,0 & 37,7 & 2,2 & 0,31 \\
\hline & & 9,0 & 2,7 & 3,0 & 1,5 & 26,7 & 39,0 & 10,7 & 1,46 \\
\hline
\end{tabular}


Tabela 3.5 - Comparação de trabalhos para produção de hidrogênio (continuação)

\begin{tabular}{|c|c|c|c|c|c|c|c|c|c|}
\hline Referências & $\begin{array}{l}\text { Configuração / } \\
\text { Substrato }\end{array}$ & $\begin{array}{l}\mathrm{t}_{\mathrm{C}} \\
(\mathrm{h})\end{array}$ & $\mathrm{N}$ & $\begin{array}{l}\mathrm{V}_{\mathrm{R}} \\
(\mathrm{L}) \\
\end{array}$ & $\begin{array}{l}\mathrm{V}_{\mathrm{A}} \\
(\mathrm{L}) \\
\end{array}$ & $\begin{array}{c}\text { COVA } \\
\left(\mathrm{gDQO}^{-1} \cdot \mathrm{d}^{-1}\right)\end{array}$ & 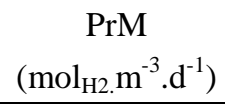 & $\begin{array}{c}\operatorname{PrME} \\
\mathrm{mol}_{\mathrm{H} 2} \cdot \mathrm{kg}_{\mathrm{SVT}}{ }^{-1} \cdot \mathrm{d}^{-1}\end{array}$ & $\begin{array}{c}\mathrm{RMCA} \\
\left(\mathrm{mol}_{\mathrm{H} 2} \cdot \mathrm{kgDQO}^{-1}\right)\end{array}$ \\
\hline \multirow{4}{*}{ Badiei et al. (2011) } & \multirow{4}{*}{$\begin{array}{l}\text { ASBR RFL / } \\
\text { Efluente de } \\
\text { moinho de óleo } \\
\text { de palma }\end{array}$} & 24,0 & 1,0 & 3,0 & 0,8 & 5,0 & 33,4 & & 6,68 \\
\hline & & 24,0 & 1,0 & 3,0 & 1,0 & 6,6 & 100,0 & & 15,15 \\
\hline & & 24,0 & 1,0 & 3,0 & 1,5 & 10,0 & 49,0 & & 4,90 \\
\hline & & 24,0 & 1,0 & 3,0 & 2,0 & 13,3 & 11,9 & & 0,89 \\
\hline \multirow{4}{*}{$\begin{array}{l}\text { Saraphirom } \\
\text { Reungsang (2011) }\end{array}$} & \multirow{4}{*}{$\begin{array}{l}\text { ASBR AM / } \\
\text { Xarope de } \\
\text { sorgo doce }\end{array}$} & 48,0 & 0,5 & 1,3 & 0,7 & 4,4 & 22,0 & 5,02 & 1,95 \\
\hline & & 24,0 & 1,0 & 1,3 & 0,7 & 8,8 & 45,0 & 5,13 & 2,30 \\
\hline & & 12,0 & 2,0 & 1,3 & 0,7 & 17,5 & 147,5 & 8,41 & 2,51 \\
\hline & & 6,0 & 4,0 & 1,3 & 0,7 & 35,1 & 375,0 & 10,70 & 1,17 \\
\hline \multirow{12}{*}{$\begin{array}{l}\text { Searmsirimongkol et } \\
\text { al. (2011) }\end{array}$} & \multirow{12}{*}{ 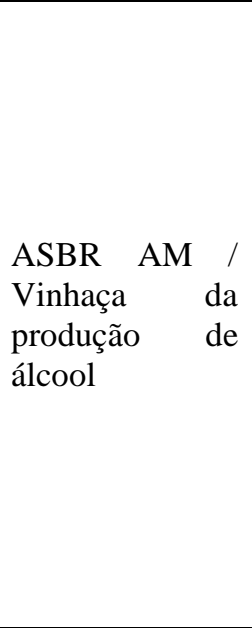 } & 4,0 & 6,0 & 4,0 & 0,5 & 15,0 & 0,0 & & 0,00 \\
\hline & & 4,0 & 6,0 & 4,0 & 0,8 & 22,5 & 6,4 & & 0,29 \\
\hline & & 4,0 & 6,0 & 4,0 & 1,0 & 30,0 & 38,5 & & 1,28 \\
\hline & & 4,0 & 6,0 & 4,0 & 1,3 & 37,5 & 85,7 & & 2,28 \\
\hline & & 4,0 & 6,0 & 4,0 & 0,5 & 30,0 & 5,4 & & 0,18 \\
\hline & & 4,0 & 6,0 & 4,0 & 0,8 & 45,0 & 60,0 & & 1,33 \\
\hline & & 4,0 & 6,0 & 4,0 & 1,0 & 60,0 & 145,6 & & 2,43 \\
\hline & & 4,0 & 6,0 & 4,0 & 1,3 & 75,0 & 100,6 & & 1,34 \\
\hline & & 4,0 & 6,0 & 4,0 & 0,5 & 45,0 & 48,2 & & 1,07 \\
\hline & & 4,0 & 6,0 & 4,0 & 0,8 & 67,5 & 46,0 & & 0,68 \\
\hline & & 4,0 & 6,0 & 4,0 & 1,0 & 90,0 & 55,7 & & 0,62 \\
\hline & & 4,0 & 6,0 & 4,0 & 1,3 & 112,5 & 134,9 & & 1,20 \\
\hline \multirow{5}{*}{ Wu et al. (2009) } & \multirow{5}{*}{$\begin{array}{l}\text { ASBR RFL / } \\
\text { Estrume líquido } \\
\text { de suíno } \\
\text { suplementado } \\
\text { com glicose }\end{array}$} & 4,0 & 6,0 & 4,0 & 0,7 & 13,9 & 72,5 & & 5,20 \\
\hline & & 4,0 & 6,0 & 4,0 & 0,8 & 16,7 & 108,5 & & 6,49 \\
\hline & & 4,0 & 6,0 & 4,0 & 1,0 & 20,9 & 137,4 & & 6,57 \\
\hline & & 4,0 & 6,0 & 4,0 & 1,3 & 27,9 & 176,4 & & 6,33 \\
\hline & & 4,0 & 6,0 & 4,0 & 2,0 & 41,8 & 202,3 & & 4,84 \\
\hline
\end{tabular}




\subsubsection{Influência do substrato}

O substrato que foi utilizado no presente trabalho é o efluente do processo de produção de biodiesel obtido na etapa de transesterificação, que é a glicerina. A glicerina, teoricamente, pode ser convertida em 3 mols de hidrogênio e um mol de ácido acético (Equação 3.7)

$$
\begin{gathered}
\mathrm{C}_{3} \mathrm{H}_{8} \mathrm{O}_{3}+2 \mathrm{H}_{2} \mathrm{O} \rightarrow \mathrm{CH}_{3} \mathrm{COO}^{-}+\mathrm{HCO}_{3}{ }^{-}+2 \mathrm{H}^{+}+3 \mathrm{H}_{2} \\
\left(\Delta \mathrm{G}^{\mathrm{o}}=-73 \mathrm{~kJ} / \text { reação }\right)
\end{gathered}
$$

A literatura relativa a esse assunto mostra baixos rendimentos de produção de hidrogênio e a maior parte dos trabalhos realizados até o momento utilizou vidros de soro de pequenos volumes como reator e culturas puras como inóculo (ver Tabela 3.6, na qual GPA é o glicerol puro e GBI é a glicerina oriunda do processo de produção de biodiesel). Entre os trabalhos realizados com culturas mistas, Sá et al. (2013) atingiu um rendimento de 0,80 mol $\mathrm{H}_{2} \cdot \mathrm{mol}^{-1}$ glicerina utilizando vidro de soro e tratamento HST em seu inóculo (estudo comparativo entre diferentes substratos realizado por este trabalho é mostrado na Tabela 3.7); Selembo et al. (2009) investigou a produção de $\mathrm{H}_{2}$ com inóculo tratado por calor e obteve por volta de 0,28 e 0,31 $\mathrm{mol} \mathrm{H}_{2} \cdot \mathrm{mol}_{\text {glicerina }}{ }^{-1}$, utilizando glicerina pura e resíduo de biodiesel, respectivamente. Temudo et al. (2008) observou formação de $0,05 \mathrm{~mol} \mathrm{de} \mathrm{H}_{2} \cdot \mathrm{mol}$ glicerina ${ }^{-1}$ operando um CSTR com cultura mista. A Tabela 3.8 mostra uma comparação entre estes trabalhos.

Analisando as tabelas mostradas nessa seção, vê-se a dificuldade em conseguir um bom rendimento para a produção de hidrogênio a partir da glicerina, seja ela pura ou o resíduo da produção de biodiesel; então este trabalho foi realizado no intuito de conseguir um melhor rendimento utilizando culturas mistas e um reator em escala laboratorial funcionando em batelada. 
Tabela 3.6 - Estudo comparativo entre culturas puras para produção de $\mathrm{H}_{2}$

\begin{tabular}{|c|c|c|c|}
\hline Substrato & Inóculo & $\begin{array}{l}\text { Rendimento máximo de } \\
\mathrm{H}_{2} \\
\left(\mathrm{~mol} \mathrm{H}_{2} \cdot \mathrm{mol} \mathrm{substrato}^{-1}\right)\end{array}$ & Referência \\
\hline GPA & Enterobacter aerogenes & 1,05 & Ito et al. (2005) \\
\hline GBI & Enterobacter aerogenes & 1,12 & Ito et al. (2005) \\
\hline GPA & Enterobacter aerogenes & 0,62 & Nakashimada et al. (2002) \\
\hline GPA & Escherichia coli & 0,94 & Murarka et al. (2008) \\
\hline GPA & Klebsiella pneumoniae & 0,61 & Biebl et al. (1998) \\
\hline
\end{tabular}

Tabela 3.7 - Estudo comparativo entre diferentes substratos para produção de $\mathrm{H}_{2}$ (adaptado de Sá et al., 2013)

\begin{tabular}{cccc}
\hline Substrato & $\begin{array}{c}\text { Consumo de } \\
\text { substrato }(\%)\end{array}$ & $\begin{array}{c}\text { Rendimento máximo de } \mathrm{H}_{2} \\
\left(\mathrm{~mol} \mathrm{H} \cdot \mathrm{mol} \mathrm{substrato}^{-1}\right)\end{array}$ & $\begin{array}{c}\text { Rendimento máximo teórico de } \\
\mathrm{H}_{2}\left(\mathrm{~mol} \mathrm{H}_{2} \text { mol substrato }^{-1}\right)\end{array}$ \\
\hline Sacarose & $96 \pm 0,87$ & $4,17 \pm 0,49$ & 8 \\
Glicose & $95 \pm 1,62$ & $2,19 \pm 0,55$ & 4 \\
Frutose & $87 \pm 1,21$ & $2,09 \pm 0,19$ & 4 \\
Xylose & $93 \pm 0,60$ & $1,88 \pm 0,23$ & 6 \\
Glicerina & $97 \pm 0,22$ & $0,80 \pm 0,14$ & 3 \\
\hline
\end{tabular}

Tabela 3.8 - Estudo comparativo entre culturas mistas para produção de $\mathrm{H}_{2}$

\begin{tabular}{|c|c|c|c|c|}
\hline Substrato & Inóculo & Reator & $\begin{array}{c}\text { Rendimento } \\
\text { máximo de } \mathrm{H}_{2} \\
\left(\mathrm{~mol} \mathrm{H}_{2} \cdot \mathrm{mol} \mathrm{substrato}^{-1}\right)\end{array}$ & Referência \\
\hline GPA & $\begin{array}{l}\text { Lodo de planta de } \\
\text { tratamento de esgoto } \\
\text { doméstico }\end{array}$ & Vidro de soro & 0,80 & Sá et al. (2013) \\
\hline GPA & $\begin{array}{l}\text { Solo de cultivo de } \\
\text { trigo }\end{array}$ & Vidro de soro & 0,28 & Selembo et al. (2009) \\
\hline GBI & $\begin{array}{c}\text { Solo de cultivo de } \\
\text { trigo }\end{array}$ & Vidro de soro & 0,31 & Selembo et al. (2009) \\
\hline GBI & $\begin{array}{l}\text { Lodos de estações de } \\
\text { tratamento de água } \\
\text { residuária de destilaria } \\
\text { e de processamento de } \\
\text { fécula de batata }\end{array}$ & CSTR & 0,05 & $\begin{array}{l}\text { Termudo et al. } \\
\text { (2008) }\end{array}$ \\
\hline
\end{tabular}




\subsubsection{Modelagem cinética do processo de produção de $\mathrm{H}_{2}$ (Wu et al. 2013)}

Investigações avançadas sobre qualquer processo biológico sempre envolvem estudos cinéticos porque as constantes cinéticas obtidas podem ser utilizadas para o design, operação e aumento de escala de outros reatores com o mesmo processo biológico. Muitos modelos cinéticos de acidogênese têm sido desenvolvidos e aplicados com sucesso para estes processos biológicos, incluindo o modelo de Monod, modelo de Monod modificado e modelo de Contois. Embora o modelo de Monod seja o preferido por muitos pesquisadores, a aplicação com sucesso deste modelo para acidogênese complexa com culturas mistas tem se provado relativamente problemática. Portanto, o esforço para encontrar outros modelos que podem ser utilizados para descrever a produção fermentativa de hidrogênio é válido.

Um dos modelos que tem recebido atenção crescente dos pesquisadores é o modelo de Gompertz, que foi desenvolvido no começo dos anos 90 para descrever o crescimento de culturas puras e tem sido cada vez mais utilizado para descrever o processo de produção fermentativo do $\mathrm{H}_{2}$.

O modelo de consumo de substrato usando o modelo modificado de Gompertz pode ser visualizado a seguir na Equação (3.8):

$$
\mathrm{S}_{0}-\mathrm{S}=\Delta \mathrm{S}_{\max } \times \exp \left\{-\exp \left[\frac{\mathrm{R}_{\max , \mathrm{S}} \times \mathrm{e}}{\Delta \mathrm{S}_{\max }}\left(\lambda_{\mathrm{S}}-\mathrm{t}\right)+1\right]\right\}
$$

Na qual:

$\mathrm{S}_{0}$ : concentração inicial de substrato $\left(\mathrm{g} \cdot \mathrm{L}^{-1}\right)$

S: concentração de substrato $\left(\mathrm{g} \cdot \mathrm{L}^{-1}\right)$

$\Delta \mathrm{S}_{\text {max }}$ : máxima concentração de consumo de substrato (g.L $\left.\mathrm{L}^{-1}\right)$

$\mathrm{R}_{\max , \mathrm{S}}$ : velocidade máxima de consumo de substrato $\left(\mathrm{g} \cdot \mathrm{L}^{-1} \cdot \mathrm{h}^{-1}\right)$

$\lambda_{\mathrm{s}}:$ tempo de fase lag de consumo de substrato (h) 
Diferenciando a Equação (3.8), tem-se a velocidade de consumo de substrato descrita na Equação (3.9):

$$
\mathrm{r}_{\mathrm{S}}=\mathrm{R}_{\mathrm{max}, \mathrm{S}} \times \exp \left\{-\exp \left[\frac{\mathrm{R}_{\max , \mathrm{S}} \times \mathrm{e}}{\Delta \mathrm{S}_{\max }}\left(\lambda_{\mathrm{S}}-\mathrm{t}\right)+1\right]+\left[\frac{\mathrm{R}_{\max , \mathrm{S}} \times \mathrm{e}}{\Delta \mathrm{S}_{\max }}\left(\lambda_{\mathrm{S}}-\mathrm{t}\right)+1\right]+1\right\}
$$

Na qual: $\mathrm{r}_{\mathrm{S}}$ : velocidade de consumo de substrato $\left(\mathrm{g} \cdot \mathrm{L}^{-1} \cdot \mathrm{h}^{-1}\right)$

A produção de $\mathrm{H}_{2}$ também poderia ser descrita pelo modelo modificado de Gompertz, expresso na Equação (3.10), na qual os parâmetros podem ser explicados na Figura 3.13:

$$
\mathrm{H}=\mathrm{H}_{\max } \times \exp \left\{-\exp \left[\frac{\mathrm{R}_{\max , \mathrm{H} 2} \times \mathrm{e}}{\mathrm{H}_{\max }}\left(\lambda_{\mathrm{H}}-\mathrm{t}\right)+1\right]\right\}
$$

Na qual:

H: hidrogênio acumulado (L)

$\mathrm{H}_{\max }$ : máximo hidrogênio acumulado (L)

$\mathrm{R}_{\max , \mathrm{H} 2}$ : máxima velocidade de produção de hidrogênio $\left(\mathrm{L} \cdot \mathrm{h}^{-1}\right)$

$\lambda_{\mathrm{H}}$ : tempo de fase lag da produção de hidrogênio $(\mathrm{h})$

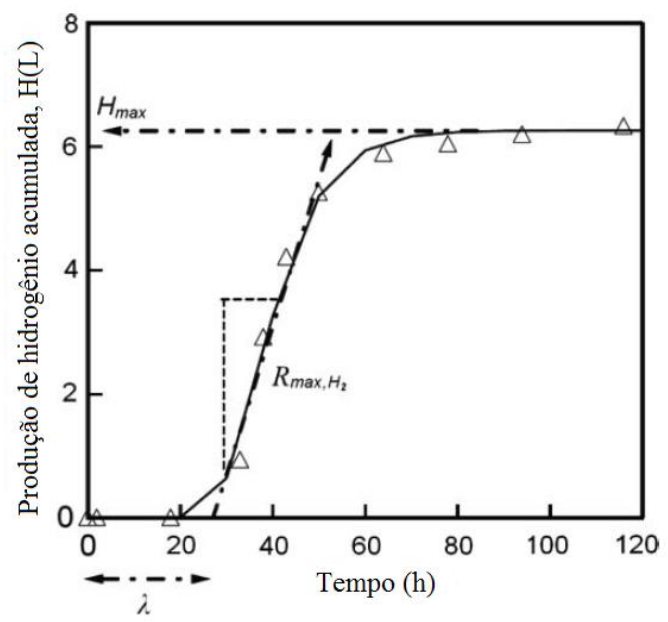

Figura 3.13 - Curva típica de produção de hidrogênio ajustada pelo modelo modificado de Gompertz 
Diferenciando a Equação (3.10), tem-se a velocidade de produção de hidrogênio expressa pela Equação (3.11):

$$
\mathrm{r}_{\mathrm{H} 2}=\mathrm{R}_{\mathrm{max}, \mathrm{H} 2} \times \exp \left\{-\exp \left[\frac{\mathrm{R}_{\max , \mathrm{H} 2} \times \mathrm{e}}{\mathrm{H}_{\max }}\left(\lambda_{\mathrm{H}}-\mathrm{t}\right)+1\right]+\left[\frac{\mathrm{R}_{\max , \mathrm{H} 2} \times \mathrm{e}}{\mathrm{H}_{\max }}\left(\lambda_{\mathrm{H}}-\mathrm{t}\right)+1\right]+1\right\}
$$

Na qual:

$\mathrm{r}_{\mathrm{H} 2}$ : velocidade de produção de hidrogênio $\left(\mathrm{L} \cdot \mathrm{L}^{-1} \cdot \mathrm{h}^{-1}\right)$

O modelo modificado de Gompertz foi utilizado com sucesso por vários trabalhos até agora (Selembo et al.,2009; Akutsu et al.,2009; Gioannis et al., 2013).

\subsection{CONSIDERAÇÕES FINAIS}

A produção biológica de hidrogênio tem se mostrado uma alternativa interessante por disponibilizar um combustível limpo e ao mesmo tempo tratar efluentes. Por ser um tema relativamente novo, os trabalhos disponíveis são poucos, sendo a maior parte referente a reatores operados de modo contínuo em diferentes escalas e também a sistemas operados de modo batelada, mas não em bateladas alimentadas. Além disso, a grande diversidade de substratos utilizados em literatura dificulta a elucidação dos fenômenos fundamentais e o ajuste das condições ótimas de operação.

Neste contexto, a Escola de Engenharia de São Carlos da Universidade de São Paulo (EESC/USP) e a Escola de Engenharia Mauá do Instituto Mauá de Tecnologia (EEM/IMT) iniciaram a investigação da produção de hidrogênio em novas configurações de reatores recentemente através dos trabalhos de Inoue (2013) em um AnSBBR com agitação mecânica e operado em batelada alimentada, Manssouri et al. (2013) em um AnSBBR com agitação mecânica e Santos (2012) em um AnSBBR com recirculação da fase líquida. Portanto, 
visando dar continuidade a novas configurações de reatores, esse projeto objetiva a aplicação do reator operado em batelada alimentada com recirculação da fase líquida e biomassa imobilizada em suporte inerte (AnSBBR), aplicado ao tratamento de efluente do processo de produção de biodiesel para a produção de biohidrogênio, avaliando-se a influência da carga orgânica, do tempo de ciclo e do tempo de enchimento sobre a eficiência de remoção de matéria orgânica, produção e produtividade de hidrogênio, e fator de conversão entre hidrogênio produzido e matéria orgânica removida.

O efluente do processo de produção de biodiesel - glicerina - é um substrato de difícil degradação, como mostrado na seção 3.5.1, então são esperados resultados de produtividade e rendimento menores do que nos trabalhos de Inoue (2013) e Santos (2012), mas é esperado que esse sistema se apresente robusto, estável e viável para a produção de biohidrogênio. 


\section{MATERIAIS E MÉTODOS}

\subsection{ANSBBR COM BIOMASSA IMOBILIZADA E RECIRCULAÇÃO DA FASE LÍQUIDA}

As Figuras 4.1 e 4.2 mostram o esquema do sistema utilizado para a produção de biohidrogênio a partir do tratamento anaeróbio do efluente do processo de produção de biodiesel. O reator, com capacidade para 2,0 L de meio líquido além do suporte inerte e biomassa, foi constituído por um frasco de acrílico, cilíndrico, com as seguintes dimensões: $540 \mathrm{~mm}$ de altura, $100 \mathrm{~mm}$ de diâmetro externo e 3,5 mm de espessura de parede (volume total de 3,6 L). Foi utilizada uma unidade de controle para automatizar as operações de carga, descarga e recirculação.

O suporte de imobilização da biomassa foi acondicionado entre telas de aço Inox - 314, dividindo a altura de $540 \mathrm{~mm}$ do reator em 4 estágios para evitar a compactação do leito. $\mathrm{Na}$ parte inferior do reator houve um compartimento de $20 \mathrm{~mm}$ de altura destinado a favorecer a distribuição da água residuária e, na parte superior, um compartimento com $40 \mathrm{~mm}$ de altura que funcionou como câmara coletora de biogás $\left(\mathrm{H}_{2}, \mathrm{CH}_{4} \mathrm{e} \mathrm{CO}_{2}\right)$.

O sistema de recirculação foi composto (i) por um reservatório lateral, o qual conteve um volume de meio de 1,5 L, constituído por um frasco de acrílico, cilíndrico, com as seguintes dimensões: $300 \mathrm{~mm}$ de altura, $100 \mathrm{~mm}$ de diâmetro externo e 3,5 $\mathrm{mm}$ de espessura de parede (volume total de 2,0 L); e (ii) bomba diafragma marca Prominet ${ }^{\circledR}$ modelo Beta/5, com capacidade de até $30 \mathrm{~L}^{-1} \mathrm{~h}^{-1}$. Uma bureta de $100 \mathrm{~mL}$ foi interligada ao sistema de recirculação para medidas da vazão de recirculação. O volume total de meio reacional, resultante da soma do volume de meio contido no reator $(2,0$ L) e no reservatório paralelo $(1,5 \mathrm{~L})$ foi de $3,5 \mathrm{~L}$. 
A alimentação e descarga foram realizadas por bombas tipo diafragma marca Prominent $^{\circledR}$, modelos Beta/4 (com capacidade de até 23 L.h ${ }^{-1}$ ) e Beta/5 (com capacidade de até $30 \mathrm{~L} \cdot \mathrm{h}^{-1}$ ), respectivamente, auxiliadas por um sistema de automação composto por temporizadores marca $\mathrm{Coel}^{\circledR}$, modelo RTST/20.

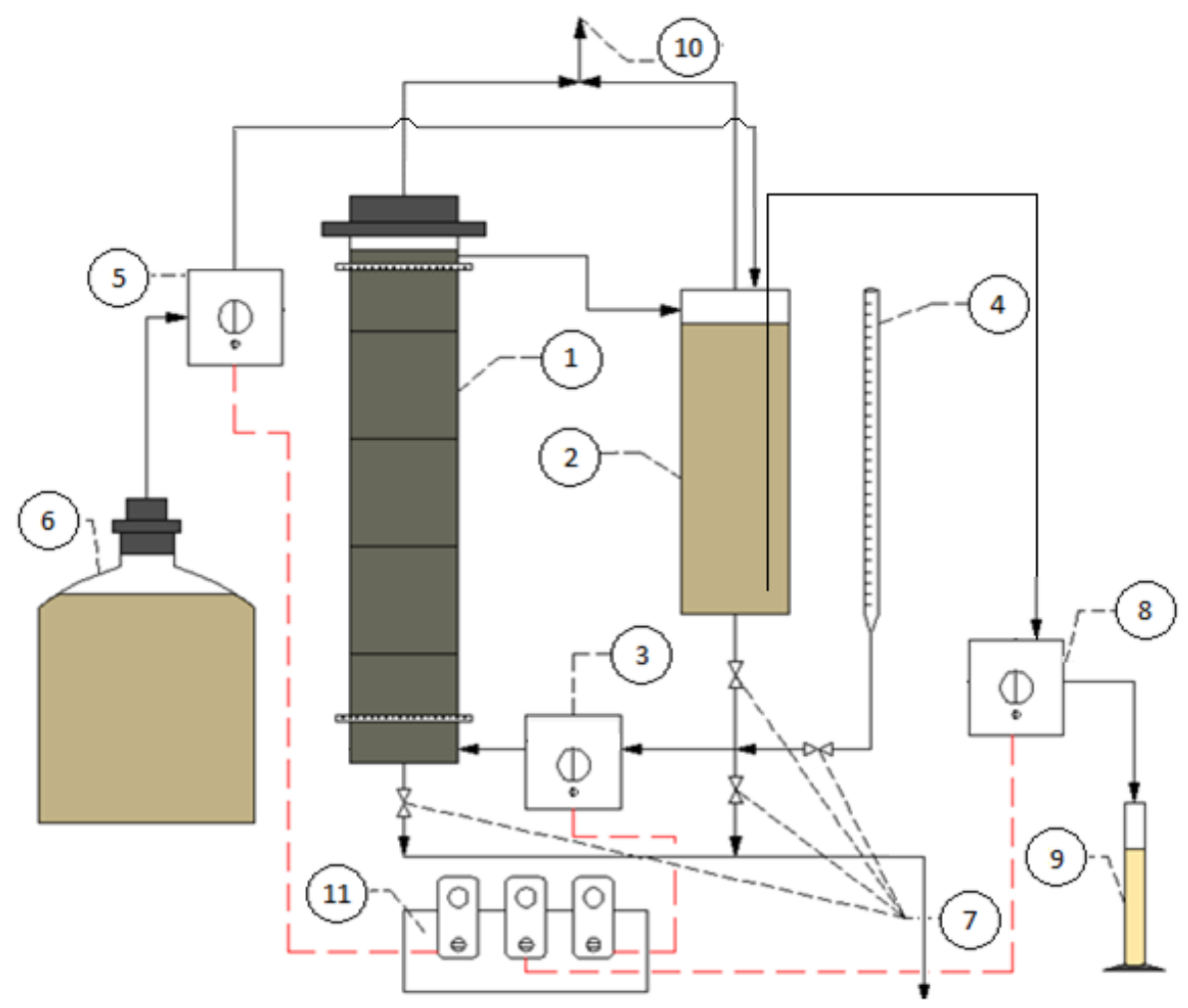

Figura 4.1 - Esquema do AnSBBR com recirculação utilizado nos ensaios

[Notação: 1 - reator contendo biomassa imobilizada; 2 - reservatório lateral; 3 - bomba de reciclo; 4 - medidor de vazão; 5 - bombas de alimentação; 6 - reservatório de água residuária; 7 - válvulas de descarga para expurgo; 8 - bomba de descarga; 9 - saída do efluente; 10 - saída de biogás; 11 - unidade de controle; — ligações hidráulicas; - - ligações elétricas].
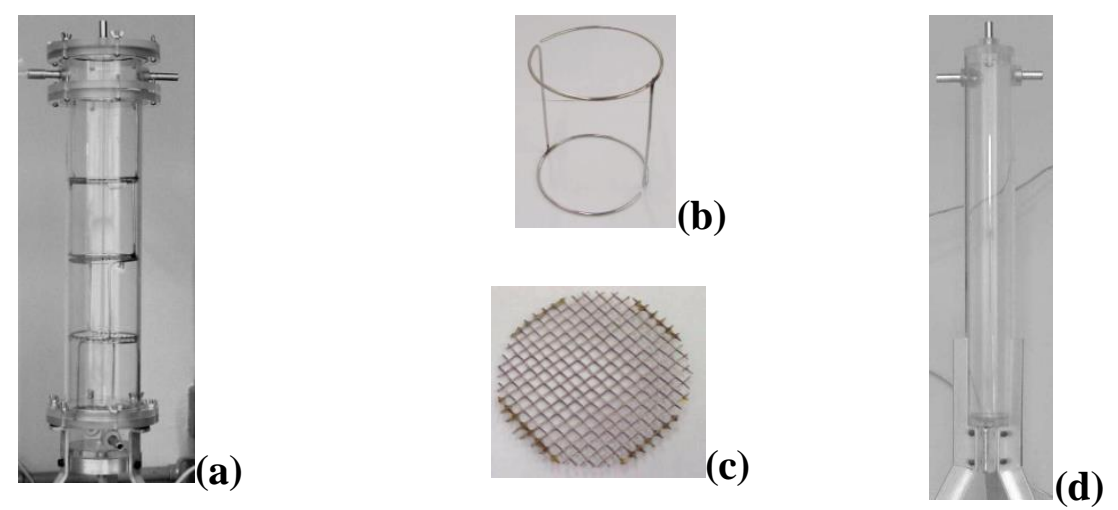

Figura 4.2 - Detalhes do: ( $a$ ) reator, $(b)$ suporte da tela de aço, $(c)$ tela de aço, $(d)$ reservatório 
O reator foi colocado em uma câmara mantida a $30 \pm 1^{\circ} \mathrm{C}$, na qual a manutenção da temperatura foi realizada por um sistema composto de sensor, controlador (Novus ${ }^{\circledR}$, modelo N480), ventilador e resistência elétrica. A Figura 4.3 mostra uma fotografia da aparelhagem experimental e a Tabela 4.1 sumariza os aspectos de projeto do reator.

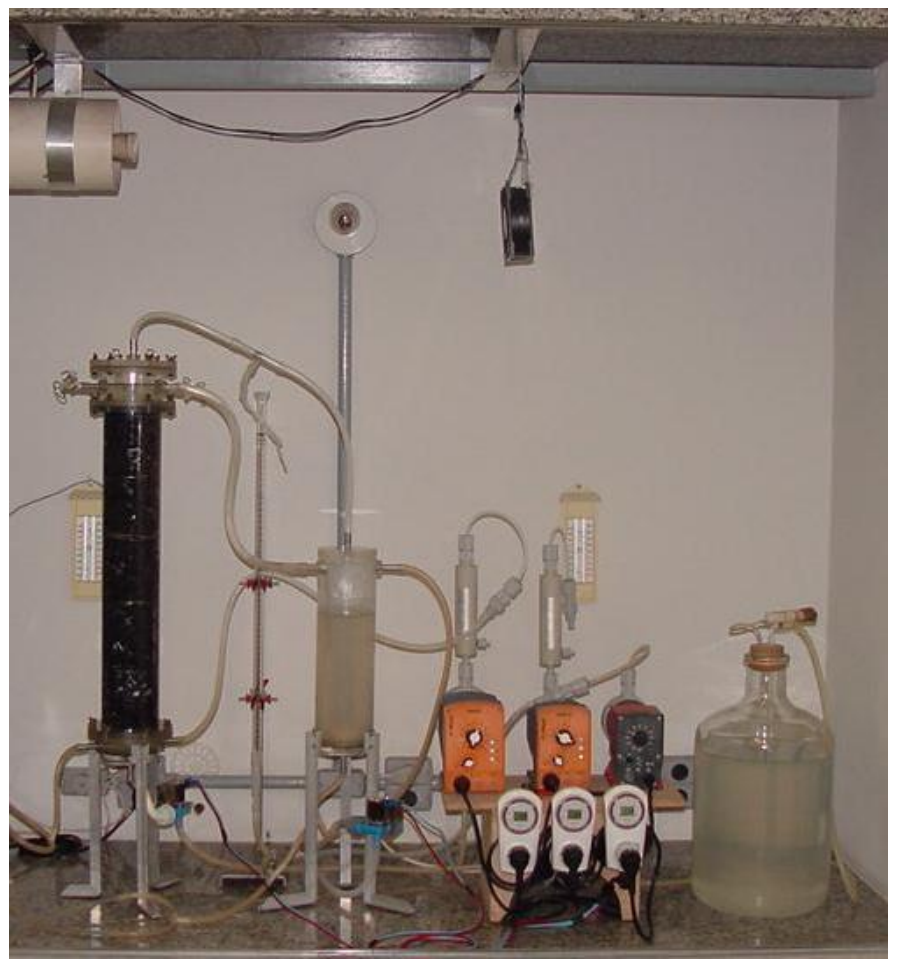

Figura 4.3 - Fotografia do aparato experimental utilizado nos ensaios

Tabela 4.1 - Parâmetros operacionais do biorreator

\begin{tabular}{cc}
\hline Parâmetro & Valor \\
\hline Volume da fase líquida (reator e reservatório) & $3,5 \mathrm{~L}$ \\
Volume do inóculo com suporte inerte (reator) & $1,5 \mathrm{~L}$ \\
Volume da fase líquida (reator) & $2,0 \mathrm{~L}$ \\
Volume da fase líquida (reservatório) & $1,5 \mathrm{~L}$ \\
Volume alimentado/descarregado por ciclo & (reservatório) \\
Volume da fase líquida residual entre ciclos (reator) & $1,5 \mathrm{~L}$ \\
Porosidade do leito $(\varphi)$ & $2,0 \mathrm{~L}$ \\
Velocidade ascensional do líquido (v) & 0,4 \\
Tempo total de ciclo & 10,20 e $30 \mathrm{~L} \cdot \mathrm{h}^{-1}$ \\
Tempo de alimentação & $4 \mathrm{~h} \mathrm{e} 3 \mathrm{~h}$ \\
Tempo de descarga & $2 \mathrm{~h} \mathrm{e} 1,5 \mathrm{~h}$ \\
\hline
\end{tabular}




\subsection{SUPORTE DE IMOBILIZAÇÃO DA BIOMASSA ANAERÓBIA E INÓCULO}

Para a imobilização da biomassa foram utilizados grânulos de polietileno de baixa densidade (PEBD) (Figura 4.4) como suporte inerte com as características descritas na Tabela 4.2, cuja empresa doadora está localizada em São Carlos-SP. Este material é um produto intermediário do processo de reciclagem de plásticos de resíduos domésticos. Cabe destacar o baixo custo, a disponibilidade e a adequação ambiental de tal material.

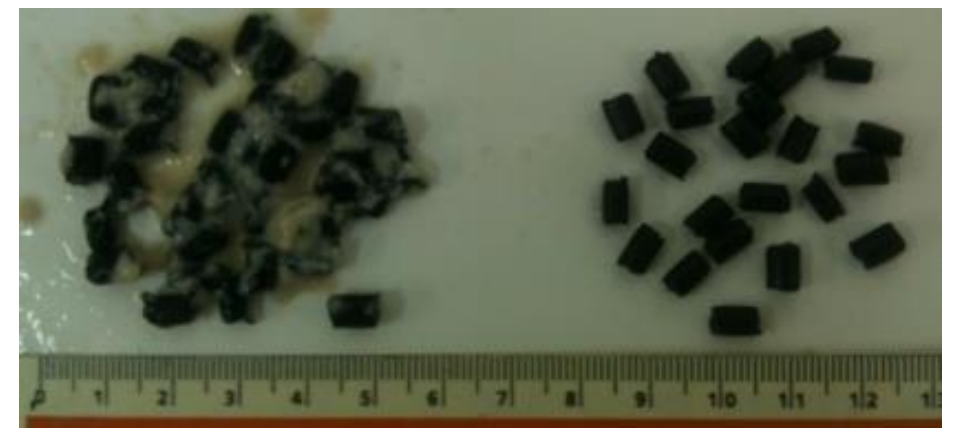

Figura 4.4 - Fotografia do material suporte com (esquerda) e sem (direita) biomassa

Tabela 4.2 - Características do material suporte inerte

\begin{tabular}{cc}
\hline Propriedades & Valor / Descrição \\
\hline Composição & Polietileno de baixa densidade \\
Diâmetro de um grânulo & $3 \mathrm{~mm}$ \\
Comprimento de um grânulo & $6 \mathrm{~mm}$ \\
Comportamento & Flutuante \\
\end{tabular}

Foram realizados dois ensaios com uma mistura de polietileno de baixa densidade com espuma de poliuretano (PU) cortada em cubos de $1 \mathrm{~cm}$ de aresta com densidade de $23 \mathrm{~kg} . \mathrm{m}^{-3}$ e $95 \%$ de porosidade (suporte tipicamente utilizado para reatores metanogênicos) para verificar se esse suporte poderia apresentar uma melhora em relação ao suporte apenas de PEBD.

Foram utilizados quatro tipos de inóculo nos experimentos mostrados na Tabela 4.3. 


\begin{tabular}{|c|c|c|}
\hline & Fonte & Pré-Tratamento \\
\hline Inóculo 1 & $\begin{array}{l}\text { Grânulos de UASB tratando água } \\
\text { residuária de abatedouro de aves } \\
\text { (Dacar Industrial S.A.) }\end{array}$ & Nenhum \\
\hline Inóculo 2 & $\begin{array}{l}\text { Grânulos de UASB tratando água } \\
\text { residuária de abatedouro de aves } \\
\text { (Dacar Industrial S.A.) }\end{array}$ & $\begin{array}{l}\text { Adaptação da biomassa primeiramente com } \\
\text { sacarose e depois com uma mistura de } \\
\text { sacarose e glicerina. }\end{array}$ \\
\hline Inóculo 3 & $\begin{array}{l}\text { Grânulos de UASB tratando água } \\
\text { residuária de abatedouro de aves } \\
\text { (Dacar Industrial S.A.) }\end{array}$ & $\begin{array}{l}\text { Heat Shock Treatment }\left(90^{\circ} \mathrm{C} \text { por } 10 \text { minutos }\right. \\
\left.\text { e depois banho de gelo até atingir } 25^{\circ} \mathrm{C}\right) \text {, } \\
\text { método adaptado de Kim et al. (2006). }\end{array}$ \\
\hline Inóculo 4 & $\begin{array}{c}\text { Biomassa de AnSBBR acidogênico } \\
\text { destinado à produção de } \\
\text { biohidrogênio usado por } \\
\text { Manssouri et al. (2013) }\end{array}$ & Adaptação da biomassa com sacarose \\
\hline
\end{tabular}

\section{3 ÁGUA RESIDUÁRIA}

A água residuária utilizada foi formulada a base do resíduo do processo de produção de biodiesel, Figura 4.5, fixando-se a razão entre a fonte de carbono e a fonte de nitrogênio-ureia $(\mathrm{C} / \mathrm{N})$ em aproximadamente 110 e razão DQO/P menor que 500 (1000:2). A Tabela 4.4 mostra os três tipos de glicerina utilizados nos experimentos e a Tabela 4.5 descreve a composição da água residuária para uma concentração em termos de DQO igual a 1000 mg.L'

${ }^{1}$ (adaptado de Del Nery, 1987). 


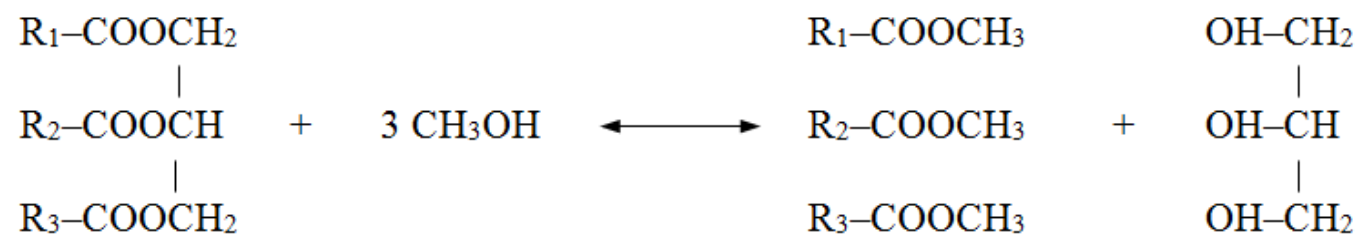

$\begin{array}{llll}\text { (Gordura) (Metanol) } & \text { (Biodiesel) }\end{array}$

Figura 4.5 - Reação de transesterificação de glicerídeos que produz glicerina

Tabela 4.4 - Tipos de glicerina utilizados nos experimentos

Tipo

GBI Glicerina bruta efluente do processo de produção industrial de biodiesel

GBL Glicerina bruta efluente do processo de produção em laboratório de biodiesel

GPA Glicerina pura comercial P.A.

O pH da saída do reator foi controlado ao valor próximo de 5,0, o ajuste desse parâmetro foi feito através de modificações no afluente, tanto na concentração de bicarbonato quanto na adição de um HCL (12 M).

Tabela 4.5 - Composição da água residuária utilizada nos ensaios de produção de biohidrogênio em AnSBBR com recirculação

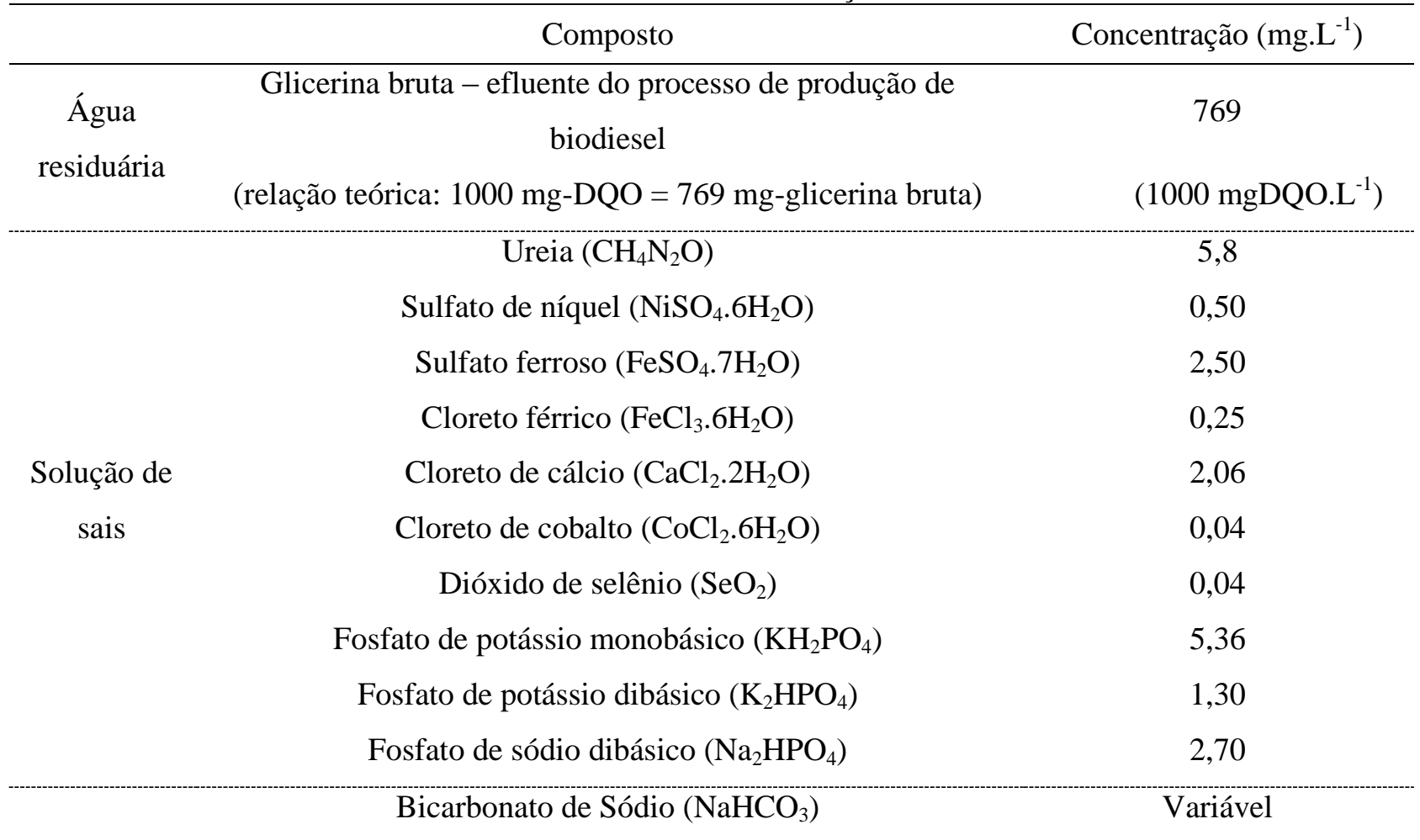


A relação $\mathrm{C} / \mathrm{N}(\mathrm{g}-\mathrm{C} / \mathrm{g}-\mathrm{N})$ foi calculada de acordo com a porcentagem em massa de carbono e nitrogênio dos elementos que constituíram parte do meio: glicerina $\left(\mathrm{C}_{3} \mathrm{H}_{8} \mathrm{O}_{3}-\right.$ 36g-C/92g-glicerina) e uréia $\left(\mathrm{CH}_{4} \mathrm{~N}_{2} \mathrm{O}-28 \mathrm{~g}-\mathrm{N} / 60 \mathrm{~g}\right.$-uréia). Assim, a relação $\mathrm{C} / \mathrm{N}$ utilizada nesse estudo foi: $(769 \cdot 36 / 92) /(5,8 \cdot 28 / 60)=300,9 / 2,7=111,2 \mathrm{~g}-\mathrm{C} / \mathrm{g}-\mathrm{N}$.

A relação $\mathrm{C} / \mathrm{P}(\mathrm{g}-\mathrm{C} / \mathrm{g}-\mathrm{P})$ foi calculada de acordo com a porcentagem em massa de carbono e fósforo dos elementos que constituíram parte do meio: glicerina $\left(\mathrm{C}_{3} \mathrm{H}_{8} \mathrm{O}_{3}-36 \mathrm{~g}-\right.$ $\mathrm{C} / 92 \mathrm{~g}$-glicerina) e sais de fósforo $\left(\mathrm{KH}_{2} \mathrm{PO}_{4}-31 \mathrm{~g}-\mathrm{P} / 136 \mathrm{~g}-\mathrm{KH}_{2} \mathrm{PO}_{4} ; \mathrm{K}_{2} \mathrm{HPO}_{4}-31 \mathrm{~g}-\mathrm{P} / 174 \mathrm{~g}-\right.$ $\left.\mathrm{K}_{2} \mathrm{HPO}_{4} ; \mathrm{Na}_{2} \mathrm{HPO}_{4}-31 \mathrm{~g}-\mathrm{P} / 142 \mathrm{~g}-\mathrm{Na}_{2} \mathrm{HPO}_{4}\right)$. Assim, a relação C/P utilizada nesse estudo foi (i) em termos de C: $(769 \cdot 36 / 92) /(5,36 \cdot 31 / 136+1,30 \cdot 31 / 174+2,70 \cdot 31 / 142)=300,9 / 2,04=$ 147,3 g-C/g-P; e (ii) em termos de DQO: $(1000) /(5,36 \cdot 31 / 136+1,30 \cdot 31 / 174+2,70 \cdot 31 / 142)$ $=1000 / 2,04=490,2 \mathrm{~g}-\mathrm{DQO} / \mathrm{g}-\mathrm{P}$.

\subsection{ANÁLISES FÍSICO-QUÍMICAS E EXAMES MICROBIOLÓGICOS}

O monitoramento do reator foi efetuado medindo-se, em amostras do afluente e do efluente, as concentrações de matéria orgânica nas formas não filtrada $\left(\mathrm{C}_{\mathrm{ST}}\right)$ e filtrada $\left(\mathrm{C}_{\mathrm{SF}}\right)$ (como demanda química de oxigênio - método de DQO), alcalinidade parcial (AP), alcalinidade intermediária (AI), alcalinidade total (AT), alcalinidade a bicarbonato (AB), ácidos voláteis totais (AVT), sólidos totais (ST), sólidos totais voláteis (SVT), sólidos suspensos totais (SST) e sólidos suspensos voláteis (SSV), além da medida do pH e do volume de meio alimentado/descarregado por ciclo $\left(\mathrm{V}_{\mathrm{A}}\right)$. Tais análises foram realizadas de acordo com o Standard Methods for the Examination of Water and Wastewater (1995), considerando também o método proposto por Dilallo e Albertson (1961), o qual foi modificado por Ripley et al. (1986) na determinação da alcalinidade. A frequência das análises está descrita na Tabela 4.6. 
Tabela 4.6 - Cronograma das análises realizadas nos ensaios

\begin{tabular}{cccc}
\hline Análise & Amostra & Frequência & Método \\
\hline DQO & Afluente e Efluente & Diariamente & Standard Methods (1995) \\
Alcalinidade/AVT & Afluente e Efluente & Diariamente & Ripley et al. (1986) \\
Série de sólidos & Afluente e Efluente & 2 vezes por semana & Standard Methods (1995) \\
Ácidos e álcoois & Efluente & 1 vez por condição & Cromatografia gasosa \\
Volume de gás & Saída de gás & Diariamente & Medidor de gás Ritter \\
Composição do gás & Saída de gás & Diariamente & Cromatografia gasosa \\
\hline
\end{tabular}

Os compostos intermediários do metabolismo anaeróbio (solventes: acetona, metanol, etanol, n-butanol; ácidos voláteis: ácidos acético, propiônico, butírico, iso-butírico, valérico, iso-valérico e capróico) foram analisados por cromatografia em fase gasosa com padrão externo (iso-butanol para os solventes e ácido crotônico para os ácidos voláteis) utilizando-se um cromatógrafo Hewlett Packard ${ }^{\circledR}$ modelo 7890 equipado com detector de ionização de chama e coluna HP-Innowax com $30 \mathrm{~m} \times 0,25 \mathrm{~mm} \times 0,25 \mu \mathrm{m}$ de espessura do filme. O gás de arraste utilizado foi o hidrogênio com vazão de $1,56 \mathrm{~mL} \cdot \mathrm{min}^{-1}$ (velocidade linear constante de $41,8 \mathrm{~cm} \cdot \mathrm{s}^{-1}$ ), a temperatura do injetor foi de $250^{\circ} \mathrm{C}$, a razão de "split" de 10 ("head-space") e o volume de injeção de $400 \mu \mathrm{L}$, utilizando-se injetor automático. A temperatura do forno foi programada da seguinte forma: de $35^{\circ} \mathrm{C}$ à $38^{\circ} \mathrm{C} \mathrm{em} 2^{\circ} \mathrm{C} \cdot \mathrm{min}^{-1}$, de $38^{\circ} \mathrm{C}$ à $75^{\circ} \mathrm{C} \mathrm{em} 10^{\circ} \mathrm{C} \cdot \mathrm{min}^{-1}$, de $75^{\circ} \mathrm{C}$ à $120^{\circ} \mathrm{C} \mathrm{em} 35^{\circ} \mathrm{C} \cdot \mathrm{min}^{-1}$, em $120^{\circ} \mathrm{C}$ por $1 \mathrm{~min}$, de $120^{\circ} \mathrm{C}$ à $170^{\circ} \mathrm{C}$ em $10^{\circ} \mathrm{C} \cdot \mathrm{min}^{-1} \mathrm{e}$ em $170^{\circ} \mathrm{C}$ por 2 min ("head-space”). A temperatura do detector foi de $280^{\circ} \mathrm{C}$ ("head-space”) com fluxo de hidrogênio (combustível) de $30 \mathrm{~mL} \cdot \mathrm{min}^{-1}$, de ar sintético (comburente) de 300 mL.min ${ }^{-1}$ e vazão de "make up" de nitrogênio de $30 \mathrm{~mL} \cdot \mathrm{min}^{-1}$. Foi utilizado nessa análise o método por "head-space".

A composição do biogás formado pelo metabolismo anaeróbio (hidrogênio, metano e dióxido de carbono) foi analisada por cromatografia em fase gasosa utilizando-se um 
cromatógrafo Agilent ${ }^{\circledR}$ modelo 7890 equipado com detector de condutividade térmica e coluna GS-Carbonplot com $30 \mathrm{~m} \times 0,53 \mathrm{~mm} \times 3,0 \mu \mathrm{m}$ de espessura do filme. O gás de arraste utilizado foi o argônio com vazão de $3,67 \mathrm{~mL} \cdot \mathrm{min}^{-1}$, a temperatura do injetor foi de $185^{\circ} \mathrm{C}$, a razão de "split" de 10 e o volume de injeção de $200 \mu \mathrm{L}$. A temperatura do forno foi programada em $40^{\circ} \mathrm{C}$ isotérmico em 5 min. A temperatura do detector foi de $150^{\circ} \mathrm{C}$, com vazão de “make up" de argônio de 8,33 mL.min ${ }^{-1}$.

A produção total do biogás durante o ciclo $\left(\mathrm{V}_{\mathrm{G}}\right)$ foi analisada por medidor de gás Ritter modelo MilligasCounter, sendo que tais medições foram realizadas na forma de perfis ao longo do ciclo em medida acumulada de volume. A medição era feita a cada 30 minutos.

Os ensaios realizados continham dois períodos distintos em termos de modo de operação: batelada alimentada e batelada. No período em que o sistema foi operado em batelada, o volume de biogás produzido foi quantificado diretamente pelo medidor de gás Ritter, já que durante a quantificação do biogás não ocorre à entrada de afluente e saída de efluente. Entretanto, tal procedimento não pôde ser realizado da mesma maneira para o período em que o sistema foi operado em batelada alimentada, já que nesse período a produção de biogás ocorria concomitantemente com a alimentação de afluente ao reator. Desta forma, o medidor de gás quantificava tanto o volume referente à produção do biogás quanto o volume de afluente alimentado ao reator durante o ciclo. Para que fosse obtido apenas o volume da produção do biogás, após o termino do ciclo, foi feita medição do volume alimentado durante o mesmo ciclo para que esta medida pudesse ser subtraída do valor obtido pelo medidor de gás.

Como a vazão de alimentação era constante e ocorreu durante o início até a metade do período do ciclo, os volumes acumulados em cada ponto puderam ser obtidos pela Equação (4.1) para o período em batelada alimentada e pela Equação (4.2) para o período em batelada, sendo $\mathrm{V}_{\mathrm{Gi}-\mathrm{BA}} \mathrm{o}$ volume acumulado de biogás obtido em determinado ponto do período em 
batelada alimentada, $\mathrm{V}_{\mathrm{M}-\mathrm{i}} \mathrm{O}$ volume obtido pelo medidor de biogás, $\mathrm{N}_{\mathrm{i}} \mathrm{o}$ número do ponto do perfil do biogás, $\mathrm{N}_{\mathrm{t}-\mathrm{BA}} \mathrm{O}$ número total de pontos do perfil durante a batelada alimentada, $\mathrm{V}_{\mathrm{A}} \mathrm{O}$ volume de afluente alimentado durante o ciclo, e $\mathrm{V}_{\mathrm{Gi}-\mathrm{B}} \mathrm{o}$ volume acumulado de biogás obtido em determinado ponto do período em batelada.

$$
\begin{gathered}
V_{G i-B A}=V_{M-i}-\frac{N_{i}}{N_{t-B A}} V_{A} \\
V_{G i-B}=V_{M-i}-V_{A}
\end{gathered}
$$

Após a correção do volume obtido pelo medidor de biogás em relação ao volume alimentado, foi necessária a conversão desse volume para as CNTP, uma vez que o volume depende das condições de operação existentes no momento em que é realizada a medição. A conversão foi feita de acordo com a lei geral dos gases através da Equação (4.3), que se encontra no manual do equipamento, sendo $\mathrm{V}_{\mathrm{N}} \mathrm{o}$ volume nas $\mathrm{CNTP}, \mathrm{V}_{\mathrm{i}}$ o volume de biogás a ser convertido (ou seja $\mathrm{V}_{\mathrm{Gi}-\mathrm{BA}}$ ou $\mathrm{V}_{\mathrm{Gi}-\mathrm{B}}$ ), $\mathrm{P}_{\mathrm{a}}$ a pressão do ar no local da medição, $\mathrm{P}_{\mathrm{V}}$ a pressão parcial de vapor d’água, $P_{L}$ a pressão da coluna líquida acima da câmara de medição (2 mbar), $\mathrm{P}_{\mathrm{N}}$ a pressão normal (1013,25 mbar), $\mathrm{T}_{\mathrm{N}}$ a temperatura normal $(273,15 \mathrm{~K})$ e $\mathrm{T}_{\mathrm{a}}$ a temperatura no local da medição.

$$
\mathrm{V}_{\mathrm{N}}=\mathrm{V}_{\mathrm{i}} \frac{\left(\mathrm{P}_{\mathrm{a}}-\mathrm{P}_{\mathrm{V}}+\mathrm{P}_{\mathrm{L}}\right)}{\mathrm{P}_{\mathrm{N}}} \frac{\mathrm{T}_{\mathrm{N}}}{\mathrm{T}_{\mathrm{a}}}
$$

Ao final de cada condição experimental foi realizada a quantificação da biomassa no interior do reator. Primeiramente foi feita a drenagem do sistema, sendo verificado o volume de meio líquido do reator $\left(\mathrm{V}_{\mathrm{R}}\right)$. Em seguida, todo o suporte inerte junto com a biomassa foi retirado do tubo de acrílico e quantificados $\left(\mathrm{M}_{\mathrm{T}-\mathrm{SI}+\mathrm{B}}\right)$, esse material foi homogeneizado para 
que fosse coletada uma amostra de suporte inerte com biomassa e quantificada $\left(\mathrm{M}_{\mathrm{A}-\mathrm{SI}+\mathrm{B}}\right)$. A partir dessa amostra foi realizada uma "lavagem" com água destilada do suporte inerte, dividindo essa amostra em duas partes, uma fase sólida apenas com os grânulos de PEBD e uma fase líquida contendo a biomassa do reator. Na fase sólida foi realizada a análise de ST e na fase líquida as análises de ST e SVT. A partir da quantidade de ST dos grânulos de PEBD $\left(\mathrm{M}_{\mathrm{A}-\mathrm{ST}}\right)$ e a quantidade de SVT da amostra $\left(\mathrm{M}_{\mathrm{A}-\mathrm{SVT}}\right)$, foi possível estimar a quantidade de biomassa do reator, sendo tal informação apresentada por três diferentes formas.

Na quantidade total de biomassa do reator $\left(\mathrm{M}_{\mathrm{SVT}}\right)$, calculada pela Equação (4.4):

$$
\mathrm{M}_{\mathrm{SVT}}=\frac{\mathrm{M}_{\mathrm{A}-\mathrm{SVT}} \cdot \mathrm{M}_{\mathrm{T}-\mathrm{SI}+\mathrm{B}}}{\mathrm{M}_{\mathrm{A}-\mathrm{SI}+\mathrm{B}}}
$$

Pela quantidade total de biomassa do reator $\left(\mathrm{M}_{\mathrm{SVT}}\right)$ mede-se a capacidade do reator na retenção da biomassa, sendo essa variável importante também devido à sua utilização em outros indicadores utilizados na análise do reator, como a carga orgânica específica aplicada (COEA), a carga orgânica específica removida (COER) e a produtividade molar específica (PrME).

$\mathrm{Na}$ relação entre a quantidade de biomassa e o volume de meio líquido do reator $\left(\mathrm{C}_{\mathrm{X}}\right)$, calculada pela Equação (4.5):

$$
\mathrm{C}_{\mathrm{X}}=\frac{\mathrm{M}_{\mathrm{SVT}}}{\mathrm{V}_{\mathrm{R}}}
$$

Pela concentração de biomassa no reator por volume de meio líquido tratado por ciclo $\left(\mathrm{C}_{\mathrm{X}}\right)$ mede-se a relação entre a quantidade de meio líquido disponível ao tratamento e a biomassa envolvida nas biotransformações inerentes ao processo biológico em estudo. 
Na relação entre a quantidade de biomassa e a quantidade de suporte inerte presente no reator $\left(\mathrm{C}_{\mathrm{X}}{ }^{\prime}\right)$, calculada pela Equação (4.6):

$$
\mathrm{C}_{\mathrm{X}}{ }^{\prime}=\frac{\mathrm{M}_{\mathrm{A}-\mathrm{SVT}}}{\mathrm{M}_{\mathrm{A}-\mathrm{SI}}}
$$

Pela concentração de biomassa no reator por massa de suporte inerte presente no reator $\left(\mathrm{C}_{\mathrm{X}}{ }^{\prime}\right)$ mede-se a relação entre a quantidade de suporte inerte disponível para a imobilização/retenção da biomassa e a biomassa envolvida nas biotransformações inerentes ao processo biológico em estudo.

Foram retiradas também do reator amostras de biomassa para exame microbiológico. As amostras foram examinadas em lâminas de vidro, por microscopia óptica comum e de contraste de fase por fluorescência, utilizando microscópio Olympus® modelo BX41, com sistema de câmera digital Optronics e aquisição de imagens feita pelo software Image ProPlus® versão 4.5.0.

\subsection{PROCEDIMENTO EXPERIMENTAL DA OPERAÇÃO DO REATOR}

Os ensaios foram realizados utilizando-se diferentes cargas orgânicas volumétricas modificadas em função da concentração afluente, de 3000, 4000 e $5000 \mathrm{mgDQO} . \mathrm{L}^{-1}$ e do tempo de ciclo de 4 e 3 h, ou seja, 6 e 8 ciclos diários. O tempo de enchimento foi sempre igual à metade do tempo de ciclo, ou seja, usando $\mathrm{t}_{\mathrm{F}} / \mathrm{t}_{\mathrm{C}}=0,5$.

O procedimento experimental pode ser dividido em três fases de operação, conforme Tabela 4.7. Houve também o "Ensaio 0", que não é parte de nenhuma das três fases; ele foi realizado como condição preliminar apenas para verificar o funcionamento do sistema e ajustar detalhes referentes ao procedimento experimental. 


\section{Objetivo}

Com concentração constante de $3000 \mathrm{mg}$ DQO.L $\mathrm{L}^{-1}$ e tempo de ciclo de 4 horas, foi estudado o efeito do tipo de inóculo, a diferença entre tipo

Fase I de glicerina, o tipo de suporte, a concentração de bicarbonato de sódio,

Ensaios de 1 a 11 . a velocidade ascensional e foi verificado a influência da solução de sais para encontrar os melhores parâmetros para apenas estudar o efeito do tempo de ciclo e carga orgânica volumétrica na Fase II.

Fazendo ensaios com GPA (para eliminar qualquer possibilidade de interferência de resíduos), foi estudada a influência da carga orgânica

Fase II volumétrica pela variação da concentração do afluente e do tempo de Ensaios de 12 a 19. ciclo. Mudou-se também a velocidade ascensional de 3,5 para 10,6 m.h. $\mathrm{h}^{-1}$ para dificultar o crescimento de arquéias metanogênicas na biomassa do reator.

Foram feitos dois ensaios utilizando as melhores condições obtidas na

Fase III Fase II. Um ensaio para verificar a produção de biohidrogênio com o

Ensaios 20 e 21. resíduo industrial e outro ensaio para comprovar se há a necessidade de pré-tratamento do inóculo (utilizando glicerina P.A.).

A Figura 4.6 esquematiza as três fases de operação para um melhor entendimento e a Tabela 4.8 resume os ensaios realizados. 
Fase I

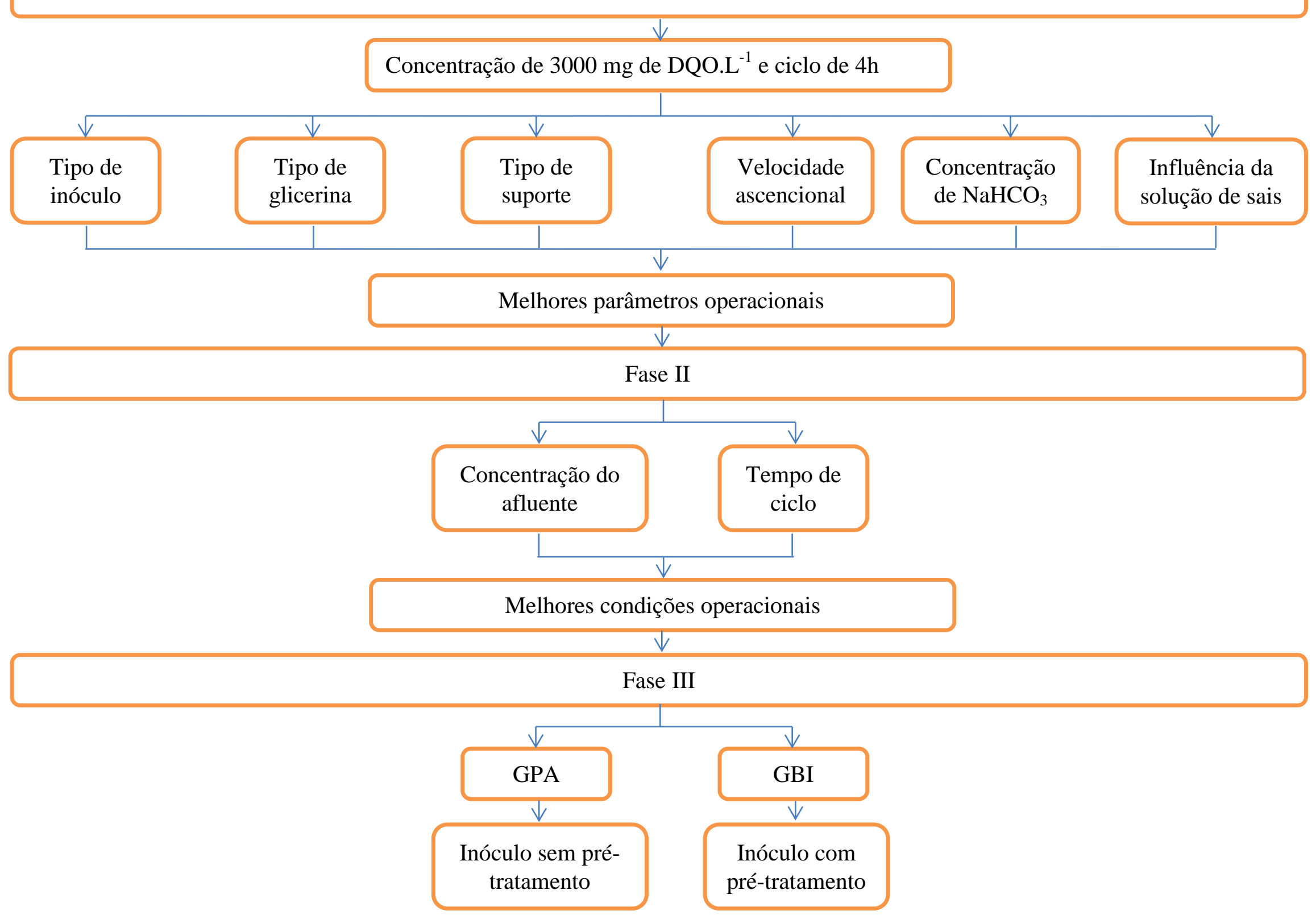


Tabela 4.8 - Resumo das condições experimentais estudadas

\begin{tabular}{|c|c|c|c|c|c|c|c|c|c|c|}
\hline Ensaio & $\begin{array}{l}\text { Concentração } \\
\left(\mathrm{mgDQO} \mathrm{L}^{-1}\right)\end{array}$ & $\begin{array}{c}\text { Tempo de } \\
\text { enchimento } \\
\text { (h) }\end{array}$ & $\begin{array}{l}\text { Tempo } \\
\text { de ciclo } \\
\text { (h) }\end{array}$ & $\begin{array}{l}\text { Carga orgânica } \\
\text { volumétrica } \\
\left(\mathrm{gDQO} \cdot \mathrm{L}^{-1} \cdot \mathrm{d}^{-1}\right)\end{array}$ & $\begin{array}{l}\text { Tipo de } \\
\text { Inóculo }\end{array}$ & $\begin{array}{c}\text { Água } \\
\text { residuária }\end{array}$ & $\begin{array}{l}\text { Tipo de } \\
\text { suporte }\end{array}$ & $\begin{array}{l}\text { Concentração } \\
\text { de } \mathrm{NaHCO}_{3} \\
\left(\mathrm{mg} \cdot \mathrm{L}^{-1}\right)\end{array}$ & $\begin{array}{c}\text { Solução de sais } \\
\text { para preparação do } \\
\text { meio }\end{array}$ & $\begin{array}{l}\text { Velocidade } \\
\text { ascensional } \\
\quad\left(\mathrm{m} \cdot \mathrm{h}^{-1}\right)\end{array}$ \\
\hline 0 & 3000 & 2 & 4 & 9,0 & 4 & Sacarose & PEBD & 500 & Completa & 7,1 \\
\hline 1 & 3000 & 2 & 4 & 9,0 & 4 & GBI & PEBD & 500 & Completa & 7,1 \\
\hline 2 & 3000 & 2 & 4 & 9,0 & 4 & GBI & PEBD & 200 & Completa & 7,1 \\
\hline 3 & 3000 & 2 & 4 & 9,0 & 4 & GBI & PEBD & 100 & Completa & 7,1 \\
\hline 4 & 3000 & 2 & 4 & 9,0 & 4 & GBI & PEBD & 0 & Nenhuma & 7,1 \\
\hline 5 & 3000 & 2 & 4 & 9,0 & 4 & GBI & PEBD & 0 & $\begin{array}{l}\text { Apenas sais que } \\
\text { não contivessem } \\
\text { enxofre }\end{array}$ & 7,1 \\
\hline 6 & 3000 & 2 & 4 & 9,0 & 4 & GBL & PEBD & 0 & $\begin{array}{l}\text { Apenas sais que } \\
\text { não contivessem } \\
\text { enxofre e sem ureia }\end{array}$ & 7,1 \\
\hline 7 & 3000 & 2 & 4 & 9,0 & $2+4$ & GBL & PEBD & 0 & Completa & 7,1 \\
\hline 8 & 3000 & 2 & 4 & 9,0 & $2+4$ & GBL & PEBD & 0 & Completa & 3,5 \\
\hline 9 & 3000 & 2 & 4 & 9,0 & $2+4$ & GBL & PEBD & 0 & Nenhuma & 3,5 \\
\hline 10 & 3000 & 2 & 4 & 9,0 & 4 & GBL + Sac. & $\mathrm{PEBD}+\mathrm{PU}$ & 250 & Completa & 3,5 \\
\hline 11 & 3000 & 2 & 4 & 9,0 & 4 & GBL + Sac. & $\mathrm{PEBD}+\mathrm{PU}$ & 100 & Completa & 3,5 \\
\hline 12 & 1000 & 2 & 4 & 2,6 & 3 & GPA & PEBD & 100 & Completa & 3,5 \\
\hline 13 & 2000 & 2 & 4 & 5,1 & 3 & GPA & PEBD & 100 & Completa & 3,5 \\
\hline 14 & 3000 & 2 & 4 & 7,7 & 3 & GPA & PEBD & 100 & Completa & 10,6 \\
\hline 15 & 4000 & 2 & 4 & 10,3 & 3 & GPA & PEBD & 100 & Completa & 10,6 \\
\hline 16 & 5000 & 2 & 4 & 12,9 & 3 & GPA & PEBD & 100 & Completa & 10,6 \\
\hline 17 & 3000 & 1,5 & 3 & 10,3 & 3 & GPA & PEBD & 100 & Completa & 10,6 \\
\hline 18 & 4000 & 1,5 & 3 & 13,7 & 3 & GPA & PEBD & 100 & Completa & 10,6 \\
\hline 19 & 5000 & 1,5 & 3 & 17,1 & 3 & GPA & PEBD & 100 & Completa & 10,6 \\
\hline 20 & 5000 & 1,5 & 3 & 17,1 & 1 & GPA & PEBD & 100 & Completa & 10,6 \\
\hline 21 & 5000 & 1,5 & 3 & 17,1 & 3 & GBI & PEBD & 100 & Completa & 10,6 \\
\hline
\end{tabular}


A operação do reator foi realizada da seguinte maneira: no final do ciclo foram descarregados 1,5 L de meio em $10 \mathrm{~min}$ e 2,0 L de meio (volume residual) foi mantido no reator, ou seja, o volume total de meio no reator foi de $3,5 \mathrm{~L}$, sendo o volume alimentado/descarregado por ciclo aquele presente no reservatório paralelo (1,5 L), sendo o restante de meio, denominado de volume residual $(2,0 \mathrm{~L})$, mantido no interior do reator a cada ciclo. Logo após essa descarga, um novo ciclo teve início, no qual houve a recirculação do meio e o tempo de alimentação (2 e 1,5 h) variou em função do tempo total de ciclo (4 e 3 h) conforme a condição estudada, com vazão de alimentação constante de um volume de $1,5 \mathrm{~L}$ (50\% do volume de meio reacional) de meio a ser tratado. Ao término do ciclo, a recirculação foi interrompida e, em seguida, iniciou-se a descarga e, assim, o ciclo foi repetido, caracterizando as bateladas alimentadas sequenciais.

Uma vez atingida a estabilidade nas condições experimentais, foram obtidos perfis ao longo do ciclo de operação de algumas das variáveis monitoradas. Nestes perfis foram retiradas amostras ao longo do tempo de operação de um ciclo. As variáveis de interesse foram: concentrações de matéria orgânica na forma filtrada, de alcalinidade a bicarbonato, de ácidos voláteis totais, de metabólitos intermediários (acetona, ácidos voláteis e alcoóis), de biogás (composição e produção), além do pH. Desta forma, foi possível obter uma melhor compreensão das rotas metabólicas ao longo de um ciclo. As amostras retiradas para obtenção do perfil anteriormente citado foram colhidas em intervalos de tempo ao longo do ciclo de 30 a 60 min. O volume total retirado nas amostragens foi de no máximo $300 \mathrm{~mL}$, ou seja, 10\% do volume de meio reacional do sistema. Após cada operação, amostras do lodo foram retiradas do reator para análise microbiológica. Dessa forma, uma nova condição experimental foi implementada alterando-se a concentração afluente e/ou os tempos de ciclo e de alimentação do reator.

Os resultados experimentais obtidos no monitoramento do sistema e nos perfis ao longo 
de um ciclo, em cada condição operacional, foram analisados considerando-se a influência das variáveis estudadas sobre a estabilidade e o desempenho do processo, além do fator de conversão entre hidrogênio formado e matéria orgânica consumida.

\subsection{FUNDAMENTOS TEÓRICOS}

As eficiências de remoção de matéria orgânica na forma de DQO em amostras filtradas e não filtradas no sistema foram calculadas pelas Equações (4.7) e (4.8), nas quais $\mathrm{C}_{\mathrm{SAFL}}$ é a concentração de matéria orgânica no afluente em amostras não filtradas e $\mathrm{C}_{\mathrm{ST}}$ e $\mathrm{C}_{\mathrm{SF}}$ são as concentrações de matéria orgânica em amostras não filtradas e filtradas, respectivamente, do efluente.

$$
\begin{aligned}
& \varepsilon_{\mathrm{ST}}(\%)=\frac{\mathrm{C}_{\mathrm{SAFL}}-\mathrm{C}_{\mathrm{ST}}}{\mathrm{C}_{\mathrm{SAFL}}} .100 \\
& \varepsilon_{\mathrm{SF}}(\%)=\frac{\mathrm{C}_{\mathrm{SAFL}}-\mathrm{C}_{\mathrm{SF}}}{\mathrm{C}_{\mathrm{SAFL}}} .100
\end{aligned}
$$

A eficiência de remoção de matéria orgânica em amostras filtradas do meio líquido contido no reator $\left(\varepsilon_{S}\right)$ para os perfis ao longo do ciclo foram calculadas pelas Equações (4.9) e (4.10), sendo a primeira equação utilizada para o período em batelada alimentada e a segunda para o período em batelada, nas quais $\mathrm{C}_{\mathrm{S} 0}$ é a concentração de matéria orgânica em amostras filtradas do meio líquido contido no reator no tempo zero, $\mathrm{V}_{\mathrm{Res}}$ é o volume do meio líquido contido no reator no tempo zero ou volume residual, $\mathrm{F}_{\mathrm{AFL}}$ é a vazão de alimentação de afluente no período em batelada alimentada, $\mathrm{t}_{\mathrm{i}}$ é o tempo de alimentação percorrido (período em batelada alimentada), $\mathrm{C}_{\mathrm{SF}}$ é a concentração de matéria orgânica na forma de DQO em amostras filtradas do meio líquido contido no reator no tempo ti, e $\mathrm{t}_{\mathrm{BA}}$ é o tempo de batelada alimentada na condição experimental. 


$$
\begin{gathered}
\varepsilon_{S}(\%)=\frac{\left(\mathrm{C}_{\mathrm{S} 0} \cdot \mathrm{V}_{\mathrm{ReS}}+\mathrm{C}_{\mathrm{SAFL}} \cdot \mathrm{F}_{\mathrm{AFL}} \cdot \mathrm{t}_{\mathrm{i}}\right)-\left(\mathrm{C}_{\mathrm{SF}} \cdot\left(V_{R e S}+F_{A F L} \cdot t_{i}\right)\right)}{\left(\mathrm{C}_{\mathrm{S} 0} \cdot \mathrm{V}_{\mathrm{Res}}+\mathrm{C}_{\mathrm{SAFL}} \cdot \mathrm{F}_{\mathrm{AFL}} \cdot \mathrm{t}_{\mathrm{i}}\right)} \cdot 100 \\
\varepsilon_{S}(\%)=\frac{\left(\mathrm{C}_{\mathrm{S} 0} \cdot \mathrm{V}_{\mathrm{Res}}+\mathrm{C}_{\mathrm{SAFL}} \cdot \mathrm{F}_{\mathrm{AFL}} \cdot \mathrm{t}_{\mathrm{BA}}\right)-\left(\mathrm{C}_{\mathrm{SF}} \cdot\left(V_{R e s}+F_{A F L} \cdot t_{B A}\right)\right)}{\left(\mathrm{C}_{\mathrm{S} 0} \cdot \mathrm{V}_{\mathrm{Res}}+\mathrm{C}_{\mathrm{SAFL}} \cdot \mathrm{F}_{\mathrm{AFL}} \cdot \mathrm{t}_{\mathrm{BA}}\right)} .100
\end{gathered}
$$

A porosidade do leito do reator $(\varphi)$ é definida como o volume de vazios no interior do reator $\left(\mathrm{V}_{\text {Vazios }}\right)$ dividido pelo volume total do reator $\left(\mathrm{V}_{\text {Total }}\right)$, segundo Equação (4.11).

$$
\varphi=\frac{V_{\text {Vazios }}}{V_{\text {Total }}}
$$

A área da seção transversal real utilizada pelo reator $\left(A_{R}\right)$ e o volume real utilizado do reator $\left(\mathrm{V}_{\mathrm{R}}\right)$ são dados pela multiplicação da área da seção transversal nominal do reator (A) pela porosidade e pela multiplicação da área real pela altura nominal do reator, respectivamente, segundo Equações (4.12) e (4.13).

$$
\begin{gathered}
A_{R}=\text { A. } \varphi \\
V_{R}=A_{R} \cdot h
\end{gathered}
$$

A velocidade ascensional do líquido no interior do reator (v) é dada pela vazão de recirculação (Q) dividida pela área real utilizada, como mostrado na Equação (4.14).

$$
\mathrm{v}=\frac{Q}{A_{R}}
$$

A carga orgânica volumétrica aplicada (COVA) é definida como a quantidade de matéria orgânica aplicada ao reator por unidade de tempo e por volume de meio do reator (em gDQO. $\left.L^{-1} \cdot d^{-1}\right)$. Para reatores operados em batelada é calculada pela Equação (4.15), na qual $\mathrm{V}_{\mathrm{A}}$ é o volume de água residuária alimentada ao reator por ciclo, $\mathrm{N}$ é o número de ciclos por dia e $V_{R}$ é o volume de total de água residuária contida no reator por ciclo. 


$$
\operatorname{COVA}=\frac{\left(\mathrm{V}_{\mathrm{A}} \cdot \mathrm{N}\right) \cdot \mathrm{C}_{\mathrm{SAFL}}}{\mathrm{V}_{\mathrm{R}}}
$$

A carga orgânica específica aplicada (COEA) é definida como a quantidade de matéria orgânica aplicada ao reator por unidade de tempo e por massa de sólidos totais voláteis no reator $\left(\mathrm{gDQO} . \mathrm{gSVT}^{-1} \cdot \mathrm{d}^{-1}\right)$. Para reatores operados em batelada é calculada pela Equação (4.16).

$$
\text { COEA }=\frac{\left(V_{\mathrm{A}} \cdot \mathrm{N}\right) \cdot \mathrm{C}_{\mathrm{SAFL}}}{\mathrm{M}_{\mathrm{SVT}}}
$$

A carga orgânica volumétrica removida (COVR), para amostras filtradas, é definida como a quantidade de matéria orgânica removida pelo reator por unidade de tempo e por volume de meio do reator $\left(\mathrm{gDQO} \cdot \mathrm{L}^{-1} \cdot \mathrm{d}^{-1}\right)$. Para reatores operados em batelada é calculada pela Equação (4.17).

$$
\operatorname{COVR}=\frac{\left(\mathrm{V}_{\mathrm{A}} \cdot \mathrm{N}\right) \cdot\left(\mathrm{C}_{\mathrm{SAFL}}-\mathrm{C}_{\mathrm{SF}}\right)}{\mathrm{V}_{\mathrm{R}}}
$$

A carga orgânica específica removida (COER), para amostras filtradas, é definida como a quantidade de matéria orgânica removida pelo reator por unidade de tempo e por massa de sólidos totais voláteis no reator $\left(\mathrm{gDQO} . \mathrm{gSVT}^{-1} \cdot \mathrm{d}^{-1}\right)$. Para reatores operados em batelada é calculada pela Equação (4.18).

$$
\operatorname{COER}=\frac{\left(\mathrm{V}_{\mathrm{A}} \cdot \mathrm{N}\right) \cdot\left(\mathrm{C}_{\mathrm{SAFL}}-\mathrm{C}_{\mathrm{SF}}\right)}{\mathrm{M}_{\mathrm{SVT}}}
$$

A produtividade molar volumétrica $(\operatorname{PrM})$ é definida pela quantidade de hidrogênio $\left(\mathrm{H}_{2}\right)$ produzida por unidade de tempo e por volume útil do reator $\left(\mathrm{molH}_{2} \cdot \mathrm{m}^{-3} \cdot \mathrm{d}^{-1}\right)$, calculada 
pela Equação (4.19), na qual $n_{H 2}$ é a quantidade molar de hidrogênio produzido por dia e $\mathrm{V}_{\mathrm{R}}$ é o volume de total de água residuária contida no reator por ciclo.

$$
\operatorname{PrM}=\frac{\mathrm{n}_{\mathrm{H} 2}}{\mathrm{~V}_{\mathrm{R}}}
$$

A produtividade molar específica (PrME) é definida pela quantidade de hidrogênio $\left(\mathrm{H}_{2}\right)$ produzida por unidade de tempo e por massa de sólidos voláteis totais no interior do reator $\left(\mathrm{molH}_{2} \cdot \mathrm{kgSVT}^{-1} \cdot \mathrm{d}^{-1}\right)$, calculada pela Equação (4.20). A produtividade é um parâmetro particularmente interessante no dimensionamento de unidades, permitindo avaliar a capacidade de produção de um reator a partir do volume (ou massa de microrganismos presente) ou, ao contrário, de estimar volume (ou massa de microrganismos) necessário para alcançar uma produção desejada.

$$
\operatorname{PrME}=\frac{\mathrm{n}_{\mathrm{H} 2}}{\mathrm{M}_{\mathrm{SVT}}}
$$

O rendimento entre hidrogênio (molar) produzido e matéria orgânica (massa) aplicada (RMCA) é definido pela quantidade de hidrogênio $\left(\mathrm{H}_{2}\right)$ produzida (em mol) pela quantidade de matéria orgânica aplicada (em massa) $\left(\mathrm{molH}_{2} \cdot \mathrm{kgDQO}^{-1}\right)$, calculado pela Equação (4.21).

$$
\mathrm{RMCA}=\frac{\mathrm{n}_{\mathrm{H} 2}}{\mathrm{~N} \cdot \mathrm{V}_{\mathrm{A}} \cdot \mathrm{C}_{\mathrm{SAFL}}}
$$

O rendimento entre hidrogênio (molar) produzido e matéria orgânica (massa) removida (RMCR) é definido pela quantidade de hidrogênio $\left(\mathrm{H}_{2}\right)$ produzida pela quantidade de matéria orgânica removida $\left(\mathrm{molH}_{2} \cdot \mathrm{kgDQO}^{-1}\right)$, calculado pela Equação (4.22).

$$
\mathrm{RMCR}=\frac{\mathrm{n}_{\mathrm{H} 2}}{\mathrm{~N} \cdot \mathrm{V}_{\mathrm{A}} \cdot\left(\mathrm{C}_{\mathrm{SAFL}}-\mathrm{C}_{\mathrm{SF}}\right)}
$$


Para o cálculo do balanço de massa do processo durante o monitoramento diário, utilizaram-se a Equação (4.23) e (4.24), na qual $\mathrm{DQO}_{\mathrm{CAFL}}$ é a DQO do afluente, $\mathrm{DQO}_{\mathrm{GC}}$ é a DQO da glicerina consumida, $\mathrm{DQO}_{\mathrm{CSF}}$ é a DQO do efluente filtrado, $\mathrm{DQO}_{\mathrm{AVT}}$ é a DQO dos ácidos voláteis totais durante o monitoramento diário, $\mathrm{DQO}_{\text {Biomassa }}$ é a DQO resultante do crescimento da biomassa e $\mathrm{DQO}_{\mathrm{GNCD}}$ é uma aproximação do que seria a DQO real da glicerina não consumida no monitoramento diário.

$$
\begin{gathered}
D Q O_{C A F L}=D Q O_{G C}+D Q O_{C S F}-D Q O_{A V T}-D Q O_{B i o m a s s a} \\
D Q O_{G N C D}=D Q O_{C S F}-D Q O_{A V I}-D Q O_{\text {Biomassa }}
\end{gathered}
$$

Para o cálculo do balanço de massa durante os perfis, utilizou-se a Equação 4.25 e 4.26, na qual $\mathrm{DQO}_{\mathrm{AVI}}$ é a DQO dos ácidos voláteis intermediários discriminados durante o perfil e $\mathrm{DQO}_{\mathrm{GNCP}}$ é uma aproximação do que seria a DQO real da glicerina não consumida no monitoramento do perfil.

$$
\begin{gathered}
D Q O_{C A F L}=D Q O_{G C}+D Q O_{C S F}-D Q O_{A V I}-D Q O_{\text {Biomassa }} \\
D Q O_{G N C P}=D Q O_{C S F}-D Q O_{A V I}-D Q O_{\text {Biomassa }}
\end{gathered}
$$

$\mathrm{O}$ rendimento entre hidrogênio (molar) produzido e glicerina aplicada $\left(\mathrm{RMCA}_{\mathrm{Glicerina}}\right)$ é definido pela quantidade de hidrogênio $\left(\mathrm{H}_{2}\right)$ produzida (em mol) pela quantidade molar de glicerina aplicada $\left(\mathrm{molH}_{2} \cdot\right.$ molglicerina $\left.^{-1}\right)$, calculado pela Equação (4.27). O fator 1,216 é o equivalente-grama DQO/glicerina e 92,08 é a massa molecular da glicerina.

$$
\mathrm{RMCA}_{\text {Glicerina }}=\frac{\mathrm{n}_{\mathrm{H} 2 \cdot 1,216 \cdot 92,08 \cdot 1000}}{\mathrm{~N} \cdot \mathrm{V}_{\mathrm{A}} \cdot \mathrm{C}_{\mathrm{SAFL}}}
$$

O rendimento entre hidrogênio (molar) produzido e glicerina removida ( $\mathrm{RMCR}_{\mathrm{Glicerina}}$ ) é definido pela quantidade de hidrogênio $\left(\mathrm{H}_{2}\right)$ produzida pela quantidade de glicerina 
removida $\left(\mathrm{molH}_{2} \cdot\right.$ molglicerina $\left.^{-1}\right)$, calculado pelas Equações (4.28) e (4.29). Os rendimentos podem ser calculados por duas formas: utilizando o balanço do monitoramento diário $\left(\mathrm{RMCR}_{\mathrm{GlicerinaAVT}}\right)$ e o monitoramento durante o perfil ( $\left.\mathrm{RMCR}_{\mathrm{GlicerinaAVI}}\right)$.

$$
\begin{aligned}
& \mathrm{RMCR}_{\mathrm{GlicerinaAVT}}=\frac{\mathrm{n}_{\mathrm{H} 2}}{\mathrm{~N} \cdot \mathrm{V}_{\mathrm{A}} \cdot\left(\frac{\mathrm{C}_{\mathrm{SAFL}}-D Q O_{G N C D}}{1,216.92,08 \cdot 1000}\right)} \\
& \mathrm{RMCR}_{\mathrm{GlicerinaAVI}}=\frac{\mathrm{n}_{\mathrm{H} 2}}{\mathrm{~N} \cdot \mathrm{V}_{\mathrm{A}} \cdot\left(\frac{\mathrm{C}_{\mathrm{SAFL}}-D Q O_{G N C P}}{1,216.92,08.1000}\right)}
\end{aligned}
$$




\section{RESULTADOS E DISCUSSÃO}

\subsection{CONDIÇÃO EXPERIMENTAL PRELIMINAR - ENSAIO 0}

\subsubsection{Monitoramento}

A montagem do reator, a partida da operação e todo o período até a estabilidade do sistema ser atingida foram considerados como etapa preliminar. Esse período foi utilizado também para a preparação das curvas de calibração dos métodos analíticos (DQO, alcalinidade e ácidos voláteis totais) e ajuste dos detalhes referente ao procedimento experimental.

Essa etapa foi operada com as mesmas características da primeira condição experimental, ou seja, valor nominal de carga orgânica volumétrica aplicada (COVA) de 9,0 gDQO. $\mathrm{L}^{-1} \cdot \mathrm{d}^{-1}$, sendo a única diferença implementada referente ao substrato alimentado que foi sacarose ao invés de glicerina. Tal estratégia teve por objetivo a familiarização com a operação do sistema, pois os resultados a serem obtidos deveriam ser próximos aos anteriormente medidos em projetos já finalizados que utilizaram sacarose, e também para promover o crescimento da biomassa inicial (inóculo). Após 17 dias da partida do sistema, os parâmetros operacionais medidos na condição de final de ciclo apresentaram um comportamento estável, ou seja, uma variação média dentro da precisão das medidas efetuadas.

Vale ressaltar que, por ser uma condição preliminar, não foram realizadas a quantificação da biomassa presente no reator, as análises de sólidos do afluente e efluente, e as análises de efluente referentes aos compostos intermediários do metabolismo anaeróbio por cromatografia (solventes: acetona, metanol, etanol, n-butanol; ácidos voláteis: ácidos acético, propiônico, butírico, iso-butírico, valérico, iso-valérico e capróico). A Tabela 5.1 apresenta os 
valores médios dos parâmetros experimentais monitorados. Nesta etapa foi realizada a quantificação de matéria orgânica na forma de carboidratos pelo método de Dubois et al. (1956) por ter sido utilizado sacarose como substrato. Com a utilização desse método, determinou-se que o afluente teve um valor médio de $2621 \mathrm{mgSacarose} . \mathrm{L}^{-1}$ e o efluente $131 \mathrm{mgSacarose} . \mathrm{L}^{-1}$, ou seja, uma eficiência de remoção de matéria orgânica na forma de carboidratos em amostras filtradas de $99,5 \%$.

\begin{tabular}{|c|c|c|c|c|c|c|c|c|c|}
\hline \multicolumn{2}{|r|}{ Parâmetro } & \multicolumn{4}{|c|}{ Afluente } & \multicolumn{4}{|c|}{ Efluente } \\
\hline $\mathrm{C}_{\mathrm{ST}}$ & $\left(\mathrm{mgDQO} \cdot \mathrm{L}^{-1}\right)$ & 2963 & \pm & 98 & (12) & 2323 & \pm & 86 & (11) \\
\hline $\mathrm{C}_{\mathrm{SF}}$ & $\left(\mathrm{mgDQO} . \mathrm{L}^{-1}\right)$ & $\longrightarrow$ & & & & 2167 & \pm & 111 & (11) \\
\hline$\varepsilon_{\mathrm{ST}}$ & $(\%)$ & - & & - & & 22 & \pm & 3 & (11) \\
\hline$\varepsilon_{\mathrm{SF}}$ & $(\%)$ & - & & - & & 27 & \pm & 4 & (11) \\
\hline $\mathrm{pH}$ & (u) & 8,0 & \pm & 0,1 & ( 12 ) & 4,7 & \pm & 0,2 & (11) \\
\hline AVT & $\left(\mathrm{mgHAc} . \mathrm{L}^{-1}\right)$ & 28 & \pm & 9 & ( 12 ) & 877 & \pm & 74 & (11) \\
\hline $\mathrm{AT}$ & $\left(\mathrm{mgCaCO}_{3} \cdot \mathrm{L}^{-1}\right)$ & 412 & \pm & 20 & ( 12 ) & 155 & \pm & 58 & (11) \\
\hline $\mathrm{AP}$ & $\left(\mathrm{mgCaCO}_{3} \cdot \mathrm{L}^{-1}\right)$ & 314 & \pm & 12 & (12) & 0 & \pm & 0 & (11) \\
\hline AI & $\left(\mathrm{mgCaCO}_{3} \cdot \mathrm{L}^{-1}\right)$ & 98 & \pm & 9 & (12) & 155 & \pm & 58 & (11) \\
\hline $\mathrm{AB}$ & $\left(\mathrm{mgCaCO}_{3} \cdot \mathrm{L}^{-1}\right)$ & 392 & \pm & 22 & (12) & 0 & \pm & 0 & (11) \\
\hline $\mathrm{V}_{\mathrm{G}}$ & $(\mathrm{NmL})$ & - & & - & & 902 & \pm & 359 & ( 3 ) \\
\hline $\mathrm{V}_{\mathrm{H} 2}$ & $(\mathrm{NmL})$ & - & & - & & 427 & \pm & 228 & ( 3 ) \\
\hline COVA & $\left(\right.$ gDQO.L $\left.{ }^{-1} \cdot d^{-1}\right)$ & 8,89 & & - & & - & & - & \\
\hline COVR & $\left(\right.$ gDQO.L $\left.L^{-1} \cdot d^{-1}\right)$ & - & & - & & 2,39 & & - & \\
\hline COER & (gDQO.gSVT ${ }^{-1} \cdot \mathrm{d}^{-1}$ ) & - & & - & & - & & - & \\
\hline $\mathrm{n}_{\mathrm{H} 2}$ & $\left(\mathrm{molH}_{2} \cdot \mathrm{d}^{-1}\right)$ & - & & - & & 0,11 & & - & \\
\hline PrM & $\left(\mathrm{molH}_{2} \cdot \mathrm{m}^{-3} \cdot \mathrm{d}^{-1}\right)$ & - & & - & & 38,1 & & - & \\
\hline RMCA & $\left(\mathrm{molH}_{2} \cdot \mathrm{kgDQO}^{-1}\right)$ & - & & - & & 4,28 & & - & \\
\hline RMCR & $\left(\mathrm{molH}_{2} \cdot \mathrm{kgDQO}^{-1}\right)$ & 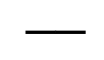 & & - & & 15,9 & & - & \\
\hline $\mathrm{V}_{\mathrm{A}}$ & $(\mathrm{L})$ & 1,49 & \pm & 0,06 & ( 12 ) & 10 & & - & \\
\hline $\mathrm{V}_{\mathrm{R}}$ & $(\mathrm{L})$ & 3,00 & \pm & 0,00 & (1) & - & & - & \\
\hline
\end{tabular}

(*) Entre parêntese o número de amostras considerado no cálculo da média

A Figura 5.1 apresenta os valores de matéria orgânica na forma de DQO para o afluente (amostras não filtradas) e efluente (amostras não filtradas e filtradas) e na Figura 5.2 tem-se as eficiências na remoção de matéria orgânica na forma de DQO. A concentração média do afluente aplicada ao reator foi de $2963 \mathrm{mgDQO} . \mathrm{L}^{-1}$, a concentração média obtida para o efluente em amostras não filtradas foi de $2323 \mathrm{mgDQO} . \mathrm{L}^{-1}$ e para amostras filtradas foi de 2167 mgDQO.L $\mathrm{L}^{-1}$. Portanto, foram obtidas eficiências de remoção de matéria orgânica na 
forma de DQO de 22,3\% para amostras não filtradas e de 27,4\% para amostras filtradas, sendo que a estabilização desse parâmetro pode ser considerada a partir do $8^{\circ}$ dia.

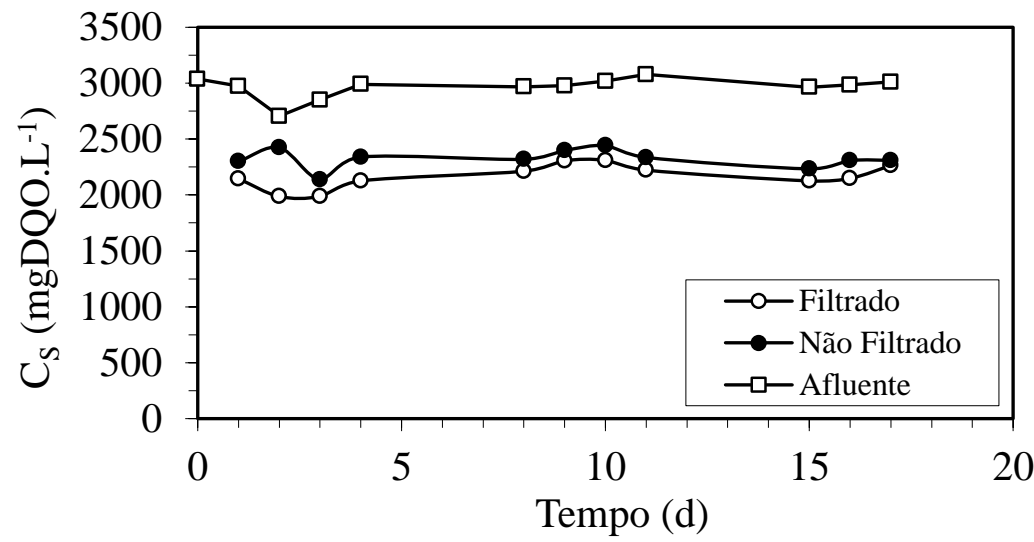

Figura 5.1 - Concentração de matéria orgânica na forma de DQO na Condição Preliminar: — - afluente amostras não filtradas; • - efluente amostras não filtradas; ○ - efluente amostras filtradas

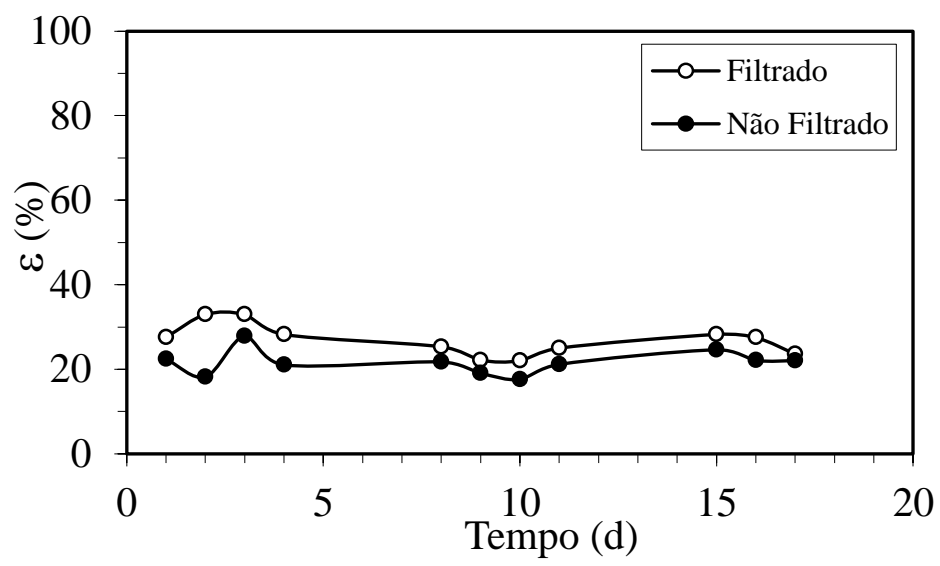

Figura 5.2 - Eficiência de remoção de matéria orgânica na forma de DQO na Condição Preliminar: amostras não filtradas; ○ - amostras filtradas

As Figuras 5.3, 5.4 e 5.5 apresentam os resultados obtidos de $\mathrm{pH}$, alcalinidade total (AT) e ácidos voláteis totais (AVT), respectivamente. O valor médio de $\mathrm{pH}$ afluente foi de 8,0 e do efluente de 4,7. A alcalinidade total afluente teve média de $412 \mathrm{mgCaCO}_{3} \cdot \mathrm{L}^{-1}$ sendo consumida durante o ciclo, obtendo-se no efluente uma média de $155 \mathrm{mgCaCO} \cdot \mathrm{L}^{-1}$. A queda do $\mathrm{pH}$ e da AT foram consequência do acúmulo de ácidos no sistema, sendo que a média de AVT do afluente foi de $28 \mathrm{mgHAc} . \mathrm{L}^{-1}$ e no efluente de $877 \mathrm{mgHAc} . \mathrm{L}^{-1}$. 


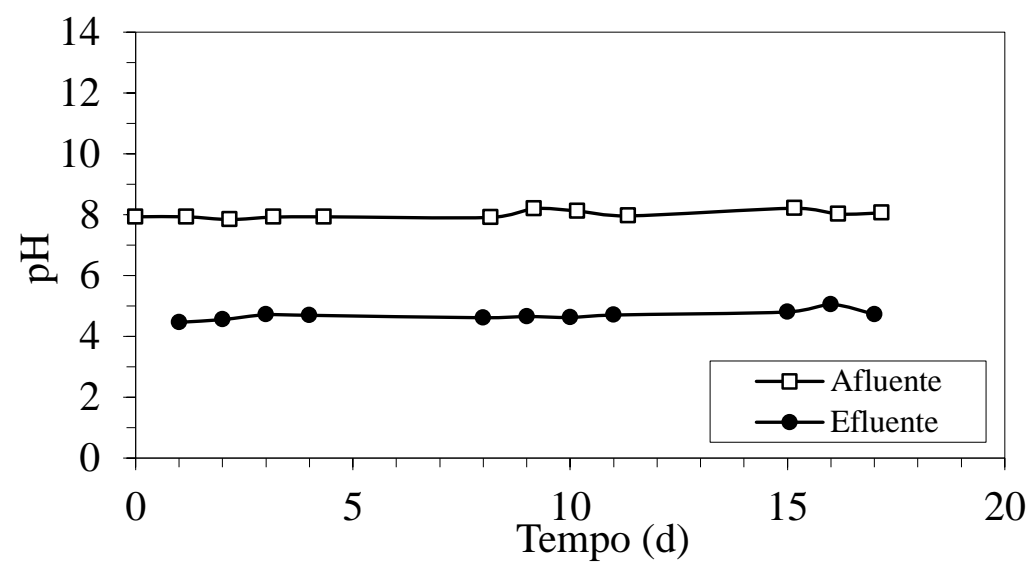

Figura 5.3 - Valores de pH na Condição Preliminar: $\square-$ afluente; $\bullet$ - efluente

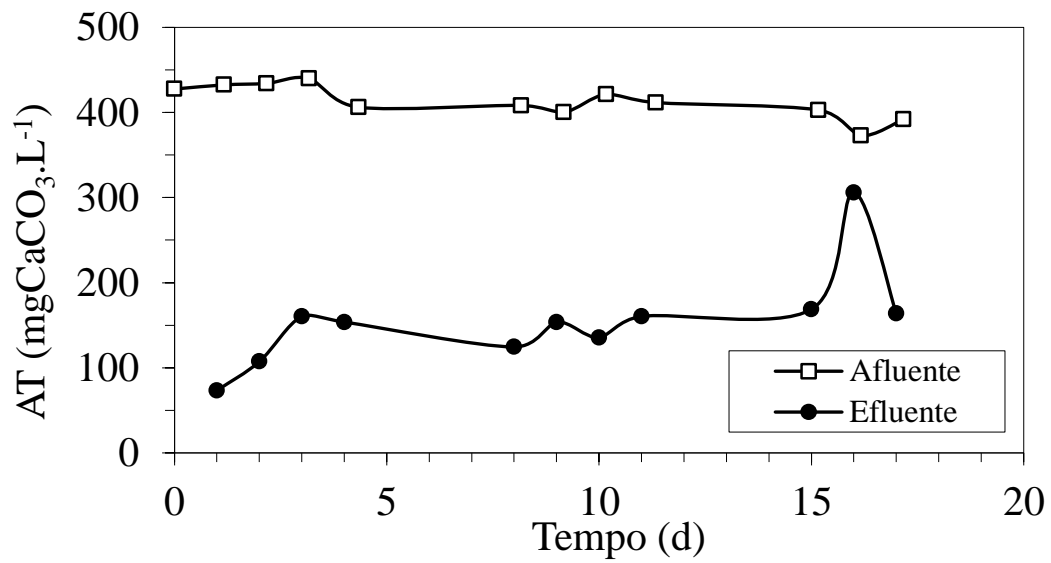

Figura 5.4 - Valores de alcalinidade total (AT) na Condição Preliminar: $\square$-afluente; • - efluente

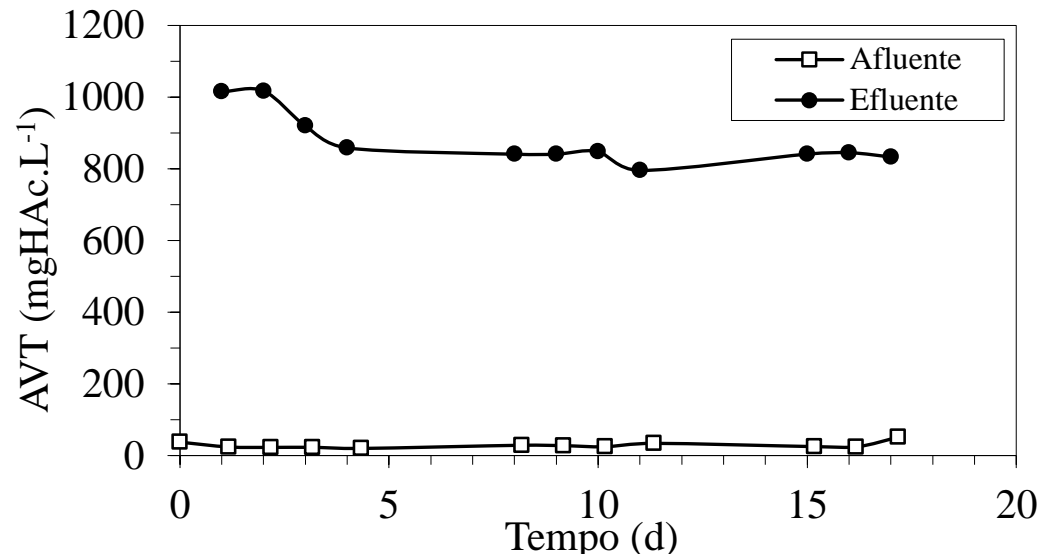

Figura 5.5 - Valores de ácidos voláteis totais (AVT) na Condição Preliminar: $\square$ - afluente; $\bullet$ - efluente

A produção de biogás e de hidrogênio por ciclo, em aspecto quantitativo, pode ser observada na Figura 5.6, com média de $902 \mathrm{NmL}$ de biogás e $426 \mathrm{NmL}$ de hidrogênio. A Tabela 5.2 mostra os valores médios da produção, fração molar e volume de hidrogênio total 
obtido por ciclo, sendo possível notar que a produção de metano foi completamente inibida nesta condição. Os valores das variáveis obtidos nesta condição preliminar também foram importantes para comparar o desempenho deste reator tratando a sacarose e tratando a glicerina.

Tabela 5.2 - Produção e fração molar referente ao biogás na Condição Preliminar

\begin{tabular}{ccccccccc}
\hline $\begin{array}{c}\text { Tempo } \\
\text { (dia) }\end{array}$ & $\mathrm{V}_{\mathrm{G}}$ & \multicolumn{2}{c}{$\mathrm{C}_{\mathrm{G}}\left(\mathrm{mmol}^{-\mathrm{L}^{-1}}\right)$} & \multicolumn{3}{c}{$\mathrm{Y}_{\mathrm{G}}(\%)$} & $\mathrm{V}_{\mathrm{H} 2}$ \\
\hline 11 & 666 & 4,11 & 0,00 & 7,20 & 36 & 0 & 64 & 242 \\
16 & 1377 & 4,93 & 0,00 & 4,38 & 53 & 0 & 47 & 729 \\
17 & 1129 & 5,73 & 0,00 & 6,73 & 46 & 0 & 54 & 519 \\
\hline
\end{tabular}

\subsubsection{Perfis ao longo do ciclo}

A Figura 5.6 mostra os perfis de produção de biogás no sistema nos dias de ensaio 16 e 17. Nota-se que a maior produção de biogás ocorreu durante a alimentação do reator (duas horas iniciais) e cessou em aproximadamente 30 minutos após o término do período em batelada alimentada; esse fato pode ser considerado um indício que tempos de ciclos menores favoreceriam a produtividade molar de hidrogênio.

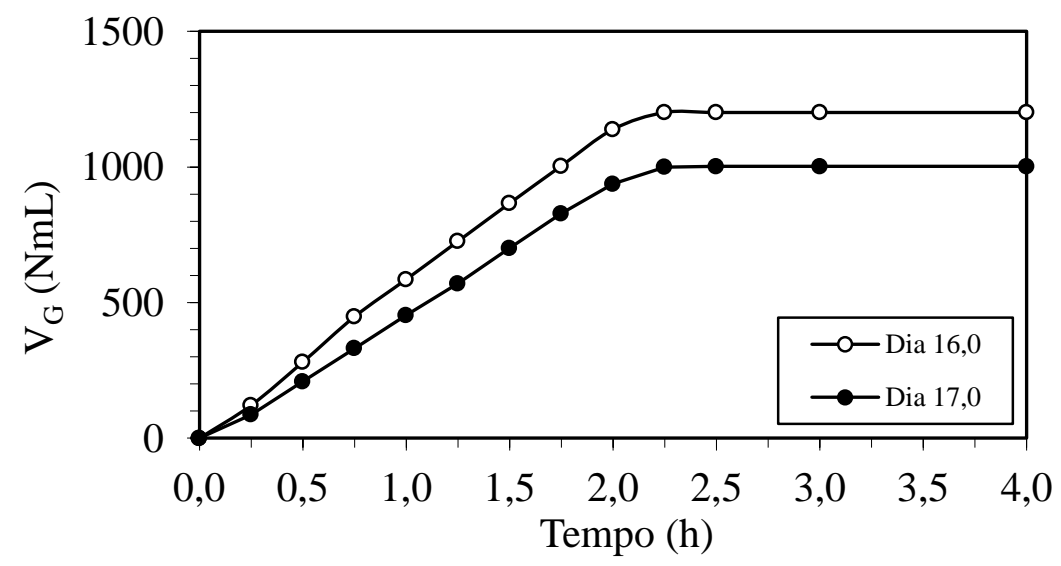

Figura 5.6 - Perfis de produção de biogás (dias de ensaio 16 e 17) na Condição Preliminar 


\subsection{FASE I}

Nesta primeira fase foram estudados o efeito do tipo de inóculo, a diferença entre tipo de glicerina, o tipo de suporte, a concentração de bicarbonato de sódio, a velocidade ascensional e a influência da solução de sais para encontrar os melhores parâmetros para dar seguimento com a Fase II do projeto.

Nesta fase, como na condição preliminar, também não foram realizadas a quantificação da biomassa presente no reator e as análises de efluente referentes aos compostos intermediários do metabolismo anaeróbio por cromatografia (solventes: acetona, metanol, etanol, n-butanol; ácidos voláteis: ácidos acético, propiônico, butírico, iso-butírico, valérico, iso-valérico e capróico), também não foram feitos perfis das variáveis ao longo do ciclo por não se tratar do objetivo dessa fase. A série de sólidos do afluente e do efluente foi realizada em apenas algumas das condições somente para se ter uma base dos valores esperados na Fase II.

A Tabela 5.3 apresenta os valores médios dos parâmetros experimentais monitorados nos onze ensaios (total de 50 dias) que englobam esta primeira etapa. 
Tabela 5.3 - Parâmetros monitorados na Fase I

\begin{tabular}{|c|c|c|c|c|c|c|c|c|c|c|c|c|c|c|c|c|c|c|c|c|c|c|c|c|c|}
\hline \multirow{2}{*}{\multicolumn{2}{|c|}{ Parâmetro }} & \multicolumn{8}{|c|}{1} & \multicolumn{8}{|c|}{2} & \multicolumn{8}{|c|}{3} \\
\hline & & \multicolumn{4}{|c|}{ Afluente } & \multicolumn{4}{|c|}{ Efluente } & \multicolumn{4}{|c|}{ Afluente } & \multicolumn{4}{|c|}{ Efluente } & \multicolumn{4}{|c|}{ Afluente } & \multicolumn{4}{|c|}{ Efluente } \\
\hline $\mathrm{C}_{\mathrm{ST}}$ & $\left(\mathrm{mgDQO} \cdot \mathrm{L}^{-1}\right)$ & 3174 & \pm & 50 & $(2)$ & 2078 & \pm & 160 & $(2)$ & 3278 & \pm & 72 & $(2)$ & 1990 & \pm & 87 & $(2)$ & 2925 & \pm & 214 & $(6)$ & 1646 & \pm & 58 & $(3)$ \\
\hline $\mathrm{C}_{\mathrm{SF}}$ & $\left(\mathrm{mgDQO} . \mathrm{L}^{-1}\right)$ & - & & - & & 1992 & \pm & 154 & ( 2 ) & - & & - & & 1970 & \pm & 29 & $(2)$ & - & & - & & 1478 & \pm & 14 & (3) \\
\hline$\varepsilon_{\mathrm{ST}}$ & $(\%)$ & - & & - & & 37 & \pm & 5 & $(2)$ & - & & - & & 46,0 & \pm & 0,9 & $(2)$ & $\longrightarrow$ & & - & & 49,5 & \pm & 0,5 & ( 3 ) \\
\hline$\varepsilon_{\mathrm{SF}}$ & $(\%)$ & - & & - & & 35 & \pm & 5 & ( 2 ) & - & & - & & 39 & \pm & 3 & $(2)$ & - & & - & & 44 & \pm & 2 & ( 3 ) \\
\hline $\mathrm{pH}$ & (u) & 7,9 & \pm & 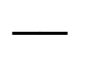 & ( 1 ) & 6,7 & \pm & 0,2 & ( 2 ) & 7,7 & \pm & 0,3 & ( 2 ) & 5,6 & \pm & 0,3 & $(2)$ & 7,2 & \pm & 0,7 & ( 5 ) & 5,0 & \pm & 0,4 & ( 3 ) \\
\hline AVT & $\left(\mathrm{mgHAc} . \mathrm{L}^{-1}\right)$ & 113 & \pm & - & ( 1 ) & 378 & \pm & 36 & ( 2 ) & 107 & \pm & 8 & ( 2 ) & 375 & \pm & 55 & $(2)$ & 101 & \pm & 13 & ( 4 ) & 325 & \pm & 100 & ( 3 ) \\
\hline AT & $\left(\mathrm{mgCaCO}_{3} \cdot \mathrm{L}^{-1}\right)$ & 475 & \pm & - & ( 1 ) & 355 & \pm & 20 & $(2)$ & 282 & \pm & 35 & ( 2 ) & 197 & \pm & 35 & $(2)$ & 204 & \pm & 46 & ( 4 ) & 112 & \pm & 58 & ( 3 ) \\
\hline AP & $\left(\mathrm{mgCaCO}_{3} \cdot \mathrm{L}^{-1}\right)$ & 323 & \pm & 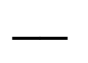 & ( 1 ) & 120 & \pm & 31 & $(2)$ & 195 & \pm & 20 & ( 2 ) & 0,0 & \pm & 0,0 & $(2)$ & 134 & \pm & 49 & ( 4 ) & 0,0 & \pm & 0,0 & ( 3 ) \\
\hline AI & $\left(\mathrm{mgCaCO}_{3} \cdot \mathrm{L}^{-1}\right)$ & 152 & \pm & - & ( 1 ) & 235 & \pm & 10 & ( 2 ) & 87 & \pm & 15 & ( 2 ) & 197 & \pm & 35 & $(2)$ & 70 & \pm & 21 & ( 4 ) & 112 & \pm & 58 & ( 3 ) \\
\hline $\mathrm{AB}$ & $\left(\mathrm{mgCaCO}_{3} \cdot \mathrm{L}^{-1}\right)$ & 295 & \pm & - & ( 1 ) & 87 & \pm & 46 & ( 2 ) & 206 & \pm & 29 & ( 2 ) & 0,0 & \pm & 0,0 & $(2)$ & 132 & \pm & 54 & ( 4 ) & 0,0 & \pm & 0,0 & ( 3 ) \\
\hline ST & $\left(\mathrm{mg} \cdot \mathrm{L}^{-1}\right)$ & - & & - & & - & & - & & 1324 & & 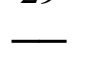 & ( 1 ) & 1178 & & - & ( 1 ) & 1510 & & 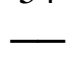 & ( 1 ) & 1518 & & 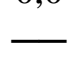 & ( 1 ) \\
\hline SVT & $\left(\mathrm{mg} \cdot \mathrm{L}^{-1}\right)$ & - & & 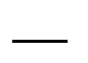 & & - & & - & & 194 & & $\longrightarrow$ & ( 1 ) & 1172 & & & ( 1 ) & 986 & & - & ( 1 ) & 1016 & & 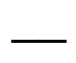 & ( 1 ) \\
\hline SST & $\left(\mathrm{mg} \cdot \mathrm{L}^{-1}\right)$ & - & & 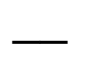 & & - & & - & & 166 & & $\longrightarrow$ & ( 1 ) & 84 & & - & ( 1 ) & 263 & & - & ( 1 ) & 144 & & - & ( 1 ) \\
\hline SSV & $\left(\mathrm{mg} \cdot \mathrm{L}^{-1}\right)$ & - & & 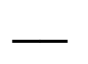 & & - & & 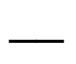 & & 186 & & 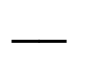 & ( 1 ) & 76 & & - & ( 1 ) & 193 & & - & ( 1 ) & 126 & & & ( 1 ) \\
\hline $\mathrm{V}_{\mathrm{G}}$ & $(\mathrm{NmL})$ & - & & $\longrightarrow$ & & 0,0 & & 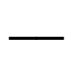 & ( 1 ) & - & & - & & 0,0 & \pm & 0,0 & ( 2 ) & - & & - & & 84 & \pm & 8 & ( 2 ) \\
\hline $\mathrm{V}_{\mathrm{H} 2}$ & $(\mathrm{NmL})$ & - & & $\longrightarrow$ & & 0,0 & & - & ( 1 ) & - & & - & & 0,0 & \pm & 0,0 & $(2)$ & - & & - & & 0,0 & \pm & 0,0 & ( 2 ) \\
\hline COVA & $\left(\mathrm{gDQO} \cdot \mathrm{L}^{-1} \cdot \mathrm{d}^{-1}\right)$ & 9,41 & & $\longrightarrow$ & & - & & $\longrightarrow$ & & 9,83 & & $\longrightarrow$ & & - & & - & & 8,85 & & - & & - & & $\longrightarrow$ & \\
\hline COVR & $\left(\mathrm{gDQO} \cdot \mathrm{L}^{-1} \cdot \mathrm{d}^{-1}\right)$ & - & & $\longrightarrow$ & & 3,50 & & $\longrightarrow$ & & - & & $\longrightarrow$ & & 4,52 & & & & - & & - & & 4,38 & & $\longrightarrow$ & \\
\hline $\mathrm{n}_{\mathrm{H} 2}$ & $\left(\mathrm{molH}_{2} \cdot \mathrm{d}^{-1}\right)$ & 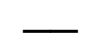 & & 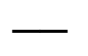 & & 0,0 & & & & - & & - & & 0,0 & & & & - & & - & & 0,0 & & - & \\
\hline PrM & $\left(\mathrm{molH}_{2} \cdot \mathrm{m}^{-3} \cdot \mathrm{d}^{-1}\right)$ & - & & 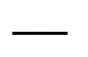 & & 0,0 & & - & & - & & - & & 0,0 & & & & - & & - & & 0,0 & & - & \\
\hline RMCA & $\left(\mathrm{molH}_{2} \cdot \mathrm{kgDQO}^{-1}\right)$ & - & & 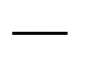 & & 0,0 & & - & & - & & - & & 0,0 & & & & - & & - & & 0,0 & & - & \\
\hline RMCR & $\left(\mathrm{molH}_{2} \cdot \mathrm{kgDQO}^{-1}\right)$ & - & & - & & 0,0 & & & & - & & - & & 0,0 & & & & - & & - & & 0,0 & & - & \\
\hline $\mathrm{V}_{\mathrm{A}}$ & $(\mathrm{L})$ & 1,48 & \pm & 0,05 & ( 4 ) & $\longrightarrow$ & & - & & 1,50 & \pm & 0,03 & ( 2 ) & $\longrightarrow$ & & $\longrightarrow$ & & 1,51 & \pm & 0,01 & ( 3 ) & - & & - & \\
\hline $\mathrm{V}_{\mathrm{R}}$ & (L) & - & & - & & 3,0 & & $\longrightarrow$ & ( 1 ) & - & & - & & 3,0 & & $\longrightarrow$ & ( 1 ) & - & & - & & 3,0 & & 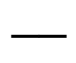 & ( 1 ) \\
\hline & de operação & & & & 6 , & 0 & & & & & & & $2,($ & & & & & & & & 5,0 & & & & \\
\hline
\end{tabular}

* Entre parênteses o número de amostras consideradas no cálculo da média 
Tabela 5.3 - Parâmetros monitorados na Fase I. (Continuação)

\begin{tabular}{|c|c|c|c|c|c|c|c|c|c|c|c|c|c|c|c|c|c|c|c|c|c|c|c|c|}
\hline \multirow{2}{*}{\multicolumn{2}{|c|}{ Parâmetro }} & \multicolumn{8}{|c|}{4} & \multicolumn{8}{|c|}{5} & \multicolumn{7}{|c|}{6} \\
\hline & & \multicolumn{4}{|c|}{ Afluente } & \multicolumn{4}{|c|}{ Efluente } & \multicolumn{4}{|c|}{ Afluente } & \multicolumn{4}{|c|}{ Efluente } & \multicolumn{4}{|c|}{ Afluente } & \multicolumn{3}{|c|}{ Efluente } \\
\hline $\mathrm{C}_{\mathrm{ST}}$ & $\left(\mathrm{mgDQO} \cdot \mathrm{L}^{-1}\right)$ & 2842 & \pm & 233 & $(4)$ & 1888 & \pm & 97 & (3) & 2610 & \pm & 329 & $(4)$ & 1828 & \pm & 355 & (3) & 2978 & \pm & 421 & $(2)$ & 1507 & - & (1) \\
\hline $\mathrm{C}_{\mathrm{SF}}$ & $\left(\mathrm{mgDQO} \cdot \mathrm{L}^{-1}\right)$ & - & & - & & 1652 & \pm & 57 & ( 3 ) & - & & - & & 1477 & \pm & 273 & ( 3 ) & $\longrightarrow$ & & - & & 1541 & - & ( 1 ) \\
\hline$\varepsilon_{\mathrm{ST}}$ & $(\%)$ & - & & - & & 34 & \pm & 3 & ( 3 ) & - & & - & & 30 & \pm & 14 & ( 3 ) & - & & - & & 49 & 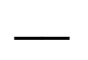 & ( 1 ) \\
\hline$\varepsilon_{\mathrm{SF}}$ & $(\%)$ & - & & - & & 42 & \pm & 2 & ( 3 ) & - & & - & & 43 & \pm & 10 & ( 3 ) & - & & - & & 48 & - & ( 1 ) \\
\hline $\mathrm{pH}$ & (u) & 7,4 & \pm & 0,3 & ( 4 ) & 4,5 & \pm & 0,3 & ( 3 ) & 7,5 & \pm & 0,4 & ( 4 ) & 4,6 & \pm & 0,2 & ( 3 ) & 10,1 & \pm & 0,5 & ( 2 ) & 4,4 & & ( 1 ) \\
\hline AVT & $\left(\right.$ mgHAc. $\left.L^{-1}\right)$ & 89 & \pm & 10 & ( 4 ) & 437 & \pm & 46 & ( 3 ) & 88 & \pm & 11 & ( 4 ) & 390 & \pm & 21 & ( 3 ) & 37 & \pm & 5 & ( 2 ) & 347 & & ( 1 ) \\
\hline $\mathrm{AT}$ & $\left(\mathrm{mgCaCO}_{3} \cdot \mathrm{L}^{-1}\right)$ & 132 & \pm & 13 & ( 4 ) & 46 & \pm & 40 & ( 3 ) & 120 & \pm & 24 & ( 4 ) & 44 & \pm & 27 & ( 3 ) & 132 & \pm & 9 & ( 2 ) & 23 & & ( 1 ) \\
\hline $\mathrm{AP}$ & $\left(\mathrm{mgCaCO}_{3} \cdot \mathrm{L}^{-1}\right)$ & 107 & \pm & 11 & ( 4 ) & 0,0 & \pm & 0,0 & ( 3 ) & 85 & \pm & 20 & ( 4 ) & 0,0 & \pm & 0,0 & ( 3 ) & 111 & \pm & 7 & ( 2 ) & 0,0 & & ( 1 ) \\
\hline AI & $\left(\mathrm{mgCaCO}_{3} \cdot \mathrm{L}^{-1}\right)$ & 25 & \pm & 8 & ( 4 ) & 46 & \pm & 40 & ( 3 ) & 35 & \pm & 5 & ( 4 ) & 44 & \pm & 27 & ( 3 ) & 21 & \pm & 2 & ( 2 ) & 23 & & ( 1 ) \\
\hline $\mathrm{AB}$ & $\left(\mathrm{mgCaCO}_{3} \cdot \mathrm{L}^{-1}\right)$ & 132 & \pm & 13 & ( 4 ) & 0,0 & \pm & 0,0 & ( 3 ) & 120 & \pm & 24 & ( 4 ) & 0,0 & \pm & 0,0 & ( 3 ) & 132 & \pm & 9 & ( 2 ) & 0,0 & & ( 1 ) \\
\hline ST & $\left(\mathrm{mg} \cdot \mathrm{L}^{-1}\right)$ & 1254 & & $\longrightarrow$ & $(1)$ & 1352 & & - & ( 1 ) & 1274 & & - & ( 1 ) & 1252 & \pm & 337 & $(2)$ & 868 & & ( & ( 1 ) & - & & \\
\hline SVT & $\left(\mathrm{mg} \cdot \mathrm{L}^{-1}\right)$ & 938 & & 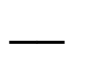 & ( 1 ) & 1000 & & - & ( 1 ) & 958 & & - & ( 1 ) & 972 & \pm & 264 & $(2)$ & 742 & & - & ( 1 ) & - & & \\
\hline SST & $\left(\mathrm{mg} \cdot \mathrm{L}^{-1}\right)$ & 164 & & - & ( 1 ) & 104 & & - & ( 1 ) & 68 & & - & ( 1 ) & 221 & \pm & 111 & $(2)$ & 96 & & - & ( 1 ) & - & & \\
\hline SSV & $\left(\mathrm{mg} \cdot \mathrm{L}^{-1}\right)$ & 116 & & - & ( 1 ) & 82 & & - & ( 1 ) & 164 & & - & ( 1 ) & 220 & \pm & 161 & ( 2 ) & 112 & & - & ( 1 ) & - & & \\
\hline $\mathrm{V}_{\mathrm{G}}$ & $(\mathrm{NmL})$ & - & & - & & 0,0 & \pm & 0,0 & ( 2 ) & - & & - & & 301 & \pm & 40 & $(2)$ & - & & - & & 67 & & ( 1 ) \\
\hline $\mathrm{V}_{\mathrm{H} 2}$ & $(\mathrm{NmL})$ & - & & - & & 0,0 & \pm & 0,0 & ( 2 ) & - & & - & & 43 & \pm & 61 & $(2)$ & - & & - & & 13 & & ( 1 ) \\
\hline COVA & $\left(\mathrm{gDQO} \cdot \mathrm{L}^{-1} \cdot \mathrm{d}^{-1}\right)$ & 8,26 & & $\longrightarrow$ & & $\longrightarrow$ & & - & & 7,64 & & - & & - & & - & & 8,70 & & - & & - & - & \\
\hline COVR & $\left(\mathrm{gDQO} \cdot \mathrm{L}^{-1} \cdot \mathrm{d}^{-1}\right)$ & - & & - & & 3,46 & & - & & - & & - & & 3,32 & & - & & $\longrightarrow$ & & - & & 4,20 & - & \\
\hline $\mathrm{n}_{\mathrm{H} 2}$ & $\left(\mathrm{molH}_{2} \cdot \mathrm{d}^{-1}\right)$ & . & & & & 0,0 & & - & & - & & - & & 0,012 & & - & & - & & & & 0,004 & - & \\
\hline PrM & $\left(\mathrm{molH}_{2} \cdot \mathrm{m}^{-3} \cdot \mathrm{d}^{-1}\right)$ & - & & - & & 0,0 & & - & & - & & - & & 7,93 & & & & - & & - & & 2,44 & - & \\
\hline RMCA & $\left(\mathrm{molH}_{2} \cdot \mathrm{kgDQO}^{-1}\right)$ & - & & - & & 0,0 & & - & & - & & - & & 0,51 & & - & & - & & - & & 0,14 & - & \\
\hline RMCR & $\left(\mathrm{molH}_{2} \cdot \mathrm{kgDQO}^{-1}\right)$ & - & & - & & 0,0 & & - & & - & & - & & 1,17 & & - & & - & & & & 0,28 & - & \\
\hline $\mathrm{V}_{\mathrm{A}}$ & $(\mathrm{L})$ & 1,45 & \pm & 0,04 & ( 3 ) & - & & - & & 1,46 & \pm & 0,03 & ( 3 ) & - & & - & & 1,46 & \pm & - & ( 1 ) & - & - & \\
\hline $\mathrm{V}_{\mathrm{R}}$ & (L) & - & & - & & 3,0 & & - & ( 1 ) & - & & - & & 3,0 & & - & $(1)$ & & & - & & 3,0 & - & ( 1 ) \\
\hline \multicolumn{2}{|c|}{ Dias de operação } & \multicolumn{8}{|c|}{7,0} & \multicolumn{8}{|c|}{6,0} & \multicolumn{7}{|c|}{2,0} \\
\hline
\end{tabular}

* Entre parênteses o número de amostras consideradas no cálculo da média 
Tabela 5.3 - Parâmetros monitorados na Fase I. (Continuação)

\begin{tabular}{|c|c|c|c|c|c|c|c|c|c|c|c|c|c|c|c|c|c|c|c|c|c|c|c|c|c|}
\hline \multirow{2}{*}{\multicolumn{2}{|c|}{ Parâmetro }} & \multicolumn{8}{|c|}{7} & \multicolumn{8}{|c|}{8} & \multicolumn{8}{|c|}{9} \\
\hline & & \multicolumn{4}{|c|}{ Afluente } & \multicolumn{4}{|c|}{ Efluente } & \multicolumn{4}{|c|}{ Afluente } & \multicolumn{4}{|c|}{ Efluente } & \multicolumn{4}{|c|}{ Afluente } & \multicolumn{4}{|c|}{ Efluente } \\
\hline $\mathrm{C}_{\mathrm{ST}}$ & $\left(\mathrm{mgDQO} \cdot \mathrm{L}^{-1}\right)$ & 2986 & \pm & 222 & $(3)$ & 2157 & \pm & 142 & $(3)$ & 2855 & \pm & 111 & $(4)$ & 1304 & & - & (1) & 3226 & \pm & 139 & $(2)$ & 2749 & \pm & 76 & $(2)$ \\
\hline $\mathrm{C}_{\mathrm{SF}}$ & $\left(\mathrm{mgDQO} \cdot \mathrm{L}^{-1}\right)$ & - & & - & & 1740 & \pm & 196 & ( 3 ) & $\longrightarrow$ & & - & & 1093 & & - & $(1)$ & - & & $\longrightarrow$ & & 2592 & \pm & 120 & ( 2 ) \\
\hline$\varepsilon_{\mathrm{ST}}$ & $(\%)$ & - & & - & & 28 & \pm & 5 & ( 3 ) & - & & - & & 54 & & 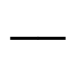 & $(1)$ & - & & - & & 15 & \pm & 2 & ( 2 ) \\
\hline$\varepsilon_{\mathrm{SF}}$ & $(\%)$ & - & & - & & 42 & \pm & 7 & ( 3 ) & - & & - & & 62 & & - & $(1)$ & $\longrightarrow$ & & - & & 20 & \pm & 4 & ( 2 ) \\
\hline $\mathrm{pH}$ & (u) & 9,6 & \pm & 0,3 & ( 3 ) & 4,8 & \pm & 0,2 & ( 3 ) & 10,1 & \pm & 0,4 & ( 3 ) & 4,5 & \pm & 0,1 & $(2)$ & 9,8 & \pm & 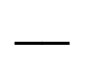 & ( 1 ) & 5,5 & \pm & 0,1 & ( 2 ) \\
\hline AVT & $\left(\right.$ mgHAc. $\left.L^{-1}\right)$ & 37 & \pm & 2 & ( 3 ) & 339 & \pm & 2 & ( 3 ) & 36 & \pm & 4 & ( 3 ) & 450 & \pm & 64 & $(2)$ & 43 & \pm & 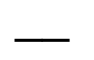 & ( 1 ) & 163 & \pm & 6 & ( 2 ) \\
\hline $\mathrm{AT}$ & $\left(\mathrm{mgCaCO}_{3} \cdot \mathrm{L}^{-1}\right)$ & 141 & \pm & 2 & ( 3 ) & 76 & \pm & 18 & ( 3 ) & 160 & \pm & 31 & ( 3 ) & 49 & \pm & 11 & $(2)$ & 152 & \pm & 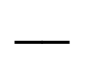 & ( 1 ) & 97 & \pm & 8 & ( 2 ) \\
\hline $\mathrm{AP}$ & $\left(\mathrm{mgCaCO}_{3} \cdot \mathrm{L}^{-1}\right)$ & 116 & \pm & 4 & ( 3 ) & 0,0 & \pm & 0,0 & ( 3 ) & 32 & \pm & 25 & ( 3 ) & 0,0 & \pm & 0,0 & $(2)$ & 134 & \pm & _ & ( 1 ) & 0,0 & \pm & 0,0 & ( 2 ) \\
\hline AI & $\left(\mathrm{mgCaCO}_{3} \cdot \mathrm{L}^{-1}\right)$ & 25 & \pm & 4 & ( 3 ) & 76 & \pm & 18 & ( 3 ) & 28 & \pm & 8 & ( 3 ) & 49 & \pm & 11 & $(2)$ & 18 & \pm & 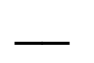 & ( 1 ) & 97 & \pm & 8 & ( 2 ) \\
\hline $\mathrm{AB}$ & $\left(\mathrm{mgCaCO}_{3} \cdot \mathrm{L}^{-1}\right)$ & 115 & \pm & 1 & ( 3 ) & 0,0 & \pm & 0,0 & ( 3 ) & 135 & \pm & 32 & ( 3 ) & 0,0 & \pm & 0,0 & $(2)$ & 122 & \pm & 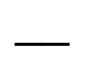 & ( 1 ) & 0,0 & \pm & 0,0 & ( 2 ) \\
\hline ST & $\left(\mathrm{mg} \cdot \mathrm{L}^{-1}\right)$ & 816 & & 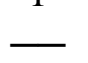 & ( 1 ) & 812 & & 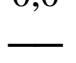 & ( 1 ) & 984 & & - & (1) & 772 & & 0,0 & $(1)$ & 890 & & - & ( 1 ) & 744 & & & ( 1 ) \\
\hline SVT & $\left(\mathrm{mg} \cdot \mathrm{L}^{-1}\right)$ & 702 & & - & $(1)$ & 660 & & 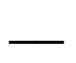 & ( 1 ) & 728 & & 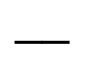 & ( 1 ) & 526 & & $\longrightarrow$ & $(1)$ & 800 & & 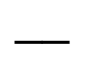 & (1) & 754 & & & ( 1 ) \\
\hline SST & $\left(\mathrm{mg} \cdot \mathrm{L}^{-1}\right)$ & 196 & & - & $(1)$ & 180 & & 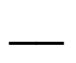 & ( 1 ) & 62 & & - & ( 1 ) & 14 & & 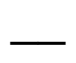 & $(1)$ & 202 & & - & ( 1 ) & 62 & & - & ( 1 ) \\
\hline SSV & $\left(\mathrm{mg} \cdot \mathrm{L}^{-1}\right)$ & 182 & & - & $(1)$ & 186 & & 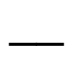 & $(1)$ & 30 & & $\underline{ }$ & ( 1 ) & 20 & & & $(1)$ & 194 & & 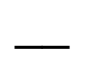 & ( 1 ) & 72 & & & ( 1 ) \\
\hline $\mathrm{V}_{\mathrm{G}}$ & $(\mathrm{NmL})$ & - & & - & & 0,0 & & & ( 3 ) & - & & $\longrightarrow$ & & 48,52 & & $\longrightarrow$ & $(1)$ & - & & - & & 0,0 & & & ( 2 ) \\
\hline $\mathrm{V}_{\mathrm{H} 2}$ & $(\mathrm{NmL})$ & - & & $\longrightarrow$ & & 0,0 & & $\longrightarrow$ & ( 3 ) & - & & $\longrightarrow$ & & 0,0 & & $\longrightarrow$ & $(1)$ & $\longrightarrow$ & & - & & 0,0 & & & ( 2 ) \\
\hline COVA & $\left(\mathrm{gDQO} \cdot \mathrm{L}^{-1} \cdot \mathrm{d}^{-1}\right)$ & 7,69 & & - & & - & & - & & 7,99 & & - & & - & & $\longrightarrow$ & & 10,07 & & - & & - & & $\longrightarrow$ & \\
\hline COVR & $\left(\mathrm{gDQO} \cdot \mathrm{L}^{-1} \cdot \mathrm{d}^{-1}\right)$ & - & & - & & 3,21 & & - & & $\longrightarrow$ & & - & & 4,93 & & $\longrightarrow$ & & - & & - & & 1,98 & & - & \\
\hline $\mathrm{n}_{\mathrm{H} 2}$ & $\left(\mathrm{molH}_{2} \cdot \mathrm{d}^{-1}\right)$ & . & & $\longrightarrow$ & & 0,0 & & $\longrightarrow$ & & - & & - & & 0,0 & & $\longrightarrow$ & & - & & - & & 0,0 & & - & \\
\hline PrM & $\left(\mathrm{molH}_{2} \cdot \mathrm{m}^{-3} \cdot \mathrm{d}^{-1}\right)$ & $\longrightarrow$ & & $\longrightarrow$ & & 0,0 & & 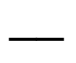 & & - & & - & & 0,0 & & - & & - & & - & & 0,0 & & - & \\
\hline RMCA & $\left(\mathrm{molH}_{2} \cdot \mathrm{kgDQO}^{-1}\right)$ & - & & - & & 0,0 & & - & & - & & - & & 0,0 & & $\longrightarrow$ & & - & & - & & 0,0 & & - & \\
\hline RMCR & $\left(\mathrm{molH}_{2} \cdot \mathrm{kgDQO}^{-1}\right)$ & - & & - & & 0,0 & & - & & - & & - & & 0,0 & & $\longrightarrow$ & & - & & - & & 0,0 & & - & \\
\hline $\mathrm{V}_{\mathrm{A}}$ & $(\mathrm{L})$ & 1,29 & \pm & 0,39 & ( 3 ) & - & & - & & 1,40 & \pm & 0,14 & ( 2 ) & $\longrightarrow$ & & 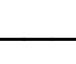 & & 1,56 & \pm & 0,06 & ( 2 ) & - & & - & \\
\hline $\mathrm{V}_{\mathrm{R}}$ & (L) & - & & - & & 3,0 & & $\longrightarrow$ & ( 1 ) & - & & - & & 3,0 & & $\longrightarrow$ & $(1)$ & $\longrightarrow$ & & $\longrightarrow$ & & 3,0 & & - & ( 1 ) \\
\hline \multicolumn{2}{|c|}{ Dias de operação } & \multicolumn{8}{|c|}{3,0} & \multicolumn{8}{|c|}{7,0} & \multicolumn{8}{|c|}{4,0} \\
\hline
\end{tabular}

* Entre parênteses o número de amostras consideradas no cálculo da média 
Tabela 5.3 - Parâmetros monitorados na Fase I. (Continuação)

\begin{tabular}{|c|c|c|c|c|c|c|c|c|c|c|c|c|c|c|c|c|c|c|c|}
\hline \multirow{2}{*}{\multicolumn{2}{|c|}{ Parâmetro }} & \multicolumn{9}{|c|}{10} & \multicolumn{9}{|c|}{11} \\
\hline & & \multicolumn{4}{|c|}{ Afluente } & & \multicolumn{4}{|c|}{ Efluente } & \multicolumn{5}{|c|}{ Afluente } & \multicolumn{4}{|c|}{ Efluente } \\
\hline $\mathrm{C}_{\mathrm{ST}}$ & $\left(\mathrm{mgDQO} \cdot \mathrm{L}^{-1}\right)$ & 3029 & \pm & 135 & ( 3 & ) & 2231 & \pm & 197 & $(3)$ & 2983 & \pm & 121 & ( 3 & ) & 1834 & \pm & 210 & $(2)$ \\
\hline $\mathrm{C}_{\mathrm{SF}}$ & $\left(\mathrm{mgDQO} \cdot \mathrm{L}^{-1}\right)$ & - & & - & & & 2192 & \pm & 192 & $(3)$ & - & & - & & & 1891 & \pm & \pm 116 & $(2)$ \\
\hline$\varepsilon_{\mathrm{ST}}$ & $(\%)$ & - & & - & & & 26 & \pm & 6 & $(3)$ & - & & - & & & 39 & \pm & 7 & $(2)$ \\
\hline$\varepsilon_{\mathrm{SF}}$ & $(\%)$ & - & & - & & & 28 & \pm & 6 & $\left(\begin{array}{ll}3\end{array}\right)$ & - & & - & & & 37 & \pm & 4 & $\left(\begin{array}{l}2 \\
)\end{array}\right.$ \\
\hline $\mathrm{pH}$ & (u) & 8,1 & \pm & 0,5 & ( 3 & ) & 4,3 & \pm & 0,3 & $(3)$ & 8,73 & \pm & 0,04 & ( 2 & ) & 4,1 & \pm & 0,1 & $(2)$ \\
\hline AVT & $\left(\mathrm{mgHAc} . \mathrm{L}^{-1}\right)$ & 18 & \pm & 5 & ( 3 & ) & 585 & \pm & 94 & $(3)$ & 27 & \pm & 3 & ( 2 & ) & 523 & \pm & 2 & $(2)$ \\
\hline AT & $\left(\mathrm{mgCaCO}_{3} \cdot \mathrm{L}^{-1}\right)$ & 224 & \pm & 144 & ( 3 & ) & 36 & \pm & 63 & $(3)$ & 170 & \pm & 14 & ( 2 & ) & 0,0 & \pm & 0,0 & $(2)$ \\
\hline AP & $\left(\mathrm{mgCaCO}_{3} \cdot \mathrm{L}^{-1}\right)$ & 165 & \pm & 88 & ( 3 & ) & 0,0 & \pm & 0,0 & $(3)$ & 125 & \pm & 6 & $(2$ & ) & 0,0 & \pm & 0,0 & $(2)$ \\
\hline AI & $\left(\mathrm{mgCaCO}_{3} \cdot \mathrm{L}^{-1}\right)$ & 59 & \pm & 56 & ( 3 & ) & 36 & \pm & 63 & $(3)$ & 45 & \pm & 8 & $(2$ & ) & 0,0 & \pm & 0,0 & $(2)$ \\
\hline $\mathrm{AB}$ & $\left(\mathrm{mgCaCO}_{3} \cdot \mathrm{L}^{-1}\right)$ & 212 & \pm & 147 & ( 3 & ) & 0,0 & \pm & 0,0 & $(3)$ & 151 & \pm & 11 & ( 2 & ) & 0,0 & \pm & 0,0 & $(2)$ \\
\hline $\mathrm{ST}$ & $\left(\mathrm{mg} \cdot \mathrm{L}^{-1}\right)$ & - & & - & & & - & & - & & - & & - & & & - & & - & \\
\hline SVT & $\left(\mathrm{mg} \cdot \mathrm{L}^{-1}\right)$ & - & & - & & & - & & - & & - & & - & & & - & & - & \\
\hline SST & $\left(\mathrm{mg} \cdot \mathrm{L}^{-1}\right)$ & - & & - & & & - & & - & & - & & - & & & - & & - & \\
\hline SSV & $\left(\mathrm{mg} \cdot \mathrm{L}^{-1}\right)$ & - & & - & & & - & & - & & - & & - & & & - & & - & \\
\hline $\mathrm{V}_{\mathrm{G}}$ & $(\mathrm{NmL})$ & - & & - & & & 483,4 & & - & $(3)$ & - & & - & & & 164,4 & & - & $(2)$ \\
\hline $\mathrm{V}_{\mathrm{H} 2}$ & $(\mathrm{NmL})$ & - & & - & & & 241,2 & & - & $(3)$ & - & & - & & & 42,4 & & - & $(2)$ \\
\hline COVA & $\left(\mathrm{gDQO} \cdot \mathrm{L}^{-1} \cdot \mathrm{d}^{-1}\right)$ & 9,25 & & - & & & - & & - & & 8,35 & & - & & & - & & - & \\
\hline COVR & $\left(\mathrm{gDQO} \cdot \mathrm{L}^{-1} \cdot \mathrm{d}^{-1}\right)$ & - & & - & & & 2,56 & & - & & - & & - & & & 3,06 & & - & \\
\hline $\mathrm{n}_{\mathrm{H} 2}$ & $\left(\mathrm{molH}_{2} \cdot \mathrm{d}^{-1}\right)$ & - & & - & & & 0,065 & & - & & - & & - & & & 0,011 & & - & \\
\hline PrM & $\left(\mathrm{molH}_{2} \cdot \mathrm{m}^{-3} \cdot \mathrm{d}^{-1}\right)$ & $\longrightarrow$ & & - & & & 42,66 & & - & & - & & - & & & 7,80 & & - & \\
\hline RMCA & $\left(\mathrm{molH}_{2} \cdot \mathrm{kgDQO}^{-1}\right)$ & - & & - & & & 2,33 & & - & & - & & - & & & 0,45 & & - & \\
\hline RMCR & $\left(\mathrm{molH}_{2} \cdot \mathrm{kgDQO}^{-1}\right)$ & - & & - & & & 8,42 & & - & & - & & - & & & 1,24 & & - & \\
\hline $\mathrm{V}_{\mathrm{A}}$ & (L) & 1,53 & \pm & 0,01 & ( 3 & ) & - & & - & & 1,40 & \pm & 0,00 & $(2$ & ) & - & & - & \\
\hline $\mathrm{V}_{\mathrm{R}}$ & (L) & - & & - & & & 3,0 & & - & $\left(\begin{array}{ll}1 & 1\end{array}\right)$ & - & & - & & & 3,0 & & - & $(1)$ \\
\hline & de operação & & & & & 3 & & & & & & & & & 5,0 & & & & \\
\hline
\end{tabular}


Para início da comparação, deve-se ressaltar que nenhuma das onze condições alcançou os mesmos parâmetros operacionais que foram obtidos quando o reator foi operado unicamente com sacarose, comprovando a dificuldade de degradação do efluente do processo de produção do biodiesel como foi ressaltado na Seção 3.5.1 da Revisão Bibliográfica.

A Figura 5.7 apresenta os valores de matéria orgânica na forma de DQO para o afluente (amostras não filtradas) e efluente (amostras não filtradas e filtradas) nas onze condições estudadas para facilitar a comparação. Deste gráfico, pode-se observar que o sistema sentiu a retirada da solução de sais nos ensaios 4 e 9, com consequente aumento da concentração de matéria orgânica nas amostras do efluente e que a diminuição da concentração de bicarbonato nos ensaios 1, 2 e 3 favoreceu a eficiência de remoção de DQO. A redução da velocidade ascensional do líquido também diminui a concentração de matéria orgânica no efluente, mas deve-se ter cuidado com este último parâmetro, pois o mesmo favorece o crescimento de arquéias metanogênicas. A Figura 5.8 mostra os valores de eficiência de remoção de matéria orgânica para amostras filtradas e não filtradas.

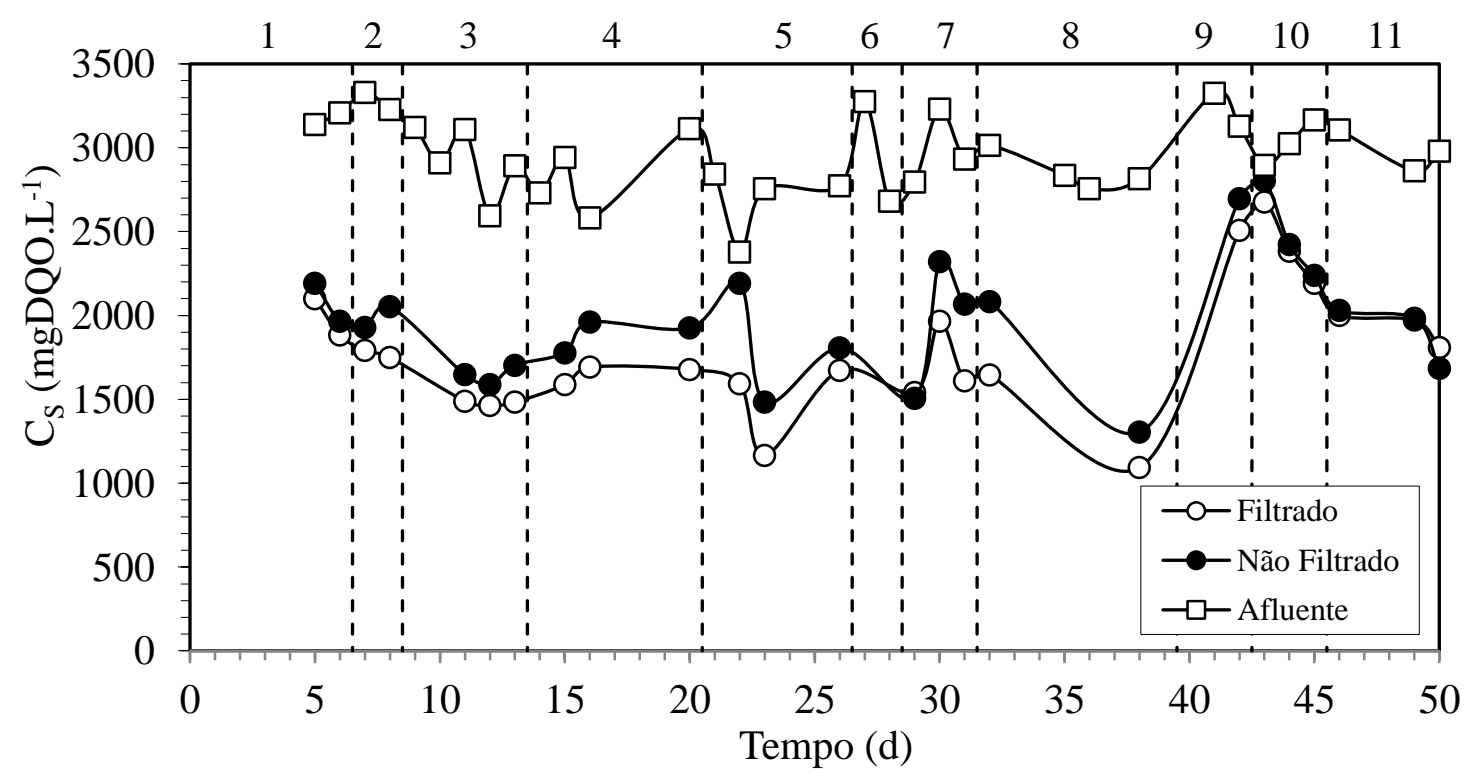

Figura 5.7 - Concentração de matéria orgânica na forma de DQO na Fase I: घ - afluente amostras não filtradas; • - efluente amostras não filtradas; $\bigcirc-$ efluente amostras filtradas 


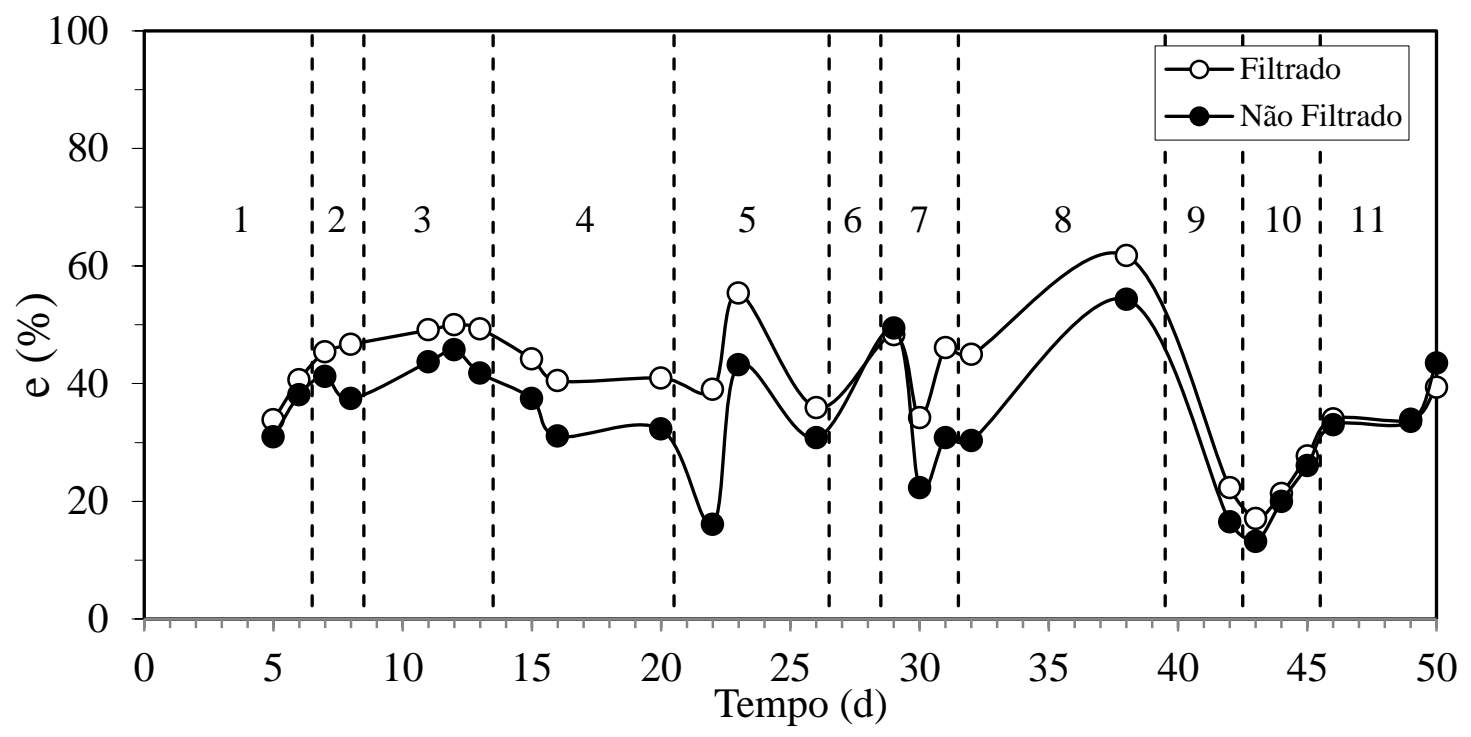

Figura 5.8 - Eficiência de remoção de matéria orgânica na forma de DQO na Fase I: • - amostras não filtradas; $\circ-$ amostras filtradas

As Figuras 5.9, 5.10 e 5.11 apresentam os resultados obtidos de $\mathrm{pH}$, alcalinidade total (AT) e ácidos voláteis totais (AVT), respectivamente. Primeiramente, observando a Figura 5.9 e 5.10, nota-se que a glicerina bruta de laboratório (ensaios 6 a 11) gera um afluente mais alcalino do que a glicerina bruta industrial (devido a maior concentração de resíduo de hidróxido de sódio que aquela tem), também é possível notar a redução do pH com a redução do bicarbonato de sódio (ensaios 1 a 3), fazendo com que o mesmo se estabilizasse entre 4 e 5, ou seja, condição favorável para a produção de hidrogênio.

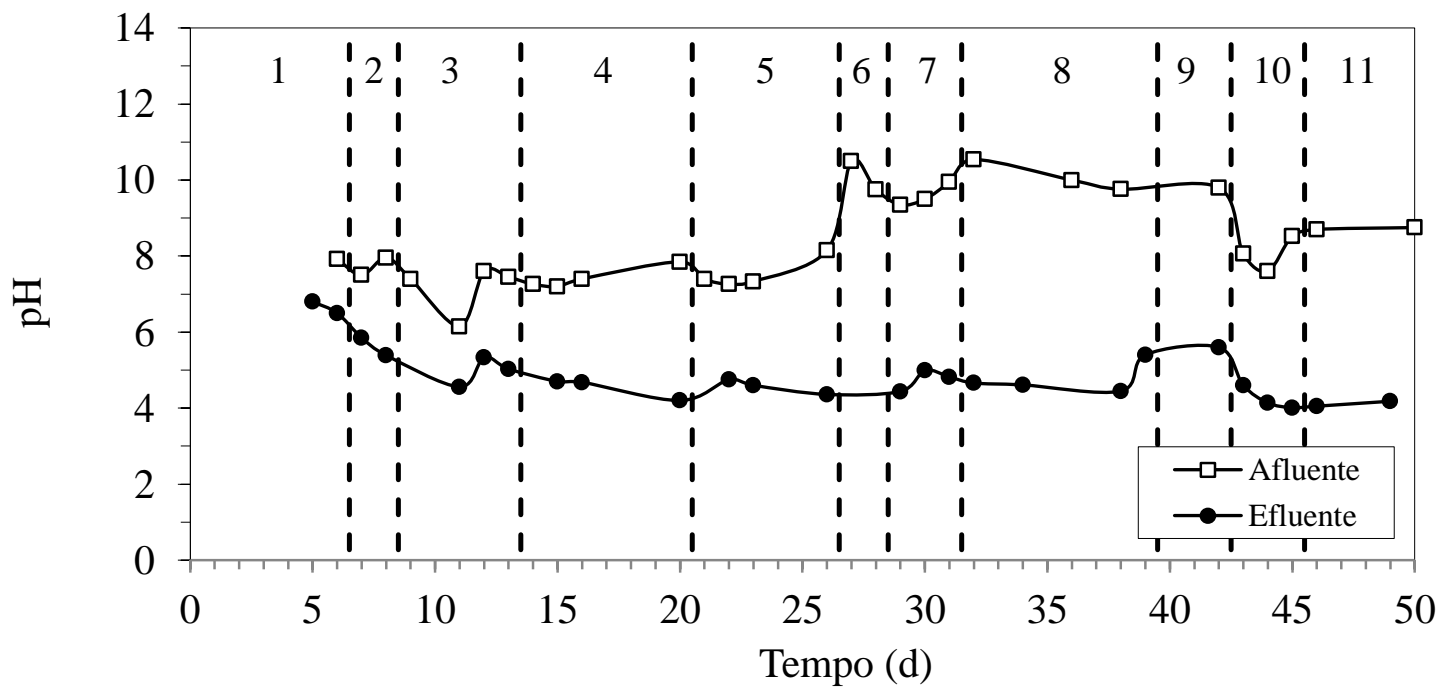

Figura 5.9 - Valores de pH na Fase I: $\square-$ afluente; $\bullet$ - efluente 


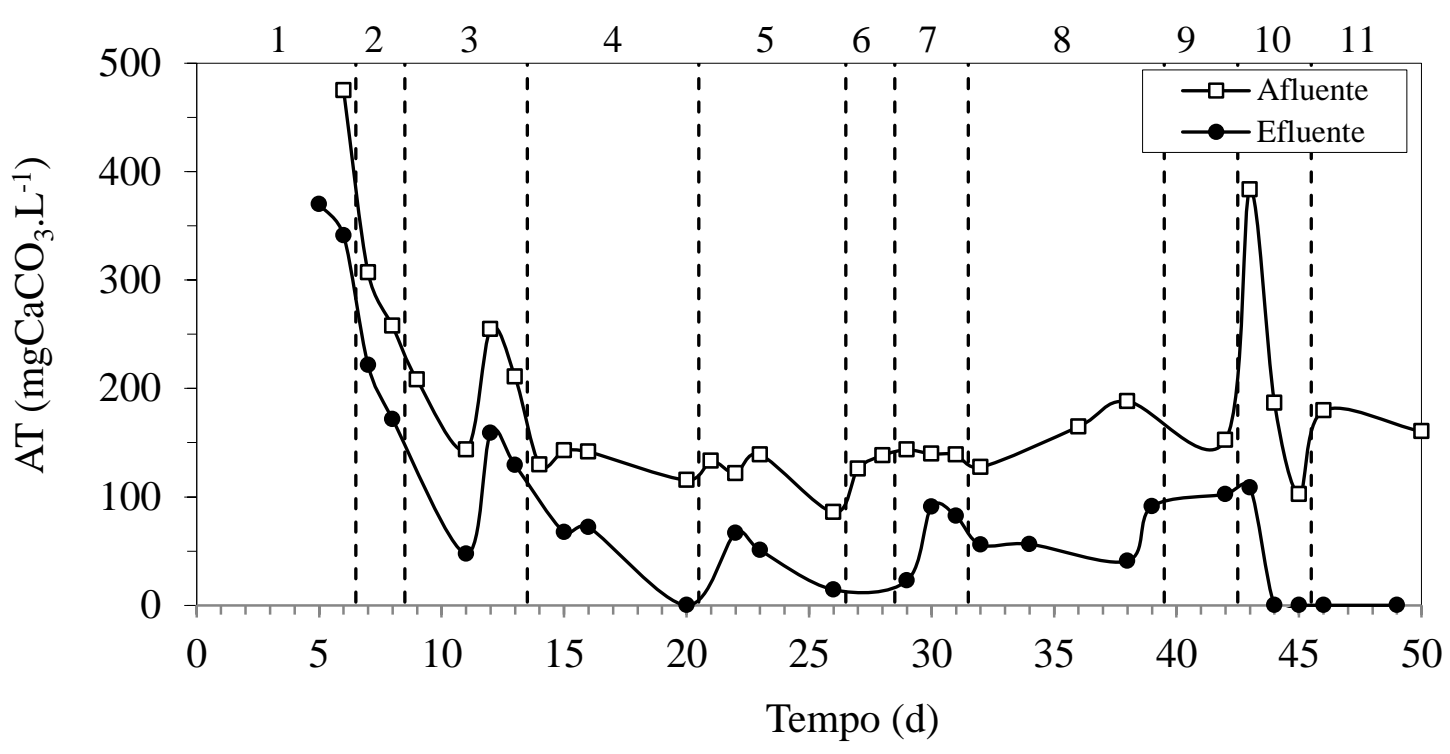

Figura 5.10 - Valores de alcalinidade total (AT) na Fase I: $\square$-afluente; $\bullet$ - efluente

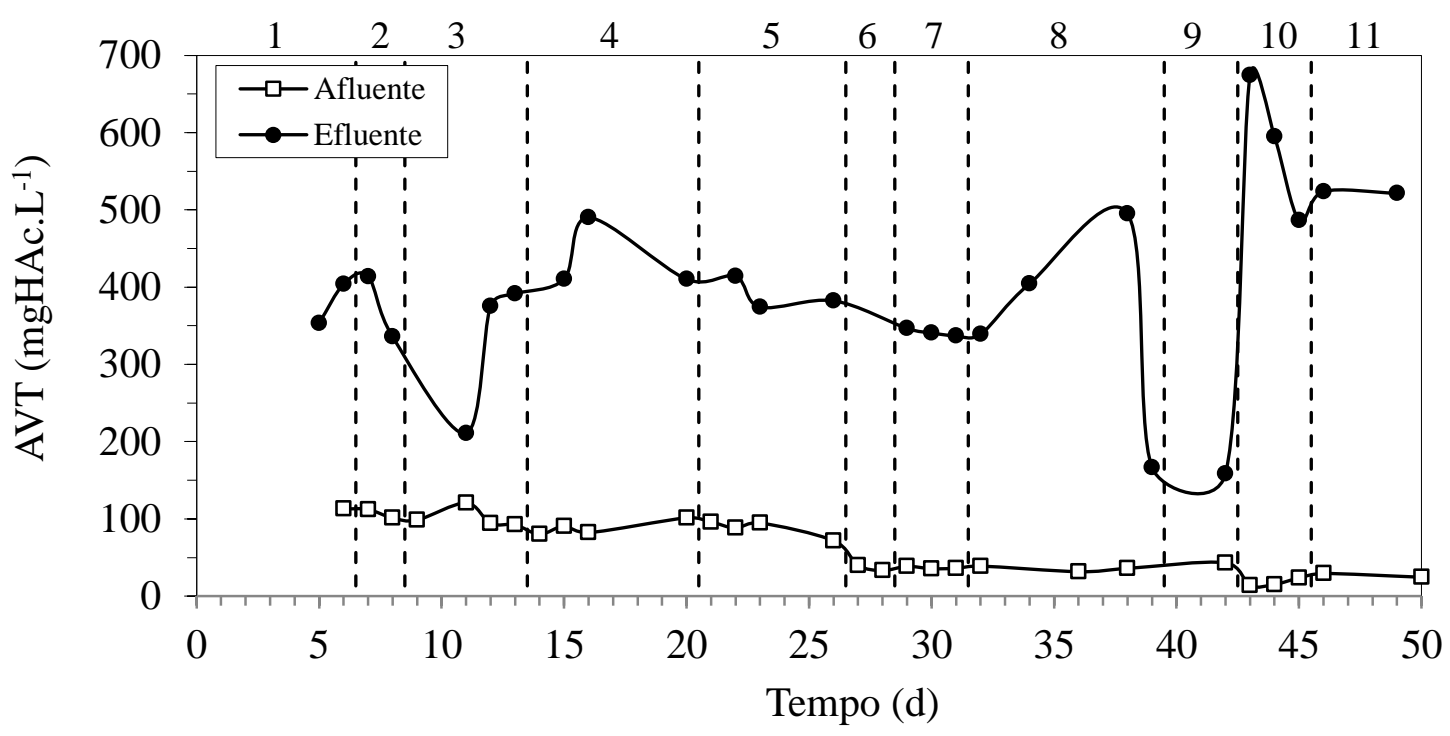

Figura 5.11 - Valores de ácidos voláteis totais (AVT) na Fase I: $\square$-afluente; • - efluente

Examinando a Figura 5.11 percebe-se que o reator não conseguiu atingir um ambiente acidogênico como naquele obtido na condição preliminar (operada com sacarose). Além disso, quando a glicerina bruta foi utilizada como substrato, notou-se uma gradual contaminação no frasco de armazenamento de afluente que era alimentado ao sistema, culminando na diminuição dos AVT no início na condição 3. Para prevenir nova contaminação do frasco que armazenava o afluente, realizou-se diariamente a lavagem destes 
com detergente (da mesma forma que já eram lavados) e posterior limpeza com etanol $70 \%$. Nota-se também que a diminuição da velocidade ascensional na condição 8 culminou na diminuição da produção dos ácidos voláteis totais com posterior recuperação da mesma na seguinte condição.

Finalmente, para analisar a produção de biogás e hidrogênio, tem-se a Tabela 5.4 e a Figura 5.12 para ilustrar melhor os dados obtidos. Estudando os ensaios de 1 a 9 (na qual apenas glicerina foi alimentada ao reator), o sistema não produziu quantidades significativas de biogás na maior parte dos ensaios, sendo que essa geração reduzida de biogás não continha quantidades maiores que $1 \mathrm{mmol} . \mathrm{L}^{-1}$ de hidrogênio. Na condição 3 , foi detectada a presença de metano no biogás produzido e a geração de hidrogênio cessou, provavelmente pela decorrência da contaminação do frasco que continha o afluente, anteriormente citada, acarretando a alimentação de um afluente previamente acidificado, favorecendo a rota metabólica metanogênica. A partir deste dia de operação não foi possível atingir a estabilidade do sistema e recuperar a produção de hidrogênio, decidindo-se pela limpeza do reator. Mesmo com essas medidas, não foi possível eliminar a presença deste gás nas condições 4, 5 e 6, provando que a geração de hidrogênio e inibição do metano devem ser alcançados por otimização das condições experimentais e não por limpeza do sistema ou escolha do inóculo (não houve diferença visível entre os dois tipos de inóculos usados nos experimentos).

Ainda comparando os ensaios de 1 a 9, pode-se notar que a glicerina bruta industrial superou a produção de hidrogênio da glicerina bruta de laboratório nos únicos dois ensaios em que foi possível obter uma medida significativa de biogás (as condições dos ensaios 5 e 6 foram bem similares entre si).

Verificando os ensaios 10 e 11, que usaram uma mistura de polietileno e poliuretano como suporte, observa-se que os mesmos apresentaram metano em seu biogás mesmo com 
um afluente contendo dois terços de sacarose e apenas um terço de glicerina. Um resultado que era esperado devido ao PU ser um suporte tradicional para reatores metanogênicos; provavelmente esse tipo de biomassa se adere melhor ao suporte poroso.

Tabela 5.4 - Produção e fração molar referente ao biogás na Fase I

\begin{tabular}{cccccccccc}
\hline \multirow{2}{*}{ Ensaio } & $\mathrm{V}_{\mathrm{G}}$ & \multicolumn{3}{c}{$\mathrm{C}_{\mathrm{G}}\left(\mathrm{mmol} \cdot \mathrm{L}^{-1}\right)$} & \multicolumn{3}{c}{$\mathrm{Y}_{\mathrm{G}}(\%)$} & $\mathrm{V}_{\mathrm{H} 2}$ & $\begin{array}{c}\mathrm{PrM} \\
\end{array}$ \\
& $(\mathrm{NmL})$ & $\mathrm{H}_{2}$ & $\mathrm{CH}_{4}$ & $\mathrm{CO}_{2}$ & $\mathrm{H}_{2}$ & $\mathrm{CH}_{4}$ & $\mathrm{CO}_{2}$ & $(\mathrm{NmL})$ & $\left(\mathrm{molH}_{2} \cdot \mathrm{m}^{-3} \cdot \mathrm{d}^{-1}\right)$ \\
\hline 1 & 0,0 & 0,75 & 0,00 & 2,87 & 21 & 0 & 79 & 0,0 & 0 \\
2 & 0,0 & 0,90 & 0,00 & 2,73 & 25 & 0 & 75 & 0,0 & 0 \\
3 & 83,6 & 0,00 & 0,19 & 2,34 & 0 & 8 & 92 & 0,0 & 0 \\
4 & 0,0 & 0,00 & 0,20 & 1,88 & 0 & 10 & 90 & 0,0 & 0 \\
5 & 300,6 & 0,37 & 0,09 & 0,95 & 26 & 6 & 67 & 43,4 & 7,9 \\
6 & 67,4 & 0,76 & 0,37 & 2,71 & 20 & 10 & 71 & 13,4 & 2,4 \\
7 & 0,0 & 0,10 & 0,00 & 1,60 & 6 & 0 & 94 & 0,0 & 0 \\
8 & 48,5 & 0,00 & 0,00 & 1,27 & 0 & 0 & 100 & 0,0 & 0 \\
9 & 0,0 & 0,00 & 0,00 & 0,00 & 0 & 0 & 0 & 0,0 & 0 \\
10 & 483,4 & 6,38 & 0,21 & 6,32 & 49 & 2 & 49 & 241,2 & 42,7 \\
11 & 164,4 & 1,43 & 0,65 & 3,46 & 26 & 12 & 63 & 42,4 & 7,8 \\
\hline
\end{tabular}
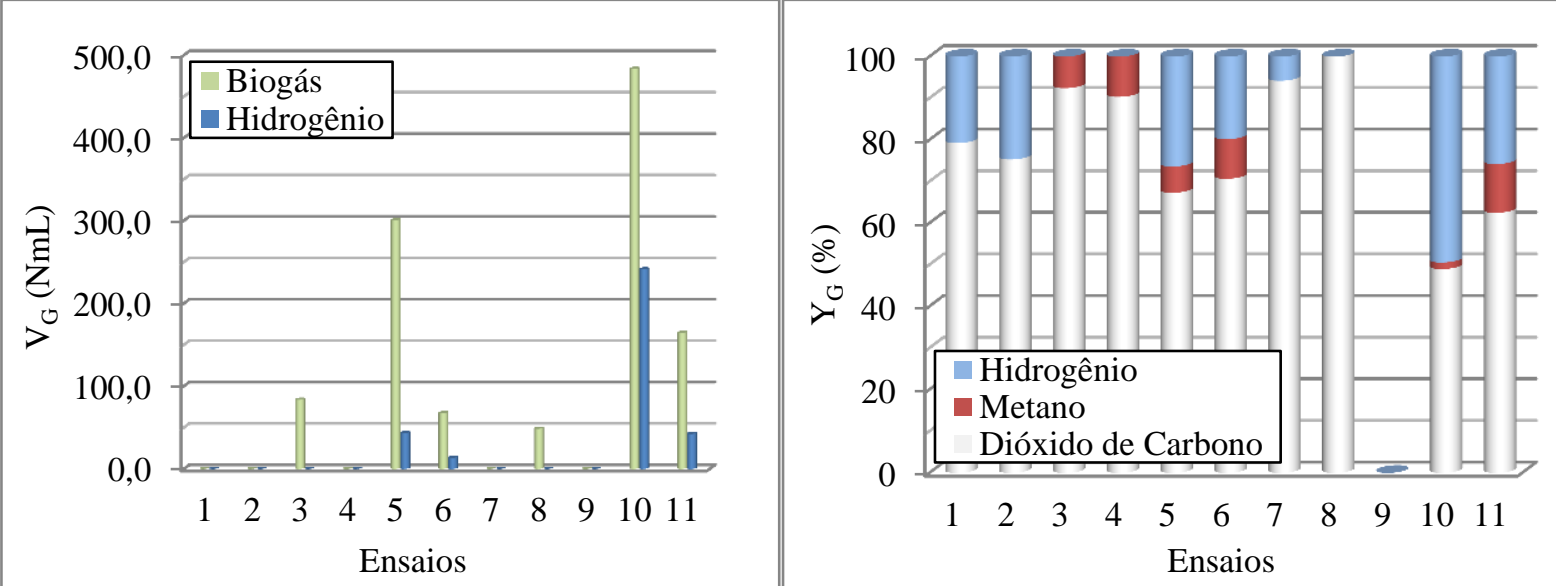

Figura 5.12 - Volume de biogás $\left(\mathrm{V}_{\mathrm{G}}\right)$ e de hidrogênio $\left(\mathrm{V}_{\mathrm{H} 2}\right)$ na CNTP na Fase I e porcentagens $\left(\mathrm{Y}_{\mathrm{G}}\right)$ dos compostos do biogás: • - biogás, • - hidrogênio, • - metano, ○ - dióxido de carbono

A partir dos resultados obtidos na Fase I, os seguintes parâmetros foram escolhidos para a

Fase II:

- Inóculo: Como não houve diferença visível entre os dois tipos de inóculo usados e não foram obtidos bons resultados em relação à produção de hidrogênio, foi utilizado um inóculo de lodo de abatedouro de aves tratado por HST (Heat Shock Treatment $-90^{\circ} \mathrm{C}$ 
por 10 minutos, seguido de banho de gelo até $25^{\circ} \mathrm{C}$ ) que é tipicamente utilizado para a produção desse biogás (Inóculo 3).

- Glicerina: Foi utilizada glicerina P.A. para eliminar qualquer interferência de possíveis resíduos do processo de produção de biodiesel.

- Suporte: Foi utilizado polietileno de baixa densidade.

- Velocidade ascensional do líquido: Foi utilizada $10,6 \mathrm{~m} \cdot \mathrm{h}^{-1}$ para inibir a fixação de arquéias metanogênica.

- $\mathrm{NaHCO}_{3}$ : Foi utilizada uma concentração de $100 \mathrm{mg} \cdot \mathrm{L}^{-1}$ para manter o $\mathrm{pH}$ do efluente entre 4 e 5 .

- Solução de sais: Foi utilizada solução de sais completa, pois não houve indício de nenhum tipo de melhora com a retirada parcial ou completa da mesma.

\subsection{FASE II}

A Fase II compreendeu os ensaios de 12 a 19 e teve como objetivo encontrar a condição ótima de concentração de matéria orgânica do afluente e tempo de ciclo do sistema. Os ensaios 12 e 13 foram unicamente para verificar a adaptação do sistema aos parâmetros encontrados na Fase I e podem, portanto, serem considerados como condições preliminares.

Cada ensaio desta fase foi operado por 14 dias e, ao final do mesmo, foi realizada uma lavagem do sistema (reator, reservatório e bombas) e o polietileno, juntamente com as mangueiras, era esterilizado em autoclave e novamente inoculado com o lodo pré-tratado.

\subsubsection{Ensaios 12 e 13 (1000 e 2000 mgDQO.L ${ }^{-1}$ e 4 h de tempo de ciclo)}

Os valores nominais de COVA para os ensaios 12 e 13 , respectivamente, foram de 2,6 gDQO.L $\mathrm{L}^{-1} \cdot \mathrm{d}^{-1}$ e 5,1 gDQO.L $\mathrm{L}^{-1} \cdot \mathrm{d}^{-1}$ e, excepcionalmente neste caso, cada ensaio durou 7 dias. 
A Tabela 5.5 apresenta a média dos parâmetros monitorados; nestes ensaios não foram realizados perfis e a quantificação da biomassa do reator.

Tabela 5.5 - Parâmetros médios monitorados nos ensaios 12 e 13

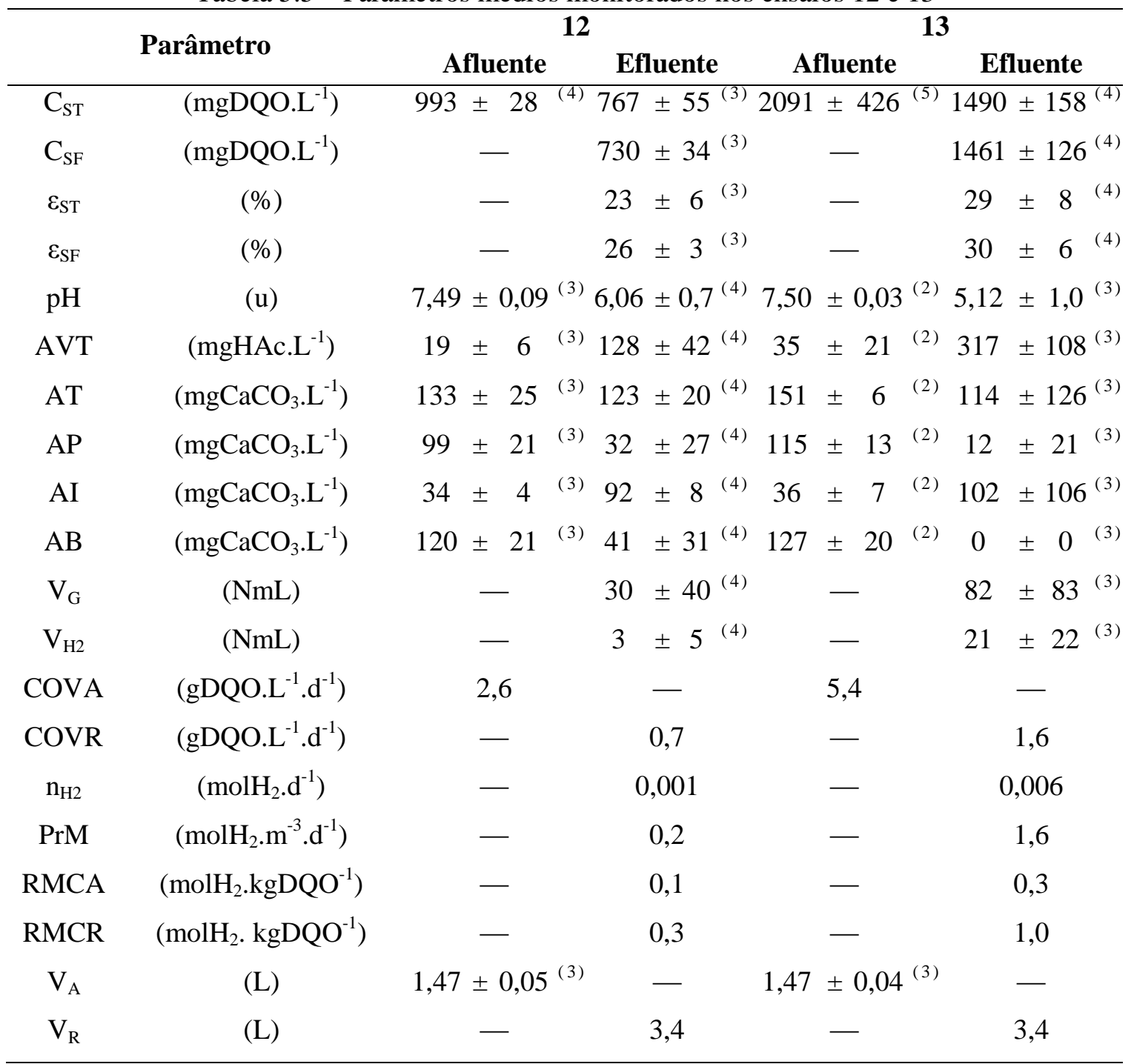

(*) Entre parêntese o número de amostras considerado no cálculo da média

A Figura 5.13 apresenta os valores das concentrações de DQO afluente (não filtrada) e efluente (não filtrada e filtrada), e na Figura 5.14 as eficiências na remoção de DQO durante o monitoramento diário. A concentração média afluente real aplicada ao reator foi de $993 \mathrm{mgDQO} . \mathrm{L}^{-1}$ e $2091 \mathrm{mgDQO} . \mathrm{L}^{-1}$, as concentrações médias obtidas para o efluente não filtrado foram de $767 \mathrm{mgDQO} . \mathrm{L}^{-1} \mathrm{e} 1490 \mathrm{mgDQO} . \mathrm{L}^{-1}$; para o efluente filtrado de $730 \mathrm{mgDQO} . \mathrm{L}^{-1}$ e $1461 \mathrm{mgDQO} . \mathrm{L}^{-1}$ para os ensaios 12 e 13, respectivamente. Portanto, para 
o ensaio 12 foram obtidas eficiências de remoção de DQO de $23 \%$ para amostras não filtradas e $26 \%$ para amostras filtradas e, para o ensaio 13, foram obtidas eficiências de remoção de DQO de 29 \% para amostras não filtradas e $30 \%$ para amostras filtradas.

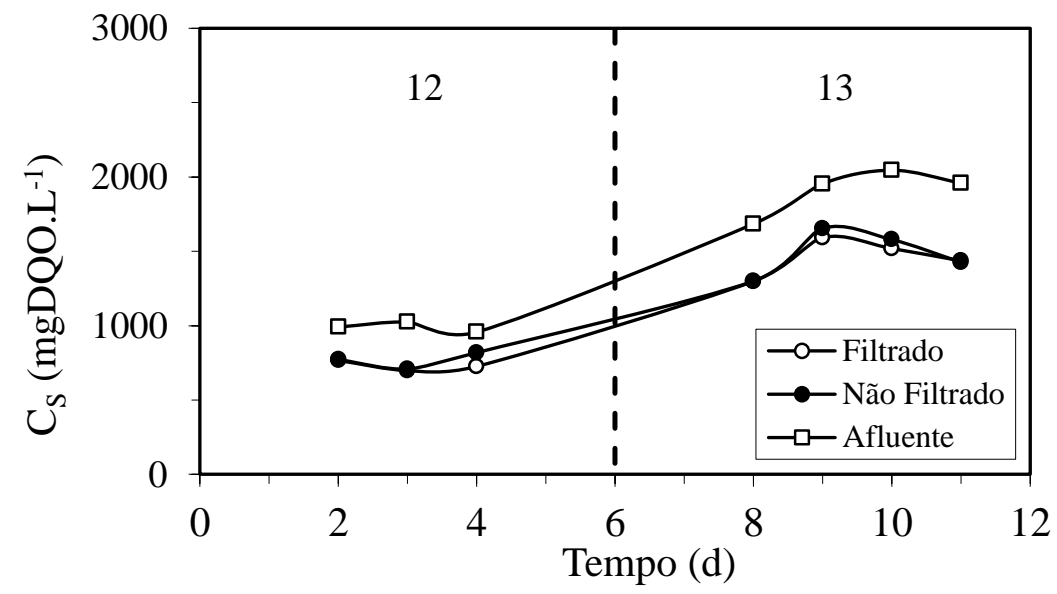

Figura 5.13 - Concentração de matéria orgânica na forma de DQO nos ensaios 12 e 13: $\square-$ afluente amostras não filtradas; • - efluente amostras não filtradas; $\bigcirc$ - efluente amostras filtradas

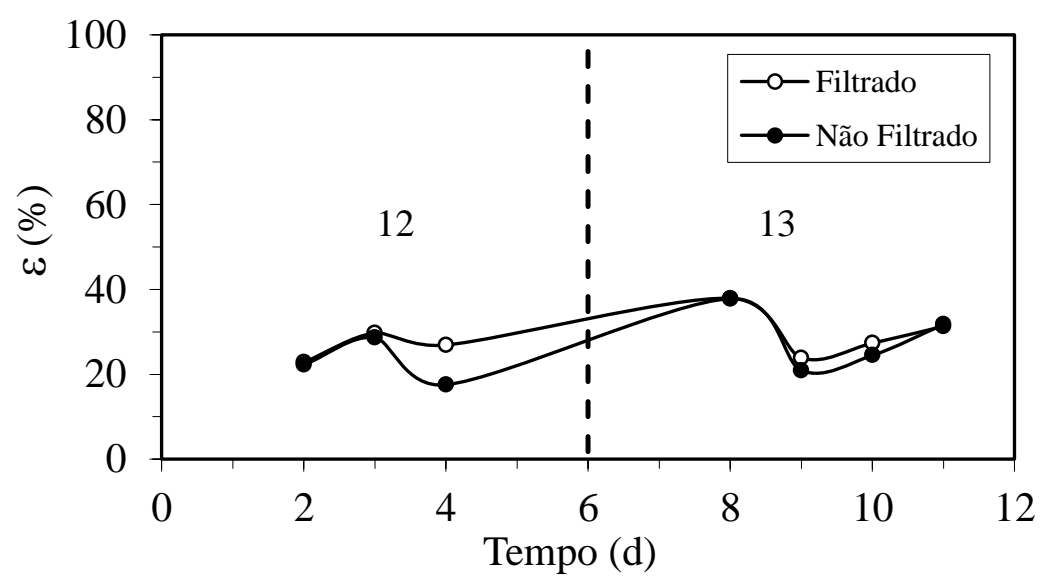

Figura 5.14 - Eficiência de remoção de matéria orgânica na forma de DQO nos ensaios 12 e 13: amostras não filtradas; $\bigcirc-$ amostras filtradas

As Figuras 5.15, 5.16 e 5.17 apresentam os dados obtidos de $\mathrm{pH}$, alcalinidade total e ácidos voláteis totais, respectivamente. Para o ensaio 12, a média do $\mathrm{pH}$ afluente foi de 7,49 e do efluente de 6,1; a alcalinidade total afluente teve média de $133 \mathrm{mgCaCO}_{3} \cdot \mathrm{L}^{-1}$ e no efluente uma média de $123 \mathrm{mgCaCO}_{3} \cdot \mathrm{L}^{-1}$; a média de AVT do afluente foi de $19 \mathrm{mgHAc} . \mathrm{L}^{-1}$, aumentando para uma média de AVT do efluente de 128 mgHAc. $\mathrm{L}^{-1}$. Para o ensaio 13, a 
média do pH afluente foi de 7,50 e do efluente de 5,1; a alcalinidade total afluente teve média de $150 \mathrm{mgCaCO} 3 \cdot \mathrm{L}^{-1}$ e no efluente uma média de $114 \mathrm{mgCaCO}_{3} \cdot \mathrm{L}^{-1}$; a média de AVT do

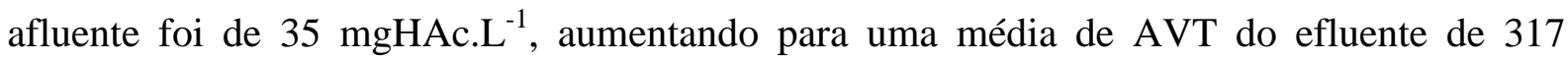
$\operatorname{mgHAc} \cdot \mathrm{L}^{-1}$.

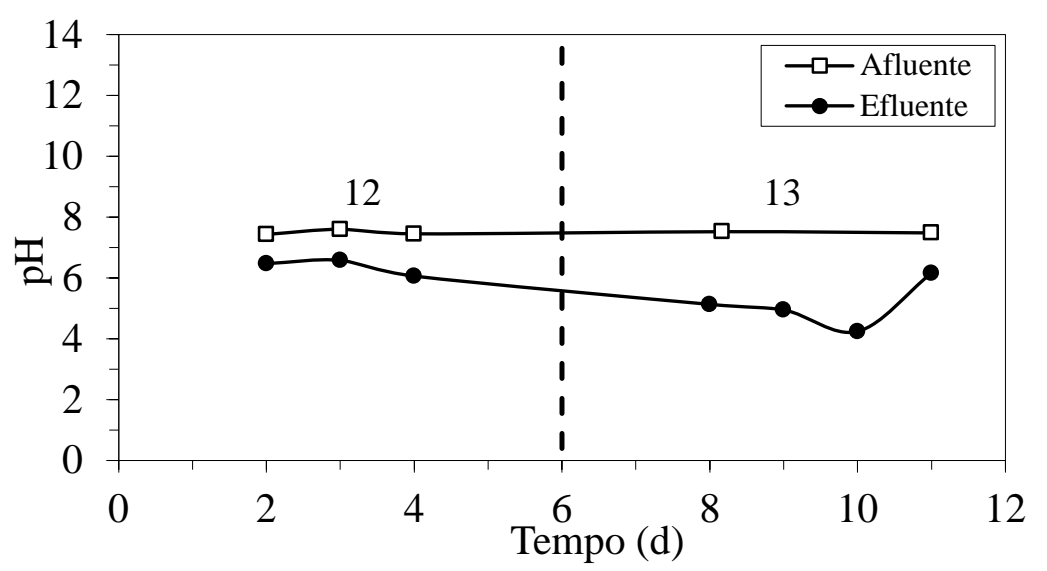

Figura 5.15 - Valores de pH nos ensaios 12 e 13: $\square$-afluente; $\bullet$ - efluente

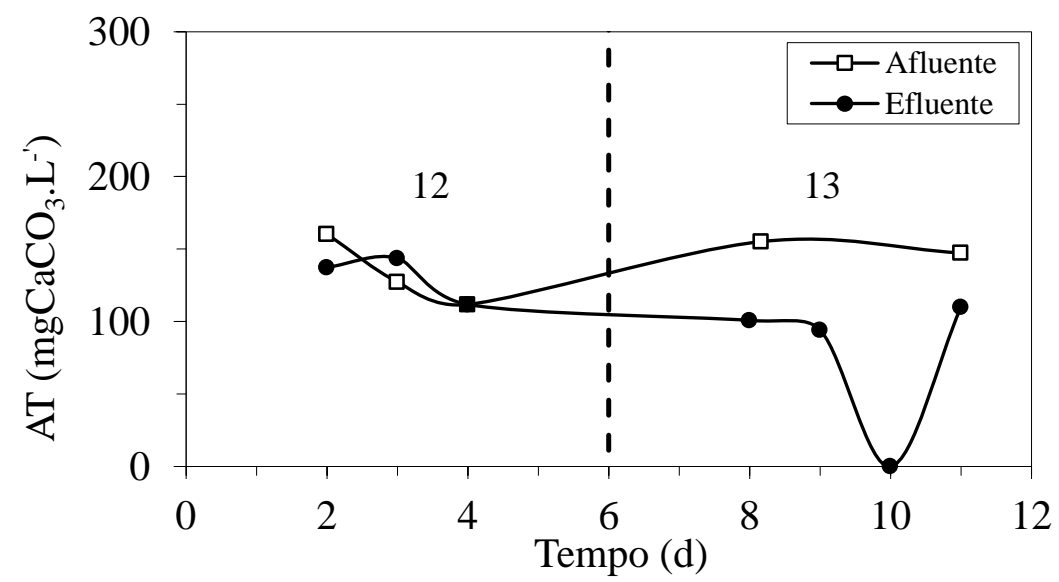

Figura 5.16 - Valores de alcalinidade total (AT) nos ensaios 12 e 13: $\square$-afluente; $\bullet$ - efluente

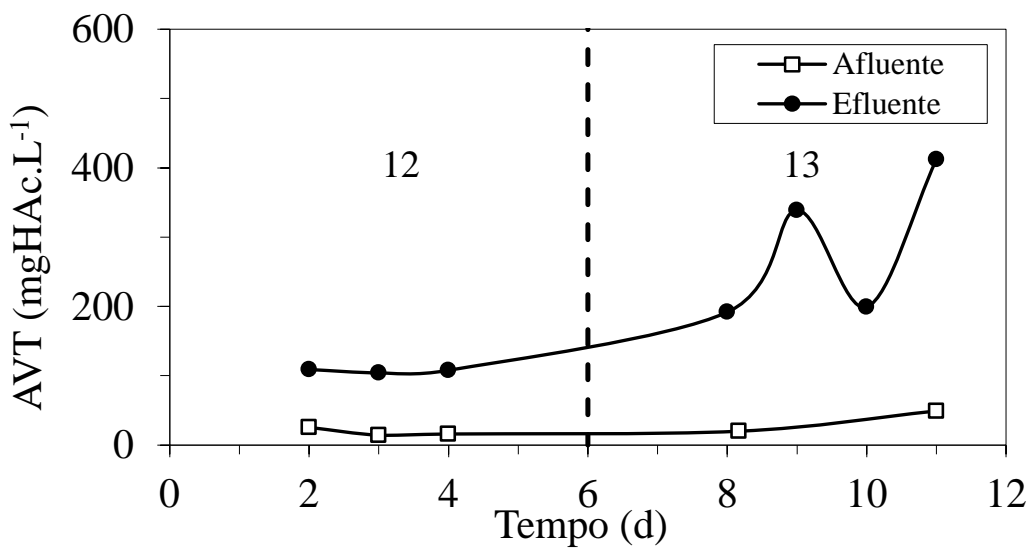

Figura 5.17 - Valores de ácidos voláteis totais (AVT) nos ensaios 12 e 13: $\square$-afluente; $\bullet$ - efluente 
A produção de biogás por ciclo, em aspecto quantitativo, pode ser observada pela Figura 5.18, com média de $30 \mathrm{~mL}$ de biogás e $3 \mathrm{~mL}$ de hidrogênio no ensaio 12 e $82 \mathrm{~mL}$ de biogás e $21 \mathrm{~mL}$ de hidrogênio no ensaio 13. A Tabela 5.6 apresenta a distribuição dos gases que compõem o biogás no final do ciclo ao final de cada ensaio.

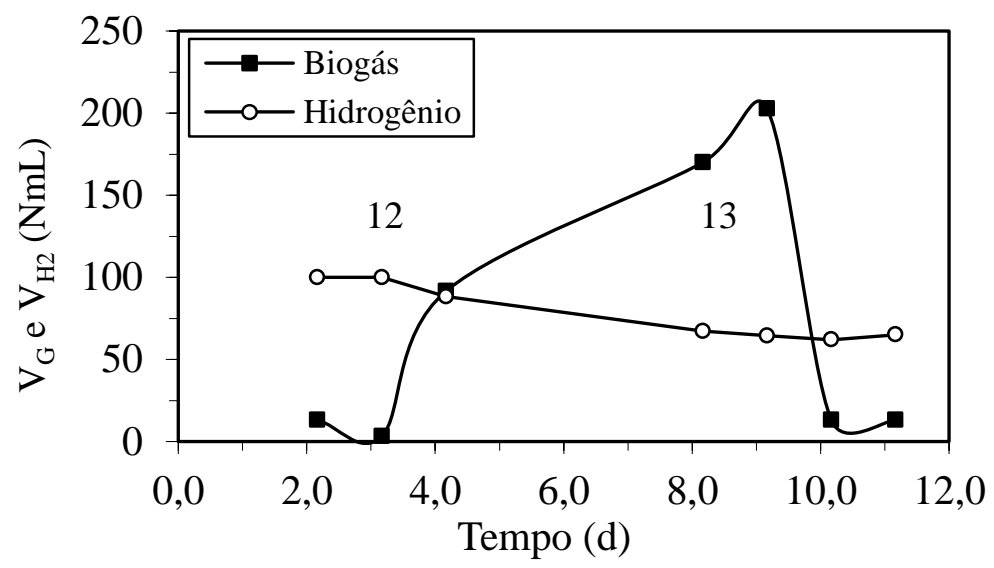

Figura 5.18 - Volume de biogás $\left(\mathrm{V}_{\mathrm{G}}\right)$ e de hidrogênio $\left(\mathrm{V}_{\mathrm{H} 2}\right)$ na CNTP nos ensaios 12 e 13: - -biogás; - - hidrogênio

Tabela 5.6 - Produção e fração molar referente ao biogás nos ensaios 12 e 13

\begin{tabular}{ccccccccc}
\hline \multirow{2}{*}{ Ensaio } & $\mathrm{V}_{\mathrm{G}}$ & \multicolumn{3}{c}{$\mathrm{C}_{\mathrm{G}}\left(\mathrm{mmol} \cdot \mathrm{L}^{-1}\right)$} & \multicolumn{3}{c}{$\mathrm{Y}_{\mathrm{G}}(\%)$} & $\mathrm{V}_{\mathrm{H} 2}$ \\
& $(\mathrm{NmL})$ & $\mathrm{H}_{2}$ & $\mathrm{CH}_{4}$ & $\mathrm{CO}_{2}$ & $\mathrm{H}_{2}$ & $\mathrm{CH}_{4}$ & $\mathrm{CO}_{2}$ & $(\mathrm{NmL})$ \\
\hline 12 & 30 & 0,25 & 0,00 & 1,84 & 12 & 0 & 88 & 3 \\
13 & 82 & 0,72 & 1,16 & 3,51 & 13 & 21 & 65 & 21 \\
\hline
\end{tabular}

\subsubsection{Ensaio 14 (3000 mgDQO.L $\mathrm{L}^{-1}$ e $4 \mathrm{~h}$ de tempo de ciclo)}

O valor nominal de COVA para o ensaio 14 foi de $7,7 \mathrm{gDQO} \cdot \mathrm{L}^{-1} \cdot \mathrm{d}^{-1}$, a COVA real foi de 7,6 gDQO.L $\mathrm{L}^{-1} \cdot \mathrm{d}^{-1}$ e a COVR atingida foi de 2,0 gDQO.L $\mathrm{L}^{-1} \cdot \mathrm{d}^{-1}$. A Tabela 5.5 apresenta a média dos parâmetros monitorados; a biomassa de sólidos voláteis totais dentro do reator medida ao final do ensaio foi de $7,1 \mathrm{~g}$. 
Tabela 5.7 - Parâmetros médios monitorados no ensaio 14

\begin{tabular}{|c|c|c|c|c|c|}
\hline & \multirow{2}{*}{ Parâmetro } & \multicolumn{4}{|c|}{14} \\
\hline & & & luente & & Efluente \\
\hline $\mathrm{C}_{\mathrm{ST}}$ & $\left(\mathrm{mgDQO} . \mathrm{L}^{-1}\right)$ & 2850 & \pm 246 & (8) & $2217 \pm 122^{(7)}$ \\
\hline $\mathrm{C}_{\mathrm{SF}}$ & $\left(\mathrm{mgDQO} \cdot \mathrm{L}^{-1}\right)$ & & - & & $2112 \pm 136^{(7)}$ \\
\hline$\varepsilon_{\mathrm{ST}}$ & $(\%)$ & & - & & $22 \pm 4$ \\
\hline$\varepsilon_{\mathrm{SF}}$ & $(\%)$ & & - & & $26 \pm 5$ \\
\hline $\mathrm{pH}$ & (u) & 7,63 & $\pm 0,09$ & (7) & $4,6 \pm 0,3^{(7)}$ \\
\hline AVT & $\left(\mathrm{mgHAc} . \mathrm{L}^{-1}\right)$ & 21 & \pm 3 & (7) & $464 \pm 43$ \\
\hline $\mathrm{AT}$ & $\left(\mathrm{mgCaCO}_{3} \cdot \mathrm{L}^{-1}\right)$ & 133 & \pm 31 & (7) & $64 \pm 47$ \\
\hline $\mathrm{AP}$ & $\left(\mathrm{mgCaCO}_{3} \cdot \mathrm{L}^{-1}\right)$ & 109 & \pm 24 & (7) & $0 \pm 0^{(7)}$ \\
\hline AI & $\left(\mathrm{mgCaCO}_{3} \cdot \mathrm{L}^{-1}\right)$ & 24 & \pm 9 & (7) & $64 \pm 47$ \\
\hline $\mathrm{AB}$ & $\left(\mathrm{mgCaCO}_{3} \cdot \mathrm{L}^{-1}\right)$ & 118 & \pm 32 & (7) & $0 \pm 0^{(7)}$ \\
\hline ST & $\left(\mathrm{mg} \cdot \mathrm{L}^{-1}\right)$ & 472 & \pm 78 & (3) & $797 \pm 129^{(4)}$ \\
\hline SVT & $\left(\mathrm{mg} \cdot \mathrm{L}^{-1}\right)$ & 287 & \pm 67 & (3) & $609 \pm 85$ \\
\hline SST & $\left(\mathrm{mg} \cdot \mathrm{L}^{-1}\right)$ & 31 & \pm 15 & (3) & $48 \pm 9$ \\
\hline SSV & $\left(\mathrm{mg} \cdot \mathrm{L}^{-1}\right)$ & 25 & \pm 13 & (3) & $43 \pm 15^{(4)}$ \\
\hline $\mathrm{M}_{\mathrm{SVT}}$ & (g) & & - & & 7,1 \\
\hline $\mathrm{Cx}$ & $\left(\mathrm{g} . \mathrm{L}^{-1}\right)$ & & - & & 2,1 \\
\hline $\mathrm{Cx}^{\prime}$ & (g.gsuporte ${ }^{-1}$ ) & & - & & 0,0057 \\
\hline $\mathrm{V}_{\mathrm{G}}$ & $(\mathrm{NmL})$ & & - & & $139 \pm 47$ \\
\hline $\mathrm{V}_{\mathrm{H} 2}$ & $(\mathrm{NmL})$ & & - & & $71 \pm 31$ \\
\hline COVA & $\left(\mathrm{gDQO} \cdot \mathrm{L}^{-1} \cdot \mathrm{d}^{-1}\right)$ & & 7,6 & & - \\
\hline COVR & $\left(\right.$ gDQO.L $\left.{ }^{-1} \cdot d^{-1}\right)$ & & - & & 2,0 \\
\hline COEA & $\left(\right.$ gDQO.gSVT $\left.{ }^{-1} \cdot \mathrm{d}^{-1}\right)$ & & 3,6 & & - \\
\hline COER & $\left(\right.$ gDQO.gSVT $\left.{ }^{-1} \cdot d^{-1}\right)$ & & - & & 0,9 \\
\hline $\mathrm{n}_{\mathrm{H} 2}$ & $\left(\mathrm{molH}_{2} \cdot \mathrm{d}^{-1}\right)$ & & - & & 0,02 \\
\hline PrM & $\left(\mathrm{molH}_{2} \cdot \mathrm{m}^{-3} \cdot \mathrm{d}^{-1}\right)$ & & - & & 5,6 \\
\hline PrME & $\left(\mathrm{molH}_{2} \cdot \mathrm{kgSVT}^{-1} \cdot \mathrm{d}^{-1}\right)$ & & - & & 2,7 \\
\hline RMCA & $\left(\mathrm{molH}_{2} \cdot \mathrm{kgDQO}^{-1}\right)$ & & - & & 0,7 \\
\hline RMCR & $\left(\mathrm{molH}_{2} \cdot \mathrm{kgDQO}^{-1}\right)$ & & - & & 2,9 \\
\hline $\mathrm{V}_{\mathrm{A}}$ & (L) & 1,51 & $\pm 0,03$ & (4) & - \\
\hline $\mathrm{V}_{\mathrm{R}}$ & (L) & & - & & 3,4 \\
\hline
\end{tabular}

(*) Entre parêntese o número de amostras considerado no cálculo da média

O monitoramento diário apresentou baixo consumo de matéria orgânica na forma de DQO, com média de concentração afluente não filtrada de $2850 \mathrm{mgDQO} . \mathrm{L}^{-1}$, efluente não filtrada de $2217 \mathrm{mgDQO} . \mathrm{L}^{-1}$ e efluente filtrada de $2112 \mathrm{mgDQO} . \mathrm{L}^{-1}$ (Figura 5.19), que representa um baixo rendimento em relação a esse parâmetro, com remoção média para amostras não filtradas de $22 \%$ e para amostras filtradas de 26\% (Figura 5.20). Esses resultados são explicados pela geração de ácidos no processo. 


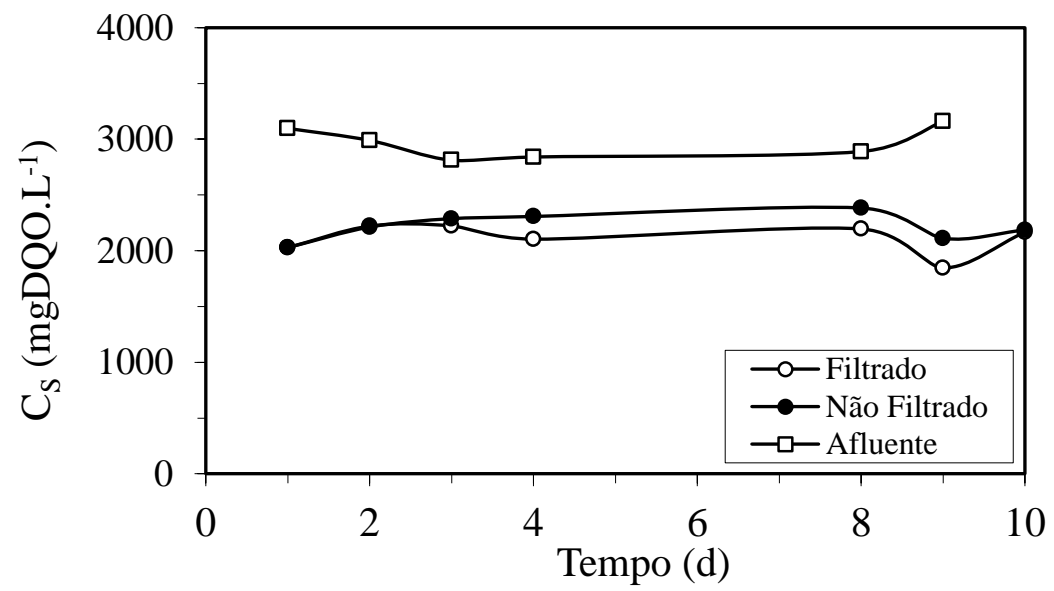

Figura 5.19 - Concentração de matéria orgânica na forma de DQO no ensaio 14: $\square$ - afluente amostras não filtradas; • - efluente amostras não filtradas; ○ - efluente amostras filtradas

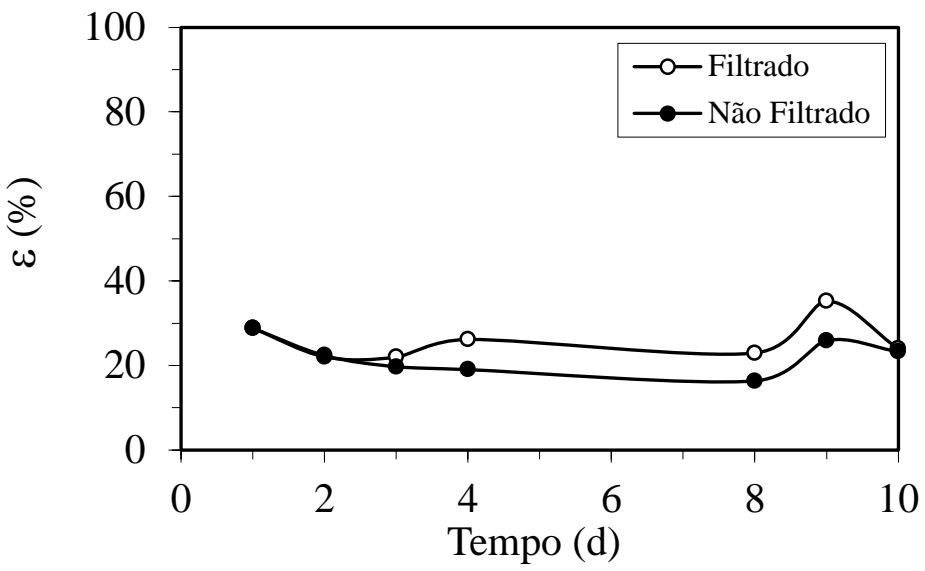

Figura 5.20 - Eficiência de remoção de matéria orgânica na forma de DQO no ensaio 14: • - amostras não filtradas; $\bigcirc-$ amostras filtradas

As Figuras 5.21, 5.22 e 5.23 apresentam os dados obtidos de $\mathrm{pH}$, alcalinidade total e ácidos voláteis totais, respectivamente. A média do $\mathrm{pH}$ afluente foi de 7,63 e do efluente de 4,6. A alcalinidade total afluente teve média de $133 \mathrm{mgCaCO}_{3} \cdot \mathrm{L}^{-1}$ sendo reduzida no efluente para uma média de $64 \mathrm{mgCaCO}_{3} \cdot \mathrm{L}^{-1}$. A média de AVT do afluente foi de $21 \mathrm{mgHAc} . \mathrm{L}^{-1}$ e a média de AVT do efluente de 464 mgHAc. $\mathrm{L}^{-1}$. 


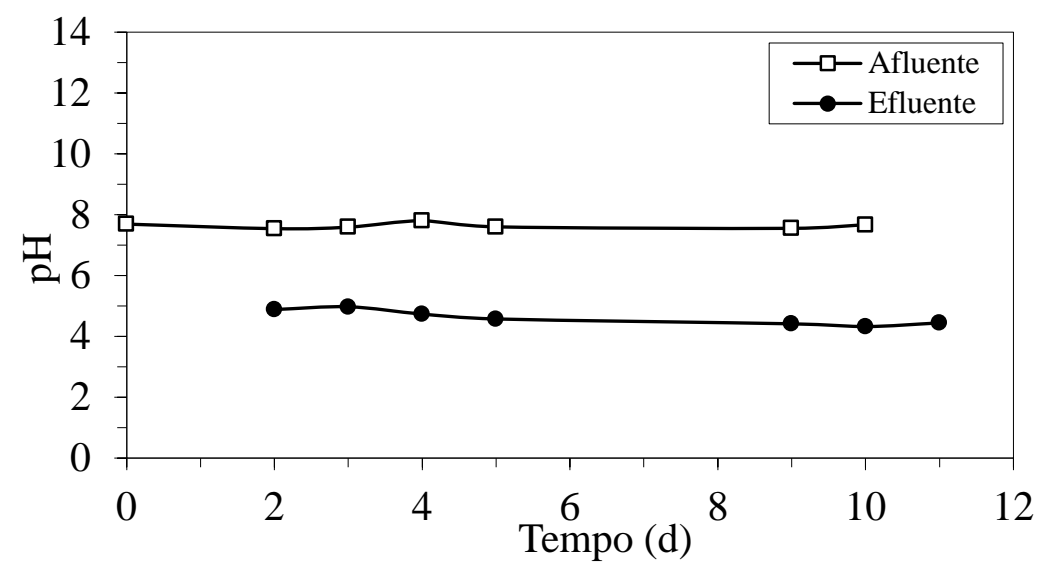

Figura 5.21 - Valores de pH no ensaio 14: $\square-$ afluente; $\bullet$ - efluente

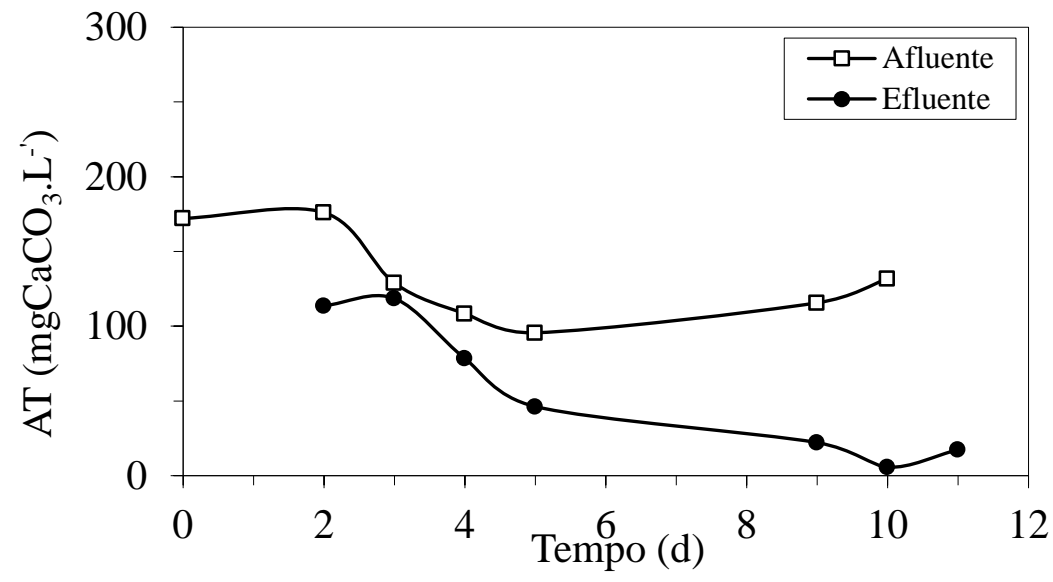

Figura 5.22 - Valores de alcalinidade total (AT) no ensaio 14: $\square$-afluente; $\bullet$ - efluente

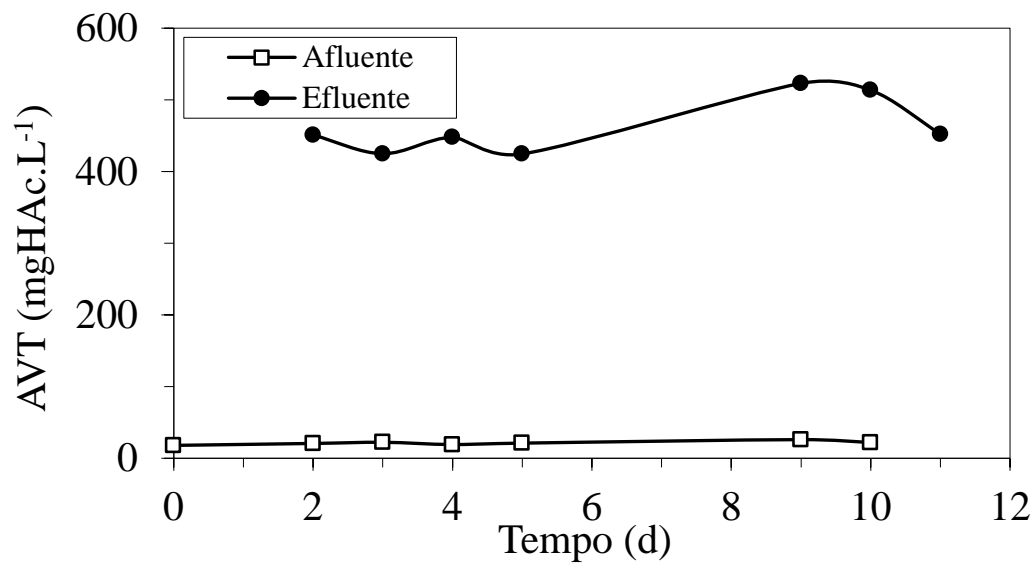

Figura 5.23 - Valores de ácidos voláteis totais (AVT) no ensaio 14: $\square$-afluente; • - efluente 
A produção de biogás por ciclo, em aspecto quantitativo, pode ser observada na Figura 5.24, com média de $139 \mathrm{~mL}$ de biogás e $71 \mathrm{~mL}$ de hidrogênio. A Figura 5.25 apresenta a distribuição dos gases que compõem o biogás no final do ciclo.

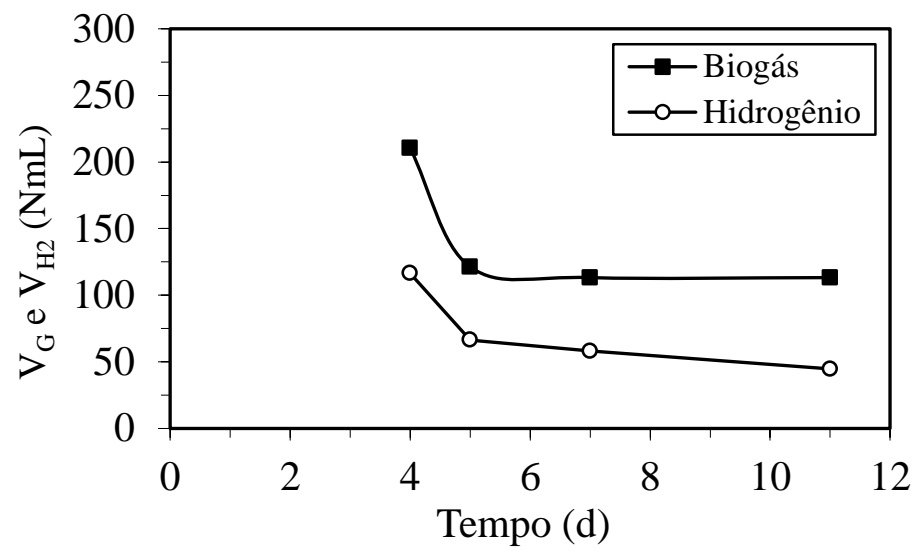

Figura 5.24 - Volume de biogás $\left(\mathrm{V}_{\mathrm{G}}\right)$ e de hidrogênio $\left(\mathrm{V}_{\mathrm{H} 2}\right)$ na CNTP no ensaio 14: - -Biogás; $\circ$ - Hidrogênio

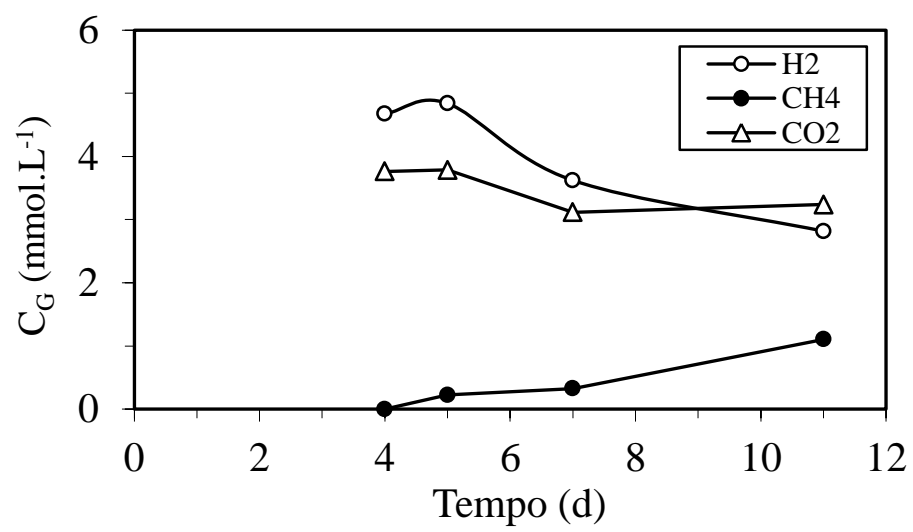

Figura 5.25 - Concentrações dos componentes do biogás no final do ciclo no ensaio 14: $\circ-\mathrm{H}_{2}$; $\bullet-\mathrm{CH}_{4} ; \Delta-\mathrm{CO}_{2}$

Após a estabilização dos parâmetros monitorados, foram realizados perfis ao longo do ciclo para que fosse feita uma análise do comportamento durante o consumo do substrato. A Figura 5.26 apresenta o perfil de DQO durante o ciclo, nota-se que não há grandes variações na medida de DQO durante o ciclo, já que há o consumo da DQO gerada pela glicerina e o aumento de DQO devido a geração dos ácidos. A máxima eficiência de remoção atingida durante o ciclo é de $38 \%$. 


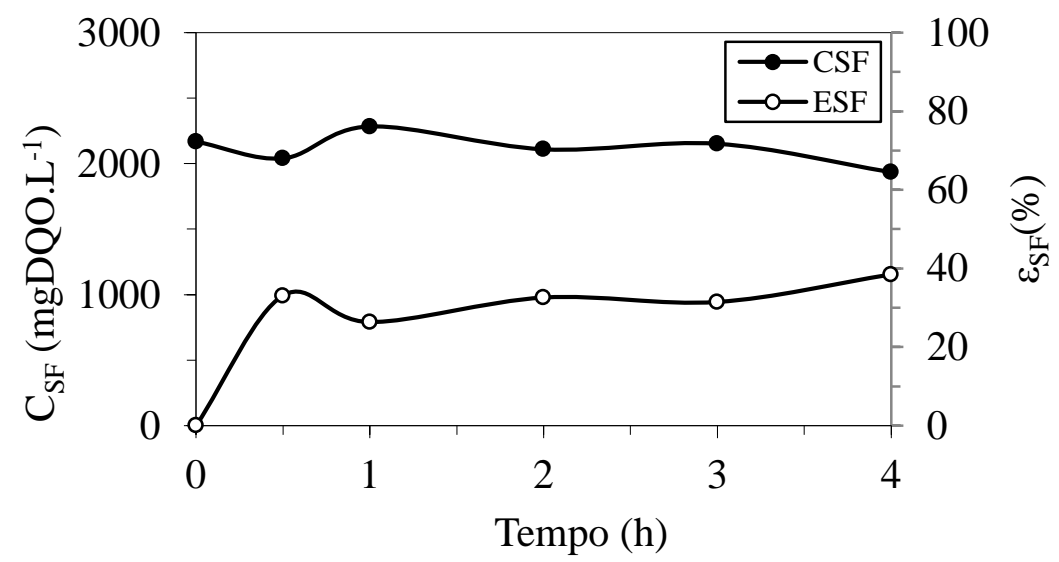

Figura 5.26 - Concentração e eficiência de degradação de matéria orgânica durante o ciclo ensaio 14: - $-\mathrm{C}_{\mathrm{SF}} ; \circ-\varepsilon_{\mathrm{SF}}$

As Figuras 5.27 e 5.28 apresentam os perfis de $\mathrm{pH}$ e alcalinidade total ao longo do ciclo. $\mathrm{O}$ pH permanece constante ao longo do ciclo por volta de 4,3 , devido à presença da alcalinidade que é fornecida gradualmente através do afluente e consumida pelo processo.

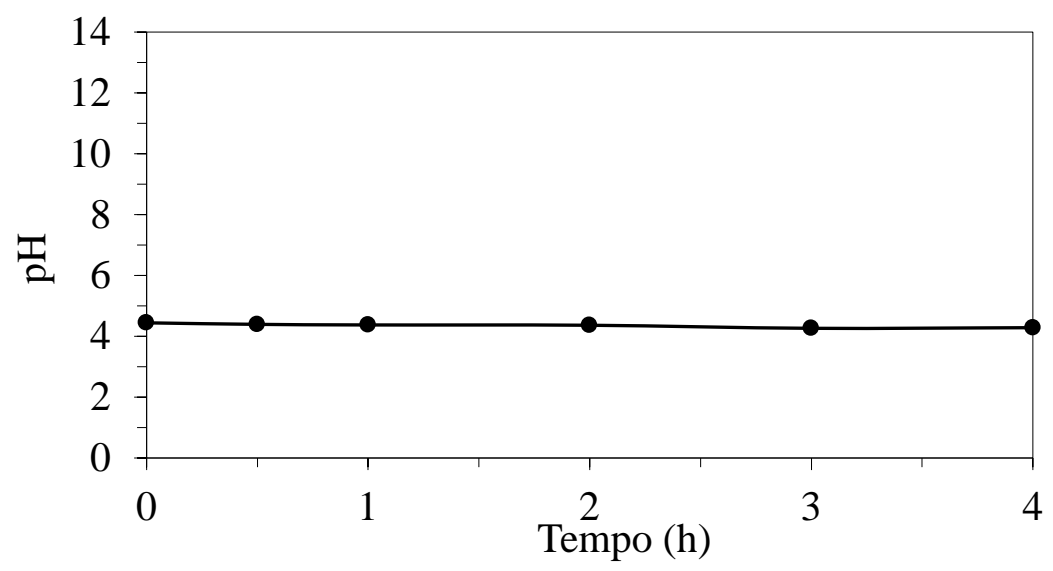

Figura 5.27 - Valores de pH durante o ciclo no ensaio 14

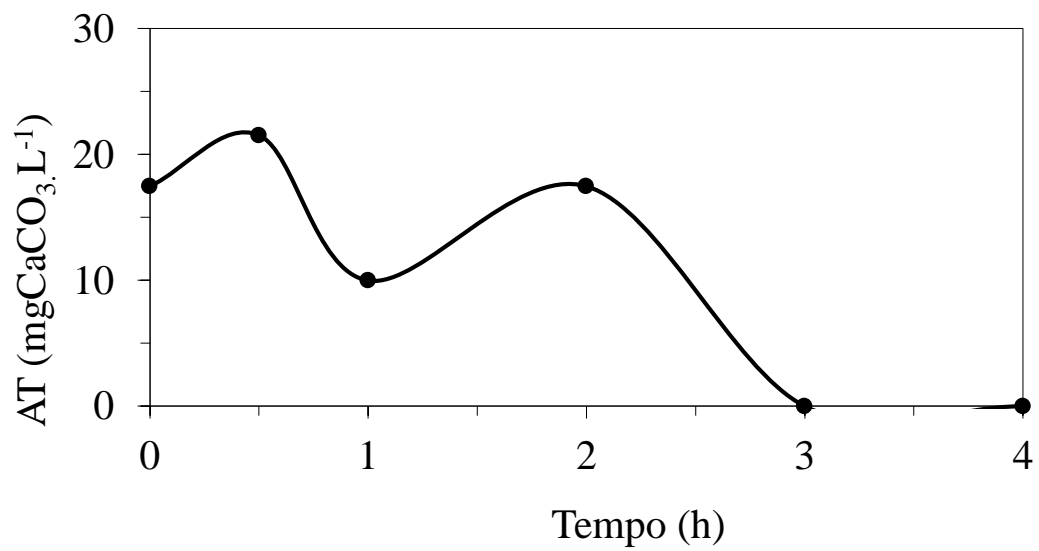

Figura 5.28 - Concentração de alcalinidade total durante o ciclo no ensaio 14 
Os perfis de ácidos voláteis totais por titulação e dos compostos intermediários do metabolismo são apresentados nas Figuras 5.29 e 5.30. É possível verificar uma ligeira queda na concentração inicial de ácidos e solventes no sistema devido à diluição do afluente no meio reacional, e à medida que o substrato era consumido estes retornam as concentrações iniciais. Os ácidos voláteis intermediários com maiores concentrações molares foram o ácido acético e o ácido butírico, seguidos pelo etanol.

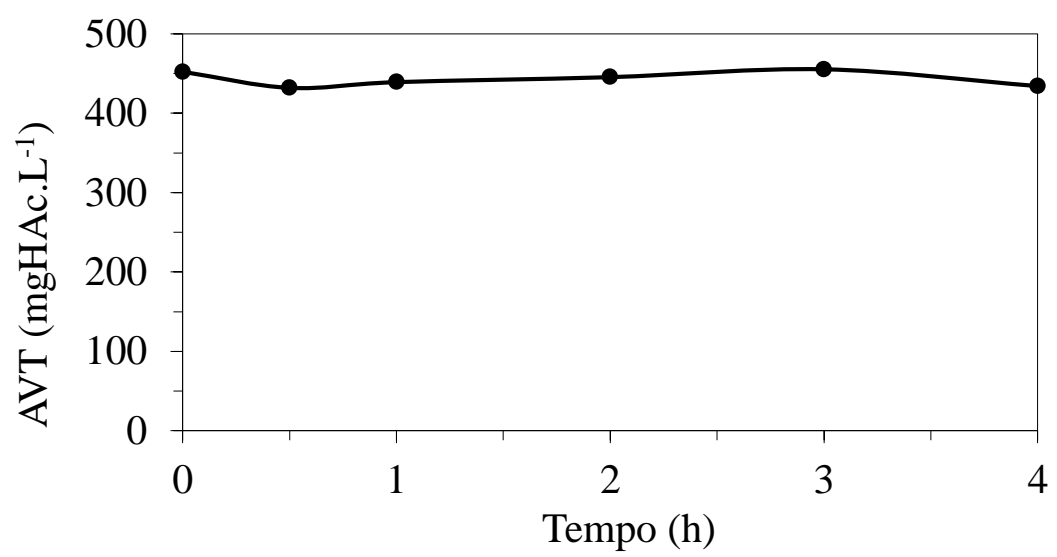

Figura 5.29 - Concentração de AVT durante o ciclo no ensaio 14

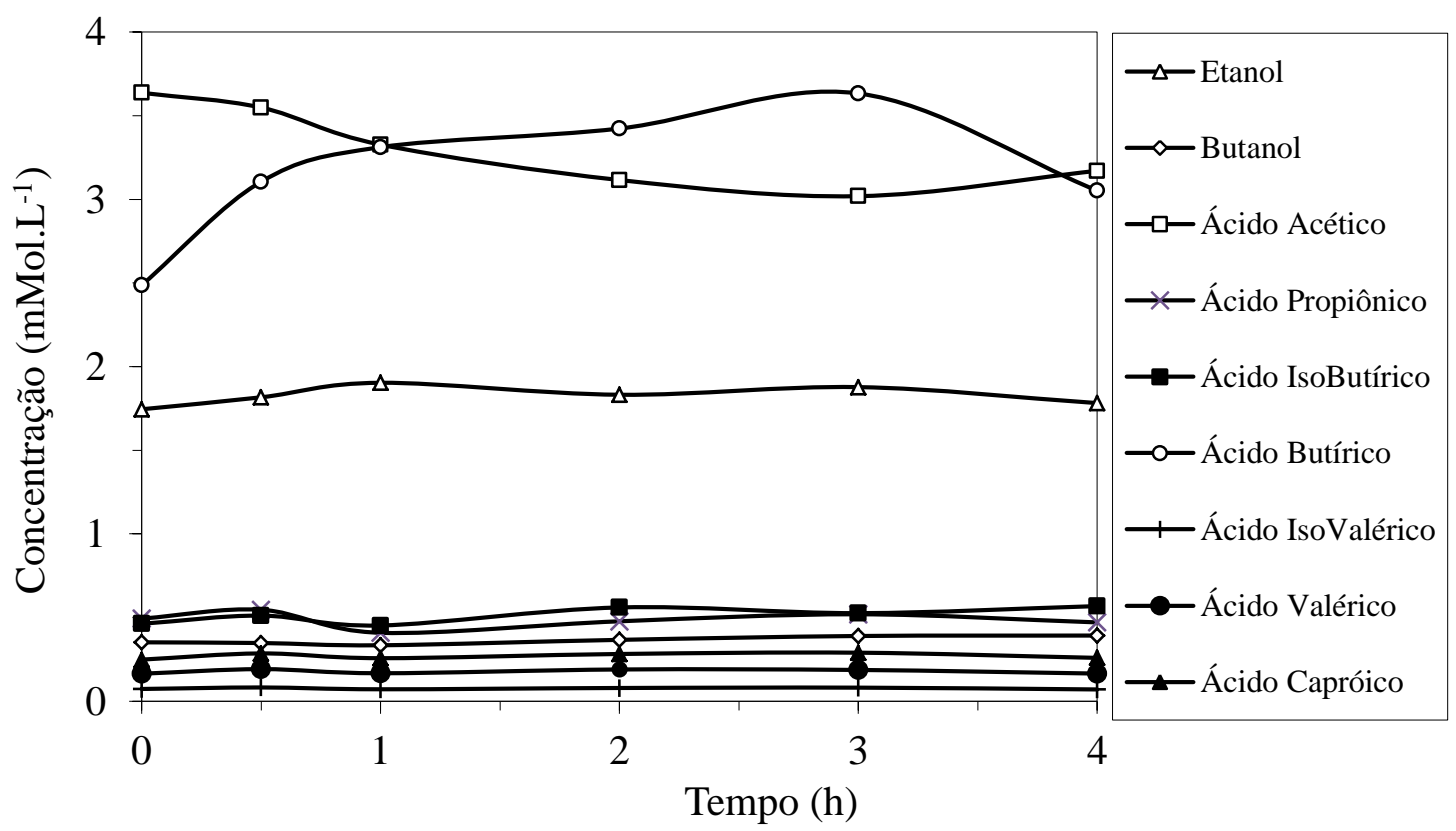

Figura 5.30 - Concentração dos compostos intermediários ao longo do ciclo no ensaio 14: $\square$ - ácido acético; $\Delta$ - etanol; ○ - ácido butírico; - ácido isobutírico; $\boldsymbol{\Delta}$ - ácido capróico; • ácido valérico; -x-ácido propiônico; $\diamond$ butanol; + ácido isovalérico 
A produção volumétrica acumulada de biogás e os desvios padrões de cada um dos pontos podem ser observados na Figura 5.31 e o perfil das concentrações de cada um dos gases e suas respectivas porcentagens podem ser observados na Figura 5.32. Houve grande variação no volume de gás recolhido diariamente em relação à média desse parâmetro e, ao final do ensaio, tinha-se $48 \%$ de $\mathrm{CO}_{2}, 42 \%$ de $\mathrm{H}_{2}$ e $10 \%$ de $\mathrm{CH}_{4}$.

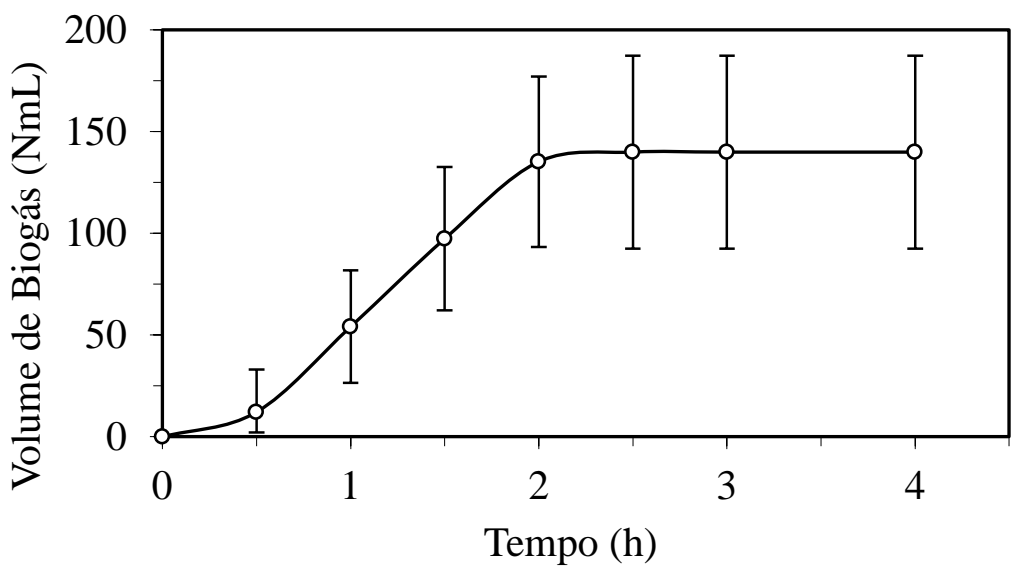

Figura 5.31 - Produção volumétrica média acumulada do biogás durante o ciclo no ensaio 14
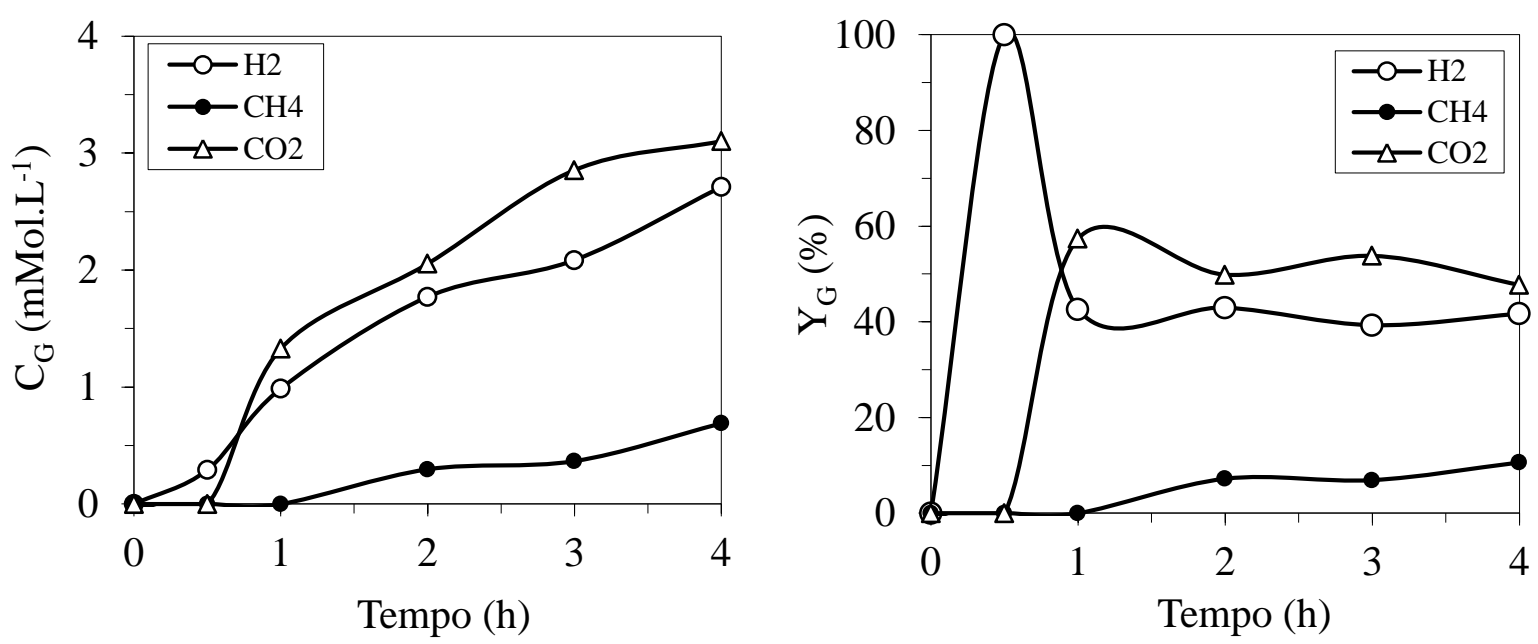

Figura 5.32 - Concentração dos compostos do biogás durante o ciclo e suas respectivas porcentagens no ensaio 14: $\odot-\mathrm{H}_{2} ; \bullet-\mathrm{CH}_{4} ; \Delta-\mathrm{CO}_{2}$ 


\subsubsection{Ensaio 15 (4000 mgDQO.L $\mathrm{L}^{-1}$ e $4 \mathrm{~h}$ de tempo de ciclo)}

O valor nominal de COVA para o ensaio 15 foi de $10,3 \mathrm{gDQO} \cdot \mathrm{L}^{-1} \cdot \mathrm{d}^{-1}$, a COVA real foi de $10,4 \mathrm{gDQO} . \mathrm{L}^{-1} \cdot \mathrm{d}^{-1}$ e a COVR atingida foi de 2,8 gDQO.L $\mathrm{L}^{-1} \cdot \mathrm{d}^{-1}$. A Tabela 5.8 apresenta a média dos parâmetros monitorados; a biomassa de sólidos voláteis totais durante o ensaio foi de $7,8 \mathrm{~g}$.

Tabela 5.8 - Parâmetros médios monitorados no ensaio 15

\begin{tabular}{|c|c|c|c|c|c|c|c|c|c|}
\hline \multirow{2}{*}{\multicolumn{2}{|c|}{ Parâmetro }} & \multicolumn{8}{|c|}{15} \\
\hline & & \multicolumn{4}{|c|}{ Afluente } & \multicolumn{4}{|c|}{ Efluente } \\
\hline$\overline{\mathrm{C}_{\mathrm{ST}}}$ & $\left(\mathrm{mgDQO} . \mathrm{L}^{-1}\right)$ & 3840 & \pm & 138 & $(8)$ & 2965 & \pm & 151 & (7) \\
\hline $\mathrm{C}_{\mathrm{SF}}$ & $\left(\operatorname{mgDQO} \cdot \mathrm{L}^{-1}\right)$ & & - & & & 2823 & \pm & 173 & ( 7 ) \\
\hline$\varepsilon_{\mathrm{ST}}$ & $(\%)$ & & - & & & 23 & \pm & 4 & ( 7 ) \\
\hline$\varepsilon_{\mathrm{SF}}$ & $(\%)$ & & - & & & 26 & \pm & 4 & ( 7 ) \\
\hline $\mathrm{pH}$ & (u) & 7,50 & \pm & 0,07 & ( 7 ) & 4,46 & \pm & 0,08 & ( 7 ) \\
\hline AVT & $\left(\mathrm{mgHAc} . \mathrm{L}^{-1}\right)$ & 31 & \pm & 5 & ( 7 ) & 597 & \pm & 107 & ( 7 ) \\
\hline AT & $\left(\mathrm{mgCaCO}_{3} \cdot \mathrm{L}^{-1}\right)$ & 163 & \pm & 15 & ( 7 ) & 46 & \pm & 13 & ( 7 ) \\
\hline AP & $\left(\mathrm{mgCaCO}_{3} \cdot \mathrm{L}^{-1}\right)$ & 134 & \pm & 15 & ( 7 ) & 0 & \pm & 0 & ( 7 ) \\
\hline $\mathrm{AI}$ & $\left(\mathrm{mgCaCO}_{3} \cdot \mathrm{L}^{-1}\right)$ & 29 & \pm & 9 & ( 7 ) & 46 & \pm & 13 & ( 7 ) \\
\hline $\mathrm{AB}$ & $\left(\mathrm{mgCaCO}{ }_{3} \cdot \mathrm{L}^{-1}\right)$ & 140 & \pm & 13 & ( 7 ) & 0 & \pm & 0 & ( 7 ) \\
\hline ST & $\left(\mathrm{mg} \cdot \mathrm{L}^{-1}\right)$ & 553 & \pm & 96 & (3) & 998 & \pm & 93 & ( 7 ) \\
\hline SVT & $\left(\mathrm{mg} \cdot \mathrm{L}^{-1}\right)$ & 298 & \pm & 71 & (3) & 818 & \pm & 112 & ( 7 ) \\
\hline SST & $\left(\mathrm{mg} \cdot \mathrm{L}^{-1}\right)$ & 21 & \pm & 15 & ( 3 ) & 94 & \pm & 89 & ( 7 ) \\
\hline SSV & $\left(\mathrm{mg} \cdot \mathrm{L}^{-1}\right)$ & 27 & \pm & 6 & (3) & 96 & \pm & 84 & ( 7 ) \\
\hline $\mathrm{M}_{\mathrm{SVT}}$ & (g) & & - & & & & 7 , & & \\
\hline $\mathrm{Cx}$ & $\left(\mathrm{g} . \mathrm{L}^{-1}\right)$ & & - & & & & 2 , & & \\
\hline $\mathrm{Cx}$ & (g.gsuporte $\left.{ }^{-1}\right)$ & & - & & & & $0,0 \mathrm{C}$ & & \\
\hline $\mathrm{V}_{\mathrm{G}}$ & $(\mathrm{NmL})$ & & - & & & 1346 & \pm & 915 & ( 6 ) \\
\hline $\mathrm{V}_{\mathrm{H} 2}$ & $(\mathrm{NmL})$ & & - & & & 890 & \pm & 679 & ( 6 ) \\
\hline COVA & $\left(\right.$ gDQO. $\left.L^{-1} \cdot d^{-1}\right)$ & & 10 & & & & - & & \\
\hline COVR & $\left(\mathrm{gDQO} \cdot \mathrm{L}^{-1} \cdot \mathrm{d}^{-1}\right)$ & & - & & & & 2 , & & \\
\hline COEA & $\left(\right.$ gDQO.gSVT $\left.{ }^{-1} \cdot \mathrm{d}^{-1}\right)$ & & 4 , & & & & - & & \\
\hline COER & $\left(\mathrm{gDQO} \mathrm{gSVT}^{-1} \cdot \mathrm{d}^{-1}\right)$ & & - & & & & 1 , & & \\
\hline $\mathrm{n}_{\mathrm{H} 2}$ & $\left(\mathrm{molH}_{2} \cdot \mathrm{d}^{-1}\right)$ & & - & & & & 0,2 & & \\
\hline PrM & $\left(\mathrm{molH}_{2} \cdot \mathrm{m}^{-3} \cdot \mathrm{d}^{-1}\right)$ & & - & & & & 70 & & \\
\hline PrME & $\left(\mathrm{molH}_{2} \cdot \mathrm{kgSVT}^{-1} \cdot \mathrm{d}^{-1}\right)$ & & - & & & & 30 & & \\
\hline RMCA & $\left(\mathrm{molH}_{2} \cdot \mathrm{kgDQO}^{-1}\right)$ & & - & & & & 6 , & & \\
\hline RMCR & $\left(\mathrm{molH}_{2} \cdot \mathrm{kgDQO}^{-1}\right)$ & & - & & & & 25 & & \\
\hline $\mathrm{V}_{\mathrm{A}}$ & (L) & 1,53 & \pm & 0,07 & ( 6 ) & & - & & \\
\hline $\mathrm{V}_{\mathrm{R}}$ & (L) & & - & & & & 3 , & & \\
\hline
\end{tabular}

O monitoramento diário apresentou baixo consumo de matéria orgânica na forma de

DQO, assim como no ensaio 14, com média de concentração afluente não filtrada de 
$3840 \mathrm{mgDQO} . \mathrm{L}^{-1}$, efluente não filtrada de $2965 \mathrm{mgDQO} . \mathrm{L}^{-1}$ e de efluente filtrada de $2823 \mathrm{mgDQO}^{-1}$ (Figura 5.33), que representa um baixo rendimento em relação a esse parâmetro, com remoção média para amostras não filtradas de $23 \%$ e para amostras filtradas de $26 \%$ (Figura 5.34).

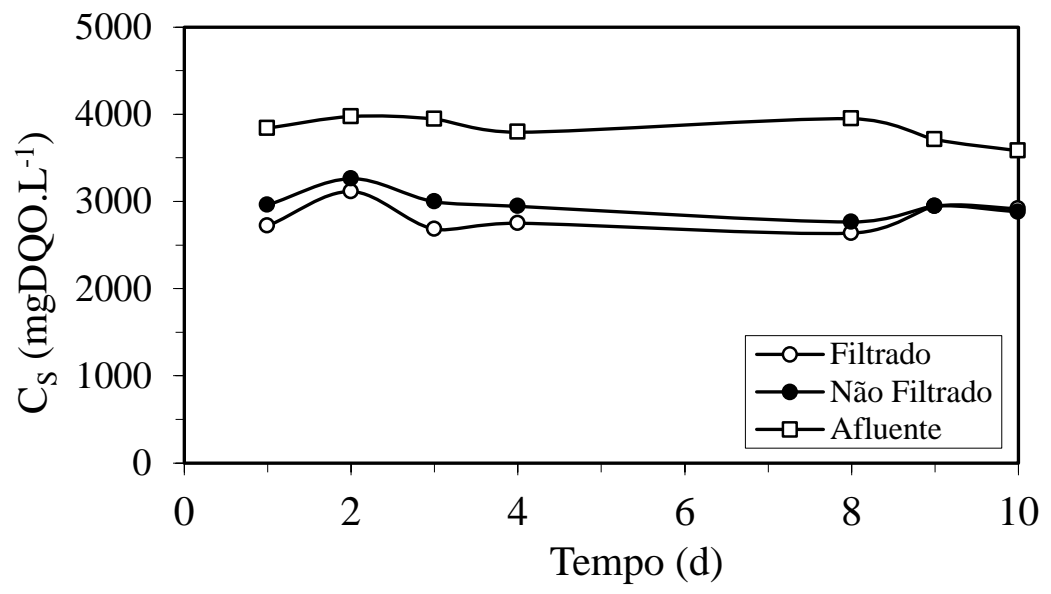

Figura 5.33 - Concentração de matéria orgânica na forma de DQO no ensaio 15: $\square-$ afluente amostras não filtradas; $\bullet$ - efluente amostras não filtradas; $\bigcirc-$ efluente amostras filtradas

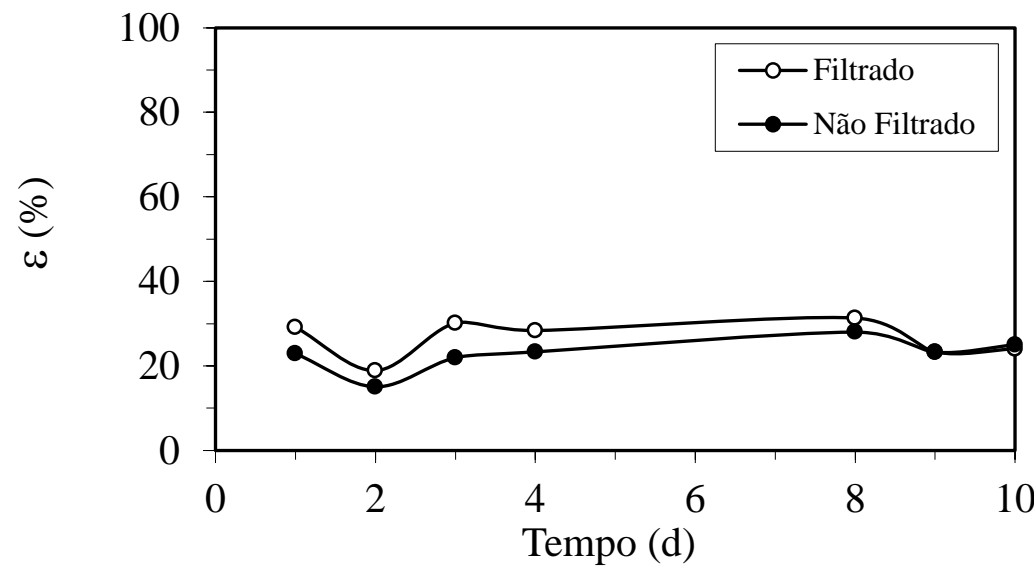

Figura 5.34 - Eficiência de remoção de matéria orgânica na forma de DQO no ensaio 15: • - amostras não filtradas; ○ - amostras filtradas

As Figuras 5.35, 5.36 e 5.37 apresentam os dados obtidos de $\mathrm{pH}$, alcalinidade total e ácidos voláteis totais, respectivamente. A média do $\mathrm{pH}$ afluente foi de 7,50 e do efluente de 4,46. A alcalinidade total afluente teve média de $163 \mathrm{mgCaCO}_{3} \cdot \mathrm{L}^{-1}$ sendo reduzida no efluente para uma média de $46 \mathrm{mgCaCO}_{3} \cdot \mathrm{L}^{-1}$. A média de $\mathrm{AVT}$ do afluente foi de 31 
mgHAc. $\mathrm{L}^{-1}$ e a média de AVT do efluente de 597 mgHAc. $\mathrm{L}^{-1}$, acidificação ligeiramente maior do que no ensaio 14.

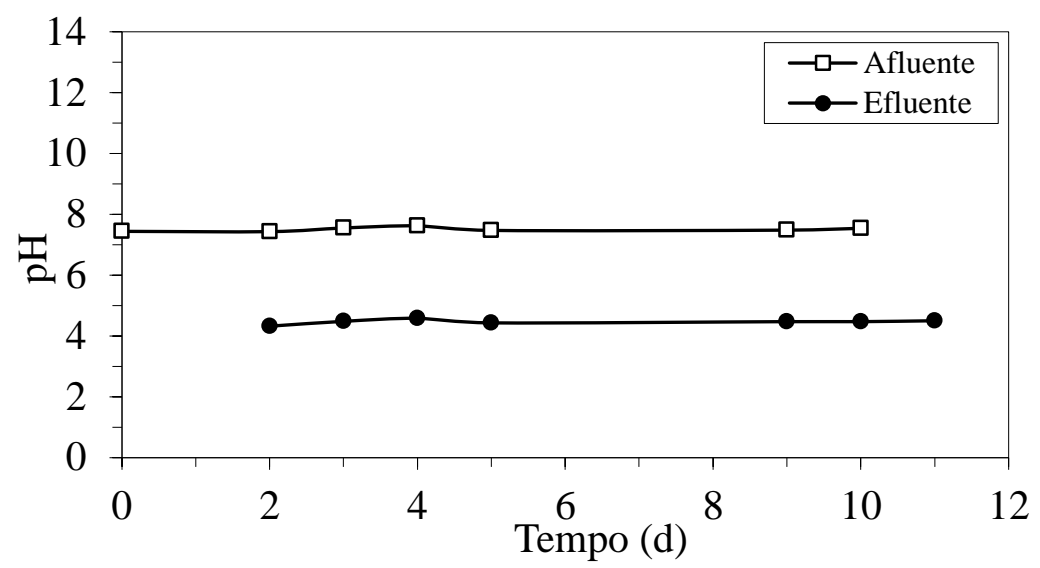

Figura 5.35 - Valores de pH no ensaio 15: $\square$ - afluente; $\bullet$ - efluente

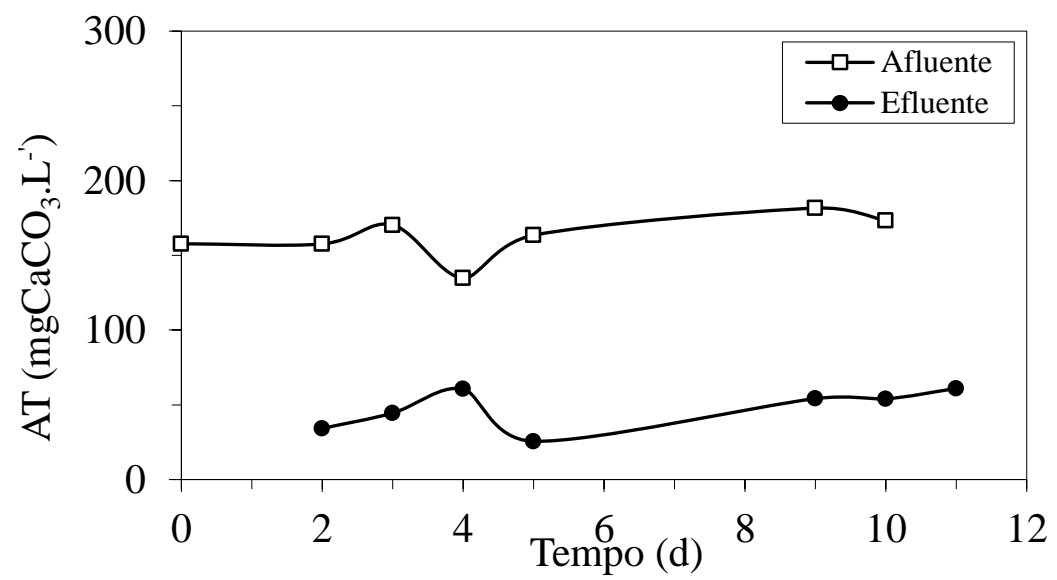

Figura 5.36 - Valores de alcalinidade total (AT) no ensaio 15: $\square$-afluente; $\bullet$ - efluente

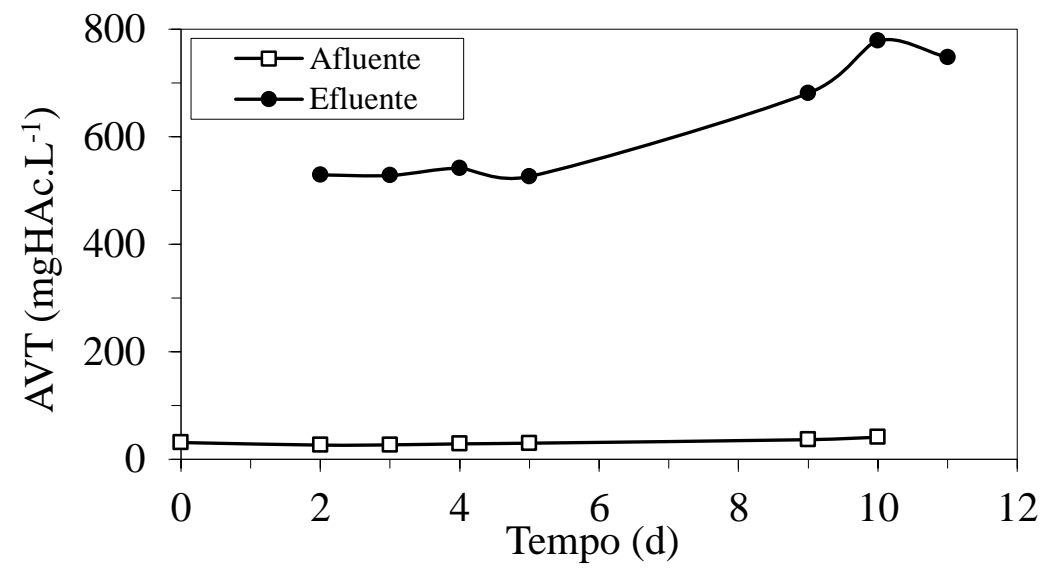

Figura 5.37 - Valores de ácidos voláteis totais (AVT) no ensaio 15: $\square$-afluente; $\bullet$ - efluente 
A produção de biogás por ciclo, em aspecto quantitativo, pode ser observada na Figura 5.38, com média de $1346 \mathrm{~mL}$ de biogás e $890 \mathrm{~mL}$ de hidrogênio, aumento substancial quando comparado ao ensaio 14. A Figura 5.39 apresenta a distribuição dos gases que compõem o biogás no final do ciclo.

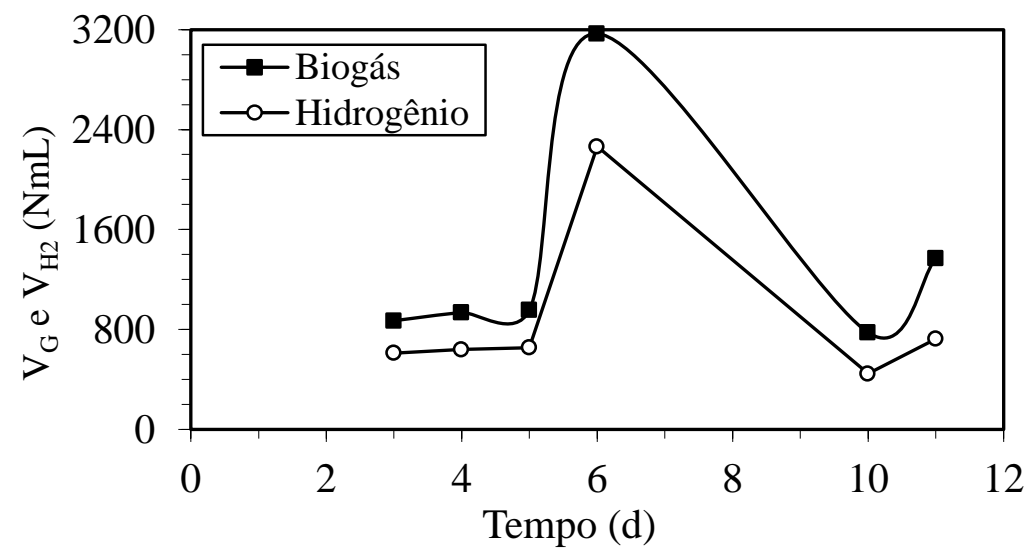

Figura 5.38 - Volume de biogás $\left(\mathrm{V}_{\mathrm{G}}\right)$ e de hidrogênio $\left(\mathrm{V}_{\mathrm{H} 2}\right)$ na CNTP no ensaio 15: - -Biogás; o - Hidrogênio

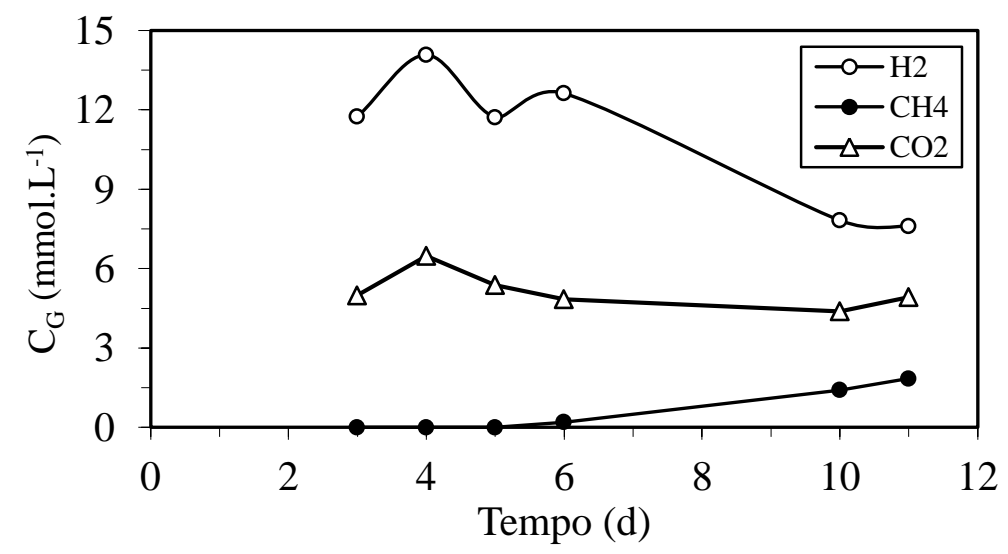

Figura 5.39 - Concentrações dos componentes do biogás no final do ciclo no ensaio 15 : $\circ-\mathrm{H}_{2}$; - $-\mathrm{CH}_{4} ; \Delta-\mathrm{CO}_{2}$

Após a estabilização dos parâmetros monitorados, foram realizados perfis ao longo do ciclo. A Figura 5.40 apresenta o perfil de DQO durante o ciclo. A máxima eficiência de remoção atingida durante o ciclo é de $30 \%$.

As Figuras 5.41 e 5.42 apresentam os perfis de $\mathrm{pH}$ e alcalinidade total ao longo do ciclo. $\mathrm{O}$ pH permanece constante ao longo do ciclo por volta de 4,4, assim como no ensaio 14 , 
devido à presença da alcalinidade que é fornecida gradualmente através do afluente e é consumida pelo processo.

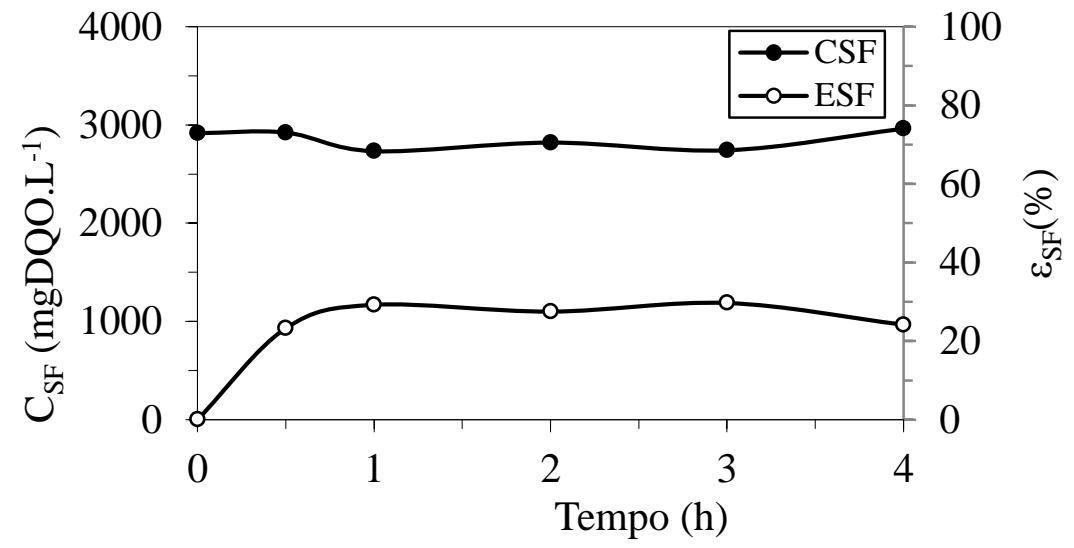

Figura 5.40 - Concentração e eficiência de degradação de matéria orgânica durante o ciclo ensaio 15: - $\mathrm{C}_{\mathrm{SF}} ; \circ-\varepsilon_{\mathrm{SF}}$

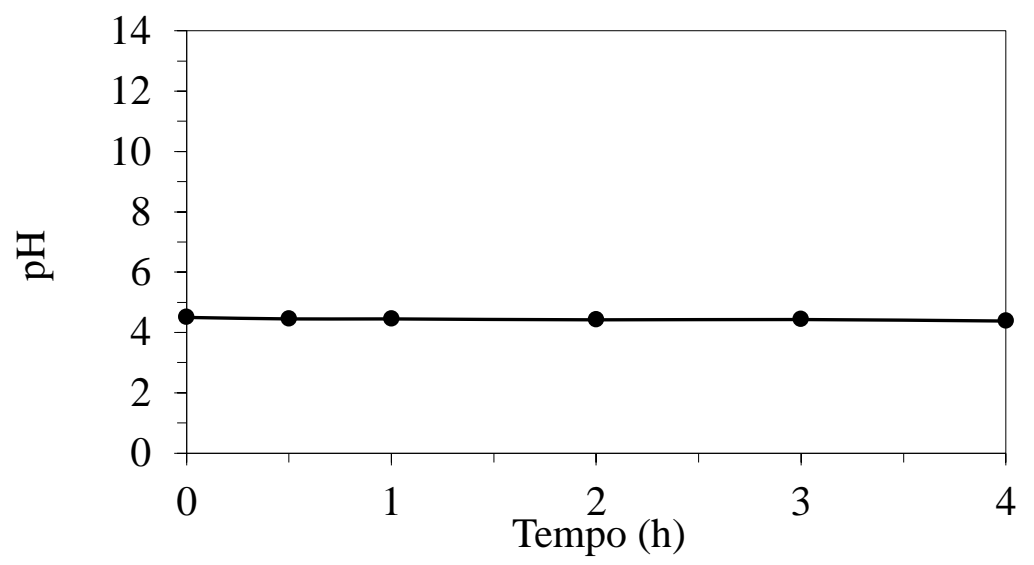

Figura 5.41 - Valores de $\mathrm{pH}$ durante o ciclo no ensaio 15

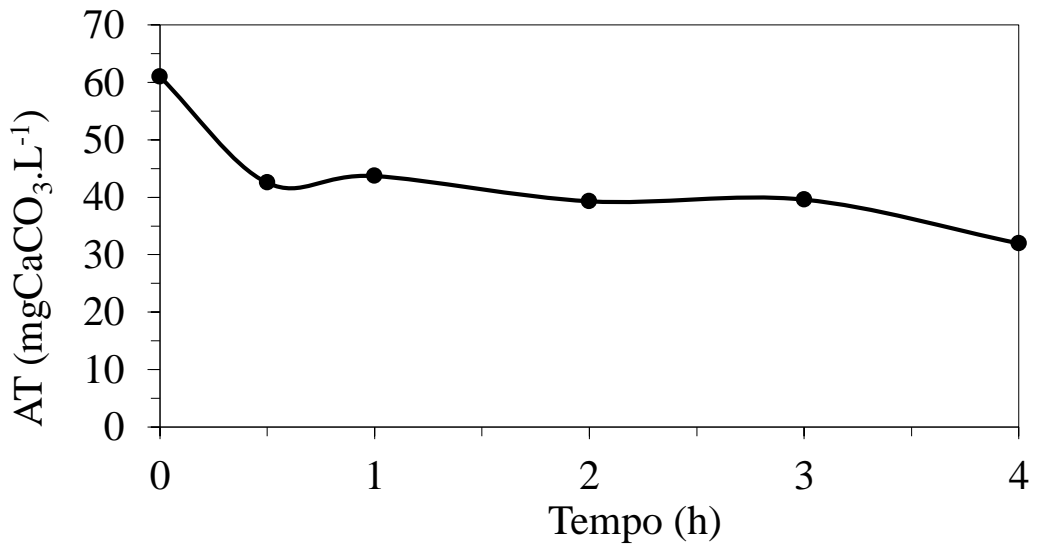

Figura 5.42 - Concentração de alcalinidade total durante o ciclo no ensaio 15 
Os perfis de ácidos voláteis totais por titulação e dos compostos intermediários do metabolismo são apresentados nas Figuras 5.43 e 5.44. Neste ensaio, houve predomínio do ácido butírico e do ácido acético, seguidos pelo butanol.

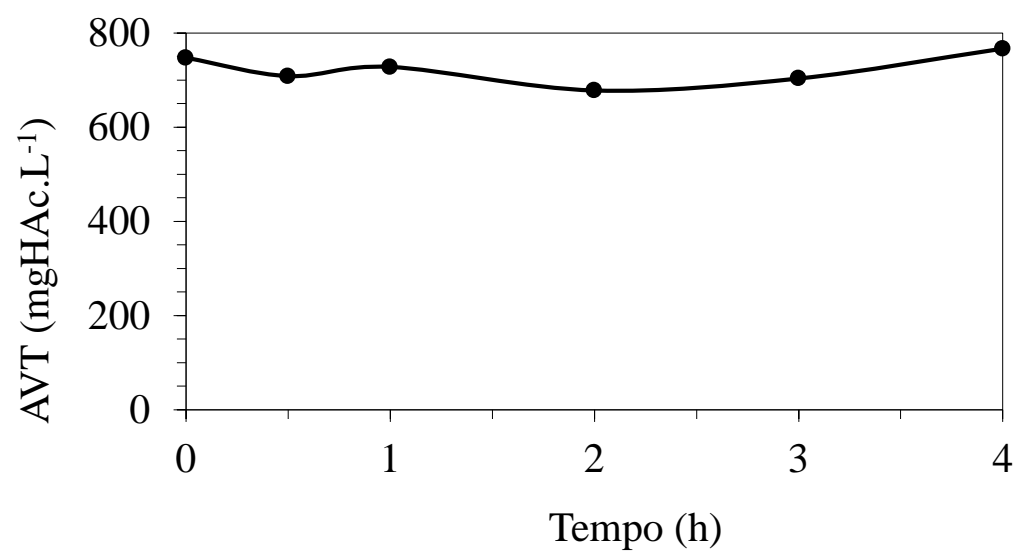

Figura 5.43 - Concentração de AVT durante o ciclo no ensaio 15

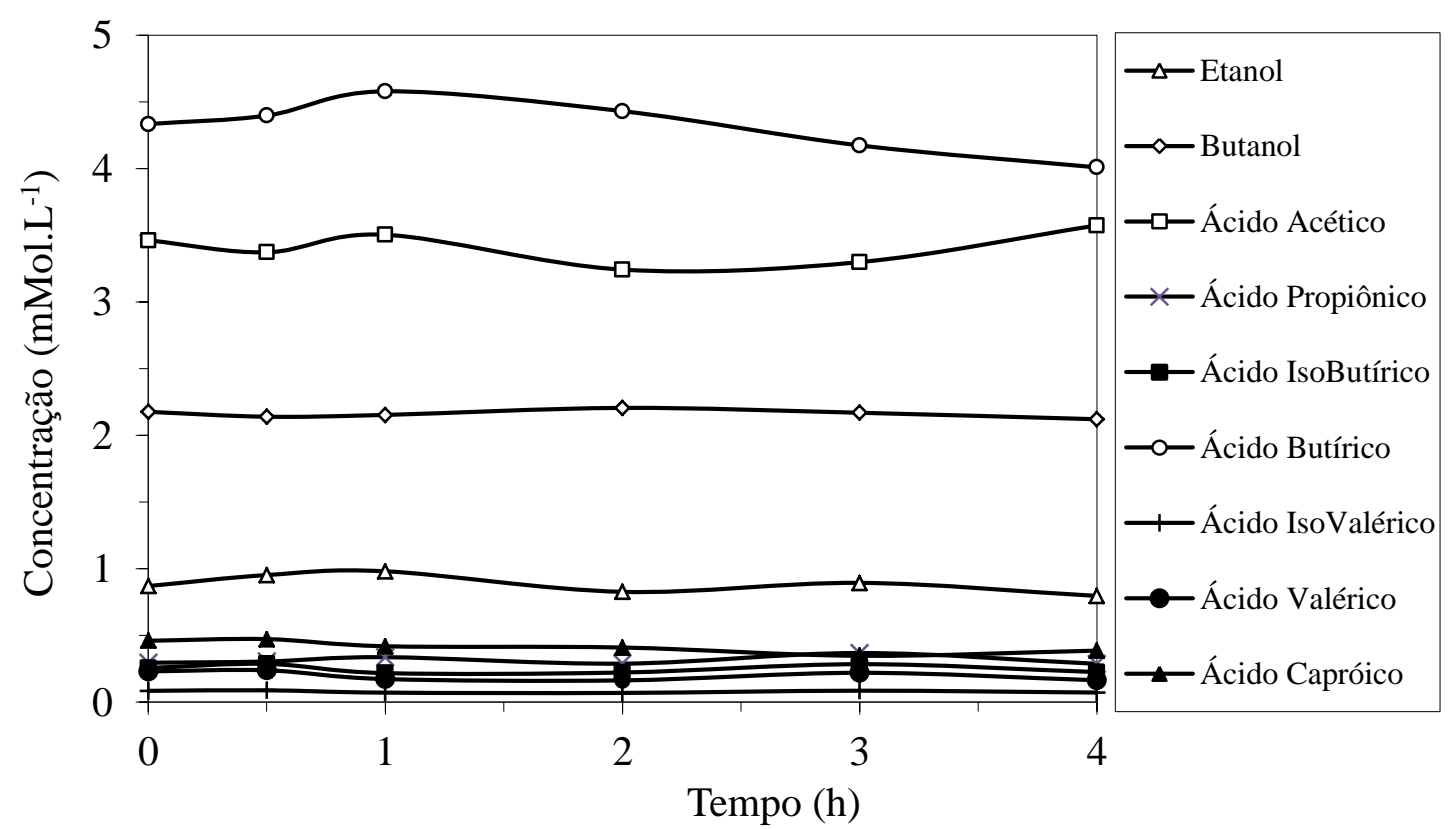

Figura 5.44 - Concentração dos compostos intermediários ao longo do ciclo no ensaio 15: $\square$ - ácido acético; $\Delta$ - etanol; o - ácido butírico; - - ácido isobutírico; $\boldsymbol{\Delta}$ - ácido capróico; - - ácido valérico; -x-ácido propiônico; $\diamond$ butanol; + ácido isovalérico

A produção volumétrica acumulada de biogás e os desvios padrões de cada um dos pontos podem ser observados na Figura 5.45 e o perfil das concentrações de cada um dos 
gases e suas respectivas porcentagens podem ser observadas na Figura 5.46. O aumento da carga orgânica, neste ensaio, favoreceu muito a produção de biogás e hidrogênio em relação ao ensaio anterior, a variação do volume de gás foi menor em relação à média e, ao final do ciclo, havia $53 \%$ de $\mathrm{H}_{2}, 34 \%$ de $\mathrm{CO}_{2}$ e $13 \%$ de $\mathrm{CH}_{4}$.

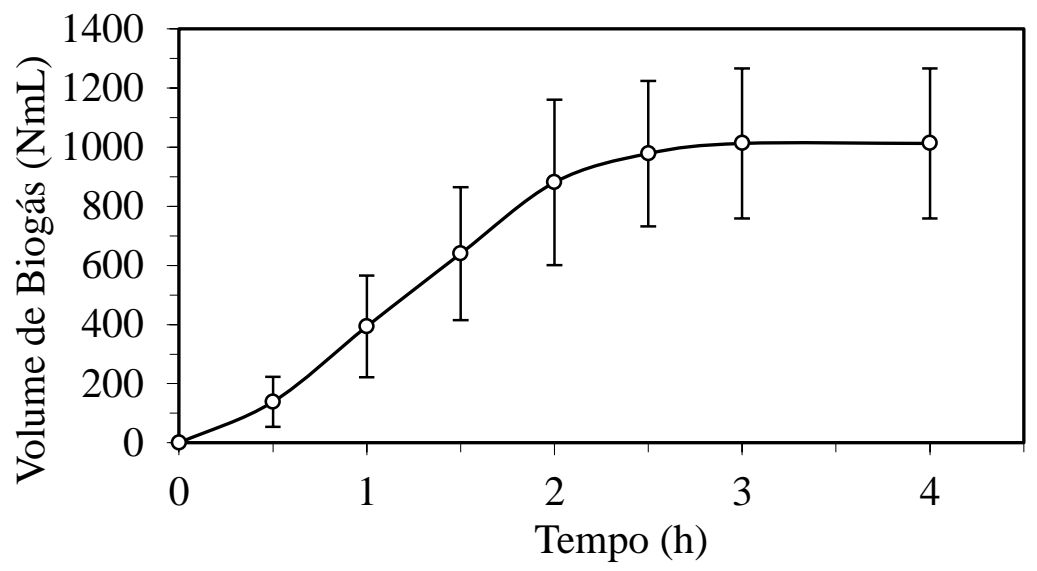

Figura 5.45 - Produção volumétrica média acumulada do biogás durante o ciclo no ensaio 15
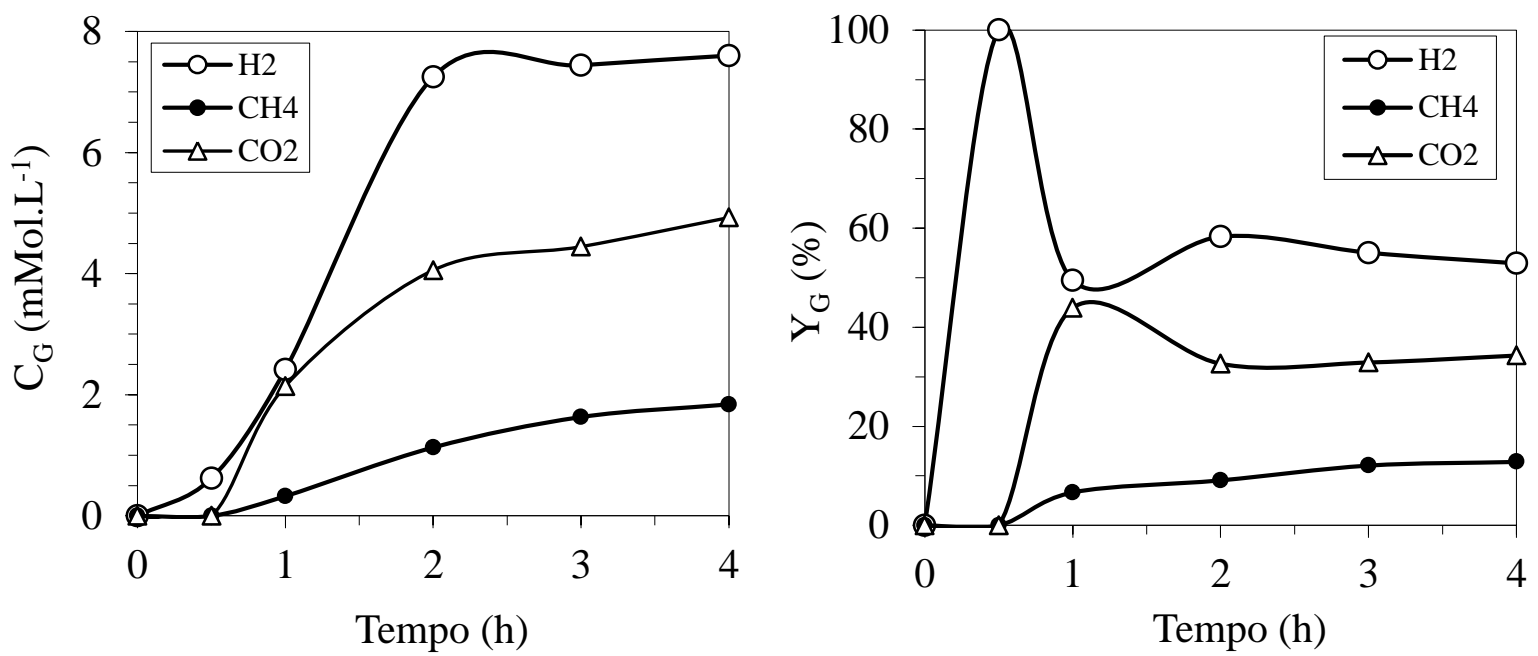

Figura 5.46 - Concentração dos compostos do biogás durante o ciclo e suas respectivas porcentagens no ensaio 15: $\odot-\mathrm{H}_{2} ; \bullet-\mathrm{CH}_{4} ; \Delta-\mathrm{CO}_{2}$ 


\subsubsection{Ensaio 16 (5000 $\mathrm{mgDQO}^{-1}$ e $4 \mathrm{~h}$ de tempo de ciclo)}

O valor nominal de COVA para o ensaio 16 foi de 12,9 gDQO. $\mathrm{L}^{-1} \cdot \mathrm{d}^{-1}$, a COVA real foi de 13,3 gDQO. $\mathrm{L}^{-1} \cdot \mathrm{d}^{-1}$ e a COVR atingida foi de 3,0 gDQO. $\mathrm{L}^{-1} \cdot \mathrm{d}^{-1}$. A Tabela 5.9 apresenta a média dos parâmetros monitorados; a biomassa de sólidos voláteis no reator totais durante o ensaio foi de 5,7 g, valor menor do que os encontrados nos ensaios anteriores com COVAs mais baixas.

Tabela 5.9 - Parâmetros médios monitorados no ensaio 16

\begin{tabular}{|c|c|c|c|c|c|c|c|c|c|c|}
\hline \multirow{2}{*}{\multicolumn{2}{|c|}{ Parâmetro }} & \multicolumn{9}{|c|}{16} \\
\hline & & \multicolumn{4}{|c|}{ Afluente } & \multicolumn{5}{|c|}{ Efluente } \\
\hline $\mathrm{C}_{\mathrm{ST}}$ & $\left(\mathrm{mgDQO} \cdot \mathrm{L}^{-1}\right)$ & 5018 & \pm & 304 & (7) & 4024 & \pm & 108 & & 6 \\
\hline $\mathrm{C}_{\mathrm{SF}}$ & $\left(\operatorname{mgDQO} . L^{-1}\right)$ & & - & & & 3880 & \pm & 191 & & $6)$ \\
\hline$\varepsilon_{\mathrm{ST}}$ & $(\%)$ & & - & & & 20 & \pm & 2 & & 6 \\
\hline$\varepsilon_{\mathrm{SF}}$ & $(\%)$ & & - & & & 23 & \pm & 4 & & 6 ) \\
\hline $\mathrm{pH}$ & (u) & 7,57 & \pm & 0,06 & ( 5 ) & 4,18 & \pm & 0,04 & & $6)$ \\
\hline AVT & $\left(\mathrm{mgHAc} . \mathrm{L}^{-1}\right)$ & 25 & \pm & 2 & ( 5 ) & 708 & \pm & 27 & ( & $6)$ \\
\hline AT & $\left(\mathrm{mgCaCO}{ }_{3} \cdot \mathrm{L}^{-1}\right)$ & 150 & \pm & 11 & ( 5 ) & 0 & \pm & 0 & ( & $6)$ \\
\hline $\mathrm{AP}$ & $\left(\mathrm{mgCaCO}_{3} \cdot \mathrm{L}^{-1}\right)$ & 121 & \pm & 10 & ( 5 ) & 0 & \pm & 0 & ( & 6 ) \\
\hline AI & $\left(\mathrm{mgCaCO}_{3} \cdot \mathrm{L}^{-1}\right)$ & 30 & \pm & 4 & ( 5 ) & 0 & \pm & 0 & ( & 6 ) \\
\hline $\mathrm{AB}$ & $\left(\mathrm{mgCaCO}{ }_{3} \cdot \mathrm{L}^{-1}\right)$ & 132 & \pm & 11 & ( 5 ) & 0 & \pm & 0 & & $6)$ \\
\hline $\mathrm{ST}$ & $\left(\mathrm{mg} \cdot \mathrm{L}^{-1}\right)$ & 549 & \pm & 48 & (3) & 1022 & \pm & 75 & ( & $4)$ \\
\hline SVT & $\left(\mathrm{mg} \cdot \mathrm{L}^{-1}\right)$ & 348 & \pm & 122 & (3) & 820 & \pm & 111 & ( & $4)$ \\
\hline SST & $\left(\mathrm{mg} \cdot \mathrm{L}^{-1}\right)$ & 23 & \pm & 36 & (3) & 55 & \pm & 16 & ( & $4)$ \\
\hline SSV & $\left(\mathrm{mg} \cdot \mathrm{L}^{-1}\right)$ & 11 & \pm & 13 & ( 3 ) & 41 & \pm & 27 & & $4 \quad)$ \\
\hline $\mathrm{M}_{\mathrm{SVT}}$ & (g) & & - & & & & 5 & 7 & & \\
\hline $\mathrm{Cx}$ & $\left(\mathrm{g} \cdot \mathrm{L}^{-1}\right)$ & & - & & & & 1 & 7 & & \\
\hline $\mathrm{Cx}$ & (g.gsuporte ${ }^{-1}$ ) & & - & & & & 0,0 & 047 & & \\
\hline $\mathrm{V}_{\mathrm{G}}$ & $(\mathrm{NmL})$ & & - & & & 1211 & & 183 & & 5 ) \\
\hline $\mathrm{V}_{\mathrm{H} 2}$ & $(\mathrm{NmL})$ & & - & & & 848 & & 140 & & $5)$ \\
\hline COVA & $\left(\mathrm{gDQO} \cdot \mathrm{L}^{-1} \cdot \mathrm{d}^{-1}\right)$ & & 13 & & & & - & - & & \\
\hline COVR & $\left(\mathrm{gDQO} \cdot \mathrm{L}^{-1} \cdot \mathrm{d}^{-1}\right)$ & & - & & & & 3 & 0 & & \\
\hline COEA & $\left(\mathrm{gDQO} \cdot \mathrm{gSVT}^{-1} \cdot \mathrm{d}^{-1}\right)$ & & 7 , & & & & - & - & & \\
\hline COER & $\left(\right.$ gDQO.gSVT $\left.{ }^{-1} \cdot d^{-1}\right)$ & & - & & & & 1 & 8 & & \\
\hline $\mathrm{n}_{\mathrm{H} 2}$ & $\left(\mathrm{molH}_{2} \cdot \mathrm{d}^{-1}\right)$ & & - & & & & 0 , & 23 & & \\
\hline PrM & $\left(\mathrm{molH}_{2} \cdot \mathrm{m}^{-3} \cdot \mathrm{d}^{-1}\right)$ & & - & & & & 66 & 7 & & \\
\hline PrME & $\left(\mathrm{molH}_{2} \cdot \mathrm{kgSVT}^{-1} \cdot \mathrm{d}^{-1}\right)$ & & - & & & & 39 &, 7 & & \\
\hline RMCA & $\left(\mathrm{molH}_{2} \cdot \mathrm{kgDQO}^{-1}\right)$ & & - & & & & 5 & 0 & & \\
\hline RMCR & $\left(\mathrm{molH}_{2} \cdot \mathrm{kgDQO}^{-1}\right)$ & & - & & & & 22 & 2 & & \\
\hline $\mathrm{V}_{\mathrm{A}}$ & (L) & 1,50 & \pm & 0,01 & ( 5 ) & & - & - & & \\
\hline $\mathrm{V}_{\mathrm{R}}$ & (L) & & - & & & & 3 & 4 & & \\
\hline
\end{tabular}

(*) Entre parêntese o número de amostras considerado no cálculo da média 
O monitoramento diário apresentou média de concentração afluente não filtrada de $5018 \mathrm{mgDQO} . \mathrm{L}^{-1}$, efluente não filtrada $4029 \mathrm{mgDQO}^{-1}$ e de efluente filtrada de 3880 mgDQO.L - $^{-1}$ (Figura 5.47), com remoção média para amostras não filtradas de $20 \%$ e para amostras filtradas de 23\% (Figura 5.48).

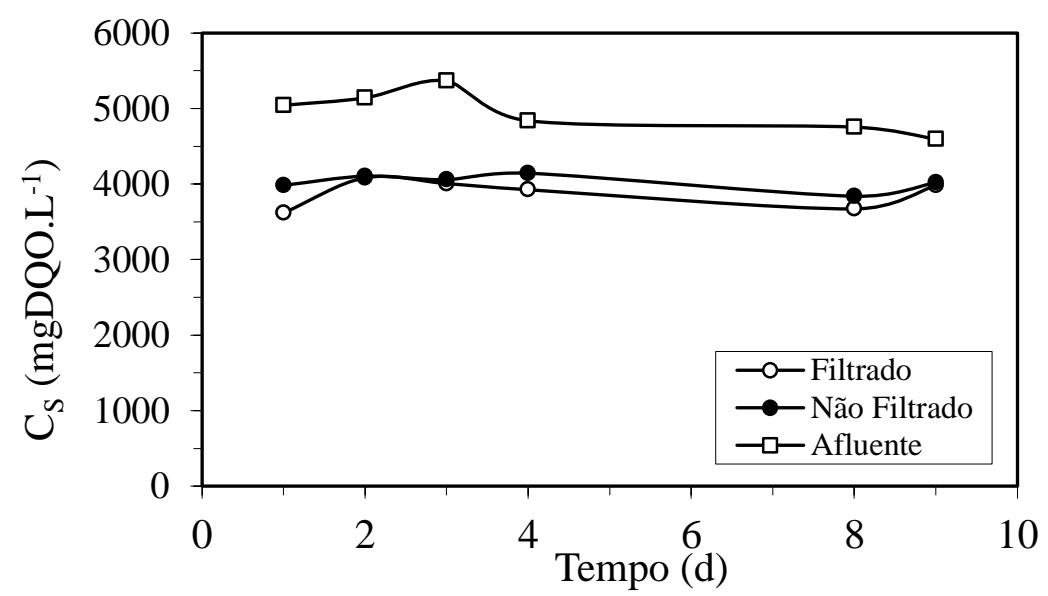

Figura 5.47 - Concentração de matéria orgânica na forma de DQO no ensaio 16: $\square$ - afluente amostras não filtradas; • - efluente amostras não filtradas; ○ - efluente amostras filtradas

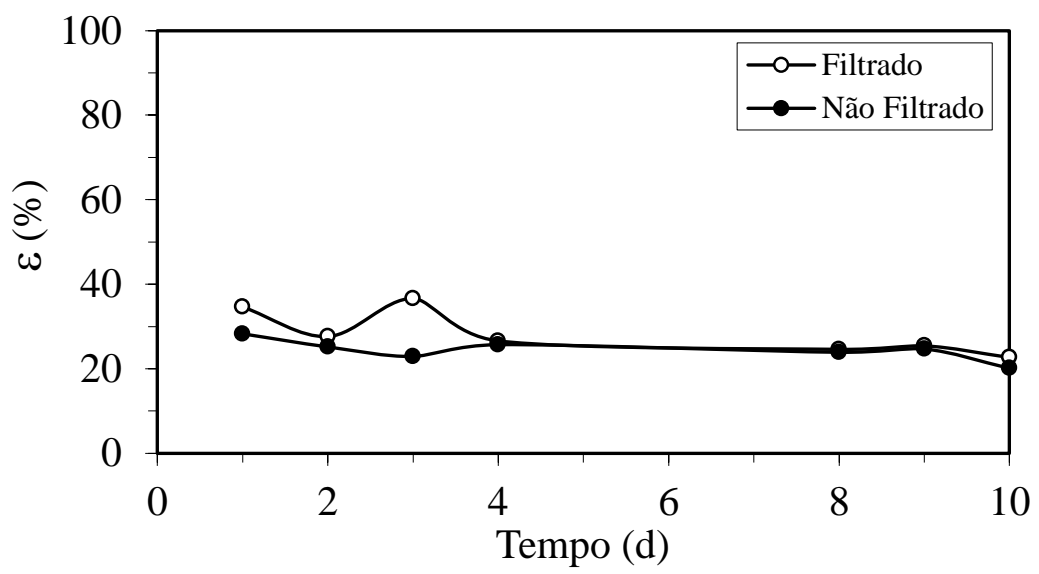

Figura 5.48 - Eficiência de remoção de matéria orgânica na forma de DQO no ensaio 16: • - amostras não filtradas; $\bigcirc-$ amostras filtradas

As Figuras 5.49, 5.50 e 5.51 apresentam os dados obtidos de $\mathrm{pH}$, alcalinidade total e ácidos voláteis totais, respectivamente. A média do $\mathrm{pH}$ afluente foi de 7,57 e do efluente de 4,18. A alcalinidade total afluente teve média de $150 \mathrm{mgCaCO} \cdot \mathrm{L}^{-1}$ sendo consumida 
totalmente no efluente. A média de AVT do afluente foi de 255 mgHAc. $\mathrm{L}^{-1}$ e a média de AVT do efluente de $708 \mathrm{mgHAc} . \mathrm{L}^{-1}$, processo mais acidificado do que o ensaio anterior.

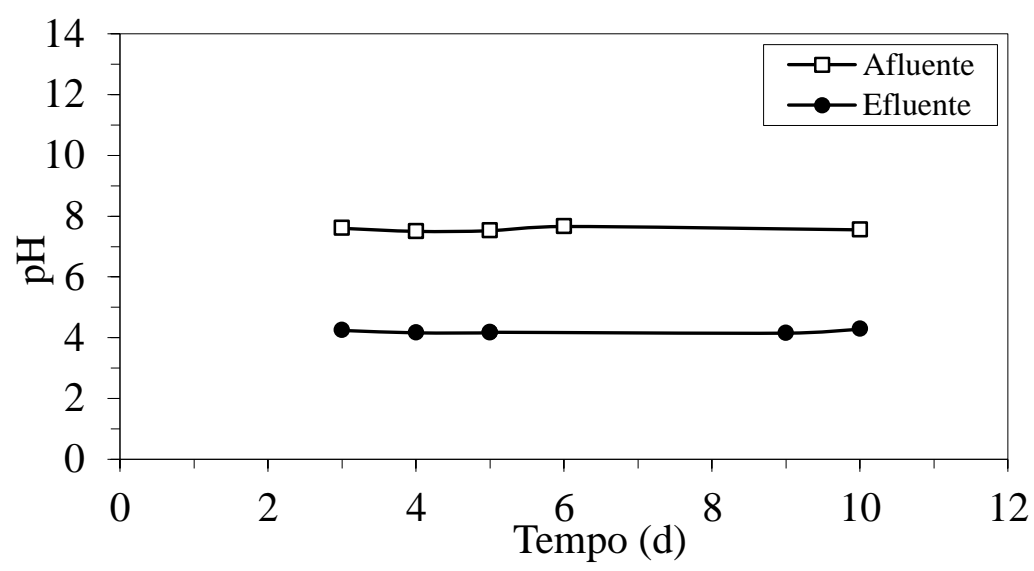

Figura 5.49 - Valores de pH no ensaio 16: $\square-$ afluente; • - efluente

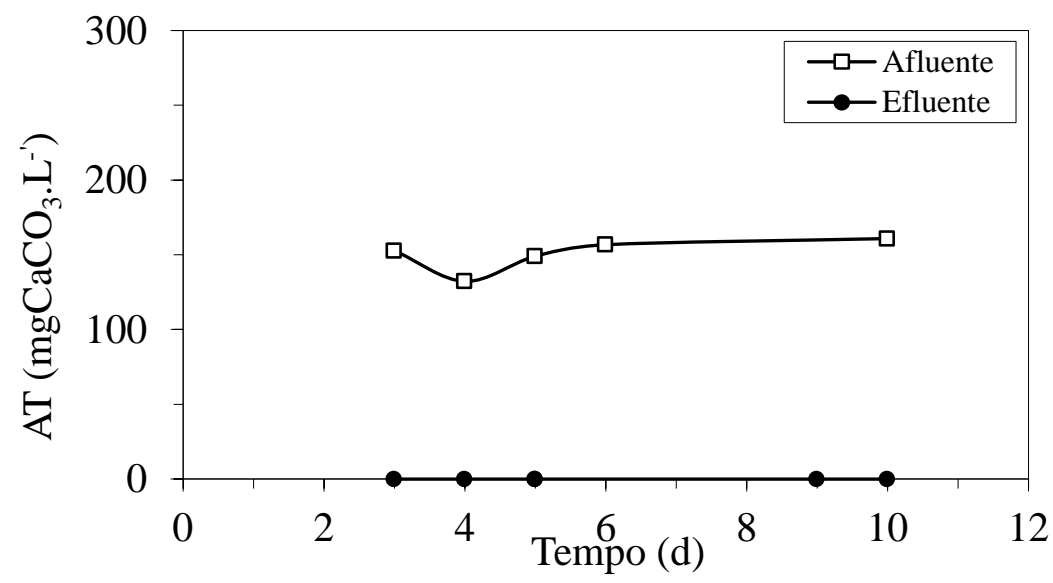

Figura 5.50 - Valores de alcalinidade total (AT) no ensaio 16: $\square$-afluente; $\bullet-$ efluente

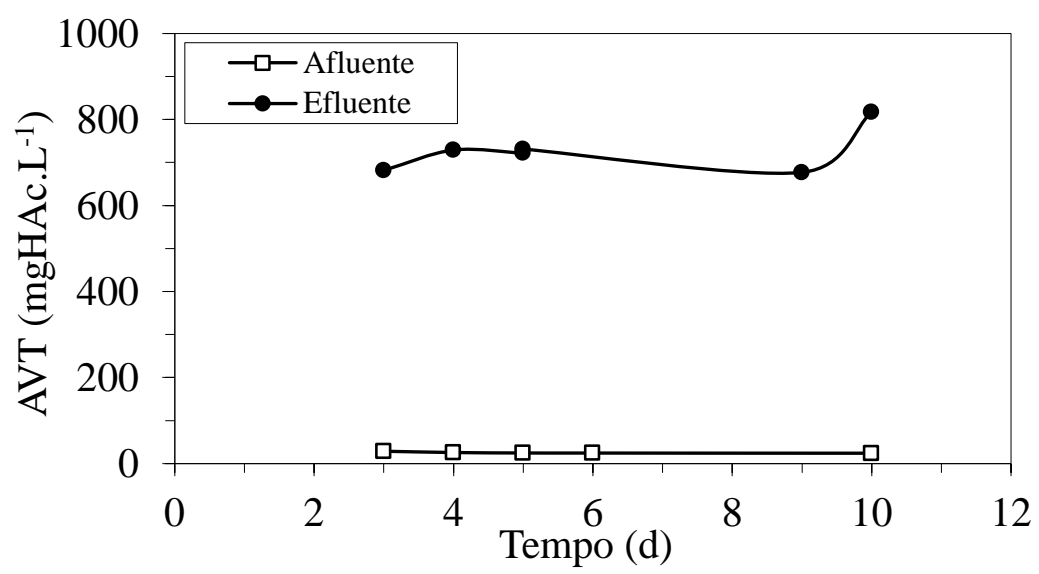

Figura 5.51 - Valores de ácidos voláteis totais (AVT) no ensaio 16: $\square$-afluente; $\bullet$ - efluente 
A produção de biogás por ciclo, em aspecto quantitativo, pode ser observada pela Figura 5.52, com média de $1211 \mathrm{~mL}$ de biogás e $848 \mathrm{~mL}$ de hidrogênio, o que significa uma produção média menor do que no ensaio 15, mas mais estável. A Figura 5.53 apresenta a distribuição dos gases que compõem o biogás no final do ciclo.

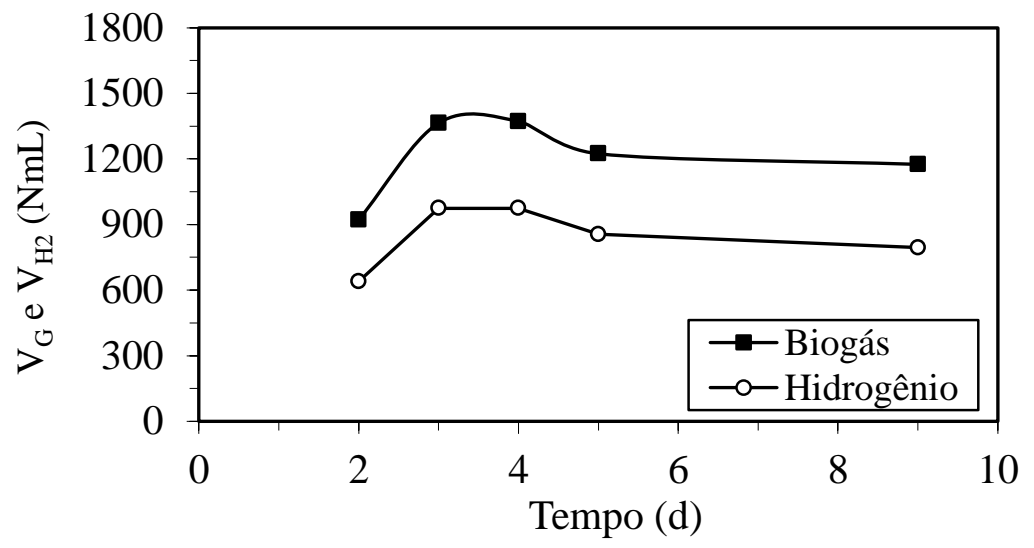

Figura 5.52 - Volume de biogás $\left(\mathrm{V}_{\mathrm{G}}\right)$ e de hidrogênio $\left(\mathrm{V}_{\mathrm{H} 2}\right)$ na CNTP no ensaio 16: - -Biogás; o - Hidrogênio

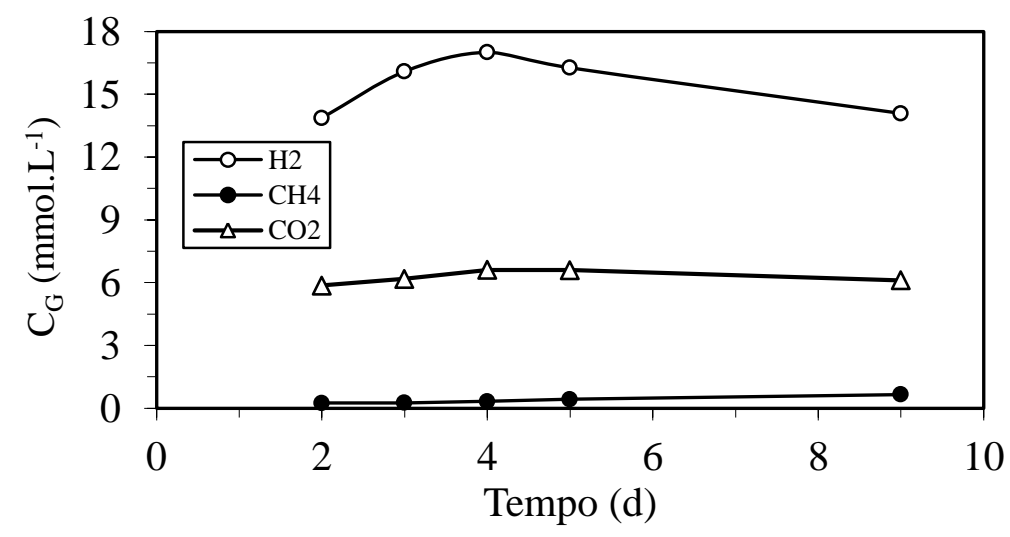

Figura 5.53 - Concentrações dos componentes do biogás no final do ciclo no ensaio 16: $\bigcirc-\mathrm{H}_{2}$; $\bullet-\mathrm{CH}_{4} ; \Delta-\mathrm{CO}_{2}$

A Figura 5.54 apresenta o perfil de DQO durante o ciclo. A máxima eficiência de remoção atingida durante o ciclo é de $12 \%$. 


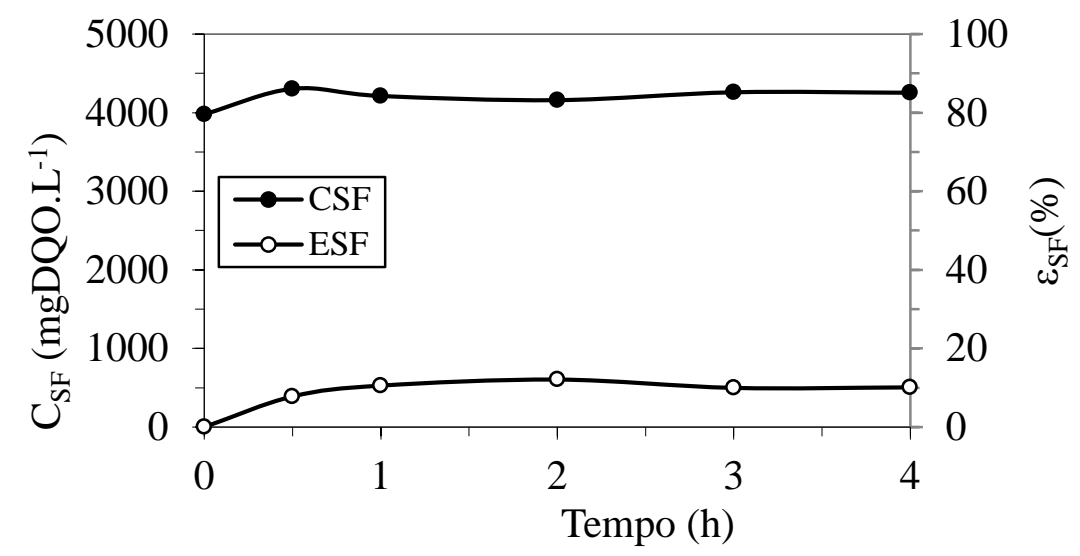

Figura 5.54 - Concentração e eficiência de degradação de matéria orgânica durante o ciclo ensaio 16: - $-\mathrm{C}_{\mathrm{SF}} ; \circ-\varepsilon_{\mathrm{SF}}$

As Figuras 5.55 e 5.56 apresentam os perfis de $\mathrm{pH}$ e alcalinidade total ao longo do ciclo. $\mathrm{O}$ pH permanece constante ao longo do ciclo por volta de 4,2 devido à presença da alcalinidade que é fornecida gradualmente através do afluente e é consumida totalmente pelo processo.

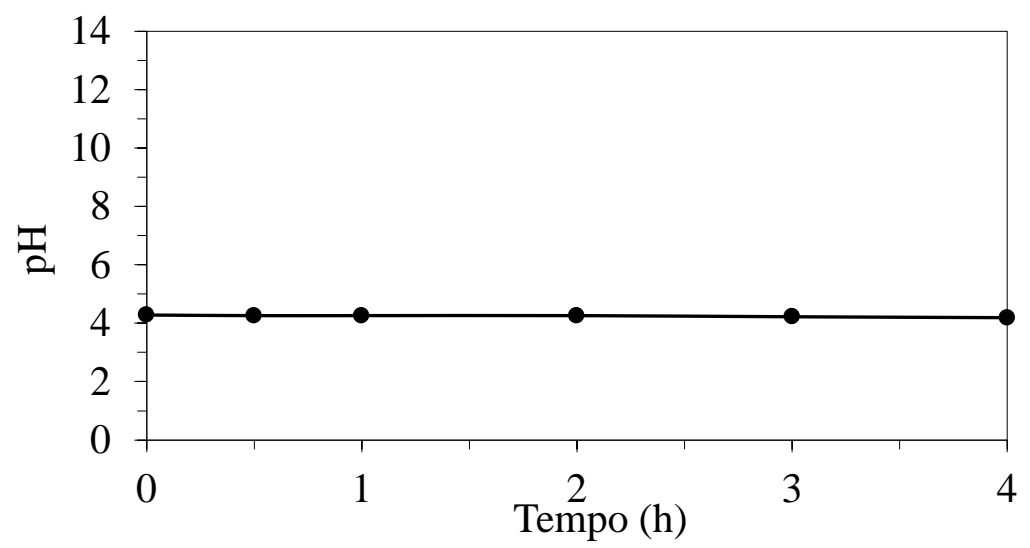

Figura 5.55 - Valores de $\mathrm{pH}$ durante o ciclo no ensaio 16

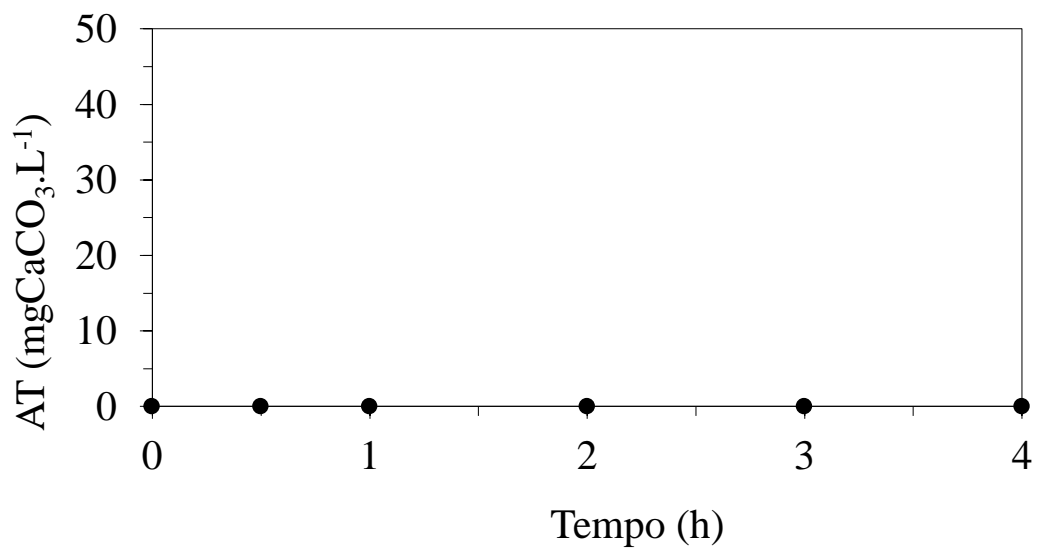

Figura 5.56 - Concentração de alcalinidade total durante o ciclo no ensaio 16 
Os perfis de ácidos voláteis totais por titulação e dos compostos intermediários do metabolismo são apresentados nas Figuras 5.57 e 5.58, tanto os ácidos quanto os solventes apresentam poucas variações durante o perfil. Novamente houve predomínio do ácido acético e do ácido butírico, seguidos pelo butanol.

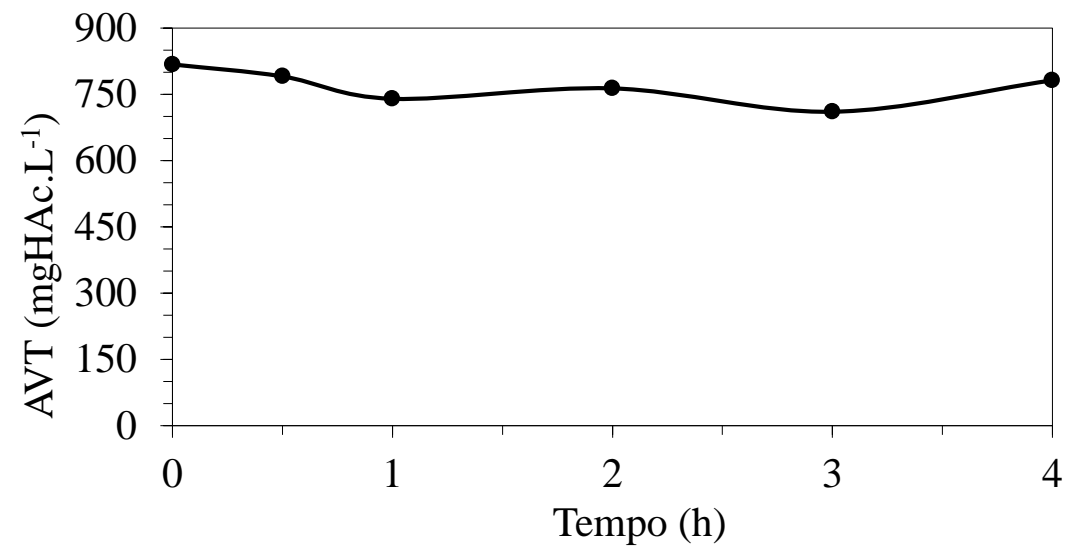

Figura 5.57 - Concentração de AVT durante o ciclo no ensaio 16

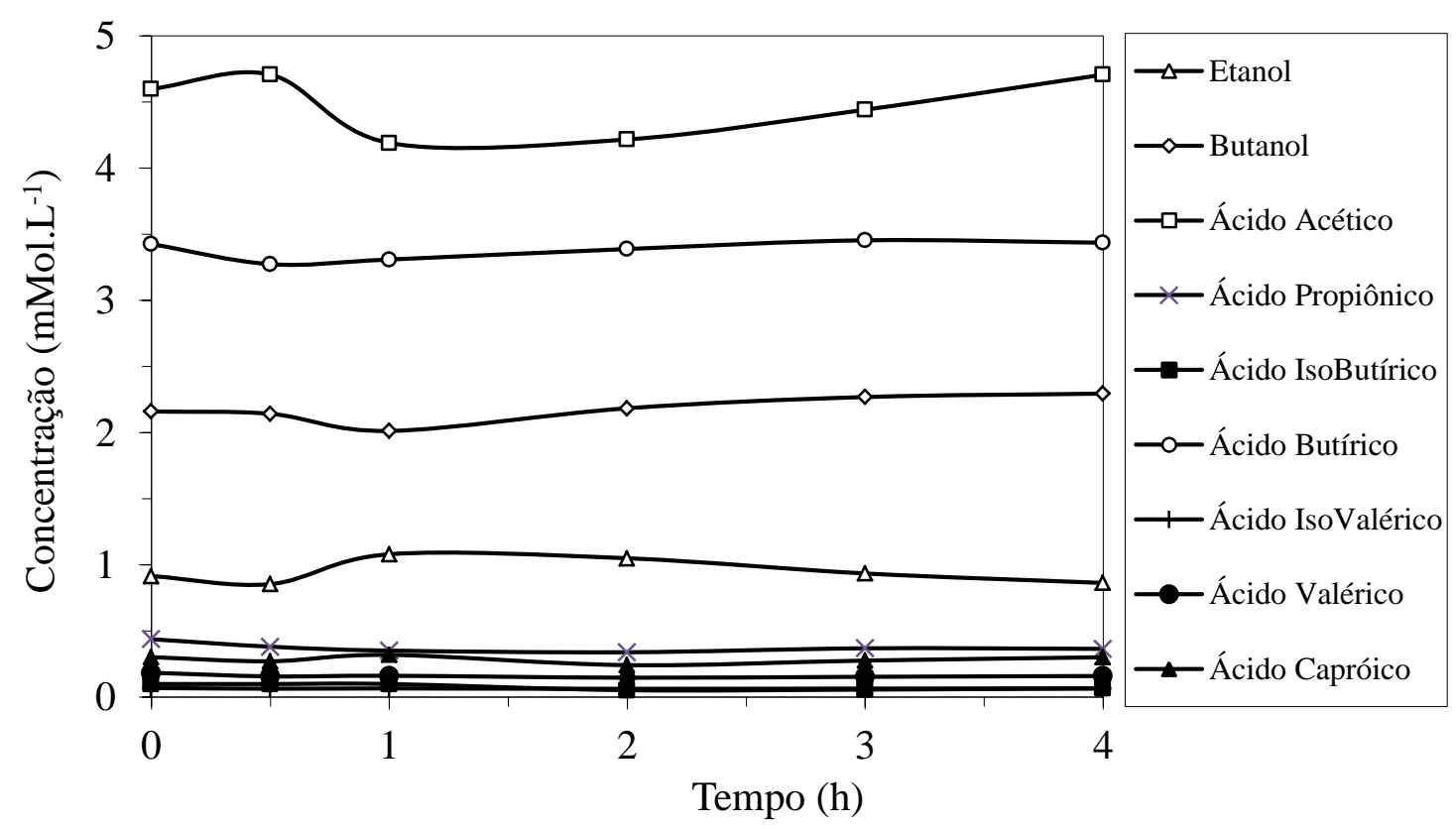

Figura 5.58 - Concentração dos compostos intermediários ao longo do ciclo no ensaio 16: $\square$ - ácido acético; $\Delta$ - etanol; ○ - ácido butírico; - ácido isobutírico; $\boldsymbol{\Delta}$ - ácido capróico; • ácido valérico; -x-ácido propiônico; $\diamond$ butanol; + ácido isovalérico 
A produção volumétrica acumulada de biogás e os desvios padrões de cada um dos pontos podem ser observados na Figura 5.59 e o perfil das concentrações de cada um dos gases e suas respectivas porcentagens podem ser observados na Figura 5.60. Houve pouca variação no volume de biogás medido ao final do ciclo com uma produção muito estável; ao final do ciclo, tinha-se $68 \%$ de $\mathrm{H}_{2}, 29 \%$ de $\mathrm{CO}_{2}$ e $3 \%$ de $\mathrm{CH}_{4}$, representando uma excelente qualidade de biogás, já que há uma grande quantidade de hidrogênio e a uma boa inibição da rota metanogênica.

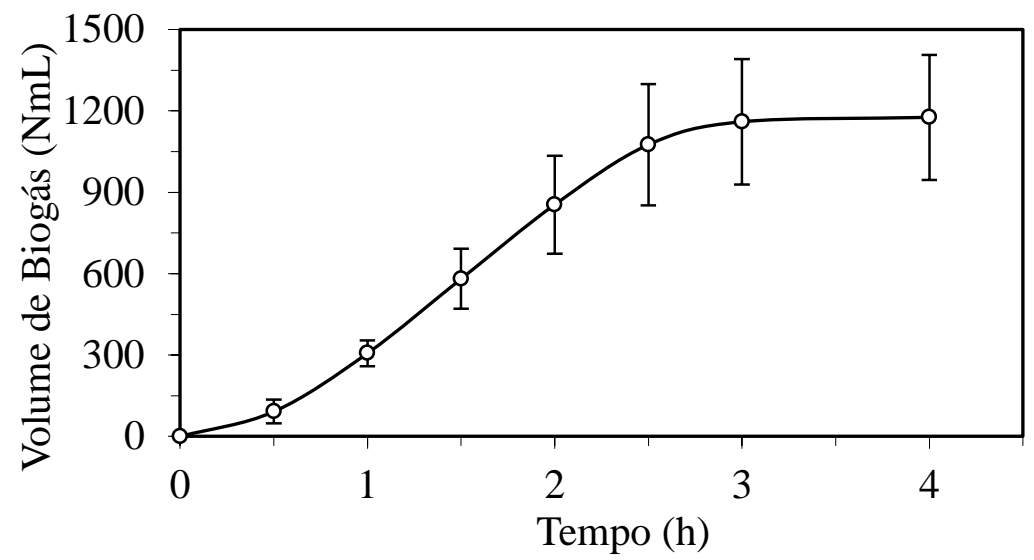

Figura 5.59 - Produção volumétrica média acumulada do biogás durante o ciclo no ensaio 16
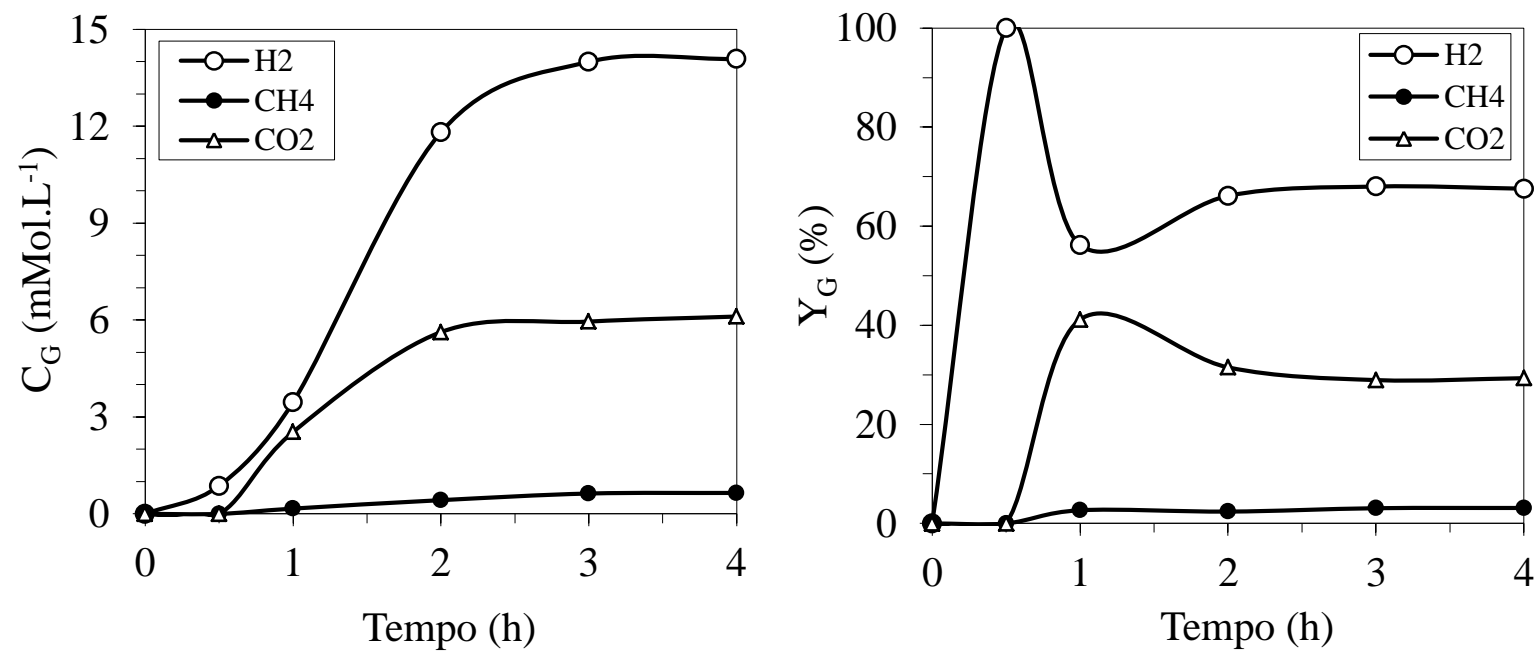

Figura 5.60 - Concentração dos compostos do biogás durante o ciclo e suas respectivas porcentagens no ensaio 16: $\circ-\mathrm{H}_{2} ; \bullet-\mathrm{CH}_{4} ; \Delta-\mathrm{CO}_{2}$ 


\subsubsection{Ensaio 17 (3000 mgDQO.L $\mathrm{L}^{-1}$ e 3 h de tempo de ciclo)}

O valor nominal de COVA para o ensaio 17 foi de $10,3 \mathrm{gDQO} \cdot \mathrm{L}^{-1} \cdot \mathrm{d}^{-1}$, a COVA real foi de 10,6 gDQO. $\mathrm{L}^{-1} \cdot \mathrm{d}^{-1}$ e a COVR atingida foi de 3,0 gDQO. $\mathrm{L}^{-1} \cdot \mathrm{d}^{-1}$. A Tabela 5.10 apresenta a média dos parâmetros monitorados; a biomassa de sólidos voláteis totais no reator durante o ensaio foi de 7,8 g, o que representa um acréscimo em relação ao ensaio 14 (ensaio que foi realizado com a mesma concentração de afluente $-4000 \mathrm{mgDQO} . \mathrm{L}^{-1}$ )

Tabela 5.10 - Parâmetros médios monitorados no ensaio 17

\begin{tabular}{|c|c|c|c|c|c|c|c|c|c|}
\hline \multirow{2}{*}{\multicolumn{2}{|c|}{ Parâmetro }} & \multicolumn{8}{|c|}{17} \\
\hline & & \multicolumn{4}{|c|}{ Afluente } & \multicolumn{4}{|c|}{ Efluente } \\
\hline $\mathrm{C}_{\mathrm{ST}}$ & $\left(\mathrm{mgDQO} \cdot \mathrm{L}^{-1}\right)$ & 3072 & \pm & 190 & $(8)$ & 2421 & \pm & 158 & $(7)$ \\
\hline $\mathrm{C}_{\mathrm{SF}}$ & $\left(\operatorname{mgDQO} \cdot L^{-1}\right)$ & & - & & & 2232 & \pm & 194 & ( 7 ) \\
\hline$\varepsilon_{\mathrm{ST}}$ & $(\%)$ & & - & & & 21 & \pm & 5 & ( 7 ) \\
\hline$\varepsilon_{\mathrm{SF}}$ & $(\%)$ & & - & & & 27 & \pm & 6 & $(7)$ \\
\hline $\mathrm{pH}$ & (u) & 7,67 & \pm & 0,07 & ( 6 ) & 4,66 & \pm & 0,04 & ( 7 ) \\
\hline AVT & $\left(\mathrm{mgHAc} . \mathrm{L}^{-1}\right)$ & 23 & \pm & 4 & ( 6 ) & 513 & \pm & 33 & $(7)$ \\
\hline AT & $\left(\mathrm{mgCaCO}_{3} \cdot \mathrm{L}^{-1}\right)$ & 151 & \pm & 9 & $(6)$ & 74 & \pm & 12 & $(7)$ \\
\hline AP & $\left(\mathrm{mgCaCO}_{3} \cdot \mathrm{L}^{-1}\right)$ & 128 & \pm & 7 & ( 6 ) & 0 & \pm & 0 & $(7)$ \\
\hline $\mathrm{AI}$ & $\left(\mathrm{mgCaCO}_{3} \cdot \mathrm{L}^{-1}\right)$ & 23 & \pm & 8 & ( 6 ) & 74 & \pm & 12 & $(7)$ \\
\hline $\mathrm{AB}$ & $\left(\mathrm{mgCaCO}_{3} \cdot \mathrm{L}^{-1}\right)$ & 134 & \pm & 11 & ( 6 ) & 0 & \pm & 0 & $(7)$ \\
\hline ST & $\left(\mathrm{mg} . \mathrm{L}^{-1}\right)$ & 411 & \pm & 74 & ( 3 ) & 550 & \pm & 113 & $(4)$ \\
\hline SVT & $\left(\mathrm{mg} \cdot \mathrm{L}^{-1}\right)$ & 221 & \pm & 10 & (3) & 389 & \pm & 84 & $(4)$ \\
\hline SST & $\left(\mathrm{mg} . \mathrm{L}^{-1}\right)$ & 23 & \pm & 10 & ( 3 ) & 66 & \pm & 16 & ( 4 ) \\
\hline SSV & $\left(m g . L^{-1}\right)$ & 5 & \pm & 5 & ( 3 ) & 86 & \pm & 88 & $(4)$ \\
\hline $\mathrm{M}_{\mathrm{SVT}}$ & (g) & \multicolumn{4}{|c|}{-} & \multicolumn{4}{|c|}{7,8} \\
\hline $\mathrm{Cx}$ & $\left(\mathrm{g} . \mathrm{L}^{-1}\right)$ & \multicolumn{4}{|c|}{ - } & \multicolumn{4}{|c|}{2,3} \\
\hline $\mathrm{Cx}^{\prime}$ & (g.gsuporte ${ }^{-1}$ ) & \multicolumn{4}{|c|}{ - } & \multicolumn{4}{|c|}{0,0062} \\
\hline $\mathrm{V}_{\mathrm{G}}$ & $(\mathrm{NmL})$ & \multicolumn{4}{|c|}{-} & 643 & \pm & 197 & $(7)$ \\
\hline $\mathrm{V}_{\mathrm{H} 2}$ & $(\mathrm{NmL})$ & \multicolumn{4}{|c|}{-} & 275 & \pm & 50 & $(7)$ \\
\hline COVA & $\left(\mathrm{gDQO} \cdot \mathrm{L}^{-1} \cdot \mathrm{d}^{-1}\right)$ & \multicolumn{4}{|c|}{10,6} & \multicolumn{4}{|c|}{ - } \\
\hline COVR & $\left(\right.$ gDQO.L $\left.L^{-1} \cdot d^{-1}\right)$ & \multicolumn{4}{|c|}{ - } & \multicolumn{4}{|c|}{2,9} \\
\hline COEA & $\left(\right.$ gDQO.gSVT $\left.{ }^{-1} \cdot \mathrm{d}^{-1}\right)$ & \multicolumn{4}{|c|}{4,6} & \multicolumn{4}{|c|}{ - } \\
\hline COER & $\left(\right.$ gDQO.gSVT $\left.{ }^{-1} \cdot \mathrm{d}^{-1}\right)$ & \multicolumn{4}{|c|}{ - } & \multicolumn{4}{|c|}{1,3} \\
\hline $\mathrm{n}_{\mathrm{H} 2}$ & $\left(\mathrm{molH}_{2} \cdot \mathrm{d}^{-1}\right)$ & \multicolumn{4}{|c|}{-} & \multicolumn{4}{|c|}{0,10} \\
\hline PrM & $\left(\mathrm{molH}_{2} \cdot \mathrm{m}^{-3} \cdot \mathrm{d}^{-1}\right)$ & \multicolumn{4}{|c|}{-} & \multicolumn{4}{|c|}{28,9} \\
\hline PrME & $\left(\mathrm{molH}_{2} \cdot \mathrm{kgSVT}^{-1} \cdot \mathrm{d}^{-1}\right)$ & \multicolumn{4}{|c|}{ - } & \multicolumn{4}{|c|}{12,6} \\
\hline RMCA & $\left(\mathrm{molH}_{2} \cdot \mathrm{kgDQO}^{-1}\right)$ & \multicolumn{4}{|c|}{ - } & \multicolumn{4}{|c|}{2,7} \\
\hline RMCR & $\left(\mathrm{molH}_{2} \cdot \mathrm{kgDQO}^{-1}\right)$ & & - & & & & &, 0 & \\
\hline $\mathrm{V}_{\mathrm{A}}$ & (L) & 1,46 & & 0,07 & ( 6 ) & & & - & \\
\hline $\mathrm{V}_{\mathrm{R}}$ & (L) & & - & & & & & 4 & \\
\hline
\end{tabular}

(*) Entre parêntese o número de amostras considerado no cálculo da média 
A concentração média afluente não filtrada foi de $3072 \mathrm{mgDQO} . \mathrm{L}^{-1}$, efluente não filtrada $2421 \mathrm{mgDQO} . \mathrm{L}^{-1}$ e de efluente filtrada de $2232 \mathrm{mgDQO}^{-1}$ (Figura 5.61), com remoção média para amostras não filtradas de $21 \%$ e para amostras filtradas de $27 \%$ (Figura 5.63).

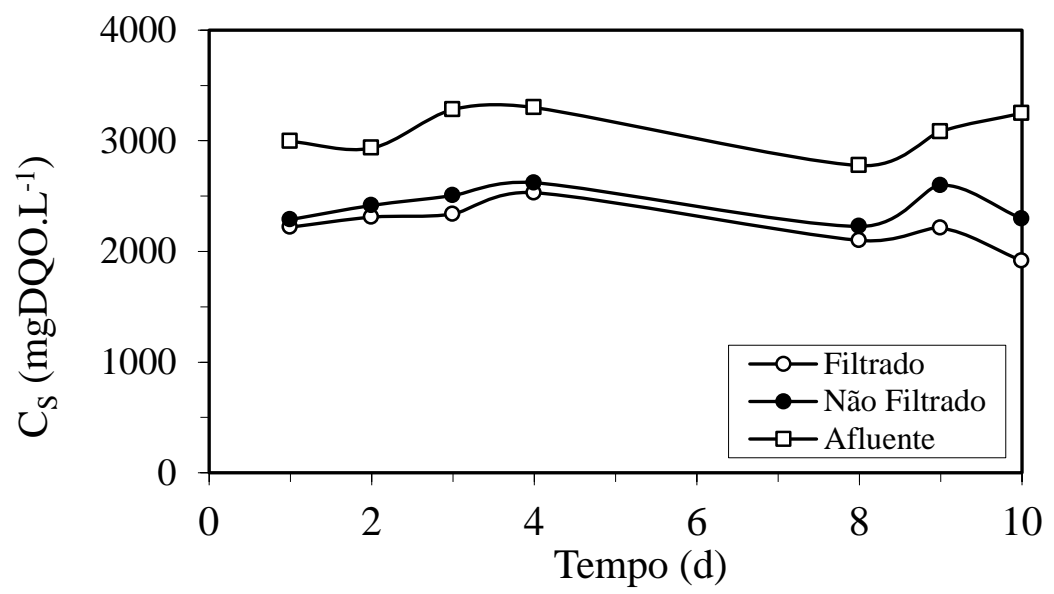

Figura 5.61 - Concentração de matéria orgânica na forma de DQO no ensaio 17: $\square$ - afluente amostras não filtradas; $\bullet$ - efluente amostras não filtradas; $\bigcirc-$ efluente amostras filtradas

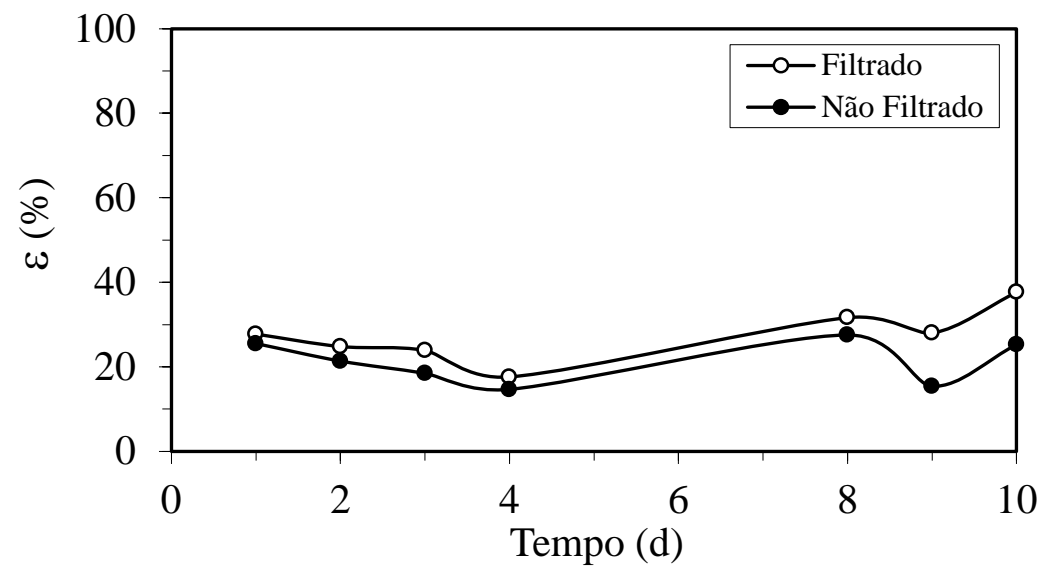

Figura 5.62 - Eficiência de remoção de matéria orgânica na forma de DQO no ensaio 17: • - amostras não filtradas; $\bigcirc-$ amostras filtradas

As Figuras 5.63, 5.64 e 5.65 apresentam os dados obtidos de $\mathrm{pH}$, alcalinidade total e ácidos voláteis totais, respectivamente. A média do $\mathrm{pH}$ afluente foi de 7,67 e do efluente de 4,66. A alcalinidade total afluente teve média de $151 \mathrm{mgCaCO}_{3} \cdot \mathrm{L}^{-1}$ sendo consumida e saindo no efluente com $74 \mathrm{mgCaCO}_{3} \cdot \mathrm{L}^{-1}$. A média de AVT do afluente foi de $23 \mathrm{mgHAc} \cdot \mathrm{L}^{-1}$ e a 
média de AVT do efluente de 513 mgHAc. $\mathrm{L}^{-1}$, a diminuição do tempo de ciclo do sistema resultou em uma acidificação maior do que a atingida no ensaio 14.

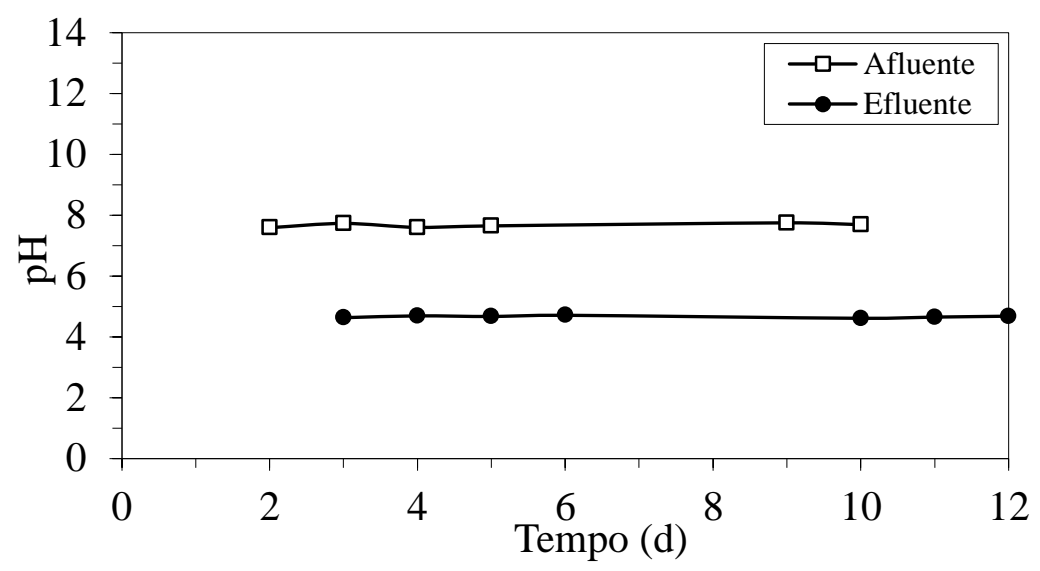

Figura 5.63 - Valores de pH no ensaio 17: $\square-$ afluente; $\bullet$ - efluente

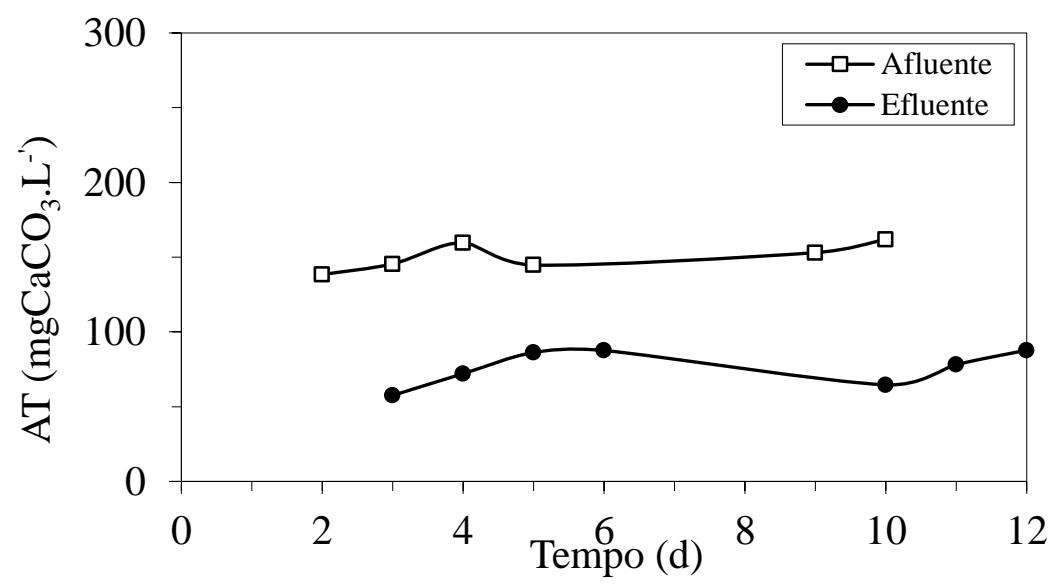

Figura 5.64 - Valores de alcalinidade total (AT) no ensaio 17: $\square$-afluente; $\bullet$ - efluente

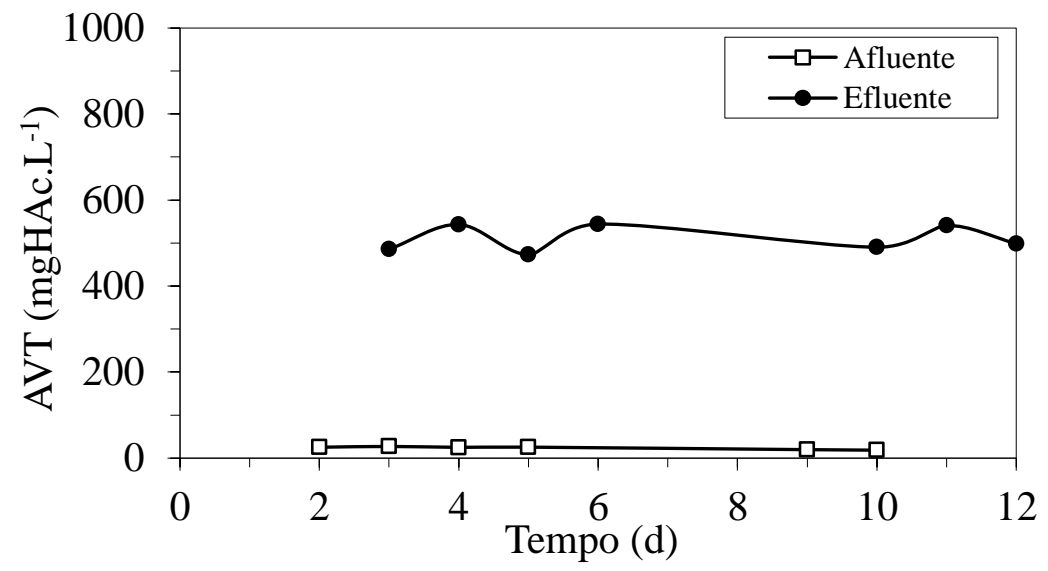

Figura 5.65 - Valores de ácidos voláteis totais (AVT) no ensaio 17: $\square$-afluente; $\bullet$ - efluente 106 
A produção de biogás por ciclo, em aspecto quantitativo, pode ser observada pela Figura 5.66, com média de $643 \mathrm{~mL}$ de biogás e $275 \mathrm{~mL}$ de hidrogênio, a diminuição do tempo de ciclo favoreceu a produção de hidrogênio e biogás quando comparado ao ensaio 14. A Figura 5.67 apresenta a distribuição dos gases que compõem o biogás no final do ciclo.

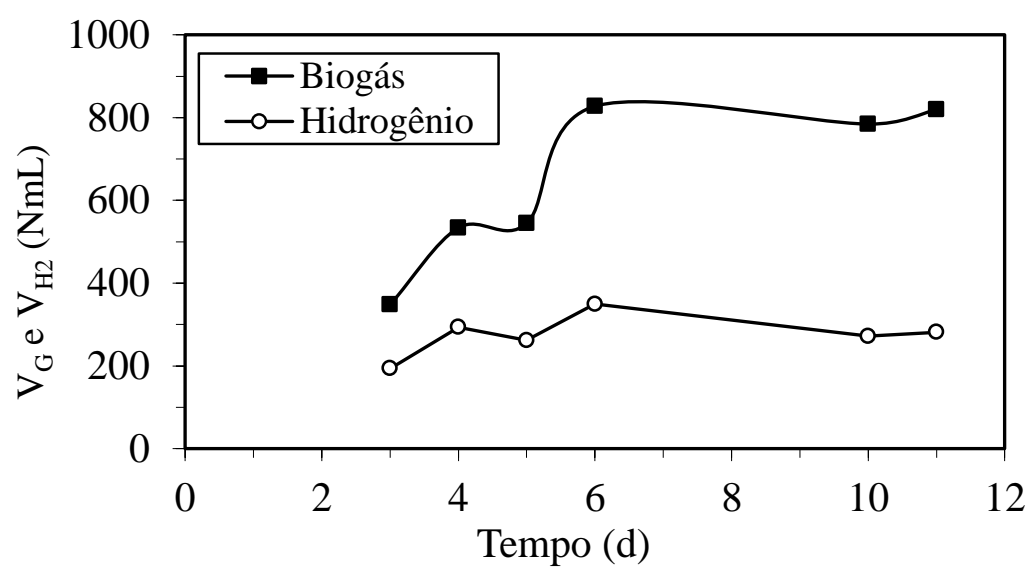

Figura 5.66 - Volume de biogás $\left(\mathrm{V}_{\mathrm{G}}\right)$ e de hidrogênio $\left(\mathrm{V}_{\mathrm{H} 2}\right)$ na CNTP no ensaio 17: a -Biogás; $\circ$ - Hidrogênio

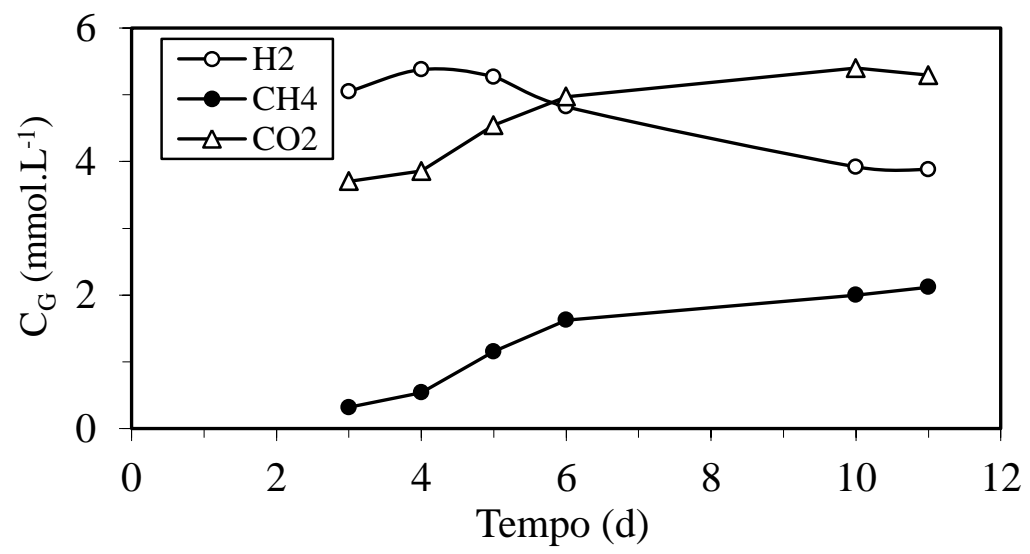

Figura 5.67 - Concentrações dos componentes do biogás no final do ciclo no ensaio 17: $\bigcirc-\mathrm{H}_{2}$; $\bullet-\mathrm{CH}_{4} ; \Delta-\mathrm{CO}_{2}$

A Figura 5.68 apresenta o perfil de DQO durante o ciclo. A máxima eficiência de remoção atingida durante o ciclo foi de $35 \%$. 


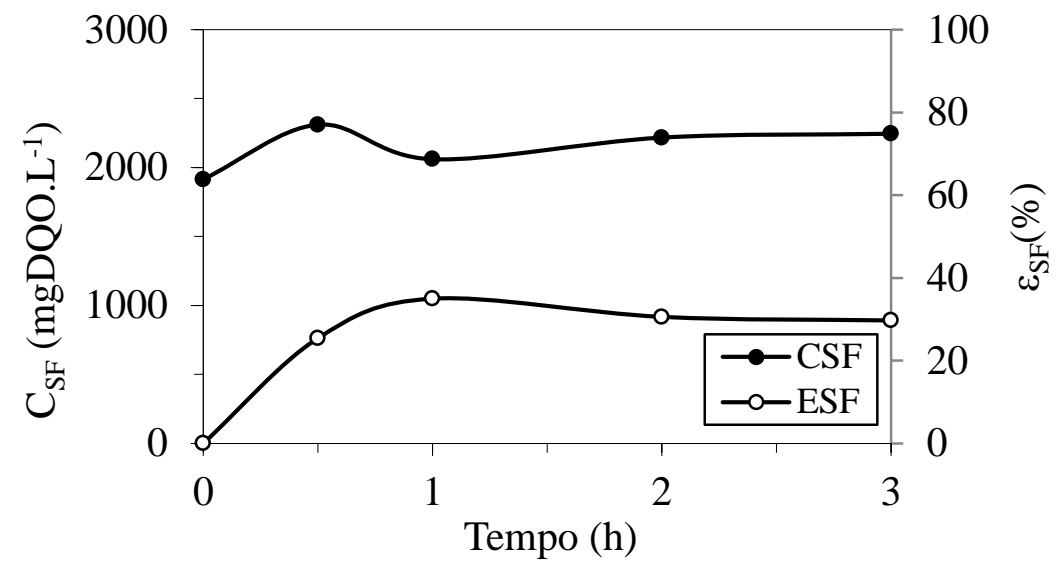

Figura 5.68 - Concentração e eficiência de degradação de matéria orgânica durante o ciclo ensaio 17: - $-\mathrm{C}_{\mathrm{SF}} ; \circ-\varepsilon_{\mathrm{SF}}$

As Figuras 5.69 e 5.70 apresentam os perfis de $\mathrm{pH}$ e alcalinidade total ao longo do ciclo. $\mathrm{O}$ pH permanece constante ao longo do ciclo por volta de 4,6 devido à presença da alcalinidade que é fornecida gradualmente através do afluente e é consumida durante o ciclo.

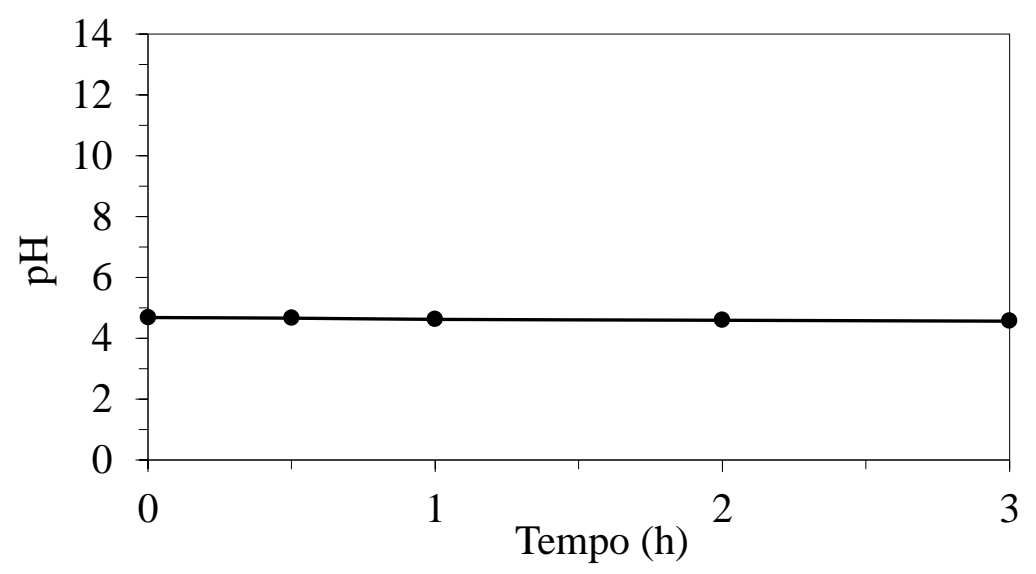

Figura 5.69 - Valores de pH durante o ciclo no ensaio 17

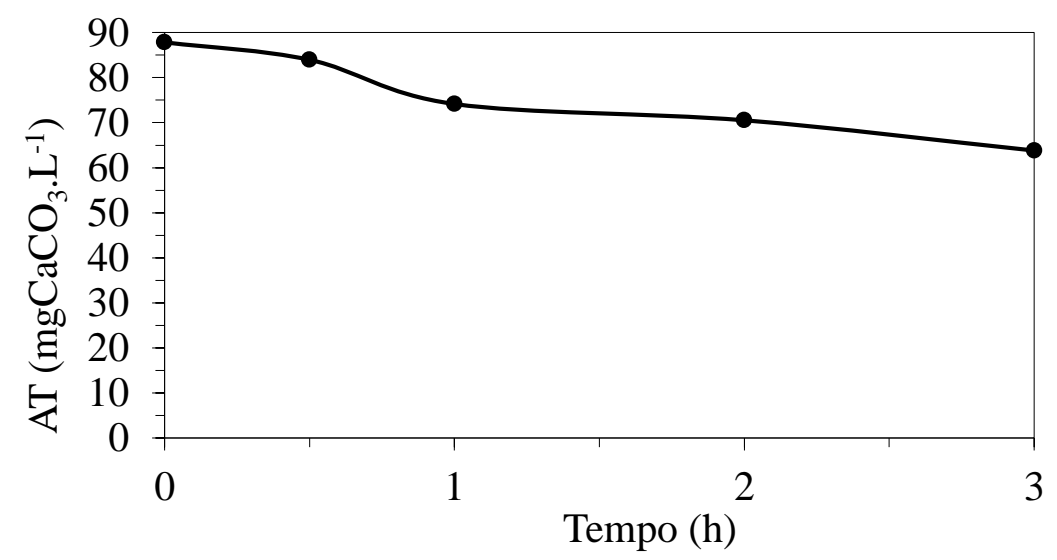

Figura 5.70 - Concentração de alcalinidade total durante o ciclo no ensaio 17 
Os perfis de ácidos voláteis totais por titulação e dos compostos intermediários do metabolismo são apresentados nas Figuras 5.71 e 5.72, tanto os ácidos quanto os solventes apresentam poucas variações durante o perfil. Neste ensaio, houve uma quantidade expressiva de ácido acético, seguido pelo ácido butírico e o etanol.

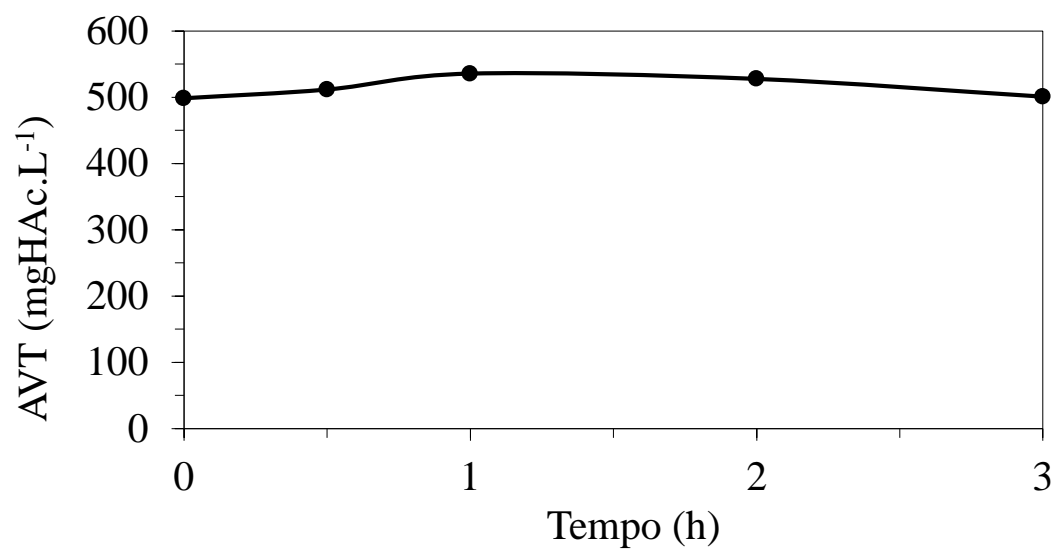

Figura 5.71 - Concentração de AVT durante o ciclo no ensaio 17

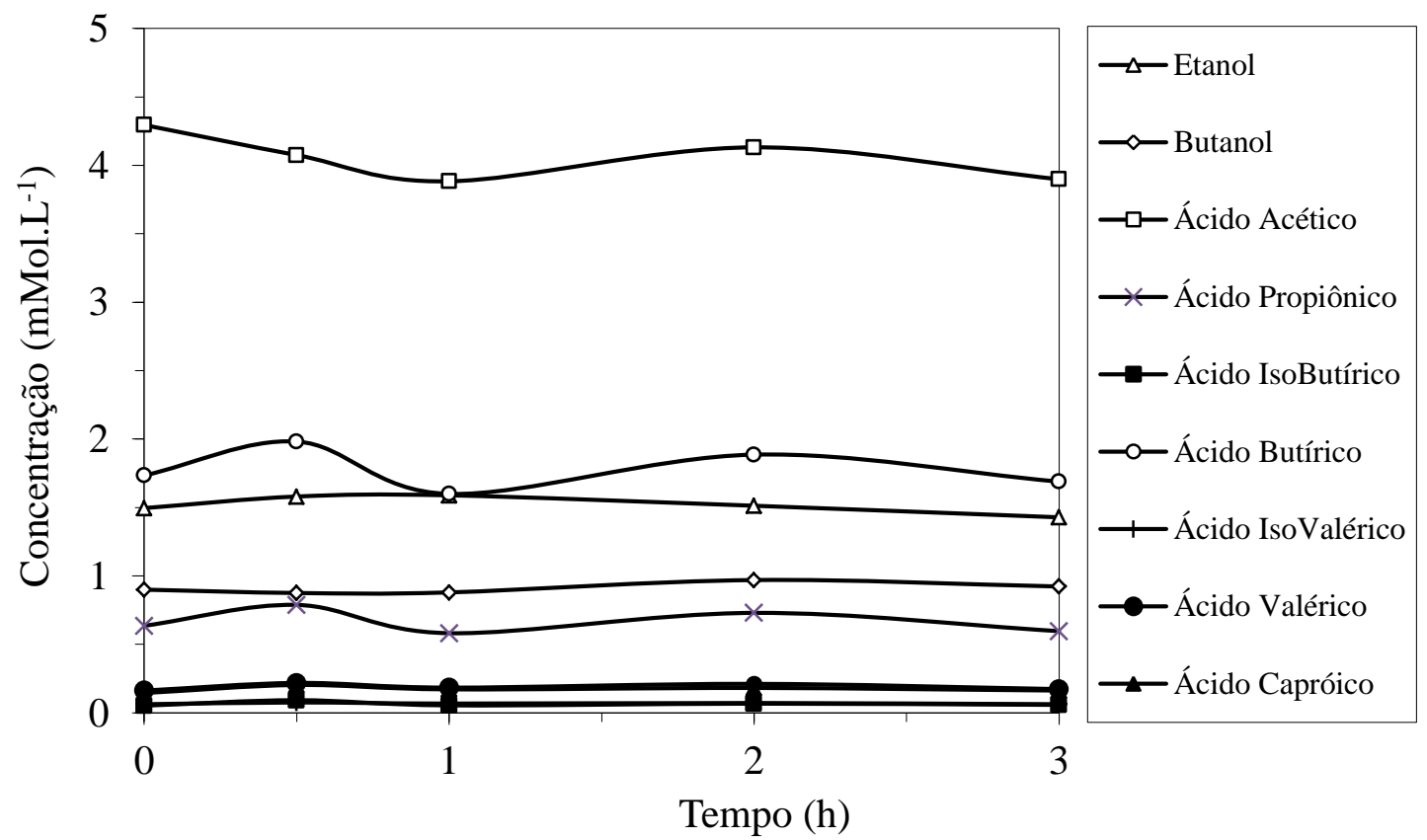

Figura 5.72 - Concentração dos compostos intermediários ao longo do ciclo no ensaio 17: $\square$ - ácido acético; $\Delta$ - etanol; ○ - ácido butírico; - ácido isobutírico; $\boldsymbol{\Delta}$ - ácido capróico; ácido valérico; -X-ácido propiônico; $\diamond$ butanol; + ácido isovalérico 
A produção volumétrica acumulada de biogás e os desvios padrões de cada um dos pontos podem ser observados na Figura 5.73 e o perfil das concentrações de cada um dos gases e suas respectivas porcentagens podem ser observados na Figura 5.74. Neste ensaio houve grande variação do volume de gás medido e, ao final do ciclo, tinha-se $37 \%$ de $\mathrm{H}_{2}$, $46 \%$ de $\mathrm{CO}_{2}$ e $17 \%$ de $\mathrm{CH}_{4}$, o que representa uma baixa qualidade de biogás e pior do que a obtida no ensaio 14.

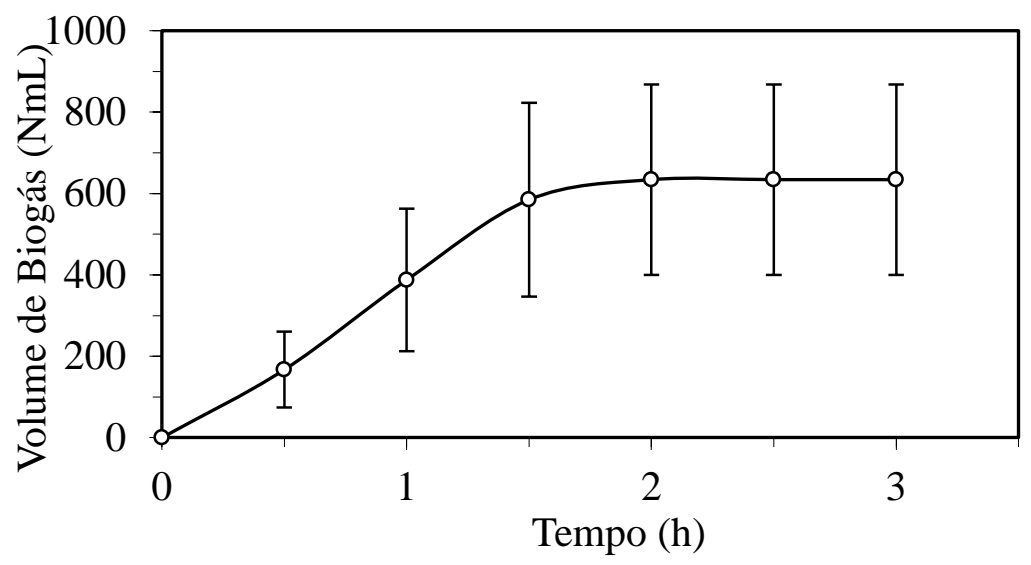

Figura 5.73 - Produção volumétrica média acumulada do biogás durante o ciclo no ensaio 17
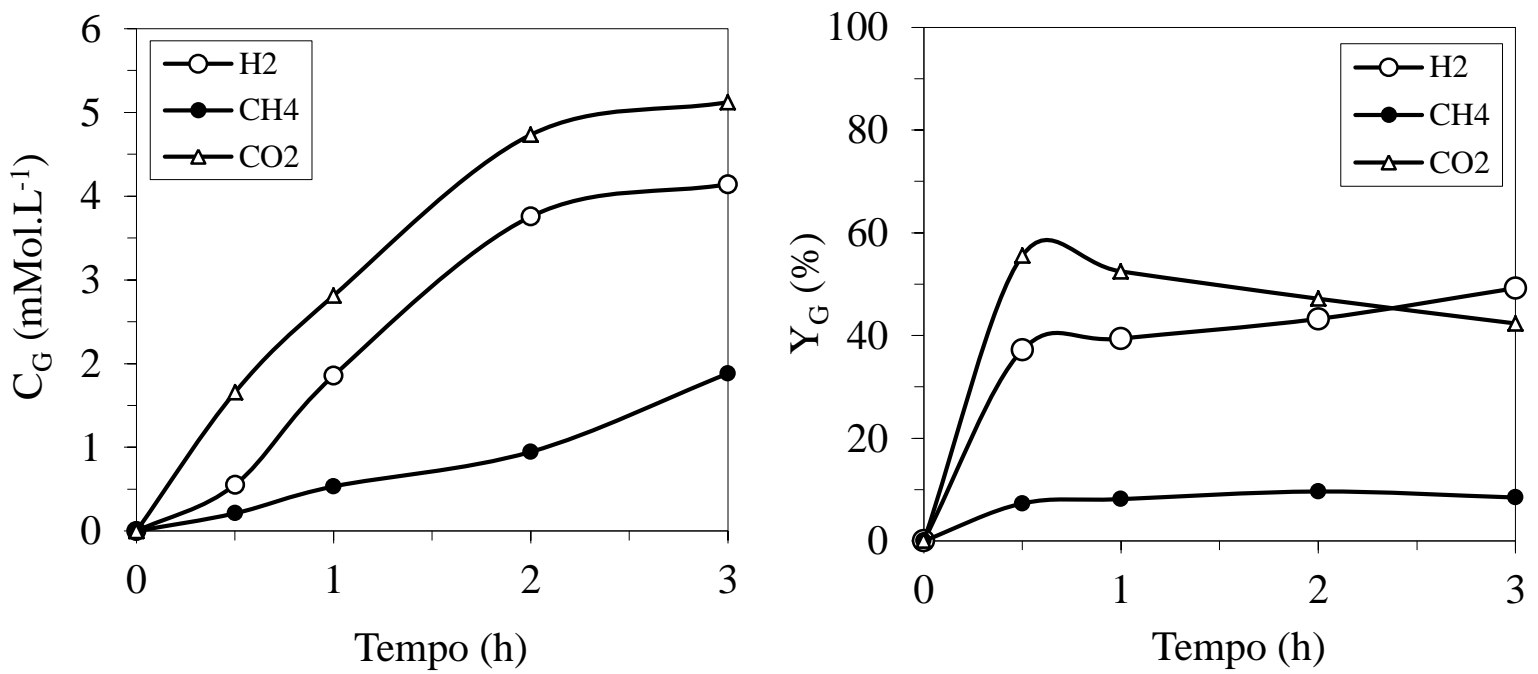

Figura 5.74 - Concentração dos compostos do biogás durante o ciclo e suas respectivas porcentagens no ensaio 17: $\circ-\mathrm{H}_{2} ; \bullet-\mathrm{CH}_{4} ; \Delta-\mathrm{CO}_{2}$ 


\subsubsection{Ensaio 18 (4000 $\mathrm{mgDQO} . \mathrm{L}^{-1}$ e $3 \mathrm{~h}$ de tempo de ciclo)}

O valor nominal de COVA para o ensaio 18 foi de 13,7 gDQO. $\mathrm{L}^{-1} \cdot \mathrm{d}^{-1}$, a COVA real foi de 13,9 gDQO. $\mathrm{L}^{-1} \cdot \mathrm{d}^{-1}$ e a COVR atingida foi de 3,5 gDQO. $\mathrm{L}^{-1} \cdot \mathrm{d}^{-1}$. A Tabela 5.11 apresenta a média dos parâmetros monitorados; a biomassa de sólidos voláteis totais no reator durante o ensaio foi de $8,5 \mathrm{~g}$, novamente representando um aumento na quantidade de biomassa quando comparado aos ensaios anteriores.

Tabela 5.11 - Parâmetros médios monitorados no ensaio 18

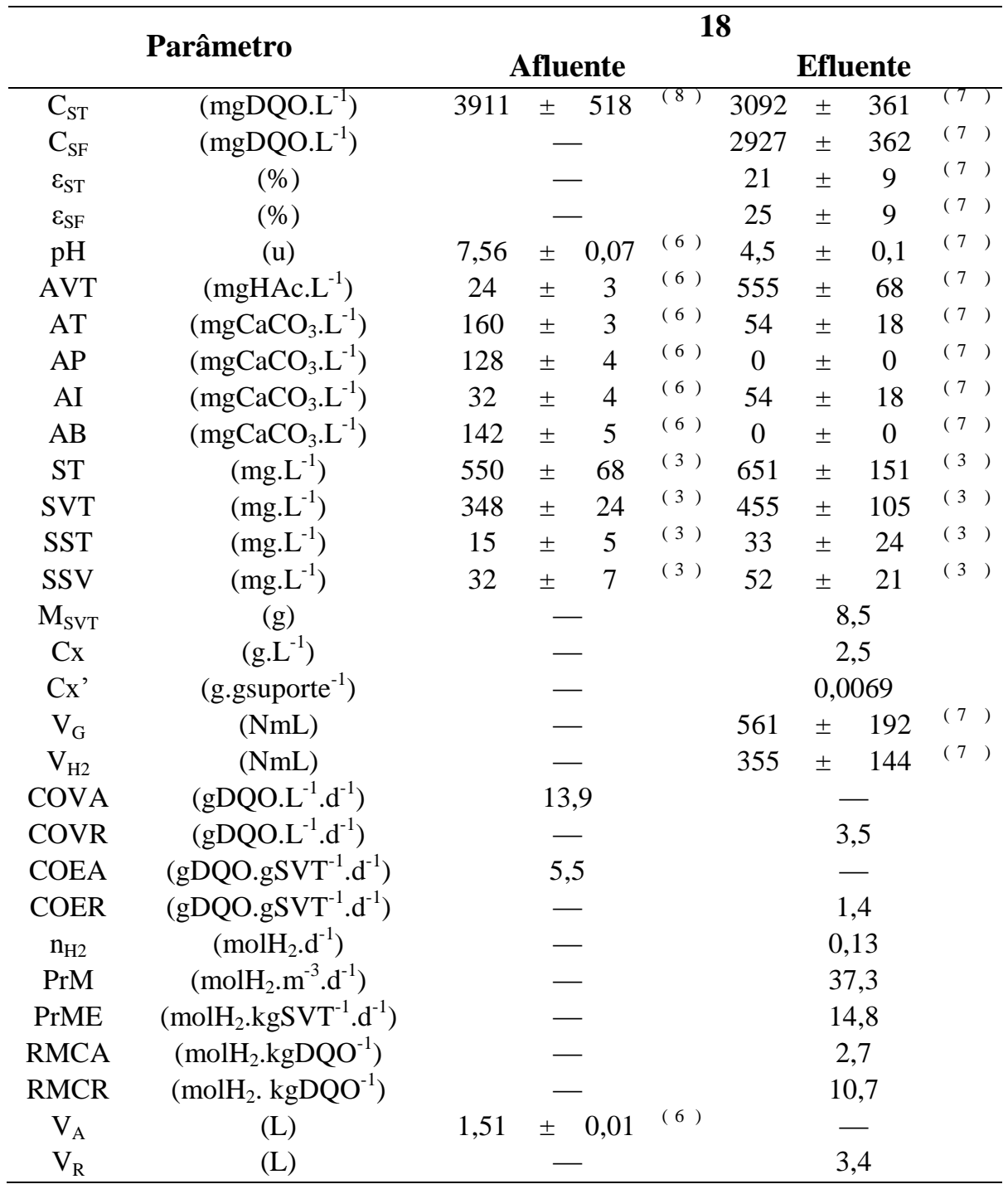

(*) Entre parêntese o número de amostras considerado no cálculo da média 
A concentração média afluente não filtrada foi de $3911 \mathrm{mgDQO} . \mathrm{L}^{-1}$, efluente não filtrada $3092 \mathrm{mgDQO} . \mathrm{L}^{-1}$ e de efluente filtrada de $2927 \mathrm{mgDQO}^{-1}$ (Figura 5.75), com remoção média para amostras não filtradas de $21 \%$ e para amostras filtradas de 25 (Figura 5.76).

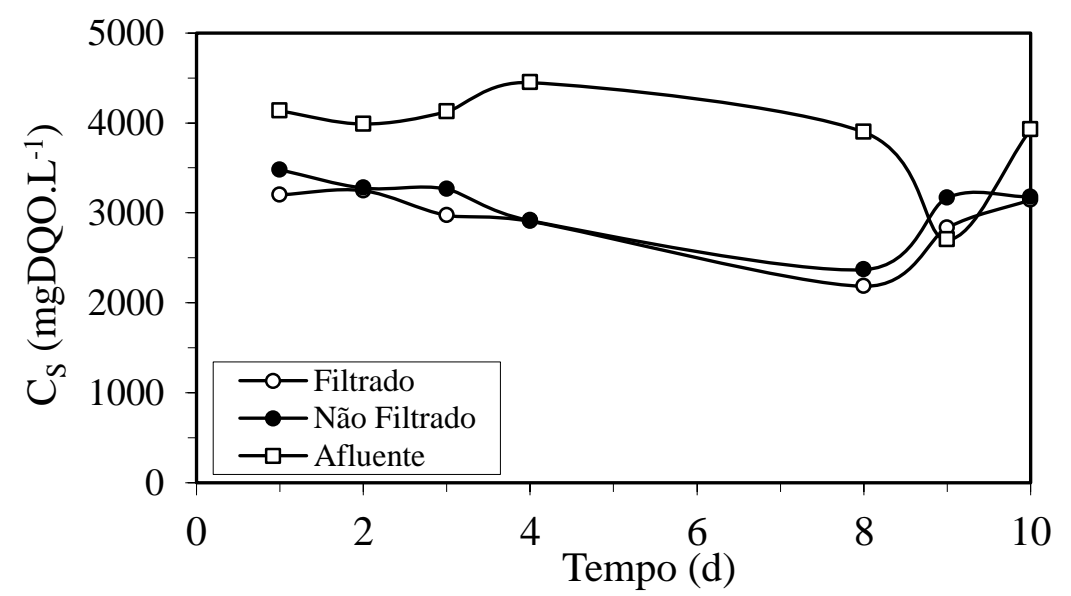

Figura 5.75 - Concentração de matéria orgânica na forma de DQO no ensaio 18: $\square-$ afluente amostras não filtradas; • - efluente amostras não filtradas; ○ - efluente amostras filtradas

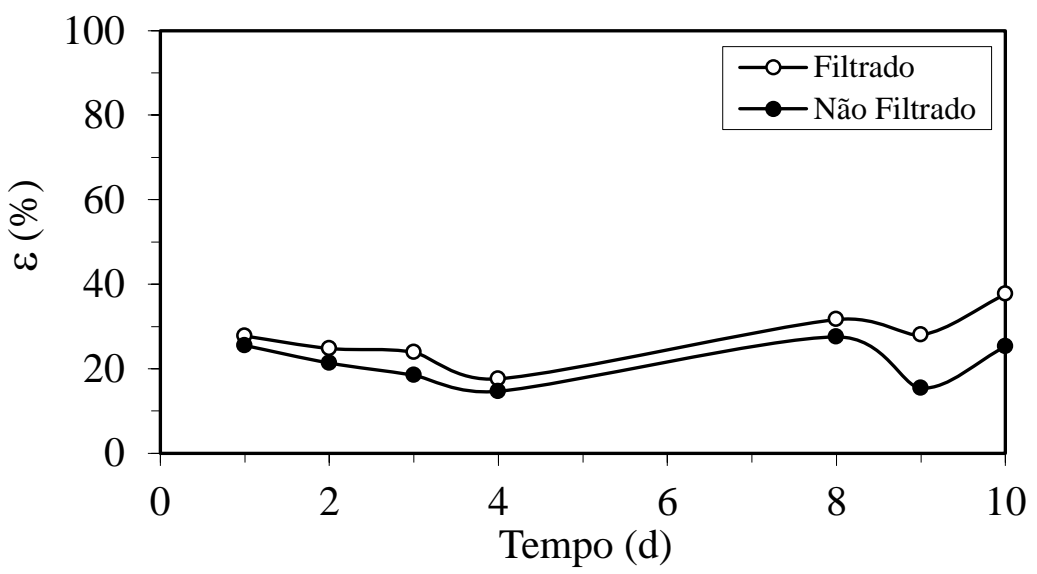

Figura 5.76 - Eficiência de remoção de matéria orgânica na forma de DQO no ensaio 18: • - amostras não filtradas; ○ - amostras filtradas

As Figuras 5.77, 5.78 e 5.79 apresentam os dados obtidos de $\mathrm{pH}$, alcalinidade total e ácidos voláteis totais, respectivamente. A média do $\mathrm{pH}$ afluente foi de 7,56 e do efluente de 4,5. A alcalinidade total afluente teve média de $160 \mathrm{mgCaCO} 3 \cdot \mathrm{L}^{-1}$ sendo consumida e saindo 
no efluente com $54 \mathrm{mgCaCO} 3 \cdot \mathrm{L}^{-1}$. A média de AVT do afluente foi de $24 \mathrm{mgHAc} . \mathrm{L}^{-1}$ e a média de AVT do efluente de 555 mgHAc. $\mathrm{L}^{-1}$.

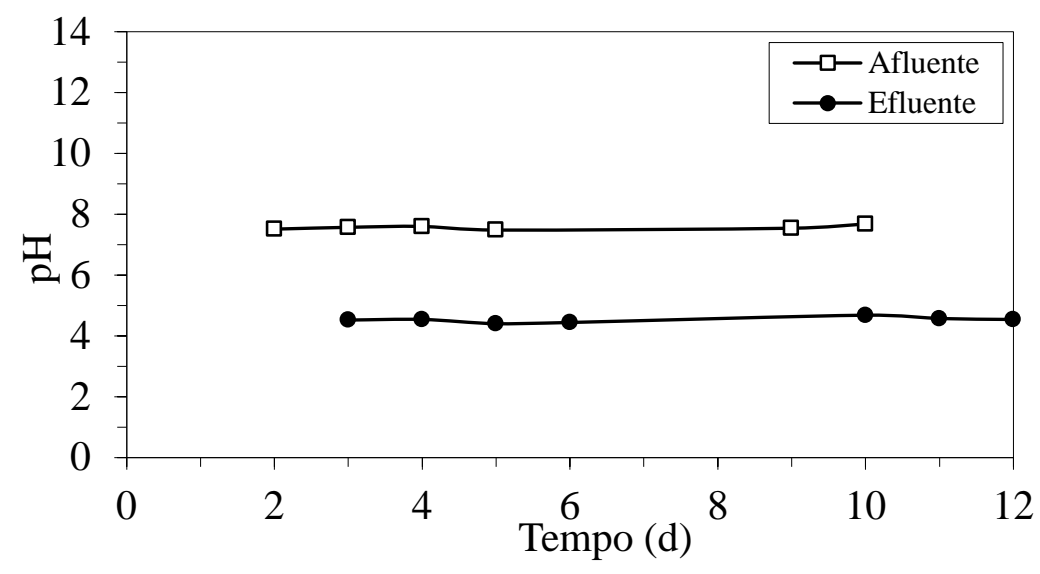

Figura 5.77 - Valores de pH no ensaio 18: $\square$ - afluente; • - efluente

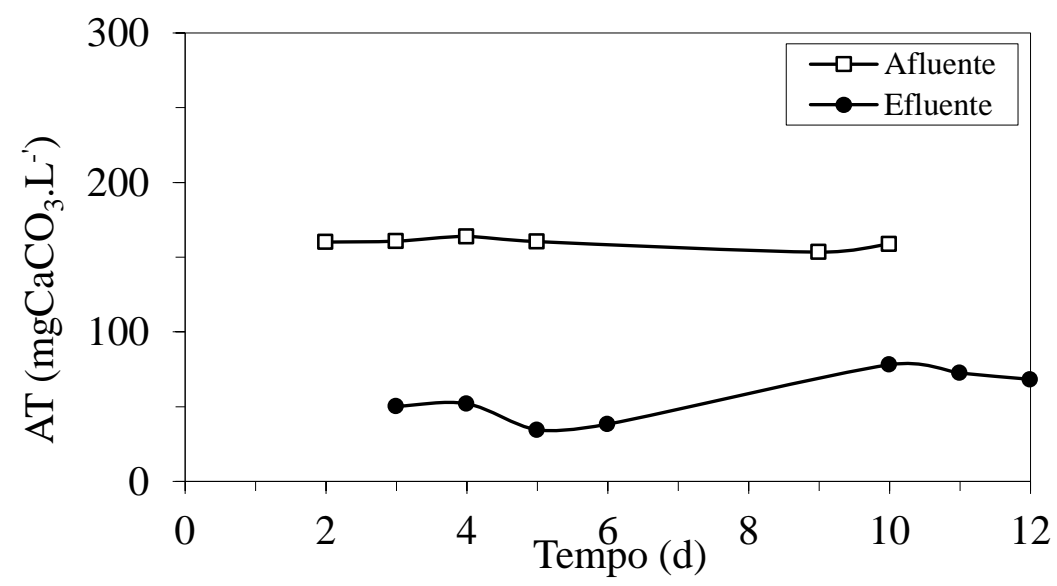

Figura 5.78 - Valores de alcalinidade total (AT) no ensaio 18: $\square$-afluente; $\bullet$ - efluente

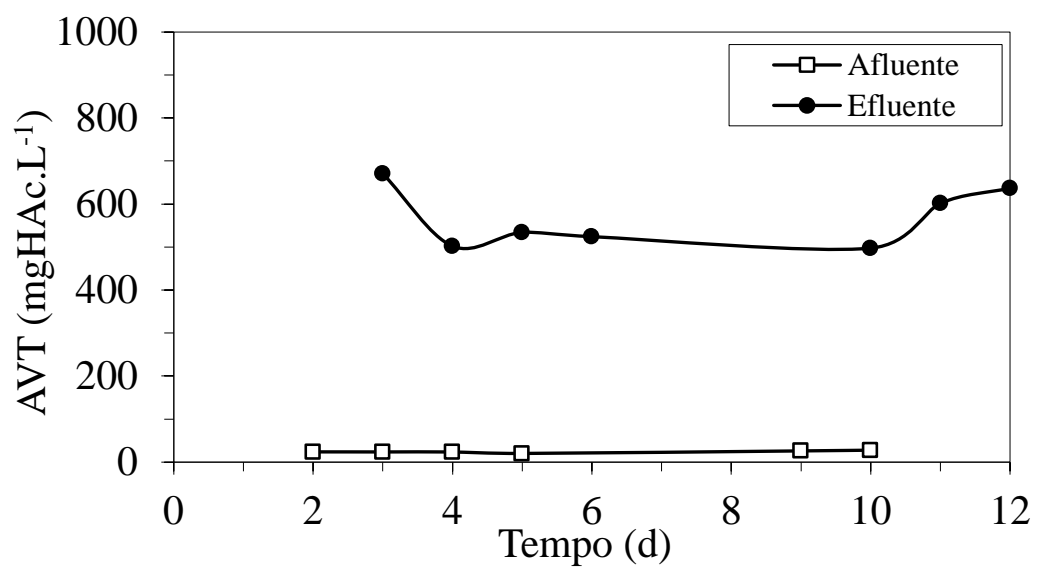

Figura 5.79 - Valores de ácidos voláteis totais (AVT) no ensaio 18: $\square$-afluente; $\bullet$ - efluente 
A produção de biogás por ciclo, em aspecto quantitativo, pode ser observada na Figura 5.80, com média de $561 \mathrm{~mL}$ de biogás e $355 \mathrm{~mL}$ de hidrogênio. A Figura 5.81 apresenta a distribuição dos gases que compõem o biogás no final do ciclo.

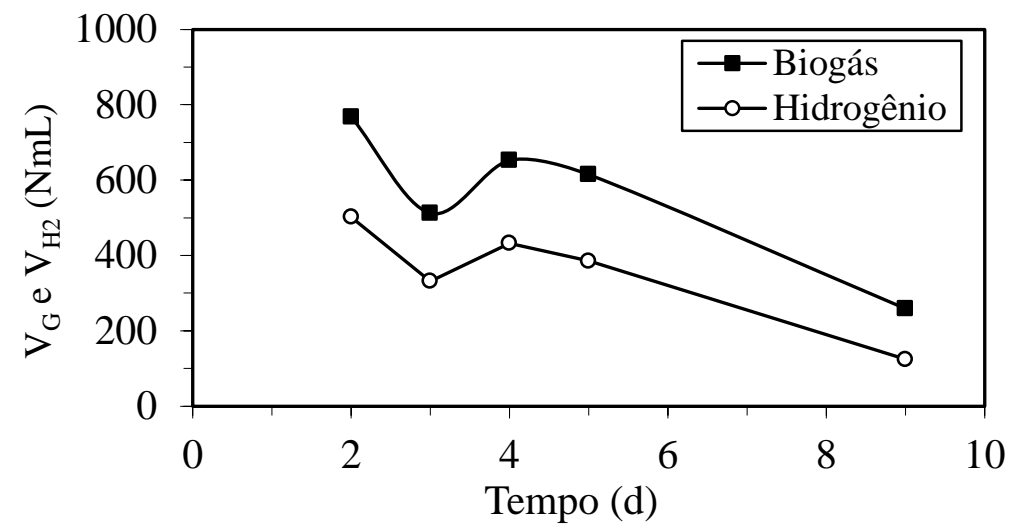

Figura 5.80 - Volume de biogás $\left(\mathrm{V}_{\mathrm{G}}\right)$ e de hidrogênio $\left(\mathrm{V}_{\mathrm{H} 2}\right)$ na CNTP no ensaio 18: - -Biogás; o - Hidrogênio

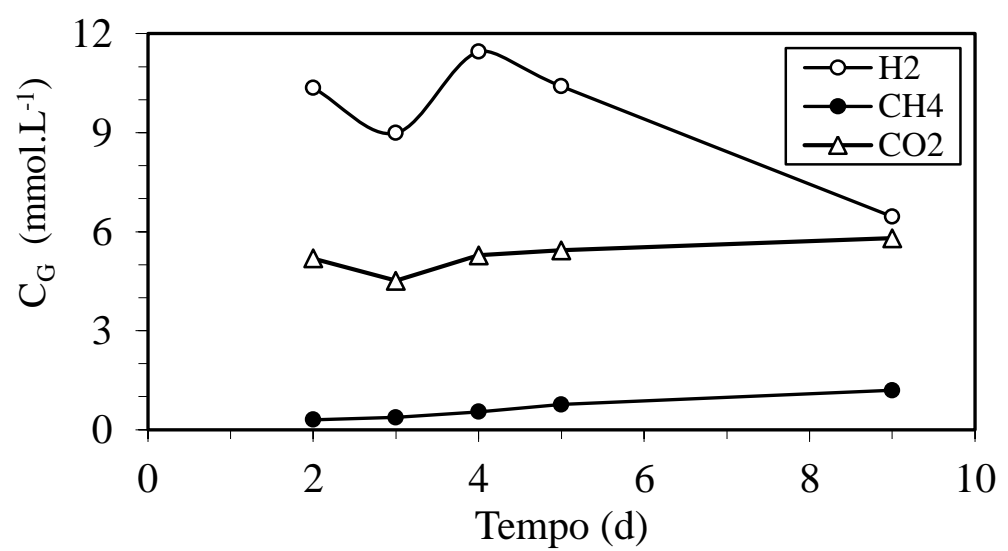

Figura 5.81 - Concentrações dos componentes do biogás no final do ciclo no ensaio 18 : $\circ-\mathrm{H}_{2}$; $\bullet-\mathrm{CH}_{4} ; \Delta-\mathrm{CO}_{2}$

A Figura 5.82 apresenta o perfil de DQO durante o ciclo. A máxima eficiência de remoção atingida durante o ciclo é de $28 \%$. 


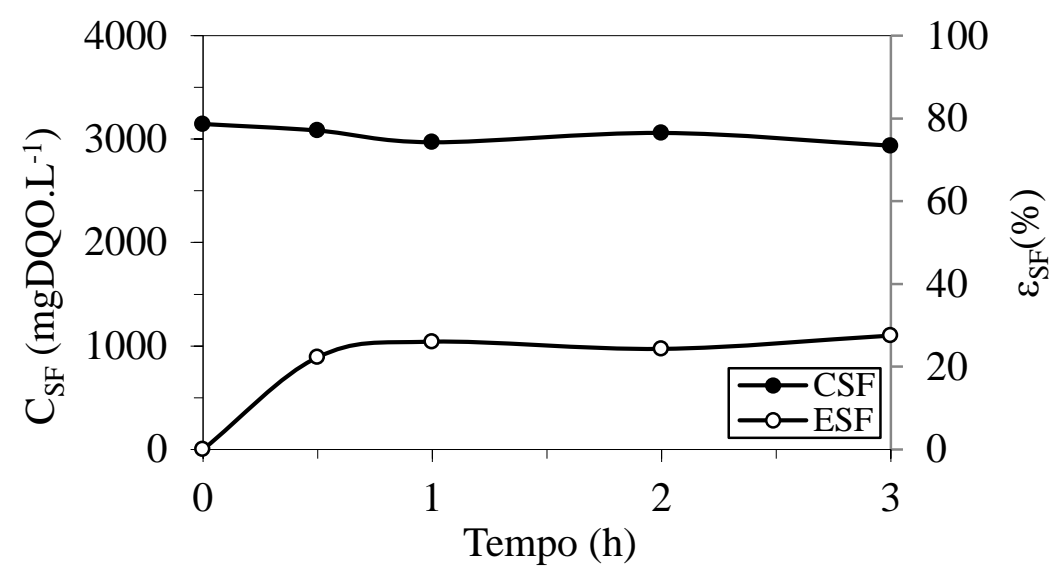

Figura 5.82 - Concentração e eficiência de degradação de matéria orgânica durante o ciclo ensaio 18: - $-\mathrm{C}_{\mathrm{SF}} ; \circ-\varepsilon_{\mathrm{SF}}$

As Figuras 5.83 e 5.84 apresentam os perfis de $\mathrm{pH}$ e alcalinidade total ao longo do ciclo. $\mathrm{O}$ pH permanece constante ao longo do ciclo por volta de 4,5 devido à presença da alcalinidade que é fornecida gradualmente através do afluente e é consumida durante o ciclo.

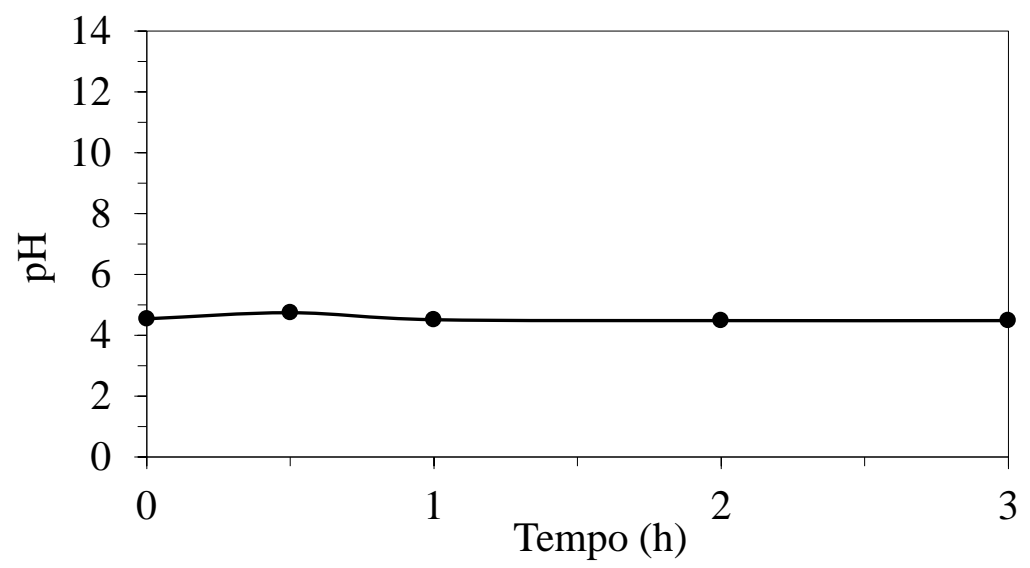

Figura 5.83 - Valores de pH durante o ciclo no ensaio 18

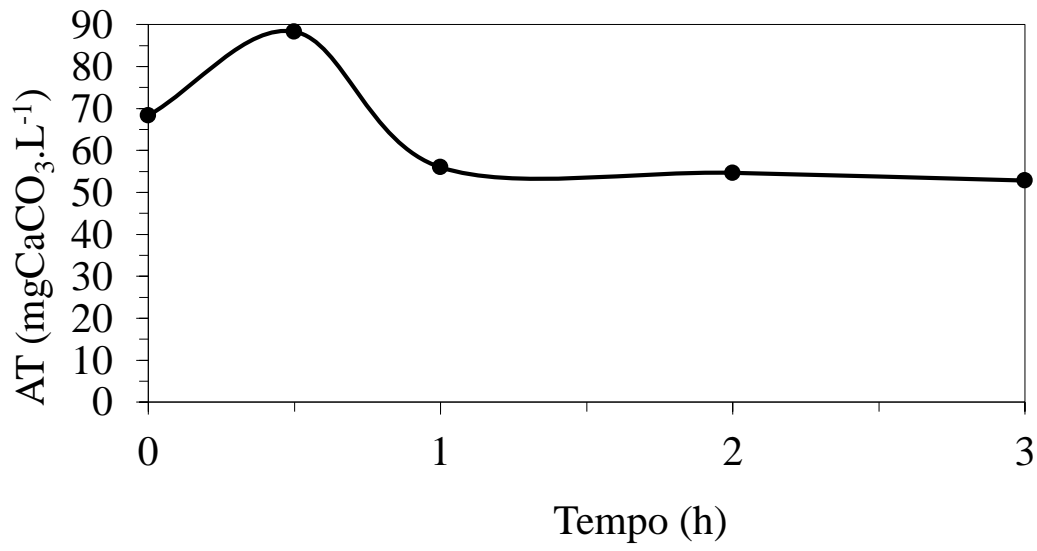

Figura 5.84 - Concentração de alcalinidade total durante o ciclo no ensaio 18 
Os perfis de ácidos voláteis totais por titulação e dos compostos intermediários do metabolismo são apresentados nas Figuras 5.85 e 5.86. Não houve grandes variações nas concentrações dos AVI e dos AVT durante o ciclo, sendo que neste ensaio, houve predomínio do ácido acético e do ácido butírico, seguido pela produção de etanol.

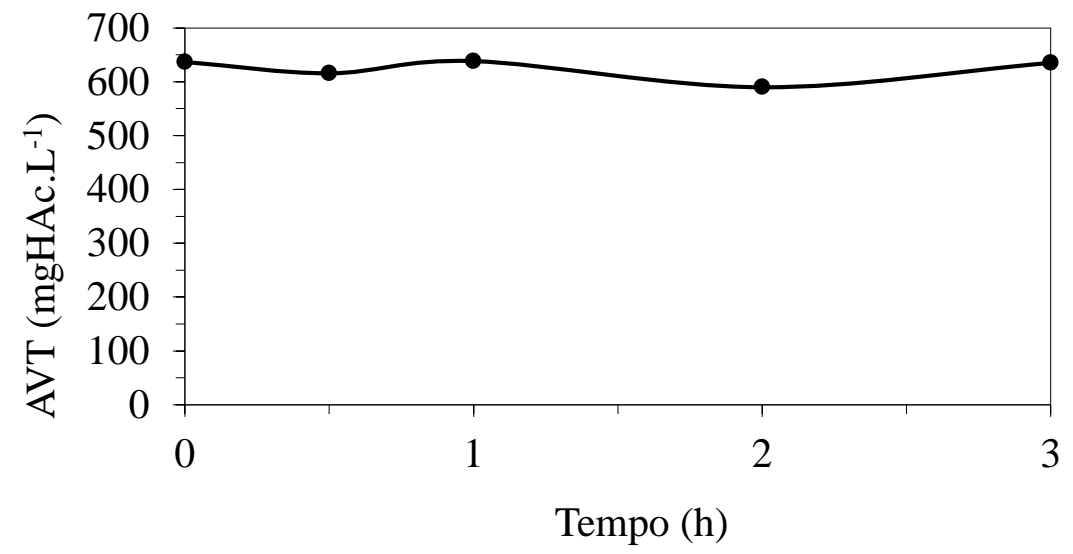

Figura 5.85 - Concentração de AVT durante o ciclo no ensaio 18

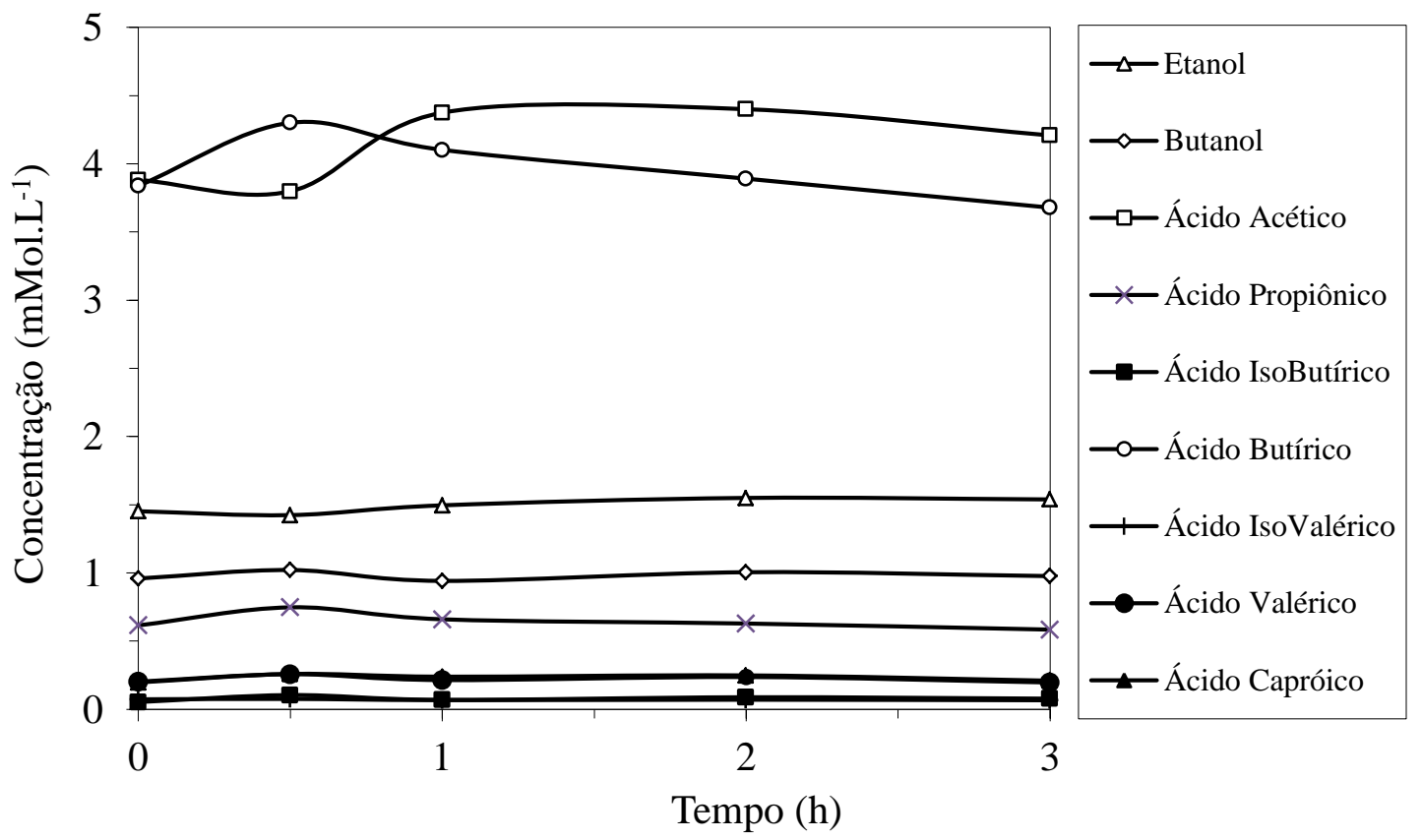

Figura 5.86 - Concentração dos compostos intermediários ao longo do ciclo no ensaio 18: $\square$ - ácido acético; $\Delta$ - etanol; ○ - ácido butírico; - ácido isobutírico; $\boldsymbol{\Lambda}$ - ácido capróico; • ácido valérico; -x-ácido propiônico; $\diamond$ butanol; + ácido isovalérico 
A produção volumétrica acumulada de biogás e os desvios padrões de cada um dos pontos podem ser observados na Figura 5.87 e o perfil das concentrações de cada um dos gases e suas respectivas porcentagens podem ser observados na Figura 5.88. Houve baixíssima variação no volume de biogás medido ao longo do ciclo e, ao final do mesmo, obteve-se $49 \%$ de $\mathrm{H}_{2}, 42 \%$ de $\mathrm{CO}_{2}$ e $8 \%$ de $\mathrm{CH}_{4}$.

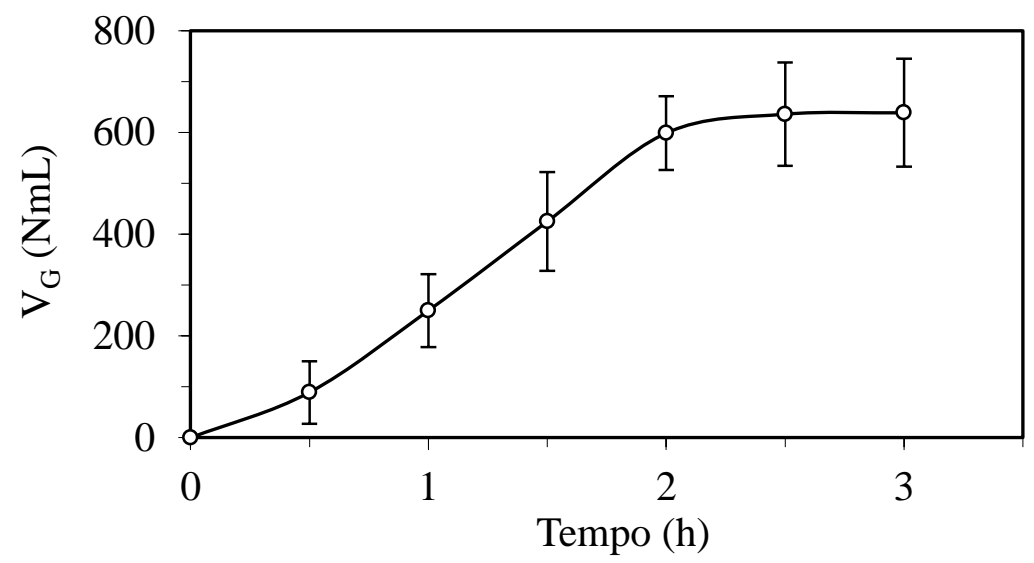

Figura 5.87 - Produção volumétrica média acumulada do biogás durante o ciclo no ensaio 18
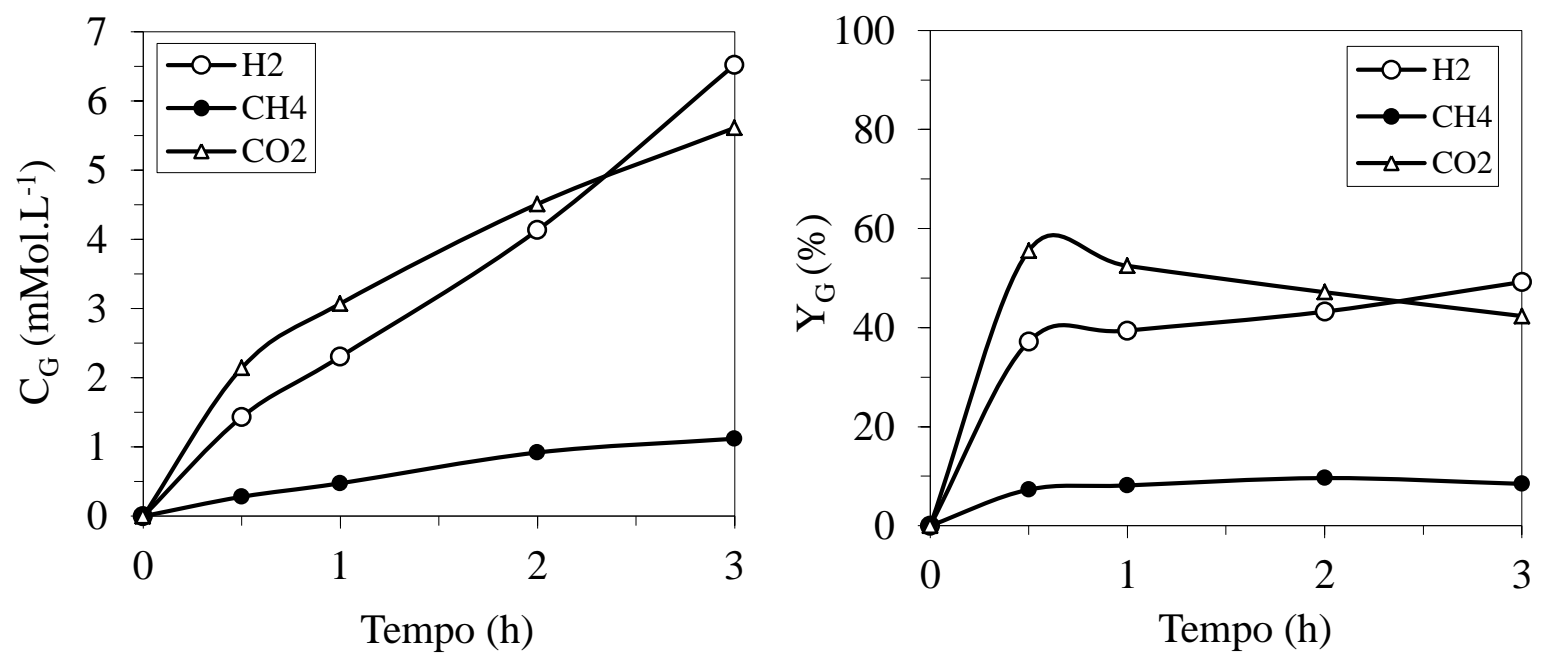

Figura 5.88 - Concentração dos compostos do biogás durante o ciclo e suas respectivas porcentagens no ensaio 18: $\odot-\mathrm{H}_{2} ; \bullet-\mathrm{CH}_{4} ; \Delta-\mathrm{CO}_{2}$ 


\subsubsection{Ensaio 19 (5000 $\mathrm{mgDQO}^{-1}$ e $3 \mathrm{~h}$ de tempo de ciclo)}

O valor nominal de COVA para o ensaio 19 foi de $17,1 \mathrm{gDQO} \cdot \mathrm{L}^{-1} \cdot \mathrm{d}^{-1}$, a COVA real foi de $17,8 \mathrm{gDQO} . \mathrm{L}^{-1} \cdot \mathrm{d}^{-1}$ e a COVR atingida foi de 5,0 gDQO. $\mathrm{L}^{-1} \cdot \mathrm{d}^{-1}$. A Tabela 5.12 apresenta a média dos parâmetros monitorados; a biomassa de sólidos voláteis totais presente no reator durante o ensaio foi de $10,2 \mathrm{~g}$, novamente representando um aumento na quantidade de biomassa quando comparado aos ensaios anteriores.

Tabela 5.12 - Parâmetros médios monitorados no ensaio 19

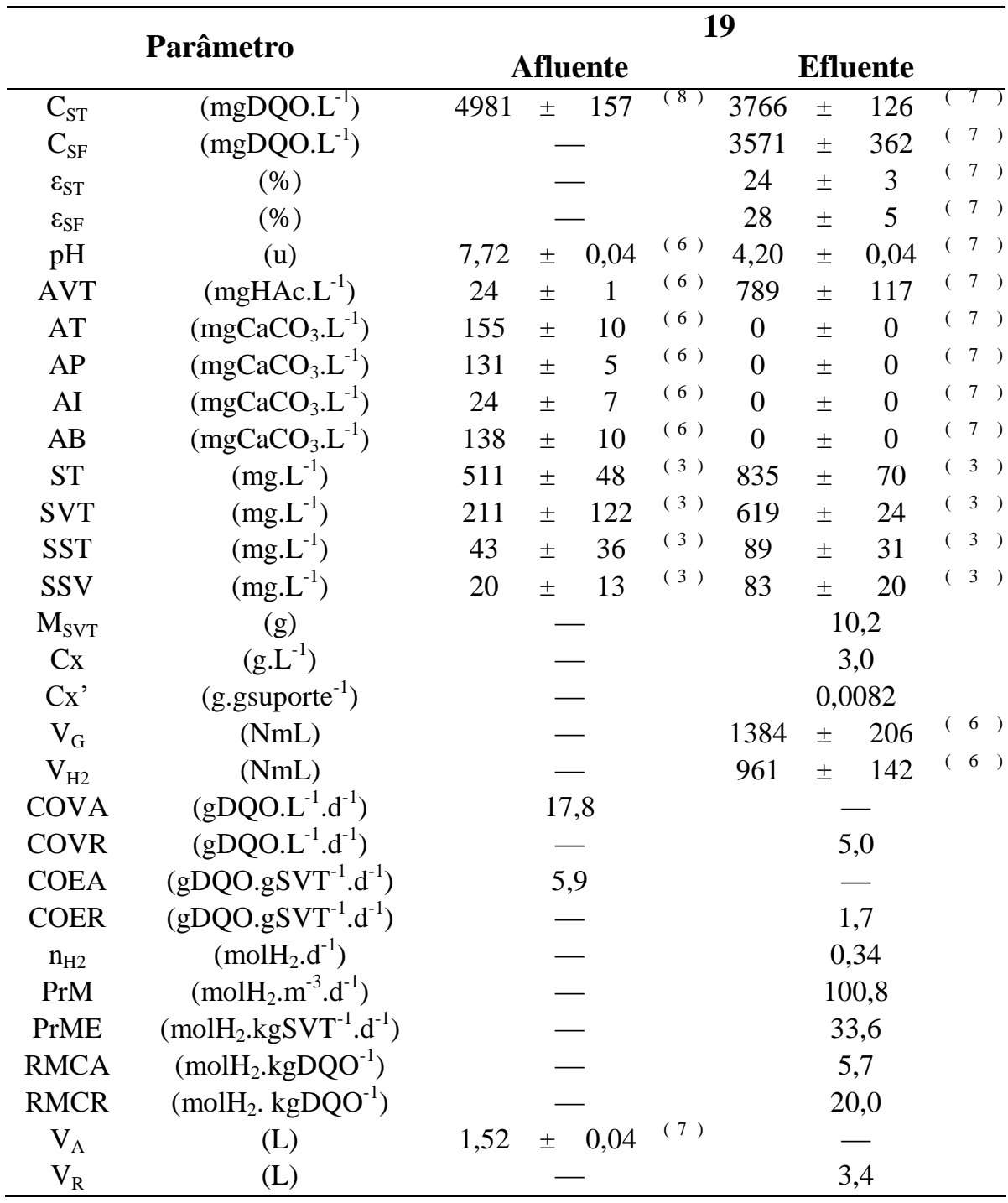

(*) Entre parêntese o número de amostras considerado no cálculo da média 
A concentração média afluente não filtrada foi de $4981 \mathrm{mgDQO} . \mathrm{L}^{-1}$, efluente não filtrada $3766 \mathrm{mgDQO} . \mathrm{L}^{-1}$ e de efluente filtrada de $3571 \mathrm{mgDQO}^{-1}$ (Figura 5.89), com remoção média para amostras não filtradas de $24 \%$ e para amostras filtradas de $28 \%$ (Figura 5.90).

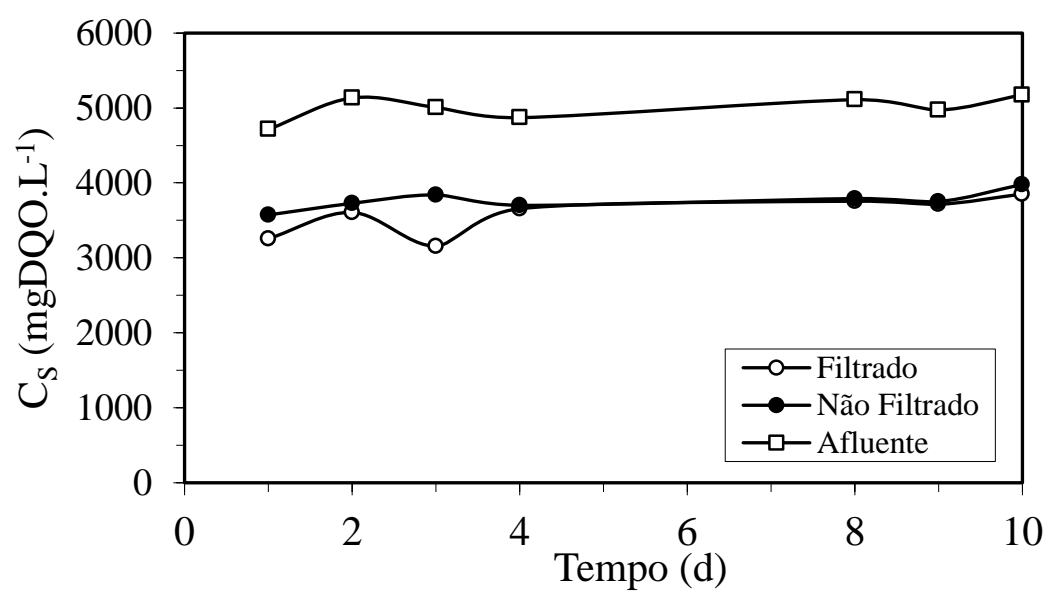

Figura 5.89 - Concentração de matéria orgânica na forma de DQO no ensaio 19: $\square$ - afluente amostras não filtradas; • - efluente amostras não filtradas; $\bigcirc-$ efluente amostras filtradas

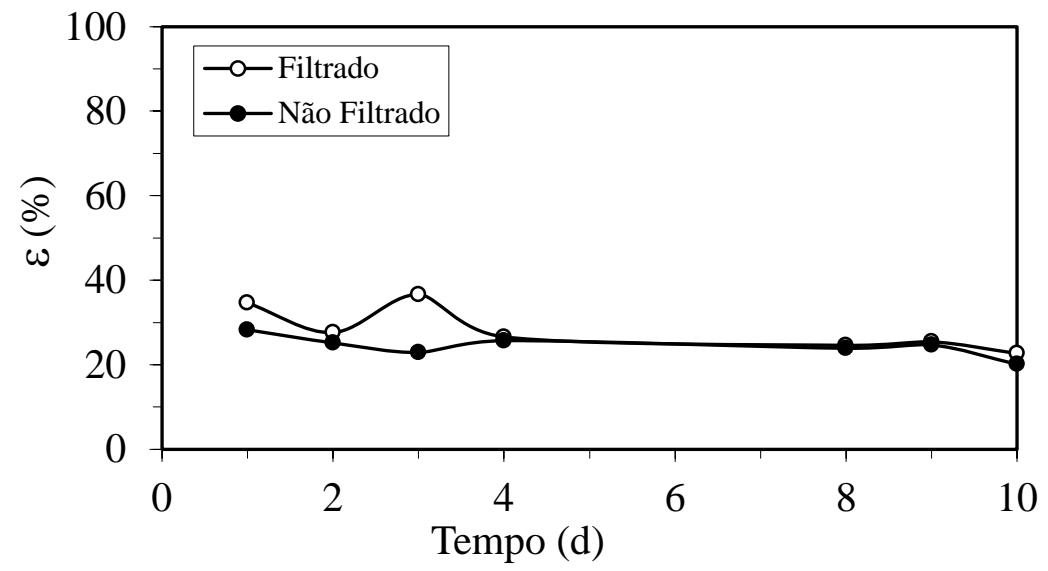

Figura 5.90 - Eficiência de remoção de matéria orgânica na forma de DQO no ensaio 19: • - amostras não filtradas; $\bigcirc-$ amostras filtradas

As Figuras 5.91, 5.92 e 5.93 apresentam os dados obtidos de $\mathrm{pH}$, alcalinidade total e ácidos voláteis totais, respectivamente. A média do $\mathrm{pH}$ afluente foi de 7,72 e do efluente de 4,20. A alcalinidade total afluente teve média de $155 \mathrm{mgCaCO}_{3} \cdot \mathrm{L}^{-1}$ sendo consumida 
totalmente pelo processo. A média de AVT do afluente foi de $24 \mathrm{mgHAc} . \mathrm{L}^{-1}$ e a média de AVT do efluente de 789 mgHAc. $\mathrm{L}^{-1}$.

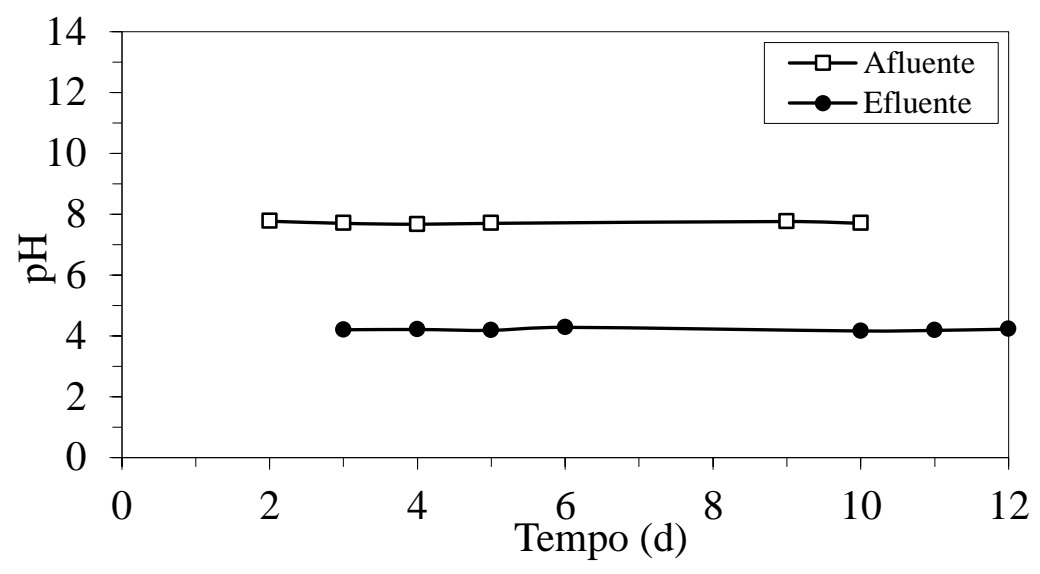

Figura 5.91 - Valores de pH no ensaio 19: $\square$ - afluente; • - efluente

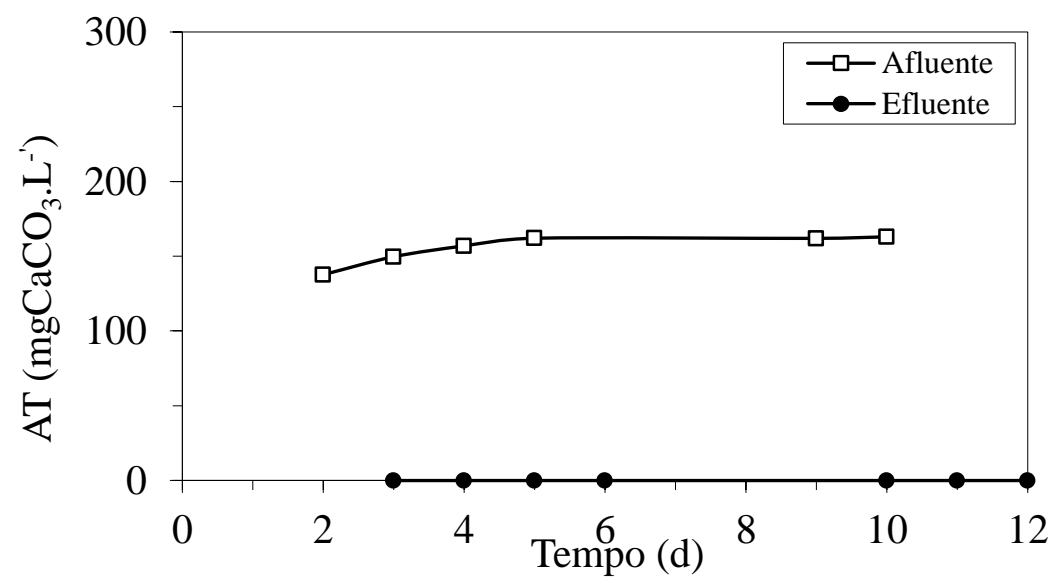

Figura 5.92 - Valores de alcalinidade total (AT) no ensaio 19: $\square$-afluente; $\bullet$ - efluente

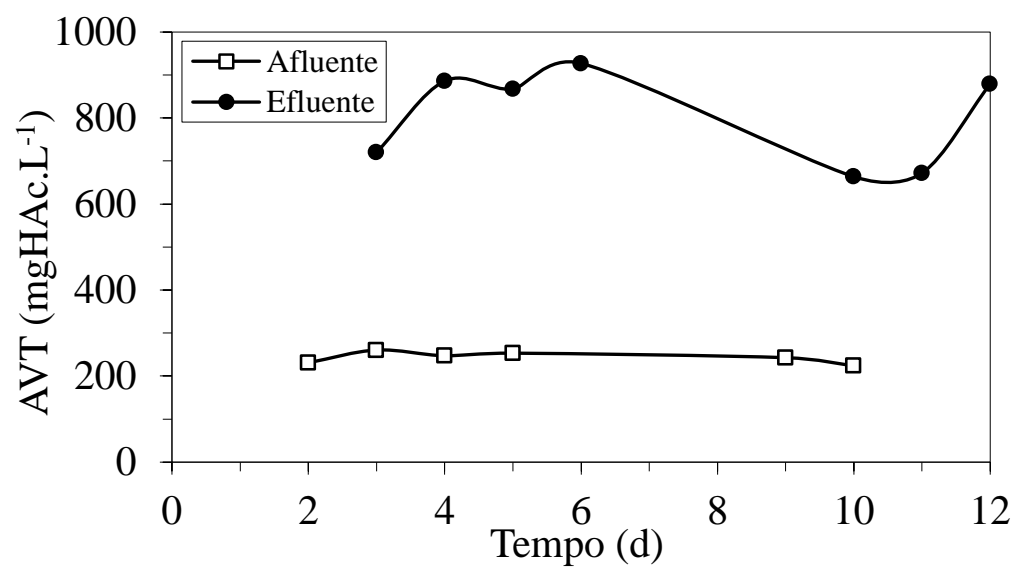

Figura 5.93 - Valores de ácidos voláteis totais (AVT) no ensaio 19: $\square$-afluente; $\bullet$ - efluente 
A produção de biogás por ciclo, em aspecto quantitativo, pode ser observada pela Figura 5.96, com média de $1384 \mathrm{~mL}$ de biogás e $965 \mathrm{~mL}$ de hidrogênio, foi a melhor produtividade atingida dentre os seis ensaios. A Figura 5.97 apresenta a distribuição dos gases que compõem o biogás no final do ciclo.

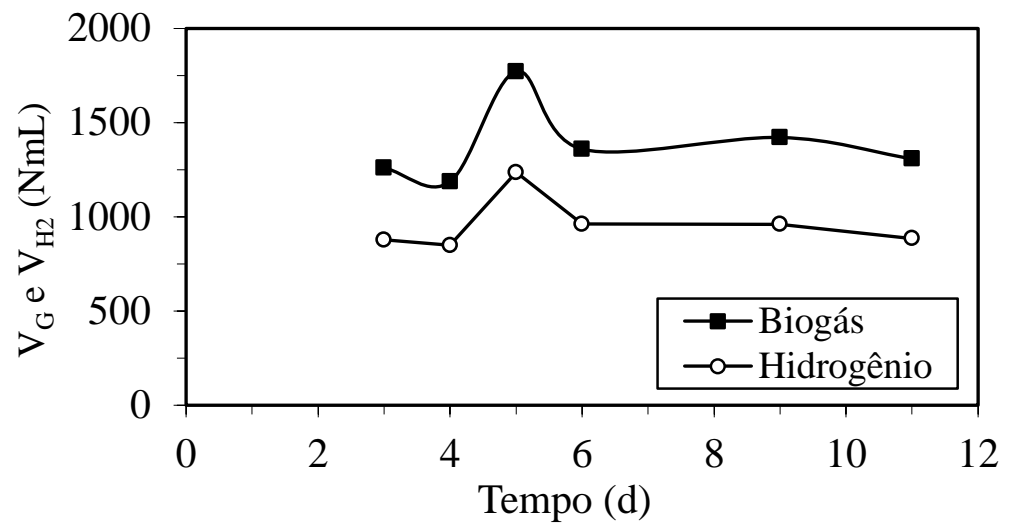

Figura 5.94 - Volume de biogás $\left(\mathrm{V}_{\mathrm{G}}\right)$ e de hidrogênio $\left(\mathrm{V}_{\mathrm{H} 2}\right)$ na CNTP no ensaio 19: - -Biogás; ○ - Hidrogênio

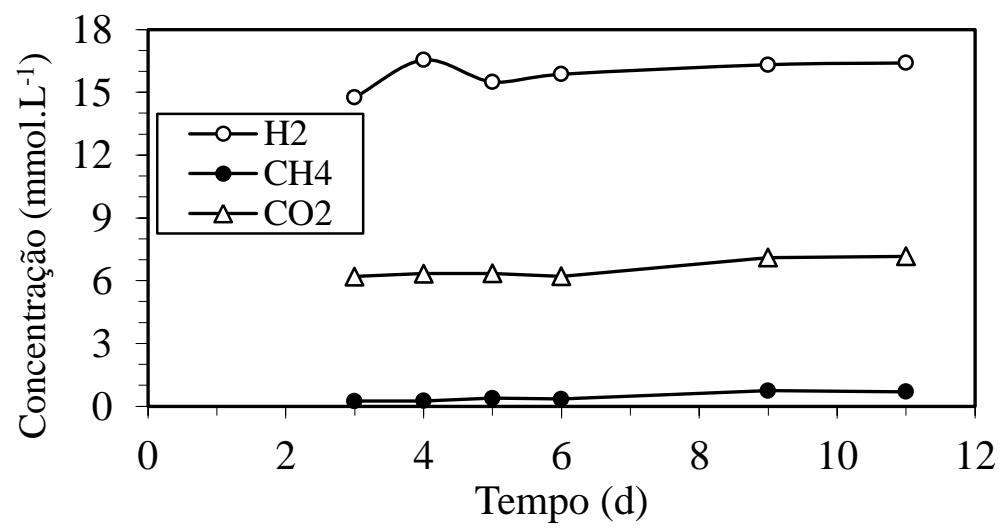

Figura 5.95 - Concentrações dos componentes do biogás no final do ciclo no ensaio 19: $\bigcirc-\mathrm{H}_{2}$; $\bullet-\mathrm{CH}_{4} ; \Delta-\mathrm{CO}_{2}$

A Figura 5.96 apresenta o perfil de DQO durante o ciclo. A máxima eficiência de remoção atingida durante o ciclo é de $27 \%$. 


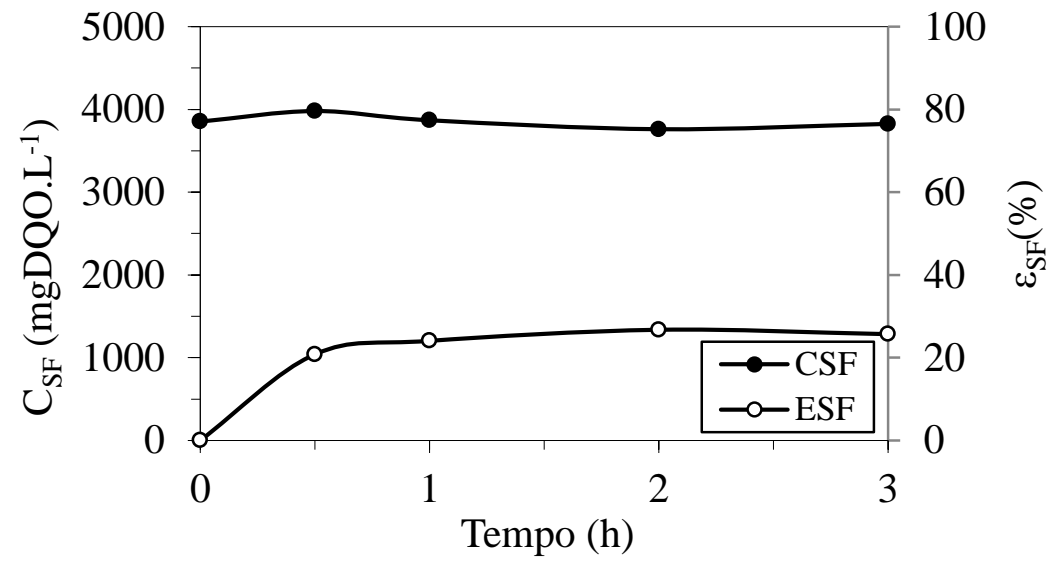

Figura 5.96 - Concentração e eficiência de degradação de matéria orgânica durante o ciclo ensaio 19: $\bullet-\mathrm{C}_{\mathrm{SF}} ; \circ-\varepsilon_{\mathrm{SF}}$

As Figuras 5.97 e 5.98 apresentam os perfis de $\mathrm{pH}$ e alcalinidade total ao longo do ciclo. $\mathrm{O}$ pH permanece constante ao longo do ciclo por volta de 4,2 devido à presença da alcalinidade que é fornecida gradualmente através do afluente e é consumida completamente pelo sistema.

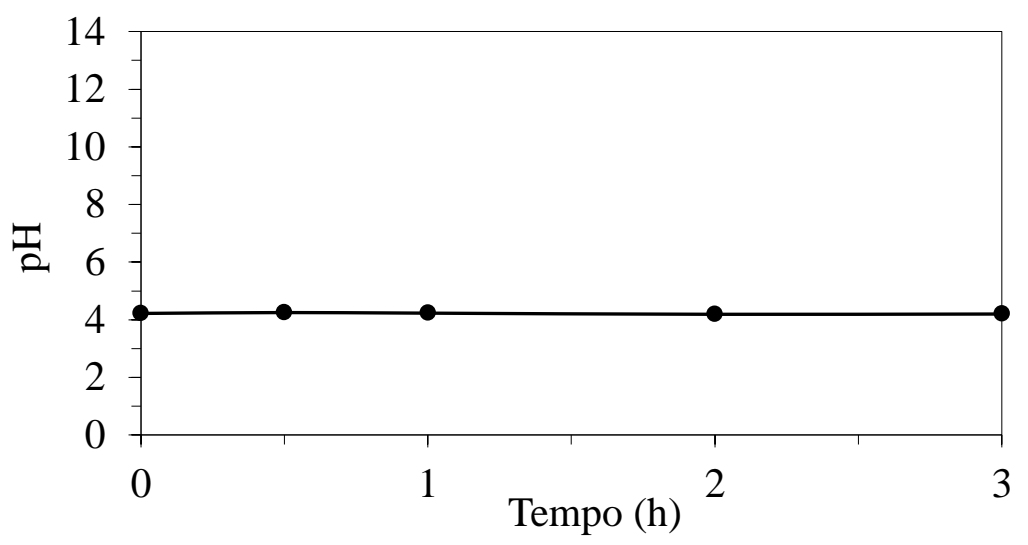

Figura 5.97 - Valores de $\mathrm{pH}$ durante o ciclo no ensaio 19

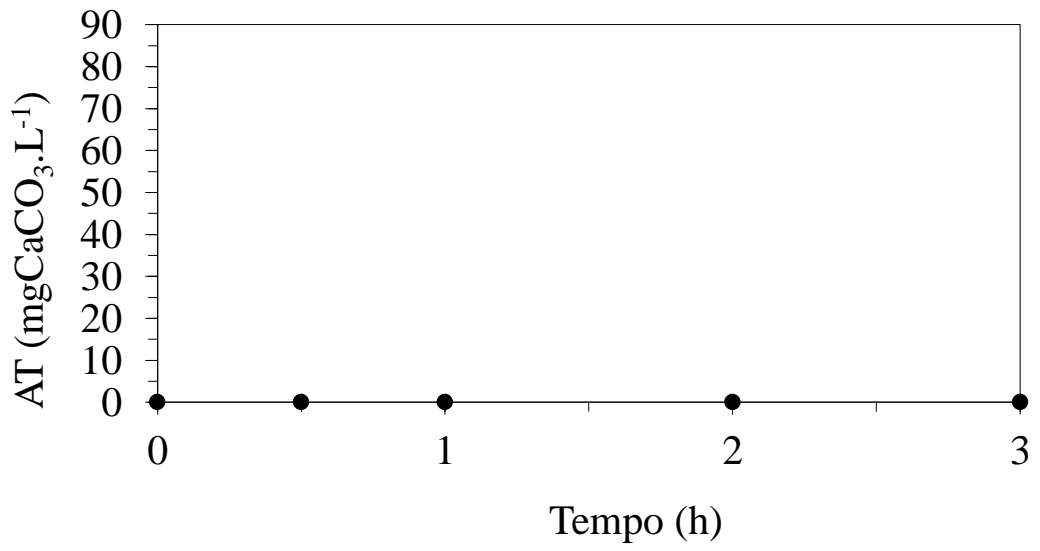

Figura 5.98 - Concentração de alcalinidade total durante o ciclo no ensaio 19 
Os perfis de ácidos voláteis totais por titulação e dos compostos intermediários do metabolismo são apresentados nas Figuras 5.99 e 5.100. Houve predomínio do ácido acético e do ácido butírico como na maior parte dos outros ensaios, mas não houve concentrações significativas de nenhum álcool.

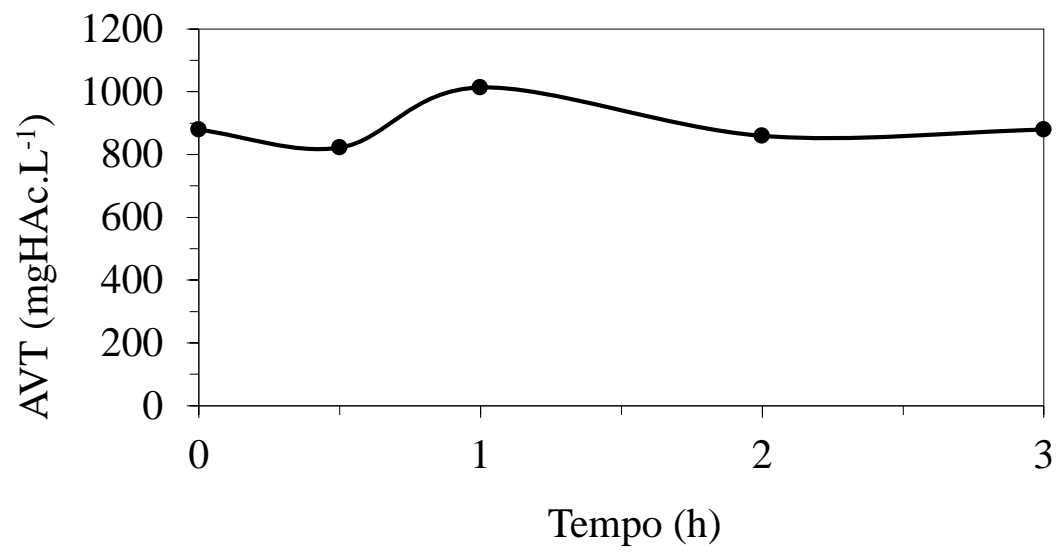

Figura 5.99 - Concentração de AVT durante o ciclo no ensaio 19

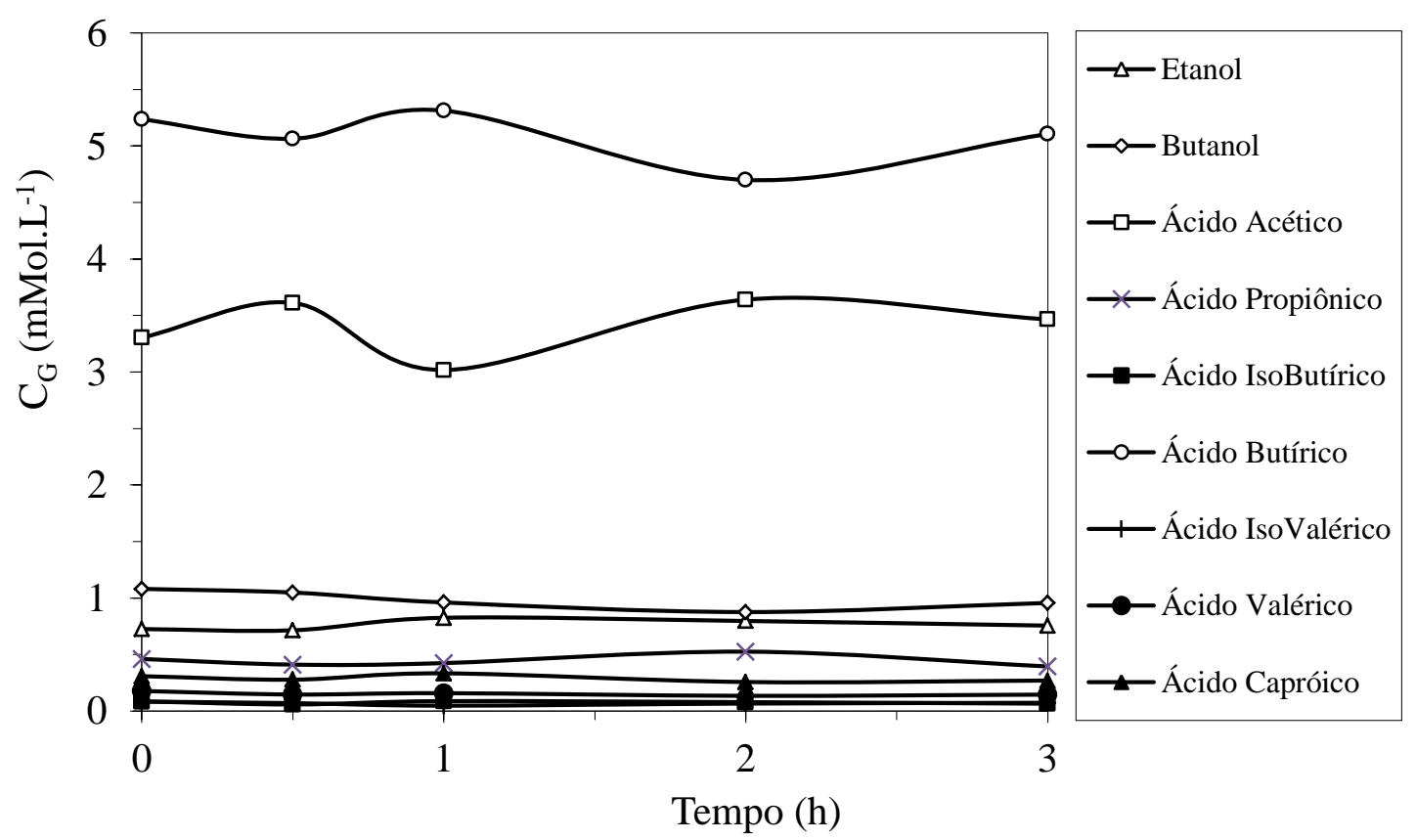

Figura 5.100 - Concentração dos compostos intermediários ao longo do ciclo no ensaio 19: $\square$ - ácido acético; $\Delta$ - etanol; O - ácido butírico; - ácido isobutírico; $\boldsymbol{\Delta}$ - ácido capróico; ácido valérico; -x-ácido propiônico; $\diamond$ butanol; + ácido isovalérico 
A produção volumétrica acumulada de biogás e os desvios padrões de cada um dos pontos podem ser observados na Figura 5.101 e o perfil das concentrações de cada um dos gases e suas respectivas porcentagens podem ser observados na Figura 5.102. A produção de biogás foi altíssima e muito estável, contendo $68 \%$ de $\mathrm{H}_{2}, 30 \%$ de $\mathrm{CO}_{2}$ e apenas $2 \%$ de $\mathrm{CH}_{4}$, revelando-se como a melhor qualidade de biogás dentre todos os ensaios.

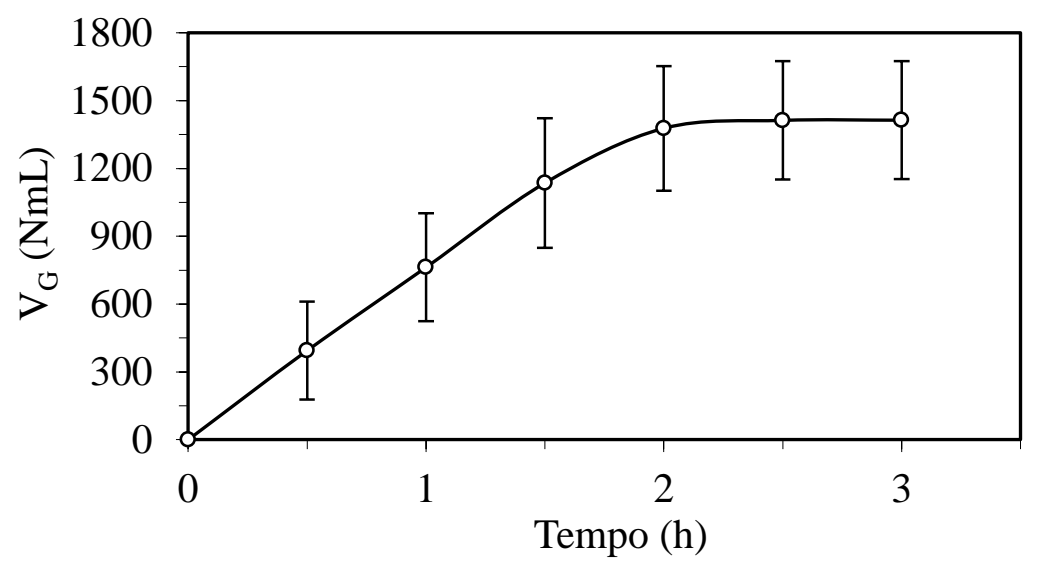

Figura 5.101 - Produção volumétrica média acumulada do biogás durante o ciclo no ensaio 19
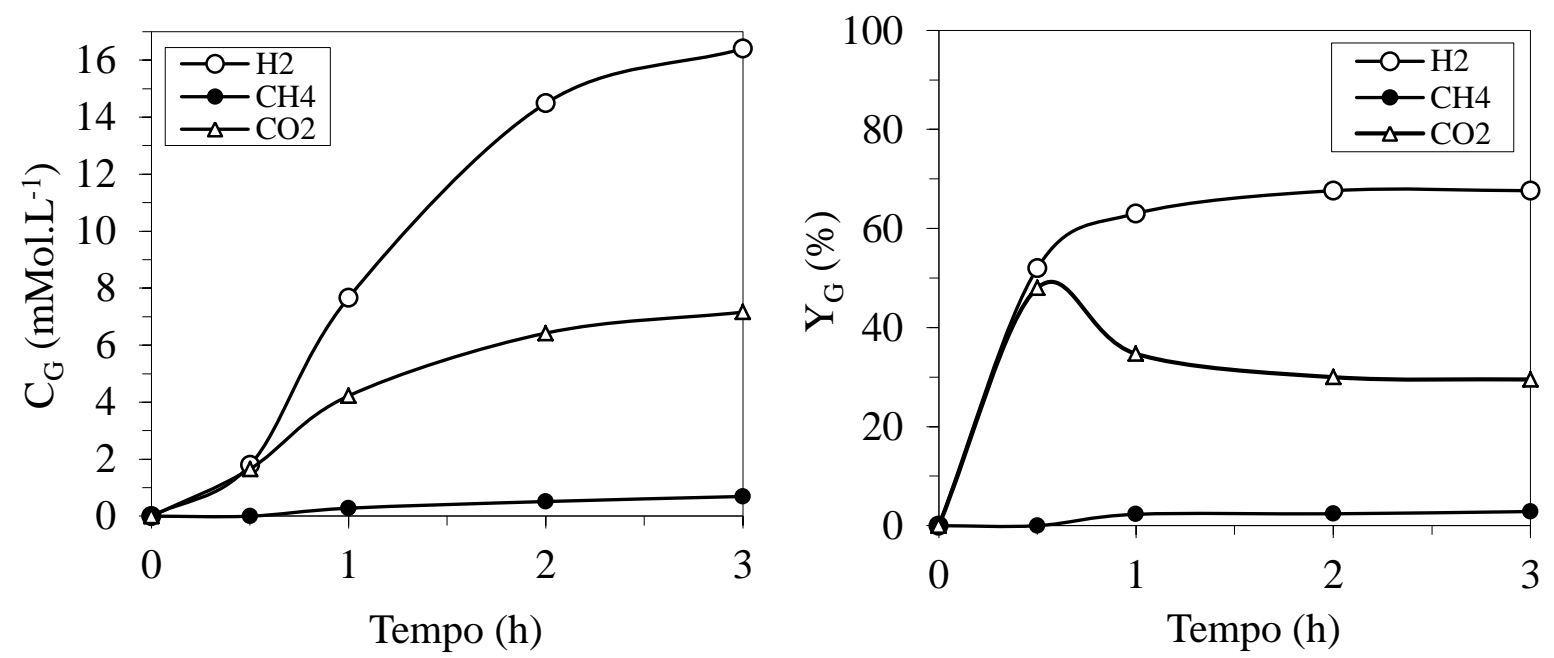

Figura 5.102 - Concentração dos compostos do biogás durante o ciclo e suas respectivas porcentagens no ensaio 19: $\odot-\mathrm{H}_{2} ; \bullet-\mathrm{CH}_{4} ; \Delta-\mathrm{CO}_{2}$ 


\subsubsection{Análise comparativa entre os ensaios 12 a 19}

O objetivo desta seção é comparar os ensaios de 12 a 19 para verificar quais parâmetros foram favorecidos em cada ensaio. Os parâmetros comparados serão a matéria orgânica (englobando DQO, carga orgânica aplicada e removida e balanços de massa para verificar a remoção da glicerina); pH, alcalinidade e ácidos (AVT e AVI) e, por último, parâmetros relativos à produção de biohidrogênio.

\section{(a) Matéria orgânica}

Primeiramente, as Figuras 5.103 e 5.104 mostram, respectivamente, o monitoramento da DQO e as eficiências de remoção de matéria orgânica para amostras filtradas e não filtradas. Analisando essas figuras, percebe-se que, embora haja a diferença nas concentrações de matéria orgânica no afluente e no efluente devido às diferentes COVAs aplicadas, não há grandes variações nas eficiências de remoção de matéria orgânica entre os ensaios; de fato, a máxima eficiência atingida foi de 38\% para amostras filtradas no ensaio 17 (COVA igual a 10,6 gDQO. $\mathrm{L}^{-1} \cdot \mathrm{d}^{-1}$ ) e a eficiência mínima foi de $17 \%$ para amostras filtradas no ensaio 18 (COVA igual a 13,9 gDQO.L $\left.\mathrm{L}^{-1} \cdot \mathrm{d}^{-1}\right)$. Essa baixa remoção era esperada, já que a remoção de matéria orgânica na forma de DQO corresponde apenas a uma parcela de dióxido de carbono do biogás e a absorção da biomassa para a formação de novas células, sendo a maior parte convertida para ácidos orgânicos e solventes. Para que o sistema apresente um alto índice de remoção de matéria orgânica, seria necessário um reator metanogênico na sequência do processo para converter esses ácidos voláteis totais e intermediários em biogás. 


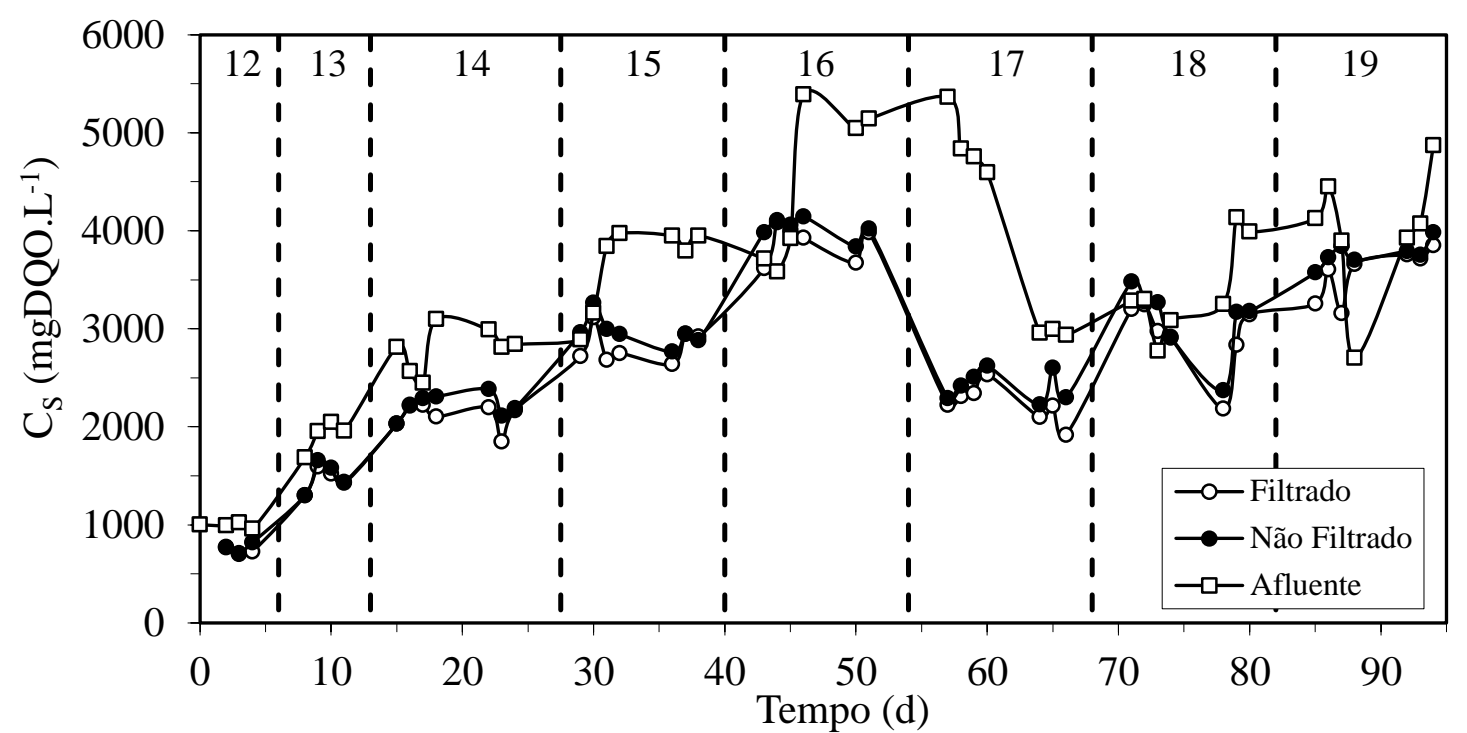

Figura 5.103 - Monitoramento da DQO nos ensaios de 12 a 19: $\square-$ afluente amostras não filtradas; - - efluente amostras não filtradas; ○ - efluente amostras filtradas

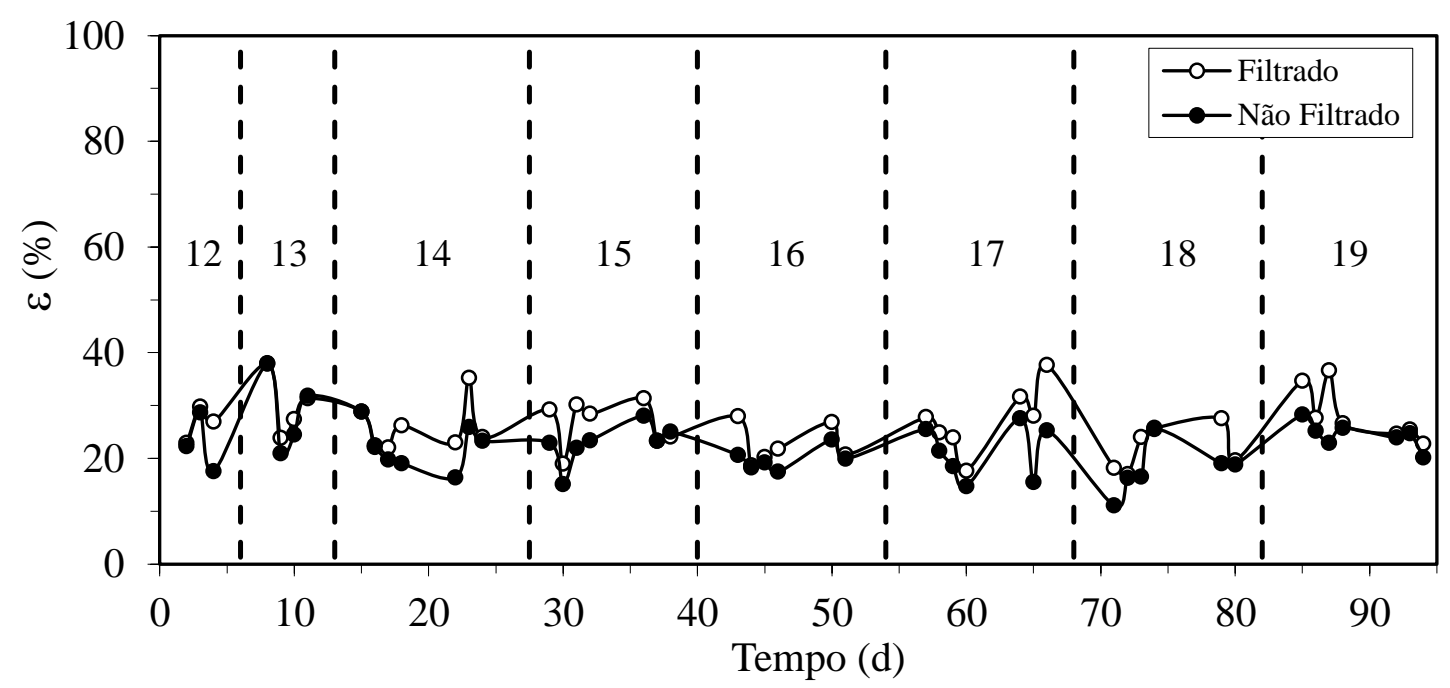

Figura 5.104 - Eficiência de remoção de matéria orgânica na forma de DQO nos ensaios de 12 a 19: - - amostras não filtradas; 0 - amostras filtradas

Para realizar a comparação de remoção de DQO em termos de COVA e COVR, temse a Tabela 5.13. O ensaio 19 foi o que atingiu a maior carga orgânica volumétrica removida (5,0 gDQO. $\left.\mathrm{L}^{-1} \cdot \mathrm{d}^{-1}\right)$, o que também representa a maior remoção em relação a carga orgânica volumétrica aplicada quando se comparam os ensaios de 14 a 19.

Em relação à carga orgânica específica aplicada e removida, o ensaio 16 foi o que apresentou a maior COEA (7,9 gDQO.gSVT $\left.{ }^{-1} \cdot \mathrm{d}^{-1}\right)$ e a maior COER $\left(1,8 \mathrm{gDQO} \cdot \mathrm{gSVT}^{-1} \cdot \mathrm{d}^{-1}\right)$. 
É importante ressaltar que não foi notada uma tendência clara em relação à variação da carga orgânica (tanto a volumétrica quanto a específica) influenciar na remoção de matéria orgânica do efluente; resultado que era esperado, já que a demanda química de oxigênio não é um bom parâmetro para avaliar reatores acidogênicos.

Tabela 5.13 - Comparação entre COVA, COVR, COEA e COER nos ensaios de 12 a 19

\begin{tabular}{cccccccccc}
\hline & Parâmetro & 12 & 13 & 14 & 15 & 16 & 17 & 18 & 19 \\
\hline COVA & $\left(\right.$ gDQO.L $\left.{ }^{-1} \cdot \mathrm{d}^{-1}\right)$ & 2,6 & 5,4 & 7,6 & 10,4 & 13,3 & 10,6 & 13,9 & 17,8 \\
COVR & $\left(\mathrm{gDQO}^{-1} \cdot \mathrm{d}^{-1}\right)$ & 0,7 & 1,6 & 2,0 & 2,8 & 3,0 & 2,9 & 3,5 & 5,0 \\
COEA & $\left(\mathrm{gDQO} . \mathrm{gSVT}^{-1} \cdot \mathrm{d}^{-1}\right)$ & - & - & 3,6 & 4,5 & 7,9 & 4,6 & 5,5 & 5,9 \\
COER & $\left(\mathrm{gDQO}_{\mathrm{gSVT}}{ }^{-1} \cdot \mathrm{d}^{-1}\right)$ & - & - & 0,9 & 1,2 & 1,8 & 1,3 & 1,4 & 1,7 \\
\hline
\end{tabular}

A conversão da glicerina, em principalmente ácidos orgânicos e solventes, pôde ser verificada por um balanço de massa nas amostras do efluente do reator. Foi feita a comparação do valor de DQO no efluente com a soma dos valores DQO dos ácidos, dos solventes e da biomassa, calculados pelo equivalente-grama de cada um dos compostos (Tabela 5.14) para se ter uma estimativa da glicerina consumida pelo processo.

O cálculo do balanço de massa para todos os ensaios no monitoramento diário encontra-se na Tabela 5.15. Esta tabela mostra o balanço da DQO com os AVT (valores médios para cada ensaio utilizando a Equação 4.23); para este balanço, foi considerado que os AVT tinham o equivalente-grama do ácido acético (como o ácido acético tem o menor equivalente-grama dentre todos os ácidos, foi assegurado que o cálculo da glicerina removida não foi superestimado). Esse balanço consiste na ideia de que a DQO real da glicerina não consumida $\left(\mathrm{DQO}_{\mathrm{GNC}}\right)$ seria a DQO do efluente medida no monitoramento diário menos a DQO dos ácidos voláteis totais e a DQO da biomassa; então a DQO da glicerina consumida $\left(\mathrm{DQO}_{\mathrm{GC}}\right)$ é a DQO do afluente menos a DQO real do efluente.

A Tabela 5.16 mostra o balanço da DQO considerando todos os AVI durante os perfis (Equações 4.25 e 4.26). É a mesma ideia do balanço realizado para o monitoramento diário, 
mas, neste caso, os ácidos voláteis totais foram discriminados em ácidos voláteis intermediários e foi utilizado o equivalente-grama de cada um dos ácidos.

As eficiências considerando apenas a remoção de glicerina $\left(\varepsilon_{\text {SFReal }}\right)$ apresentam valores bem superiores: o ensaio 19 chegou a $46 \%$ de remoção em relação ao monitoramento diário e o ensaio 14 chegou a $77 \%$ de remoção durante o perfil.

Tabela 5.14 - Equações bioquímicas e equivalente-grama dos compostos em DQO

\section{Componente}

Equivalente-

$\operatorname{grama}\left(\mathrm{gO}_{2} / \mathrm{g}\right)$

\begin{tabular}{crr}
\hline Glicerina & $\mathrm{C}_{3} \mathrm{H}_{8} \mathrm{O}_{3}+\frac{7}{2} \mathrm{O}_{2} \rightarrow 3 \mathrm{CO}_{2}+4 \mathrm{H}_{2} \mathrm{O}$ & 1,216 \\
Etanol & $\mathrm{C}_{2} \mathrm{H}_{6} \mathrm{O}+2 \mathrm{O}_{2} \rightarrow 2 \mathrm{CO}_{2}+3 \mathrm{H}_{2} \mathrm{O}$ & 1,391 \\
n-Butanol & $\mathrm{C}_{4} \mathrm{H}_{10} \mathrm{O}+6 \mathrm{O}_{2} \rightarrow 4 \mathrm{CO}_{2}+5 \mathrm{H}_{2} \mathrm{O}$ & 2,590 \\
Ácido acético & $\mathrm{C}_{2} \mathrm{H}_{4} \mathrm{O}_{2}+2 \mathrm{O}_{2} \rightarrow 2 \mathrm{CO}_{2}+2 \mathrm{H}_{2} \mathrm{O}$ & 1,006 \\
Ácido propiônico & $\mathrm{C}_{3} \mathrm{H}_{6} \mathrm{O}_{2}+\frac{7}{2} \mathrm{O}_{2} \rightarrow 3 \mathrm{CO}_{2}+3 \mathrm{H}_{2} \mathrm{O}$ & 1,514 \\
Ácido isobutírico & $\mathrm{C}_{4} \mathrm{H}_{8} \mathrm{O}_{2}+5 \mathrm{O}_{2} \rightarrow 4 \mathrm{CO}_{2}+4 \mathrm{H}_{2} \mathrm{O}$ & 1,818 \\
Ácido butírico & $\mathrm{C}_{4} \mathrm{H}_{8} \mathrm{O}_{2}+5 \mathrm{O}_{2} \rightarrow 4 \mathrm{CO}_{2}+4 \mathrm{H}_{2} \mathrm{O}$ & 2,036 \\
Ácido valérico & $\mathrm{C}_{5} \mathrm{H}_{10} \mathrm{O}_{2}+\frac{13}{2} \mathrm{O}_{2} \rightarrow 5 \mathrm{CO}_{2}+5 \mathrm{H}_{2} \mathrm{O}$ & 2,036 \\
Ácido iso-valérico & $\mathrm{C}_{5} \mathrm{H}_{10} \mathrm{O}_{2}+\frac{13}{2} \mathrm{O}_{2} \rightarrow 5 \mathrm{CO}_{2}+5 \mathrm{H}_{2} \mathrm{O}$ & 2,196 \\
Ácido capróico & $\mathrm{C}_{6} \mathrm{H}_{12} \mathrm{O}_{2}+8 \mathrm{O}_{2} \rightarrow 6 \mathrm{CO}_{2}+6 \mathrm{H}_{2} \mathrm{O}$ & 1,343 \\
Biomassa & $\mathrm{C}_{5} \mathrm{H}_{9} \mathrm{O}_{3} \mathrm{~N}+\frac{11}{2} \mathrm{O}_{2} \rightarrow 5 \mathrm{CO}_{2}+\frac{9}{2} \mathrm{H}_{2} \mathrm{O}$ & \\
\hline
\end{tabular}

Tabela 5.15 - Balanço de massa durante o monitoramento diário nos ensaios de 12 a 19

\begin{tabular}{cccccccc}
\hline Ensaio & $\begin{array}{c}\text { DQO }_{\mathrm{CAFL}} \\
\left(\mathrm{mgDQO} . \mathrm{L}^{-1}\right)\end{array}$ & $\begin{array}{c}\mathrm{DQO}_{\mathrm{CSF}} \\
\left(\mathrm{mgDQO} . \mathrm{L}^{-1}\right)\end{array}$ & $\begin{array}{c}\mathrm{AVT} \\
\left(\mathrm{mgH}_{\left.\mathrm{AC} \cdot \mathrm{L}^{-1}\right)}\right.\end{array}$ & $\begin{array}{c}\mathrm{DQO}_{\mathrm{AVT}} \\
\left(\mathrm{mgDQO} . \mathrm{L}^{-1}\right)\end{array}$ & $\begin{array}{c}\mathrm{DQO}_{\text {Biomassa }} \\
\left(\mathrm{mgSSV} . \mathrm{L}^{-1}\right)\end{array}$ & $\begin{array}{c}\mathrm{DQO}_{\mathrm{GC}} \\
\left(\mathrm{mgDQO} . \mathrm{L}^{-1}\right)\end{array}$ & $\begin{array}{c}\varepsilon_{\text {SFReal }} \\
(\%)\end{array}$ \\
\hline 14 & 2804 & 2103 & 464 & 467 & 86 & 1254 & 45 \\
15 & 3808 & 2808 & 597 & 601 & 52 & 1653 & 43 \\
16 & 5138 & 3861 & 708 & 712 & 83 & 2073 & 40 \\
17 & 3953 & 2900 & 619 & 623 & 43 & 1719 & 43 \\
18 & 3887 & 2890 & 555 & 558 & 96 & 1650 & 42 \\
19 & 4968 & 3524 & 789 & 794 & 41 & 2279 & 46 \\
\hline
\end{tabular}


Tabela 5.16 - Balanço de massa durante os perfis nos ensaios de 12 a 19

\begin{tabular}{|c|c|c|c|c|c|c|c|}
\hline Ensaio & $\begin{array}{l}\text { Tempo } \\
\text { (h) }\end{array}$ & $\begin{array}{c}\mathrm{DQO}_{\mathrm{CAFL}} \\
\left(\mathrm{mgDQO} . \mathrm{L}^{-1}\right)\end{array}$ & 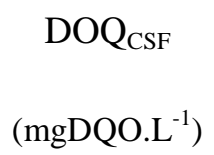 & $\begin{array}{c}\mathrm{DQO}_{\mathrm{AVI}} \\
\left(\mathrm{mgDQO} . \mathrm{L}^{-1}\right)\end{array}$ & $\begin{array}{c}\mathrm{DQO}_{\text {Biomassa }} \\
\left(\mathrm{mgDQO} . \mathrm{L}^{-1}\right)\end{array}$ & $\begin{array}{c}\mathrm{C}_{\text {SFReal }} \\
\left(\mathrm{mgDQO} . \mathrm{L}^{-1}\right)\end{array}$ & $\begin{array}{r}\varepsilon_{\text {SFReal }} \\
(\%)\end{array}$ \\
\hline \multirow{6}{*}{14} & 0,0 & \multirow{6}{*}{3160,0} & 2168 & 1040 & \multirow{6}{*}{86} & 1042 & 0 \\
\hline & 0,5 & & 2040 & 1168 & & 786 & 73 \\
\hline & 1,0 & & 2284 & 1151 & & 1046 & 66 \\
\hline & 2,0 & & 2110 & 1196 & & 828 & 73 \\
\hline & 3,0 & & 2152 & 1232 & & 834 & 73 \\
\hline & 4,0 & & 1935 & 1129 & & 720 & 77 \\
\hline \multirow{6}{*}{15} & 0,0 & \multirow{6}{*}{3920,5} & 2916 & 1634 & \multirow{6}{*}{52} & 1230 & 0 \\
\hline & 0,5 & & 2922 & 1649 & & 1222 & 66 \\
\hline & 1,0 & & 2733 & 1652 & & 1029 & 73 \\
\hline & 2,0 & & 2820 & 1603 & & 1165 & 70 \\
\hline & 3,0 & & 2742 & 1581 & & 1109 & 71 \\
\hline & 4,0 & & 2962 & 1533 & & 1377 & 64 \\
\hline \multirow{6}{*}{16} & 0,0 & \multirow{6}{*}{4754,0} & 3980 & 1493 & \multirow{6}{*}{83} & 2403 & 0 \\
\hline & 0,5 & & 4304 & 1442 & & 2779 & 38 \\
\hline & 1,0 & & 4212 & 1418 & & 2711 & 41 \\
\hline & 2,0 & & 4159 & 1437 & & 2639 & 44 \\
\hline & 3,0 & & 4259 & 1484 & & 2692 & 43 \\
\hline & 4,0 & & 4253 & 1507 & & 2664 & 44 \\
\hline \multirow{5}{*}{17} & 0,0 & \multirow{5}{*}{3248,5} & 1915 & 969 & \multirow{5}{*}{43} & 903 & 0 \\
\hline & 0,5 & & 2311 & 1049 & & 1219 & 59 \\
\hline & 1,0 & & 2060 & 931 & & 1086 & 65 \\
\hline & 2,0 & & 2217 & 1033 & & 1142 & 64 \\
\hline & 3,0 & & 2245 & 941 & & 1261 & 61 \\
\hline \multirow{5}{*}{18} & 0,0 & \multirow{5}{*}{4070,0} & 3146 & 1312 & \multirow{5}{*}{96} & 1738 & 0 \\
\hline & 0,5 & & 3083 & 1442 & & 1545 & 59 \\
\hline & 1,0 & & 2969 & 1403 & & 1471 & 63 \\
\hline & 2,0 & & 3060 & 1151 & & 1813 & 55 \\
\hline & 3,0 & & 2936 & 1316 & & 1524 & 62 \\
\hline \multirow{5}{*}{19} & 0,0 & \multirow{5}{*}{5174,1} & 3853 & 1490 & \multirow{5}{*}{41} & 2321 & 0 \\
\hline & 0,5 & & 3980 & 1447 & & 2492 & 49 \\
\hline & 1,0 & & 3869 & 1460 & & 2368 & 53 \\
\hline & 2,0 & & 3761 & 1370 & & 2349 & 54 \\
\hline & 3,0 & & 3825 & 1428 & & 2356 & 54 \\
\hline
\end{tabular}


(b) pH, alcalinidade e ácidos voláteis

As Figuras 5.105 e 5.106 mostram a variação do $\mathrm{pH}$ e da alcalinidade total durante os ensaios, respectivamente. É possível notar que não há variações significativas de pH entre os ensaios 14 a 19 (nos ensaios 12 e 13, o efluente saiu pouco acidificado devido a baixa COVA aplicada ao sistema). Para ter-se uma ideia: o pH médio do afluente (ensaios de 14 a 19) foi de 7,6 com um desvio padrão de 0,1 e o pH médio do efluente nesses mesmos ensaios foi de 4,5 com um desvio padrão de 0,2 . Há um desacordo entre estudos sobre qual seria o pH ótimo para a produção de hidrogênio: Zhang et al (2006) achou um pH ótimo para o seu sistema de 4,5, mas Kumar (2000) achou um pH ótimo de 6,0 e Zhao (2008) achou um pH de 7,0. Para este trabalho, o pH por volta de 4,5 foi excelente para a produção de hidrogênio.

A alcalinidade total do afluente foi quase que completamente consumida na maior parte dos ensaios, chegando a $0 \mathrm{mgCaCO}_{3} \cdot \mathrm{L}^{-1}$ nos ensaios 16 e 19 (concentração do afluente de $\left.5000 \mathrm{mgDQO} \cdot \mathrm{L}^{-1}\right)$.

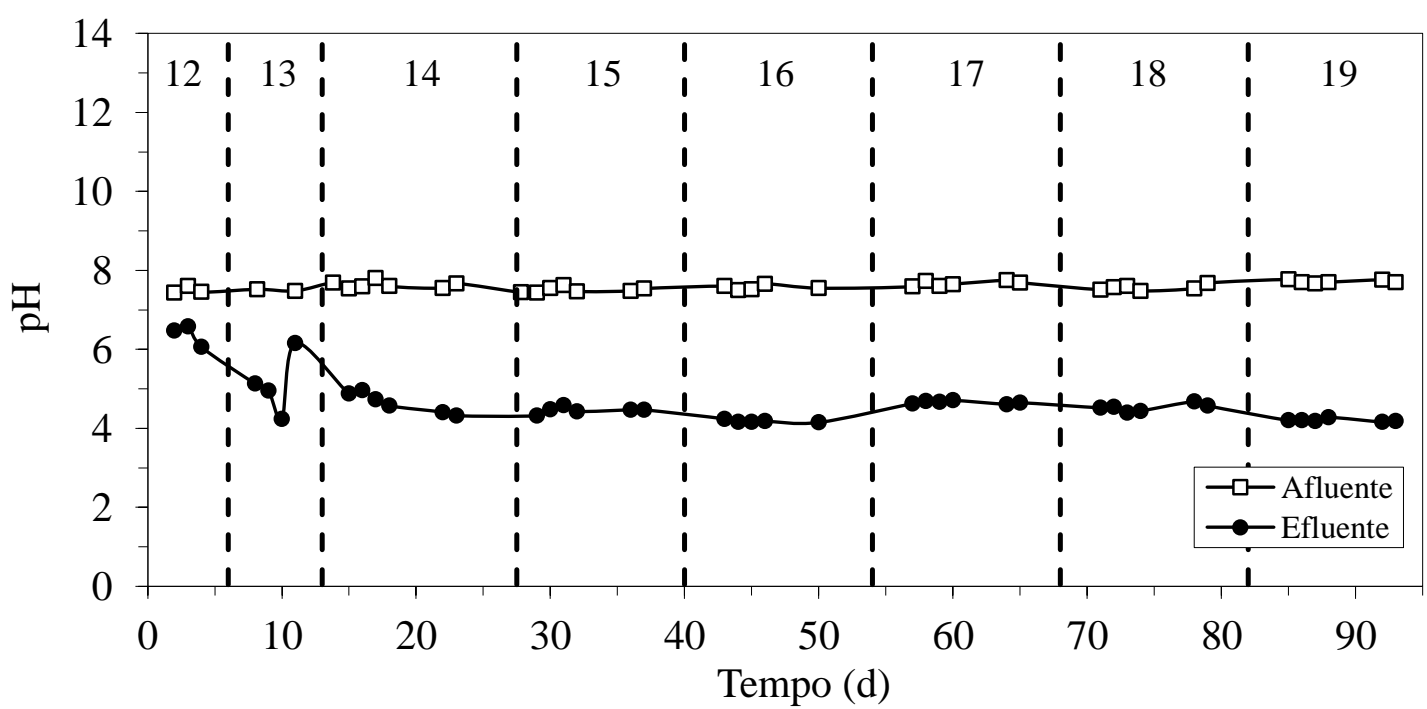

Figura 5.105 - Valores de pH nos ensaios de 12 a 19: $\square-$ afluente; $\bullet-$ efluente 


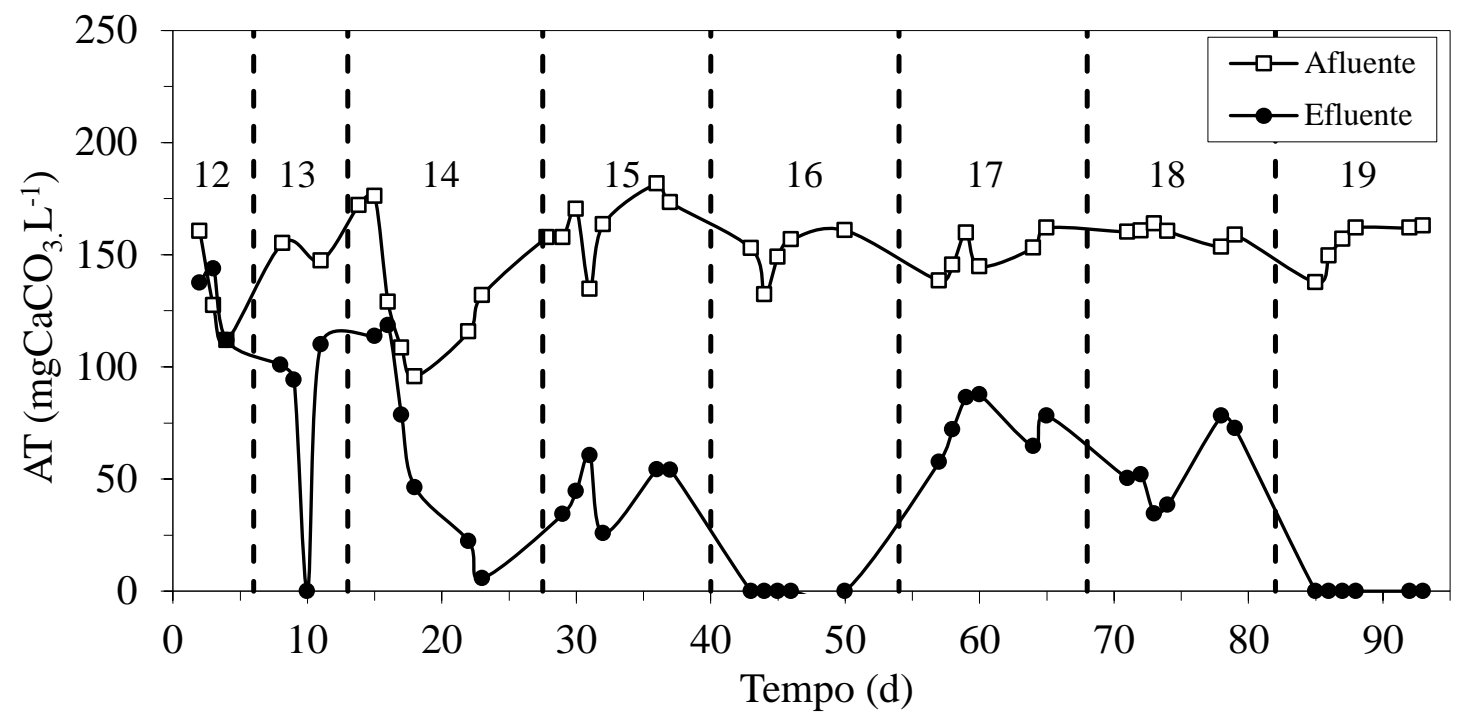

Figura 5.106 - Valores de alcalinidade total (AT) entre os ensaios de 12 a 19: $\square$-afluente; $\bullet$ - efluente

A Figura 5.107 mostra a concentração de ácidos voláteis totais ao longo dos ensaios, observa-se que o ensaio 19 obteve o ambiente mais acidificado, com uma média de 789 mgHAc. $\mathrm{L}^{-1}$, o que representa uma boa acidificação do meio, mas ainda assim não igual a conseguida com sacarose na primeira condição preliminar deste trabalho (877 mgHAc. $\left.\mathrm{L}^{-1}\right)$.

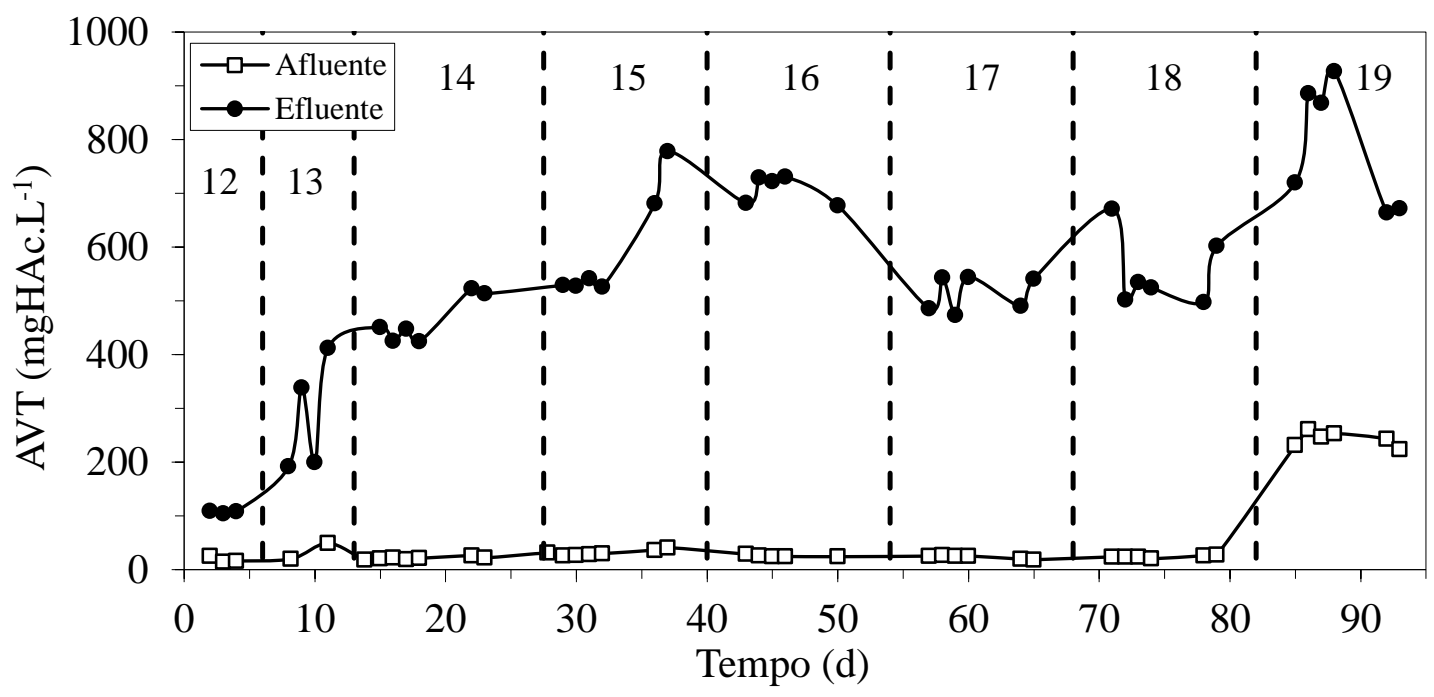

Figura 5.107 - Valores de ácidos voláteis totais (AVT) nos ensaios de 12 a 19: $\square$-afluente; - - efluente

Analisando os ácidos voláteis intermediários, nota-se que há um predomínio da via do ácido acético e do ácido butírico (como é esperado devido aos caminhos metabólicos da 
acidogênese), seguido do etanol e do butanol, porém não foi observado uma tendência clara quanto à distribuição molar desses compostos em relação ao $t_{C}$ ou na concentração afluente. A Tabela 5.17 mostra as porcentagens molares para todos os ensaios.

Tabela 5.17 - Porcentagens molares dos ácidos voláteis intermediários para todos os ensaios

\section{Ensaio}

\begin{tabular}{ccccccc} 
& 14 & 15 & 16 & 17 & 18 & 19 \\
\hline Acetona & 0,0 & 0,0 & 0,0 & 0,0 & 0,0 & 0,0 \\
Metanol & 0,0 & 0,0 & 0,0 & 0,0 & 0,0 & 0,0 \\
Etanol & 17,9 & 7,4 & 8,0 & 16,2 & 12,6 & 6,8 \\
Butanol & 3,6 & 18,0 & 18,2 & 9,7 & 8,3 & 8,7 \\
Ácido Acético & 32,5 & 28,3 & 37,4 & 43,1 & 35,0 & 30,3 \\
Ácido Propiônico & 4,8 & 2,6 & 3,1 & 7,1 & 5,5 & 3,9 \\
Ácido Isobutírico & 5,0 & 2,1 & 0,7 & 0,7 & 0,7 & 0,7 \\
Ácido Butírico & 31,0 & 35,9 & 28,3 & 18,8 & 33,5 & 45,1 \\
Ácido Isovalérico & 0,7 & 0,7 & 0,6 & 0,7 & 0,6 & 0,6 \\
Ácido Valérico & 1,7 & 1,6 & 1,3 & 2,0 & 1,9 & 1,3 \\
Ácido Capróico & 2,7 & 3,5 & 2,4 & 1,8 & 2,0 & 2,6 \\
Total (mg.L - $^{-1}$ ) & 10,2 & 12,0 & 12,0 & 9,4 & 11,8 & 11,3 \\
\hline
\end{tabular}

\section{(c) Produção de biohidrogênio}

A Tabela 5.18 mostra a comparação entre os ensaios nos parâmetros relativos à produção de biohidrogênio. O ensaio 19 foi o que obteve a maior produtividade molar por uma grande margem $\left(100,8 \mathrm{molH}_{2} \cdot \mathrm{m}^{-3} \mathrm{~d}^{-1}\right.$ contra $70,1 \mathrm{molH}_{2} \cdot \mathrm{m}^{-3} \mathrm{~d}^{-1}$ do ensaio 15$)$; no entanto, o ensaio 15 obteve o maior rendimento molar de hidrogênio em relação à carga orgânica aplicada $\left(6,7 \mathrm{molH}_{2} \cdot \mathrm{kgDQO}^{-1}\right)$, mas deve-se levar em conta que este ensaio em particular teve uma produção instável de biogás e esse RMCA deve-se a um dia de produção excepcionalmente alta que aconteceu durante a operação.

Em relação à produtividade molar específica, o ensaio 16 mostrou o melhor resultado $\left(39,7 \mathrm{molH}_{2} \cdot \mathrm{kgSVT}^{-1} \cdot \mathrm{d}^{-1}\right)$. 
Tabela 5.18 - Comparação entre $\mathrm{n}_{\mathrm{H} 2}$, PrM, PrME, RMCA e RMCR nos ensaios de 12 a 19.

\begin{tabular}{cccccccccc}
\hline \multicolumn{2}{c}{ Parâmetro } & 12 & 13 & 14 & 15 & 16 & 17 & 18 & 19 \\
\hline $\mathrm{n}_{\mathrm{H} 2}$ & $\left(\mathrm{molH}_{2} \cdot \mathrm{d}^{-1}\right)$ & 0,001 & 0,006 & 0,02 & 0,24 & 0,23 & 0,10 & 0,13 & 0,34 \\
$\mathrm{PrM}$ & $\left(\mathrm{molH}_{2} \cdot \mathrm{m}^{-3} \mathrm{~d}^{-1}\right)$ & 0,2 & 1,6 & 5,6 & 70,1 & 66,7 & 28,9 & 37,3 & 100,8 \\
$\mathrm{PrME}$ & $\left(\mathrm{molH}_{2} \cdot \mathrm{kgSVT}^{-1} \mathrm{~d}^{-1}\right)$ & 0,1 & 0,3 & 2,7 & 30,5 & 39,7 & 12,6 & 14,8 & 33,6 \\
$\mathrm{RMCA}_{\mathrm{DQO}}$ & $\left(\mathrm{molH}_{2} \cdot \mathrm{kgDQO}^{-1}\right)$ & 0,3 & 1,0 & 0,7 & 6,7 & 5,0 & 2,7 & 2,7 & 5,7 \\
$\mathrm{RMCR}_{\mathrm{DQO}}$ & $\left(\mathrm{molH}_{2} \cdot \mathrm{kgDQO}^{-1}\right)$ & 0,001 & 0,006 & 2,9 & 25,5 & 22,2 & 10,0 & 10,7 & 20,0 \\
\hline
\end{tabular}

A Tabela 5.19 mostra a comparação em relação à concentração molar e porcentagem de cada um dos biogases produzidos durante a operação e a Figura 5.108 facilita a visualização das porcentagens molares dos biogases no final da operação em cada um dos ensaios. Os ensaios 16 e 19 foram os que obtiveram maior porcentagem de hidrogênio (68\%) e menor porcentagem de metano (3\%).

Tabela 5.19 - Fração molar referente ao biogás nos ensaios de 12 a 19.

\begin{tabular}{ccccccc}
\hline \multirow{2}{*}{ Ensaio } & \multicolumn{3}{c}{$\mathrm{C}_{\mathrm{G}}\left(\mathrm{mmol} . \mathrm{L}^{-1}\right)$} & \multicolumn{3}{c}{$\mathrm{Y}_{\mathrm{G}}(\%)$} \\
& $\mathrm{H}_{2}$ & $\mathrm{CH}_{4}$ & $\mathrm{CO}_{2}$ & $\mathrm{H}_{2}$ & $\mathrm{CH}_{4}$ & $\mathrm{CO}_{2}$ \\
\hline 12 & 1,06 & 0,29 & 2,77 & 26 & 7 & 67 \\
13 & 0,72 & 1,16 & 3,51 & 13 & 21 & 65 \\
14 & 2,82 & 1,11 & 3,24 & 39 & 15 & 45 \\
15 & 7,60 & 1,84 & 4,93 & 53 & 13 & 34 \\
16 & 14,08 & 0,65 & 6,11 & 68 & 3 & 29 \\
17 & 3,88 & 2,12 & 5,29 & 34 & 19 & 47 \\
18 & 6,46 & 1,19 & 5,80 & 48 & 9 & 43 \\
19 & 16,40 & 0,69 & 7,16 & 68 & 3 & 30 \\
\hline
\end{tabular}




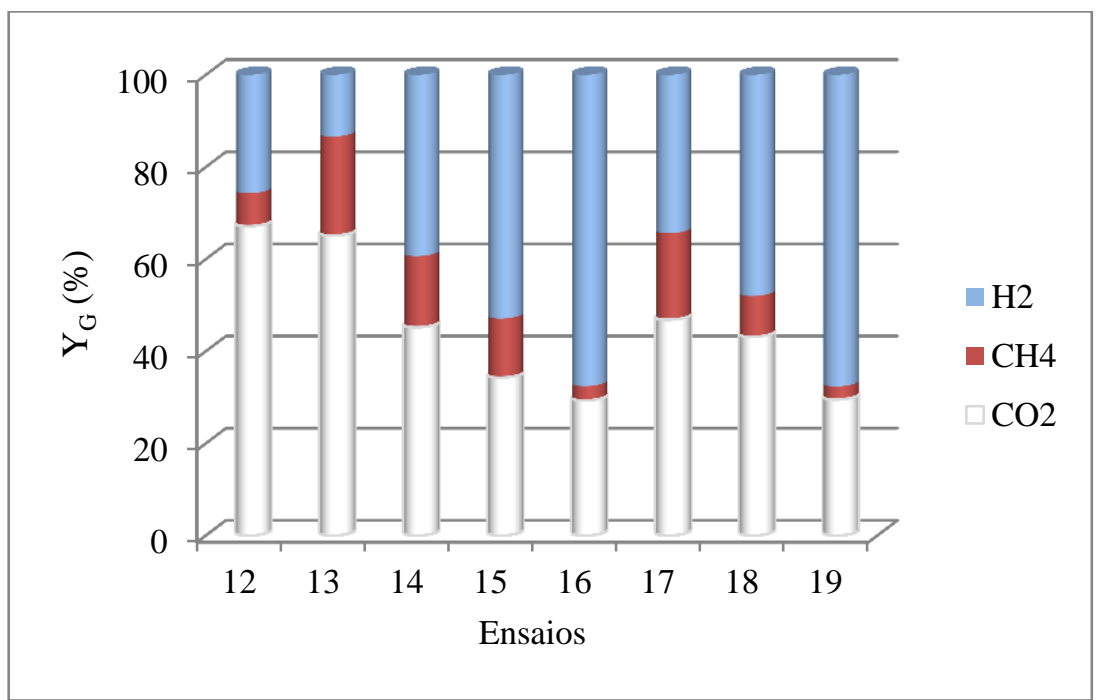

Figura 5.108 - Porcentagens $\left(\mathrm{Y}_{\mathrm{G}}\right)$ dos compostos do biogás:• - hidrogênio, • - metano, o- dióxido de carbono.

Nesta segunda fase, observou-se que maiores valores de COVA aumentaram a acidificação do efluente e, consequentemente, resultaram em maiores produtividades molares de hidrogênio, ajudando na inibição parcial da produção de metano.

Realizando uma comparação com trabalhos anteriores, Inoue (2013) obteve uma produtividade máxima de $67,9 \mathrm{molH}_{2} \cdot \mathrm{m}^{-3} \mathrm{~d}^{-1}$ tratando sacarose em AnSBBR operado em batelada alimentada com agitação mecânica, Manssouri et al. (2012) obteve produtividade máxima de 21,4 molH $\mathrm{m}_{2} \cdot \mathrm{m}^{-3} \mathrm{~d}^{-1}$ tratando esse mesmo efluente em AnSBBR com agitação mecânica (mas com operação em batelada sequencial) - ambos os trabalhos atingiram essa produtividade com COVA igual a 18,0 molH $2 \cdot \mathrm{kgDQO}^{-1}$ e Santos (2012) obteve $27,9 \mathrm{molH} 2 \cdot \mathrm{m}^{-3} \mathrm{~d}^{-1}$ em um AnSBBR com recirculação da fase líquida também tratando sacarose (COVA de 27,0 molH $2 \cdot \mathrm{kgDQO}^{-1}$ ). Esses dados mostram a relevância dos resultados encontrados nessa Fase, já que se obteve para o tratamento da glicerina, um substrato reconhecidamente mais difícil de degradar, $100,8 \mathrm{molH}_{2} \cdot \mathrm{m}^{-3} \mathrm{~d}^{-1}$.

Para aprofundar a comparação deste trabalho com os de outros pesquisadores que também utilizaram a glicerina como substrato, é necessário calcular o rendimento molar de hidrogênio em relação ao consumo molar de glicerina. Para isso, utilizou-se as Equações 4.27, 
4.28 e 4.29 que calculam o $\mathrm{RMCA}_{\text {Glicerina, o }} \mathrm{RMCR}_{\text {GlicerinaAVT }}$ e o $\mathrm{RMCR}_{\mathrm{GlicerinaAVI}}$ $\left(\mathrm{molH}_{2} \cdot \mathrm{molglicerina}^{-1}\right)$. A única diferença entre o cálculo do $\mathrm{RMCR}_{\mathrm{GlicerinaAvT}} \mathrm{e}$ do $\mathrm{RMCR}_{\text {GlicerinaAvI }}$ é que o primeiro foi feito com o balanço da glicerina levando em conta os AVT (mgHAc.L ${ }^{-1}$ ) no monitoramento diário e o segundo foi calculado pelo balanço de glicerina do perfil que levava em conta a discriminação dos AVI em todos os ácidos voláteis (através da medida dos AVI no início do ciclo do perfil). Para efeito de comparação, foi

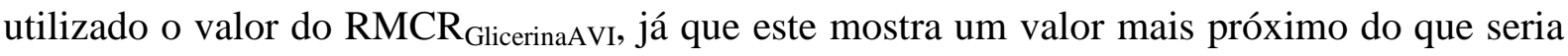
encontrado na realidade se houvesse sido feito um método para determinação de glicerina.

É interessante ter como referência o rendimento máximo que pode ser obtido com o uso da glicerina como substrato, esse rendimento é calculado considerando que toda a glicerina foi convertida em ácido acético. Como mostra a Figura 5.109, o RMCR Glicerina máximo teórico é $3 \mathrm{molH}_{2}$.mol glicerina ${ }^{-1}$.

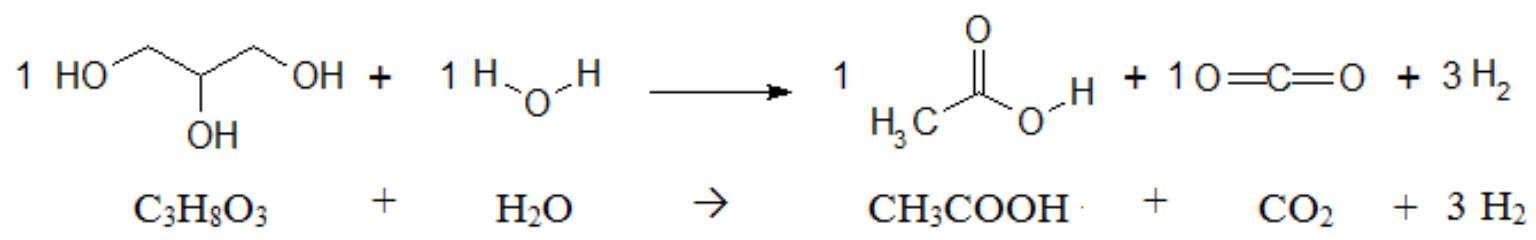

Figura 5.109 - Reação de transformação da glicerina em ácido acético e hidrogênio

A Tabela 5.20 mostra os rendimentos alcançados nos ensaios de 14 a 19 e a Tabela 5.21 a comparação entre os rendimentos de vários trabalhos. Novamente, o ensaio 19 é o que apresenta o melhor RMCR dentre os ensaios realizados na Fase II e dentre os outros trabalhos que também almejaram a produção de biohidrogênio a partir de glicerina. Lembrando que o rendimento calculado neste trabalho é uma estimativa do valor real. 
Tabela 5.20 - Rendimento molar de hidrogênio em relação a glicerina nos ensaios de 14 a 19

\begin{tabular}{|c|c|c|c|c|c|c|}
\hline & 14 & 15 & 16 & 17 & 18 & 19 \\
\hline $\begin{array}{c}\mathrm{RMCA}_{\text {Glicerina }} \\
\left(\mathrm{mol} \mathrm{H}_{2} \cdot \text { mol glicerina }^{-1}\right)\end{array}$ & 0,08 & 0,76 & 0,56 & 0,31 & 0,30 & 0,64 \\
\hline $\begin{array}{l}\mathrm{RMCR}_{\text {GlicerinaAVT }} \\
\left(\text { mol H}_{2} \text { mol glicerina }^{-1}\right)\end{array}$ & 0,18 & 1,72 & 1,45 & 1,12 & 0,70 & 1,38 \\
\hline $\begin{array}{l}\mathrm{RMCR}_{\text {GlicerinaAVI }} \\
\left(\text { mol H}_{2} \text {.mol glicerina }\right. \\
\end{array}$ & 0,13 & 1,11 & 1,08 & 0,52 & 0,54 & 1,19 \\
\hline
\end{tabular}

Tabela 5.21 - Comparação entre trabalhos para avaliar o rendimento molar de hidrogênio em relação a glicerina

\begin{tabular}{|c|c|c|c|c|}
\hline Substrato & Inóculo & Reator & $\begin{array}{c}\mathrm{RMCR}_{\text {Glicerina }} \\
\text { (mol H}_{2} \text {.mol glicerina } \\
\end{array}$ & Referência \\
\hline GPA & Enterobacter aerogenes & PBR & 1,05 & Ito et al. (2005) \\
\hline GBI & Enterobacter aerogenes & PBR & 1,12 & Ito et al. (2005) \\
\hline GPA & Enterobacter aerogenes & Vidro de soro & 0,62 & $\begin{array}{c}\text { Nakashimada et al. } \\
\text { (2002) }\end{array}$ \\
\hline GPA & Escherichia coli & Vidro de soro & 0,94 & $\begin{array}{l}\text { Murarka et al. } \\
\text { (2008) }\end{array}$ \\
\hline GPA & Klebsiella pneumoniae & Vidro de soro & 0,61 & Biebl et al. (1998) \\
\hline GPA & $\begin{array}{c}\text { Lodo de planta de } \\
\text { tratamento de esgoto } \\
\text { doméstico }\end{array}$ & Vidro de soro & 0,80 & Sá et al. (2013) \\
\hline GPA & Solo de cultivo de trigo & Vidro de soro & 0,28 & $\begin{array}{l}\text { Selembo et } \\
\text { al.(2009) }\end{array}$ \\
\hline GBI & Solo de cultivo de trigo & Vidro de soro & 0,31 & $\begin{array}{l}\text { Selembo et al. } \\
\text { (2009) }\end{array}$ \\
\hline GBI & $\begin{array}{l}\text { Lodos de estações de } \\
\text { tratamento de água } \\
\text { residuária de destilaria e } \\
\text { de processamento de } \\
\text { fécula de batata }\end{array}$ & CSTR & 0,05 & $\begin{array}{l}\text { Termudo et al. } \\
\qquad(2008)\end{array}$ \\
\hline GPA & $\begin{array}{l}\text { Lodo de abatedouro de } \\
\text { aves tratado por HST }\end{array}$ & AnSBBR & 1,19 & Este trabalho \\
\hline
\end{tabular}


Levando em consideração todos os resultados encontrados na Fase II, decidiu-se utilizar as condições operacionais do ensaio 19 (5000 mgDQO.L $\mathrm{L}^{-1}$ e 3 horas de tempo de ciclo) para prosseguir com a Fase III.

\subsection{FASE III}

Na Fase III, foram feitos dois ensaios utilizando as melhores condições obtidas na Fase II. O ensaio 20 foi realizado para comprovar se há a necessidade de pré-tratamento do inóculo (utilizando a glicerina P.A.) e o ensaio 21 foi realizado para verificar a produção de biohidrogênio com o resíduo industrial. Lembrando que os dois ensaios foram conduzidos com 5000 mgDQO. $\mathrm{L}^{-1}, 3$ horas de tempo de ciclo e por 14 dias.

\subsubsection{Ensaio 20 (5000 $\mathrm{mgDQO}^{-1}, 3$ horas de tempo de ciclo e inóculo sem tratamento)}

Este ensaio foi realizado utilizando o mesmo procedimento experimental dos ensaios de 12 a 19, com exceção que o inóculo de lodo de abatedouro de aves não passou por nenhum tipo de tratamento térmico (Inóculo 1).

O valor nominal de COVA para o ensaio 20 foi de 17,1 gDQO. $\mathrm{L}^{-1} \cdot \mathrm{d}^{-1}$, a COVA real foi de $17,6 \mathrm{gDQO} \cdot \mathrm{L}^{-1} \cdot \mathrm{d}^{-1} \mathrm{e}$ a COVR atingida foi de 4,6 gDQO. $\mathrm{L}^{-1} \cdot \mathrm{d}^{-1}$. A Tabela 5.20 apresenta a média dos parâmetros monitorados; a biomassa de sólidos voláteis totais no interior do reator ao final do ensaio foi de 9,3 g. Todos os parâmetros mencionados anteriormente sofreram uma redução quando a comparação é feita com o ensaio 19 (no qual foi utilizado lodo com pré-tratamento térmico). 
Tabela 5.22 - Parâmetros médios monitorados no ensaio 20

\begin{tabular}{|c|c|c|c|c|c|c|c|c|c|}
\hline \multirow{2}{*}{\multicolumn{2}{|c|}{ Parâmetro }} & \multicolumn{8}{|c|}{20} \\
\hline & & \multicolumn{4}{|c|}{ Afluente } & \multicolumn{4}{|c|}{ Efluente } \\
\hline $\mathrm{C}_{\mathrm{ST}}$ & $\left(\mathrm{mgDQO} \cdot \mathrm{L}^{-1}\right)$ & 4967 & \pm & 240 & $(8)$ & 3917 & \pm & 184 & $(7)$ \\
\hline $\mathrm{C}_{\mathrm{SF}}$ & $\left(\mathrm{mgDQO} \cdot \mathrm{L}^{-1}\right)$ & & - & & & 3663 & \pm & 176 & ( 7 ) \\
\hline$\varepsilon_{\mathrm{ST}}$ & $(\%)$ & & - & & & 23 & \pm & 4 & $\left(\begin{array}{l}7 \\
\text { ) }\end{array}\right.$ \\
\hline$\varepsilon_{\mathrm{SF}}$ & $(\%)$ & & - & & & 26 & \pm & 4 & ( 7 ) \\
\hline $\mathrm{pH}$ & (u) & 7,7 & \pm & 0,1 & ( 6 ) & 4,3 & \pm & 0,1 & $(7)$ \\
\hline AVT & $\left(\mathrm{mgHAc} . \mathrm{L}^{-1}\right)$ & 25 & \pm & 3 & ( 6 ) & 740 & \pm & 62 & ( 7 ) \\
\hline $\mathrm{AT}$ & $\left(\mathrm{mgCaCO}{ }_{3} \cdot \mathrm{L}^{-1}\right)$ & 142 & \pm & 9 & ( 6 ) & 5 & \pm & 8 & $(7)$ \\
\hline AP & $\left(\mathrm{mgCaCO}_{3} \cdot \mathrm{L}^{-1}\right)$ & 116 & \pm & 7 & ( 6 ) & 0 & \pm & 0 & $(7)$ \\
\hline $\mathrm{AI}$ & $\left(\mathrm{mgCaCO}{ }_{3} \cdot \mathrm{L}^{-1}\right)$ & 26 & \pm & 5 & ( 6 ) & 5 & \pm & 8 & $(7)$ \\
\hline $\mathrm{AB}$ & $\left(\mathrm{mgCaCO}_{3} \cdot \mathrm{L}^{-1}\right)$ & 124 & \pm & 10 & ( 6 ) & 0 & \pm & 0 & $(7)$ \\
\hline ST & $\left(\mathrm{mg} . \mathrm{L}^{-1}\right)$ & 519 & \pm & 52 & (3) & 957 & \pm & 94 & ( 4 ) \\
\hline SVT & $\left(\mathrm{mg} \cdot \mathrm{L}^{-1}\right)$ & 301 & \pm & 87 & (3) & 762 & \pm & 85 & $(4)$ \\
\hline SST & $\left(\mathrm{mg} \cdot \mathrm{L}^{-1}\right)$ & 28 & \pm & 12 & (3) & 84 & \pm & 29 & $(4)$ \\
\hline SSV & $\left(\mathrm{mg} \cdot \mathrm{L}^{-1}\right)$ & 29 & \pm & 12 & (3) & 88 & \pm & 25 & $(4)$ \\
\hline $\mathrm{M}_{\mathrm{SVT}}$ & (g) & & - & & & & & & \\
\hline $\mathrm{Cx}$ & $\left(\mathrm{g} \cdot \mathrm{L}^{-1}\right)$ & & - & & & & & & \\
\hline $\mathrm{Cx}^{\prime}$ & (g.gsuporte ${ }^{-1}$ ) & & - & & & & 0,0 & 976 & \\
\hline $\mathrm{V}_{\mathrm{G}}$ & $(\mathrm{NmL})$ & & - & & & 1272 & \pm & 193 & $\left(\begin{array}{ll}6 & \end{array}\right)$ \\
\hline $\mathrm{V}_{\mathrm{H} 2}$ & $(\mathrm{NmL})$ & & - & & & 873 & \pm & 135 & $\left(\begin{array}{ll}6 & )\end{array}\right.$ \\
\hline COVA & $\left(\mathrm{gDQO} \cdot \mathrm{L}^{-1} \cdot \mathrm{d}^{-1}\right)$ & & 17 & & & & & & \\
\hline COVR & $\left(\right.$ gDQO. $\left.L^{-1} \cdot d^{-1}\right)$ & & - & & & & & & \\
\hline COEA & $\left(\right.$ gDQO.gSVT $\left.{ }^{-1} \cdot d^{-1}\right)$ & & 6 , & & & & & & \\
\hline COER & $\left(\right.$ gDQO.gSVT $\left.{ }^{-1} \cdot d^{-1}\right)$ & & - & & & & & & \\
\hline $\mathrm{n}_{\mathrm{H} 2}$ & $\left(\mathrm{molH}_{2} \cdot \mathrm{d}^{-1}\right)$ & & - & & & & & & \\
\hline PrM & $\left(\mathrm{molH}_{2} \cdot \mathrm{m}^{-3} \cdot \mathrm{d}^{-1}\right)$ & & - & & & & & & \\
\hline PrME & $\left(\mathrm{molH}_{2} \cdot \mathrm{kgSVT}^{-1} \cdot \mathrm{d}^{-1}\right)$ & & - & & & & & & \\
\hline RMCA & $\left(\mathrm{molH}_{2} \cdot \mathrm{kgDQO}^{-1}\right)$ & & - & & & & & & \\
\hline RMCR & $\left(\mathrm{molH}_{2} \cdot \mathrm{kgDQO}^{-1}\right)$ & & - & & & & & 8 & \\
\hline $\mathrm{V}_{\mathrm{A}}$ & (L) & 1,5 & \pm & 0,03 & ( 7 ) & & & & \\
\hline $\mathrm{V}_{\mathrm{R}}$ & (L) & & - & & & & & & \\
\hline
\end{tabular}

(*) Entre parêntese o número de amostras considerado no cálculo da média

A concentração média afluente não filtrada foi de $4967 \mathrm{mgDQO} . \mathrm{L}^{-1}$, efluente não filtrada $3912 \mathrm{mgDQO} . \mathrm{L}^{-1}$ e de efluente filtrada de $3663 \mathrm{mgDQO} . \mathrm{L}^{-1}$ (Figura 5.110), com remoção média para amostras não filtradas de $23 \%$ e para amostras filtradas de $26 \%$ (Figura 5.111). 


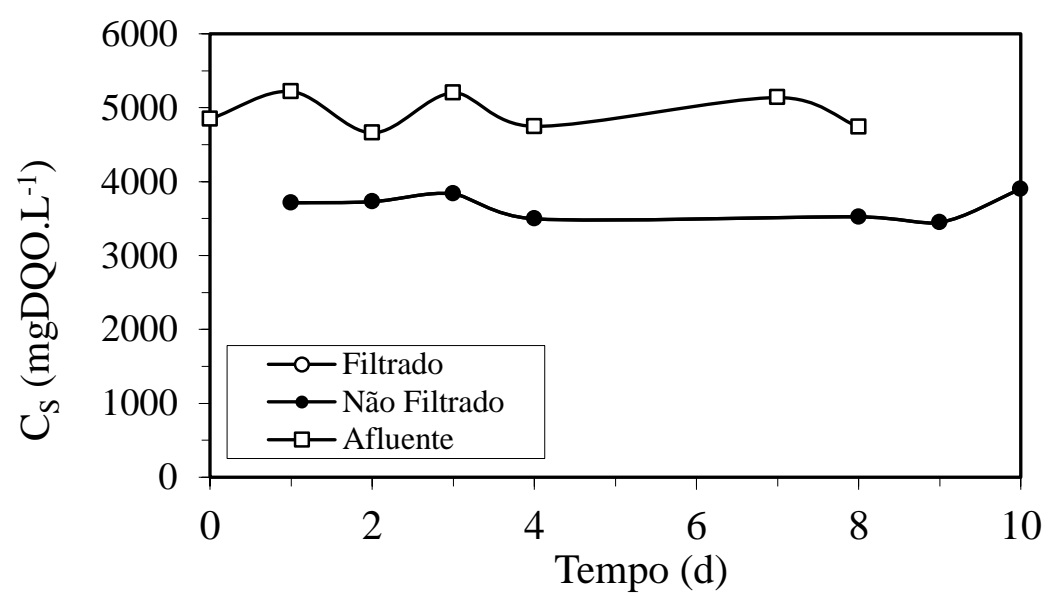

Figura 5.110 - Concentração de matéria orgânica na forma de DQO no ensaio 20: $\square$ - afluente amostras não filtradas; • - efluente amostras não filtradas; $\bigcirc$ - efluente amostras filtradas

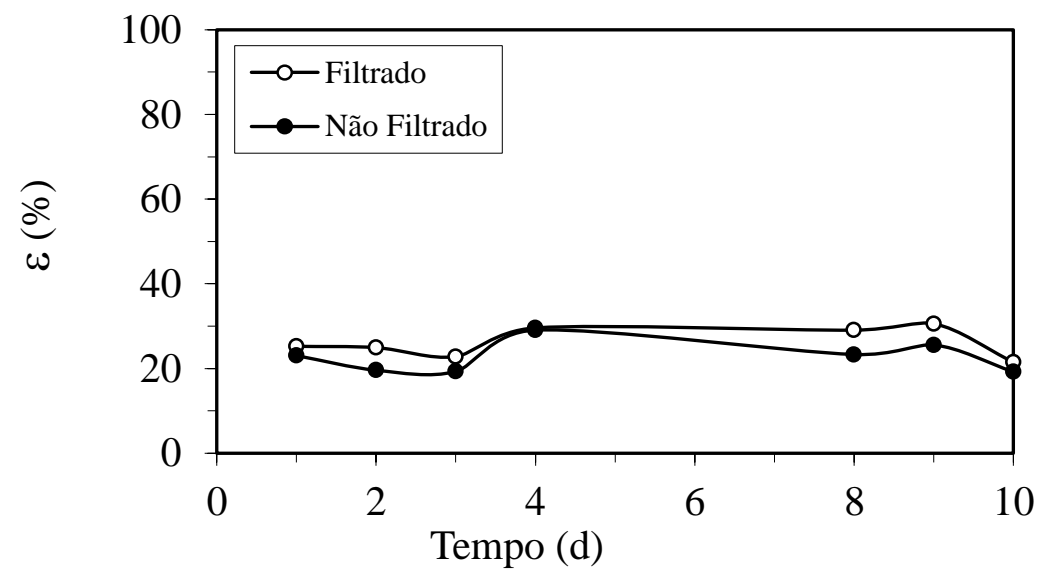

Figura 5.111 - Eficiência de remoção de matéria orgânica na forma de DQO no ensaio 20: amostras não filtradas; $\bigcirc-$ amostras filtradas

As Figuras 5.112, 5.113 e 5.114 apresentam os dados obtidos de pH, alcalinidade total e ácidos voláteis totais, respectivamente. A média do $\mathrm{pH}$ afluente foi de 7,7 e do efluente de 4,3. A alcalinidade total afluente teve média de $142 \mathrm{mgCaCO}_{3} \cdot \mathrm{L}^{-1}$ sendo consumida quase totalmente pelo processo, a alcalinidade total do efluente teve média de $5 \mathrm{mgCaCO} 3 . \mathrm{L}^{-1}$. A média de AVT do afluente foi de 25 mgHAc. $\mathrm{L}^{-1}$ e a média de AVT do efluente de 740 mgHAc. $\mathrm{L}^{-1}$, ambiente ligeiramente menos acidificado do que no ensaio com lodo prétratado que obteve 789 mgHAc. $\mathrm{L}^{-1}$. 


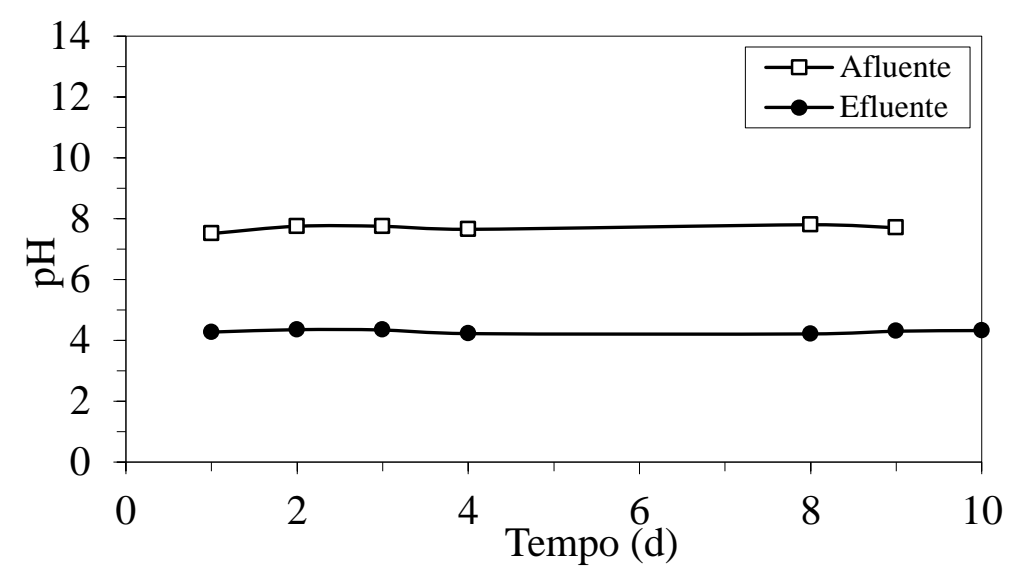

Figura 5.112 - Valores de pH no ensaio 20: $\square-$ afluente; $\bullet$ - efluente

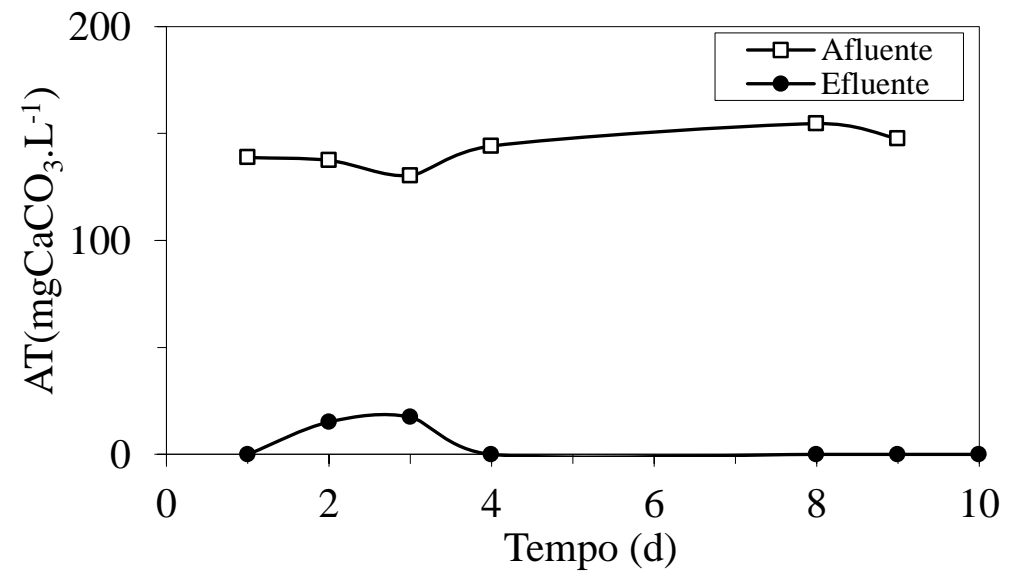

Figura 5.113 - Valores de alcalinidade total (AT) no ensaio 20: $\square$-afluente; $\bullet$ - efluente

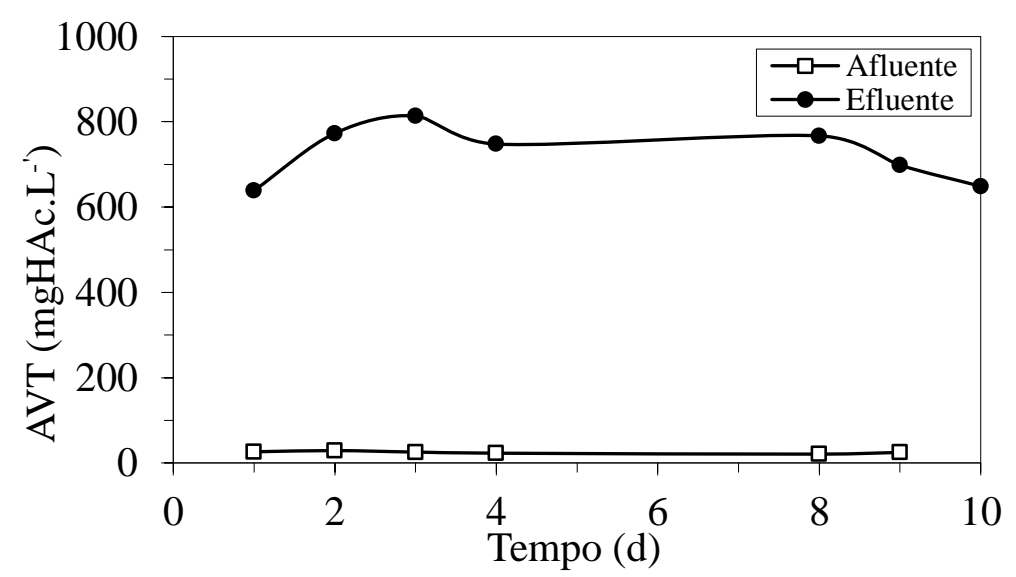

Figura 5.114 - Valores de ácidos voláteis totais (AVT) no ensaio 20: $\square$-afluente; $\bullet$ - efluente

A produção de biogás por ciclo, em aspecto quantitativo, pode ser observada pela Figura 5.115, com média de $1272 \mathrm{~mL}$ de biogás e $873 \mathrm{~mL}$ de hidrogênio, produção 
ligeiramente menor que a obtida no ensaio 19. A Figura 5.116 apresenta a distribuição dos gases que compõem o biogás no final do ciclo.

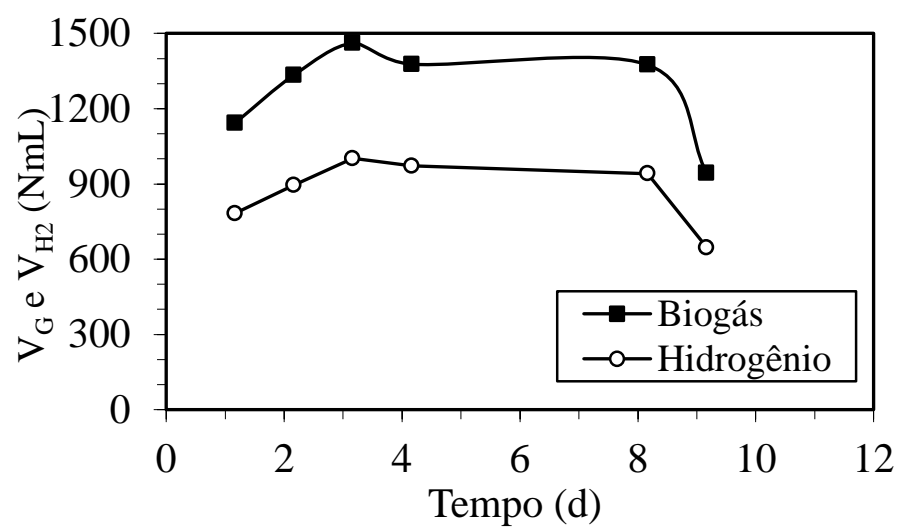

Figura 5.115 - Volume de biogás $\left(\mathrm{V}_{\mathrm{G}}\right)$ e de hidrogênio $\left(\mathrm{V}_{\mathrm{H} 2}\right)$ na CNTP no ensaio 20: — -Biogás; o- Hidrogênio

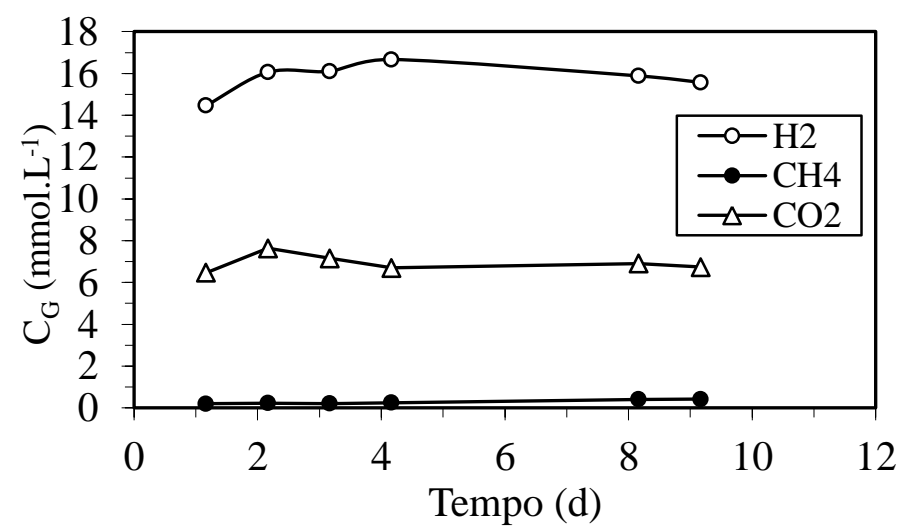

Figura 5.116 - Concentrações dos componentes do biogás no final do ciclo no ensaio 20: $\circ-\mathrm{H}_{2}$; $\bullet-\mathrm{CH}_{4} ; \Delta-\mathrm{CO}_{2}$

A Figura 5.117 apresenta o perfil de DQO durante o ciclo. A máxima eficiência de remoção atingida durante o ciclo é de $25 \%$. 


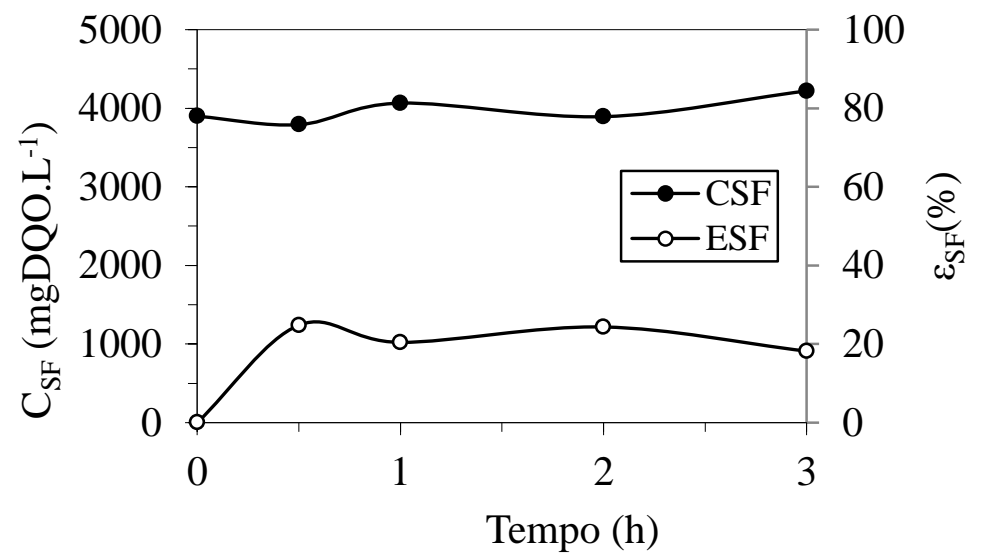

Figura 5.117 - Concentração e eficiência de degradação de matéria orgânica durante o ciclo ensaio 20: - $-\mathrm{C}_{\mathrm{SF}} ; \circ-\varepsilon_{\mathrm{SF}}$

As Figuras 5.118 e 5.119 apresentam os perfis de $\mathrm{pH}$ e alcalinidade total ao longo do ciclo. $\mathrm{O}$ pH permanece constante ao longo do ciclo por volta de 4,3 devido à presença da alcalinidade que é fornecida gradualmente através do afluente e é consumida completamente pelo sistema até o final do ciclo.

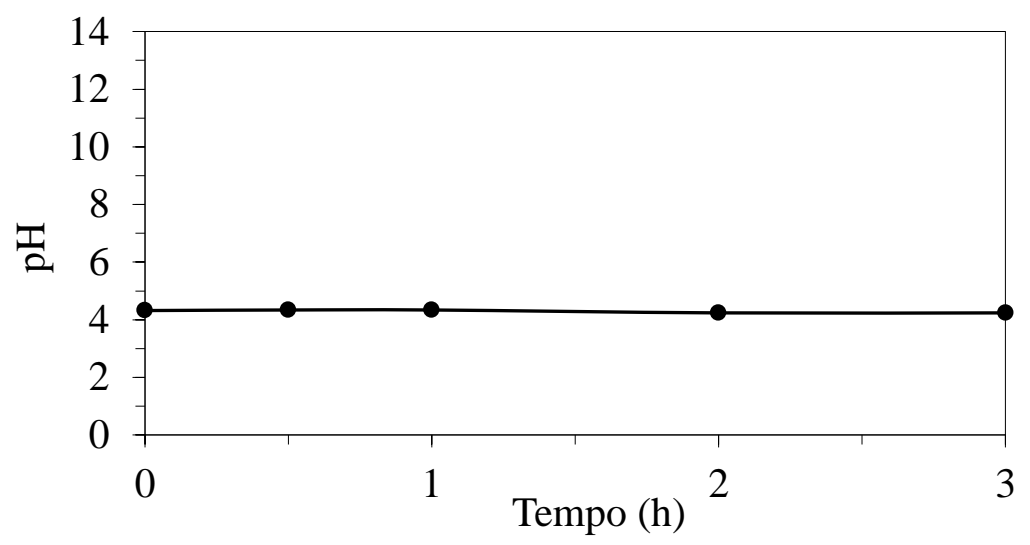

Figura 5.118 - Valores de $\mathrm{pH}$ durante o ciclo no ensaio 20

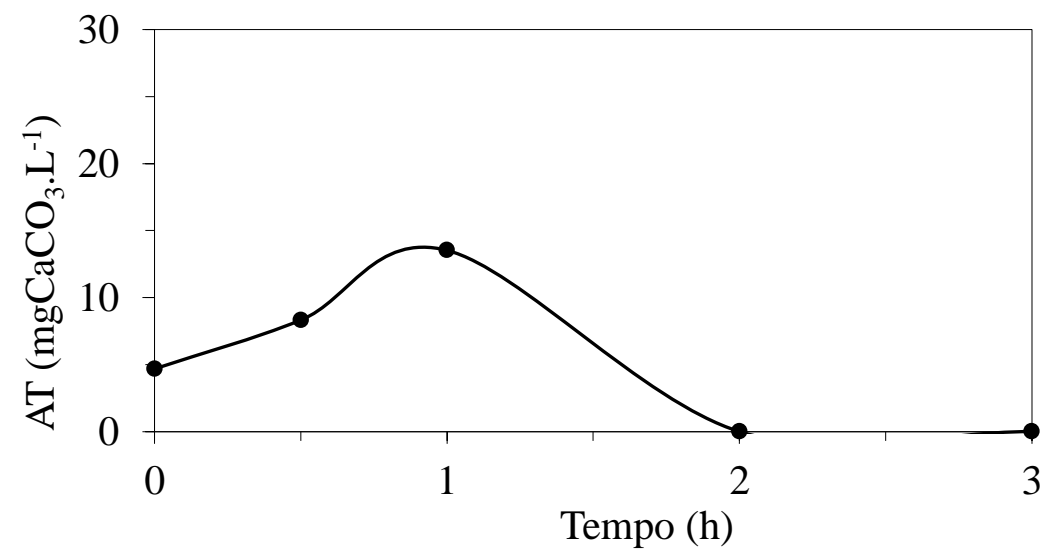

Figura 5.119 - Concentração de alcalinidade total durante o ciclo no ensaio 20 
Os perfis de ácidos voláteis totais por titulação e dos compostos intermediários do metabolismo são apresentados nas Figuras 5.120 e 5.121. Os AVT se mantiveram praticamente constantes ao longo do ciclo e houve predomínio do ácido acético e do ácido butanoico, seguido pelo butanol.

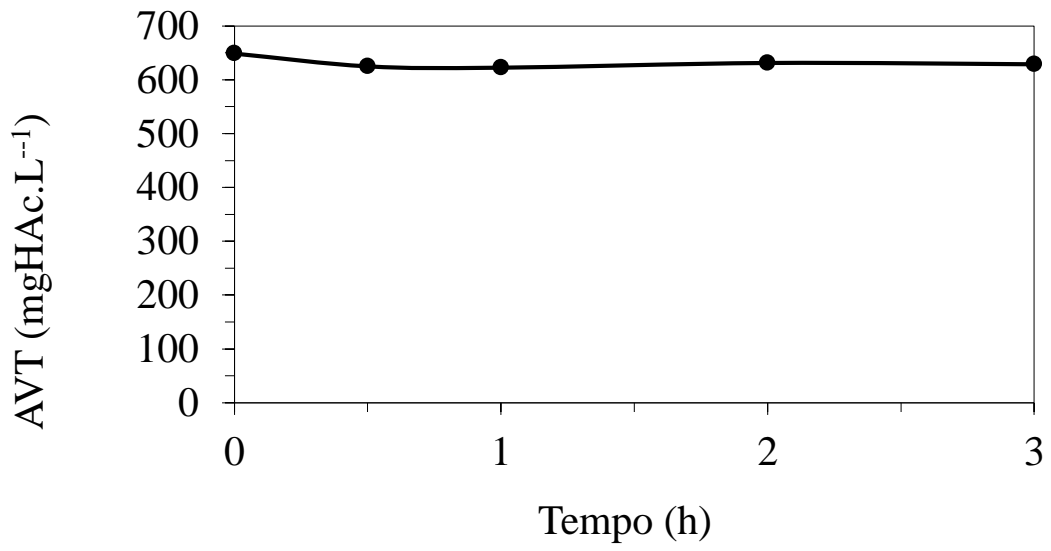

Figura 5.120 - Concentração de AVT durante o ciclo no ensaio 20

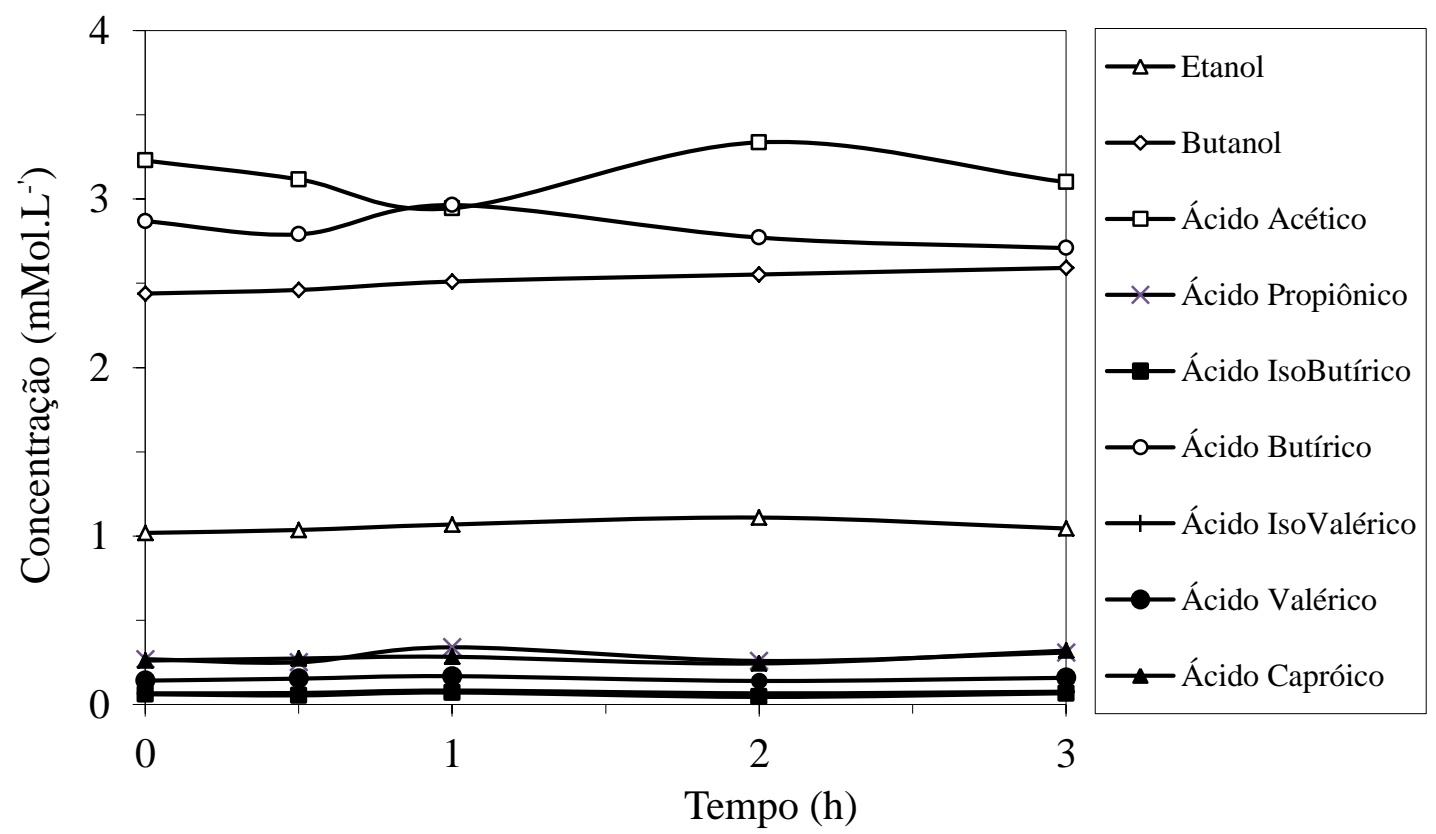

Figura 5.121 - Concentração dos compostos intermediários ao longo do ciclo no ensaio 20: $\square$ - ácido acético; $\Delta$ - etanol; ○ - ácido butírico; - - ácido isobutírico; $\boldsymbol{\Lambda}$ - ácido capróico; ácido valérico; -x-ácido propiônico; $\diamond$ butanol; + ácido isovalérico 
A produção volumétrica acumulada de biogás e os desvios padrões de cada um dos pontos podem ser observados na Figura 5.122, o perfil das concentrações de cada um dos gases e suas respectivas porcentagens podem ser observados na Figura 5.123. A produção de biogás de manteve estável ao longo da operação e, ao final do ciclo, tinha-se $68 \%$ de $\mathrm{H}_{2}, 30 \%$ de $\mathrm{CO}_{2}$ e $2 \%$ de $\mathrm{CH}_{4}$. É interessante notar que o inóculo sem nenhum tipo de tratamento obteve uma boa inibição da rota metanogênica, comprovando que essa rota deve ser inibida por condições operacionais e não por tratamento do inóculo, o que representa uma solução muito mais viável economicamente.

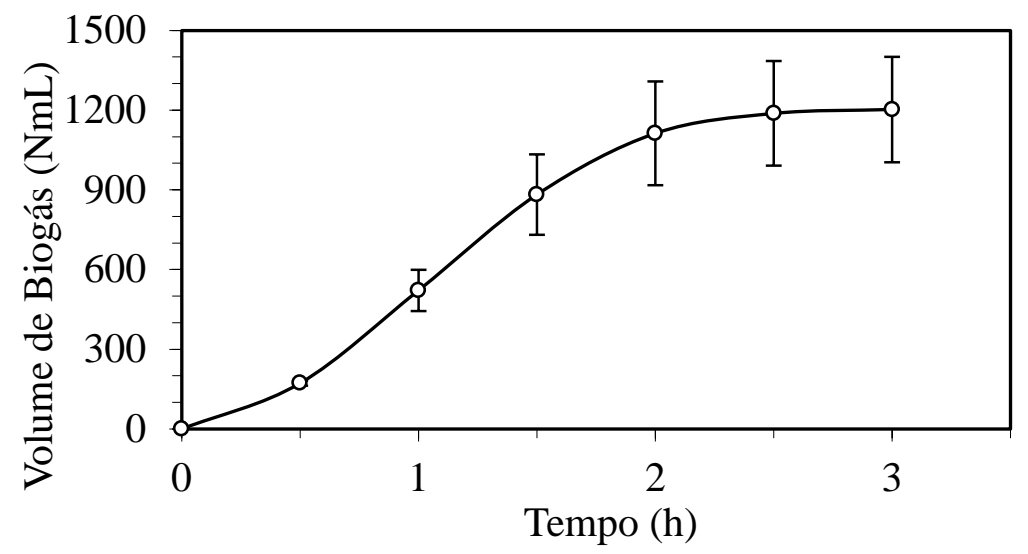

Figura 5.122 - Produção volumétrica média acumulada do biogás durante o ciclo no ensaio 20
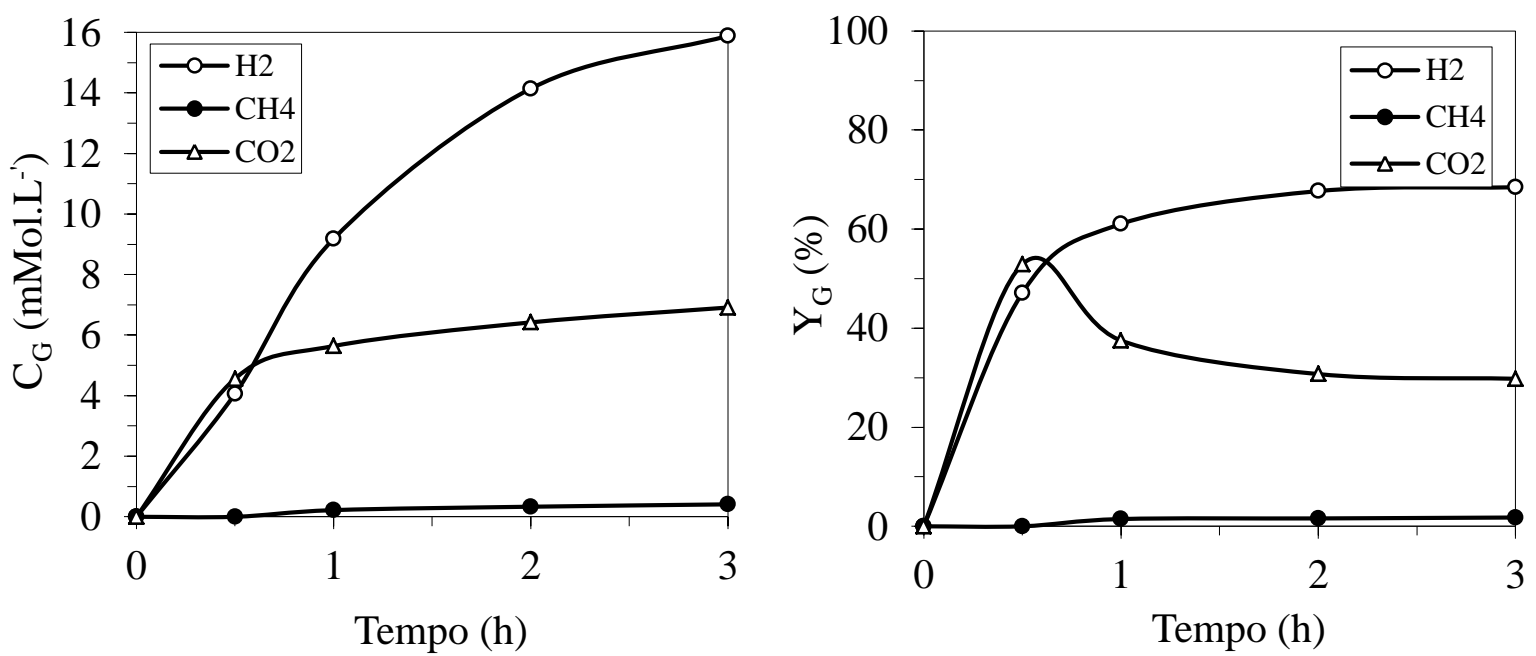

Figura 5.123 - Concentração dos compostos do biogás durante o ciclo e suas respectivas porcentagens no ensaio 20: $\odot-\mathrm{H}_{2} ; \bullet-\mathrm{CH}_{4} ; \Delta-\mathrm{CO}_{2}$ 


\subsubsection{Ensaio 21 (5000 $\mathrm{mgDQO}^{-1}, 3$ horas de tempo de ciclo e GBI)}

Este ensaio foi realizado utilizando o mesmo procedimento experimental dos ensaios de 12 a 19, mas o substrato utilizado foi glicerina bruta oriunda do processo industrial de produção de biodiesel.

O valor nominal de COVA para o ensaio 21 foi de 17,1 gDQO. $\mathrm{L}^{-1} \cdot \mathrm{d}^{-1}$, a COVA real foi de 19,0 gDQO. $\mathrm{L}^{-1} \cdot \mathrm{d}^{-1}$ e a COVR atingida foi de 7,3 $\mathrm{gDQO} \cdot \mathrm{L}^{-1} \cdot \mathrm{d}^{-1}$. A diferença entre os valores de COVA nominal e real foi devida à dificuldade em produzir um afluente com concentração de DQO próxima de $5000 \mathrm{mgDQO} . \mathrm{L}^{-1}$, já que a massa teórica de glicerina necessária para fazer um meio com 1000 mgDQO. ${ }^{\mathrm{L}-1}$ não se mostrou verdadeira quando se usou a glicerina bruta industrial. A biomassa de sólidos voláteis totais no interior do reator ao final do ensaio foi de 50,8 g, aumento de mais de 5 vezes quando comparado aos outros ensaios. A Figura 5.124 mostra o reator ao final da operação para ilustrar o crescimento da biomassa e a Tabela 5.23 apresenta a média dos parâmetros monitorados.

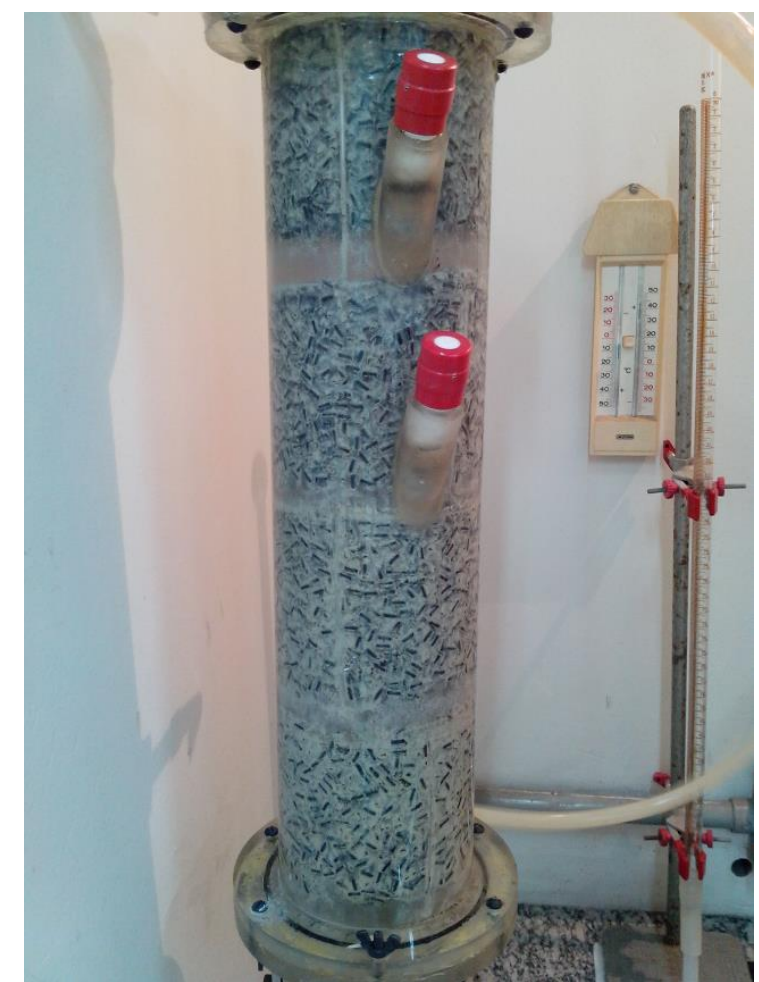

Figura 5.124 - Reator ao final da operação do ensaio 21 
Tabela 5.23 - Parâmetros médios monitorados no ensaio 21

\begin{tabular}{|c|c|c|c|c|c|c|c|c|c|c|}
\hline \multirow{2}{*}{\multicolumn{2}{|c|}{ Parâmetro }} & \multicolumn{9}{|c|}{21} \\
\hline & & \multicolumn{4}{|c|}{ Afluente } & \multicolumn{5}{|c|}{ Efluente } \\
\hline $\mathrm{C}_{\mathrm{ST}}$ & $\left(\mathrm{mgDQO} \cdot \mathrm{L}^{-1}\right)$ & 5311 & \pm & 310 & (9) & 3573 & \pm & 431 & & 85 \\
\hline $\mathrm{C}_{\mathrm{SF}}$ & $\left(\operatorname{mgDQO} . L^{-1}\right)$ & & - & & & 3276 & \pm & 485 & & $8)$ \\
\hline$\varepsilon_{\mathrm{ST}}$ & $(\%)$ & & & & & 33 & \pm & 8 & & $8 \quad$ \\
\hline$\varepsilon_{\mathrm{SF}}$ & $(\%)$ & & & & & 38 & \pm & 9 & ( & $8)$ \\
\hline $\mathrm{pH}$ & (u) & 8,2 & \pm & 0,2 & ( 7 ) & 5,2 & \pm & 0,3 & ( & $8)$ \\
\hline AVT & $\left(\mathrm{mgHAc} . \mathrm{L}^{-1}\right)$ & 144 & \pm & 11 & ( 7 ) & 670 & \pm & 71 & ( & $8 \quad$ \\
\hline AT & $\left(\mathrm{mgCaCO}{ }_{3} \cdot \mathrm{L}^{-1}\right)$ & 287 & \pm & 23 & ( 7 ) & 217 & \pm & 40 & ( & $8 \quad$ \\
\hline AP & $\left(\mathrm{mgCaCO}_{3} \cdot \mathrm{L}^{-1}\right)$ & 210 & \pm & 26 & ( 7 ) & 0 & \pm & 0 & 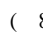 & $8)$ \\
\hline $\mathrm{AI}$ & $\left(\mathrm{mgCaCO}{ }_{3} \cdot \mathrm{L}^{-1}\right)$ & 76 & \pm & 12 & ( 7 ) & 217 & \pm & 40 & $(\varepsilon$ & $8)$ \\
\hline $\mathrm{AB}$ & $\left(\mathrm{mgCaCO}{ }_{3} \cdot \mathrm{L}^{-1}\right)$ & 185 & \pm & 19 & ( 7 ) & 0 & \pm & 0 & . & $8 \quad$ \\
\hline ST & $\left(\mathrm{mg} . \mathrm{L}^{-1}\right)$ & 2193 & \pm & 376 & (4) & 1820 & \pm & 158 & ( & 4 ) \\
\hline SVT & $\left(\mathrm{mg} \cdot \mathrm{L}^{-1}\right)$ & 1601 & \pm & 435 & (4) & 1198 & \pm & 167 & ( & 4 ) \\
\hline SST & $\left(\mathrm{mg} \cdot \mathrm{L}^{-1}\right)$ & 146 & \pm & 58 & (4) & 89 & \pm & 18 & ( & $4 \quad)$ \\
\hline SSV & $\left(\mathrm{mg} \cdot \mathrm{L}^{-1}\right)$ & 120 & \pm & 52 & (4) & 85 & \pm & 36 & & 4 ) \\
\hline $\mathrm{M}_{\mathrm{SVT}}$ & (g) & & & & & & &, 8 & & \\
\hline $\mathrm{Cx}$ & $\left(\mathrm{g} \cdot \mathrm{L}^{-1}\right)$ & & & & & & & 9 & & \\
\hline $\mathrm{Cx}^{\prime}$ & (g.gsuporte ${ }^{-1}$ ) & & & & & & & 41 & & \\
\hline $\mathrm{V}_{\mathrm{G}}$ & $(\mathrm{NmL})$ & & & & & 297 & \pm & 60 & 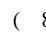 & $8)$ \\
\hline $\mathrm{V}_{\mathrm{H} 2}$ & $(\mathrm{NmL})$ & & & & & 92 & \pm & 24 & & $8)$ \\
\hline COVA & $\left(\right.$ gDQO. $\left.L^{-1} \cdot d^{-1}\right)$ & & & & & & & - & & \\
\hline COVR & $\left(g D Q O \cdot L^{-1} \cdot d^{-1}\right)$ & & & & & & & 3 & & \\
\hline COEA & $\left(\right.$ gDQO.gSVT $\left.{ }^{-1} \cdot d^{-1}\right)$ & & & & & & & - & & \\
\hline COER & $\left(\right.$ gDQO.gSVT $\left.{ }^{-1} \cdot d^{-1}\right)$ & & & & & & & 5 & & \\
\hline $\mathrm{n}_{\mathrm{H} 2}$ & $\left(\mathrm{molH}_{2} \cdot \mathrm{d}^{-1}\right)$ & & & & & & & 03 & & \\
\hline PrM & $\left(\mathrm{molH}_{2} \cdot \mathrm{m}^{-3} \cdot \mathrm{d}^{-1}\right)$ & & & & & & & 71 & & \\
\hline PrME & $\left(\mathrm{molH}_{2} \cdot \mathrm{kgSVT}^{-1} \cdot \mathrm{d}^{-1}\right)$ & & & & & & & 65 & & \\
\hline RMCA & $\left(\mathrm{molH}_{2} \cdot \mathrm{kgDQO}^{-1}\right)$ & & & & & & & 5 & & \\
\hline RMCR & $\left(\mathrm{molH}_{2} \cdot \mathrm{kgDQO}^{-1}\right)$ & & & & & & & 3 & & \\
\hline $\mathrm{V}_{\mathrm{A}}$ & (L) & 1,52 & \pm & 0,04 & $(8)$ & & & - & & \\
\hline $\mathrm{V}_{\mathrm{R}}$ & (L) & & & & & & & 4 & & \\
\hline
\end{tabular}

(*) Entre parêntese o número de amostras considerado no cálculo da média

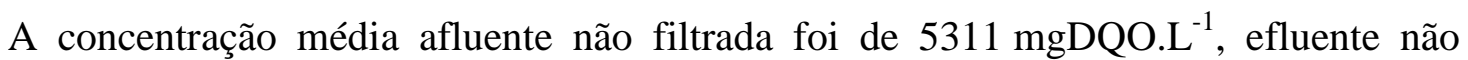
filtrada $3573 \mathrm{mgDQO} . \mathrm{L}^{-1}$ e de efluente filtrada de $3276 \mathrm{mgDQO}^{-1}$ (Figura 5.125), com remoção média para amostras não filtradas de $33 \%$ e para amostras filtradas de $38 \%$ (Figura 5.126). Foi a maior eficiência de remoção de matéria orgânica dentre todos os ensaios da Fase II e Fase III, provavelmente o processo consumiu mais matéria orgânica para gerar biomassa e não para a produção de biogás, como será visto mais adiante nesta mesma seção. 


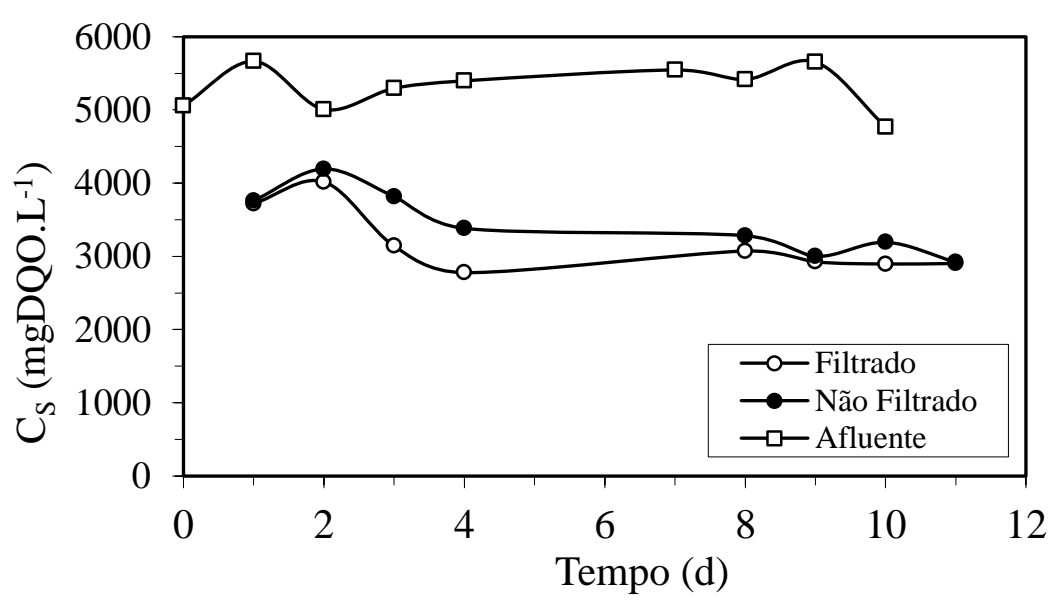

Figura 5.125 - Concentração de matéria orgânica na forma de DQO no ensaio 21: $\square$ - afluente amostras não filtradas; • - efluente amostras não filtradas; $\bigcirc$ - efluente amostras filtradas

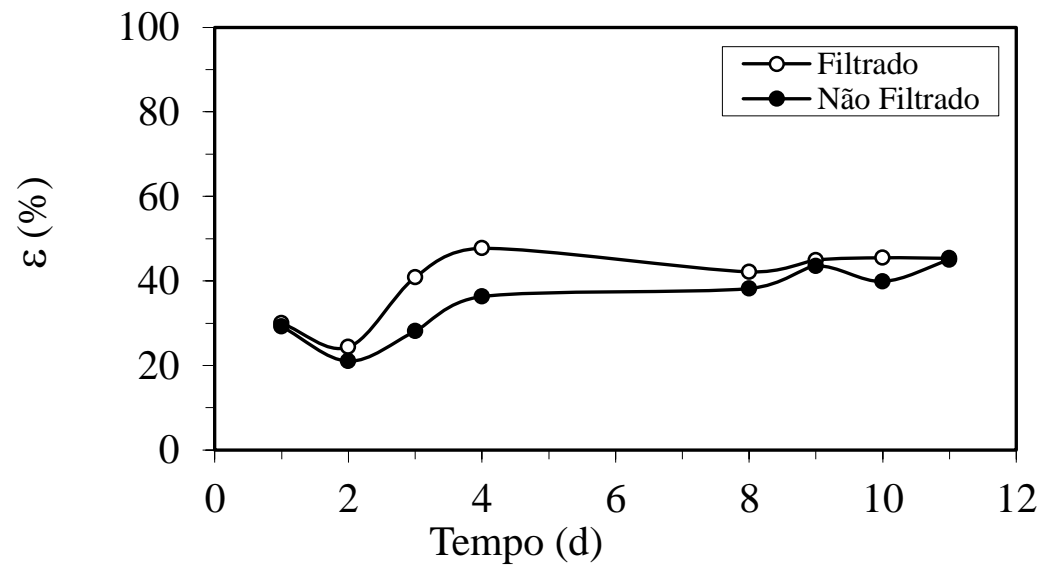

Figura 5.126 - Eficiência de remoção de matéria orgânica na forma de DQO no ensaio 21: - - amostras não filtradas; $\bigcirc$ - amostras filtradas

As Figuras 5.127, 5.128 e 5.129 apresentam os dados obtidos de pH, alcalinidade total e ácidos voláteis totais, respectivamente. A média do $\mathrm{pH}$ afluente foi de 8,2 e do efluente de 5,2. A alcalinidade total afluente teve média de $287 \mathrm{mgCaCO}_{3} \cdot \mathrm{L}^{-1}$ sendo consumida pelo processo e saindo com $217 \mathrm{mgCaCO}_{3} \cdot \mathrm{L}^{-1}$ no efluente. A média de AVT do afluente foi de 144 mgHAc. $\mathrm{L}^{-1}$ e a média de AVT do efluente de 670 mgHAc. $\mathrm{L}^{-1}$. Neste ensaio, tanto o afluente quanto o efluente apresentam $\mathrm{pH}$ e alcalinidade total maiores do que todos os outros ensaios, isso se deve ao hidróxido de sódio que é usado como catalisador no processo de produção de biodiesel e que está presente como um resíduo na glicerina bruta industrial. 


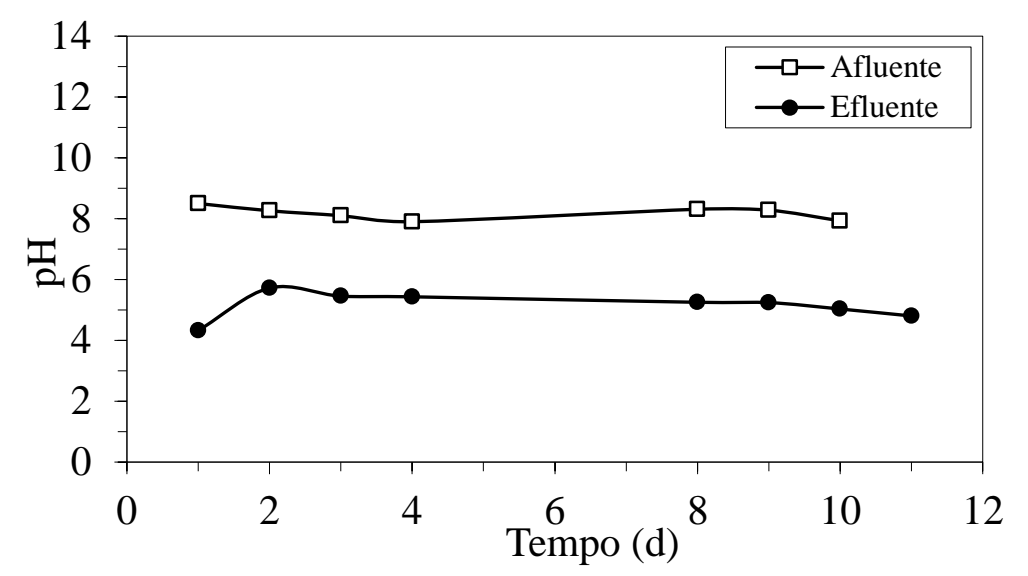

Figura 5.127 - Valores de pH no ensaio 21: $\square$-afluente; • - efluente

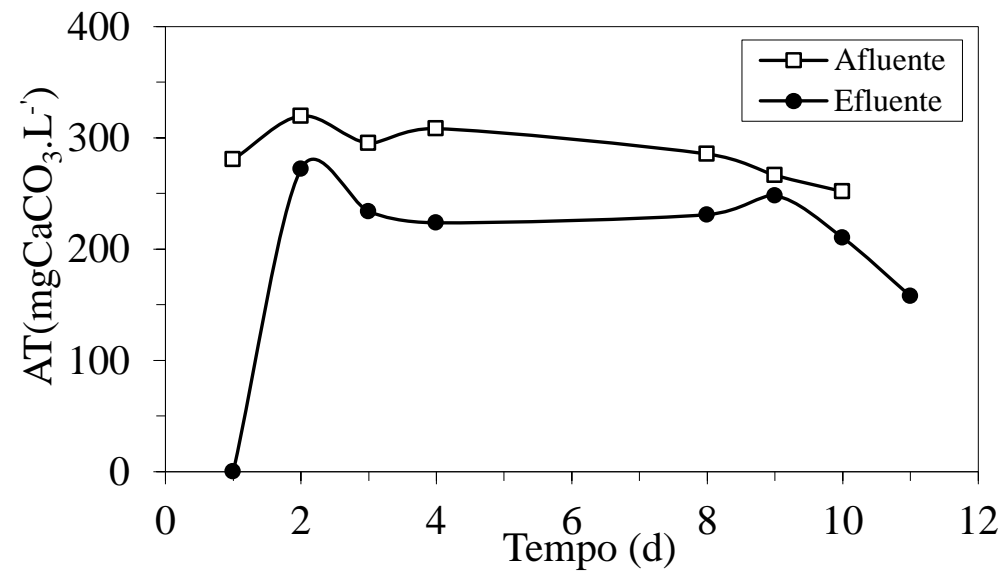

Figura 5.128 - Valores de alcalinidade total (AT) no ensaio 21: $\square$-afluente; $\bullet$ - efluente

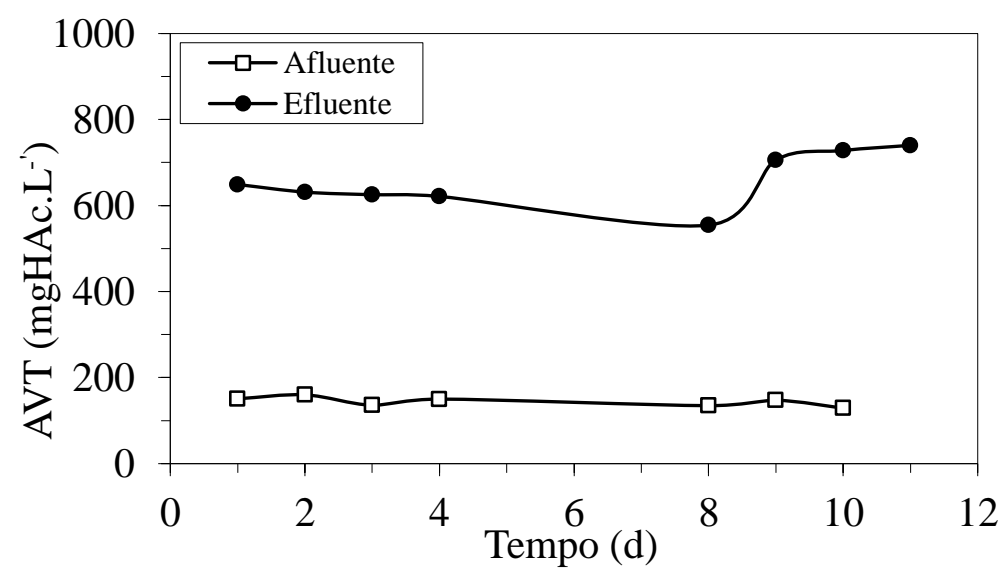

Figura 5.129 - Valores de ácidos voláteis totais (AVT) no ensaio 21: $\square$-afluente; $\bullet$ - efluente

A produção de biogás por ciclo, em aspecto quantitativo, pode ser observada pela Figura 5.130, com média de $297 \mathrm{~mL}$ de biogás e $92 \mathrm{~mL}$ de hidrogênio, uma produção muito 
menor do que a encontrada no ensaio que utilizou glicerina comercial. A Figura 5.131 apresenta a distribuição dos gases que compõem o biogás no final do ciclo.

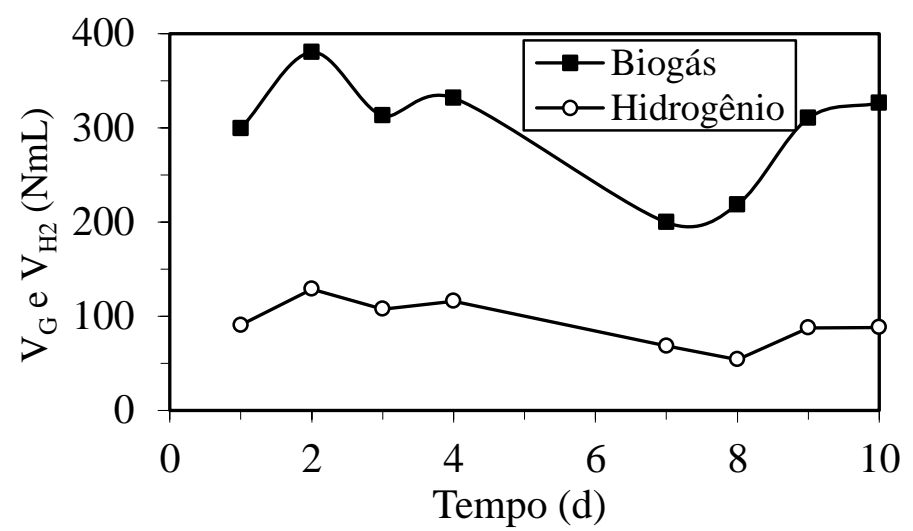

Figura 5.130 - Volume de biogás $\left(\mathrm{V}_{\mathrm{G}}\right)$ e de hidrogênio $\left(\mathrm{V}_{\mathrm{H} 2}\right)$ na CNTP no ensaio 21: - -Biogás; o- Hidrogênio

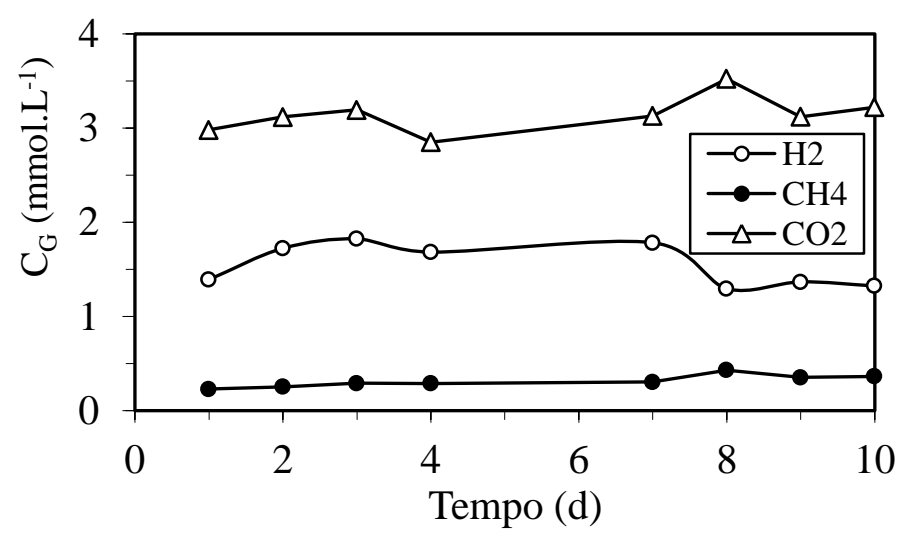

Figura 5.131 - Concentrações dos componentes do biogás no final do ciclo no ensaio 21: $\circ-\mathrm{H}_{2}$; $\bullet-\mathrm{CH}_{4} ; \Delta-\mathrm{CO}_{2}$

A Figura 5.132 apresenta o perfil de DQO durante o ciclo. A máxima eficiência de remoção atingida durante o ciclo é de $45 \%$. 


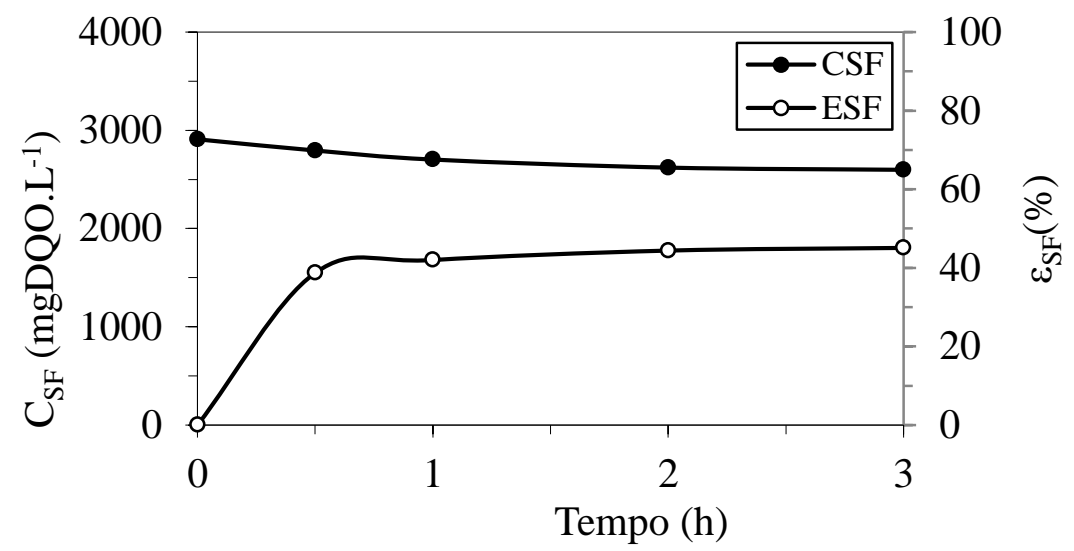

Figura 5.132 - Concentração e eficiência de degradação de matéria orgânica durante o ciclo ensaio 21:

- $-\mathrm{C}_{\mathrm{SF}} ; \circ-\varepsilon_{\mathrm{SF}}$

As Figuras 5.133 e 5.134 apresentam os perfis de $\mathrm{pH}$ e alcalinidade total ao longo do ciclo. $\mathrm{O}$ pH permanece constante ao longo do ciclo por volta de 4,8 devido à presença da alcalinidade que é fornecida gradualmente através do afluente e pelo sistema.

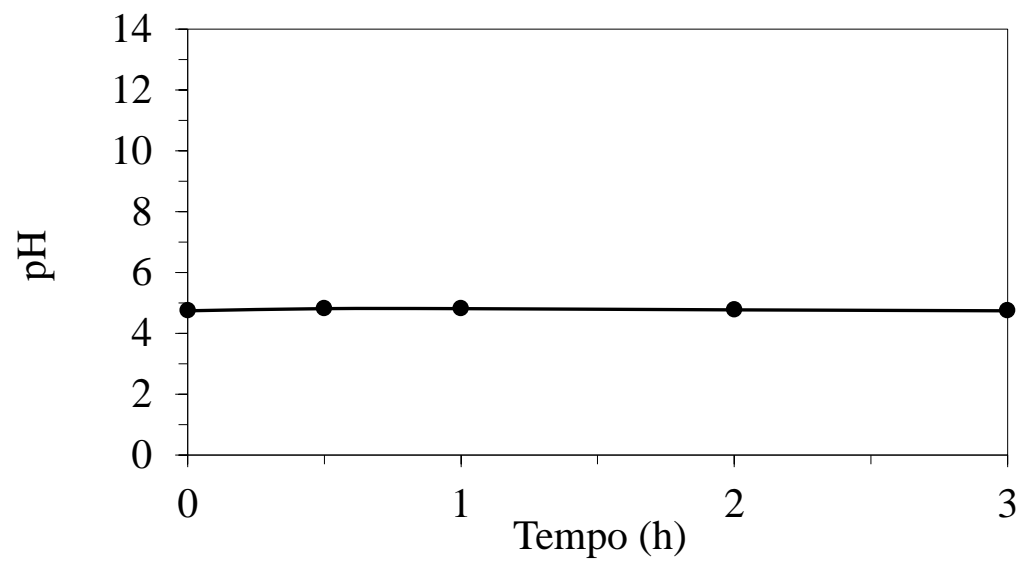

Figura 5.133 - Valores de $\mathrm{pH}$ durante o ciclo no ensaio 21

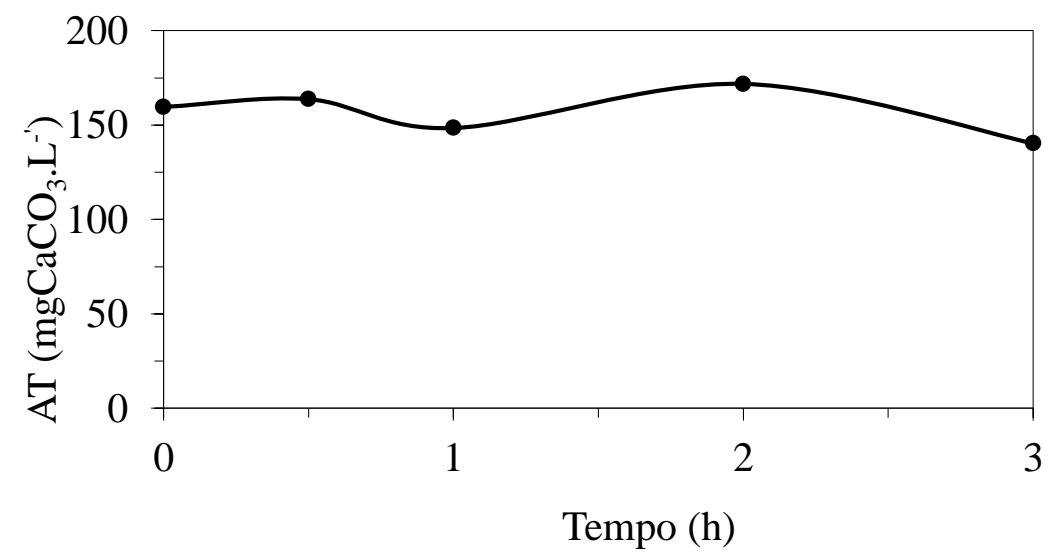

Figura 5.134 - Concentração de alcalinidade total durante o ciclo no ensaio 21 
Os perfis de ácidos voláteis totais por titulação e dos compostos intermediários do metabolismo são apresentados nas Figuras 5.135 e 5.136.

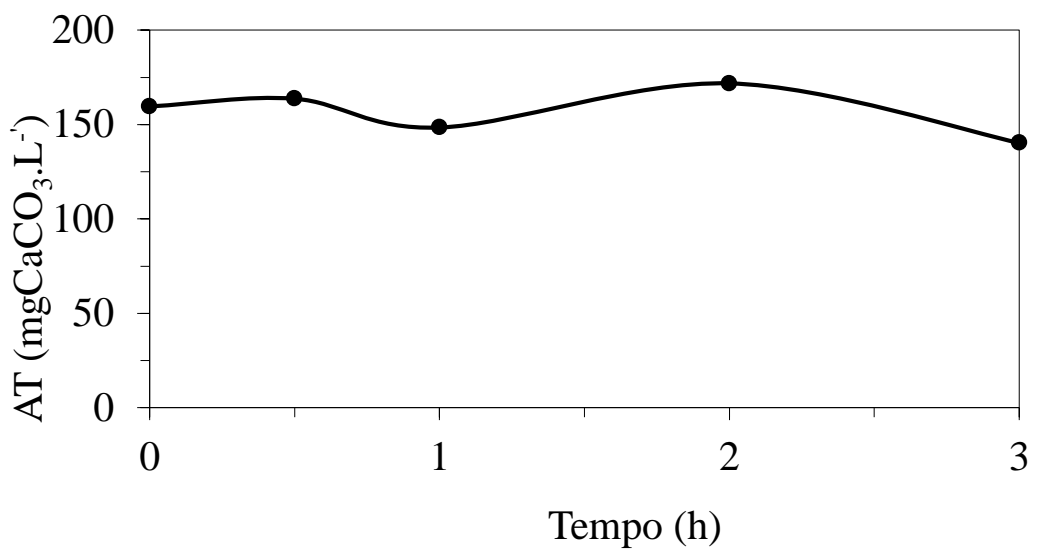

Figura 5.135 - Concentração de AVT durante o ciclo no ensaio 21

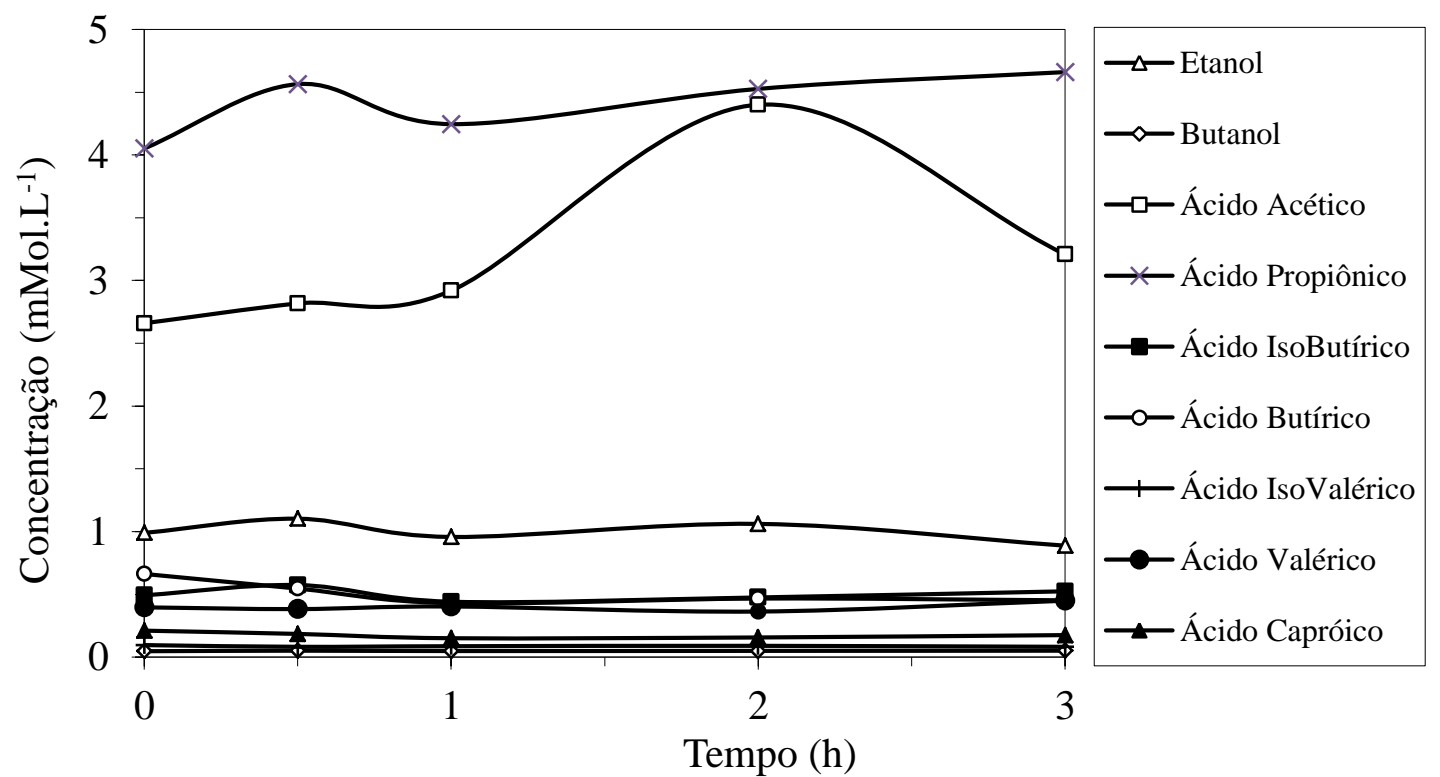

Figura 5.136 - Concentração dos compostos intermediários ao longo do ciclo no ensaio 21: $\square$ - ácido acético; $\Delta$ - etanol; ○ - ácido butírico; - - ácido isobutírico; $\boldsymbol{\Lambda}$ - ácido capróico; ácido valérico; -x-ácido propiônico; $\diamond$ butanol; + ácido isovalérico

As concentrações dos AVT e dos AVI não foram constantes como nos outros ensaios e houve predomínio do ácido propiônico e do ácido acético, o que não aconteceu em nenhum dos outros experimentos. Como o ácido propiônico é subproduto do fosfoenolpiruvato na rota metabólica da fermentação biológica do glicerol, há a menor formação de piruvato e, portanto, as rotas do acetato e do butirato ficam prejudicadas, com consequente diminuição da 
produção de hidrogênio, já que é necessário o fosfoenolpiruvato para fazer o piruvato. Além disso, há o consumo de hidrogênio para transformar o fosfoenolpiruvato em ácido propiônico, então a produção desse ácido é prejudicial para o processo de produção de biohidrogênio (Yazdani e Gonzalez, 2007 e Silva et al., 2007).

A produção volumétrica acumulada de biogás e os desvios padrões de cada um dos pontos podem ser observados na Figura 5.137, o perfil das concentrações de cada um dos gases e suas respectivas porcentagens podem ser observados na Figura 5.138. A produção de biogás de manteve estável ao longo da operação e, ao final do ciclo, tinha-se $28 \%$ de $\mathrm{H}_{2}, 65 \%$ de $\mathrm{CO}_{2}$ e $7 \%$ de $\mathrm{CH}_{4}$ - uma qualidade de biogás baixa em comparação aos outros experimentos.

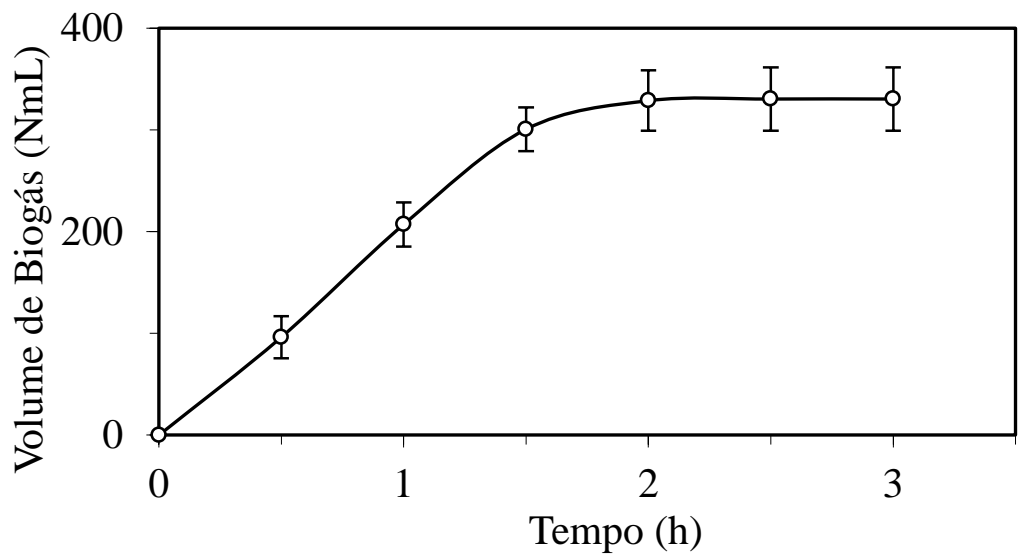

Figura 5.137 - Produção volumétrica média acumulada do biogás durante o ciclo no ensaio 21
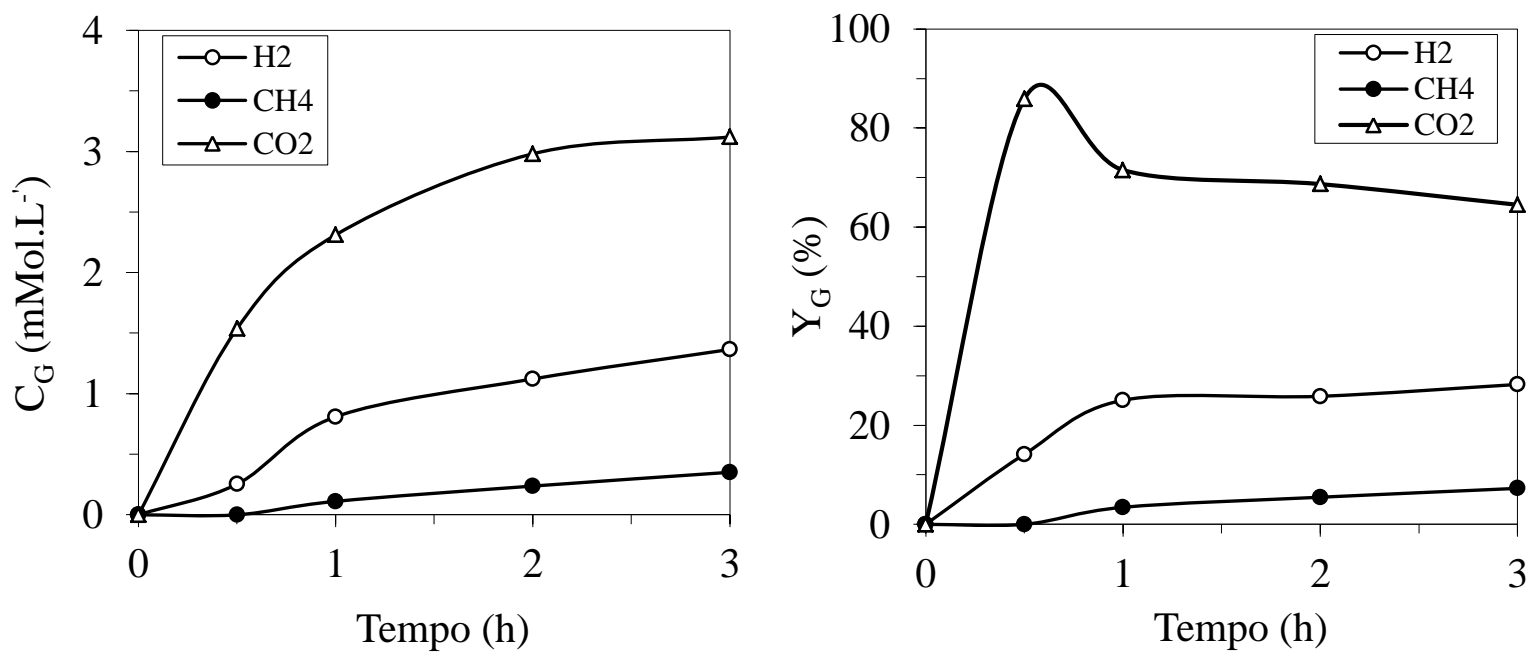

Figura 5.138 - Concentração dos compostos do biogás durante o ciclo e suas respectivas porcentagens no ensaio 21: $\odot-\mathrm{H}_{2} ; \bullet-\mathrm{CH}_{4} ; \Delta-\mathrm{CO}_{2}$ 


\subsubsection{Comparação entre os ensaios 19, 20 e 21}

O estudo comparativo da Fase III foi realizado da mesma forma que a comparação da Fase II, os parâmetros foram: matéria orgânica; $\mathrm{pH}$, alcalinidade e ácidos; balanço de massa (apenas para os ensaios 20 e 21) e produção de biohidrogênio. A Tabela 5.24 relembra as condições experimentais dos ensaios.

Tabela 5.24 - Condições experimentais dos ensaios 19, 20 e 21

\begin{tabular}{cccc}
\hline & 19 & 20 & 21 \\
\hline Tipo de Glicerina & GPA & GPA & GBI \\
Tipo de Inóculo & Pré-tratado por HST & Sem tratamento & Pré-tratado por HST \\
Condição & $\begin{array}{c}5000 \mathrm{mgDQO}^{-1} \mathrm{e} \\
\text { 3 horas de ciclo }\end{array}$ & $\begin{array}{c}5000 \mathrm{mgDQO}^{-1} \mathrm{e} \\
\text { 3 horas de ciclo }\end{array}$ & $\begin{array}{c}5000 \mathrm{mgDO}^{-1} \mathrm{e} \\
\text { 3 horas de ciclo }\end{array}$ \\
\hline
\end{tabular}

\section{(a) Matéria orgânica}

A Tabela 5.25 mostra os parâmetros para a matéria orgânica nos ensaios 19, 20 e 21 . Nota-se que não há grande diferença entre os ensaios 19 e 20 em relação à remoção de matéria orgânica e crescimento de biomassa, então se pode concluir que, para esse parâmetro, o tratamento HST não teve nenhum tipo de influência. Já o uso de glicerina bruta industrial no ensaio 21, resultou em um grande crescimento de biomassa e numa remoção bem maior de matéria orgânica do afluente, isso indica que provavelmente o sistema utilizou a matéria orgânica disponível no afluente mais para o crescimento celular do que para a para a acidogênese, como já foi dito anteriormente. 
Tabela 5.25 - Parâmetros relacionados a matéria orgânica nos ensaios 19, 20 e 21

\begin{tabular}{|c|c|c|c|}
\hline Parâmetro & 19 & 20 & 21 \\
\hline$\varepsilon_{\mathrm{F}}(\%)$ & 28 & 26 & 38 \\
\hline $\mathrm{M}_{\mathrm{SVT}}(\mathrm{g})$ & 10,2 & 9,3 & 50,8 \\
\hline $\operatorname{COVA}\left(\mathrm{gDQO} \cdot \mathrm{L}^{-1} \cdot \mathrm{d}^{-1}\right)$ & 17,8 & 17,6 & 19,0 \\
\hline COEA (gDQO.gSVT $\left.{ }^{-1} \cdot \mathrm{d}^{-1}\right)$ & 5,9 & 6,4 & 1,3 \\
\hline $\operatorname{COVR}\left(\mathrm{gDQO} \cdot \mathrm{L}^{-1} \cdot \mathrm{d}^{-1}\right)$ & 5,0 & 4,6 & 7,3 \\
\hline COER (gDQO.gSVT $\left.{ }^{-1} \cdot \mathrm{d}^{-1}\right)$ & 1,7 & 1,7 & 0,5 \\
\hline
\end{tabular}

(b) pH, alcalinidade e ácidos

Em relação ao pH, AT e AVT do afluente nos três ensaios, houve apenas diferença no ensaio 21 devido ao uso da glicerina industrial que produz um afluente muito mais alcalino do que o produzido com glicerina comercial; por isso, o efluente do ensaio 21 também mostra um pH maior, uma quantidade maior de alcalinidade total e menor formação de ácidos do que os outros dois ensaios. Percebe-se também acidificação ligeiramente menor no ensaio 20 do que no ensaio 19, mas é difícil dizer se o tratamento do inóculo teve alguma influência nesse parâmetro.

Os ácidos voláteis totais mostram que o ensaio 19 foi o que obteve maiores concentrações de ácido acético e de ácido butírico, o que é extremamente favorável na produção de biodrogênio. O ensaio 20 também obteve boas concentrações de ácido acético, no entanto, houve uma grande produção de etanol e butanol e, como os caminhos metabólicos para a produção desses álcoois ocorrem paralelamente aos caminhos da acidogênese (Silva et al., 2007), a produção de biogás é reduzida (o pré tratamento do inóculo foi benéfico neste caso). É o mesmo efeito que ocorre com o ácido propiônico no ensaio 21 - sua produção 
interfere na produção de hidrogênio. A Tabela 5.26 resume os parâmetros de pH, alcalinidade e ácidos.

Tabela 5.26 -Parâmetros relacionados a alcalinidade e ácidos nos ensaios 19, 20 e 21

\begin{tabular}{|c|c|c|c|c|}
\hline & Parâmetro & 19 & 20 & 21 \\
\hline \multirow{3}{*}{ Afluente } & $\mathrm{pH}(\mathrm{u})$ & 7,7 & 7,7 & 8,2 \\
\hline & $\mathrm{AT}\left(\mathrm{mgCaCO}_{3} \cdot \mathrm{L}^{-1}\right)$ & 155 & 142 & 287 \\
\hline & AVT $\left(m g H A c . L^{-1}\right)$ & 24 & 25 & 144 \\
\hline \multirow{3}{*}{ Efluente } & $\mathrm{pH}(\mathrm{u})$ & 4,20 & 4,3 & 5,2 \\
\hline & $\mathrm{AT}\left(\mathrm{mgCaCO}_{3} \cdot \mathrm{L}^{-1}\right)$ & 0 & 5 & 217 \\
\hline & $\operatorname{AVT}\left(\operatorname{mgHAc} . \mathrm{L}^{-1}\right)$ & 802 & 727 & 670 \\
\hline \multirow{6}{*}{ AVI* } & Ácido acético (\%) & 30,3 & 30,3 & 30,7 \\
\hline & Ácido butírico (\%) & 45,8 & 27,8 & 9,9 \\
\hline & Ácido propiônico (\%) & 3,9 & 2,7 & 42,8 \\
\hline & Etanol $(\%)$ & 6,8 & 10,2 & 9,7 \\
\hline & Butanol (\%) & 8,7 & 24,2 & 0,5 \\
\hline & Concentração total $\left(\mathrm{mmol} . \mathrm{L}^{-1}\right)$ & 11,3 & 10,4 & 10,3 \\
\hline
\end{tabular}

(*) Resultados dos AVI em porcentagem molar

(c) Balanço de massa dos ensaios 20 e 21

Para ter-se uma estimativa do valor real da concentração de DQO do efluente e da eficiência de remoção de matéria orgânica, além do cálculo do $\mathrm{RMCR}_{\mathrm{Glicerina}}$, foram realizados os balanços de massa dos ensaios 20 e 21 . A Tabela 5.27 mostra o balanço para o monitoramento diário e a Tabela 5.28 mostra o balanço para os perfis. É possível notar que a eficiência de remoção do ensaio 21 continua sendo a maior dentre os ensaios comparados, com $54 \%$ de eficiência de remoção de matéria orgânica para o monitoramento diário e $69 \%$ eficiência de remoção de matéria orgânica para o perfil. 
Tabela 5.27 - Balanço de massa durante o monitoramento diário nos ensaios 19, 20 e 21

\begin{tabular}{cccccccc}
\hline Ensaio & $\begin{array}{c}\mathrm{DQO}_{\mathrm{CAFL}} \\
\left(\mathrm{mgDQO} . \mathrm{L}^{-1}\right)\end{array}$ & $\begin{array}{c}\mathrm{DQO}_{\mathrm{CSF}} \\
\left(\mathrm{mgDQO} . \mathrm{L}^{-1}\right)\end{array}$ & $\begin{array}{c}\mathrm{AVT} \\
\left(\mathrm{mgH}_{\left.\mathrm{AC} \cdot \mathrm{L}^{-1}\right)}\right.\end{array}$ & $\begin{array}{c}\mathrm{DQO}_{\mathrm{AVT}} \\
\left(\mathrm{mgDQO} . \mathrm{L}^{-1}\right)\end{array}$ & $\begin{array}{c}\mathrm{DQO}_{\text {Biomassa }} \\
\left(\mathrm{mgSSV} . \mathrm{L}^{-1}\right)\end{array}$ & $\begin{array}{c}\mathrm{DQO} \\
(\mathrm{mgDQ}\end{array}$ & $\begin{array}{c}\varepsilon_{\text {SFReal }} \\
(\%)\end{array}$ \\
\hline 19 & 4968 & 3524 & 789 & 794 & 41 & 2279 & 46 \\
20 & 4998 & 3663 & 727 & 731 & 88 & 2154 & 43 \\
21 & 5301 & 3181 & 670 & 674 & 85 & 2878 & 54 \\
\hline
\end{tabular}

Tabela 5.28 - Balanço de massa durante os perfis nos ensaios 19, 20 e 21

\begin{tabular}{|c|c|c|c|c|c|c|c|}
\hline Ensaio & $\begin{array}{l}\text { Tempo } \\
\text { (h) }\end{array}$ & $\begin{array}{c}\mathrm{DQO}_{\mathrm{CAFL}} \\
(\mathrm{mgDQO} \cdot \mathrm{L}-1)\end{array}$ & $\begin{array}{c}\mathrm{DQO}_{\mathrm{CSF}} \\
(\mathrm{mgDQO} \cdot \mathrm{L}-1)\end{array}$ & $\begin{array}{c}\mathrm{DQO}_{\mathrm{AVI}} \\
\text { (mgDQO.L-1) }\end{array}$ & $\begin{array}{c}\mathrm{DQO}_{\text {Biomassa }} \\
\text { (mgDQO.L-1) }\end{array}$ & $\begin{array}{c}\mathrm{C}_{\text {SFReal }} \\
(\mathrm{mgDQO} . \mathrm{L}-1)\end{array}$ & $\begin{array}{c}\varepsilon_{\text {SFReal }} \\
(\%)\end{array}$ \\
\hline \multirow{5}{*}{19} & 0,00 & \multirow{5}{*}{5174,1} & 3853 & 1490 & \multirow{5}{*}{41} & 2321 & 0 \\
\hline & 0,50 & & 3980 & 1447 & & 2492 & 49 \\
\hline & 1,00 & & 3869 & 1460 & & 2368 & 53 \\
\hline & 2,00 & & 3761 & 1370 & & 2349 & 54 \\
\hline & 3,00 & & 3825 & 1428 & & 2356 & 54 \\
\hline \multirow{5}{*}{20} & 0,00 & & 3898 & 1337 & \multirow{5}{*}{88} & 2465 & 0 \\
\hline & 0,50 & & 3791 & 1326 & & 2369 & 51 \\
\hline & 1,00 & 5184,9 & 4065 & 1376 & & 2593 & 48 \\
\hline & 2,00 & & 3893 & 1347 & & 2450 & 52 \\
\hline & 3,00 & & 4220 & 1361 & & 2764 & 46 \\
\hline \multirow{5}{*}{21} & 0,00 & \multirow{5}{*}{4768,4} & 2908 & 1029 & \multirow{5}{*}{85} & 1838 & 0 \\
\hline & 0,50 & & 2795 & 1086 & & 1668 & 62 \\
\hline & 1,00 & & 2702 & 1003 & & 1658 & 64 \\
\hline & 2,00 & & 2620 & 1040 & & 1539 & 67 \\
\hline & 3,00 & & 2598 & 1095 & & 1462 & 69 \\
\hline
\end{tabular}

(c) Produção de biohidrogênio

A Tabela 5.29 mostra os parâmetros em relação à produção de biohidrogênio para os ensaios 19, 20 e 21. 
Tabela 5.29 - Comparação entre os parâmetros relativos à produção de biohidrogênio nos ensaios 19, 20 e 21

\begin{tabular}{|c|c|c|c|}
\hline Parâmetro & 19 & 20 & 21 \\
\hline $\operatorname{PrM}\left(\mathrm{molH}_{2} \cdot \mathrm{m}^{-3} \cdot \mathrm{d}^{-1}\right)$ & 100,9 & 91,7 & 9,7 \\
\hline $\operatorname{PrME}\left(\mathrm{molH}_{2} \cdot \mathrm{kgSVT}^{-1} \cdot \mathrm{d}^{-1}\right)$ & 33,6 & 33,4 & 0,6 \\
\hline $\mathrm{RMCA}\left(\mathrm{molH}_{2} \cdot \mathrm{kgDQO}^{-1}\right)$ & 5,7 & 5,2 & 0,5 \\
\hline $\operatorname{RMCR}\left(\mathrm{molH}_{2} \cdot \mathrm{kgDQO}^{-1}\right)$ & 20,0 & 19,8 & 1,3 \\
\hline $\operatorname{RMCA}_{\text {Glicerina }}\left(\mathrm{molH}_{2} \cdot\right.$ molglicerina $\left.{ }^{-1}\right)$ & 0,64 & 0,58 & 0,06 \\
\hline $\mathrm{RMCR}_{\text {GlicerinaAVI }}\left(\mathrm{molH}_{2}\right.$. molgliceirna $\left.{ }^{-1}\right)$ & 1,19 & 1,16 & 0,10 \\
\hline$\%$ de $\mathrm{H}_{2}$ ao final do ciclo & 68 & 68 & 28 \\
\hline$\%$ de $\mathrm{CO}_{2}$ ao final do ciclo & 30 & 30 & 65 \\
\hline$\%$ de $\mathrm{CH}_{4}$ ao final do ciclo & 2 & 2 & 7 \\
\hline
\end{tabular}

Estudando os ensaios 19 e 20, nota-se que há uma ligeira diminuição tanto na produtividade quanto no rendimento do processo em relação ao biohidrogênio, mas os dois apresentam a mesma qualidade de biogás; então é possível concluir que o pré-tratamento do lodo melhora a produção de hidrogênio, mas não desempenha nenhum papel visível na inibição da rota metanogênica. Em trabalhos futuros, seria necessário realizar um estudo econômico do gasto energético do pré-tratamento do lodo por HST para decidir se o mesmo é viável, já que há uma melhora na produtividade do processo de apenas $10 \%$.

Ainda nessa comparação, foram realizadas duas análises estatísticas a nível de 5\% de significância para verificar se há ou se não há diferença significativa entre os dados de produção de hidrogênio obtidos com o inóculo pré-tratado e com o inóculo sem tratamento.

A primeira análise realizada foi um teste-T para amostras emparelhadas. A Tabela 5.30 mostra os resultados dessa análise; como o valor de p bi-caudal é maior do que 0,05 , não há diferença significativa entre os dois tipos de inóculo a nível de 5\% de significância. 
Tabela 5.30 - Resultado para o teste-T para amostras emparelhadas nos ensaios 19 e 20

\begin{tabular}{|c|c|c|}
\hline & Lodo pré-tratado & Lodo não tratado \\
\hline Média & 960,7 & 873,2 \\
\hline Variância & 20145 & 18247 \\
\hline Observações & 6 & 6 \\
\hline Correlação de Pearson & \multicolumn{2}{|c|}{0,603} \\
\hline Hipótese da diferença de média & \multicolumn{2}{|c|}{0,0} \\
\hline gl & \multicolumn{2}{|c|}{5} \\
\hline Stat $\mathrm{t}$ & \multicolumn{2}{|c|}{1,735} \\
\hline $\mathrm{P}(\mathrm{T}<=\mathrm{t})$ bi-caudal & \multicolumn{2}{|c|}{0,143} \\
\hline t crítico bi-caudal & \multicolumn{2}{|c|}{2,571} \\
\hline
\end{tabular}

A segunda análise realizada foi o teste ANOVA para fator único (teste mais comumente utilizado). A Tabela 5.31 mostra os resultados dessa análise; novamente, como o valor de $\mathrm{p}$ é maior do que 0,05 , não há diferença significativa entre os dois tipos de inóculo a nível de 5\% de significância.

Tabela 5.31 - Resultado para o teste ANOVA nos ensaios 19 e 20

\begin{tabular}{ccccccc}
\hline Fonte da variação & $S Q$ & $g l$ & $M Q$ & $F$ & valor-P & F crítico \\
\hline Entre grupos & 22972,5 & 1 & 22972,51 & 1,197 & 0,2996 & 4,965 \\
Dentro dos grupos & 191958,2 & 10 & 19195,82 & & & \\
Total & 214930,7 & 11 & & & & \\
\hline
\end{tabular}

Estudando agora o ensaio 21, nota-se que tanto a quantidade quanto a qualidade do biogás caíram consideravelmente em comparação aos dois outros ensaios, tendo também um rendimento molar de hidrogênio em relação à carga orgânica aplicada/removida muito baixo $\left(0,01 \mathrm{molH}_{2} \cdot\right.$ molglicerina $\left.^{-1}\right)$.

Trabalhos anteriores que tiveram como objetivo a produção de biohidrogênio a partir do efluente industrial, obtiveram rendimentos melhores do que o encontrado neste trabalho; no entanto, o único trabalho que foi realizado em um reator (PBR, BSTR ou CSTR) e com culturas mistas (Termudo et al., 2008) também obteve um baixo rendimento (0,05 $\mathrm{molH}_{2}$ molglicerina). Lo et al. (2013) e Ito et al. (2005) observam uma tendência que a 
água residuária produzida com glicerina bruta industrial obteve melhores rendimentos do que a água residuária produzida com glicerina pura, o que não foi observado neste trabalho. A Tabela 5.32 mostra a comparação entre os artigos que trabalharam com GBI.

Tabela 5.32 - Comparação entre trabalhos que utilizaram glicerina bruta industrial como efluente

\begin{tabular}{ccccc} 
Substrato & Inóculo & Reator & $\begin{array}{c}\mathrm{RMCR}_{\text {Glicerina }} \\
\left(\mathrm{mol} \mathrm{H}_{2} \cdot \mathrm{mol}_{\text {glicerina }}{ }^{-10}\right)\end{array}$ & Referência \\
\hline GBI & $\begin{array}{c}\text { Enterobacter aerogenes } \\
\text { GBI }\end{array}$ & PBR & 1,12 & Ito et al. (2005) \\
pasteurianum CH4 & CSTR & 0,77 & Lo et al. (2013) \\
GBI & $\begin{array}{c}\text { Solo de cultivo de trigo } \\
\text { Lodos de estações de } \\
\text { tratamento de água }\end{array}$ & Vidro de soro & 0,31 & $\begin{array}{c}\text { Selembo et al. } \\
\text { (2009) }\end{array}$ \\
GBI & $\begin{array}{c}\text { residuária de destilaria e } \\
\text { de processamento de } \\
\text { fécula de batata }\end{array}$ & CSTR & 0,05 & Termudo et al. \\
& $\begin{array}{c}\text { Lodo de abatedouro de } \\
\text { aves tratado por HST }\end{array}$ & AnSBBR & 0,01 & Este trabalho \\
GBI & & & & \\
\hline
\end{tabular}

O AnSBBR não mostrou problemas de estabilidade ao longo de nenhum dos ensaios, já que não houve indícios na redução de biogás durante as condições experimentais impostas durante o estudo, porém não foi conseguida a inibição completa da metanogênese em nenhum dos ensaios propostos tanto na Fase II quanto na Fase III.

Conclui-se que o sistema AnSBBR é viável para a produção de biohidrogênio a partir do efluente do processo de produção de biodiesel, como mostram os dados obtidos com a glicerina pura; mas ainda são necessários mais estudos para otimizar as condições operacionais desse sistema com a glicerina bruta industrial. 


\subsection{EXAME MICROBIOLÓGICO}

O exame microbiológico foi realizado utilizando a biomassa retirada do interior do reator no último ensaio realizado (ensaio 21). A Figura 5.139 apresenta a análise de microscopia da biomassa do reator.

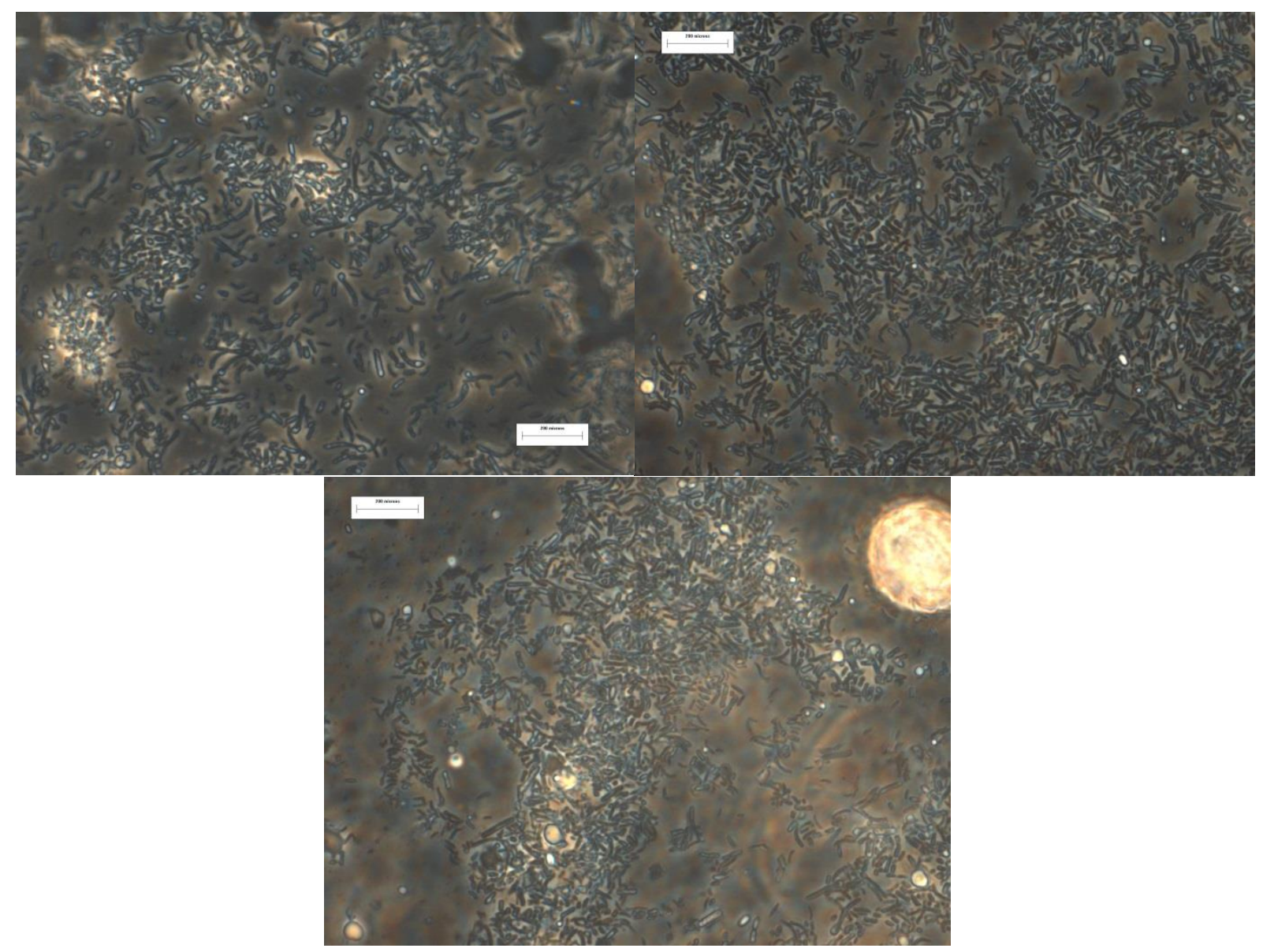

Figura 5.139 - Exame microbiológico realizado na biomassa do reator no ensaio 21

A análise do exame microbiológico não indica grandes diferenças morfológicas entre o encontrado neste trabalho e no de Inoue (2013) e Santos (2012), sendo que foi observado o predomínio de bacilos. 


\section{CONCLUSÕES}

Os resultados obtidos e a discussão apresentada sobre o desempenho do AnSBBR com recirculação da fase líquida tratando água residuária a base de glicerina (efluente do processo de produção de biodiesel) visando à produção de biohidrogênio, submetido a diferentes cargas orgânicas volumétricas (implementadas variando-se a concentração afluente, tempos de ciclo e de enchimento), permitem que sejam realizadas as seguintes conclusões:

- O sistema obteve baixo desempenho na remoção de matéria orgânica (DQO), entre 26 e $38 \%$ nos ensaios com glicerol e $38 \%$ no ensaio com glicerina bruta;

- Quanto aos metabólitos intermediários, houve o predomínio do ácido acético e do ácido butírico em todos os ensaios com glicerol, o que foi extremamente favorável para a produção de biohidrogênio, entretanto, o ensaio com glicerina bruta apresentou predomínio de ácido propiônico, que é prejudicial para a produção de biohidrogênio;

- A carga orgânica volumétrica aplicada, obtida pela combinação de diferentes tempos de ciclo e concentrações afluente, exerceu influência sobre a produtividade e rendimento molares de hidrogênio, mas não apresentou uma tendência clara, indicando que a análise dos parâmetros intrínsecos devem ser considerados na aplicação desses reatores.

- O aumento da concentração afluente, utilizando a mesma estratégia de alimentação, está diretamente ligado ao aumento da produtividade de hidrogênio;

- Em relação ao tempo de ciclo, os ensaios com tempo de enchimento de 3 horas tenderam a ter melhores resultados de produtividade e rendimento molares do que os ensaios com tempo de enchimento de 4 horas; 
- O AnSBBR não mostrou problemas de estabilidade ao longo de nenhum dos ensaios, porém não foi conseguida a inibição completa da metanogênese em nenhum dos ensaios propostos;

- O pré-tratamento do lodo por HST (Heat Shock Treatment) melhorou ligeiramente a produtividade e o rendimento molares, mas não apresenta diferença significativa a nível de 5\% de significância em relação ao lodo não tratado e não afeta a rota metanogênica.

- O uso da glicerina bruta industrial como fonte de carbono diminuiu consideravelmente a quantidade e qualidade do biogás obtido, bem como o rendimento do processo, sendo necessários mais estudos para atingir a condição ótima de operação para esse sistema utilizando o resíduo industrial, principalmente nos fatores que ajudem a inibir a rota de produção de ácido propiônico. 


\section{SUGESTÕES}

Levando em consideração as experiências obtidas no presente trabalho, são apresentadas a seguir sugestões para futuros estudos de produção de hidrogênio em reatores anaeróbios de biomassa imobilizada utilizando o efluente do processo de produção de biodiesel:

- Estudo mais detalhado da influência dos seguintes parâmetros: velocidade ascensional, tipo de suporte e solução de sais;

- Estudo sobre a variação do tempo de enchimento em relação a variação do tempo de ciclo com a água residuária utilizada neste trabalho;

- Realização de um estudo microbiológico mais aprofundado com o intuito de identificar os principais grupos de microrganismos presentes;

- Realização de mais ensaios com a glicerina bruta industrial para achar a condição ótima de operação do sistema proposto com essa água residuária;

- Estudo de um método para inibição de produção de ácido propiônico quando o efluente industrial é utilizado. 


\section{REFERÊNCIAS BIBLIOGRÁFICAS}

AKUTSU, Y.; LEE, D.; LI, Y.; NOIKE, T. Hydrogen production potentials and fermentative characteristics of various substrates with different heat-pretreated natural microflora. International Journal of Hydrogen Energy, v.34, p.5365-5372, 2009.

ALBANEZ, R.; CANTO, C.S.A.; RATUSZNEI, S.M.; RODRIGUES, J.A.D.; ZAIAT, M.; FORESTI, E. Feasibility of a sequencing reactor operated in batch and fed-batch mode applied to nitrification and denitrification processes. Revista de Química Teórica Y Aplicada - Afinidad, v. 66, p. 44-55, 2009.

ALZATE-GAVIRIA, L.M.; SEBASTIAN, P.J.; PÉREZ, A.; EAPEN, D. Comparison of two anaerobic systems for hydrogen production from the organic fraction of municipal solid waste and synthetic wastewater. International Journal of Hydrogen Energy, v.32, p.3141-3146, 2007.

ARCHILHA, N.C., CANTO, C.S.A.; RATUSZNEI, S.M.; RODRIGUES, J.A.D.; ZAIAT, M, FORESTI, E Effect of feeding strategy and COD/sulfate ratio on the removal of sulfate in an AnSBBR with recirculation of the liquid phase Journal of Environmental Management, v.91, n.8, p. 1756-1765, 2010.

ARGUN, H.; KARGI, F.; KAPDAN, I.; OZTEKIN, R. Biohydrogen production by dark fermentation of wheat powder solution: Effects of $\mathrm{C} / \mathrm{N}$ an $\mathrm{C} / \mathrm{P}$ ratio hydrogen yield and formation rate. International Journal of Hydrogen Energy, v.33, p.1813-1819, 2008 .

AROOJ, M. F.; HAN, S.; KIM, S.; KIM, D.; SHIN, H. Effect of HRT on ASBR converting starch into biological hydrogen. International Journal of Hydrogen Energy, v. 33, p. $6509-6514,2008$

BADIEI, M.; JAHIM, J.M.; ANUAR, N.; ABDULLAH, S.R.S. Effect of hydraulic retention time on biohydrogen production from palm oil mill effluent in anaerobic sequencing batch reactor. International Journal of Hydrogen Energy, v. 36, p. 5912-5919, 2011.

BEZERRA, R.A., RODRIGUES, J.A.D., RATUSZNEI, S.M., ZAIAT, M., \& FORESTI, E. Whey treatment by AnSBBR with circulation: Effects of organic loading, shock 
loads, and alkalinity supplementation. Applied Biochemistry and Biotechnology, v.143, n.3, 257-275, 2007.

BEZERRA, R.A., RODRIGUES, J.A.D., RATUSZNEI, S.M., ZAIAT, M., FORESTI, E. Effects of feed time, organic loading and shock loads in the anaerobic whey treatment by an AnSBBR with circulation. Applied Biochemistry and Biotechnology, v. 157, n.2, p. 140-158, 2009.

BEZERRA, R.A.; RODRIGUES, J.A.D.; RATUSZNEI, S.M.; CANTO, C.S.A.; ZAIAT, E. Effect of organic load on the performance and methane production of an AnSBBR treating effluent from biodiesel production. Applied Biochemistry and Biotechnology, v. 165, n.1, p. 347-368, 2011.

BIEBL, H.; ZENG, A.P.; MENZEL, K.; DECKWER, W.D. Fermentation of glycerol to 1,3propanediol and 2,3-butanediol by Klebsiella pneumoniae. Applied Microbiology and Biotechnology, v. 50, p. 24-29, 1998.

BORGES, A.C.; SIMAN, R.R.; RODRIGUES, J.A.D.; RATUSZNEI, S.M.; ZAIAT, M.; FORESTI, E.; BORZANI, W. Stirred anaerobic sequencing batch reactor containing immobilized biomass: a behavior study when submitted to different fill times. Water Science and Technology, v. 49, p. 311-318, 2004.

BUITRÓN, G.; CARVAJAL, C. Biohydrogen production from Tequila vinasses in an anaerobic sequencing batch reactor: Effect of initial substrate concentration, temperature and hydraulic retention time. Bioresource Technology, v. 101, p. 90719077, 2010.

CAMARGO, E.F.M.; CANTO, C.S.A.; RATUSZNEI, S.M.; RODRIGUES, J.A.D.; ZAIAT, M.; BORZANI, W. Hydrodynamic analysis of an anaerobic sequencing batch biofilm reactor with liquid-phase external circulation. Interciencia v. 30, p. 188-194, 2005.

CANTO, C.S.A.; RATUSZNEI, S.M; RODRIGUES, J.A.D.; ZAIAT, M.; FORESTI, E. Effect of ammonia load on efficiency of nitrogen removal in an SBBR with liquidphase circulation. Brazilian Journal of Chemical Engineering v. 25, p. 275-289, 2008 .

CARVALHINHA, P.P., FLÔRES, A, RODRIGUES, J.A.D.; RATUSZNEI, S.M.; ZAIAT, M.; FORESTI, E AnSBBR applied to the treatment of metalworking fluid 
wastewater: effect of organic and shock load. Applied Biochemistry and Biotechnology, v. 162, n.6, p. 1708-1724, 2010.

CHANDRA, R.; TAKEUCHI, H.; HASEGAWA, T. Methane production from lignocellulosic agricultural crop wastes: A review in context to second generation of biofuel production. Renewable and Sustainable Energy Reviews v. 16, p. 1462- 1476, 2012.

CHEN, W.; SUNG, G,S.; CHEN, S. Biological hydrogen production in an anaerobic sequencing batch reactor: $\mathrm{pH}$ and cyclic duration effects. International Journal of Hydrogen Energy, v. 34, p. 227-234, 2009.

CHEONG, D.-YEOL; HANSEN, C.L.; STEVENS, D. K. Production of Bio-Hydrogen by Mesophilic Anaerobic Fermentation in an Acid-Phase Sequencing Batch Reactor. Biotechnology , v. 96, n. 3, p. 421-432, 2007.

COSTABILE, A.L., CANTO, C.S.A.; RATUSZNEI, S.M.; RODRIGUES, J.A.D.; ZAIAT, M, FORESTI, E. Temperature and feed strategy effects on sulfate and organic matter removal in an AnSBB. Journal of Environmental Management, v. 92, n. 7, p. 1714-1723, 2011.

CUBAS, S.A., FORESTI, E.; RODRIGUES, J.A.D.; RATUSZNEI, S.M., ZAIAT, M. Effect of impeller type and stirring frequency on the behavior of an AnSBBR in the treatment of low-strength wastewater. Bioresource Technology v. 102, n. 2, p. 889893, 2011.

DAGUE, R.R.; HABBEN, C.E.; PIDAPARTI, S.R. Initial studies on the anaerobic sequencing batch reactor. Water Science and Technology, v. 26, p. 2429-2432, 1992.

DAMASCENO, L.H.S.; RODRIGUES, J.A.D.; RATUSZNEI, S.; ZAIAT, M.; FORESTI, E. Effects of feeding time and organic loading in an anaerobic sequencing batch biofilm reactor (ASBBR) treating diluted whey. Journal of Environmental Management, v. 85 , n. 4, p. 927-35, 2007. 
DAMASCENO, L.H.S.; RODRIGUES, J.A.D.; RATUSZNEI, S.; ZAIAT, M.; FORESTI, E. Effect of mixing mode on the behavior of an ASBBR with immobilized biomass in the treatment of cheese whey. Brazilian Journal of Chemical Engineering, v. 25, n. 2, p. $291-298,2008$.

DAS, D.; VEZIROGLU, T. N. Hydrogen production by biological processes : a survey of literature. International Journal of Hydrogen Energy, v. 26, p. 13-28, 2001.

DAVILA-VAZQUEZ, G.; ARRIAGA, S.; ALATRISTE-MONDRAGÓN, F. Fermentative biohydrogen production: trends and perspectives. Reviews in Environmental Science and Bio/Technology, v. 7, n. 1, p. 27-45, 2007.

DEL NERY, V. Utilização de lodo anaeróbio imobilizado em gel no estudo de partida de reatores de fluxo ascendente com manta de lodo. Dissertação (Mestrado) - Escola de Engenharia de São Carlos - Departamento de Hidráulica e Saneamento, Universidade de São Paulo, 1987.

DILALLO, R.; ALBERTSON, O.E. Volatile acids by direct titration. Journal of Water Pollution Control Federation, v. 3, p. 356-365, 1961.

DUBOIS, S.M.; GILLES, K.A.; HAMILTON, J.L.; REBERS, P.A.; SMITH, F. Colorimetric Methods for determination of sugar and related substance. Analytical Chemistry, v. 228, p. 13-21, 1956.

FARIA, D.R.G.; LOVATO, G.; MARTIGNAGO, L.M.; RODRIGUES, J.A.D. Tratamento de Glicerina Bruta Industrial por Processo Biológico Anaeróbio Visando Produção de Metano e Adequação Ambiental. Anais de Trabalhos Completos do $1^{\circ}$ Simpósio Internacional de Iniciação Científica - USP, São Carlos-SP, CD-ROM, 2011.

FERCHICHI, M.; CRABBE, E.; GIL, G. H.; HINTZ, W.; ALMADIDY, A. Influence of initial $\mathrm{pH}$ on hydrogen production from cheese whey. Journal of Biotechnology, v. 120, p. 402-409, 2005.

FERNANDES, B. S. Produção de hidrogênio em reator anaeróbio de leito fixo, 2008. USPEESC.

FERNANDES, L.; KENNEDY, K.J.; NING, Z. Dynamic moleling of substrate degradation in sequencing batch anaerobic reactors (SBAR). Water Research, v. 27, p. 1619-1628, 1993. 
FORESTI, E. Fundamentos do tratamento anaeróbio. In: CAMPOS, J. R. Tratamento de Esgotos Sanitários por Processo Anaeróbio e Disposição Controlada no Solo. Projeto PROSAB. ed.1. Rio de Janeiro: ABES, 1999.

FRIEDL, G.F., MOCKAITIS ,G., RODRIGUES, J. A, S. M. RATUSZNEI, S.; ZAIAT, M, FORESTI, E. AnSBBR applied to organic matter and sulfate removal: interaction effect between feed strategy and COD/sulfate ratio. Applied Biochemistry and Biotechnology, v. 159, n. 1, p. 95-109, 2009.

GIOANNIS, G.; MUNTONI, A.; POLETTINI, A.; POMI, R. A review of dark fermentative hydrogen production from biodegradable municipal waste fractions. Waste Management, v. 33, n.6, p. 1345-1361, 2013.

INOUE, R.. K. Influência da carga orgânica e do tempo de enchimento na produção de biohidrogênio em AnSBBR com agitação tratando água residuária sintética. Dissertação (Mestrado) - Escola de Engenharia de São Carlos - Departamento de Hidráulica e Saneamento, Universidade de São Paulo, 2013.

ITO, T.; NAKASHIMADA, Y.; SENBA, K.; MATSUI, T.; NISHIO, N. Hydrogen and ethanol production from glycerol containing wastes discharges after biodiesel manufacturing process. Journal of Bioscience and Bioengineering, v. 100, p. 260$265,2005$.

JEONG, T.; CHA, G.; YOO, I.; KIM, D. Hydrogen production from waste activated sludge by using separation membrane acid fermentation reactor and photosynthetic reactor. International Journal of Hydrogen Energy, v.32, p.525-530, 2007.

KHANAL, S.; CHEN, W.; SUNG, S. Biological hydrogen production: effects of $\mathrm{pH}$ and intermediate products. International Journal of Hydrogen Energy, v. 29, p. 1123 1131, 2003.

KIM, S; HAN, S; SHIN, H. Effect of substrate concentration on hydrogen production and 16 $\mathrm{S}$ rDNA-based analysis of the microbial community in a continuous fermenter. Process Biochemistry, v. 41, p. 199-207, 2006.

KUMAR, N.; DAS, D. Enhancement of hydrogen production by Enterobacter cloacae IIT-BT 08. Process Biochemistry, v.35, p.589-93, 2000. 
LEE, D.-J.; SHOW, K.-Y.; SU, A. Dark fermentation on biohydrogen production: Pure culture. Bioresource Technology, v. 102, p. 8393-402, 2011.

LEITE, J.A.C.; FERNANDES, B.S.; POZZI, E.; BARBOZA,M.; ZAIAT, M. Application of an anaerobic packed-bed bioreactor for the production of hydrogen and organic acids. International Journal of Hydrogen Energy, v.33, p.579- 586, 2008.

LIN, C.; LAY, C. A nutrient formulation for fermentative hydrogen production using anaerobic sewage sludge microflora. International Journal of Hydrogen Energy, v.30, p.285-292, 2005.

LO, Y.; CHEN, X.; HUANG, C.; YUAN, Y.; CHANG, J. Dark fermentative hydrogen production with crude glycerol from biodiesel industry using indigenous hydrogenproducing bacteria. International Journal of Hydrogen Energy, v.38, i.35, p.15815-15822, 2013.

LOVATO, G., BEZERRA, R.A., RODRIGUES, J.A., RATUSZNEI, S.M., ZAIAT, M. Effect of feed strategy on methane production and performance of an AnSBBR treating effluent from biodiesel production. Applied Biochemistry and Biotechnology, v. 166, n. 8, p. 2007-2029, 2012.

MANSSOURI, M.; RODRIGUES, J.A.D.; RATUSZNEI, S.; ZAIAT, M. Effects of Organic Loading, Influent Concentration and Feed Time on Biohydrogen Production in a Mechanically Stirred AnSBBR Treating Sucrose Based Wastewater. Applied Biochemistry and Biotechnology, 2013. (in press)

MOCKAITIS, G.; FRIEDL, G.F.; RODRIGUES, J.A.D.; RATUSZNEI, S. M.; ZAIAT, M.; FORESTI, E. Influence of feed time and sulfate load on the organic and sulfate removal in an ASBR. Bioresource Technology, v. 101, p. 6642-50, 2010.

MOHAMMADI, P.; IBRAHIM, S.; ANNUAR, M.S.M. Effects of biomass, COD and bicarbonate concentrations on fermentative hydrogen production from POME by granulated sludge in a batch culture. International journal of hydrogen energy. v. 37, p. 17801-7808, 2012.

MURARKA, A.; DHARMADI, Y.; YAZDANI, S. S.; GONZALEZ, R. Fermentative utilization of glycerol by Escherichia coli and its implications for the production of fuels and chemicals. Applied Environmental Microbiology, v. 74, p. 1124-1135, 2008. 
NAKASHIMADA, Y.; RACHMAN, M. A.; KAKIZONO, T.; NISHIO, N. Hydrogen production of Enterobacter aerogenes altered by extracellular and intracellular redox states. International Journal of Hydrogen Energy, v. 27, p. 1399-1405, 2002.

NISHIO, N.; NAKASHIMADA, Y. Recent development of digestion process for energy recovery from wastes. Journal of Bioscience and Bioengineering, v.103, p.105$112,2007$.

NOVAES, L.F.; BORGES, L.O.; RODRIGUES, J.A.D.; RATUSZNEI, S.M.; ZAIAT, M.; FORESTI, E. Effect of fill time on the performance of pilot-scale ASBR and AnSBBR applied to sanitary wastewater treatment. Applied Biochemistry and Biotechnology, v. 162, p. 885-899, 2010a.

NOVAES, L.F.; SARATT, B.L.; RODRIGUES, J.A.D.; RATUSZNEI, S.M.; MORAES, D.; RIBEIRO, R.; ZAIAT, M.; FORESTI, E. Effect of impeller type and agitation on the performance of pilot scale ASBR and AnSBBR applied to sanitary wastewater treatment. Journal of Environmental Management, v. 91, p. 1647-1656, 2010 b.

OLIVEIRA, D.S.; PRINHOLATO, A.C.; RATUSZNEI, S.M.; RODRIGUES, J.A.D.; ZAIAT, M.; FORESTI, E. AnSBBR applied to the treatment of wastewater from a personal care industry: effect of organic load and fill time. Journal of Environmental Management, v. 90, p. 3070-3081, 2009.

OLIVEIRA, R.P., GHILARDI, J.A., RATUSZNEI, S.M., RODRIGUES, J.A.D., ZAIAT, M., FORESTI, E. Anaerobic sequencing batch biofilm reactor applied to automobile industry wastewater treatment: volumetric loading rate and feed strategy effects. Chemical Engineering Processing, v. 47, n. 1374-1383, 2008.

O-THONG，S.; PRASERTSAN，P.; INTRASUNGKHA，N.; DHAMWICHUKORN，S.; BIRKELAND, N. Optimization of simultaneous thermophilic fermentative hydrogen production and COD reduction from palm oil mil effluent by Thermoanaerobaterium-rich sludge. International Journal of Hydrogen Energy, v.33, p.1221-1231, 2008.

OZTEKIN, R.; KAPDAN, I.; KARGUI, F.; ARGUN, H. Optimization of media composition for hydrogen gas production from hydrolyzed wheat starch by dark fermentation. International Journal of Hydrogen Energy, v.33, p.4083-4090, 2008. 
RAMOS, A.C.T.; RATUSZNEI, S.M.; RODRIGUES, J.A.D; ZAIAT, M. Mass transfer improvement of a fixed bed anaerobic sequencing batch reactor with liquid-phase circulation. Interciencia, v. 28, p. 214-219, 2003.

RATUSZNEI, S.M., RODRIGUES, J.A.D., CAMARGO, E.F.M.; ZAIAT, M.; BORZANI, W. Feasibility of a stirred anaerobic sequencing batch reactor containing immobilized biomass for wastewater treatment. Bioresource Technology, v. 75, n. 2, p. 127-132, 2000.

REN, N.; GUO, W.; WANG, X.; XIANG, W.; LIU, B.; DING, J.; CHEN, Z. Effects of different pretreatment methods on fermentation types and dominant bacteria for hydrogen production. International Journal of Hydrogen Energy, v. 33, p. 43184324, 2006.

RIPLEY, L.E.; BOYLE, W.C.; CONVERSE, J.C. Improved Alkalimetric Monitoring for AnaerobicDigestor of High-Strength Wastes. Journal of Water Pollution Control Federation, v. 58, p. 406-411, 1986.

RODRIGUES, J.A.D., OLIVEIRA, R. P., RODRIGUES, J.A.D.; RATUSZNEI, S.; ZAIAT, M. AnSBBR applied to a personal care industry wastewater treatment: effects of fill time, volume treated per cycle, and organic load. Applied Biochemistry and Biotechnology, v. 163, n. 1, p. 127-142, 2011.

RODRIGUES, J.A.D.; PINTO, A.G.; RATUSZNEI, S.M.; ZAIAT, M.; GEDRAITE, R. Enhancement of the performance of an anaerobic sequencing batch reactor treating low strength wastewater through implementation of a variable stirring rate program. Brazilian Journal of Chemical Engineering, v. 21, p. 423-434, 2004.

RODRIGUES, J.A.D.; RATUSZNEI, S. M.; ZAIAT, M. Fed-batch and batch operating mode analysis of a stirred anaerobic sequencing reactor with self-immobilized biomass treating low-strength wastewater. Journal of Environmental Management, v. 69, p. 193-200, 2003b. 
SÁ, L. R. V; CAMMAROTA, M. C.; DE OLIVEIRA, T. C.; OLIVEIRA, E. M. M.; MATOS, A.; FERREIRA-LEITÃO, V. S. Pentoses, hexoses and glycerin as substrates for biohydrogen production: An approach for Brazilian biofuel integration. International Journal of Hydrogen Energy, v. 38, n.7, p. 2986-2997, 2013.

SANTOS, D.A. Estudo da produção de biohidrogênio em AnSBBR com recirculação da fase líquida tratando água residuária sintética - Efeito da carga orgânica. Dissertação (Mestrado) - Escola de Engenharia de São Carlos - Departamento de Hidráulica e Saneamento, Universidade de São Paulo, 2012.

SARAPHIROM, P.; REUNGSANG, A. Biological hydrogen production from sweet sorghum syrup by mixed cultures using an anaerobic sequencing batch reactor (ASBR). International Journal of Hydrogen Energy, v. 36, p. 8765-8773, 2011.

SARTI, A., SAKAMOTO, I.K., VARESCHE, M.B.A., ZAIAT, M., FORESTI, E. Domestic sewage treatment in pilot-scale anaerobic sequencing batch reactors. Engenharia Sanitária e Ambiental, v. 11, n. 1, p. 73-82, 2006.

SEARMSIRIMONGKOL， P.; RANGSUNVIGIT; P., LEETHOCHAWALIT, M.; CHAVADEJ, S. Hydrogen production from alcohol distillery wastewater containing high potassium and sulfate using an anaerobic sequencing batch reactor. International Journal of Hydrogen Energy, v. 36, p. 12810-12821, 2011.

SELEMBO, P.A.; PEREZ, J.M.; LLOYD, W.A.; LOGAN, B.E. Enhanced hydrogen and 1,3propanediol production from glycerol by fermentation using mixed cultures. Biotechnology and Bioengineering, v. 104, p. 1098-1106, 2009.

SELMA, V.C.; COTRIM, L.H.B.; RODRIGUES, J.A.D.; RATUSZNEI, S. M.; ZAIAT, M.; FORESTI, E. ASBR applied to the treatment of biodiesel production effluent: effect of organic load and fill time on performance and methane production. Applied Biochemistry and Biotechnology, v. 162, p. 2365-2380, 2010.

SHIZAS, I., BAGLEY, D.M. Improving anaerobic sequencing batch reactor performance by modifying operational parameters. Water Research, v. 36, p. 363-367, 2002.

SILVA, G. P.; MACK, M.; CONTIERO, J. Glycerol: A promising and abundant carbon source for industrial microbiology. Biotechnology Advances, v.27, i.1, p.30-39, 2009. 
SILVA, R.C.; RATUSZNEI, S.M.; RODRIGUES, J.A.D.; ZAIAT, M. Anaerobic treatment of industrial biodiesel wastewater by an ASBR for methane production. Applied Biochemistry and Biotechnology.v. 170, n. 1, p. 105-118, 2013.

Standard Methods for the Examination of Water and Wastewater. APHA, AWWA, WPCF. $19^{\text {th }}$ edition, American Public Health Association, Washington, 1995.

SUZUKI, Y. On hydrogen as fuel gas. International Journal of Hydrogen Energy, v. 7, b. 3, p. 227-230, 1982.

TANISHO, S. A scheme for developing the yield of hydrogen by fermentation. An Approach to Environmentally Acceptable Technology, p. 131-140, 2001.

TEMUDO, M.F.; POLDERMANS, R.; KLEEREBEZEM, R.; VAN LOOSDRECHT, M.C.M. Glycerol Fermentation by (Open) Mixed Cultures: A Chemostat Study. Biotechnology and Bioengineering, v. 100, n. 6, p. 1088-1098, 2008.

TURCOT, J.; BISAILLON, A.; HALLENBECK, P. Hydrogen production by continuous cultures of Escherichia coli under different nutrient regimes. International Journal of Hydrogen Energy, v.33, p.1465-1470, 2008.

WANG, J.; WAN, W. Factors influencing fermentative hydrogen production: A review. International Journal of Hydrogen Energy, v. 34, p. 799-811, 2009.

WU, X.; ZHU, J.; DONG; C., MILLER, C.; LI, Y.; WANG, L.; YAO, W. Continuous biohydrogen production from liquid swine manure supplemented with glucose using an anaerobic sequencing batch reactor. International Journal of Hydrogen Energy, v. 34, p. 6636-6645, 2009.

WU, X.; ZHU, J.;MILLER, C. Kinetics study of fermentative hydrogen production from liquid swine manure supplemented with glucose under controlled $\mathrm{pH}$, Journal of Environmental Science and Health, Part B: Pesticides, Food Contaminants, and Agricultural Wastes, v. 48, n. 6, p. 477-485, 2013.

YANG, Y.; TSUKAHARA, K.; SAWAYAMA, S. Biodegradation and methane production from glycerol-containing synthetic wastes with fixed-bed bioreactor under mesophilic and thermophilic anaerobic conditions. Process Biochemistry, v.43, p.362-367, 2008. 
YAZDANI, S.S.; GONZALEZ, R. Anaerobic fermentation of glycerol: a path to economic viability for the biofuels industry. Biotechnology, v.18, p.213-219, 2007.

ZAIAT, M.; CABRAL, A.K.A.; FORESTI, E. Horizontal-flow anaerobic immobilized sludge reactor for wastewater treatment: conception and performance evaluation. Brazilian Journal of Chemical Engineering, v. 11, p. 33-42, 1994.

ZAIAT, M.; RODRIGUES, J.A.D.; RATUSZNEI, S.M.; CAMARGO, E.F.M.; BORZANI, W. Anaerobic sequencing batch reactors for wastewater treatment: a developing technology. Applied Microbiology and Biotechnology, v. 55, p. 29-35, 2001.

ZHANG, M.L.; FAN, Y.T.; XING, Y.; PAN, C.M.; ZHANG, G.S.; LAY, J.J. Enhanced biohydrogen production from cornstalk wastes with acidification pretreatment by mixed anaerobic cultures. Biomass Bioenergy, v.31, p.250-4, 2007.

ZHAO, Q.B.; YU, H.Q. Fermentative H2 production in an upflow anaerobic sludge blanket reactor at various pH values. Bioresource Technology, v.99, p.1353-8, 2008.

ZIMMER, T. R.; MICHELAN, R.; CANTO, C. S. A.; RODRIGUES, J. A. D.; RATUSZNEI, S. Feed strategy study of a mechanically stirred anaerobic sequencing batch reactor ( ASBR ) equipped with a draft tube applied to whey treatment. Brazilian Journal of Food Technology, v. 11, p. 288-298, 2008. 


\section{ANEXO I}

Tabela AI - Concentração de matéria orgânica (DQO) afluente e efluente em todas as condições

\begin{tabular}{|c|c|c|c|c|c|c|}
\hline $\mathrm{CO}$ & $\begin{array}{c}\text { Tempo } \\
\text { (d) }\end{array}$ & $\begin{array}{c}\mathrm{C}_{\mathrm{SAFL}} \\
\left(\mathrm{mgDQO} . \mathrm{L}^{-1}\right)\end{array}$ & $\begin{array}{c}\mathrm{C}_{\mathrm{ST}} \\
\left(\mathrm{mgDQO.L^{-1 }}\right)\end{array}$ & $\begin{array}{c}\mathrm{C}_{\mathrm{SF}} \\
\left(\mathrm{mgDQO} \mathbf{L}^{-1}\right)\end{array}$ & $\begin{array}{l}\varepsilon_{\mathrm{ST}} \\
(\%)\end{array}$ & $\begin{array}{c}\varepsilon_{\mathrm{SF}} \\
(\%)\end{array}$ \\
\hline $\mathrm{P}$ & 0 & 3036 & - & - & - & - \\
\hline $\mathrm{P}$ & 1 & 2973 & 2300 & 2145 & 22 & 27 \\
\hline $\mathrm{P}$ & 2 & 2704 & 2423 & 1987 & 18 & 32 \\
\hline $\mathrm{P}$ & 3 & 2851 & 2137 & 1987 & 27 & 32 \\
\hline $\mathrm{P}$ & 4 & 2991 & 2339 & 2126 & 21 & 28 \\
\hline $\mathrm{P}$ & 8 & 2968 & 2319 & 2212 & 21 & 25 \\
\hline $\mathrm{P}$ & 9 & 2978 & 2398 & 2306 & 19 & 22 \\
\hline $\mathrm{P}$ & 10 & 3018 & 2442 & 2310 & 17 & 22 \\
\hline $\mathrm{P}$ & 11 & 3077 & 2336 & 2222 & 21 & 25 \\
\hline $\mathrm{P}$ & 15 & 2965 & 2234 & 2126 & 24 & 28 \\
\hline $\mathrm{P}$ & 16 & 2985 & 2308 & 2148 & 22 & 27 \\
\hline $\mathrm{P}$ & 17 & 3011 & 2305 & 2267 & 22 & 23 \\
\hline 1 & 21 & 3138 & 2191 & 2100 & 31 & 33 \\
\hline 1 & 22 & 3208 & 1965 & 1883 & 38 & 40 \\
\hline 2 & 23 & 3328 & 1928 & 1790 & 41 & 45 \\
\hline 2 & 24 & 3227 & 2051 & 1749 & 37 & 46 \\
\hline 3 & 25 & 3121 & - & - & - & - \\
\hline 3 & 28 & 2909 & 1647 & 1488 & 43 & 49 \\
\hline 3 & 28 & 3108 & 1586 & 1462 & 45 & 50 \\
\hline 3 & 29 & 2593 & 1702 & 1483 & 41 & 49 \\
\hline 3 & 29 & 2893 & - & - & - & - \\
\hline 4 & 30 & 2730 & - & - & - & - \\
\hline 4 & 31 & 2942 & 1777 & 1587 & 37 & 44 \\
\hline 4 & 32 & 2581 & 1959 & 1692 & 31 & 40 \\
\hline 4 & 36 & 3112 & 1925 & 1673 & 32 & 40 \\
\hline 5 & 37 & 2842 & - & - & - & - \\
\hline 5 & 38 & 2378 & 2192 & 1591 & 16 & 39 \\
\hline 5 & 39 & 2755 & 1483 & 1165 & 43 & 55 \\
\hline 5 & 42 & 2773 & 1807 & 1673 & 30 & 35 \\
\hline 6 & 43 & 3275 & - & - & - & - \\
\hline 6 & 44 & 2680 & 1506 & 1541 & 49 & 48 \\
\hline $\mathrm{P}$ & 49 & 3204 & - & - & - & - \\
\hline $\mathrm{P}$ & 50 & 2672 & 2287 & 1923 & 20 & 33 \\
\hline $\mathrm{P}$ & 51 & 3371 & 2727 & 2287 & 5 & 20 \\
\hline $\mathrm{P}$ & 52 & 2864 & 2533 & 2164 & 11 & 24 \\
\hline $\mathrm{P}$ & 53 & 2599 & 2400 & 2024 & 16 & 29 \\
\hline $\mathrm{P}$ & 56 & 2880 & 2509 & 2192 & 12 & 23 \\
\hline 7 & 57 & 2795 & 2320 & 1964 & 22 & 34 \\
\hline 7 & 58 & 3230 & 2067 & 1610 & 30 & 46 \\
\hline 7 & 59 & 2933 & 2082 & 1644 & 30 & 44 \\
\hline 8 & 60 & 3014 & - & - & - & - \\
\hline 8 & 63 & 2834 & 1303 & 1092 & 54 & 61 \\
\hline 8 & 64 & 2755 & - & - & - & - \\
\hline
\end{tabular}


Tabela AI - Concentração de matéria orgânica (DQO) afluente e efluente em todas as condições

\begin{tabular}{|c|c|c|c|c|c|c|}
\hline CO & $\begin{array}{l}\text { Tempo } \\
\text { (d) }\end{array}$ & $\begin{array}{c}\mathrm{C}_{\mathrm{SAFL}} \\
\left(\mathrm{mgDQO} . \mathrm{L}^{-1}\right)\end{array}$ & $\begin{array}{c}\mathrm{C}_{\mathrm{ST}} \\
\left(\mathrm{mgDQO} . \mathrm{L}^{-1}\right)\end{array}$ & $\begin{array}{c}\mathrm{C}_{\mathrm{SF}} \\
\left(\mathrm{mgDQO} . \mathrm{L}^{-1}\right)\end{array}$ & $\begin{array}{l}\varepsilon_{\mathrm{ST}} \\
(\%)\end{array}$ & $\begin{array}{l}\varepsilon_{\mathrm{SF}} \\
(\%)\end{array}$ \\
\hline 8 & 66 & 2815 & - & - & - & - \\
\hline 9 & 70 & 3324 & 2695 & 2506 & 16 & 22 \\
\hline 9 & 71 & 3127 & 2803 & 2676 & 13 & 17 \\
\hline $\mathrm{P}$ & 72 & 1067 & - & - & - & - \\
\hline $\mathrm{P}$ & 73 & 1186 & 998 & 956 & 88 & 84 \\
\hline $\mathrm{P}$ & 77 & 2688 & 2362 & 2348 & 16 & 16 \\
\hline $\mathrm{P}$ & 78 & 2964 & 2459 & 2388 & 12 & 15 \\
\hline $\mathrm{P}$ & 79 & 2753 & 2598 & 2130 & 8 & 24 \\
\hline $\mathrm{P}$ & 80 & 3032 & 2329 & 2167 & 17 & 23 \\
\hline $\mathrm{P}$ & 84 & 2895 & 2917 & 2256 & $-3,4$ & 20 \\
\hline 10 & 85 & 2896 & 2423 & 2383 & 20 & 21 \\
\hline 10 & 86 & 3025 & 2240 & 2192 & 26 & 27 \\
\hline 10 & 87 & 3165 & 2030 & 2000 & 33 & 34 \\
\hline 11 & 88 & 3105 & - & - & - & - \\
\hline 11 & 91 & 2863 & 1982 & 1972 & 33 & 33 \\
\hline 11 & 92 & 2979 & 1685 & 1808 & 43 & 39 \\
\hline 12 & 93 & 1001 & - & - & - & - \\
\hline 12 & 95 & 991 & 772 & 766 & 22 & 23 \\
\hline 12 & 96 & 1024 & 709 & 698 & 29 & 30 \\
\hline 12 & 97 & 957 & 819 & 726 & 18 & 27 \\
\hline 13 & 100 & 1684 & - & - & - & - \\
\hline 13 & 101 & 1954 & 1300 & 1298 & 38 & 38 \\
\hline 13 & 102 & 2045 & 1654 & 1592 & 21 & 24 \\
\hline 13 & 103 & 1959 & 1579 & 1519 & 24 & 27 \\
\hline 13 & 104 & 2813 & 1427 & 1436 & 32 & 31 \\
\hline 14 & 107 & 2565 & - & - & - & - \\
\hline 14 & 108 & 2445 & 2028 & 2028 & 29 & 29 \\
\hline 14 & 109 & 3097 & 2212 & 2221 & 22 & 22 \\
\hline 14 & 110 & 2989 & 2288 & 2223 & 20 & 22 \\
\hline 14 & 111 & 2811 & 2307 & 2104 & 19 & 26 \\
\hline 14 & 114 & 2841 & 2384 & 2196 & 16 & 23 \\
\hline 14 & 115 & 2889 & 2112 & 1847 & 26 & 35 \\
\hline 14 & 116 & 3160 & 2187 & 2167 & 23 & 24 \\
\hline 15 & 121 & 3842 & - & - & - & - \\
\hline 15 & 122 & 3975 & 2960 & 2720 & 23 & 29 \\
\hline 15 & 123 & 3945 & 3261 & 3114 & 15 & 19 \\
\hline 15 & 124 & 3794 & 2997 & 2682 & 22 & 30 \\
\hline 15 & 125 & 3949 & 2944 & 2750 & 23 & 28 \\
\hline 15 & 128 & 3711 & 2765 & 2637 & 28 & 31 \\
\hline 15 & 129 & 3581 & 2947 & 2945 & 23 & 23 \\
\hline 15 & 130 & 3921 & 2880 & 2917 & 25 & 24 \\
\hline 16 & 135 & 5389 & - & - & - & - \\
\hline 16 & 136 & 5043 & 3983 & 3618 & 21 & 28 \\
\hline 16 & 137 & 5142 & 4104 & 4083 & 18 & 19 \\
\hline 16 & 138 & 5365 & 4057 & 4006 & 19 & 20 \\
\hline 16 & 139 & 4838 & 4143 & 3925 & 17 & 22 \\
\hline
\end{tabular}


Tabela AI - Concentração de matéria orgânica (DQO) afluente e efluente em todas as condições

\begin{tabular}{|c|c|c|c|c|c|c|}
\hline $\mathrm{CO}$ & $\begin{array}{c}\text { Tempo } \\
\text { (d) }\end{array}$ & $\begin{array}{c}\mathrm{C}_{\mathrm{SAFL}} \\
\left(\mathrm{mgDQO}^{-1}\right)\end{array}$ & $\begin{array}{c}\mathrm{C}_{\mathrm{ST}} \\
\left(\mathrm{mgDQO}^{-1}\right)\end{array}$ & $\begin{array}{c}\mathrm{C}_{\mathrm{SF}} \\
\left(\mathrm{mgDQO} \cdot \mathrm{L}^{-1}\right)\end{array}$ & $\begin{array}{c}\varepsilon_{\mathrm{ST}} \\
(\%)\end{array}$ & $\begin{array}{l}\varepsilon_{\mathrm{SF}} \\
(\%)\end{array}$ \\
\hline 16 & 142 & 4754 & 3839 & 3671 & 23 & 27 \\
\hline 16 & 143 & 4595 & 4019 & 3980 & 20 & 21 \\
\hline 17 & 149 & 2958 & - & - & - & - \\
\hline 17 & 150 & 2994 & 2288 & 2219 & 26 & 28 \\
\hline 17 & 151 & 2934 & 2415 & 2310 & 21 & 25 \\
\hline 17 & 152 & 3282 & 2505 & 2338 & 18 & 24 \\
\hline 17 & 153 & 3300 & 2621 & 2531 & 15 & 18 \\
\hline 17 & 156 & 2776 & 2226 & 2100 & 28 & 32 \\
\hline 17 & 157 & 3084 & 2598 & 2211 & 15 & 28 \\
\hline 17 & 158 & 3249 & 2296 & 1915 & 25 & 38 \\
\hline 18 & 163 & 4133 & - & - & - & - \\
\hline 18 & 164 & 3988 & 3479 & 3200 & 11 & 18 \\
\hline 18 & 165 & 4125 & 3276 & 3247 & 16 & 17 \\
\hline 18 & 166 & 4448 & 3265 & 2972 & 17 & 24 \\
\hline 18 & 167 & 3897 & 2914 & 2906 & 25 & 26 \\
\hline 18 & 170 & 2701 & 2368 & 2184 & 39 & 44 \\
\hline 18 & 171 & 3925 & 3167 & 2834 & 19 & 28 \\
\hline 18 & 172 & 4070 & 3177 & 3145 & 19 & 20 \\
\hline 19 & 177 & 4870 & - & - & - & - \\
\hline 19 & 178 & 4715 & 3573 & 3256 & 28 & 35 \\
\hline 19 & 179 & 5134 & 3727 & 3605 & 25 & 28 \\
\hline 19 & 180 & 5007 & 3840 & 3157 & 23 & 37 \\
\hline 19 & 181 & 4870 & 3701 & 3656 & 26 & 27 \\
\hline 19 & 184 & 5110 & 3791 & 3756 & 24 & 25 \\
\hline 19 & 185 & 4972 & 3752 & 3715 & 25 & 25 \\
\hline 19 & 186 & 5174 & 3980 & 3851 & 20 & 23 \\
\hline 20 & 191 & 4848 & - & - & - & - \\
\hline 20 & 192 & 5218 & 3822 & 3713 & 23 & 25 \\
\hline 20 & 193 & 4659 & 3993 & 3728 & 20 & 25 \\
\hline 20 & 194 & 5200 & 4008 & 3834 & 19 & 23 \\
\hline 20 & 95 & 4748 & 3523 & 3497 & 29 & 30 \\
\hline 20 & 198 & 5137 & 3809 & 3523 & 23 & 29 \\
\hline 20 & 199 & 4740 & 3696 & 3447 & 26 & 31 \\
\hline 20 & 200 & 5185 & 4012 & 3899 & 19 & 21 \\
\hline 21 & 205 & 5055 & - & - & - & - \\
\hline 21 & 206 & 5664 & 3760 & 3719 & 29 & 30 \\
\hline 21 & 207 & 5007 & 4194 & 4017 & 21 & 24 \\
\hline 21 & 208 & 5296 & 3818 & 3142 & 28 & 41 \\
\hline 21 & 209 & 5397 & 3383 & 2777 & 36 & 48 \\
\hline 21 & 212 & 5545 & 3282 & 3073 & 38 & 42 \\
\hline 21 & 213 & 5416 & 2999 & 2925 & 44 & 45 \\
\hline
\end{tabular}




\section{ANEXO II}

Tabela AII - Valores de pH, alcalinidade parcial, alcalinidade intermediária, alcalinidade total, alcalinidade a bicarbonato e ácidos voláteis totais no afluente em todas as condições

\begin{tabular}{|c|c|c|c|c|c|c|c|}
\hline $\mathrm{CO}$ & $\begin{array}{c}\text { Tempo } \\
\text { (d) }\end{array}$ & $\begin{array}{l}\text { pH } \\
\text { (u) }\end{array}$ & $\begin{array}{c}\mathrm{AP} \\
\left(\mathrm{mgCaCO}_{3} \cdot \mathrm{L}^{-1}\right)\end{array}$ & $\begin{array}{c}\mathrm{AI} \\
\left(\mathrm{mgCaCO}_{3} \cdot \mathrm{L}^{-1}\right)\end{array}$ & $\begin{array}{c}\mathrm{AT} \\
\left(\mathrm{mgCaCO}_{3} \cdot \mathrm{L}^{-1}\right)\end{array}$ & $\begin{array}{c}\mathrm{AB} \\
\left(\mathrm{mgCaCO}_{3} \cdot \mathrm{L}^{-1}\right)\end{array}$ & $\begin{array}{c}\text { AVT } \\
\left(\text { mgHAc.L }^{-1}\right)\end{array}$ \\
\hline $\mathrm{P}$ & 0 & 7,9 & 322,3 & 105,1 & 427,4 & 401,0 & 37,2 \\
\hline $\mathrm{P}$ & 1 & 7,9 & 327,2 & 105,1 & 432,2 & 415,4 & 23,7 \\
\hline $\mathrm{P}$ & 2 & 7,8 & 330,3 & 103,7 & 434,0 & 418,0 & 22,5 \\
\hline $\mathrm{P}$ & 3 & 7,9 & 331,1 & 108,6 & 439,8 & 423,6 & 22,8 \\
\hline $\mathrm{P}$ & 4 & 7,9 & 308,7 & 97,3 & 406,1 & 392,1 & 19,6 \\
\hline $\mathrm{P}$ & 8 & 7,9 & 304,9 & 103,2 & 408,1 & 387,9 & 28,5 \\
\hline $\mathrm{P}$ & 9 & 8,2 & 307,0 & 93,1 & 400,2 & 380,8 & 27,4 \\
\hline $\mathrm{P}$ & 10 & 8,1 & 320,0 & 101,1 & 421,1 & 403,8 & 24,3 \\
\hline $\mathrm{P}$ & 11 & 7,9 & 319,6 & 91,9 & 411,5 & 387,5 & 33,8 \\
\hline $\mathrm{P}$ & 15 & 8,2 & 303,8 & 98,9 & 402,8 & 385,2 & 24,7 \\
\hline $\mathrm{P}$ & 16 & 8,0 & 293,4 & 79,3 & 372,7 & 355,9 & 23,7 \\
\hline $\mathrm{P}$ & 17 & 8,0 & 304,7 & 87,2 & 391,9 & 355,7 & 51,0 \\
\hline 1 & 22 & 7,9 & 322,6 & 152,6 & 475,3 & 394,8 & 112,8 \\
\hline 2 & 23 & 7,5 & 209,1 & 97,8 & 306,1 & 227,1 & 112,2 \\
\hline 2 & 24 & 7,9 & 180,7 & 76,8 & 257,5 & 185,7 & 101,1 \\
\hline 3 & 25 & 7,4 & 136,9 & 70,9 & 207,8 & 137,8 & 98,58 \\
\hline 3 & 28 & 6,1 & 63,9 & 79,3 & 143,3 & 57,65 & 120,7 \\
\hline 3 & 28 & 7,6 & 166,5 & 88,2 & 254,7 & 187,8 & 94,1 \\
\hline 3 & 29 & 7,4 & 170,1 & 40,4 & 210,6 & 144,9 & 92,4 \\
\hline 4 & 30 & 7,2 & 110,2 & 19,4 & 129,7 & 72,8 & 80,1 \\
\hline 4 & 31 & 7,2 & 120,1 & 22,4 & 142,6 & 78,1 & 90,7 \\
\hline 4 & 32 & 7,4 & 104,0 & 37,4 & 141,5 & 83,1 & 82,2 \\
\hline 4 & 36 & 7,8 & 93,3 & 22,0 & 115,4 & 43,4 & 101,4 \\
\hline 5 & 37 & 7,4 & 97,4 & 35,6 & 133,0 & 64,8 & 96,1 \\
\hline 5 & 38 & 7,2 & 90,0 & 31,6 & 121,6 & 59,0 & 88,1 \\
\hline 5 & 39 & 7,3 & 97,0 & 41,9 & 138,9 & 71,6 & 94,7 \\
\hline 5 & 42 & 8,1 & 54,4 & 31,2 & 85,6 & 34,6 & 71,7 \\
\hline 6 & 43 & 10,5 & 106,2 & 19,4 & 125,7 & 97,2 & 40,0 \\
\hline 6 & 44 & 9,7 & 115,7 & 22,4 & 138,2 & 114,5 & 33,2 \\
\hline $\mathrm{P}$ & 49 & 7,9 & 248,1 & 79,7 & 327,8 & 311,8 & 22,5 \\
\hline $\mathrm{P}$ & 50 & 8,9 & 180,4 & 48,1 & 228,6 & 207,4 & 29,7 \\
\hline $\mathrm{P}$ & 51 & 8,7 & 187,4 & 63,9 & 251,4 & 222,4 & 40,8 \\
\hline $\mathrm{P}$ & 52 & 8,7 & 204,7 & 48,5 & 253,2 & 223,9 & 41,2 \\
\hline $\mathrm{P}$ & 53 & 8,6 & 208,4 & 47,7 & 256,1 & 230,2 & 36,5 \\
\hline 7 & 57 & 9,3 & 117,6 & 25,7 & 143,3 & 115,9 & 38,5 \\
\hline 7 & 58 & 9,5 & 111,3 & 28,3 & 139,6 & 114,3 & 35,6 \\
\hline 7 & 59 & 9,9 & 118,7 & 20,2 & 138,9 & 113,3 & 36,0 \\
\hline 8 & 60 & 10,5 & 103,2 & 24,0 & 127,3 & 99,6 & 38,9 \\
\hline 8 & 63 & 10,0 & 142,8 & 21,9 & 164,7 & 142,2 & 31,7 \\
\hline 8 & 64 & 9,7 & 150,5 & 37,4 & 188,0 & 162,4 & 35,9 \\
\hline 9 & 71 & 9,8 & 134,2 & 18,0 & 152,3 & 121,6 & 43,2 \\
\hline $\mathrm{P}$ & 72 & 9,3 & 60,6 & 13,3 & 74,00 & 62,2 & 16,5 \\
\hline $\mathrm{P}$ & 73 & 9,0 & 81,5 & 19,8 & 101,4 & 83,5 & 25,2 \\
\hline $\mathrm{P}$ & 77 & 7,8 & 234,4 & 131,2 & 365,7 & 348,7 & 23,8 \\
\hline $\mathrm{P}$ & 78 & 7,9 & 243,6 & 111,0 & 354,7 & 337,7 & 24,0 \\
\hline
\end{tabular}


Tabela AII - Valores de pH, alcalinidade parcial, alcalinidade intermediária, alcalinidade total, alcalinidade a bicarbonato e ácidos voláteis totais no afluente em todas as condições

\begin{tabular}{|c|c|c|c|c|c|c|c|}
\hline $\mathrm{CO}$ & $\begin{array}{c}\text { Tempo } \\
\text { (d) }\end{array}$ & $\begin{array}{l}\mathbf{p H} \\
\text { (u) }\end{array}$ & $\begin{array}{c}\mathrm{AP} \\
\left(\mathrm{mgCaCO}_{3} \cdot \mathrm{L}^{-1}\right)\end{array}$ & $\begin{array}{c}\mathrm{AI} \\
\left(\mathrm{mgCaCO}_{3} \cdot \mathrm{L}^{-1}\right)\end{array}$ & $\begin{array}{c}\mathrm{AT} \\
\left(\mathrm{mgCaCO}_{3} \cdot \mathrm{L}^{-1}\right)\end{array}$ & $\begin{array}{c}\mathrm{AB} \\
\left(\mathrm{mgCaCO}_{3} \cdot \mathrm{L}^{-1}\right)\end{array}$ & $\begin{array}{c}\text { AVT } \\
\left(\text { mgHAc. }^{-1}\right)\end{array}$ \\
\hline $\mathrm{P}$ & 79 & 7,1 & 81,0 & 9,0 & 90,1 & 72,9 & 24,1 \\
\hline $\mathrm{P}$ & 80 & 7,1 & 68,1 & 21,8 & 90,0 & 73,7 & 23,0 \\
\hline $\mathrm{P}$ & 84 & 8,0 & 268,0 & 125,5 & 393,5 & 383,4 & 14,2 \\
\hline 10 & 85 & 8,0 & 262,2 & 121,0 & 383,2 & 373,5 & 13,7 \\
\hline 10 & 86 & 7,6 & 140,0 & 46,6 & 186,6 & 175,8 & 15,2 \\
\hline 10 & 87 & 8,5 & 92,1 & 10,3 & 102,4 & 85,6 & 23,6 \\
\hline 11 & 88 & 8,7 & 129,3 & 50,2 & 179,5 & 158,6 & 29,3 \\
\hline 11 & 92 & 8,7 & 121,4 & 38,8 & 160,2 & 142,8 & 24,5 \\
\hline 12 & 95 & 7,4 & 121,0 & 39,4 & 160,4 & 142,3 & 25,5 \\
\hline 12 & 96 & 7,6 & 95,0 & 32,3 & 127,4 & 117,2 & 14,3 \\
\hline 12 & 97 & 7,5 & 80,3 & 31,5 & 111,8 & 100,5 & 15,9 \\
\hline 13 & 101 & 7,5 & 124,4 & 30,7 & 155,2 & 141,0 & 19,9 \\
\hline 13 & 104 & 7,5 & 106,1 & 41,2 & 147,3 & 112,4 & 49,2 \\
\hline 14 & 107 & 7,7 & 146,4 & 25,7 & 172,1 & 159,4 & 17,9 \\
\hline 14 & 108 & 7,5 & 138,3 & 37,7 & 176,0 & 161,4 & 20,6 \\
\hline 14 & 109 & 7,6 & 99,7 & 29,2 & 128,9 & 113,2 & 22,2 \\
\hline 14 & 110 & 7,8 & 94,7 & 13,7 & 108,4 & 94,9 & 19,0 \\
\hline 14 & 111 & 7,6 & 81,8 & 13,8 & 95,6 & 80,7 & 21,0 \\
\hline 14 & 115 & 7,6 & 94,3 & 21,3 & 115,7 & 97,3 & 25,9 \\
\hline 14 & 116 & 7,7 & 107,0 & 24,9 & 131,9 & 116,3 & 21,9 \\
\hline 15 & 121 & 7,4 & 124,1 & 33,6 & 157,8 & 135,7 & 31,0 \\
\hline 15 & 122 & 7,4 & 124,6 & 33,1 & 157,6 & 139,0 & 26,3 \\
\hline 15 & 123 & 7,6 & 139,9 & 30,4 & 170,3 & 151,3 & 26,7 \\
\hline 15 & 124 & 7,6 & 116,6 & 18,1 & 134,7 & 114,5 & 28,5 \\
\hline 15 & 125 & 7,5 & 128,5 & 34,9 & 163,4 & 142,3 & 29,8 \\
\hline 15 & 129 & 7,5 & 144,6 & 37,0 & 181,6 & 155,8 & 36,4 \\
\hline 15 & 130 & 7,5 & 158,7 & 14,5 & 173,3 & 144,2 & 40,9 \\
\hline 16 & 136 & 7,6 & 122,3 & 30,5 & 152,8 & 132,4 & 28,6 \\
\hline 16 & 137 & 7,5 & 102,6 & 29,6 & 132,2 & 114,0 & 25,7 \\
\hline 16 & 138 & 7,5 & 125,8 & 23,3 & 149,0 & 131,6 & 24,6 \\
\hline 16 & 139 & 7,7 & 124,2 & 32,5 & 156,7 & 139,4 & 24,4 \\
\hline 16 & 143 & 7,6 & 128,4 & 32,5 & 160,8 & 143,8 & 24,0 \\
\hline 17 & 150 & 7,6 & 120,3 & 18,1 & 138,4 & 120,5 & 25,1 \\
\hline 17 & 151 & 7,7 & 126,9 & 18,6 & 145,5 & 126,3 & 27,0 \\
\hline 17 & 152 & 7,6 & 139,7 & 20,0 & 159,7 & 142,0 & 24,9 \\
\hline 17 & 153 & 7,7 & 130,6 & 14,1 & 144,8 & 126,7 & 25,4 \\
\hline 17 & 157 & 7,8 & 122,4 & 30,7 & 153,0 & 139,1 & 19,6 \\
\hline 17 & 158 & 7,7 & 127,0 & 34,9 & 161,9 & 148,9 & 18,3 \\
\hline 18 & 164 & 7,5 & 131,1 & 29,0 & 160,1 & 143,2 & 23,7 \\
\hline 18 & 165 & 7,6 & 127,1 & 33,7 & 160,7 & 144,0 & 23,6 \\
\hline
\end{tabular}


Tabela AII - Valores de pH, alcalinidade parcial, alcalinidade intermediária, alcalinidade total, alcalinidade a bicarbonato e ácidos voláteis totais no afluente em todas as condições

\begin{tabular}{|c|c|c|c|c|c|c|c|}
\hline $\mathrm{CO}$ & $\begin{array}{l}\text { Tempo } \\
\text { (d) }\end{array}$ & $\begin{array}{l}\mathbf{p H} \\
(\mathbf{u})\end{array}$ & $\begin{array}{c}\mathrm{AP} \\
\left(\mathrm{mgCaCO}_{3} \cdot \mathrm{L}^{-1}\right)\end{array}$ & $\begin{array}{c}\mathrm{AI} \\
\left(\mathrm{mgCaCO}_{3} \cdot \mathrm{L}^{-1}\right)\end{array}$ & $\begin{array}{c}\mathrm{AT} \\
\left(\mathrm{mgCaCO}_{3} \cdot \mathrm{L}^{-1}\right)\end{array}$ & $\begin{array}{c}\mathrm{AB} \\
\left(\mathrm{mgCaCO}_{3} \cdot \mathrm{L}^{-1}\right)\end{array}$ & $\begin{array}{c}\text { AVT } \\
\left(\text { mgHAc. }^{-1}\right)\end{array}$ \\
\hline 18 & 166 & 7,6 & 126,8 & 37,1 & 163,9 & 147,2 & 23,5 \\
\hline 18 & 167 & 7,5 & 128,6 & 31,8 & 160,4 & 146,1 & 20,1 \\
\hline 18 & 171 & 7,5 & 121,1 & 32,3 & 153,4 & 134,9 & 26,0 \\
\hline 18 & 172 & 7,7 & 132,2 & 26,7 & 158,9 & 139,2 & 27,7 \\
\hline 19 & 178 & 7,8 & 125,9 & 11,7 & 137,6 & 121,2 & 23,1 \\
\hline 19 & 179 & 7,7 & 128,4 & 21,2 & 149,6 & 131,1 & 26,0 \\
\hline 19 & 180 & 7,7 & 126,5 & 30,4 & 156,9 & 139,3 & 24,7 \\
\hline 19 & 181 & 7,7 & 131,9 & 30,1 & 162,0 & 144,0 & 25,3 \\
\hline 19 & 185 & 7,8 & 137,6 & 24,3 & 161,9 & 144,7 & 24,3 \\
\hline 19 & 186 & 7,7 & 133,6 & 29,3 & 163,0 & 147,1 & 22,4 \\
\hline 20 & 192 & 7,5 & 109,3 & 29,4 & 138,8 & 119,9 & 26,5 \\
\hline 20 & 193 & 7,8 & 120,0 & 17,5 & 137,4 & 116,6 & 29,3 \\
\hline 20 & 194 & 7,8 & 106,2 & 24,2 & 130,4 & 112,0 & 25,8 \\
\hline 20 & 195 & 7,7 & 117,3 & 26,8 & 144,1 & 127,6 & 23,3 \\
\hline 20 & 199 & 7,8 & 127,0 & 27,6 & 154,6 & 139,6 & 21,1 \\
\hline 20 & 200 & 7,7 & 115,8 & 31,7 & 147,5 & 129,7 & 25,1 \\
\hline 21 & 206 & 8,5 & 207,0 & 73,6 & 280,6 & 173,6 & 150,6 \\
\hline 21 & 207 & 8,3 & 242,0 & 77,7 & 319,6 & 206,2 & 159,8 \\
\hline 21 & 208 & 8,1 & 235,0 & 60,2 & 295,2 & 198,9 & 135,6 \\
\hline 21 & 209 & 7,9 & 213,1 & 95,2 & 308,2 & 201,8 & 149,9 \\
\hline 21 & 213 & 8,3 & 220,4 & 65,1 & 285,5 & 189,9 & 134,6 \\
\hline 21 & 214 & 8,3 & 186,3 & 80,1 & 266,4 & 161,9 & 147,2 \\
\hline 21 & 215 & 7,9 & 168,4 & 83,4 & 251,7 & 160,3 & 128,7 \\
\hline
\end{tabular}




\section{ANEXO III}

Tabela AIII - Valores de pH, alcalinidade parcial, alcalinidade intermediária, alcalinidade total, alcalinidade a bicarbonato e ácidos voláteis totais no efluente em todas as condições

\begin{tabular}{|c|c|c|c|c|c|c|c|}
\hline $\mathrm{CO}$ & $\begin{array}{c}\text { Tempo } \\
\text { (d) }\end{array}$ & $\begin{array}{l}\mathrm{pH} \\
(\mathbf{u})\end{array}$ & $\begin{array}{c}\mathrm{AP} \\
\left(\mathrm{mgCaCO}_{3} \cdot \mathrm{L}^{-1}\right)\end{array}$ & $\begin{array}{c}\mathrm{AI} \\
\left(\mathrm{mgCaCO}_{3} \cdot \mathrm{L}^{-1}\right)\end{array}$ & $\begin{array}{c}\mathrm{AT} \\
\left(\mathrm{mgCaCO}_{3} \cdot \mathrm{L}^{-1}\right)\end{array}$ & $\begin{array}{c}\mathrm{AB} \\
\left(\mathrm{mgCaCO}_{3} \cdot \mathrm{L}^{-1}\right)\end{array}$ & $\begin{array}{c}\text { AVT } \\
\left(\text { mgHAc. }^{-1}\right)\end{array}$ \\
\hline $\mathrm{P}$ & 0 & 4,46 & 0,00 & 73,30 & 73,30 & 0,00 & 1014,86 \\
\hline $\mathrm{P}$ & 1 & 4,55 & 0,00 & 107,31 & 107,31 & 0,00 & 1016,89 \\
\hline $\mathrm{P}$ & 2 & 4,71 & 0,00 & 160,30 & 160,30 & 0,00 & 919,46 \\
\hline $\mathrm{P}$ & 3 & 4,69 & 0,00 & 153,75 & 153,75 & 0,00 & 858,08 \\
\hline $\mathrm{P}$ & 7 & 4,61 & 0,00 & 124,50 & 124,50 & 0,00 & 840,41 \\
\hline $\mathrm{P}$ & 8 & 4,65 & 0,00 & 153,75 & 153,75 & 0,00 & 840,41 \\
\hline $\mathrm{P}$ & 9 & 4,62 & 0,00 & 135,37 & 135,37 & 0,00 & 848,26 \\
\hline $\mathrm{P}$ & 10 & 4,70 & 0,00 & 160,44 & 160,44 & 0,00 & 795,24 \\
\hline $\mathrm{P}$ & 14 & 4,80 & 0,00 & 168,64 & 168,64 & 0,00 & 840,72 \\
\hline $\mathrm{P}$ & 15 & 5,05 & 0,00 & 305,97 & 305,97 & 0,00 & 844,78 \\
\hline $\mathrm{P}$ & 16 & 4,72 & 0,00 & 163,63 & 163,63 & 0,00 & 832,60 \\
\hline 1 & 21 & 6,80 & 141,92 & 227,91 & 369,84 & 118,96 & 353,35 \\
\hline 1 & 22 & 6,50 & 98,51 & 242,52 & 341,04 & 54,38 & 403,74 \\
\hline 2 & 23 & 5,85 & 0,00 & 221,65 & 221,65 & 0,00 & 413,71 \\
\hline 2 & 24 & 5,39 & 0,00 & 171,56 & 171,56 & 0,00 & 335,80 \\
\hline 3 & 27 & 4,56 & 0,00 & 47,42 & 47,42 & 0,00 & 210,76 \\
\hline 3 & 28 & 5,33 & 0,00 & 158,79 & 158,79 & 0,00 & 375,53 \\
\hline 3 & 29 & 5,03 & 0,00 & 129,38 & 129,38 & 0,00 & 391,25 \\
\hline 4 & 31 & 4,70 & 0,00 & 67,26 & 67,26 & 0,00 & 410,46 \\
\hline 4 & 35 & 4,68 & 0,00 & 72,04 & 72,04 & 0,00 & 489,95 \\
\hline 4 & 36 & 4,20 & 0,00 & 0,00 & 0,00 & 0,00 & 410,29 \\
\hline 5 & 37 & 4,75 & 0,00 & 66,53 & 66,53 & 0,00 & 414,27 \\
\hline 5 & 38 & 4,60 & 0,00 & 50,72 & 50,72 & 0,00 & 374,24 \\
\hline 5 & 42 & 4,36 & 0,00 & 14,33 & 14,33 & 0,00 & 382,40 \\
\hline 6 & 43 & 4,44 & 0,00 & 22,79 & 22,79 & 0,00 & 346,55 \\
\hline $\mathrm{P}$ & 49 & 4,43 & 0,00 & 60,65 & 60,65 & 0,00 & 905,83 \\
\hline $\mathrm{P}$ & 50 & 4,67 & 0,00 & 94,10 & 94,10 & 0,00 & 696,60 \\
\hline $\mathrm{P}$ & 51 & 4,82 & 0,00 & 106,22 & 106,22 & 0,00 & 667,77 \\
\hline $\mathrm{P}$ & 52 & 4,82 & 0,00 & 116,88 & 116,88 & 0,00 & 563,49 \\
\hline $\mathrm{P}$ & 56 & 4,74 & 0,00 & 108,43 & 108,43 & 0,00 & 596,77 \\
\hline 7 & 57 & 4,99 & 0,00 & 90,79 & 90,79 & 0,00 & 340,66 \\
\hline 7 & 58 & 4,82 & 0,00 & 82,17 & 82,17 & 0,00 & 336,94 \\
\hline 7 & 59 & 4,66 & 0,00 & 55,93 & 55,93 & 0,00 & 338,93 \\
\hline 8 & 63 & 4,61 & 0,00 & 56,36 & 56,36 & 0,00 & 404,32 \\
\hline 8 & 65 & 4,45 & 0,00 & 40,87 & 40,87 & 0,00 & 494,95 \\
\hline 9 & 70 & 5,40 & 0,00 & 91,21 & 91,21 & 0,00 & 166,57 \\
\hline 9 & 71 & 5,60 & 0,00 & 102,39 & 102,39 & 0,00 & 158,62 \\
\hline $\mathrm{P}$ & 72 & 5,30 & 0,00 & 63,01 & 63,01 & 0,00 & 127,27 \\
\hline $\mathrm{P}$ & 77 & 4,42 & 0,00 & 60,94 & 60,94 & 0,00 & 883,55 \\
\hline $\mathrm{P}$ & 78 & 4,40 & 0,00 & 54,80 & 54,80 & 0,00 & 772,16 \\
\hline $\mathrm{P}$ & 79 & 3,84 & 0,00 & 0,00 & 0,00 & 0,00 & 749,51 \\
\hline $\mathrm{P}$ & 80 & 3,77 & 0,00 & 0,00 & 0,00 & 0,00 & 774,96 \\
\hline $\mathrm{P}$ & 84 & 4,59 & 0,00 & 109,03 & 109,03 & 0,00 & 581,48 \\
\hline 10 & 85 & 4,60 & 0,00 & 108,62 & 108,62 & 0,00 & 673,94 \\
\hline 10 & 86 & 4,14 & 0,00 & 0,00 & 0,00 & 0,00 & 594,74 \\
\hline
\end{tabular}


Tabela AIII - Valores de pH, alcalinidade parcial, alcalinidade intermediária, alcalinidade total, alcalinidade a bicarbonato e ácidos voláteis totais no efluente em todas as condições

\begin{tabular}{|c|c|c|c|c|c|c|c|}
\hline $\mathrm{CO}$ & $\begin{array}{c}\text { Tempo } \\
\text { (d) }\end{array}$ & $\begin{array}{l}\text { pH } \\
(\mathbf{u})\end{array}$ & $\begin{array}{c}\mathrm{AP} \\
\left(\mathrm{mgCaCO}_{3} \cdot \mathrm{L}^{-1}\right)\end{array}$ & $\begin{array}{c}\mathrm{AI} \\
\left(\mathrm{mgCaCO}_{3} \cdot \mathrm{L}^{-1}\right)\end{array}$ & $\begin{array}{c}\mathrm{AT} \\
\left(\mathrm{mgCaCO}_{3} \cdot \mathrm{L}^{-1}\right) \\
\end{array}$ & $\begin{array}{c}\mathrm{AB} \\
\left(\mathrm{mgCaCO}_{3} \cdot \mathrm{L}^{-1}\right) \\
\end{array}$ & $\begin{array}{c}\text { AVT } \\
\left(\text { mgHAc. }^{-1}\right)\end{array}$ \\
\hline 10 & 87 & 4,01 & 0,00 & 0,00 & 0,00 & 0,00 & 486,68 \\
\hline 11 & 91 & 4,05 & 0,00 & 0,00 & 0,00 & 0,00 & 523,69 \\
\hline 11 & 92 & 4,18 & 0,00 & 0,00 & 0,00 & 0,00 & 521,51 \\
\hline 12 & 95 & 6,5 & 55,6 & 81,8 & 137,4 & 60,0 & 109,0 \\
\hline 12 & 96 & 6,6 & 53,5 & 90,3 & 143,7 & 69,8 & 104,1 \\
\hline 12 & 97 & 6,1 & 18,4 & 93,4 & 111,8 & 35,2 & 107,8 \\
\hline 12 & 101 & 5,1 & 0,0 & 100,8 & 100,8 & 0,0 & 191,8 \\
\hline 13 & 102 & 5,0 & 0,0 & 94,1 & 94,1 & 0,0 & 338,6 \\
\hline 13 & 103 & 4,2 & 0,0 & 0,0 & 0,0 & 0,0 & 199,2 \\
\hline 13 & 104 & 6,2 & 37,3 & 211,9 & 249,2 & 0,0 & 412,0 \\
\hline 14 & 108 & 4,9 & 0,0 & 113,7 & 113,7 & 0,0 & 450,8 \\
\hline 14 & 109 & 5,0 & 0,0 & 118,6 & 118,6 & 0,0 & 424,7 \\
\hline 14 & 110 & 4,7 & 0,0 & 78,5 & 78,5 & 0,0 & 447,5 \\
\hline 14 & 111 & 4,6 & 0,0 & 46,3 & 46,3 & 0,0 & 424,4 \\
\hline 14 & 115 & 4,4 & 0,0 & 22,2 & 22,2 & 0,0 & 522,8 \\
\hline 14 & 116 & 4,3 & 0,0 & 5,7 & 5,7 & 0,0 & 513,3 \\
\hline 14 & 117 & 4,4 & 0,0 & 17,5 & 17,5 & 0,0 & 452,1 \\
\hline 15 & 122 & 4,3 & 0,0 & 34,3 & 34,3 & 0,0 & 528,8 \\
\hline 15 & 123 & 4,5 & 0,0 & 44,6 & 44,6 & 0,0 & 527,7 \\
\hline 15 & 124 & 4,6 & 0,0 & 60,6 & 60,6 & 0,0 & 541,1 \\
\hline 15 & 125 & 4,4 & 0,0 & 25,7 & 25,7 & 0,0 & 525,9 \\
\hline 15 & 129 & 4,5 & 0,0 & 54,2 & 54,2 & 0,0 & 680,7 \\
\hline 15 & 130 & 4,5 & 0,0 & 54,1 & 54,1 & 0,0 & 778,1 \\
\hline 15 & 131 & 4,5 & 0,0 & 61,0 & 61,0 & 0,0 & 747,4 \\
\hline 16 & 136 & 4,2 & 0,0 & 0,0 & 0,0 & 0,0 & 681,6 \\
\hline 16 & 137 & 4,2 & 0,0 & 0,0 & 0,0 & 0,0 & 729,0 \\
\hline 16 & 138 & 4,2 & 0,0 & 0,0 & 0,0 & 0,0 & 721,7 \\
\hline 16 & 139 & 4,2 & 0,0 & 0,0 & 0,0 & 0,0 & 730,8 \\
\hline 16 & 143 & 4,2 & 0,0 & 0,0 & 0,0 & 0,0 & 676,9 \\
\hline 16 & 144 & 4,3 & 0,0 & 0,0 & 0,0 & 0,0 & 817,5 \\
\hline 17 & 150 & 4,6 & 0,0 & 57,6 & 57,6 & 0,0 & 485,3 \\
\hline 17 & 151 & 4,7 & 0,0 & 72,1 & 72,1 & 0,0 & 542,9 \\
\hline 17 & 152 & 4,7 & 0,0 & 86,3 & 86,3 & 0,0 & 473,2 \\
\hline 17 & 153 & 4,7 & 0,0 & 87,6 & 87,6 & 0,0 & 543,9 \\
\hline 17 & 157 & 4,6 & 0,0 & 64,7 & 64,7 & 0,0 & 490,2 \\
\hline 17 & 158 & 4,7 & 0,0 & 78,1 & 78,1 & 0,0 & 540,6 \\
\hline 17 & 159 & 4,7 & 0,0 & 87,8 & 87,8 & 0,0 & 498,5 \\
\hline 18 & 164 & 4,5 & 0,0 & 50,3 & 50,3 & 0,0 & 670,7 \\
\hline 18 & 165 & 4,5 & 0,0 & 52,0 & 52,0 & 0,0 & 502,1 \\
\hline 18 & 166 & 4,4 & 0,0 & 34,6 & 34,6 & 0,0 & 534,1 \\
\hline 18 & 167 & 4,4 & 0,0 & 38,4 & 38,4 & 0,0 & 524,0 \\
\hline 18 & 171 & 4,7 & 0,0 & 78,1 & 78,1 & $\begin{array}{l}0,0 \\
0,0\end{array}$ & 497,3 \\
\hline 18 & 172 & 4,6 & 0,0 & 72,5 & 72,5 & $\begin{array}{l}0,0 \\
0,0\end{array}$ & 601,6 \\
\hline 18 & 173 & 4,5 & 0,0 & 68,3 & 68,3 & 0,0 & 636,8 \\
\hline 19 & 178 & 4,2 & 0,0 & 0,0 & 0,0 & 0,0 & 719,8 \\
\hline 19 & 179 & 4,2 & 0,0 & 0,0 & 0,0 & 0,0 & 885,9 \\
\hline 19 & 180 & 4,2 & 0,0 & 0,0 & 0,0 & 0,0 & 867,4 \\
\hline
\end{tabular}


Tabela AIII - Valores de $\mathrm{pH}$, alcalinidade parcial, alcalinidade intermediária, alcalinidade total, alcalinidade a bicarbonato e ácidos voláteis totais no efluente em todas as condições

\begin{tabular}{|c|c|c|c|c|c|c|c|}
\hline $\mathrm{CO}$ & $\begin{array}{c}\text { Tempo } \\
\text { (d) }\end{array}$ & $\begin{array}{c}\mathrm{pH} \\
(\mathbf{u})\end{array}$ & $\begin{array}{c}\mathrm{AP} \\
\left(\mathrm{mgCaCO}_{3} \cdot \mathrm{L}^{-1}\right)\end{array}$ & $\begin{array}{c}\mathrm{AI} \\
\left(\mathrm{mgCaCO}_{3} \cdot \mathrm{L}^{-1}\right)\end{array}$ & $\begin{array}{c}\mathrm{AT} \\
\left(\mathrm{mgCaCO}_{3} \cdot \mathrm{L}^{-1}\right)\end{array}$ & $\begin{array}{c}\mathrm{AB} \\
\left(\mathrm{mgCaCO}_{3} \cdot \mathrm{L}^{-1}\right)\end{array}$ & $\begin{array}{c}\text { AVT } \\
\left(\text { mgHAc.L }^{-1}\right)\end{array}$ \\
\hline 19 & 181 & 4,3 & 0,0 & 0,0 & 0,0 & 0,0 & 926,9 \\
\hline 19 & 185 & 4,2 & 0,0 & 0,0 & 0,0 & 0,0 & 663,5 \\
\hline 19 & 186 & 4,2 & 0,0 & 0,0 & 0,0 & 0,0 & 671,8 \\
\hline 19 & 187 & 4,2 & 0,0 & 0,0 & 0,0 & 0,0 & 879,0 \\
\hline 20 & 192 & 4,3 & 0,0 & 0,0 & 0,0 & 0,0 & 638,9 \\
\hline 20 & 193 & 4,4 & 0,0 & 15,1 & 15,1 & 0,0 & 772,9 \\
\hline 20 & 194 & 4,3 & 0,0 & 17,5 & 17,5 & 0,0 & 813,7 \\
\hline 20 & 195 & 4,2 & 0,0 & 0,0 & 0,0 & 0,0 & 747,7 \\
\hline 20 & 199 & 4,2 & 0,0 & 0,0 & 0,0 & 0,0 & 766,9 \\
\hline 20 & 200 & 4,3 & 0,0 & 0,0 & 0,0 & 0,0 & 698,3 \\
\hline 20 & 201 & 4,3 & 0,0 & 0,0 & 0,0 & 0,0 & 648,8 \\
\hline 21 & 206 & 5,7 & 0,0 & 271,9 & 271,9 & 0,0 & 631,1 \\
\hline 21 & 207 & 5,5 & 0,0 & 233,8 & 233,8 & 0,0 & 625,0 \\
\hline 21 & 208 & 5,4 & 0,0 & 223,7 & 223,7 & 0,0 & 621,0 \\
\hline 21 & 209 & 5,3 & 0,0 & 231,0 & 231,0 & 0,0 & 554,2 \\
\hline 21 & 213 & 5,2 & 0,0 & 248,1 & 248,1 & 0,0 & 705,9 \\
\hline 21 & 214 & 5,0 & 0,0 & 210,2 & 210,2 & 0,0 & 727,9 \\
\hline 21 & 215 & 4,8 & 0,0 & 157,8 & 157,8 & 0,0 & 739,8 \\
\hline 21 & 216 & 4,7 & 0,0 & 159,6 & 159,6 & 0,0 & 751,3 \\
\hline
\end{tabular}




\section{ANEXO IV}

Tabela AIV - Série de sólidos afluente e efluente em todas as condições

\begin{tabular}{|c|c|c|c|c|c|c|c|c|c|}
\hline \multirow[b]{2}{*}{$\mathrm{CO}$} & \multirow[b]{2}{*}{$\begin{array}{c}\text { Tempo } \\
\text { (d) }\end{array}$} & \multicolumn{4}{|c|}{ Afluente } & \multicolumn{4}{|c|}{ Efluente } \\
\hline & & $\begin{array}{c}\text { ST } \\
\left(\mathbf{m g . L ^ { - 1 }}\right) \\
\end{array}$ & $\begin{array}{c}\text { SVT } \\
\left(\mathbf{m g . L}^{-1}\right) \\
\end{array}$ & $\begin{array}{c}\text { SST } \\
\left(\mathrm{mg.L}^{-1}\right) \\
\end{array}$ & $\begin{array}{c}\mathrm{SSV} \\
\left(\mathrm{mg} . \mathrm{L}^{-1}\right)\end{array}$ & $\begin{array}{c}\text { ST } \\
\left(\mathrm{mg} . L^{-1}\right) \\
\end{array}$ & $\begin{array}{c}\text { SVT } \\
\left(\mathrm{mg.L} \mathbf{L}^{-1}\right)\end{array}$ & $\begin{array}{c}\text { SST } \\
\left(\mathrm{mg}^{-L^{-1}}\right)\end{array}$ & $\begin{array}{c}\mathrm{SSV} \\
\left(\mathrm{mg} . \mathrm{L}^{-1}\right)\end{array}$ \\
\hline 1 & 24 & 1324 & 194 & 166 & 186 & 1478 & 172 & 84 & 76 \\
\hline 2 & 29 & 1510 & 986 & 263 & 193 & 1518 & 1016 & 144 & 126 \\
\hline 3 & 36 & 1252 & 938 & 164 & 116 & 1352 & 1000 & 104 & 82 \\
\hline 4 & 38 & 1274 & 958 & 68 & 164 & 1490 & 1180 & 336 & 334 \\
\hline 5 & 43 & 868 & 742 & 96 & 112 & 1014 & 764 & 106 & 106 \\
\hline 6 & 59 & 816 & 702 & 196 & 182 & 812 & 660 & 180 & 186 \\
\hline 7 & 66 & 984 & 728 & 62 & 30 & 772 & 526 & 14 & 20 \\
\hline 8 & 71 & 890 & 800 & 202 & 194 & 744 & 754 & 62 & 72 \\
\hline 14 & 108 & 496 & 232 & 14 & 4 & 686 & 462 & 56 & 44 \\
\hline 14 & 110 & 356 & 212 & 20 & 10 & 566 & 424 & 48 & 38 \\
\hline 14 & 115 & 382 & 220 & 34 & 0 & 536 & 402 & 80 & 44 \\
\hline 14 & 117 & - & - & - & - & 410 & 268 & 78 & 218 \\
\hline 15 & 122 & 546 & 333 & 20 & 28 & 690 & 494 & 60 & 68 \\
\hline 15 & 124 & 484 & 336 & 14 & 28 & 484 & 336 & 14 & 28 \\
\hline 15 & 129 & 620 & 376 & 10 & 40 & 778 & 536 & 26 & 60 \\
\hline 16 & 136 & 490 & 70 & 8 & 18 & 858 & 630 & 82 & 106 \\
\hline 16 & 138 & 476 & 280 & 42 & 34 & 756 & 592 & 62 & 70 \\
\hline 16 & 143 & 566 & 284 & 80 & 8 & 890 & 636 & 122 & 72 \\
\hline 17 & 150 & 392 & 242 & 24 & 18 & 620 & 502 & 46 & 54 \\
\hline 17 & 152 & 476 & 364 & 48 & 16 & 790 & 662 & 62 & 44 \\
\hline 17 & 157 & 548 & 256 & 20 & 40 & 860 & 582 & 44 & 52 \\
\hline 17 & 159 & - & - & - & - & 918 & 690 & 42 & 22 \\
\hline 18 & 164 & 626 & 316 & 36 & 28 & 1080 & 794 & 226 & 220 \\
\hline 18 & 166 & 444 & 220 & 22 & 32 & 882 & 702 & 46 & 68 \\
\hline 18 & 171 & 590 & 358 & 6 & 20 & 964 & 804 & 36 & 46 \\
\hline 18 & 173 & - & - & - & - & 1064 & 970 & 66 & 48 \\
\hline 19 & 178 & 566 & 422 & 24 & 24 & 1082 & 970 & 52 & 66 \\
\hline 19 & 180 & 522 & 288 & 12 & 0 & 1068 & 834 & 78 & 54 \\
\hline 19 & 185 & 560 & 334 & 34 & 8 & 916 & 718 & 42 & 54 \\
\hline 19 & 187 & - & - & - & - & 1022 & 758 & 50 & 42 \\
\hline 20 & 192 & 532 & 284 & 20 & 30 & 894 & 692 & 54 & 68 \\
\hline 20 & 194 & 564 & 396 & 42 & 16 & 1052 & 874 & 122 & 94 \\
\hline 20 & 199 & 462 & 224 & 22 & 40 & 1022 & 784 & 88 & 122 \\
\hline 20 & 201 & - & - & - & - & 860 & 700 & 72 & 70 \\
\hline 21 & 206 & 2588 & 2050 & 88 & 88 & 1832 & 1226 & 100 & 122 \\
\hline 21 & 208 & 1846 & 1182 & 204 & 180 & 1606 & 994 & 108 & 106 \\
\hline 21 & 213 & 2144 & 1570 & 146 & 92 & 1984 & 1400 & 68 & 42 \\
\hline 21 & 215 & 2024 & 1410 & 124 & 84 & 1860 & 1172 & 80 & 72 \\
\hline
\end{tabular}




\section{ANEXO V}

Tabela AV - Volume de biogás produzido por ciclo em todas as condições e valores utilizados para a correção em relação ao volume alimentado e para as CNTP

\begin{tabular}{|c|c|c|c|c|c|}
\hline $\mathrm{CO}$ & $\begin{array}{l}\text { Tempo } \\
\text { (d) }\end{array}$ & $\begin{array}{c}\mathbf{V}_{\mathrm{G}} \\
\left(\mathrm{mL} \cdot \text { ciclo }^{-1}\right)\end{array}$ & $\begin{array}{l}\text { VA } \\
\text { (L) }\end{array}$ & $\begin{array}{c}\text { Ta } \\
\left({ }^{\circ} \mathbf{C}\right)\end{array}$ & $\begin{array}{c}\mathbf{P a} \\
(\mathbf{m m H g})\end{array}$ \\
\hline$P$ & 10 & 633 & 1,50 & 30 & 703 \\
\hline$P$ & 11 & 666 & 1,54 & 30 & 703 \\
\hline $\mathrm{P}$ & 16 & 1377 & 1,56 & 30 & 703 \\
\hline $\mathrm{P}$ & 17 & 1129 & 1,54 & 30 & 703 \\
\hline 1 & 23 & 0 & 1,50 & 30 & 703 \\
\hline 2 & 24 & 0 & 1,48 & 30 & 703 \\
\hline 2 & 25 & 0 & 1,52 & 30 & 703 \\
\hline 3 & 29 & 89 & 1,52 & 30 & 703 \\
\hline 3 & 30 & 78 & 1,50 & 30 & 703 \\
\hline 4 & 36 & 0 & 1,44 & 30 & 703 \\
\hline 4 & 37 & 0 & 1,50 & 30 & 703 \\
\hline 5 & 38 & 272 & 1,45 & 30 & 703 \\
\hline 5 & 43 & 329 & 1,50 & 30 & 703 \\
\hline 6 & 44 & 67 & 1,46 & 30 & 703 \\
\hline $\mathrm{P}$ & 50 & 638 & 1,48 & 30 & 703 \\
\hline $\mathrm{P}$ & 51 & 35 & 1,52 & 30 & 703 \\
\hline $\mathrm{P}$ & 52 & 468 & 1,54 & 30 & 703 \\
\hline $\mathrm{P}$ & 53 & 368 & 1,50 & 30 & 703 \\
\hline $\mathrm{P}$ & 57 & 189 & 1,50 & 30 & 703 \\
\hline 7 & 58 & 0 & 1,28 & 30 & 703 \\
\hline 7 & 59 & 0 & 0,90 & 30 & 703 \\
\hline 7 & 60 & 0 & 1,68 & 30 & 703 \\
\hline 8 & 64 & 0 & 1,50 & 30 & 703 \\
\hline 9 & 71 & 0 & 1,60 & 30 & 703 \\
\hline 9 & 72 & 0 & 1,52 & 30 & 703 \\
\hline $\mathrm{P}$ & 73 & 0 & 1,52 & 30 & 703 \\
\hline $\mathrm{P}$ & 78 & 738 & 1,48 & 30 & 703 \\
\hline $\mathrm{P}$ & 79 & 611 & 1,48 & 30 & 703 \\
\hline $\mathrm{P}$ & 80 & 573 & 1,50 & 30 & 703 \\
\hline $\mathrm{P}$ & 81 & 135 & 1,46 & 30 & 703 \\
\hline $\mathrm{P}$ & 85 & 814 & 1,54 & 30 & 703 \\
\hline 10 & 86 & 744 & 1,54 & 30 & 703 \\
\hline 10 & 87 & 519 & 1,52 & 30 & 703 \\
\hline 10 & 88 & 192 & 1,52 & 30 & 703 \\
\hline 11 & 92 & 149 & 1,40 & 30 & 703 \\
\hline 11 & 93 & 181 & 1,40 & 30 & 703 \\
\hline 12 & 95 & 11 & 1,50 & 30 & 703 \\
\hline 12 & 96 & 3 & 1,42 & 30 & 703 \\
\hline 12 & 97 & 75 & 1,50 & 30 & 703 \\
\hline 12 & 101 & 140 & 1,52 & 30 & 703 \\
\hline 13 & 102 & 167 & 1,46 & 30 & 703 \\
\hline 13 & 103 & 11 & 1,44 & 30 & 703 \\
\hline 13 & 104 & 11 & 1,56 & 30 & 703 \\
\hline 14 & 108 & 210 & 1,48 & 30 & 703 \\
\hline 14 & 109 & 121 & 1,50 & 30 & 703 \\
\hline 14 & 111 & 113 & 1,50 & 30 & 703 \\
\hline 14 & 115 & 113 & 1,60 & 30 & 703 \\
\hline
\end{tabular}


Tabela AV - Volume de biogás produzido por ciclo em todas as condições e valores utilizados para a correção em relação ao volume alimentado e para as CNTP

\begin{tabular}{|c|c|c|c|c|c|}
\hline $\mathrm{CO}$ & $\begin{array}{l}\text { Tempo } \\
\text { (d) }\end{array}$ & $\begin{array}{c}\mathbf{V}_{\mathrm{G}} \\
\left(\mathrm{mL}^{- \text {ciclo }^{-1}}\right)\end{array}$ & $\begin{array}{l}\text { VA } \\
\text { (L) }\end{array}$ & $\begin{array}{c}\text { Ta } \\
\left({ }^{\circ} \mathbf{C}\right)\end{array}$ & $\begin{array}{c}\mathbf{P a} \\
(\mathbf{m m H g})\end{array}$ \\
\hline 15 & 122 & 871 & 1,56 & 30 & 703 \\
\hline 15 & 123 & 935 & 1,58 & 30 & 703 \\
\hline 15 & 124 & 957 & 1,56 & 30 & 703 \\
\hline 15 & 125 & 3167 & 1,40 & 30 & 703 \\
\hline 15 & 129 & 776 & 1,50 & 30 & 703 \\
\hline 15 & 130 & 1369 & 1,50 & 30 & 703 \\
\hline 16 & 136 & 922 & 1,50 & 30 & 703 \\
\hline 16 & 137 & 1364 & 1,50 & 30 & 703 \\
\hline 16 & 138 & 1372 & 1,52 & 30 & 703 \\
\hline 16 & 139 & 1224 & 1,48 & 30 & 703 \\
\hline 16 & 143 & 1175 & 1,34 & 30 & 703 \\
\hline 17 & 150 & 348 & 1,40 & 30 & 703 \\
\hline 17 & 151 & 534 & 1,50 & 30 & 703 \\
\hline 17 & 152 & 545 & 1,50 & 30 & 703 \\
\hline 17 & 153 & 828 & 1,50 & 30 & 703 \\
\hline 17 & 157 & 784 & 1,52 & 30 & 703 \\
\hline 17 & 158 & 819 & 1,50 & 30 & 703 \\
\hline 18 & 164 & 768 & 1,50 & 30 & 703 \\
\hline 18 & 165 & 512 & 1,50 & 30 & 703 \\
\hline 18 & 166 & 652 & 1,51 & 30 & 703 \\
\hline 18 & 167 & 615 & 1,52 & 30 & 703 \\
\hline 18 & 171 & 259 & 1,51 & 30 & 703 \\
\hline 19 & 178 & 1259 & 1,60 & 30 & 703 \\
\hline 19 & 179 & 1186 & 1,52 & 30 & 703 \\
\hline 19 & 180 & 1771 & 1,50 & 30 & 703 \\
\hline 19 & 181 & 1359 & 1,46 & 30 & 703 \\
\hline 19 & 184 & 1421 & 1,50 & 30 & 703 \\
\hline 19 & 186 & 1307 & 1,52 & 30 & 703 \\
\hline 20 & 192 & 1143 & 1,46 & 30 & 703 \\
\hline 20 & 193 & 1334 & 1,50 & 30 & 703 \\
\hline 20 & 194 & 1461 & 1,54 & 30 & 703 \\
\hline 20 & 195 & 1377 & 1,54 & 30 & 703 \\
\hline 20 & 199 & 1375 & 1,50 & 30 & 703 \\
\hline 20 & 200 & 943 & 1,50 & 30 & 703 \\
\hline 21 & 206 & 299 & 1,50 & 30 & 703 \\
\hline 21 & 207 & 380 & 1,48 & 30 & 703 \\
\hline 21 & 208 & 313 & 1,50 & 30 & 703 \\
\hline 21 & 209 & 332 & 1,58 & 30 & 703 \\
\hline 21 & 212 & 199 & 1,54 & 30 & 703 \\
\hline 21 & 213 & 218 & 1,50 & 30 & 703 \\
\hline 21 & 214 & 310 & 1,46 & 30 & 703 \\
\hline 21 & 215 & 326 & 1,55 & 30 & 703 \\
\hline
\end{tabular}




\section{ANEXO VI}

Tabela AVI - Concentração do biogás no final do ciclo em todas as condições

\begin{tabular}{|c|c|c|c|c|}
\hline CO & $\begin{array}{c}\text { Tempo } \\
\text { (d) }\end{array}$ & $\begin{array}{c}\mathrm{C}_{\mathrm{H} 2} \\
\left(\mathrm{mmol} \mathrm{L}^{-1}\right)\end{array}$ & $\begin{array}{c}\mathbf{C}_{\mathrm{CH} 4} \\
\left(\mathrm{mmol.L^{-1 }}\right)\end{array}$ & $\begin{array}{c}\mathrm{C}_{\mathrm{CO} 2} \\
\left(\mathrm{mmol}^{-L^{-1}}\right)\end{array}$ \\
\hline $\mathrm{P}$ & 10 & 7,62 & 0,00 & 7,87 \\
\hline $\mathrm{P}$ & 11 & 4,11 & 0,00 & 7,20 \\
\hline $\mathrm{P}$ & 16 & 4,93 & 0,00 & 4,38 \\
\hline $\mathrm{P}$ & 17 & 5,73 & 0,00 & 6,73 \\
\hline 1 & 23 & 0,75 & 0,00 & 2,87 \\
\hline 2 & 24 & 0,78 & 0,00 & 2,65 \\
\hline 2 & 25 & 1,01 & 0,00 & 2,82 \\
\hline 3 & 29 & 0,00 & 0,18 & 2,41 \\
\hline 3 & 30 & 0,00 & 0,21 & 2,26 \\
\hline 4 & 36 & 0,00 & 0,19 & 1,84 \\
\hline 4 & 37 & 0,00 & 0,21 & 1,91 \\
\hline 5 & 38 & 0,00 & 0,00 & 0,00 \\
\hline 5 & 43 & 0,75 & 0,18 & 1,91 \\
\hline 6 & 44 & 0,76 & 0,37 & 2,71 \\
\hline $\mathrm{P}$ & 50 & 13,87 & 0,00 & 7,52 \\
\hline $\mathrm{P}$ & 51 & 2,92 & 0,00 & 4,01 \\
\hline $\mathrm{P}$ & 52 & 3,56 & 0,00 & 4,37 \\
\hline $\mathrm{P}$ & 53 & 3,81 & 0,00 & 4,12 \\
\hline $\mathrm{P}$ & 57 & 3,56 & 0,00 & 4,22 \\
\hline 7 & 58 & 0,00 & 0,00 & 1,76 \\
\hline 7 & 59 & 0,00 & 0,00 & 1,41 \\
\hline 7 & 60 & 0,29 & 0,00 & 1,63 \\
\hline 8 & 64 & 0,00 & 0,00 & 1,27 \\
\hline 9 & 71 & 0,00 & 0,00 & 0,00 \\
\hline 9 & 72 & 0,00 & 0,00 & 0,00 \\
\hline $\mathrm{P}$ & 73 & 0,00 & 0,00 & 0,00 \\
\hline $\mathrm{P}$ & 78 & 11,03 & 0,61 & 7,88 \\
\hline $\mathrm{P}$ & 79 & 9,04 & 0,64 & 6,48 \\
\hline $\mathrm{P}$ & 80 & 7,49 & 0,58 & 5,41 \\
\hline $\mathrm{P}$ & 81 & 7,72 & 0,67 & 5,69 \\
\hline $\mathrm{P}$ & 85 & 12,75 & 0,16 & 9,14 \\
\hline 10 & 86 & 9,61 & 0,21 & 8,07 \\
\hline 10 & 87 & 7,75 & 0,22 & 7,07 \\
\hline 10 & 88 & 1,78 & 0,18 & 3,81 \\
\hline 11 & 92 & 1,44 & 0,51 & 3,10 \\
\hline 11 & 93 & 1,42 & 0,79 & 3,82 \\
\hline 12 & 95 & 0,00 & 0,00 & 1,42 \\
\hline 12 & 96 & 0,00 & 0,00 & 1,62 \\
\hline 12 & 97 & 0,25 & 0,00 & 1,84 \\
\hline 12 & 101 & 1,06 & 0,29 & 2,77 \\
\hline 13 & 102 & 1,27 & 0,49 & 3,19 \\
\hline 13 & 103 & 0,85 & 0,66 & 2,47 \\
\hline 13 & 104 & 0,72 & 1,16 & 3,51 \\
\hline 14 & 108 & 4,67 & 0,00 & 3,76 \\
\hline 14 & 109 & 4,84 & 0,22 & 3,78 \\
\hline 14 & 111 & 3,62 & 0,32 & 3,12 \\
\hline
\end{tabular}


Tabela AVI - Concentração do biogás no final do ciclo em todas as condições

\begin{tabular}{|c|c|c|c|c|}
\hline $\mathrm{CO}$ & $\begin{array}{l}\text { Tempo } \\
\text { (d) }\end{array}$ & $\begin{array}{c}\mathrm{C}_{\mathrm{H} 2} \\
\left(\mathrm{mmol.L}^{-1}\right)\end{array}$ & $\begin{array}{c}\mathrm{C}_{\mathrm{CH} 4} \\
\left(\mathrm{mmol}^{-\mathrm{L}^{-1}}\right)\end{array}$ & $\begin{array}{c}\mathrm{C}_{\mathrm{CO} 2} \\
\left(\mathrm{mmol.L}^{-1}\right)\end{array}$ \\
\hline 14 & 115 & 2,82 & 1,11 & 3,24 \\
\hline 15 & 122 & 11,74 & 0,00 & 4,99 \\
\hline 15 & 123 & 14,08 & 0,00 & 6,48 \\
\hline 15 & 124 & 11,72 & 0,00 & 5,38 \\
\hline 15 & 125 & 12,62 & 0,19 & 4,85 \\
\hline 15 & 129 & 7,82 & 1,41 & 4,39 \\
\hline 15 & 130 & 7,60 & 1,84 & 4,93 \\
\hline 16 & 136 & 13,87 & 0,24 & 5,86 \\
\hline 16 & 137 & 16,09 & 0,26 & 6,18 \\
\hline 16 & 138 & 17,00 & 0,33 & 6,60 \\
\hline 16 & 139 & 16,26 & 0,42 & 6,59 \\
\hline 16 & 143 & 14,08 & 0,65 & 6,11 \\
\hline 17 & 150 & 5,05 & 0,32 & 3,70 \\
\hline 17 & 151 & 5,38 & 0,54 & 3,86 \\
\hline 17 & 152 & 5,27 & 1,15 & 4,55 \\
\hline 17 & 153 & 4,82 & 1,63 & 4,97 \\
\hline 17 & 157 & 3,92 & 2,00 & 5,40 \\
\hline 17 & 158 & 3,88 & 2,12 & 5,29 \\
\hline 18 & 164 & 10,36 & 0,30 & 5,19 \\
\hline 18 & 165 & 8,99 & 0,37 & 4,51 \\
\hline 18 & 166 & 11,45 & 0,54 & 5,28 \\
\hline 18 & 167 & 10,40 & 0,76 & 5,43 \\
\hline 18 & 171 & 6,46 & 1,19 & 5,80 \\
\hline 19 & 178 & 14,75 & 0,24 & 6,20 \\
\hline 19 & 179 & 16,54 & 0,25 & 6,34 \\
\hline 19 & 180 & 15,49 & 0,38 & 6,34 \\
\hline 19 & 181 & 15,86 & 0,34 & 6,21 \\
\hline 19 & 184 & 16,32 & 0,74 & 7,11 \\
\hline 19 & 186 & 16,40 & 0,69 & 7,16 \\
\hline 20 & 192 & 14,47 & 0,20 & 6,47 \\
\hline 20 & 193 & 16,06 & 0,23 & 7,64 \\
\hline 20 & 194 & 16,10 & 0,21 & 7,16 \\
\hline 20 & 195 & 16,67 & 0,25 & 6,70 \\
\hline 20 & 199 & 15,88 & 0,41 & 6,91 \\
\hline 20 & 200 & 15,57 & 0,42 & 6,74 \\
\hline 21 & 206 & 1,39 & 0,23 & 2,98 \\
\hline 21 & 207 & 1,72 & 0,25 & 3,12 \\
\hline 21 & 208 & 1,82 & 0,29 & 3,19 \\
\hline 21 & 209 & 1,68 & 0,29 & 2,85 \\
\hline 21 & 212 & 1,78 & 0,30 & 3,13 \\
\hline 21 & 213 & 1,29 & 0,43 & 3,52 \\
\hline 21 & 214 & 1,37 & 0,35 & 3,12 \\
\hline 21 & 215 & 1,32 & 0,36 & 3,22 \\
\hline
\end{tabular}




\section{ANEXO VII}

Tabela VII.1 - Concentração de matéria orgânica (DQO) ao longo do ciclo no ensaio 14

\begin{tabular}{ccc}
\hline $\begin{array}{c}\text { Tempo } \\
(\mathbf{h})\end{array}$ & $\begin{array}{c}\mathbf{C}_{\mathbf{S F}} \mathbf{P 1} \\
\left(\mathbf{m g D Q}^{\mathbf{1}} \mathbf{- 1}\right)\end{array}$ & $\begin{array}{c}\boldsymbol{\varepsilon}_{\mathbf{S F}} \\
(\boldsymbol{\%})\end{array}$ \\
\hline 0,0 & 2168,4 & 0 \\
0,5 & 2040,2 & 33 \\
1,0 & 2283,9 & 26 \\
2,0 & 2109,5 & 33 \\
3,0 & 2151,5 & 31 \\
4,0 & 1934,8 & 38 \\
\hline
\end{tabular}

Tabela VII.2 - Valores de pH, alcalinidade parcial, alcalinidade intermediária, alcalinidade total, alcalinidade a bicarbonato e ácidos orgânicos voláteis totais ao longo do ciclo no ensaio 14

\begin{tabular}{ccccccc}
\hline $\begin{array}{c}\text { Tempo } \\
(\mathbf{h})\end{array}$ & $\begin{array}{c}\mathbf{p H} \\
(\mathbf{u})\end{array}$ & $\begin{array}{c}\mathbf{A P} \\
\left(\mathbf{m g C a C O}_{\mathbf{3}} \cdot \mathbf{L}^{-\mathbf{1}}\right)\end{array}$ & $\begin{array}{c}\mathbf{A I} \\
\left(\mathbf{m g C a C O}_{\mathbf{3}} \cdot \mathbf{L}^{-\mathbf{1}}\right)\end{array}$ & $\begin{array}{c}\mathbf{A T} \\
\left(\mathbf{m g C a C O}_{\mathbf{3}} \cdot \mathbf{L}^{-\mathbf{1}}\right)\end{array}$ & $\begin{array}{c}\mathbf{A B} \\
\left(\mathbf{m g C a C O}_{\mathbf{3}} \cdot \mathbf{L}^{-\mathbf{1}}\right)\end{array}$ & $\begin{array}{c}\mathbf{A V T} \\
\left(\mathbf{m g H A c} \cdot \mathbf{L}^{-\mathbf{1}}\right)\end{array}$ \\
\hline 0,0 & 4,44 & 0 & 17 & 17 & 0 & 452 \\
0,5 & 4,39 & 0 & 22 & 22 & 0 & 432 \\
1,0 & 4,37 & 0 & 10 & 10 & 0 & 439 \\
2,0 & 4,36 & 0 & 17 & 17 & 0 & 445 \\
3,0 & 4,26 & 0 & 0 & 0 & 0 & 455 \\
4,0 & 4,28 & 0 & 0 & 0 & 0 & 434 \\
\hline
\end{tabular}

Tabela VII.3 - Concentração de compostos intermediários ao longo do ciclo no ensaio 14

\begin{tabular}{|c|c|c|c|c|c|c|c|c|c|}
\hline $\begin{array}{c}\text { Tempo } \\
\text { (h) }\end{array}$ & $\begin{array}{c}\text { EtOH } \\
\left(\mathrm{mg.L}^{-1}\right)\end{array}$ & $\begin{array}{c}\text { ButOH } \\
\left(\mathrm{mg.L}^{-1}\right)\end{array}$ & $\begin{array}{c}\text { HAc } \\
\left(\mathrm{mg.L}^{-1}\right)\end{array}$ & $\begin{array}{c}\text { HPr } \\
\left(\mathrm{mg}^{-L^{-1}}\right)\end{array}$ & $\begin{array}{l}\text { HIsoBut } \\
\left.\text { (mg.L }^{-1}\right)\end{array}$ & $\begin{array}{c}\text { HBut } \\
\left(\mathrm{mg.L}^{-1}\right)\end{array}$ & $\begin{array}{l}\text { HIsoVal } \\
\left(\mathrm{mg.L}^{-1}\right)\end{array}$ & $\begin{array}{c}\text { HVa } \\
\left(\mathrm{mg.L}^{-1}\right)\end{array}$ & $\begin{array}{c}\text { HCa } \\
\left(\mathrm{mg.L}^{-1}\right)\end{array}$ \\
\hline 0,0 & 80,4 & 26,1 & 218,4 & 36,6 & 40,8 & 219,1 & 7,5 & 16,8 & 28,9 \\
\hline 0,5 & 83,7 & 25,8 & 213,1 & 40,5 & 45,1 & 273,6 & 8,4 & 19,6 & 33,2 \\
\hline 1,0 & 87,7 & 24,8 & 199,8 & 30,3 & 39,9 & 291,8 & 7,3 & 17,1 & 29,9 \\
\hline 2,0 & 84,4 & 27,2 & 187,1 & 35,4 & 49,4 & 301,6 & 8,1 & 19,4 & 32,8 \\
\hline 3,0 & 86,5 & 28,9 & 181,3 & 38,5 & 46,4 & 320,1 & 8,3 & 19,1 & 33,7 \\
\hline 4,0 & 82,1 & 29,1 & 190,4 & 34,9 & 50,1 & 268,9 & 7,2 & 16,9 & 30,1 \\
\hline
\end{tabular}

Tabela VII.4 - Produção volumétrica acumulada do biogás ao longo do ciclo no ensaio 14

\begin{tabular}{cccccc}
$\begin{array}{c}\text { Tempo } \\
\text { (h) }\end{array}$ & P1 & P2 & Po & P4 & Média \\
\hline 0,0 & 0 & 0 & 0 & 0 & 0 \\
0,5 & 42 & 4 & 9 & 0 & 14 \\
1,0 & 95 & 43 & 46 & 32 & 54 \\
2,0 & 150 & 82 & 80 & 77 & 97 \\
3,0 & 197 & 122 & 114 & 108 & 135 \\
4,0 & 211 & 122 & 114 & 114 & 140 \\
\hline
\end{tabular}


Tabela VII.5 - Concentração dos compostos do biogás ao longo do ciclo no ensaio 14.

\begin{tabular}{cccc}
\hline $\begin{array}{c}\text { Tempo } \\
\text { (h) }\end{array}$ & $\mathbf{H}_{\mathbf{2}}$ & $\begin{array}{c}\mathbf{C}_{\mathbf{G}}\left(\mathbf{m m o l . \mathbf { L } ^ { \mathbf { - 1 } }}\right) \\
\mathbf{C O}_{\mathbf{2}}\end{array}$ & $\mathbf{C H}_{\mathbf{4}}$ \\
\hline 0,0 & 0,00 & 0,00 & 0,00 \\
0,5 & 0,29 & 0,00 & 0,00 \\
1,0 & 0,99 & 0,00 & 1,33 \\
2,0 & 1,77 & 0,30 & 2,05 \\
3,0 & 2,09 & 0,37 & 2,85 \\
4,0 & 2,71 & 0,69 & 3,10 \\
\hline
\end{tabular}




\section{ANEXO VIII}

Tabela VIII.1 - Concentração de matéria orgânica (DQO) ao longo do ciclo no ensaio 15

\begin{tabular}{ccc}
$\begin{array}{c}\text { Tempo } \\
\text { (h) }\end{array}$ & $\begin{array}{c}\mathbf{C}_{\mathbf{S F}} \mathbf{P 1} \\
\left(\mathbf{m g D Q}^{-\mathbf{1}}\right)\end{array}$ & $\begin{array}{c}\boldsymbol{\varepsilon}_{\mathbf{S F}} \\
(\boldsymbol{\%})\end{array}$ \\
\hline 0,0 & 2916,0 & 0 \\
0,5 & 2922,4 & 23 \\
1,0 & 2732,6 & 29 \\
2,0 & 2820,2 & 27 \\
3,0 & 2742,1 & 30 \\
4,0 & 2961,5 & 24 \\
\hline
\end{tabular}

Tabela VIII.2 - Valores de pH, alcalinidade parcial, alcalinidade intermediária, alcalinidade total, alcalinidade a bicarbonato e ácidos orgânicos voláteis totais ao longo do ciclo no ensaio 15

\begin{tabular}{ccccccc}
\hline $\begin{array}{c}\text { Tempo } \\
(\mathbf{h})\end{array}$ & $\begin{array}{c}\mathbf{p H} \\
(\mathbf{u})\end{array}$ & $\begin{array}{c}\mathbf{A P} \\
\left(\mathbf{m g C a C O}_{\mathbf{3}} \cdot \mathbf{L}^{\mathbf{- 1}}\right)\end{array}$ & $\begin{array}{c}\mathbf{A I} \\
\left(\mathbf{m g C a C O}_{\mathbf{3}} \cdot \mathbf{L}^{\mathbf{- 1}}\right)\end{array}$ & $\begin{array}{c}\mathbf{A T} \\
\left(\mathbf{m g C a C O}_{\mathbf{3}} \cdot \mathbf{L}^{\mathbf{- 1}}\right)\end{array}$ & $\begin{array}{c}\mathbf{A B} \\
\left(\mathbf{m g C a C O}_{\mathbf{3}} \cdot \mathbf{L}^{\mathbf{- 1}}\right)\end{array}$ & $\begin{array}{c}\mathbf{A V T} \\
\left(\mathbf{m g H A c} . \mathbf{L}^{\mathbf{- 1}}\right)\end{array}$ \\
\hline 0,0 & 4,50 & 0 & 61 & 61 & 0 & 747 \\
0,5 & 4,45 & 0 & 43 & 43 & 0 & 709 \\
1,0 & 4,45 & 0 & 44 & 44 & 0 & 728 \\
2,0 & 4,42 & 0 & 39 & 39 & 0 & 678 \\
3,0 & 4,43 & 0 & 40 & 40 & 0 & 703 \\
4,0 & 4,38 & 0 & 32 & 32 & 0 & 767 \\
\hline
\end{tabular}

Tabela VIII.3 - Concentração de compostos intermediários ao longo do ciclo no ensaio 15

\begin{tabular}{cccccccccc}
\hline $\begin{array}{c}\text { Tempo } \\
(\mathbf{h})\end{array}$ & $\begin{array}{c}\text { EtOH } \\
\left(\mathbf{m g . L}^{-\mathbf{1}}\right)\end{array}$ & $\begin{array}{c}\text { ButOH } \\
\left(\mathbf{m g . L}^{-\mathbf{1}}\right)\end{array}$ & $\begin{array}{c}\text { HAc } \\
\left(\mathbf{m g . L}^{-\mathbf{1}}\right)\end{array}$ & $\begin{array}{c}\text { HPr } \\
\left(\mathbf{m g . L} \mathbf{L}^{-\mathbf{1}}\right)\end{array}$ & $\begin{array}{c}\text { HIsoBut } \\
\left(\mathbf{m g . L}^{\mathbf{- 1}}\right)\end{array}$ & $\begin{array}{c}\text { HBut } \\
\left(\mathbf{m g . L}^{-\mathbf{1}}\right)\end{array}$ & $\begin{array}{c}\text { HIsoVal } \\
\left(\mathbf{m g . L}^{-\mathbf{1}}\right)\end{array}$ & $\begin{array}{c}\text { HVa } \\
\left(\mathbf{m g . L}^{-\mathbf{1}}\right)\end{array}$ & $\begin{array}{c}\text { HCa } \\
\left(\mathbf{m g . L}^{-\mathbf{1}}\right)\end{array}$ \\
\hline 0,0 & 40,1 & 161,3 & 207,9 & 21,9 & 22,6 & 381,8 & 8,7 & 23,6 & 53,5 \\
0,5 & 43,9 & 158,6 & 202,5 & 22,6 & 25,3 & 387,4 & 9,1 & 24,4 & 54,9 \\
1,0 & 45,2 & 159,6 & 210,4 & 25,0 & 19,2 & 403,4 & 7,3 & 17,7 & 48,7 \\
2,0 & 38,1 & 163,5 & 194,7 & 21,4 & 19,6 & 390,3 & 7,1 & 16,7 & 47,6 \\
3,0 & 41,2 & 160,8 & 198,1 & 27,3 & 25,1 & 367,7 & 8,8 & 22,5 & 40,4 \\
4,0 & 36,7 & 157,2 & 214,6 & 21,3 & 19,9 & 353,2 & 7,4 & 16,8 & 44,9 \\
\hline
\end{tabular}

Tabela VIII.4 - Produção volumétrica acumulada do biogás ao longo do ciclo no ensaio 15

\begin{tabular}{cccccc}
\hline $\begin{array}{c}\text { Tempo } \\
\text { (h) }\end{array}$ & P1 & P2 & P3 & P4 & Média \\
\hline 0,0 & 0 & 0 & 0 & 0 & 0 \\
0,5 & 99 & 131 & 66 & 258 & 139 \\
1,0 & 297 & 357 & 273 & 646 & 393 \\
2,0 & 512 & 585 & 491 & 971 & 640 \\
3,0 & 719 & 800 & 708 & 1295 & 881 \\
4,0 & 865 & 936 & 779 & 1334 & 978 \\
\hline
\end{tabular}


Tabela VIII.5 - Concentração dos compostos do biogás ao longo do ciclo no ensaio 15

\begin{tabular}{cccc}
\hline Tempo & \multicolumn{3}{c}{$\mathbf{C}_{\mathbf{G}}\left(\mathbf{m m o l . L}^{\mathbf{- 1}}\right)$} \\
$(\mathbf{h})$ & $\mathbf{H}_{\mathbf{2}}$ & $\mathbf{C O}_{\mathbf{2}}$ & $\mathbf{C H}_{\mathbf{4}}$ \\
\hline 0,0 & 0,00 & 0,00 & 0,00 \\
0,5 & 0,62 & 0,00 & 0,00 \\
1,0 & 2,41 & 0,32 & 2,14 \\
2,0 & 7,25 & 1,13 & 4,06 \\
3,0 & 7,44 & 1,63 & 4,45 \\
4,0 & 7,60 & 1,84 & 4,93 \\
\hline
\end{tabular}




\section{ANEXO IX}

Tabela VIX.1 - Concentração de matéria orgânica (DQO) ao longo do ciclo no ensaio 16

\begin{tabular}{ccc}
\hline $\begin{array}{c}\text { Tempo } \\
(\mathbf{h})\end{array}$ & $\begin{array}{c}\mathbf{C}_{\mathbf{S F}} \mathbf{P 1} \\
\left(\mathbf{m g D Q}^{\mathbf{1}} \mathbf{- 1}\right)\end{array}$ & $\begin{array}{c}\boldsymbol{\varepsilon}_{\mathbf{S F}} \\
(\boldsymbol{\%})\end{array}$ \\
\hline 0,0 & 3979,9 & 0 \\
0,5 & 4304,0 & 8 \\
1,0 & 4211,9 & 11 \\
2,0 & 4158,9 & 12 \\
3,0 & 4259,3 & 10 \\
4,0 & 4253,2 & 10 \\
\hline
\end{tabular}

Tabela VIX.2 - Valores de pH, alcalinidade parcial, alcalinidade intermediária, alcalinidade total, alcalinidade a bicarbonato e ácidos orgânicos voláteis totais ao longo do ciclo no ensaio 16

\begin{tabular}{|c|c|c|c|c|c|c|}
\hline $\begin{array}{l}\text { Tempo } \\
\text { (h) }\end{array}$ & $\begin{array}{l}\text { pH } \\
\text { (u) }\end{array}$ & $\begin{array}{c}\mathrm{AP} \\
\left(\mathrm{mgCaCO}_{3} \cdot \mathrm{L}^{-1}\right)\end{array}$ & $\begin{array}{c}\mathrm{AI} \\
\left(\mathrm{mgCaCO}_{3} \cdot \mathrm{L}^{-1}\right)\end{array}$ & $\begin{array}{c}\mathrm{AT} \\
\left(\mathrm{mgCaCO}_{3} \cdot \mathrm{L}^{-1}\right)\end{array}$ & $\begin{array}{c}\mathrm{AB} \\
\left(\mathrm{mgCaCO}_{3} \cdot \mathrm{L}^{-1}\right)\end{array}$ & $\begin{array}{c}\text { AVT } \\
\left(\text { mgHAc. }^{-1}\right)\end{array}$ \\
\hline 0,0 & 4,28 & 0 & 0 & 0 & 0 & 817 \\
\hline 0,5 & 4,26 & 0 & 0 & 0 & 0 & 790 \\
\hline 1,0 & 4,26 & 0 & 0 & 0 & 0 & 740 \\
\hline 2,0 & 4,26 & 0 & 0 & 0 & 0 & 763 \\
\hline 3,0 & 4,22 & 0 & 0 & 0 & 0 & 710 \\
\hline 4,0 & 4,19 & 0 & 0 & 0 & 0 & 781 \\
\hline
\end{tabular}

Tabela VIX.3 - Concentração de compostos intermediários ao longo do ciclo no ensaio 16

\begin{tabular}{cccccccccc}
\hline $\begin{array}{c}\text { Tempo } \\
\text { (h) }\end{array}$ & $\begin{array}{c}\text { EtOH } \\
\left(\mathbf{m g . L}^{-1}\right)\end{array}$ & $\begin{array}{c}\text { ButOH } \\
\left(\mathbf{m g . L}^{-\mathbf{1}}\right)\end{array}$ & $\begin{array}{c}\text { HAc } \\
\left(\mathbf{m g . L}^{-\mathbf{1}}\right)\end{array}$ & $\begin{array}{c}\text { HPr } \\
\left(\mathbf{m g . L}^{-\mathbf{1}}\right)\end{array}$ & $\begin{array}{c}\text { HIsoBut } \\
\left(\mathbf{m g . L}^{-\mathbf{1}}\right)\end{array}$ & $\begin{array}{c}\text { HBut } \\
\left(\mathbf{m g . L}^{-\mathbf{1}}\right)\end{array}$ & $\begin{array}{c}\text { HIsoVal } \\
\left(\mathbf{m g . L}^{-\mathbf{1}}\right)\end{array}$ & $\begin{array}{c}\text { HVa } \\
\left(\mathbf{m g . L}^{-\mathbf{1}}\right)\end{array}$ & $\begin{array}{c}\text { HCa } \\
\left(\mathbf{m g . L}^{-\mathbf{1}}\right)\end{array}$ \\
\hline 0,0 & 42,2 & 160,1 & 276,1 & 32,5 & 7,8 & 301,8 & 7,1 & 18,9 & 35,2 \\
0,5 & 39,4 & 158,8 & 282,6 & 28,3 & 4,7 & 288,4 & 6,6 & 16,1 & 31,6 \\
1,0 & 49,8 & 149,2 & 251,6 & 26,1 & 5,7 & 291,5 & 6,8 & 16,6 & 37,2 \\
2,0 & 48,4 & 161,9 & 253,2 & 25,2 & 4,7 & 298,5 & 6,5 & 15,1 & 28,2 \\
3,0 & 43,1 & 168,2 & 266,7 & 27,4 & 5,1 & 304,3 & 6,7 & 15,8 & 32,2 \\
4,0 & 39,8 & 170,1 & 282,6 & 27,1 & 5,9 & 302,7 & 6,8 & 16,4 & 35,1 \\
\hline
\end{tabular}

Tabela VIX.4 - Produção volumétrica acumulada do biogás ao longo do ciclo no ensaio 16

\begin{tabular}{|c|c|c|c|c|}
\hline \multirow{2}{*}{$\begin{array}{l}\text { Tempo } \\
\text { (h) }\end{array}$} & \multicolumn{4}{|c|}{ Volume (NmL) } \\
\hline & P1 & P2 & P3 & Média \\
\hline 0,0 & 0 & 0 & 0 & 0 \\
\hline 0,5 & 69 & 142 & 64 & 91 \\
\hline 1,0 & 251 & 333 & 335 & 306 \\
\hline 2,0 & 453 & 642 & 648 & 581 \\
\hline 3,0 & 646 & 963 & 954 & 854 \\
\hline 4,0 & 819 & 1233 & 1173 & 1075 \\
\hline
\end{tabular}


Tabela VIX.5 - Concentração dos compostos do biogás ao longo do ciclo no ensaio 16

\begin{tabular}{|c|c|c|c|}
\hline \multirow{2}{*}{$\begin{array}{l}\text { Tempo } \\
\text { (h) }\end{array}$} & \multicolumn{3}{|c|}{$\mathrm{C}_{\mathrm{G}}\left(\mathrm{mmol} \mathrm{L}^{-1}\right)$} \\
\hline & $\mathbf{H}_{2}$ & $\mathrm{CO}_{2}$ & $\mathrm{CH}_{4}$ \\
\hline 0,0 & 0,00 & 0,00 & 0,00 \\
\hline 0,5 & 0,87 & 0,00 & 0,00 \\
\hline 1,0 & 3,46 & 0,16 & 2,53 \\
\hline 2,0 & 11,81 & 0,42 & 5,63 \\
\hline 3,0 & 14,00 & 0,63 & 5,95 \\
\hline 4,0 & 14,08 & 0,65 & 6,11 \\
\hline
\end{tabular}




\section{ANEXO X}

Tabela X.1 - Concentração de matéria orgânica (DQO) ao longo do ciclo no ensaio 17

\begin{tabular}{ccc}
\hline $\begin{array}{c}\text { Tempo } \\
\text { (h) }\end{array}$ & $\begin{array}{c}\mathbf{C}_{\mathbf{S F}} \mathbf{P 1} \\
\left(\mathbf{m g D Q O} \mathbf{L}^{-1}\right)\end{array}$ & $\begin{array}{c}\mathbf{\varepsilon}_{\mathbf{S F}} \\
(\boldsymbol{\%})\end{array}$ \\
\hline 0,0 & 1915,2 & 0 \\
0,5 & 2310,9 & 25 \\
1,0 & 2060,3 & 35 \\
2,0 & 2217,3 & 31 \\
3,0 & 2245,0 & 30 \\
\hline
\end{tabular}

Tabela X.2 - Valores de pH, alcalinidade parcial, alcalinidade intermediária, alcalinidade total, alcalinidade a bicarbonato e ácidos orgânicos voláteis totais ao longo do ciclo no ensaio 17

\begin{tabular}{ccccccc}
\hline $\begin{array}{c}\text { Tempo } \\
(\mathbf{h})\end{array}$ & $\begin{array}{c}\mathbf{p H} \\
(\mathbf{u})\end{array}$ & $\begin{array}{c}\mathbf{A P} \\
\left(\mathbf{m g C a C O}_{\mathbf{3}} \cdot \mathbf{L}^{-\mathbf{1}}\right)\end{array}$ & $\begin{array}{c}\mathbf{A I} \\
\left(\mathbf{m g C a C O}_{\mathbf{3}} \cdot \mathbf{L}^{-\mathbf{1}}\right)\end{array}$ & $\begin{array}{c}\mathbf{A T} \\
\left(\mathbf{m g C a C O}_{\mathbf{3}} \cdot \mathbf{L}^{\mathbf{- 1}}\right)\end{array}$ & $\begin{array}{c}\mathbf{A B} \\
\left(\mathbf{m g C a C O}_{\mathbf{3}} \cdot \mathbf{L}^{-\mathbf{1}}\right)\end{array}$ & $\begin{array}{c}\mathbf{A V T} \\
\left(\mathbf{m g H A c} \cdot \mathbf{L}^{\mathbf{1}}\right)\end{array}$ \\
\hline 0,0 & 4,68 & 0 & 88 & 88 & 0 & 498 \\
0,5 & 4,66 & 0 & 84 & 84 & 0 & 512 \\
1,0 & 4,62 & 0 & 74 & 74 & 0 & 536 \\
2,0 & 4,59 & 0 & 71 & 71 & 0 & 528 \\
3,0 & 4,56 & 0 & 64 & 64 & 0 & 501 \\
\hline
\end{tabular}

TabelaX.3 - Concentração de compostos intermediários ao longo do ciclo no ensaio 17

\begin{tabular}{|c|c|c|c|c|c|c|c|c|c|}
\hline $\begin{array}{l}\text { Tempo } \\
\text { (h) }\end{array}$ & $\begin{array}{c}\text { EtOH } \\
\left(\mathrm{mg.L}^{-1}\right)\end{array}$ & $\begin{array}{c}\text { ButOH } \\
\left(\mathrm{mg.L}^{-1}\right)\end{array}$ & $\begin{array}{c}\text { HAc } \\
\left(\mathrm{mg}^{\prime} \mathrm{L}^{-1}\right)\end{array}$ & $\begin{array}{c}\text { HPr } \\
\left(\mathrm{mg}^{\prime} \mathrm{L}^{-1}\right)\end{array}$ & $\begin{array}{l}\text { HIsoBut } \\
\left(\text { mg.L }^{-1}\right)\end{array}$ & $\begin{array}{c}\text { HBut } \\
\left(\mathrm{mg.L}^{-1}\right)\end{array}$ & $\begin{array}{l}\text { HIsoVal } \\
\left(\text { mg.L }^{-1}\right)\end{array}$ & $\begin{array}{c}\text { HVa } \\
\left(\mathrm{mg}^{-L^{-1}}\right)\end{array}$ & $\begin{array}{c}\text { HCa } \\
\left({\left.\mathrm{mg} . \mathrm{L}^{-1}\right)}^{-1}\right.\end{array}$ \\
\hline 0,0 & 68,9 & 66,7 & 257,9 & 47,1 & 4,6 & 152,8 & 6,4 & 16,6 & 16,8 \\
\hline 0,5 & 72,8 & 64,9 & 244,7 & 58,4 & 8,1 & 174,6 & 7,7 & 22,3 & 23,6 \\
\hline 1,0 & 73,2 & 65,2 & 233,2 & 43,1 & 4,8 & 140,9 & 6,9 & 18,8 & 19,9 \\
\hline 2,0 & 69,7 & 71,9 & 248,1 & 54,1 & 5,9 & 166,2 & 7,3 & 21,6 & 21,1 \\
\hline 3,0 & 65,8 & 68,4 & 234,1 & 44,2 & 5,1 & 148,8 & 6,4 & 17,7 & 18,9 \\
\hline
\end{tabular}

Tabela X.4 - Produção volumétrica acumulada do biogás ao longo do ciclo no ensaio 17

\begin{tabular}{cccccc}
\hline $\begin{array}{c}\text { Tempo } \\
\text { (h) }\end{array}$ & P1 & P2 & Volume $(\mathbf{N m L})$ & P4 & Média \\
\hline 0,0 & 0 & 0 & 0 & 0 & 0 \\
0,5 & 62 & 116 & 230 & 260 & 167 \\
1,0 & 187 & 295 & 533 & 535 & 387 \\
2,0 & 300 & 476 & 768 & 795 & 585 \\
3,0 & 349 & 535 & 830 & 822 & 634 \\
\hline
\end{tabular}

Tabela X.5 - Concentração dos compostos do biogás ao longo do ciclo no ensaio 17

\begin{tabular}{cccc}
$\begin{array}{c}\text { Tempo } \\
\text { (h) }\end{array}$ & $\mathbf{H}_{\mathbf{2}}$ & $\mathbf{C}_{\mathbf{G}}\left(\mathbf{m m o l . \mathbf { L } ^ { - 1 }}\right)$ \\
\hline 0,0 & 0,00 & 0,00 & 0,00 \\
0,5 & 0,55 & 0,21 & 1,66 \\
1,0 & 1,86 & 0,53 & 2,81 \\
2,0 & 3,76 & 0,95 & 4,73 \\
3,0 & 4,14 & 1,88 & 5,12 \\
\hline
\end{tabular}




\section{ANEXO XI}

Tabela XI.1 - Concentração de matéria orgânica (DQO) ao longo do ciclo no ensaio 18

\begin{tabular}{ccc}
\hline $\begin{array}{c}\text { Tempo } \\
(\mathbf{h})\end{array}$ & $\begin{array}{c}\mathbf{C}_{\mathbf{S F}} \mathbf{P 1} \\
\left(\mathbf{m g D Q O} . \mathbf{L}^{-\mathbf{1}}\right)\end{array}$ & $\begin{array}{c}\boldsymbol{\varepsilon}_{\mathbf{S F}} \\
(\boldsymbol{\%})\end{array}$ \\
\hline 0,0 & 3145,8 & 0 \\
0,5 & 3082,6 & 22 \\
1,0 & 2969,4 & 26 \\
2,0 & 3059,6 & 24 \\
3,0 & 2936,3 & 28 \\
\hline
\end{tabular}

Tabela XI.2 - Valores de pH, alcalinidade parcial, alcalinidade intermediária, alcalinidade total, alcalinidade a bicarbonato e ácidos orgânicos voláteis totais ao longo do ciclo no ensaio 18

\begin{tabular}{ccccccc}
\hline $\begin{array}{c}\text { Tempo } \\
(\mathbf{h})\end{array}$ & $\begin{array}{c}\mathbf{p H} \\
(\mathbf{u})\end{array}$ & $\begin{array}{c}\mathbf{A P} \\
\left(\mathbf{m g C a C O}_{\mathbf{3}} \cdot \mathbf{L}^{-\mathbf{1}}\right)\end{array}$ & $\begin{array}{c}\mathbf{A I} \\
\left(\mathbf{m g C a C O}_{3} \cdot \mathbf{L}^{-\mathbf{1}}\right)\end{array}$ & $\begin{array}{c}\mathbf{A T} \\
\left(\mathbf{m g C a C O}_{3} \cdot \mathbf{L}^{-\mathbf{1}}\right)\end{array}$ & $\begin{array}{c}\mathbf{A B} \\
\left(\mathbf{m g C a C O}_{\mathbf{3}} \cdot \mathbf{L}^{-\mathbf{1}}\right)\end{array}$ & $\begin{array}{c}\mathbf{A V T} \\
\left(\mathbf{m g H A c} . \mathbf{L}^{-\mathbf{1}}\right)\end{array}$ \\
\hline 0,0 & 4,54 & 0 & 68 & 68 & 0 & 637 \\
0,5 & 4,74 & 0 & 88 & 88 & 0 & 616 \\
1,0 & 4,51 & 0 & 56 & 56 & 0 & 638 \\
2,0 & 4,48 & 0 & 55 & 55 & 0 & 590 \\
3,0 & 4,48 & 0 & 53 & 53 & 0 & 635 \\
\hline
\end{tabular}

TabelaXI.3 - Concentração de compostos intermediários ao longo do ciclo no ensaio 18

\begin{tabular}{|c|c|c|c|c|c|c|c|c|c|}
\hline $\begin{array}{l}\text { Tempo } \\
\text { (h) }\end{array}$ & $\begin{array}{c}\text { EtOH } \\
\left(\mathrm{mg.L}^{-1}\right)\end{array}$ & $\begin{array}{c}\text { ButOH } \\
\left(\text { mg.L }^{-1}\right)\end{array}$ & $\begin{array}{c}\text { HAc } \\
\left(\mathrm{mg}^{-L^{-1}}\right)\end{array}$ & $\begin{array}{c}\text { HPr } \\
\left(\mathrm{mg.L}^{-1}\right)\end{array}$ & $\begin{array}{c}\text { HIsoBut } \\
\text { (mg.L }{ }^{-1} \text { ) }\end{array}$ & $\begin{array}{c}\text { HBut } \\
\left(\mathrm{mg.L}^{-1}\right)\end{array}$ & $\begin{array}{l}\text { HIsoVal } \\
\left(\text { mg.L }^{-1}\right)\end{array}$ & $\begin{array}{c}\text { HVa } \\
\left({\left.\mathrm{mg} . L^{-1}\right)}^{-1}\right.\end{array}$ & $\begin{array}{c}\text { HCa } \\
\left({\left.\mathrm{mg} . L^{-1}\right)}^{-1}\right.\end{array}$ \\
\hline 0,0 & 66,9 & 71,1 & 233,1 & 45,6 & 4,7 & 338,2 & 7,5 & 20,7 & 22,9 \\
\hline 0,5 & 65,6 & 75,7 & 228,1 & 55,4 & 9,2 & 378,9 & 7,8 & 26,3 & 30,1 \\
\hline 1,0 & 68,9 & 69,8 & 262,7 & 48,9 & 6,1 & 361,4 & 6,9 & 21,9 & 27,8 \\
\hline 2,0 & 71,4 & 74,5 & 23,2 & 46,6 & 7,8 & 342,8 & 7,2 & 24,2 & 28,9 \\
\hline 3,0 & 70,9 & 72,4 & 252,7 & 43,3 & 6,9 & 324,1 & 6,8 & 20,1 & 24,4 \\
\hline
\end{tabular}

Tabela XI.4 - Produção volumétrica acumulada do biogás ao longo do ciclo no ensaio 18

\begin{tabular}{cccccc}
\hline $\begin{array}{c}\text { Tempo } \\
\text { (h) }\end{array}$ & P1 & P2 & Volume (NmL) & P4 & Média \\
\hline 0,0 & 0 & 0 & 0 & 0 & 0 \\
0,5 & 178 & 46 & 51 & 81 & 89 \\
1,0 & 343 & 205 & 268 & 184 & 250 \\
2,0 & 519 & 376 & 492 & 314 & 425 \\
3,0 & 679 & 503 & 614 & 600 & 599 \\
\hline
\end{tabular}

Tabela XI.5 - Concentração dos compostos do biogás ao longo do ciclo no ensaio 18

\begin{tabular}{|c|c|c|c|}
\hline \multirow{2}{*}{$\begin{array}{l}\text { Tempo } \\
\text { (h) }\end{array}$} & \multicolumn{3}{|c|}{$\mathrm{C}_{\mathrm{G}}\left(\mathrm{mmol} \mathrm{L}^{-1}\right)$} \\
\hline & $\mathbf{H}_{2}$ & $\mathrm{CO}_{2}$ & $\mathbf{C H}_{4}$ \\
\hline 0,0 & 0,00 & 0,00 & 0,00 \\
\hline 0,5 & 1,43 & 0,28 & 2,14 \\
\hline 1,0 & 2,31 & 0,48 & 3,07 \\
\hline 2,0 & 4,14 & 0,92 & 4,51 \\
\hline 3,0 & 6,52 & 1,12 & 5,61 \\
\hline
\end{tabular}




\section{ANEXO XII}

Tabela XII.1 - Concentração de matéria orgânica (DQO) ao longo do ciclo no ensaio 19

\begin{tabular}{ccc}
$\begin{array}{c}\text { Tempo } \\
(\mathbf{h})\end{array}$ & $\begin{array}{c}\mathbf{C}_{\mathbf{S F}} \mathbf{P 1} \\
\left(\mathbf{m g Q O}_{\mathbf{L}} \mathbf{L}^{-\mathbf{1}}\right)\end{array}$ & $\begin{array}{c}\boldsymbol{\varepsilon}_{\mathbf{S F}} \\
(\boldsymbol{\%})\end{array}$ \\
\hline 0,0 & 3852,7 & 0 \\
0,5 & 3980,2 & 21 \\
1,0 & 3869,0 & 24 \\
2,0 & 3760,7 & 27 \\
3,0 & 3825,0 & 26 \\
\hline
\end{tabular}

Tabela XII.2 - Valores de pH, alcalinidade parcial, alcalinidade intermediária, alcalinidade total, alcalinidade a bicarbonato e ácidos orgânicos voláteis totais ao longo do ciclo no ensaio 19

\begin{tabular}{|c|c|c|c|c|c|c|}
\hline $\begin{array}{l}\text { Tempo } \\
\text { (h) }\end{array}$ & $\begin{array}{l}\text { pH } \\
\text { (u) }\end{array}$ & $\begin{array}{c}\mathrm{AP} \\
\left(\mathrm{mgCaCO}_{3} \cdot \mathrm{L}^{-1}\right)\end{array}$ & $\begin{array}{c}\mathrm{AI} \\
\left(\mathrm{mgCaCO}_{3} \cdot \mathrm{L}^{-1}\right)\end{array}$ & $\begin{array}{c}\mathrm{AT} \\
\left(\mathrm{mgCaCO}_{3} \cdot \mathrm{L}^{-1}\right)\end{array}$ & $\begin{array}{c}\mathrm{AB} \\
\left(\mathrm{mgCaCO}_{3} \cdot \mathrm{L}^{-1}\right)\end{array}$ & $\begin{array}{c}\text { AVT } \\
\left(\text { mgHAc. }^{-1}\right)\end{array}$ \\
\hline 0,0 & 4,22 & 0 & 0 & 0 & 0 & 879 \\
\hline 0,5 & 4,25 & 0 & 0 & 0 & 0 & 822 \\
\hline 1,0 & 4,23 & 0 & 0 & 0 & 0 & 1014 \\
\hline 2,0 & 4,19 & 0 & 0 & 0 & 0 & 860 \\
\hline 3,0 & 4,20 & 0 & 0 & 0 & 0 & 879 \\
\hline
\end{tabular}

TabelaXII.3 - Concentração de compostos intermediários ao longo do ciclo no ensaio 19

\begin{tabular}{|c|c|c|c|c|c|c|c|c|c|}
\hline $\begin{array}{l}\text { Tempo } \\
\text { (h) }\end{array}$ & $\begin{array}{c}\text { EtOH } \\
\left(\mathrm{mg.L}^{-1}\right)\end{array}$ & $\begin{array}{c}\text { ButOH } \\
\left(\text { mg.L }^{-1}\right)\end{array}$ & $\begin{array}{c}\text { HAc } \\
\left(\mathrm{mg.L}^{-1}\right)\end{array}$ & $\begin{array}{c}\mathbf{H P r} \\
\left(\mathrm{mg.L}^{-1}\right)\end{array}$ & $\begin{array}{l}\text { HIsoBut } \\
\left(\text { mg.L }^{-1}\right)\end{array}$ & $\begin{array}{c}\text { HBut } \\
\left(\text { mg.L }^{-1}\right)\end{array}$ & $\begin{array}{l}\text { HIsoVal } \\
\left(\text { mg.L }^{-1}\right)\end{array}$ & $\begin{array}{c}\text { HVa } \\
\left(\mathrm{mg}^{-L^{-1}}\right)\end{array}$ & $\begin{array}{c}\mathrm{HCa} \\
\left(\mathrm{mg} . \mathrm{L}^{-1}\right)\end{array}$ \\
\hline 0,0 & 33,4 & 80,1 & 198,4 & 34,1 & 7,5 & 461,4 & 8,5 & 18,1 & 35,8 \\
\hline 0,5 & 32,9 & 77,7 & 216,9 & 30,4 & 5,1 & 446,2 & 7,1 & 14,9 & 32,2 \\
\hline 1,0 & 38,0 & 71,2 & 181,2 & 31,4 & 7,7 & 468,1 & 4,8 & 16,1 & 38,7 \\
\hline 2,0 & 36,7 & 64,9 & 218,6 & 38,9 & 6,9 & 414,1 & 6,7 & 13,7 & 29,8 \\
\hline 3,0 & 34,8 & 70,9 & 208,1 & 29,2 & 5,7 & 449,9 & 7,4 & 14,8 & 31,3 \\
\hline
\end{tabular}

Tabela XII.4 - Produção volumétrica acumulada do biogás ao longo do ciclo no ensaio 19

\begin{tabular}{cccccc}
\hline $\begin{array}{c}\text { Tempo } \\
\text { (h) }\end{array}$ & P1 & P2 & Polume $(\mathbf{N m L})$ & P4 & Média \\
\hline 0,0 & 0 & 0 & 0 & 0 & 0 \\
0,5 & 327 & 170 & 687 & 392 & 394 \\
1,0 & 654 & 530 & 1087 & 779 & 762 \\
2,0 & 914 & 895 & 1493 & 1241 & 1136 \\
3,0 & 1190 & 1152 & 1752 & 1417 & 1378 \\
\hline
\end{tabular}

Tabela XII.5 - Concentração dos compostos do biogás ao longo do ciclo no ensaio 19

\begin{tabular}{cccc}
$\begin{array}{c}\text { Tempo } \\
\text { (h) }\end{array}$ & \multicolumn{3}{c}{$\mathbf{C}_{\mathbf{G}}\left(\mathbf{m m o l} . \mathbf{L}^{-\mathbf{1}}\right)$} \\
\hline 0,0 & 0,00 & $\mathbf{C O}_{\mathbf{2}}$ & $\mathbf{C H}_{\mathbf{4}}$ \\
0,5 & 1,79 & 0,00 & 0,00 \\
1,0 & 7,67 & 0,28 & 1,66 \\
2,0 & 14,49 & 0,51 & 6,22 \\
3,0 & 16,40 & 0,69 & 7,16 \\
\hline
\end{tabular}




\section{ANEXO XIII}

Tabela XIII.1 - Concentração de matéria orgânica (DQO) ao longo do ciclo no ensaio 20

\begin{tabular}{ccc}
$\begin{array}{c}\text { Tempo } \\
(\mathbf{h})\end{array}$ & $\begin{array}{c}\mathbf{C}_{\mathbf{S F}} \mathbf{P 1} \\
\left(\mathbf{m g D Q O . \mathbf { L } ^ { - 1 }}\right)\end{array}$ & $\begin{array}{c}\boldsymbol{\varepsilon}_{\mathbf{S F}} \\
(\boldsymbol{\%})\end{array}$ \\
\hline 0,0 & 3898,3 & 0 \\
0,5 & 3791,3 & 25 \\
1,0 & 4065,1 & 20 \\
2,0 & 3893,1 & 24 \\
3,0 & 4220,4 & 18 \\
\hline
\end{tabular}

Tabela XIII.2 - Valores de pH, alcalinidade parcial, alcalinidade intermediária, alcalinidade total, alcalinidade a bicarbonato e ácidos orgânicos voláteis totais ao longo do ciclo no ensaio 20

\begin{tabular}{|c|c|c|c|c|c|c|}
\hline $\begin{array}{l}\text { Tempo } \\
\text { (h) }\end{array}$ & $\begin{array}{l}\text { pH } \\
\text { (u) }\end{array}$ & $\begin{array}{c}\mathrm{AP} \\
\left(\mathrm{mgCaCO}_{3} \cdot \mathrm{L}^{-1}\right)\end{array}$ & $\begin{array}{c}\mathrm{AI} \\
\left(\mathrm{mgCaCO}_{3} \cdot \mathrm{L}^{-1}\right)\end{array}$ & $\begin{array}{c}\mathrm{AT} \\
\left(\mathrm{mgCaCO}_{3} \cdot \mathrm{L}^{-1}\right)\end{array}$ & $\begin{array}{c}\mathrm{AB} \\
\left(\mathrm{mgCaCO}_{3} \cdot \mathrm{L}^{-1}\right)\end{array}$ & $\begin{array}{c}\text { AVT } \\
\left(\text { mgHAc.L }^{-1}\right)\end{array}$ \\
\hline 0,0 & 4,32 & 0 & 5 & 5 & 0 & 649 \\
\hline 0,5 & 4,34 & 0 & 8 & 8 & 0 & 625 \\
\hline 1,0 & 4,34 & 0 & 14 & 14 & 0 & 623 \\
\hline 2,0 & 4,24 & 0 & 0 & 0 & 0 & 631 \\
\hline 3,0 & 4,24 & 0 & 0 & 0 & 0 & 629 \\
\hline
\end{tabular}

TabelaXIII.3 - Concentração de compostos intermediários ao longo do ciclo no ensaio 20

\begin{tabular}{|c|c|c|c|c|c|c|c|c|c|}
\hline $\begin{array}{l}\text { Tempo } \\
\text { (h) }\end{array}$ & $\begin{array}{c}\text { EtOH } \\
\left(\text { mg.L }^{-1}\right)\end{array}$ & $\begin{array}{c}\text { ButOH } \\
\left(\text { mg.L }^{-1}\right)\end{array}$ & $\begin{array}{c}\text { HAc } \\
\left(\mathrm{mg.L}^{-1}\right)\end{array}$ & $\begin{array}{c}\text { HPr } \\
\left(\mathrm{mg}^{-L^{-1}}\right)\end{array}$ & $\begin{array}{l}\text { HIsoBut } \\
\left.\text { (mg.L }{ }^{-1}\right)\end{array}$ & $\begin{array}{c}\text { HBut } \\
\left(\mathrm{mg.L}^{-1}\right)\end{array}$ & $\begin{array}{l}\text { HIsoVal } \\
\left(\mathrm{mg.L}^{-1}\right)\end{array}$ & $\begin{array}{c}\text { HVa } \\
\left(\mathrm{mg}^{\prime} \mathrm{L}^{-1}\right)\end{array}$ & $\begin{array}{c}\mathrm{HCa} \\
\left(\mathrm{mg}^{-L^{-1}}\right)\end{array}$ \\
\hline 0,0 & 46,9 & 180,8 & 193,9 & 19,9 & 5,3 & 252,8 & 6,7 & 14,4 & 30,2 \\
\hline 0,5 & 47,7 & 182,4 & 187,2 & 18,5 & 4,7 & 245,9 & 6,9 & 15,6 & 31,6 \\
\hline 1,0 & 49,2 & 186,1 & 176,9 & 25,1 & 6,2 & 261,2 & 8,4 & 17,1 & 32,8 \\
\hline 2,0 & 51,1 & 189,2 & 200,4 & 19,1 & 3,9 & 244,2 & 6,7 & 14,2 & 28,2 \\
\hline 3,0 & 48,1 & 192,1 & 186,2 & 22,8 & 5,8 & 238,7 & 7,7 & 16,1 & 37,1 \\
\hline
\end{tabular}

Tabela XIII.4 - Produção volumétrica acumulada do biogás ao longo do ciclo no ensaio 20

\begin{tabular}{cccccc}
\hline $\begin{array}{c}\text { Tempo } \\
\text { (h) }\end{array}$ & P1 & P2 & P3 & P4 & Média \\
\hline 0,0 & 0 & 0 & 0 & 0 & 0 \\
0,5 & 160 & 173 & 181 & 176 & 172 \\
1,0 & 441 & 514 & 627 & 506 & 522 \\
2,0 & 730 & 871 & 1090 & 838 & 882 \\
3,0 & 971 & 1168 & 1365 & 946 & 1113 \\
\hline
\end{tabular}

Tabela XIII.5 - Concentração dos compostos do biogás ao longo do ciclo no ensaio 20

\begin{tabular}{cccc}
\hline $\begin{array}{c}\text { Tempo } \\
\text { (h) }\end{array}$ & \multicolumn{3}{c}{$\mathbf{C}_{\mathbf{G}}\left(\mathbf{m m o l . L ^ { - 1 }}\right)$} \\
\hline 0,0 & 0,00 & $\mathbf{C O}_{\mathbf{2}}$ & $\mathbf{C H}_{\mathbf{4}}$ \\
0,5 & 4,06 & 0,00 & 0,00 \\
1,0 & 9,18 & 0,22 & 4,56 \\
2,0 & 14,14 & 0,33 & 6,64 \\
3,0 & 15,88 & 0,41 & 6,91 \\
\hline
\end{tabular}




\section{ANEXO XIV}

Tabela XIV.1 - Concentração de matéria orgânica (DQO) ao longo do ciclo no ensaio 21

\begin{tabular}{ccc}
$\begin{array}{c}\text { Tempo } \\
(\mathbf{h})\end{array}$ & $\begin{array}{c}\mathbf{C}_{\mathbf{S F}} \mathbf{P 1} \\
\left(\mathbf{m g Q O}_{\mathbf{L}} \mathbf{L}^{-\mathbf{1}}\right)\end{array}$ & $\begin{array}{c}\boldsymbol{\varepsilon}_{\mathbf{S F}} \\
(\boldsymbol{\%})\end{array}$ \\
\hline 0,0 & 2908,2 & 0 \\
0,5 & 2794,5 & 39 \\
1,0 & 2702,0 & 42 \\
2,0 & 2620,0 & 44 \\
3,0 & 2598,0 & 45 \\
\hline
\end{tabular}

Tabela XIV.2 - Valores de pH, alcalinidade parcial, alcalinidade intermediária, alcalinidade total, alcalinidade a bicarbonato e ácidos orgânicos voláteis totais ao longo do ciclo no ensaio 21

\begin{tabular}{|c|c|c|c|c|c|c|}
\hline $\begin{array}{l}\text { Tempo } \\
\text { (h) }\end{array}$ & $\begin{array}{l}\text { pH } \\
\text { (u) }\end{array}$ & $\begin{array}{l}\mathrm{AP} \\
\left(\mathrm{mgCaCO}_{3} \cdot \mathrm{L}^{-1}\right)\end{array}$ & $\begin{array}{l}\mathrm{AI} \\
\left(\mathrm{mgCaCO}_{3} \cdot \mathrm{L}^{-1}\right)\end{array}$ & $\begin{array}{l}\mathrm{AT} \\
\left(\mathrm{mgCaCO}_{3} \cdot \mathrm{L}^{-1}\right)\end{array}$ & $\begin{array}{l}\mathrm{AB} \\
\left(\mathrm{mgCaCO}_{3} \cdot \mathrm{L}^{-1}\right)\end{array}$ & $\begin{array}{l}\text { AVT } \\
\left(\text { mgHAc. }^{-1}\right)\end{array}$ \\
\hline 0,0 & 4,74 & 0 & 160 & 160 & 0 & 751 \\
\hline 0,5 & 4,81 & 0 & 164 & 164 & 0 & 729 \\
\hline 1,0 & 4,81 & 0 & 148 & 148 & 0 & 739 \\
\hline 2,0 & 4,77 & 0 & 172 & 172 & 0 & 738 \\
\hline 3,0 & 4,74 & 0 & 140 & 140 & 0 & 711 \\
\hline
\end{tabular}

TabelaXIV.3 - Concentração de compostos intermediários ao longo do ciclo no ensaio 21

\begin{tabular}{|c|c|c|c|c|c|c|c|c|c|}
\hline $\begin{array}{l}\text { Tempo } \\
\text { (h) }\end{array}$ & $\begin{array}{c}\text { EtOH } \\
\left(\mathrm{mg.L}^{-1}\right)\end{array}$ & $\begin{array}{c}\text { ButOH } \\
\left(\mathrm{mg.L}^{-1}\right)\end{array}$ & $\begin{array}{c}\text { HAc } \\
\left(\mathrm{mg.L}^{-1}\right)\end{array}$ & $\begin{array}{c}\text { HPr } \\
\left(\mathrm{mg}^{-L^{-1}}\right)\end{array}$ & $\begin{array}{l}\text { HIsoBut } \\
\left(\text { mg.L }^{-1}\right)\end{array}$ & $\begin{array}{c}\text { HBut } \\
\left(\text { mg.L. }^{-1}\right)\end{array}$ & $\begin{array}{l}\text { HIsoVal } \\
\left(\text { mg.L. }^{-1}\right)\end{array}$ & $\begin{array}{c}\text { HVa } \\
\left(\mathrm{mg.L}^{-1}\right)\end{array}$ & $\begin{array}{c}\text { HCa } \\
\left(\mathrm{mg.L}^{-1}\right)\end{array}$ \\
\hline 0,0 & 45,6 & 3,5 & 159,7 & 300,1 & 43,4 & 58,4 & 9,8 & 40,5 & 24,5 \\
\hline 0,5 & 50,8 & 3,8 & 169,2 & 338,1 & 50,6 & 48,1 & 8,4 & 39,1 & 21,5 \\
\hline 1,0 & 44,1 & 3,6 & 175,3 & 314,5 & 38,9 & 37,9 & 8,9 & 41,2 & 17,5 \\
\hline 2,0 & 48,9 & 3,7 & 168,2 & 335,3 & 41,9 & 41,1 & 9,2 & 37,1 & 18,2 \\
\hline 3,0 & 40,9 & 3,8 & 192,6 & 345,2 & 46,2 & 39,9 & 8,4 & 45,9 & 20,4 \\
\hline
\end{tabular}

Tabela XIV.4 - Produção volumétrica acumulada do biogás ao longo do ciclo no ensaio 21

\begin{tabular}{ccccccc}
\hline $\begin{array}{c}\text { Tempo } \\
\text { (h) }\end{array}$ & $\mathbf{P 1}$ & $\mathbf{P 2}$ & $\mathbf{P 3}$ & $\mathbf{P 4}$ & $\mathbf{P 5}$ & Média \\
\hline 0,0 & 0 & 0 & 0 & 0 & 0 & 0 \\
0,5 & 65 & 105 & 87 & 116 & 108 & 96 \\
1,0 & 178 & 233 & 200 & 200 & 224 & 207 \\
2,0 & 281 & 338 & 295 & 295 & 295 & 301 \\
3,0 & 297 & 376 & 333 & 311 & 327 & 329 \\
\hline
\end{tabular}

Tabela XIV.5 - Concentração dos compostos do biogás ao longo do ciclo no ensaio 21

\begin{tabular}{cccc}
$\begin{array}{c}\text { Tempo } \\
\text { (h) }\end{array}$ & \multicolumn{3}{c}{$\mathbf{C}_{\mathbf{G}}\left(\mathbf{m m o l . \mathbf { L } ^ { - \mathbf { 1 } } )}\right.$} \\
\hline 0,0 & 0,00 & $\mathbf{C O}_{\mathbf{2}}$ & $\mathbf{C H}_{\mathbf{4}}$ \\
0,5 & 0,25 & 0,00 & 0,00 \\
1,0 & 0,81 & 0,11 & 1,54 \\
2,0 & 1,12 & 0,24 & 2,91 \\
3,0 & 1,37 & 0,35 & 3,12 \\
\hline
\end{tabular}


